\title{
AN IN-SITU HYGROTHERMAL INVESTIGATION OF AN EXTERNALLY HIGHLY INSULATED ENCLOSURE IN A COLD CLIMATE WITH SIMULATED EXTENSION TO CLIMATE SPECIFIC PERFORMANCE
}

\author{
by \\ Mark Andrew Flynn \\ B.Sc. in Civil Engineering, University of New Brunswick, 2010
}

\author{
A thesis \\ Presented to Ryerson University \\ In partial fulfillment of the \\ Requirements for the degree of \\ Master of Applied Science \\ in the Program of \\ Building Science
}

Toronto, Ontario, Canada, 2017

CMark Andrew Flynn 2017 


\section{AUTHOR'S DECLARATION FOR ELECTRONIC SUBMISSION OF A THESIS}

I hereby declare that I am the sole author of this thesis. This is a true copy of the thesis, including any required final revisions, as accepted by my examiners.

I authorize Ryerson University to lend this thesis to other institutions or individuals for scholarly research.

I further authorize Ryerson University to reproduce this thesis by photocopying or by other means, in total or in part, at the request of other institutions or individuals for the purpose of scholarly research.

I understand that my thesis may be made electronically available to the public. 


\title{
AN IN-SITU HYGROTHERMAL INVESTIGATION OF AN EXTERNALLY HIGHLY INSULATED ENCLOSURE IN A COLD CLIMATE WITH SIMULATED EXTENSION TO CLIMATE SPECIFIC PERFORMANCE
}

\author{
by
}

Mark Andrew Flynn

Master of Applied Science in Building Science, 2017

Ryerson University, Toronto, Canada

\begin{abstract}
High performance enclosures reduce building energy consumption, however, may vary from expected RSI values and be at risk of moisture damage. This research investigated the hygrothermal performance of a high performance enclosure for use in Toronto and other cold climates. The proposed enclosure utilized $228 \mathrm{~mm}$ of exterior mineral wool attached to a typical wood frame structure. The in-situ thermal resistance was compared with the nominal thermal resistance and found to differ by up to $14.4 \%$. Three-dimensional thermal modelling determined a range (-4.2\% to $-24.4 \%)$ of potential RSI reductions caused by metal-screw fasteners. In-situ measurements and calibrated one-dimensional WUFI-Pro models determined that the enclosure is not at risk of moisture damage in Toronto and other cold climates. A parametric analysis identified several climatic and materialistic variables that had an influence on the hygrothermal performance of the enclosure. The combined use of collected in-situ data and calibrated modelling allowed for a comprehensive hygrothermal analysis of the proposed enclosure.
\end{abstract}




\section{Acknowledgments}

First, I would like to thank my supervisors Dr. Russell Richman and Dr. Mark Gorgolewksi for providing me with valuable academic insight and advice. Without their continued support and valuable connections within the Toronto community this research would not have been possible. Secondly, I would like to thank the staff and students of the building science department at George Brown College. I would also like to thank Evergreen Brickworks for providing a location for in-situ testing.

Funding for this project came in the form of a Natural Sciences and Engineering Research Council of Canada Engage Grant, which promotes the connection of academia and industry to develop pertinent and relevant research. Our industry partner, Sustainable TO, developed and built the tested wall enclosure and structure. I would specifically like to thank Craig Race and Kelsey Saunders for helping to arrange the construction and transportation of the test structure.

Lastly, I would like to thank my family for the love and support they have provided over the last few years in Toronto. To my parents, Ann and Marty, your continued support and faith in me has allowed me to pursue my passion and develop academically, professionally, and personally. Thank you. 


\section{Table of Contents}

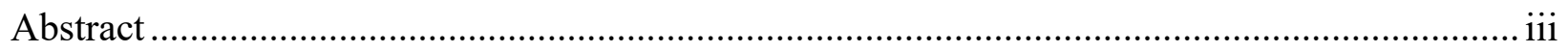

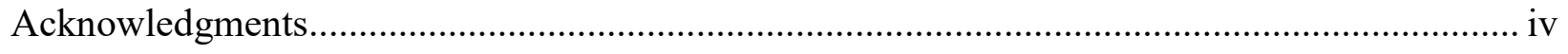

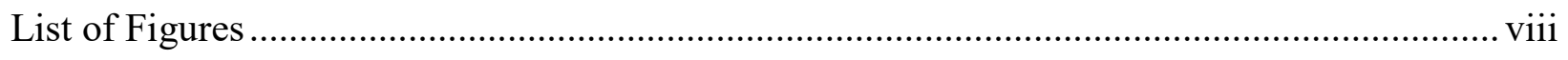

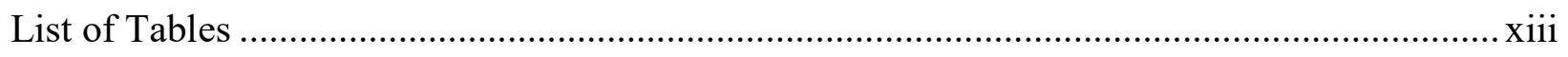

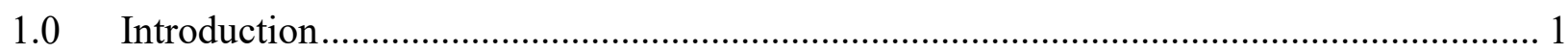

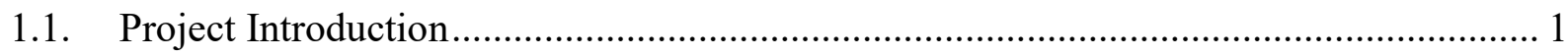

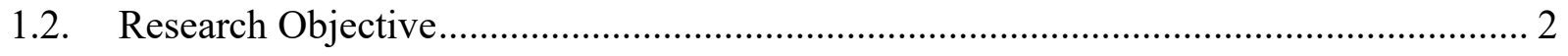

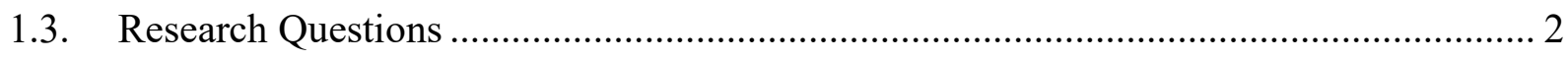

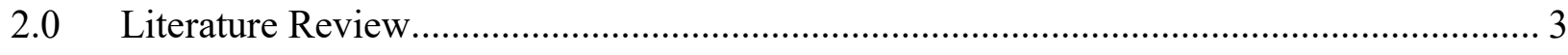

2.1. Thermal Resistance Review .......................................................................... 3

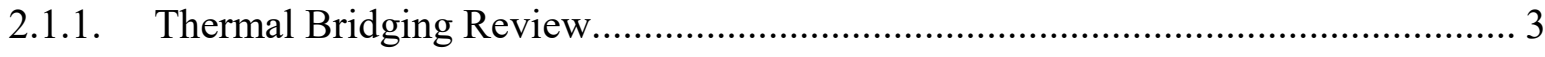

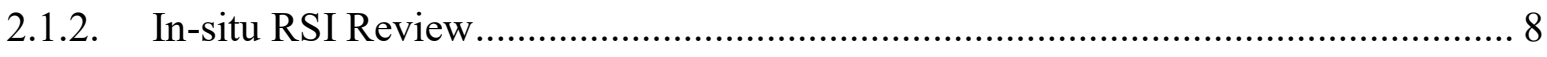

2.1.3. Thermal Resistance Summary ............................................................... 13

2.2. Moisture Management Review ................................................................... 13

2.2.1. Summary of Moisture Management Review ................................................ 21

3.0 Experimental Methodology ................................................................................ 22

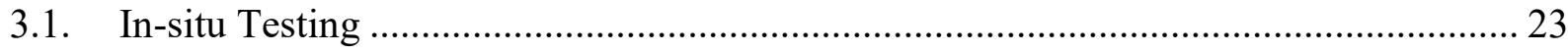

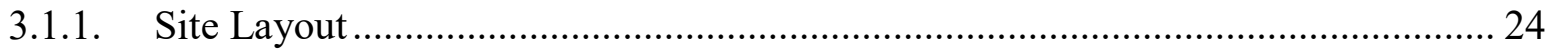

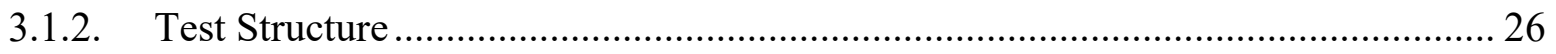

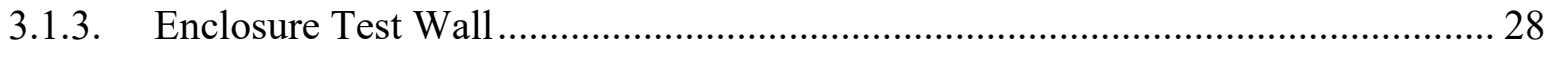

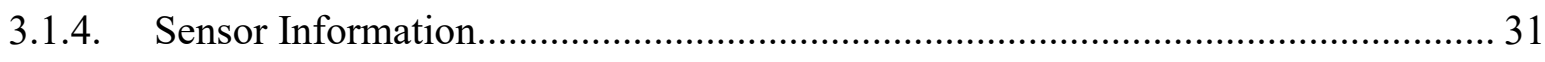

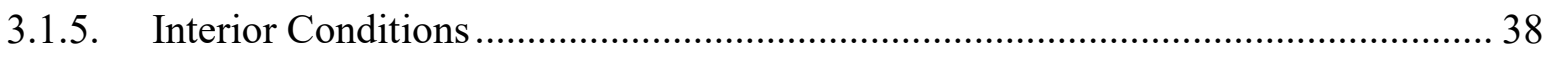

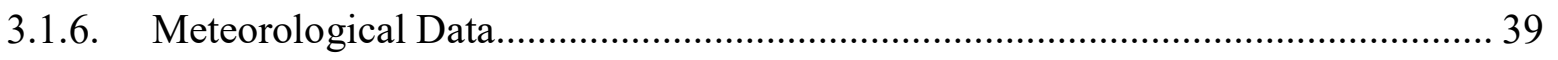




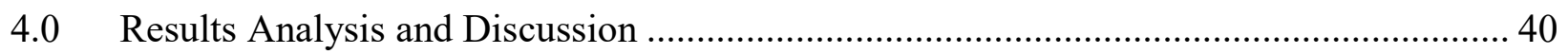

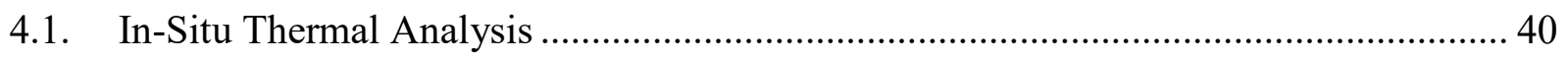

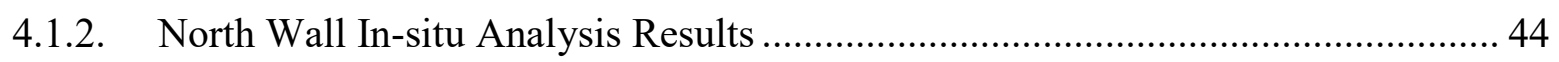

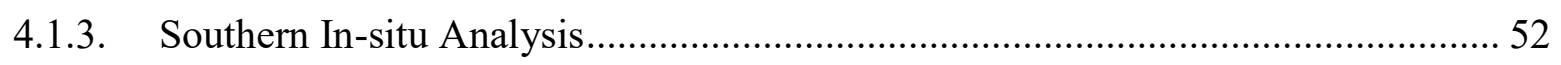

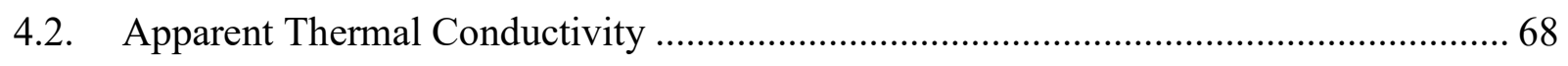

4.3. Effective Thermal Resistance Analysis.................................................................... 70

4.3.1. Three-dimensional Thermal Simulation Calibration ............................................ 70

4.3.2. Effective Thermal Resistance Analysis .............................................................. 74

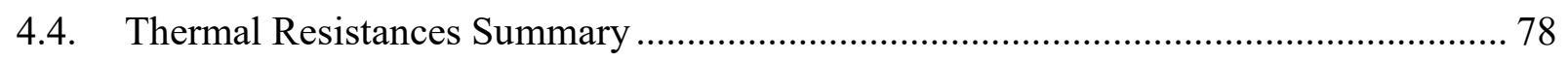

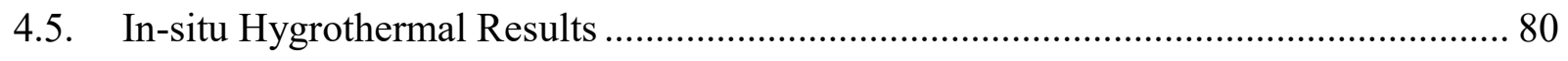

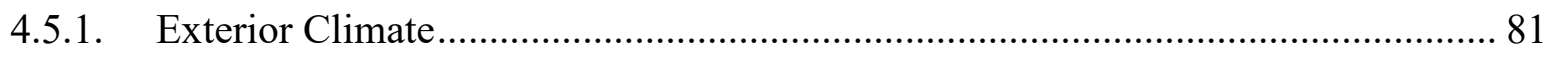

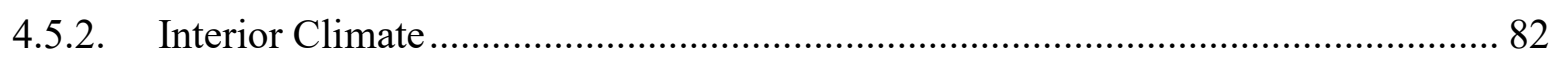

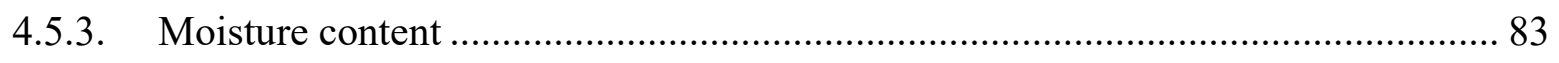

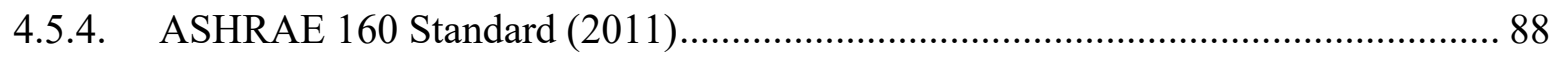

4.5.5. Interior Air Condensation Potential ........................................................................ 90

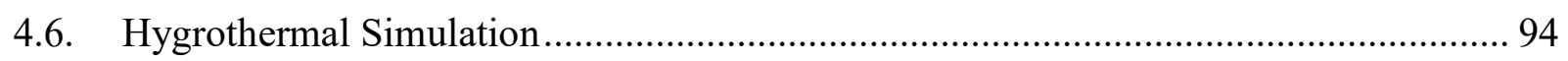

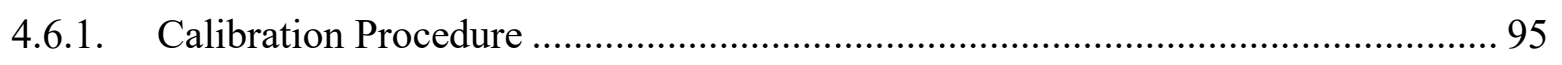

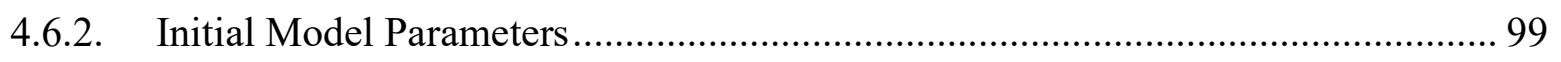

4.6.3. Hygrothermal Model Calibration..................................................................... 102

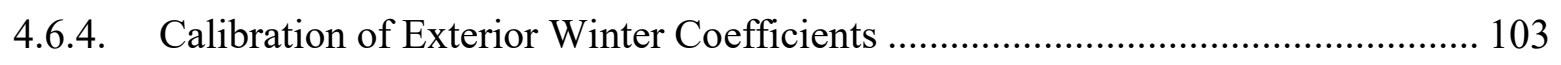

4.6.5. Calibration of Summer Coefficients ……………............................................... 113

4.6.6. Moisture Boundary Conditions........................................................................... 119

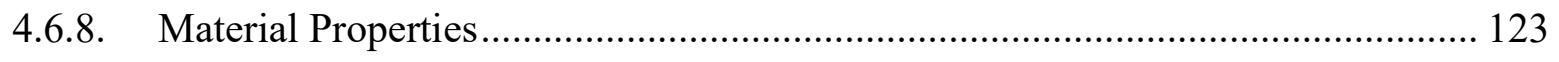

4.6.9. Hygrothermal Simulation Calibration Results.................................................... 127

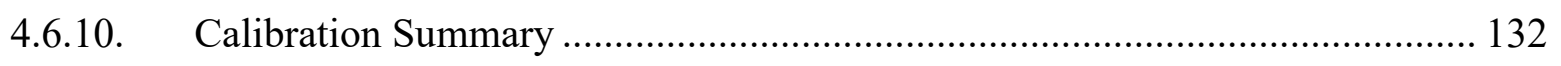




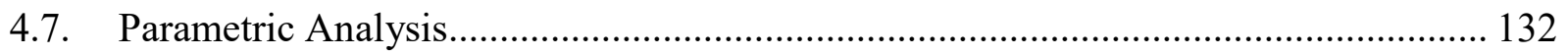

4.7.1. Parametric Analysis Approach .......................................................................... 132

4.7.2. Parametric WUFI Pro Variables ........................................................................ 140

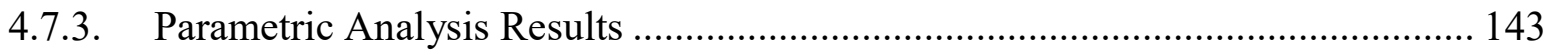

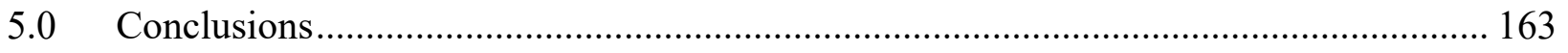

5.1. Differences in Installed Nominal and In-situ Effective RSI ..................................... 163

5.1.1. Expected Effective Thermal Resistance with Various Fastener Types, Insulation

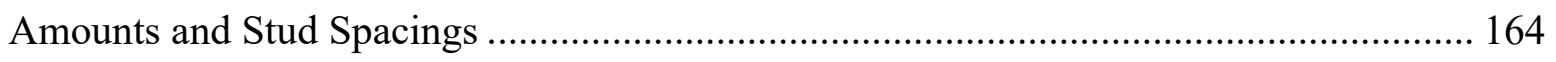

5.2. Hygrothermal Suitability for the Toronto Climate and Hygrothermal Sensitivity. ..... 165

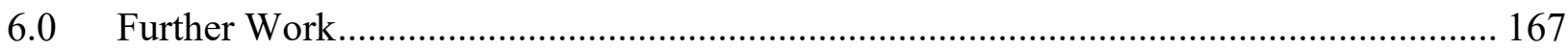

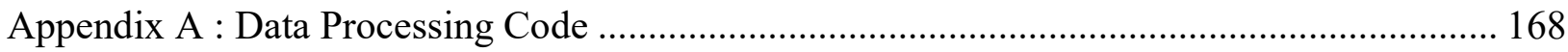

Appendix B : Sensor Location List..................................................................................... 185

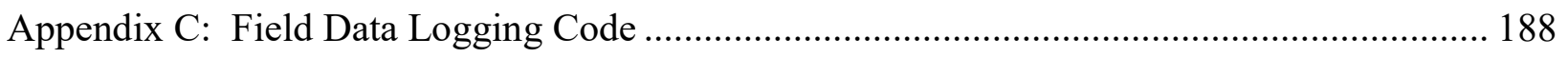

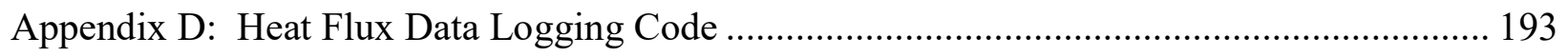

Appendix E: Temperature Sensor Differences \& Stratification ................................................. 197

Appendix F: Convergence Graphs Southern Wall Analysis......................................................... 199

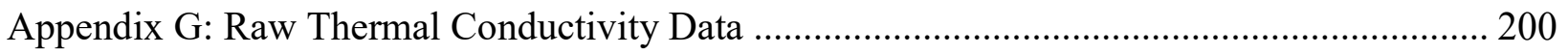

Appendix H : Heat3 Conductivity Results............................................................................... 203

Appendix I: Calibration Statistics.......................................................................................... 204

Appendix J: Cloud Index Supplementary Information........................................................... 208

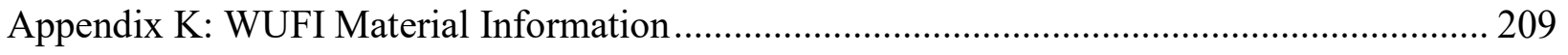

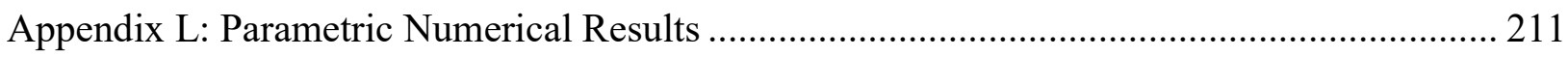

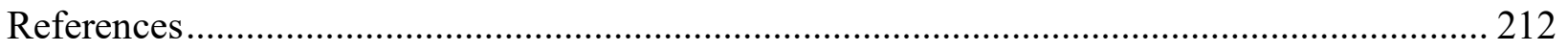




\section{List of Figures}

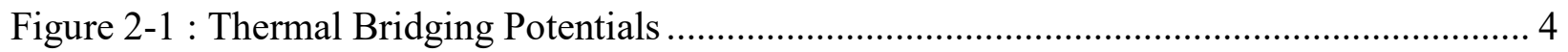

Figure 2-2 : Effects of Adding Exterior Insulation on Steel Stud Walls ......................................... 4

Figure 2-3 : Impact of Metal Fasteners on Temperature Fields.................................................... 6

Figure 2-4 : Reduction in R-Values from HEAT3 Simulations …………………….................. 7

Figure 2-5 : Effects of Wind Washing on Heat Transmission...................................................... 9

Figure 2-6 : Airflow's Affect on Thermal Resistance for Different Insulation Types.................... 9

Figure 2-7 : Lecompte (1989) Numerical Results for Gaps in Insulation in Cavity...................... 10

Figure 2-8 : Testing of Temperature Dependent Conductivity.................................................. 11

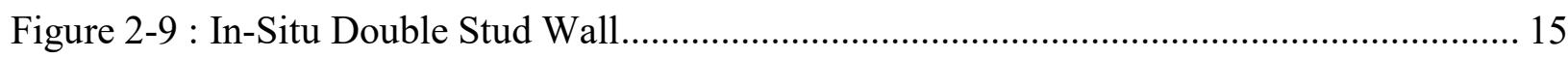

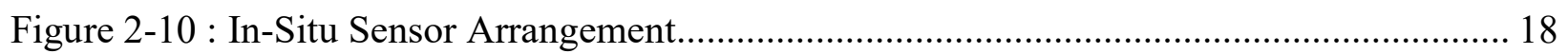

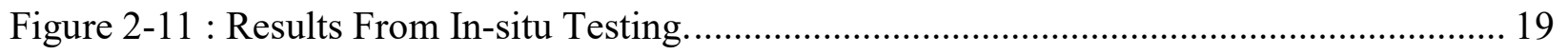

Figure 2-12 : Drying of Wall with Exterior Mineral Wool ....................................................... 20

Figure 3-1 : Experimental Methods Interaction Diagram......................................................... 23

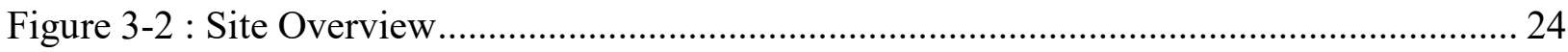

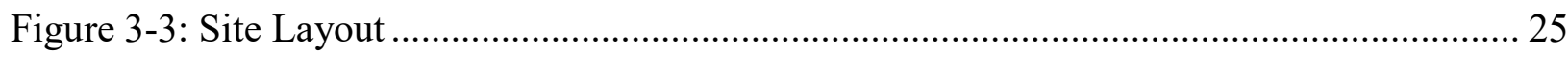

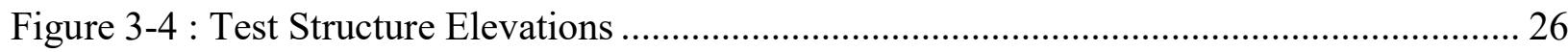

Figure 3-5 : Test Structure Section (Left) Test Structure Plane (Right)...................................... 27

Figure 3-6 : Enclosure Test Wall Isometric Drawing and Sectional Photo ................................... 28

Figure 3-7 : Sensor Location Diagram (i) Structure Section (ii) Envelope Section (iii) Sensor

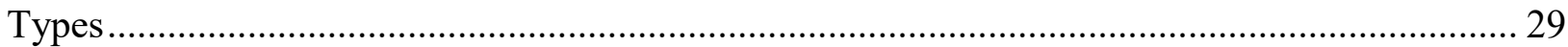

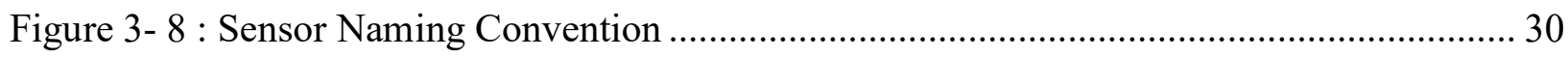

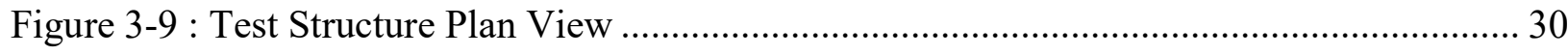

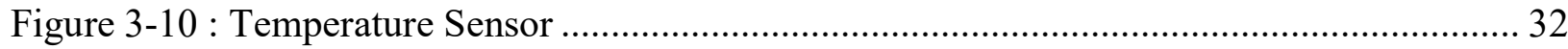

Figure 3-11 : Relative Humidity and Temperature Bundle ....................................................... 33

Figure 3-12 : Installed Moisture Content Pin Board................................................................. 34

Figure 3-13 : HFP01 Plate and Thermocouple …………………............................................. 36

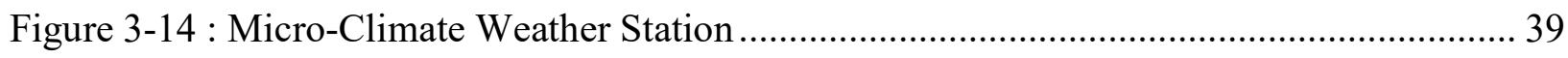

Figure 4-1 : Thermal Imagining of Sensor NH2L8-T - Example ................................................. 41

Figure 4-2 : North Wall Convergence Analysis ........................................................................... 43

Figure 4-3 : North Wall Running RSI-Value - Winter .............................................................. 44 


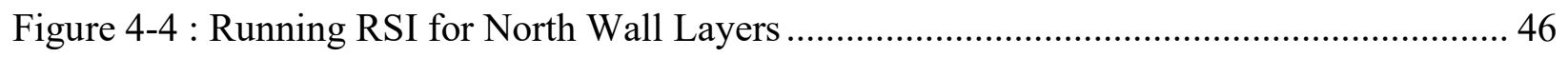

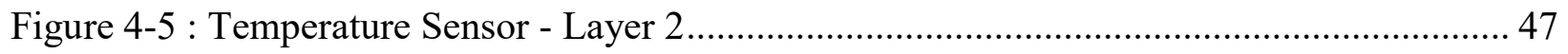

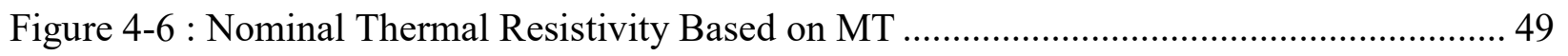

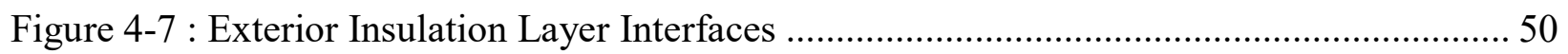

Figure 4-8 : Surface Temperature Differences and Heat Flux - North Wall ................................. 51

Figure 4-9 : Initial South Wall Running RSI-Value ……………………………………….... 52

Figure 4-10 : North and South Wall Heat Flux Comparison.......................................................... 53

Figure 4-11 : Solar Radiation and Delta Temperatures .............................................................. 54

Figure 4-12 : South Wall RSI-Value Using North Delta Temperature. ……………………….... 55

Figure 4-13 : Overcast Period Temperature Profiles ................................................................. 56

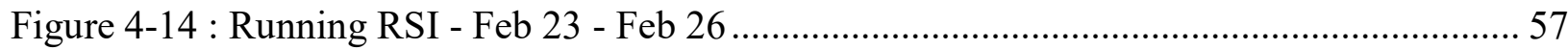

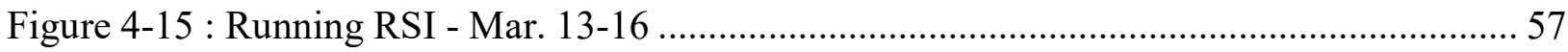

Figure 4-16 : Solar Radiation and Delta Temperatures ............................................................. 59

Figure 4-17 : Modified Comparisons of North and South Delta Temps ......................................... 60

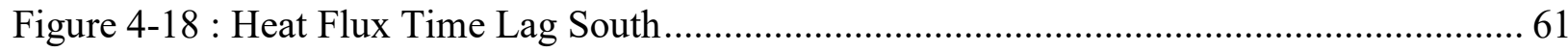

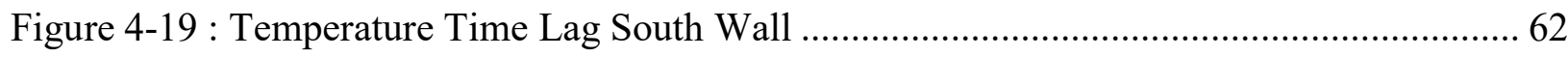

Figure 4-20 : Example of Data Removal - 11 Hour Time Lag ....................................................... 63

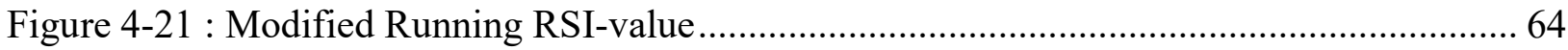

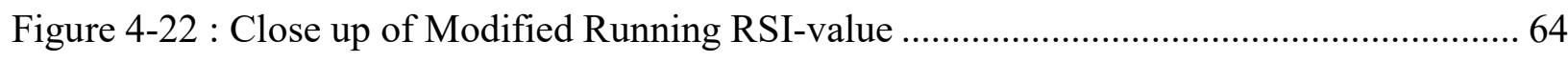

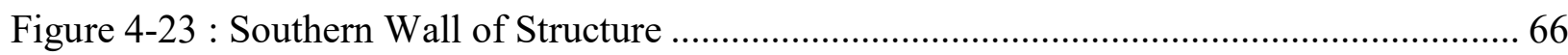

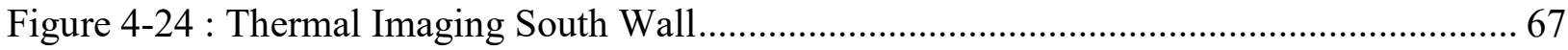

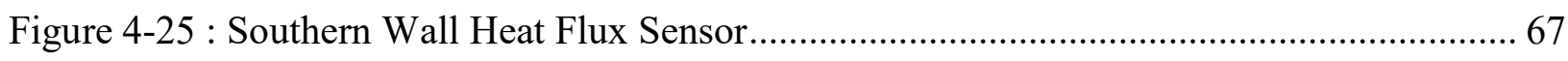

Figure 4-26 : Thermal Resistivity Compared to Mean Temperature..................................................... 69

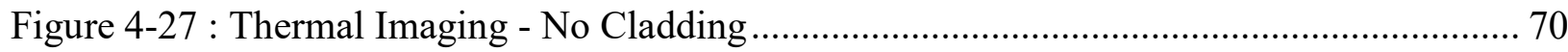

Figure 4-28 : HEAT3 Model Geometry ............................................................................ 71

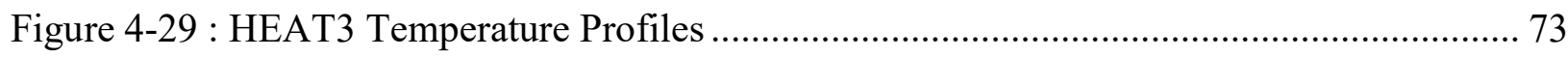

Figure 4-30 : Heat3 2D Cross Section. Materials (Left). Temperature Isotherm (Right) ............. 75

Figure 4-31 : Clear Wall Effective Thermal Resistance - Steel ..................................................... 76

Figure 4-32 : Clear Wall Effective Thermal Resistance - Stainless Steel ..................................... 77

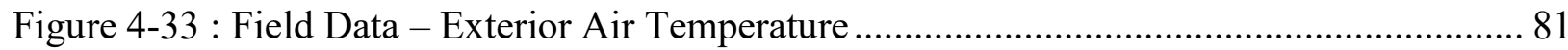

Figure 4-34 : Field Data - Exterior Air Relative Humidity .......................................................... 81 


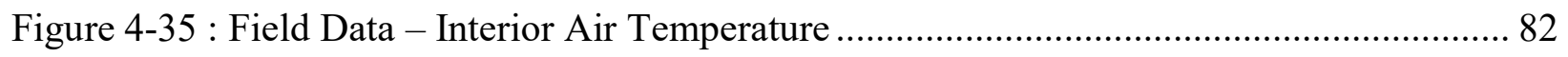

Figure 4-36 : Field Data - Interior Air Relative Humidity ................................................ 83

Figure 4-37 : North Wall Winter - Moisture Content ............................................................ 84

Figure 4-38 : South Wall Winter - Moisture Content ......................................................... 84

Figure 4-39 : North Wall Late Spring -Moisture Content .................................................. 85

Figure 4-40 : South Wall Late Spring - Moisture Content .................................................... 85

Figure 4-41 : North Wall Late Spring - Moisture Content .................................................... 86

Figure 4-42 : South Wall Late Spring - Moisture Content .................................................... 86

Figure 4-43 : North Wall Summer - Moisture Content....................................................... 87

Figure 4-44 : South Wall Summer - Moisture Content...................................................... 87

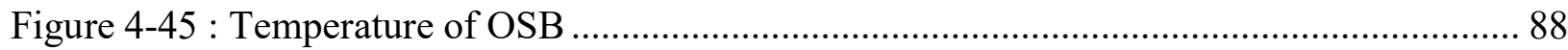

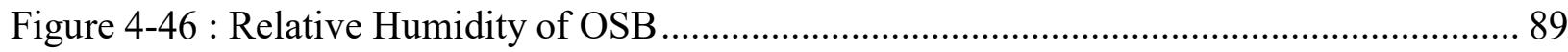

Figure 4-47 : Vapour Pressure Profile ........................................................................... 90

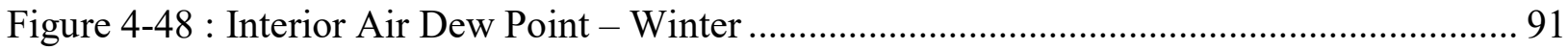

Figure 4-49 : Interior Air Dew Point - Late Spring ........................................................ 92

Figure 4-50 : Interior Air Dew Point - Summer .............................................................. 93

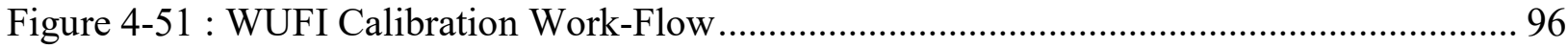

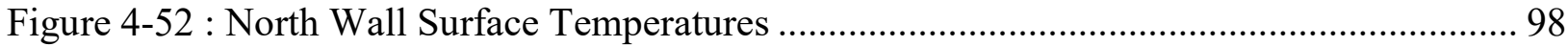

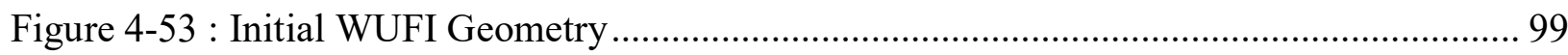

Figure 4-54 : Surface Temperature Profiles WUFI vs. DATA............................................. 102

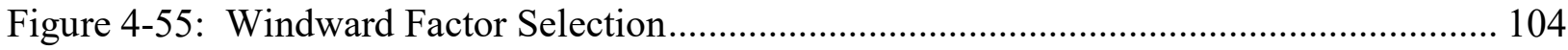

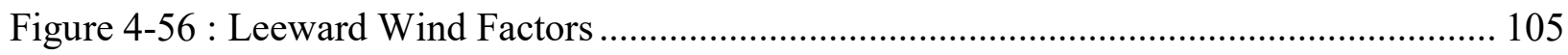

Figure 4-57 - Explicit Radiation Balance and Surface Temperatures ................................... 106

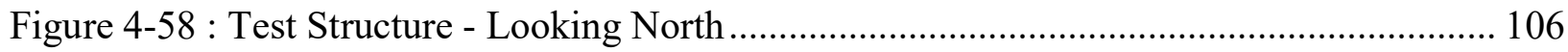

Figure 4-59 : North Wall Radiation Conductance Component …....................................... 107

Figure 4-60: Excerpt from GLWR Calibration - North Wall.............................................. 108

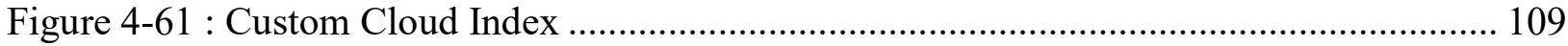

Figure 4-62 : Short Wave Absorptivity Estimation ..................................................... 110

Figure 4-63 : Short Wave Absorptivity Final Calibration ................................................ 111

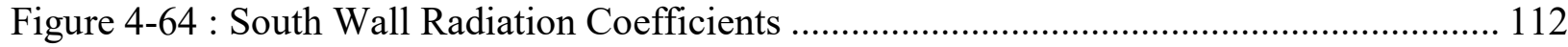

Figure 4-65 : Divergent Surface Temperatures ........................................................... 114 


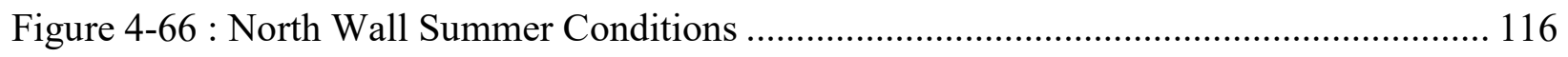

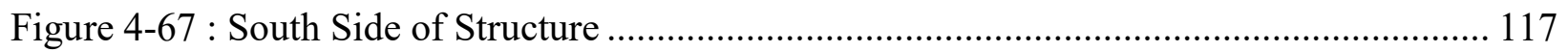

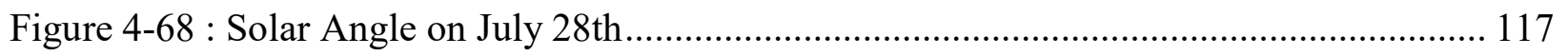

Figure 4-69 : Effect of Orientation on Cladding Temperatures............................................... 118

Figure 4-70 : ACH Effect on Rain and Cavity VP ………...................................................... 120

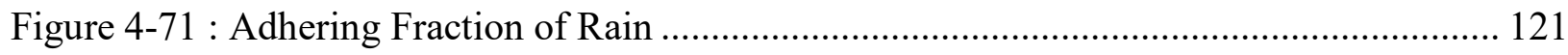

Figure 4-72 : Creation of Custom Cavity ACH File............................................................. 122

Figure 4-73 : Moisture Content of Summer Simulation (ACH) ................................................ 123

Figure 4-74 : Thermal Conductivity Assessment ……………………………………….... 124

Figure 4-75 : Temperature Assessment South Wall Summer................................................. 125

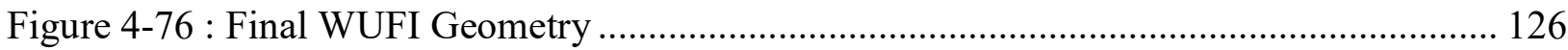

Figure 4-77 : WUFI Calibration vs. Data - North Wall Winter................................................... 127

Figure 4-78 : WUFI Calibration vs. Data - South Wall Winter................................................... 128

Figure 4-79 : WUFI Calibration vs. Data - North Wall Summer .................................................. 129

Figure 4-80 : North Wall Summer - Excerpt ....................................................................... 130

Figure 4-81 : WUFI Calibration vs. Data - South Wall Summer .............................................. 131

Figure 4-82 : Simulated Rain Leak Location......................................................................... 137

Figure 4-83 : RH of OSB Layer with Two Types of Air Layers ............................................... 142

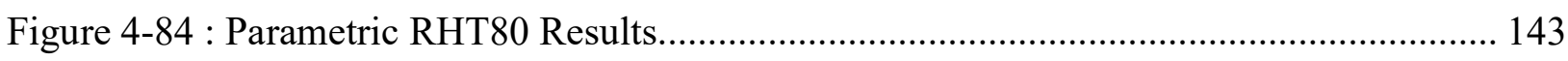

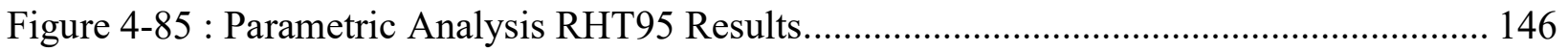

Figure 4-86 : Parametric Calgary Results ............................................................................ 147

Figure 4-87 : Driving Rain Directions - St. Johns / Calgary ………………………………... 148

Figure 4-88 : Penetrating Rain Amounts for St. Johns and Calgary............................................ 148

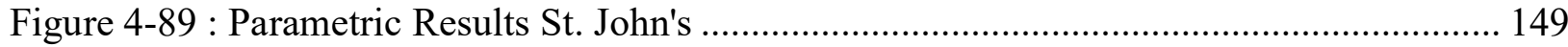

Figure 4-90 : Rain Penetration Compared with OSB RH - St. John's ...................................... 150

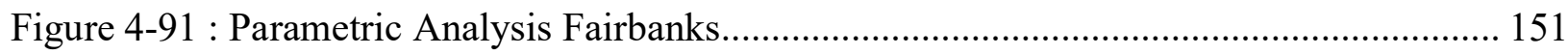

Figure 4-92 : Sheathing Temperature - Case 11 \& 12 - Fairbanks .............................................. 152

Figure 4-93 : Fairbanks Case 24 ........................................................................................ 153

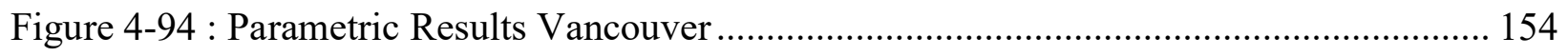

Figure 4-95 : Sheathing RH and Rain Penetration - Vancouver.................................................. 155

Figure 4-96 : Sheathing Drying Comparison - Vancouver/Toronto ............................................ 156 
Figure 4-97 : Parametric Analysis Toronto ....................................................................... 157

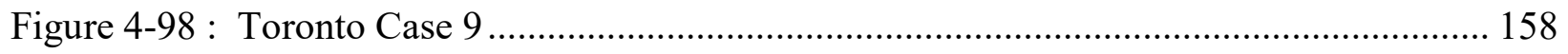

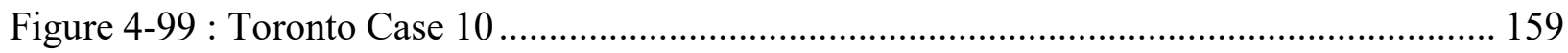

Figure 4-100 : Toronto Case 6 - High Interior RH .......................................................... 160

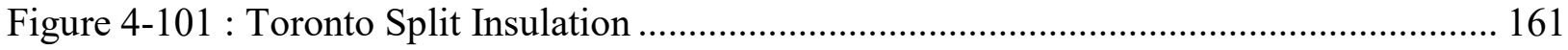




\section{List of Tables}

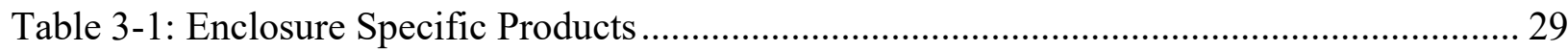

Table 3-2 : Moisture Content Species Variables …………………………………………........ 35

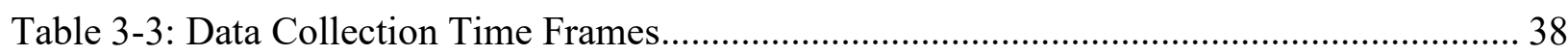

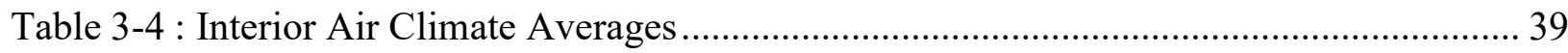

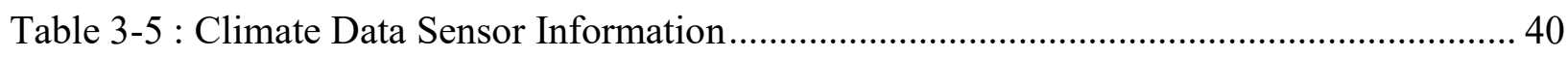

Table 4-1: Temperature Differences Between Thermocouples and Thermistors.......................... 45

Table 4-2: In-Situ Layer Analysis Results................................................................................ 46

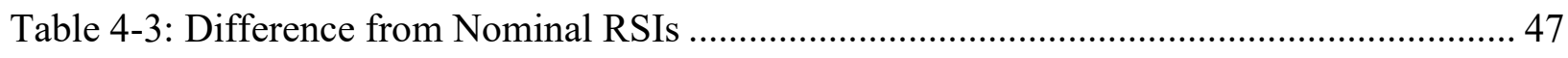

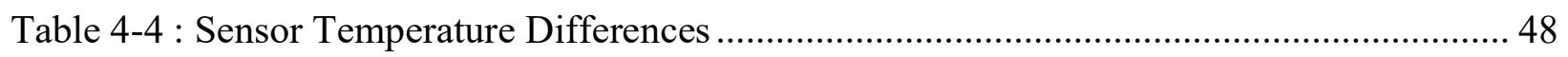

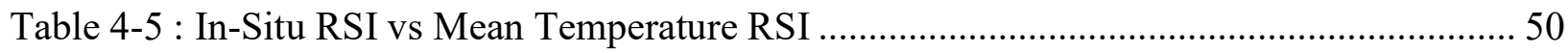

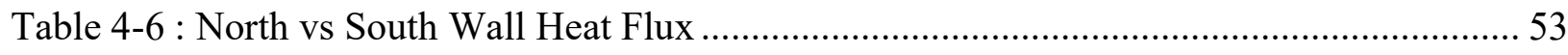

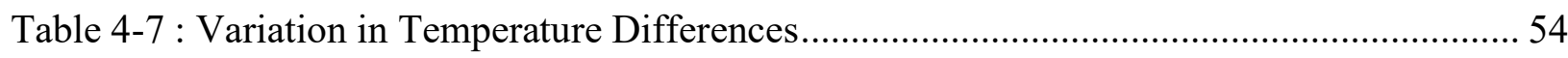

Table 4-8 : South Wall RSI Based on North Delta Temperatures................................................. 55

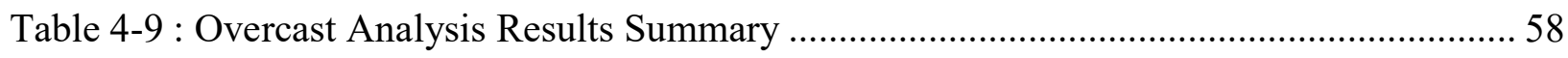

Table 4-10 : Comparison of North and South Delta Temp with Modified Data Sets ................... 60

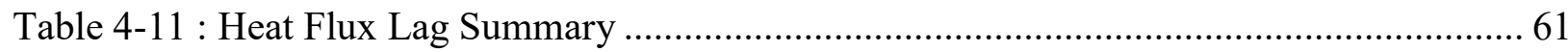

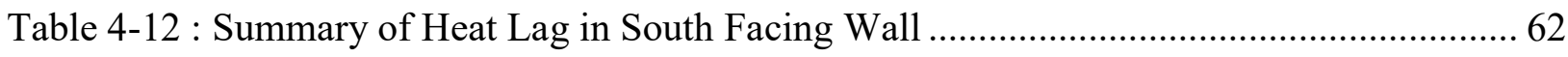

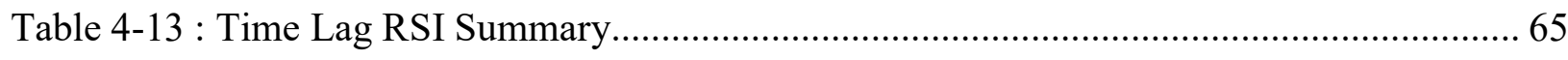

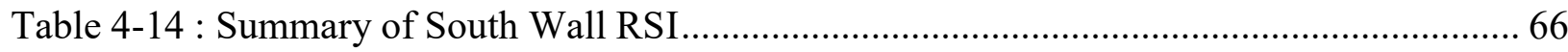

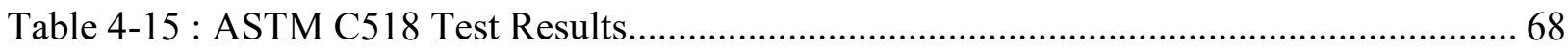

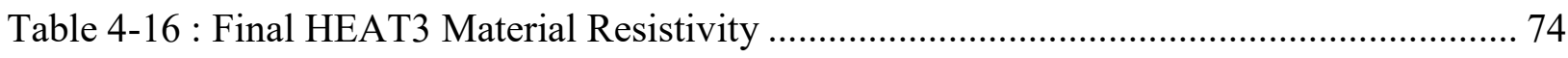

Table 4-17 : Nominal Conductivities for Enclosure Materials ................................................... 75

Table 4-18 : Thermal Resistance Summary of North and South Walls........................................ 79

Table 4-19 : Historical Averages (1981-2010) vs. Field Data. (Canadian Government) .............. 82

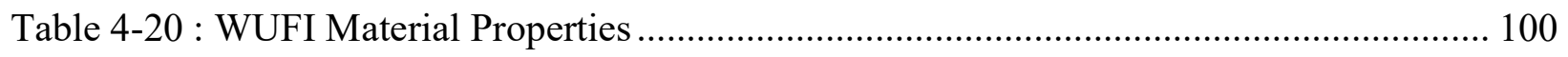

Table 4-21 : Initial WUFI Surface Coefficients ......................................................................... 101

Table 4-22 : Final North Wall Winter Coefficients ............................................................... 108

Table 4-23 : Final Winter WUFI Calibration Values ................................................................ 113

Table 4-24 : Summer Rad. and GLWR Variables .................................................................... 115

Table 4-25 : Resultant Summer WUFI Variable Coefficients..................................................... 119 
Table 4-26 : Final WUFI Conductivity Values......................................................................... 126

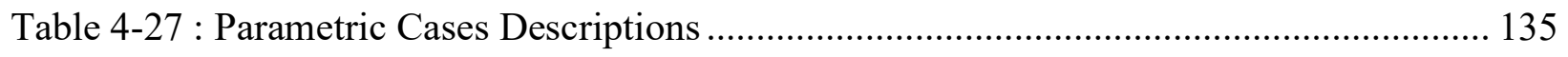

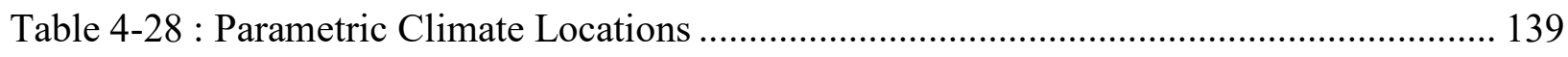

Table 4-29 : Interior Climate Variables .............................................................................. 140

Table 4-30 : Error and Accuracy of Air Layer Changes............................................................ 143 


\subsection{Introduction}

Buildings account for approximately $14 \%$ of Canada's greenhouse gas emissions and the residential sector consumes approximately 12\% of Canada's energy consumption. (Environment Canada, 2016). Typically, space heating accounts for $63 \%$ of all energy used in a Canadian home. Reducing residential building energy consumption and reducing space heating energy usage is critical to limiting the impact of climate change caused by the residential buildings (Environment Canada. 2013). Highly insulated and airtight walls can reduce the space heating energy demand and create lower energy homes. These walls are known as high thermal performance envelopes.

Incorporating high performance envelopes into the new building stock will be critical in Canada. From 2013 to 2014 Canada's population increased by 386,100 people, a 1.1\% growth rate, which has remained steady for the past 10 years (Statistics Canada, 2014). An average of 195,000 dwellings have been built every year from 2004 to 2013 (CMHC, 2016) to accommodate this population increase. All stakeholders in the building industry have recognized the need to build lower energy homes to limit green house gas emissions.

Increasing enclosure thermal resistance has implications on the systems moisture management ability. The reduced energy flow through the envelope, that is critical to lower energy buildings, impedes drying processes and may lead to an increased chance of moisture damage. There are several factors that affect the thermal resistance of an enclosure changing expected energy usage. Understanding both the thermal and hygrothermal implications of implementing newer wall systems be critical in ensuring a durable and safe housing stock.

\subsection{Project Introduction}

A local architectural firm has developed a high RSI enclosure assembly in response to the demand for new housing and the need to reduce residential greenhouse gas emissions. The enclosure approach is based off many years of building science principles for low energy buildings located in cold climates. The ideas of continuous external insulation and maintaining a vapour open system are incorporated into the enclosure. A local architecture firm has partnered with Ryerson University to investigate the implications of implementing this type of wall assembly into the built environment. The Canadian National Science and Engineering Research 
Council has made this research possible through funding in form of a NSERC Engage research grant.

The wall enclosure utilizes typical "stick-frame" construction yet modifies it by placing significant amounts of mineral wool insulation on the exterior side of the sheathing. The structure consists of typical $38 \mathrm{mmx} 89 \mathrm{~mm}$ wooden studs and orientated strand board sheathing. The internal cavity has been filled with $89 \mathrm{~mm}$ of mineral wool batt insulation. The wall consists of $230 \mathrm{~mm}$ mineral wool insulated sheathing, which is fastened to the structure via wood furring strips and long metal screw fasteners. The metal screws go through the furring strips and hold the insulation onto the structure. The cladding is fastened to the wood furring strips. A more complete description can be found in Section 4.1.3 Enclosure. The intention behind the enclosure approach was to utilize traditional construction methods while creating a durable and highly insulated wall assembly. A test structure was built by the architecture firm in the fall of 2014 to test the constructability of the system and for field testing of thermal and hygrothermal properties. The structure is located at Evergreen Brickworks close to downtown Toronto.

\subsection{Research Objective}

The objective of the following research is to quantify the thermal and hygrothermal performance of the proposed wall enclosure by analyzing in-situ performance. Further investigation is completed by calibrating software and running various simulations to gain a more robust understanding of the wall enclosure across various climates and external boundary conditions. The purpose of this research is to be able to provide architects, designers, and builders accurate information about the durability and thermal performance for this particular enclosure type to support design decisions on current and future projects. Secondly, this research will add to the literature focussing on combining in-situ testing and computer simulations to accurately assess enclosure hygrothermal performance.

\subsection{Research Questions}

Several research questions have been developed to meet the objective of this research;

1. What is the difference between the nominal and effective RSI for the proposed enclosure? 
a. What is the expected effective thermal resistance of the proposed enclosure with various fastener types, insulation amounts, and stud spacings?

2. Is the proposed enclosure suitable for the Toronto Climate in terms of hygrothermal performance?

a. How sensitive is the hygrothermal performance of the proposed enclosure under various climatic boundary conditions and under various construction modifications?

\subsection{Literature Review}

The literature review explores relevant in-situ, laboratory and computer modelling studies of highly insulated enclosure in a cold climate. For simplification, the literature review was broken into two sections; thermal resistance review and moisture management review.

\subsection{Thermal Resistance Review}

As the need for energy efficient buildings increase so to does the proper understanding of the thermal resistance of the building enclosure. Understanding the true thermal resistance of the building is critical in energy consumption and hygrothermal performance prediction. As discussed in Section 2.3 Heat in Building Enclosures, there are number of factors that may change the predicted thermal resistance of the enclosure while in service. This section will outline previous work that focuses on the impact of several of these factors.

\subsubsection{Thermal Bridging Review}

It is well known in the building industry that thermal bridging can have a large impact on the total thermal resistance of the wall and in turn energy performance. Kośny and Kossecka (2002), identified that $20-50 \%$ of wall area is not accurately represented in whole building energy modelling with respects to thermal resistance. These areas are typically occupied by thermally varied materials than the centre of cavity wall and may be thermal bridging. 


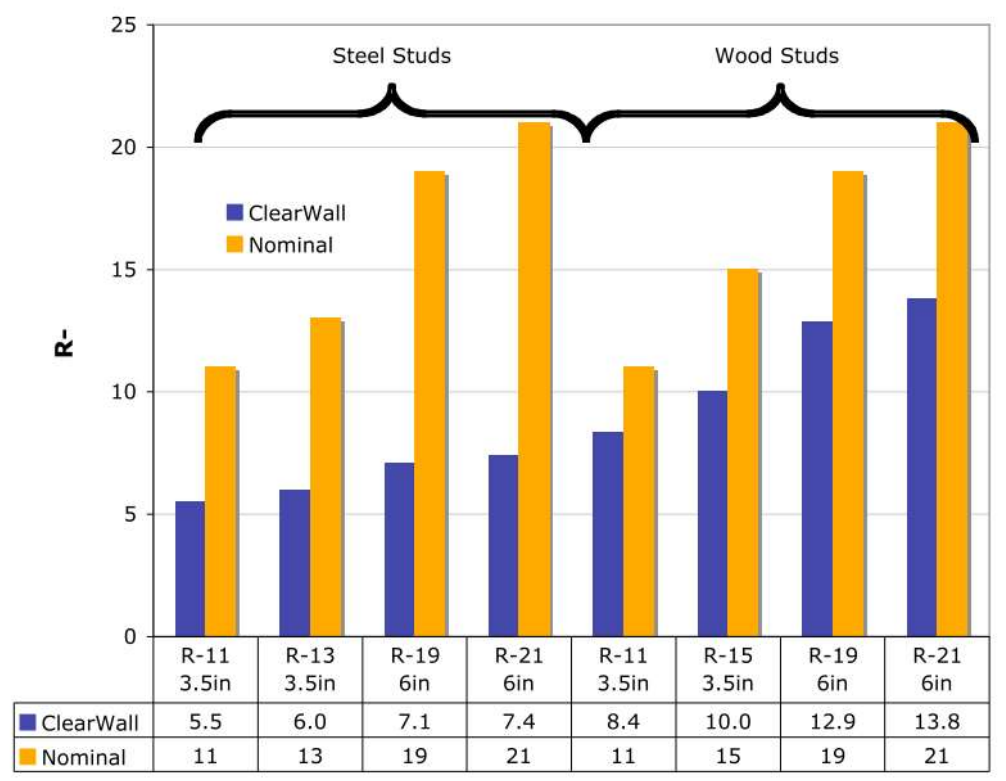

Figure 2-1 : Thermal Bridging Potentials (Straube, 2007)

Faming can occupy approximately from 19\% to 39\% (ASHRAE,2013) (Qasass et. al., 2014) of the wall area in typical wood frame construction. Reduction in expected RSI depends on construction type but can exceed $20 \%$ for wooden framing or between $50-80 \%$ if steel studs are used (Straube, 2007) (Qasass et. al., 2014). Figure 2-1 demonstrates the reductions caused by wooden and steel studs. Exterior insulation is often recommended as a solution in limiting thermal bridging. Even adding limited amounts of exterior insulation will increase the effectiveness of stud insulation as demonstrated in Bombino and Burnett (1999).

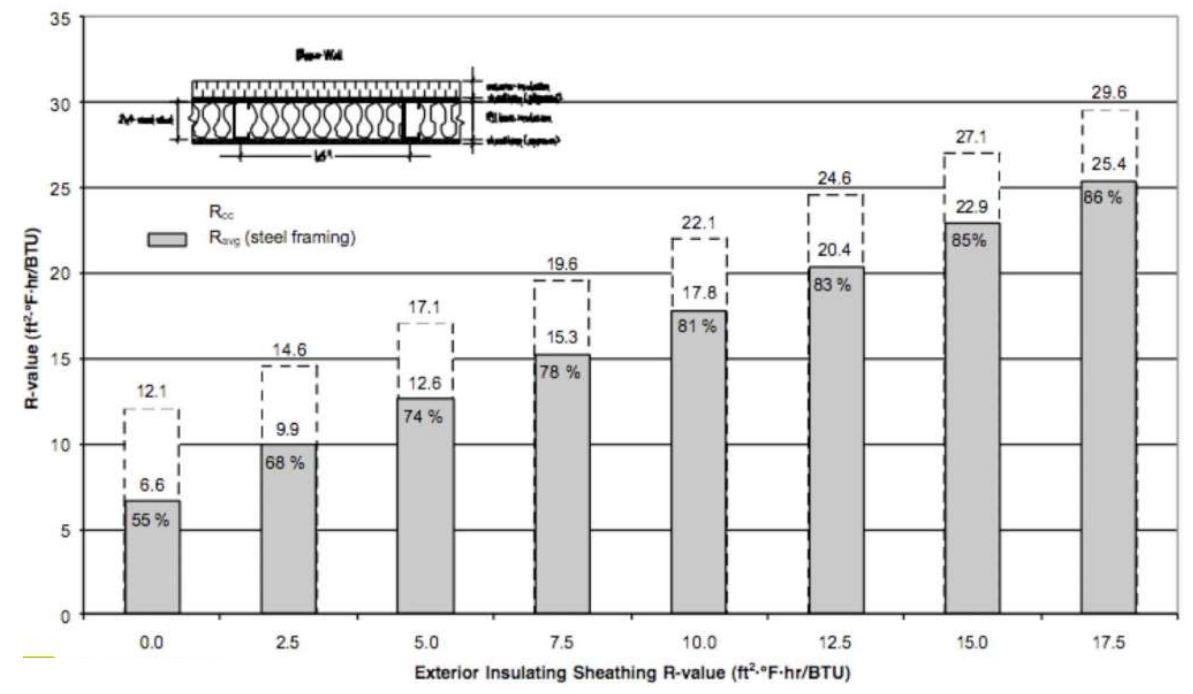

Figure 2-2 : Effects of Adding Exterior Insulation on Steel Stud Walls.

(Bombino \& Burnett, 1999) 
The ideal situation is to place all insulation on the exterior side of the structural framing. A number of objects exist outside the framing structure, such as cladding, that needs to be attached to the superstructure. Typically, these attachments consist of high-strength and highly conductive materials such as steel or concrete and penetrate the exterior insulation. Several studies have investigated the reduction in RSI caused by the penetration of the exterior insulation by such attachments and are explored below;

Lawton et. al (n.d.) investigated the impacts of slab edge details and a variety of secondary structural elements on the effective RSI of externally insulated wall assemblies. They compared whole wall effective RSI to expected nominal wall insulation values. The authors completed RSI calculations for a number of scenarios on variations of a wall type; however, only the most relevant case is presented here. The construction detail comprised of an externally insulated wall with steel studs and a concrete slab. A steel angle shelf was attached to the slab via metal spaces at $610 \mathrm{~mm}$. Insulation was continuous over the wall except where metal brick ties and shelf angle connectors penetrate. The report found a reduction in RSI between $29.3 \%$ and $49.2 \%$ from nominal, depending on external insulation amounts. The largest difference was found in the most insulated case where the nominal RSI value of $5.82 \mathrm{~m}^{2} \mathrm{~K} / \mathrm{W}$ was reduced to $2.95 \mathrm{~m}^{2} \mathrm{~K} / \mathrm{W}$ (Lawton et. al, n.d.). It should be noted that the highest externally insulated cases had the largest proportional drop in effective RSI value due to increased heat flows through the conductive components. 


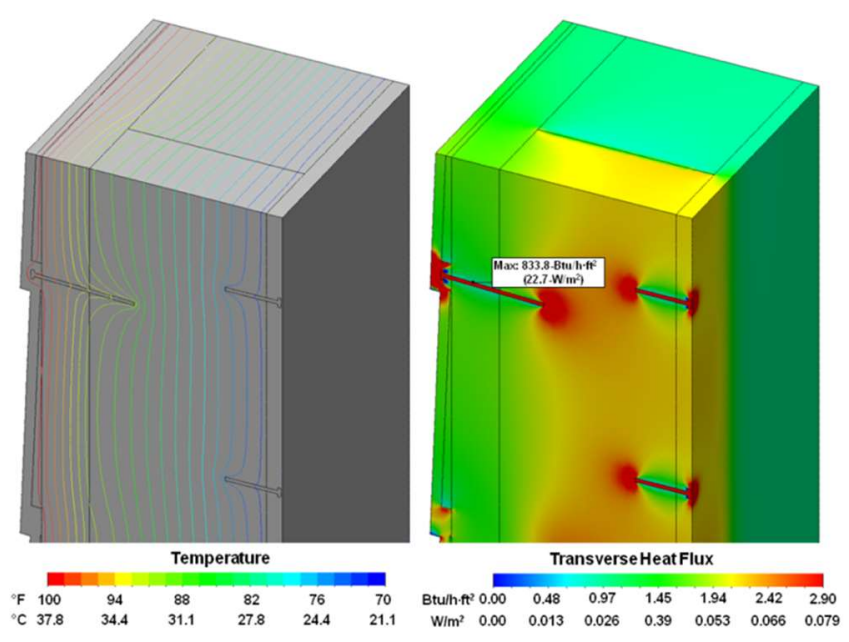

Figure 2-1 : Impact of Metal Fasteners on Temperature Fields (Christenson, 2010)

Christensen (2010) investigated the effect of fasteners in high-performance wood frame walls. The author looked at a typical 2"x6" wood-frame with interior cellulose insulation, 38mm of exterior rigid foam insulation and lapped fibre cement sheathing wall. The impact of the drywall and the fibre cement board metal fasteners on the RSI of the wall was investigated. A range of framing factors and fastener densities was tested to determine appropriate ranges for RSI. Christensen used a finite-element $3 \mathrm{~d}$ thermal modelling software to conduct the tests. The study concluded that at a maximum framing factor of $30 \%$ the combined effects of studs and metal fasteners caused a reduction in RSI of $5.076 \mathrm{~m}^{2} \mathrm{~K} / \mathrm{W}$ to $3.863 \mathrm{~m}^{2} \mathrm{~K} / \mathrm{W}(24 \%)$. The metal fasteners were calculated to cause a reduction of approximately $5 \%$ of the walls thermal resistance. 


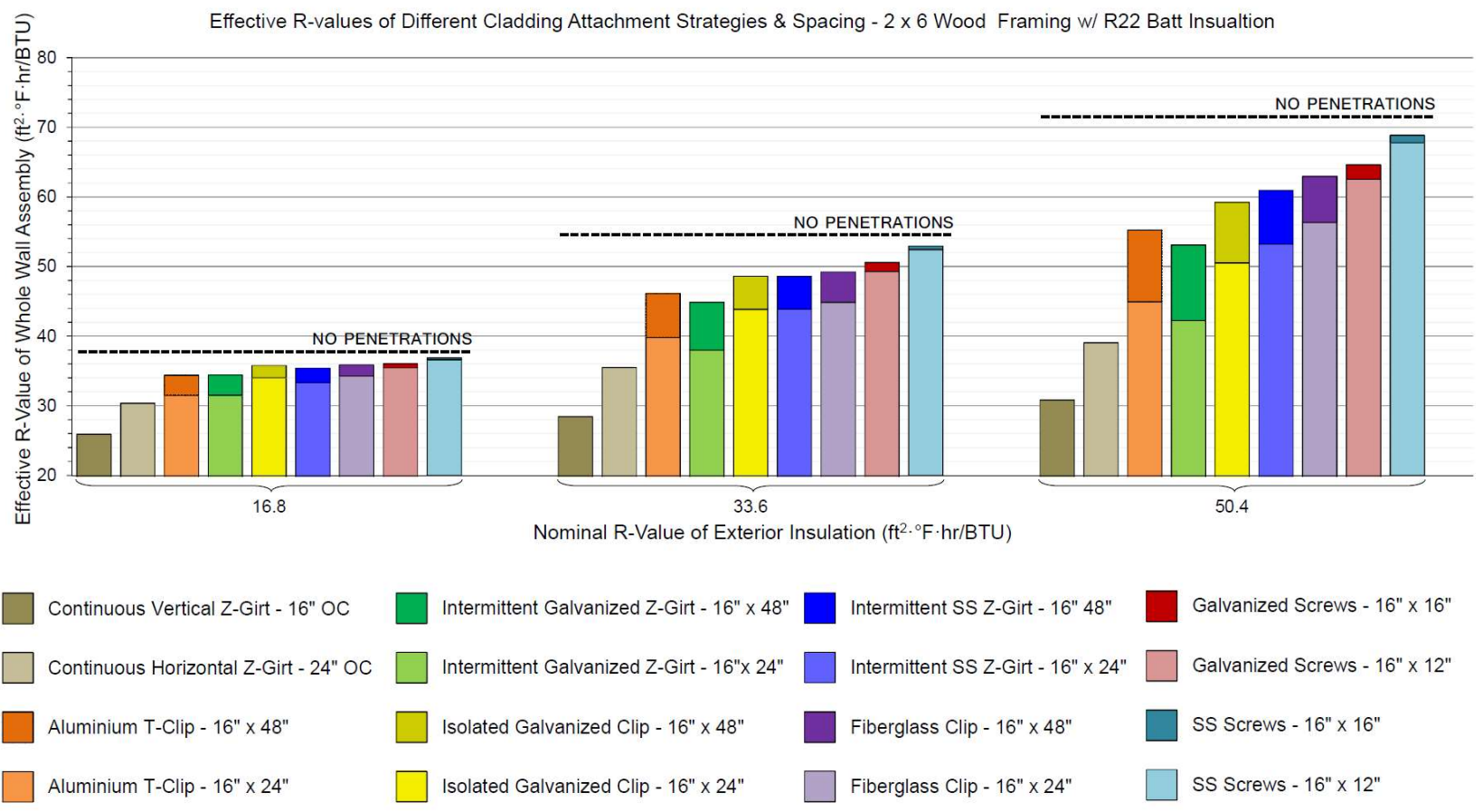

Figure 2-2: Reduction in R-Values from HEAT3 Simulations (Higgins et. al., 2014)

A number different fastening arrangements were assessed by Higgins et. al (2014) for two typical residential frame walls with varied levels of exterior insulation. The walls included 2"x6" wood and 3-5/8" steel studs both spaced at $406 \mathrm{~mm}$. Three levels of exterior insulation were assed; with install RSI's of $2.96 \mathrm{~m}^{2} \mathrm{~K} / \mathrm{W}, 5.92 \mathrm{~m}^{2} \mathrm{~K} / \mathrm{W}$ and $8.88 \mathrm{~m}^{2} \mathrm{~K} / \mathrm{W}$. The fastening methods included, stainless steel screws, galvanized screws, z-girt clips, fibreglass clips, PVC isolated galvanized clips, and aluminum clips. Screws were fastened through wooden furring strips and insulation and then imbedded into the wooden structure. This is a similar arrangement to proposed enclosure. The results from the wood frame analysis indicate that continuous vertical zgirts had the largest impact, while stainless steel screws have the least impact on the thermal resistance of the wall. Galvanized screws preformed worse than the stainless-steel screws due to their increased conductivity value. Stainless steel and galvanized screws were simulated at $305 \mathrm{~mm}$ and $406 \mathrm{~mm}$ vertical spacing. The proportional decrease in thermal insulation increased as exterior insulation increased. The most similar case to the proposed assembly was galvanized screws spaced at $406 \mathrm{~mm}$ and with $5.92 \mathrm{~m}^{2} \mathrm{~K} / \mathrm{W}$ of external insulation. The thermal resistance of clear-wall was reduced from approximately $9.69 \mathrm{~m}^{2} \mathrm{~K} / \mathrm{W}$ to approximately $8.63 \mathrm{~m}^{2} \mathrm{~K} / \mathrm{W}$, a reduction of $11 \%$. 


\subsubsection{Thermal Bridging Summary}

From the previous studies in can be concluded that thermal bridging and penetrations through exterior insulation can cause a significant difference in effective and nominal thermal resistances. The effect of metal fasteners, such as screws and nails, can cause reductions of $5 \%$ to $15 \%$, on the effective thermal resistance of externally insulated wall assemblies. Increased levels of exterior insulation cause a proportional decrease of effective RSI.

The proposed wall is intended to be used in low-energy buildings and the effects of fasteners should be properly understood before implementation. This research will investigate a wide variety of construction situations. This will allow designers a better understanding of selecting insulation levels and structural arranging on building energy usage. Similar to the studies above proposed cases include changing stud spacing, fastener spacing, and insulation levels.

Due to the small area of the studs and fasteners, it is impractical to measure the in-situ thermal resistance at their location. Methods exist to test whole walls RSI values, such as the guarded hot box method, however will not be undertaken in this research but is mentioned for possible further testing. Three-dimensional simulation was the selected method preferred in above simulations and will be used for this research. The program HEAT3, used by Higgins et al. (2014) and validated by ISO 10211:2007 (ISO, 2007) was selected to assess the impact of fasteners in the proposed enclosure.

\subsubsection{In-situ RSI Review}

There are many factors that influence the thermal resistance of both an enclosure and the insulation within the assembly. This section will relevant review past research for mineral wool insulation and exterior insulation. The past research presented here should help provide an understanding on what may be influencing the in-situ thermal resistance of the wall.

\subsubsection{Wind washing}

Wind washing has been shown to reduce thermal resistances by as much as $10-30 \%$ in lightweight wood frame walls that utilize low-density mineral wool insulation (Uvløskk,1996). Other studies have found similar effects in pitched roofs (Deseyve and Bednar, 2009) (Janssens and 
Hens, 2007) reduced surface temperatures in corners due to wind (Timusk and Seskus, 1991) and direct increase in heat loss due to air flow over insulations surface. (Yarbrough and Tooe, 1983).

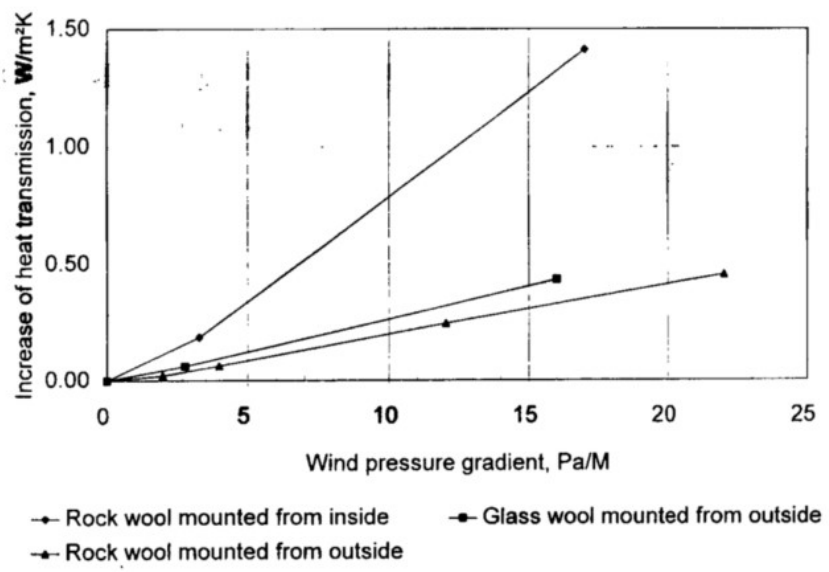

Figure 2-3 : Effects of Wind Washing on Heat Transmission (Uvloskk, 1996).

The aforementioned studies investigated the effects of wind on relativity low density insulations and constructions with defects. The extent of winds impact on thermal transmission varies greatly due to a number of factors such as; air pressure gradients, wind speed, installation gaps, and air permeability of insulation. The impact of wind washing on exterior high density mineral wool has not extensively been investigated, however one recent study was published on this topic.

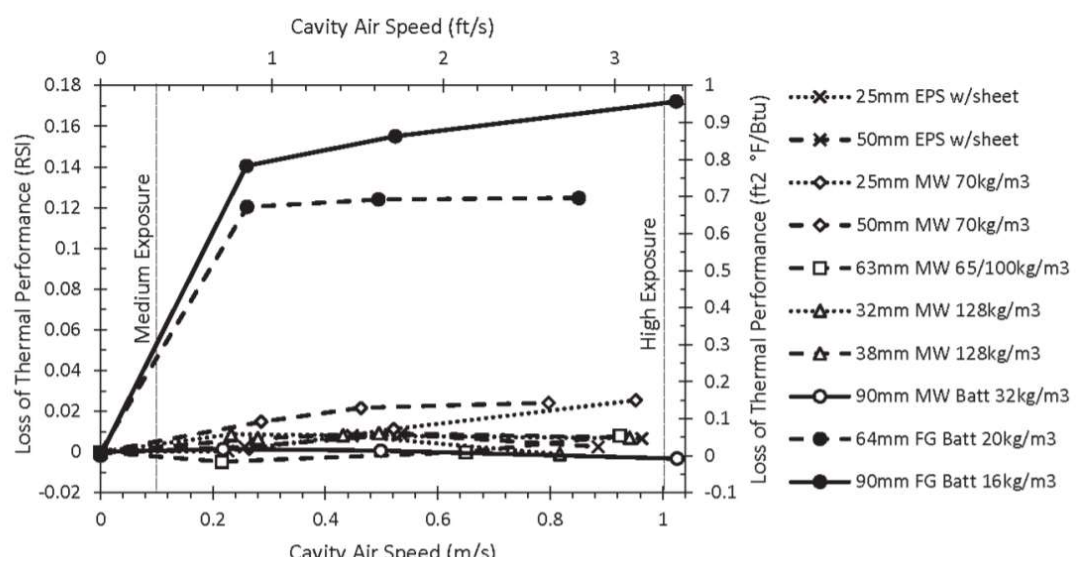

Figure 2-4 : Airflow's Affect on Thermal Resistance for Different Insulation Types (Van Straaten et. al. 2016)

In a recent study conducted by Van Straaten et. al. (2016) and titled "Wind Washing Effects on Mineral Wool Insulated Sheathings", the research team investigated the relation between air flow over different density mineral wool boards and low-density fibre glass batts. The report 
concluded that regardless of air-flow speed there was minor variation in heat flux in mineral wool with densities higher than $78 \mathrm{~kg} / \mathrm{m}^{3}$ (Figure 2-6). The study did not investigate the potential loss in thermal resistance due to exterior air flowing around the insulation. There have been several other studies in the past that have investigated this effect along with gaps on the interior side of construction.

Gaps on the interior side of insulation were looked at by Brown et. al. (1993) and found that air looping and natural convection could cause a $41 \%$ drop in thermal resistance. Factors that influenced resistance were gap sizes and exterior air temperatures. The proposed enclosure has significant exterior insulation it is suspected interior natural convection will have limited effect on thermal resistance, however, external air-looping may have implications.

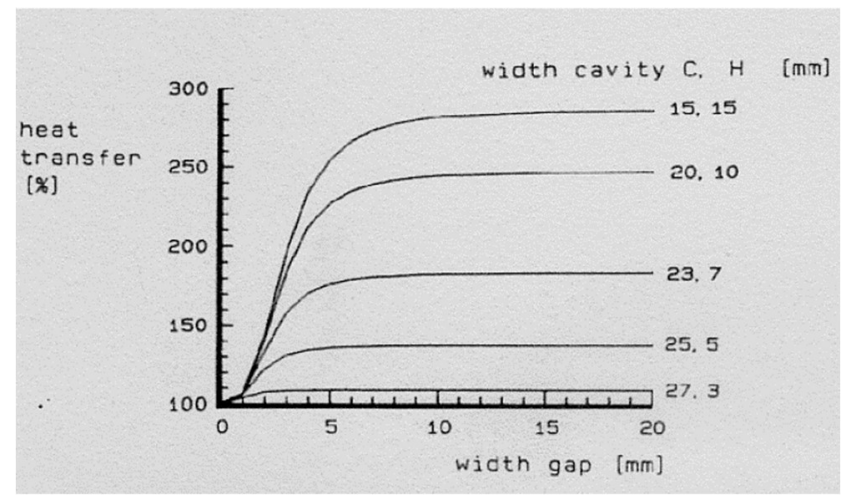

Figure 2-5 : Lecompte (1989) Numerical Results for Gaps in Insulation in Cavity.

Lecompte (1989) investigated brick wall cavity insulation and the impacts of air gaps on thermal transmission. Rigid foam insulation was placed between two layers of brick construction. Guarded hot box tests were conducted with different gaps on both the interior side and exterior side of the insulation. Testing and subsequent numerical simulations showed that gaps between the insulation and the wall would result in significantly increased heat loss. It should be noted that as the gaps decreased in size so to the heat flux. Air movement from wind was not investigated, but it is suspected that there would be increased heat transfer due to increased air flow behind and in front of the insulation. Trethiwn (1991), also looked at the effects of gaps between the insulation a wall. Results from this paper confirm findings made by the Lacompte study. 
Air movement through and around the insulation can have serious implications on the thermal resistance of enclosures depending on several factors such as, gap sizes, air permeability of assembly component, insulation density, exterior/interior temperatures, and insulation types. There are several other factors that influence thermal resistances while in service including; moisture content and conductivity temperature dependency.

Moisture Content: A study conducted by Jiřičková et. al., (2006) looked at partially saturated mineral wools and their apparent thermal conductivities. Results indicate that thermal conductivity increases with increased moisture content. Although the cases investigated by Jiřičková et. al., looked at high levels of moisture content relative to expected moisture content of the proposed enclosure, it demonstrated that there may be changes in thermal resistance due to moisture within the insulations.

Temperature Dependency: Research has been conducted by Building Science Labs on differences between polyisocyanurate and mineral wool within roofing assemblies. ASTM C518 thermal conductivity test were conducted on both insulations. The mineral wool tested, Roxul TopRock DD, is similar in density and conductivity to the external mineral wool insulation used in the proposed enclosure.

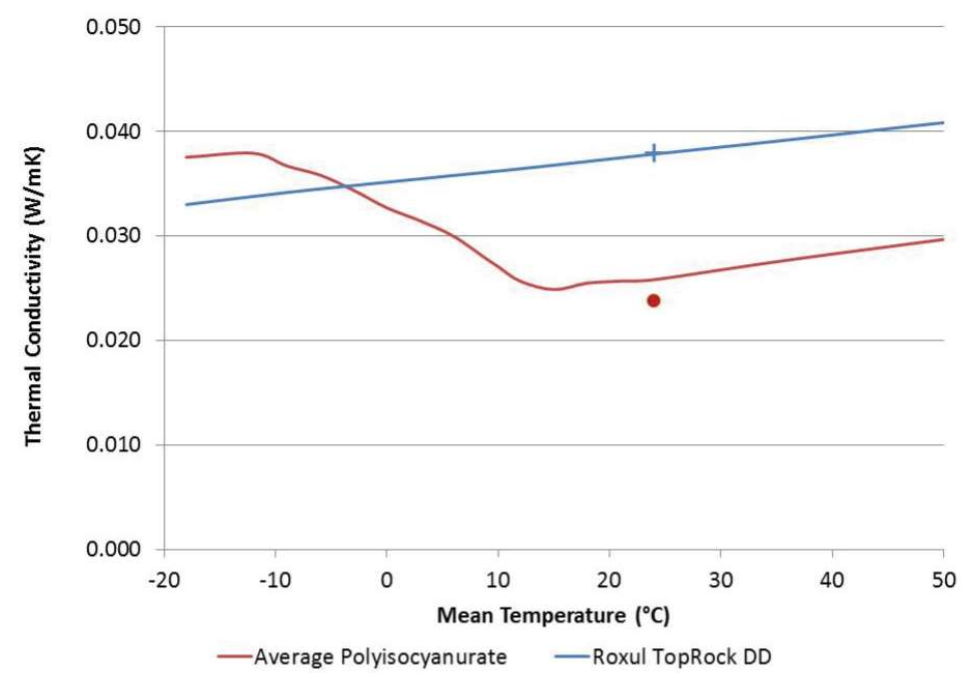

Figure 2-6 : Testing of Temperature Dependent Conductivity (BSC,2013)

Results show a clear linear dependency on the mean temperature of the insulations, with the conductivity of the material increasing as its mean temperature increases. Temperature dependent conductivity is a well known and studied phenomenon in insulation. Since the exterior 
insulation in the proposed enclosure will see drastic changes to its temperature, further testing under ASTM C518 has been carried out with varying temperatures and can be found in Section 4.2 Apparent Thermal Conductivity.

\subsubsection{In-situ Thermal Analysis}

There are many variables that may impact the in-service RSI of the enclosure. Many of the above studies investigated the effect of one variable on the thermal resistance of either the insulation or the wall assembly. To determine the overall impact of multiple variables the enclosure must be tested in-situ. A common and accepted procedure to test in-situ thermal resistance of building enclosures is the ASTM C1155 and ASTM C1046 standards (ASTM, 2013a) (ASTM,2013b). These standards are equivalent to the international standard ISO 98691:2014 (ISO, 2014). These standards require the measurement of heat flux through the wall and the measurement of surface temperatures on the interior and exterior surfaces. A number of studies have employed the used of ASTM C1155 and ISO 9869 to evaluate in-situ thermal resistance (Janssens \& Hens, 2007) (Saïd et. al.,1997) (Latif et. al., 2014).

Determining the thermal resistance of each layer was considered important to gain a better understanding of the in-situ effective RSI of the proposed assembly. Defining each layer's thermal resistance will aid in assessing changes in the thermal resistance of the enclosure. A thermal resistance study on vacuum insulated panels was conducted with both in-situ testing using ASTM-C1155 and guarded hot-box testing. To determine the RSI of the VIP within the assembly, thermocouples were placed on either side of the VIP. Using the temperature data from each layer and the heat flow from the heat flux plate, the authors calculated each layer's thermal resistance, and the overall thermal resistance of the wall (Baldwin, 2015). This technique was also used in Saïd et al. (1997). Similar method has been adopted for this research, where temperature sensors have been located between each layer and a heat flux plate collects heat flow through the assembly.

The in-situ thermal resistance measurements set-out in ASTM-C1155 and ISO 9869-1:2014 allow the operator to capture the impact of many variables on the thermal resistance of an enclosure, however these variables also cause accuracy issues within the measurement. Using ASTM-C1155 and the summation technique properly one can expect experimental error to have a coefficient of variation in the order of 10\% (ASTM. 2013a). It has been noted that to minimize 
errors collection periods should last anywhere between three days and two weeks and temperature differences between interior and exterior conditions should be at leas $10^{\circ} \mathrm{C}$ (Desogus et. al. 2011) (Bryne et. al. 2013). The time duration is dependant upon the thermal mass of the enclosure. Longer periods of time are required for more massive walls to account for the slow response of the system to adjust for changes in temperatures. The temperature difference ensures that polarity of the heat flux does not change. Other errors that may occur are variable air-flows over the heat flux sensor, disproportionate radiation exchange, and exposure to solar radiation (Flanders, 1994).

\subsubsection{Thermal Resistance Summary}

As outlined Section 2.1 Thermal Resistance Review, there are many factors that influence the thermal resistance of an enclosure. Physical properties of the materials, assembly design, environmental conditions, and construction defects can all play a large role in the thermal resistance of the building enclosure. Information provided by the manufacturer and standard test methods for determining thermal resistances of materials provide a generalized picture of performance, however, cannot account for a substantial number of variables. The technique chosen for in-situ testing can experience several errors during collection and only provides a range of certainly of $10 \%$. The small area of the studs and fasteners, which may account for a substantial loss in effective RSI value, can not be monitored directly. The use of computer simulation can be used to estimate bridging impacts but utilizes a highly-idealized model, which does not account for material and in-situ variables. It was determined through the literature review that using a combination of standard material testing, in-situ testing, and computer simulation would provide a robust understanding of the true thermal resistance of the proposed enclosure.

\subsection{Moisture Management Review}

Understanding the hygrothermal performance of enclosures is critical in determining durability and avoiding any economic and occupant health issues. There exist simple calculation methods, such as the Glaser-Method, that utilize published or tested material properties and use static boundary temperatures and relative humidity to determine relative humidity levels within enclosure. Simple methods clearly ignore highly relevant hygrothermal factors, such as dynamic 
boundary condition, material and construction defects, liquid water penetration, moist and temperate air flows, and many other factors.

Field testing of enclosures is a widely-accepted method for determining hygrothermal performance. The studies listed below present results of such testing. Several of the studies combine hygrothermal simulation with in-situ testing. Relative parameters from both in-situ testing and simulations are expanded upon.

Craven and Garber-Slaght (2014) investigated varying amounts of exterior insulation foam on residential structures in subarctic climates. The variables studied were the presence or absence of a polyethylene vapour retarder, ratio of RIS-values between exterior insulation and interior cavity insulation, interior relative humidity, and air pressure within conditioned space. The researchers monitored the moisture content of the plywood sheathing and studs. Relative humidity and temperature was collected at the inside of the sheathing and outside of the housewrap, beneath the exterior insulation. The research concluded that the ratio of external insulation was more important than the presence of a vapour barrier however the vapour barrier still had a significant role in the hygrothermal performance of the wall. A ratio of $68 \%$ of RSI -value in the exterior insulation was recommended to limit the build up of moisture within the wall. The presence of significant exterior insulation reduced the risk of moisture accumulation and damage on the vulnerable sheathing in a cold climate. It should be noted that the expected ratio of external vs. internal insulation will be different for milder climates.

Arena, et al. (2013) conducted field testing of a RSI-7.04 double stud wall in climate zone 5A. Several criteria were used for assessing hygrothermal performance of the enclosure including condensation potential, moisture content thresholds $(<20 \% \mathrm{MC})$, drying capacity and potential 
for mould growth. In-situ data collection included moisture content of studs and sheathing, relative humidity, and temperature. Sensor set up is shown in Figure 2-9.

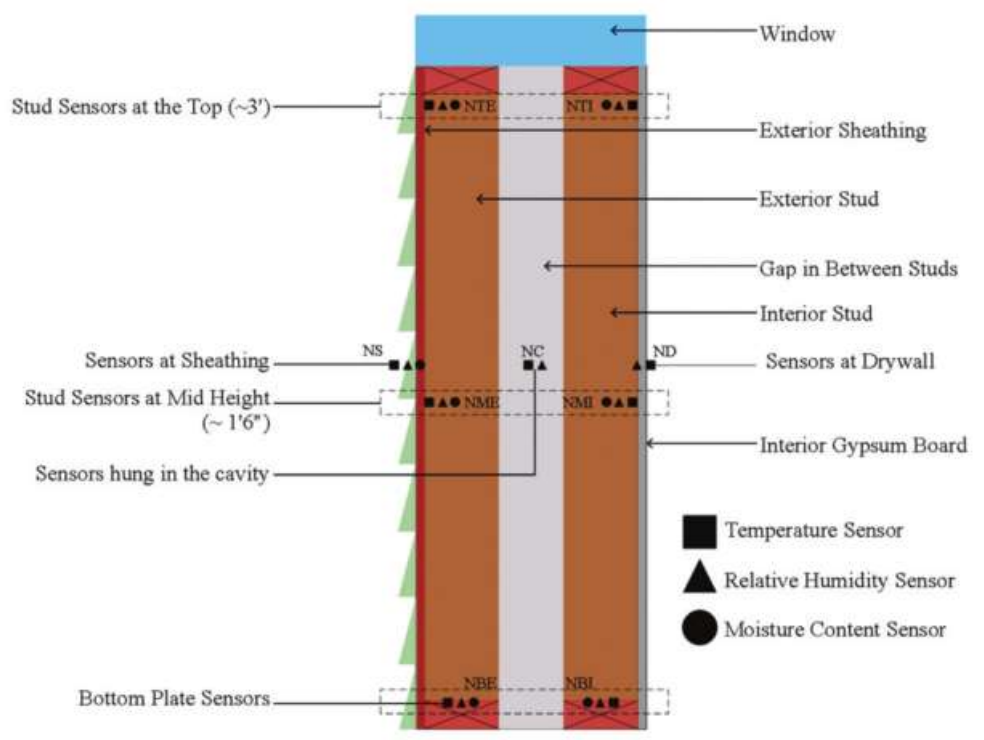

Figure 2-7 : In-Situ Double Stud Wall (Arena, 2013)

Although the wall assembly is different from the proposed enclosure techniques for monitoring the in-situ hygrothermal performance and defining performance metrics are useful for this research.

Hygrothermal simulations using WUFI was also completed in this study however models were not calibrated. ASHRAE 160 methods for the calculation of interior air conditions was used during simulations. Predicted RH using ASHRAE 160 was higher than measured data. Both walls (north and south) failed ASHRAE standard 160 30-day criteria for mould growth when modelling was conducted however the paper states that standard may be too conservative

Glass et. al. (2015) preformed field testing on nine variations of traditional wood frame walls, two of which had external insulation installed. Walls faced both north and south directions to account for differences in solar radiation exposure. Test huts were located outside of Washington, D.C (Zone 4A). Field sensor installation included temperature, relative humidity, and moisture content. Moisture content pins were placed in the bottom plate, two elevations on the stud, and three elevations on the OSB sheathing. The addition of external XPS lowered the moisture content of the sheathing as compared with similar traditional walls. The sheathing temperatures were higher during winter months for the two walls with exterior insulation. The 
exteriorly insulated wall with less interior insulation had higher sheathing temperatures due to increased heat flow to the sheathing. This research provided additional information on field collection methods, as well indicated that the addition of external insulation would warm up the sheathing temperature. This reduced moisture content and condensation potential in Washington DC compared with standard wood frame construction. This research did not investigate the implications of adding permeable insulated sheathing. The authors conducted hygrothermal simulations but noted significant divergences between simulations and field results, in some cases up to $\sim 7 \%$ different.

Glass, Yeh, and Herzog (2004) investigated temperature, relative humidity, and moisture conditions in north and south facing wall assemblies with vapour open and vapour tight exterior insulation. The walls were monitored in a field test structure in a Marine 4 climate zone for a two-year period. The test walls comprised of $38 \mathrm{~mm} \times 89 \mathrm{~mm}$ stud construction with fibreglass batt insulation within the stud cavity. One of the test walls had $32 \mathrm{~mm}$ of exterior mineral wool, while the other had $25 \mathrm{~mm}$ of XPS insulation. The mineral wool wall additionally had a spunbonded polyolefin house wrap (SBPO) on the sheathing as a weather resistance barrier. This study provided more information regarding sensor setup within the enclosure. Interior conditions were set as $21^{\circ}$ and $50 \% \mathrm{RH}$, except when ambient conditions exceeded $50 \%$. The same interior conditions have been proposed for this research. Weather collection included, wind speed, wind direction, precipitation, vertical and horizontal pyranometers. WUFI Pro simulations were also undertaken, however they were not calibrated. General trends from simulations were $\sim 4-5 \%$ different from measured values. OSB sheathing was split into $3 \mathrm{~mm}$ slices for more accurate measurements of simulated MC. Field testing showed similar performance between XPS and MW walls, however, simulations indicate that MW walls dry quicker than the XPS walls.

The National Research Council of Canada investigated the hygrothermal response caused by adding either permeable (64mm of mineral wool) or impermeable exterior insulation (50mm of XPS) to a standard wood frame wall in the Ottawa, Ontario climate (Maref, et. al.,2010). Walls were exposed to natural conditions on one side while interior conditions were carefully controlled. Results concluded that the air and vapour permeance of the exterior insulation had an impact on the flow of moisture to the outside during the winter time and affected moisture flow 
inwards during humid early summer conditions. The wall enclosure with mineral wool insulation experienced lower sheathing moisture content during the air injection phase than the XPS wall. The addition of external insulation reduced the chance of interstitial condensation, however both walls experienced interstitial condensation during the winter and dried by spring without damage.

Smeagle et. al. (2013) conducted field testing on three different wall types in Coquitlam, BC (Climate zone 4C). One of the wall types included $38 \mathrm{~mm}$ of exterior XPS insulation on a typical $38 \mathrm{~mm} \times 140 \mathrm{~mm}$ wood stud frame. Under normal operating conditions the enclosures OSB sheathing with external XPS's had lower moisture content than the comparable standard wall. Moisture content was always less than 13\%. An interior air condensation potential analysis was completed, where sheathing temperature was compared against indoor air dew point temperatures. A similar analysis is proposed for this analysis. The XPS wall had the least number of potential hours due to increased sheathing temperatures. The report concluded that the inclusion of $38 \mathrm{~mm}$ of XPS insulation improved moisture performance of standard wood frame walls in the Vancouver climate. The wall comparison analysis used both sheathing moisture content and interior air condensation potential as methods to analyze the hygrothermal performance of in-situ walls. Similar techniques are suggested as a means to measure the performance of the proposed enclosure.

McClung et. al. (2012) field tested the drying potential of cross laminated timber walls (CLT) with built in moisture at the time of construction. The authors analyzed 16 different CLT construction types including different types of external insulation that included mineral wool and EPS. Wall types were installed into a field testing structure located in Waterloo, Ontario. Temperature, relative humidity and moisture content was monitored at several locations through the assembly. Conclusions from this analysis indicated that high permeance insulated sheathing, such as mineral wool, increased drying potential as compared with lower permeable insulations. Fox (2014) combined in-situ testing and hygrothermal simulation for six different high thermal resistance walls in a southern Ontario climate. Walls were assessed by analyzing condensation potential and mould and decay risks using measured moisture content, temperature, and relative humidity. Data from the walls were also used to calibrate one-dimensional WUFI simulation models. One test wall included $76 \mathrm{~mm}$ of external mineral wool board. This was fastened to a 
typical $140 \mathrm{~mm} \times 38 \mathrm{~mm}$ wood stud frame filled with $140 \mathrm{~mm}$ of fibreglass insulation. It should be noted that a polyethylene barrier has been included in this wall, while the current research does not include a poly-barrier. Field test walls were installed in North and South orientations. The walls were instrumented with temperature, relative humidity, moisture content, and heat flux plates. Sensor arrangement can be seen in Figure 2-10.

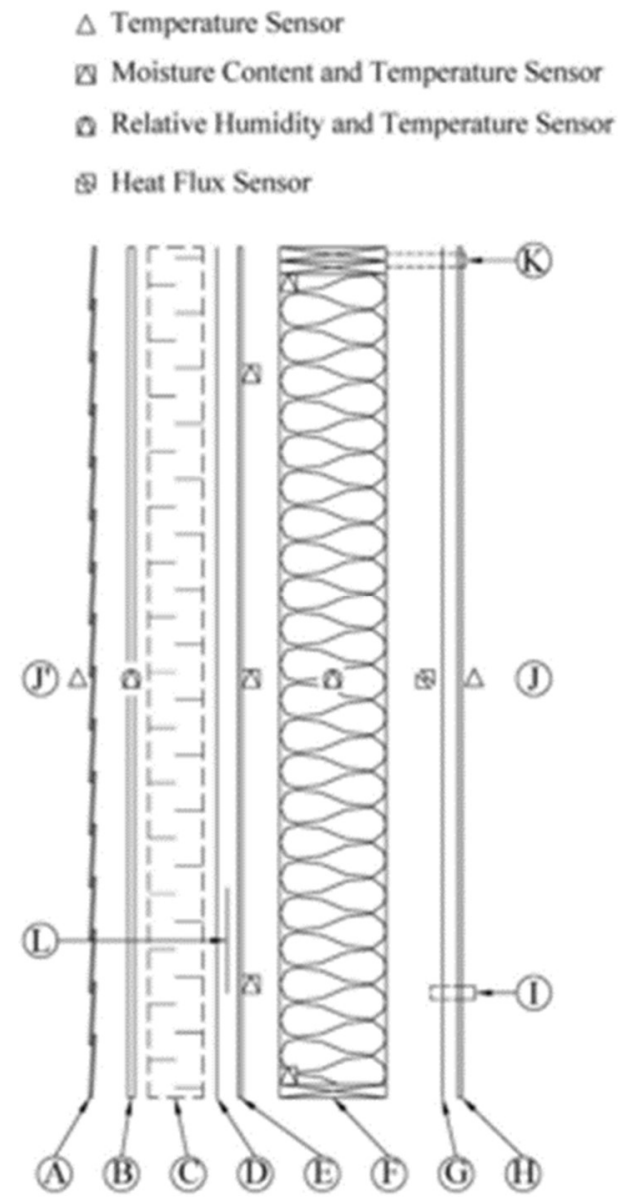

Figure 2-8 : In-Situ Sensor Arrangement (Fox, 2014)

Field testing including assessing the walls for interior air condensation potential and absolute moisture content of the sheathing. Condensation was assessed by determining the number of hours that the interior of the OSB sheathing was below the interior air dew point or above $100 \%$ RH based on recorded sensor data. The mineral wool insulated wall only experienced some condensation hours during the air injection period. The condensation was limited to the upper OSB sensor of the north wall. Mould and decay was assessed by three moisture content threshold limits. The bottom limit ranged from $16 \%-20 \%$ at a temperature greater than $5^{\circ} \mathrm{C}$ (onset of 
mould growth risk), while the middle ranged for $20 \%-28 \%$ at a temperature greater than $10^{\circ} \mathrm{C}$ (fast mould growth risk). The time when MC exceeded 28\% to until the moisture content of the wood dropped below $20 \%$ was assessed at the highest risk $\left(\mathrm{T}>10^{\circ} \mathrm{C}\right)$. OSB and stud framing were both assessed in the moisture content analysis.

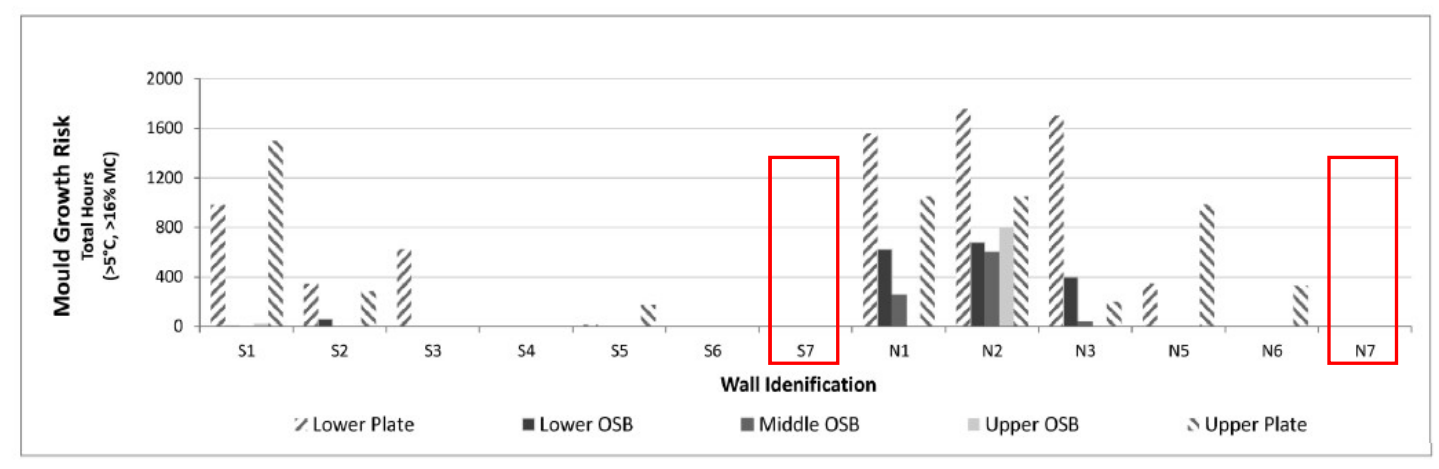

Figure 2-9: Results from In-situ Testing. (Fox,2014)

Results from this in-situ analysis indicated that the wall with external mineral wool did not experience any hours that exceeded the aforementioned criteria. S7 and N7 represent externally insulated walls with mineral wool. It was deemed that the mineral wall was not at risk of experiencing any mould growth or decay during the testing period.

Calibrated hygrothermal simulations of several wall was completed in this study. The research outlined and described several processes in using field data to calibrate WUFI-Pro models. Key methods used from the research were the solar data processing techniques and the calibration of the boundary conditions techniques.

The above studies had components involving in-situ investigation and sometimes coupled it with hygrothermal simulations. The studies above noted that external insulation provided better thermal protection of sensitive sheathings. The above studies focused on lower levels of external insulation. The studies presented next however examine larger levels of permeable external insulation, however, only completed the hygrothermal simulation component of analysis.

Lepage and Lstiburek (2013), completed a number of simulations using WUFI Pro to determine of having varying levels of exterior permeable insulation and potential implications caused by solar driven vapour drive in varying climates. The simulated mineral wool exterior insulation was modeled up to a thickness of $101 \mathrm{~mm}$. Moisture content of sheathings for a 3-year simulation period indicated that greater amounts of exterior insulation provide better hygrothermal 
performance in the Chicago climate (climate zone $5 \mathrm{~A}$ ). The sheathing was divided into $\sim 3 \mathrm{~mm}$ slices to provide relevant moisture content numbers as WUFI averages MC over an entire layer. Results also indicate that higher permeability weather resistant barriers and moisture storing claddings, like brick, increase the MC of sheathing when exposed to solar radiation. The placement of impermeable vapour barriers on the interior also increased peak MC of sheathing due to in-ward vapour drive. Results also indicated that the coldest climate simulated (International Falls - Zone 7) had the highest peak moisture content of sheathing, however, this was moderated with more external insulation.

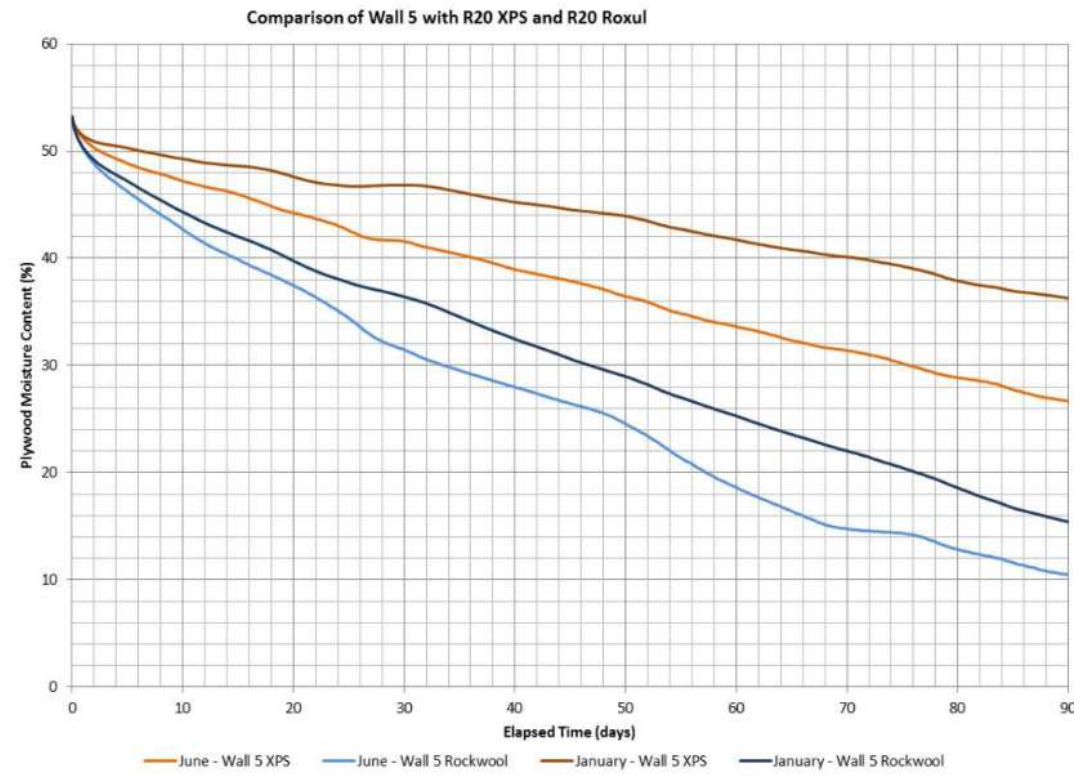

Figure 2-10 : Drying of Wall with Exterior Mineral Wool

(Smeagle and Straube,2011)

Smeagel and Straube (2011) compared the hygrothermal performance results of externally insulated walls with mineral wool against previous studies of similar insulated walls with XPS. The research was preformed with WUFI 4 and the climate was limited to Portland, Oregon. Four thicknesses of mineral wool installed on a $38 \mathrm{~mm}$ x $140 \mathrm{~m}$ wood frame wall were simulated. Thicknesses ranged from $32 \mathrm{~mm}$ to $127 \mathrm{~mm}$. Two situations were considered within this analysis and included wintertime diffusion condensation and drying potential. Results from this research indicate that all thicknesses of external mineral wool preform adequately under normal operating conditions in the Portland climate. Results from the drying analysis indicate that mineral wool walls dry quicker than equivalent RSI valued XPS walls. The wall with $127 \mathrm{~mm}$ of external mineral wool dried quicker in January than the other thicknesses of mineral wool. The research 
also identified the need to conduct field testing on enclosures with high level of external mineral wool.

\subsubsection{Summary of Moisture Management Review}

A number of the aforementioned studies have undertaken simulation and/or in-situ analysis to determine the hygrothermal performance of high RSI wall assemblies. The above studies investigated many different types of wall assemblies in a number of different climates. The hygrothermal performance of wood frame walls with external mineral wool was explored both in-situ and with computation simulation, however, used small amounts of exterior insulation and were primarily investigated in a Pacific Northwest climate. Limited analysis has been conducted on thick exterior mineral wool insulation amounts $(>76 \mathrm{~mm})$ and none have completed in-situ testing to properly define performance in Toronto and other cold climates. It was determined that in-situ testing and simulation calibration combined would provide more accurate predictive power to determine suitability of the proposed enclosure in Toronto and several other cold climates.

The proposed research methodology for in-situ analysis has been developed from the literature review and has been combined with information from Straube, Onysko, and Schumachers (2002) "Methodology and Design of Field Experiments for Monitoring the Hygrothermal Performance of Wood Frame Enclosures”. All in-situ testing on high-RSI or externally insulated walls included monitoring the temperature, relative humidity and moisture content of the enclosures at several locations and heights. The sensitive OSB sheathing was used as the primary location for gauging overall moisture performance. A number of studies used several different assessment methods as comparative tools. Three performance metrics have been selected for this research:

I. Moisture Content Analysis: The moisture content of the wooden structure will be monitored to assess the amount of time that is spent above $20 \%$. A MC of $20 \%$ has been discussed in some of the above studies as a threshold. The use of $20 \%$ also comes from a research review publication completed by Carll and Highley (1999) in an article titled "Decay of Wood and Wood-Based Products Above Ground in Buildings".

II. ASHRAE 160-2009 Criteria for Moisture-Control Design Analysis in Buildings: As an ASHRAE standard this has been used in a number of North American hygrothermal 
analysis. Experts have noted that the standard is too stringent and does not reflect decay properly. ASHRAE 160 recently been changed (ASHREA, 2016) to reflect the aforementioned strict criteria. ASHRAE 160 provides a very conservative creation for hygrothermal performance and is listed below;

- The running 30-day $\mathrm{RH}$ average must remain below $80 \% \mathrm{RH}$ when temperatures are greater than $5^{\circ} \mathrm{C}$ and below $40^{\circ} \mathrm{C}$

III. Interior Air Condensation Potential: This metric assesses the dew point temperature of the interior air and compares it to the temperature of the sensitive sheathing to determine if condensation may form. To achieve condensation interior air must be directly in contact with sheathing. Typically, limited amounts of interior air come in contact with the sheathing, unless significant air leakage exists within the assembly. This is another conservative measure for assessing hygrothermal performance.

Coupled with the development of in-situ analysis procedures and assessment metrics, general procedures for hygrothermal simulation were explored in the literature review. The program WUFI-Pro, which is commonly used in the above studies, has been selected to preform simulations. General calibration procedures have been outlined in Fox (2014) and are utilized within this research although with modification. The literature review has also identified many factors that influence the hygrothermal performance of enclosures. Many variables considered in the parametric analysis have been seen to influence hygrothermal performance of enclosures in the aforementioned studies reviewed. In summary, this review has identified the means and methods and value of coupled in-situ and calibrated hygrothermal simulation for the proposed enclosure approach.

\subsection{Experimental Methodology}

To ascertain the differences in nominal RSI compared with the in-service effective RSI and to determine the hygrothermal performance and sensitivity of the proposed wall enclosure, in-situ field testing was combined with calibrated simulation. The in-situ testing provided actual inservice performance relative to real world conditions, and data from testing was used to calibrate computational models. Computer simulation was used to assess theoretical and alterative practical conditions, which were unable to be collected during field testing. Both in-situ testing and computer simulations were divided into two elements; (i) Thermal Resistance and (ii) 
Hygrothermal Performance. While both elements were dependent on the other, there exists enough of a distinction between the two to treat them as such.

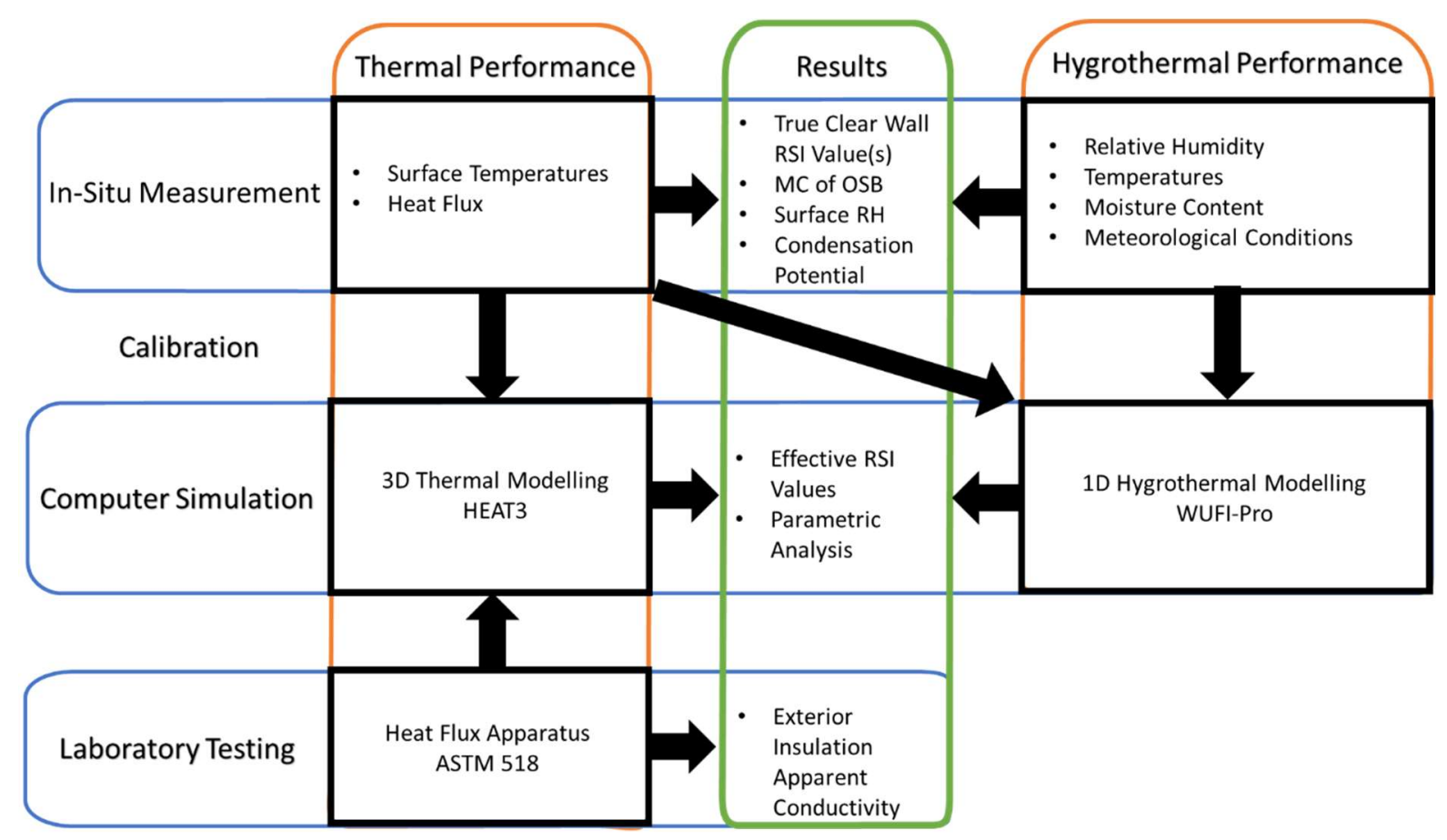

Figure 3-1 : Experimental Methods Interaction Diagram

Figure 3-1 represents the relationship between in-situ measurements, computation simulations, laboratory experiments and thermal resistance/hygrothermal performance. The coloured rectangles represent that different categories and the arrows indicate a relationship between the measurements or actions and the next phase of the research. For example, thermal conductivity testing was completed on exterior insulation in the laboratory. This information was compared with in-situ and computational values for the thermal performance. The output from each of the actions and measurements lead to the results of the study. The methodology of the in-situ testing will be expanded upon further in this section. The computer and laboratory methodology are explained further within their respective sections.

\subsection{In-situ Testing}

The intended purpose of the in-situ testing was to gain insight as to how the proposed enclosure preformed in-service in the Toronto climate and use the data for simulation calibration purposes. As outlined in the literature review, enclosures rarely performed exacted predicted in a 
field setting due to multiple uncontrollable variables. To test the in-situ performance of the wall enclosure a test structure was constructed in the fall of 2014. The test structure was placed at the Evergreen Brickwork facilities and instrumented with numerous sensors. This section will explain the in-situ set-up and provide information on data collection methods.

\subsubsection{Site Layout}

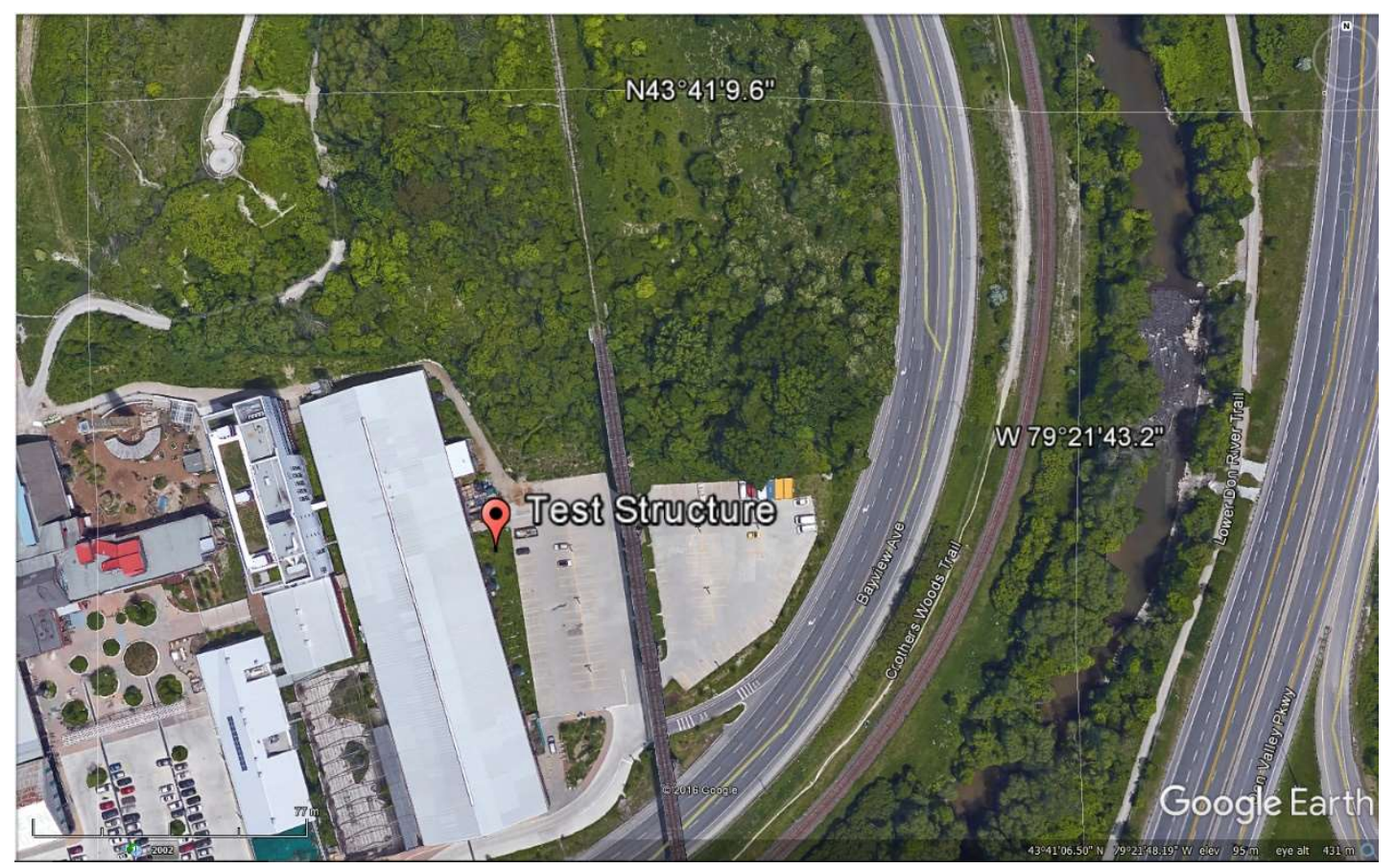

Figure 3-2 : Site Overview (Courtesy of Google Earth) 
The test structure is located on the eastern side of the Evergreen Brickworks property in an opening east of the Kiln building and west of the overflow parking lot. This clearing contained tall grass and shrubbery during the spring/summer months. Several objects had implications on direct solar radiation reaching the test structure including a tree directly to the south of the structure and the Kiln building. These objects had limiting effects to the data however, as the tree only marginally shaded one sensor location during periods of the summer, and the Kiln building only shaded the structure during the late evenings in the summer. Seasonal environmental changes however had a large impact on data as is discussed in Section 4.6.

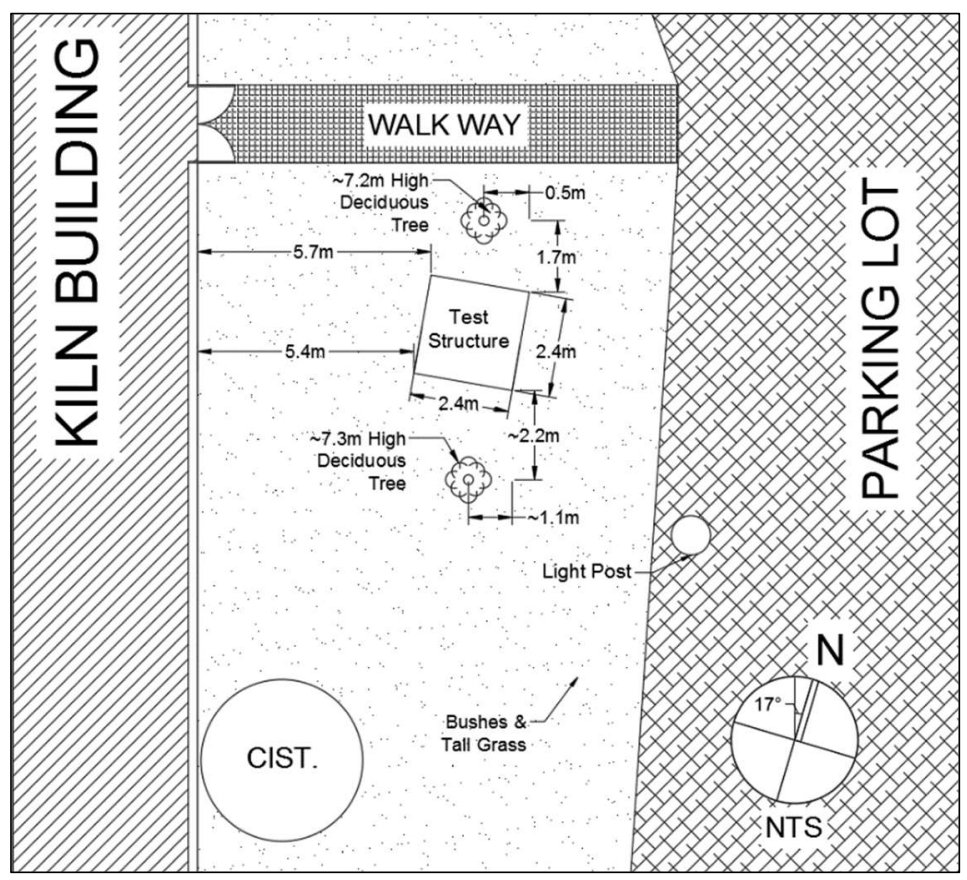

Figure 3-3: Site Layout 


\subsubsection{Test Structure}
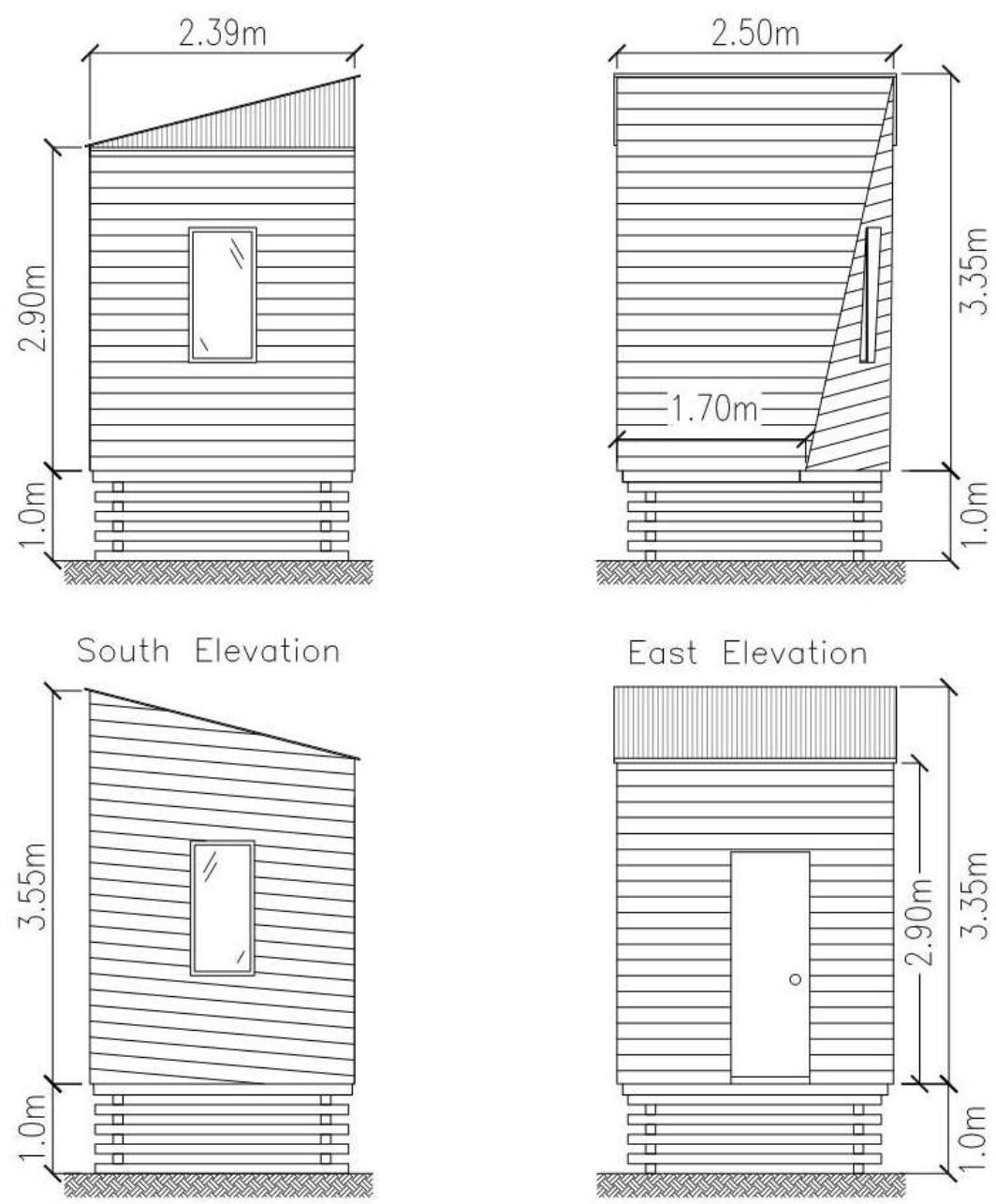

Figure 3-4 : Test Structure Elevations

The test structure was built in the summer and fall of 2014 by a local architecture firm with the help of contractors. The test structure was built to assess the constructability of the proposed envelope and the unique shape of the southern wall. The design of the test structure was completed prior to engagement with Ryerson University. Structure dimensions and elevation can be seen in Figure 3-4 and Figure 3-5. The structure was moved from its original location during the summer of 2015 to its present location at the Evergreen brickworks. Due to the original purpose of testing constructability the test structure exhibited some distinct features which had implications on data collection. 

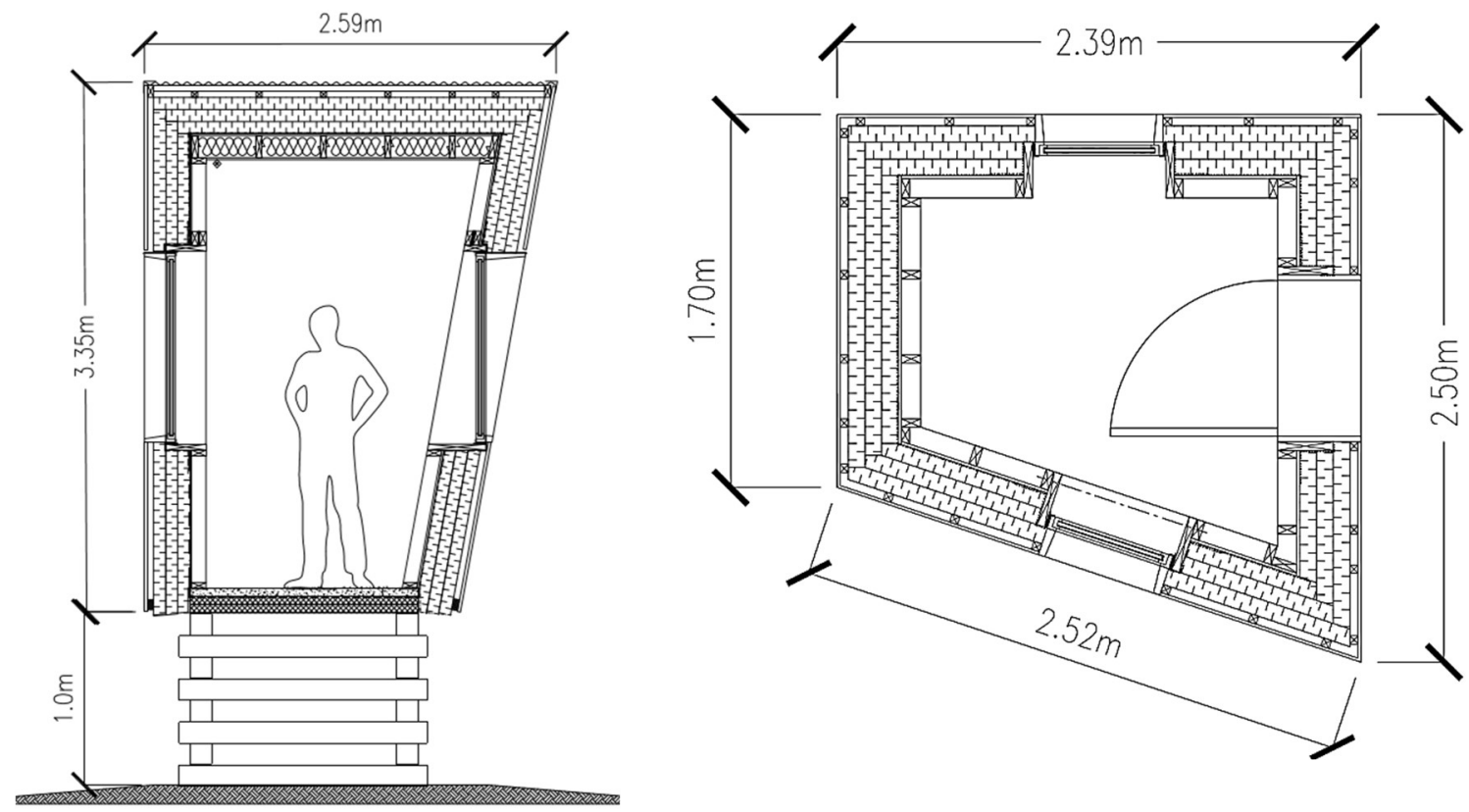

Figure 3-5 : Test Structure Section (Left) Test Structure Plane (Right)

- Slanted south wall: The southern wall was designed with a curve that can be seen in Figure 3-4. To limit the impact of the slanted wall, the sensors were installed on the eastern side of the window. This portion of the wall was essentially vertical and perpendicular to grade. The curvature of the wall, however, forced the southern façade to be oriented at $195^{\circ}$, instead of directly south. Implications from this orientation are explained in Section 4.6 Hygrothermal Calibration. The slanted wall also created issues for the installation of the rigid fibre board as explored in Section 4.1.3.10 South Wall Summary.

- Irregular framing: The southern wall had narrow framing $(\sim 300 \mathrm{~mm})$. The northern wall had more typical framing spacing of $406 \mathrm{~mm} \mathrm{c/c}$.

- Small volume: The interior floor area of the structure is approximately $2.79 \mathrm{~m}^{2}$ while the floor to ceiling height is $2.74 \mathrm{~m}$. This equates to a volume of approximately $7.65 \mathrm{~m}^{3}$. The small nature of the hut resulted in drastic changes to interior conditions when minor events occurred.

- Windows: The test structure was built with windows on both the southern and northern wall. The southern window was covered (on the interior side) to limit the impact of direct solar radiation on interior sensors. 
- Unknown Framing Lumber: The species of lumber used for studs and plates is unknown. The wood has been labeled as S-P-F. The lumber is assumed to be black spruce for the purpose of this research.

The particulars mentioned above have implications on the collected data. The implications of each feature have been discussed in more detail in relevant sections. It should also be noted that the initial structure was not insulated between the studs and insulation was added to the sensors locations and the adjacent stud spaces to limit three-dimensional heat transfer effects.

\subsubsection{Enclosure Test Wall}
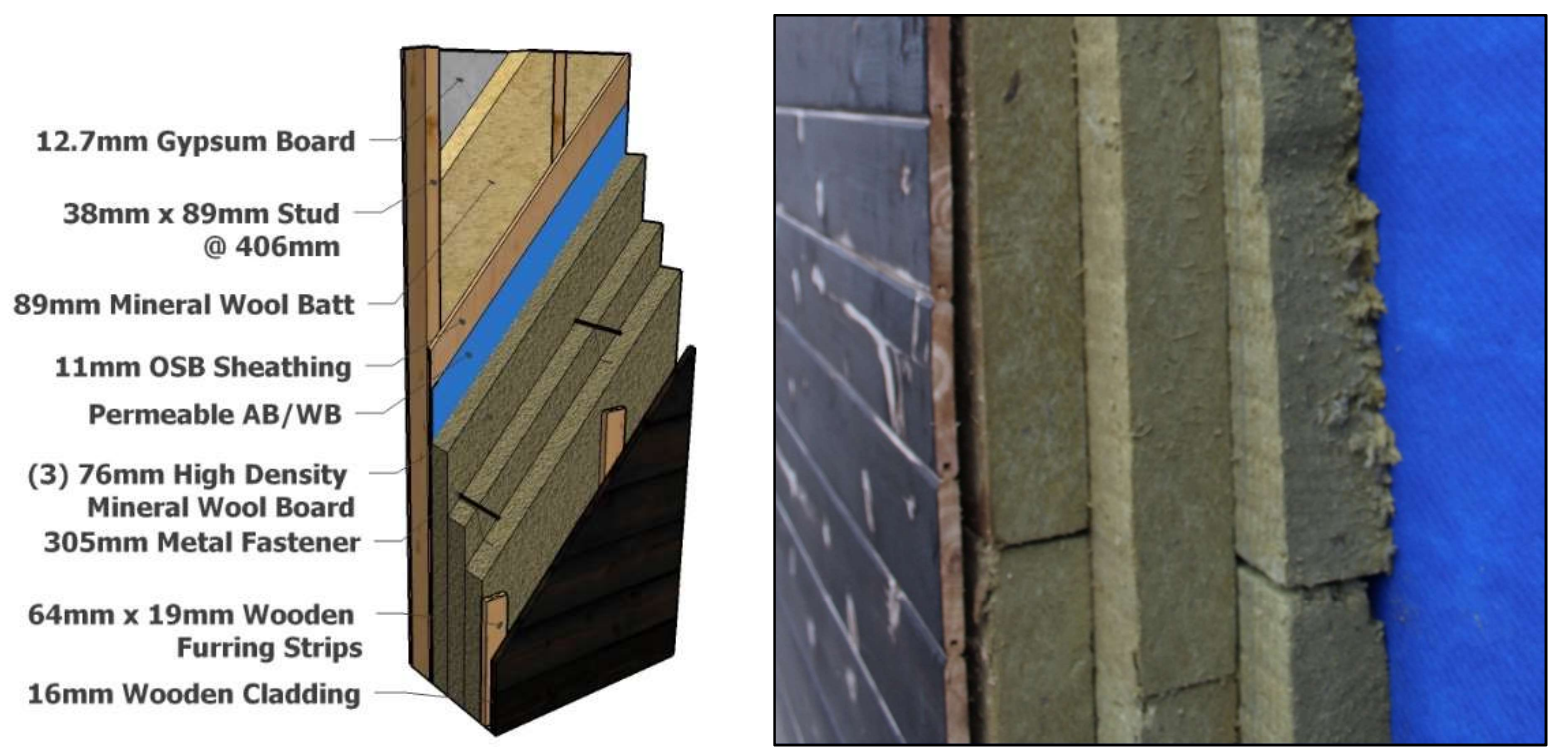

Figure 3-6:Enclosure Test Wall Isometric Drawing and Sectional Photo

As shown in Figure 3-6, the field-tested enclosure consists of $229 \mathrm{~mm}$ of high density mineral wool board on the exterior side of a $38 \mathrm{~mm} \times 89 \mathrm{~mm}$ standard wood frame construction. The external mineral wool boards were fastened back to the structure with $305 \mathrm{~mm}$ long metal screws with $4.8 \mathrm{~mm}$ diameters spaced at $305 \mathrm{~mm}$. Metal fasteners penetrate wooden furring strips and exterior insulation and were imbedded into the internal stud structure. Charred cedar plank cladding is fastened to the furring strips. A vapour permeable weather and air barrier wrapped over the oriented strand board (OSB) sheathing. Mineral wool batt insulation $(89 \mathrm{~mm})$ had been placed between the studs. Specific products used in the enclosure are listed in Table 3-1. 
Table 3-1: Enclosure Specific Products

\begin{tabular}{|c|c|c|}
\hline Enclosure Material & Thickness & Product \\
\hline Gypsum & $12.7 \mathrm{~mm}$ & CGC Sheetrock Ultralight \\
\hline Mineral Wool Batt & $89 \mathrm{~mm}$ & Roxul Comfortbatt - R14 \\
\hline Air/Weather Barrier & $23 \mathrm{mils}$ & Henrys BlueskinVP ${ }^{\circledR} 160$ \\
\hline Mineral Wool Board & $(3) \times 76 \mathrm{~mm}$ & Roxul Comfortboard 110 \\
\hline
\end{tabular}

\subsubsection{Sensor Locations}

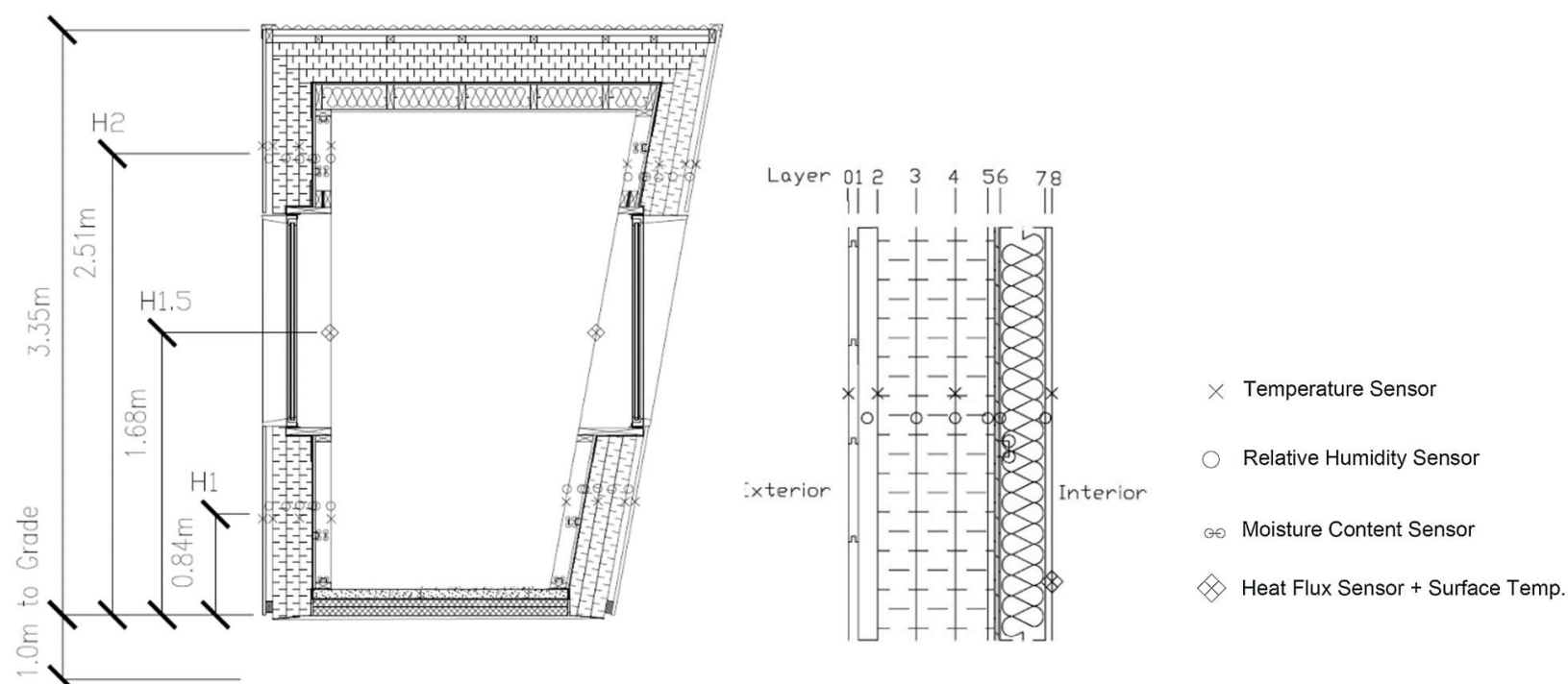

Figure 3-7 : Sensor Location Diagram (i) Structure Section (ii) Envelope Section (iii) Sensor Types

Sensor placement was based on similar studies in Section 2.2. The intention was to capture stratification and local particularities, as well as assess different orientation conditions. Sensors had been installed on both the north and south wall (Figure 3-8). All sensors had been installed in the middle of the stud cavity, except stud MC sensors, to limit three dimensional effects. MC sensors were located on OSB sheathings, bottom plates and top plates. Relative humidity and temperature sensors had been layered through the enclosure at height 1 and height 2 allowing for both vapour and temperature profiling. Temperature sensors were located on interior and exterior surfaces providing valuable boundary condition information. Heat flux plates and corresponding thermocouples had been placed at height 1.5 , which is roughly half the height of the structure. 


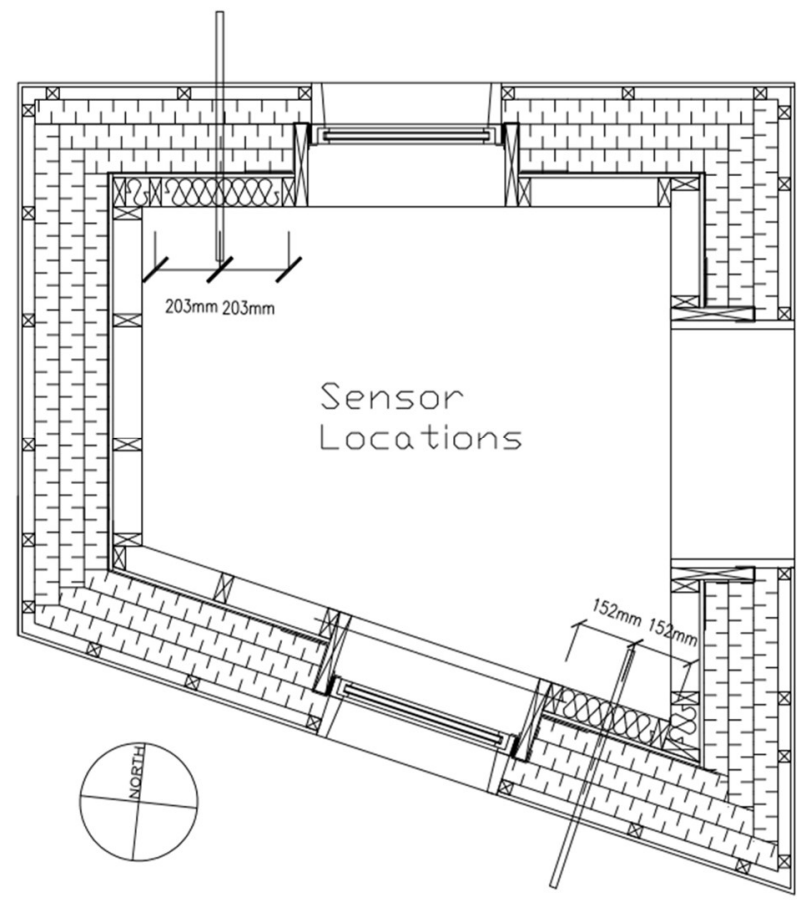

Figure 3-8: Test Structure Plan View

Sensor naming convention uses orientation, height, layer and type of sensors for quick reference. An example of sensor labelling is provided in Figure 3-9. Layers are labeled from the exterior to the interior and half number steps fall between the labeled layers. Sheathing and stud MC sensors are labeled with an A or B respectively. See Appendix B for complete sensor list. It is recommended that sensor list and layer naming information be printed for reference while reviewing this document.

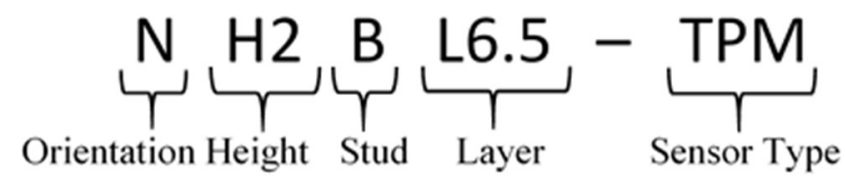

Figure 3-9 : Sensor Naming Convention

\subsubsection{Sensor Installation}

Enclosure sensor installation occurred in December of 2015 and January of 2016. The cladding and exterior insulation had to be dismantled to install the inter-layer sensors. RHT and T sensors were taped and stapled to their corresponding backing layer. Adhesion materials were kept away from sensors to limit impact of material interference. The temperature sensors located on the cladding were adhered using black tape, except for the thermocouples used with the heat flux kit. 
The black thermocouples were installed with clear tape. The intention was to maintain similar emissivities as the cladding.

\subsubsection{Sensor Installation Errors}

Several installation errors occurred during the enclosure sensor install. Sensor installation errors were not detrimental to results and are noted for clarity.

- The RHT sensor located in the south wall at height two and at layer three (Sensor \# SH2L3-TRH) was accidently installed in layer four. RH and T data collected is very similar. The error was only noticed during data analysis period.

- The thermistor for the moisture content sensor located in the north wall at height one and installed in the stud (Sensor\# NH1BL6.5-TPM) stopped working shortly after installation. An additional single thermistor was installed next to $\mathrm{MC}$ sensor to collect temperature data.

\subsubsection{Sensor Information}

The enclosure sensors were constructed at George Brown College (GBC) with the help of the staff and students in the building science department. Construction occurred between September and November of 2015. Sensors that have been constructed include; relative humidity and temperature (RHT), moisture content and temperature (TMP - temperature moisture pins), and temperature $(\mathrm{T})$. 


\subsubsection{Temperature}

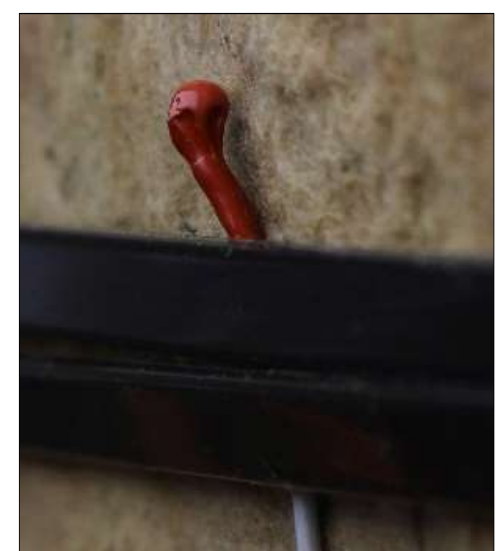

Figure 3-8 : Temperature Sensor

The temperature sensors used in this study are TDK (C) $10 \mathrm{k} \Omega$ thermistor types (Model \# NTCG163JF103FT1). Thermistors had been included on the RH, MC boards but were individually housed for pure temperature measurements. The temperature only sensor consisted of a very small ( $\sim 1 \mathrm{~mm})$ resistor (thermistor) that was soldered to wires and then coated with nonconductive acrylic paint, see Figure 3-10. Thermistors were soldered to RH and MC silicon boards and wired accordingly. Temperatures were determined through the change in resistance and a half bridge wired connection into the DAU. The resistance (in ohms) was than entered in Equation 1 to determine temperature. Numeral coefficients were determined using a best-fit software (www.mycurvefit.com) and information from the thermistor data sheet (TDK, 2015). The thermistor sensor has a $1 \%$ accuracy reading of the resistivity.

$$
T=f\left(R^{5}\right)+e\left(R^{4}\right)+d\left(R^{3}\right)+c\left(R^{2}\right)+b(R)+a
$$

$\mathrm{T}=$ Temperature $\left({ }^{\circ} \mathrm{C}\right)$

$\mathrm{R}=$ Resistance $(\Omega$-ohms $)$

$a=99.19091984$

$b=-90.25335536$

$c=20.1334894$

$d=-4.950180285$

$e=0.970147194$

$f=-0.094470561$ 


\subsubsection{Relative Humidity and Temperature (RHT)}

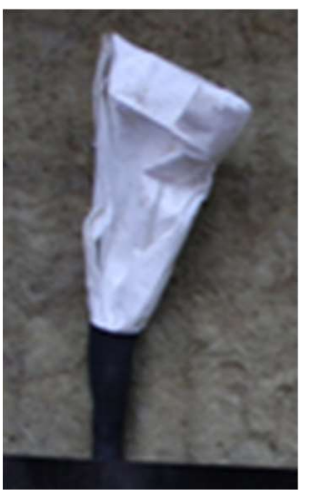

Figure 3-9: Relative Humidity and Temperature Bundle

The relative humidity sensors used in this study were the Honeywell@ HIH-5031 Humidity Sensors. The humidity sensor was attached to a silicon chip board for wiring and was paired with a thermistor for temperature readings. The RHT sensor was packaged in a spun bonded polyolefin bag (SPBO) and shrink wrapped with rubber at the wire end to ensure no liquid water could enter the assembly. See Figure 3-11.

These humidity sensors use a linear direct output method, whereas a known voltage is inputted into the sensor and the output voltage is linearly dependent upon ambient relative humidity. A supply voltage of $5 \mathrm{Vdc}$ is applied to the humidity sensor and the RH is determined by Equation 2. The accuracy of the sensor is $\pm 3 \%$ in the range of $10-90 \%$ and $\pm 7 \%$ in the $0-10 \%$ and 90 $100 \%$ RH range (Honeywell, 2010).

$$
R H=\left(m V_{\text {out }} \cdot 0.031446654\right)-23.81731
$$

$\mathrm{mVout}=$ Voltage output (milliVolts)

RH $=$ Relative Humidity (\%) 


\subsubsection{Moisture Content Pins and Temperature}

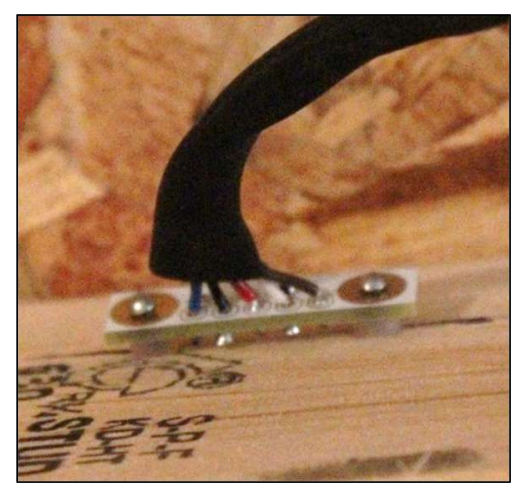

Figure 3-10: Installed Moisture Content Pin Board

The moisture content sensors used in this study were the conductive insulated two-pin type. A temperature sensor (thermistor type) was installed on the chip board. It was noted that temperature measurements should occur at depth of moisture content reading, however, the slight change in temperature should only marginally affect the MC reading. Arena et. al. (2010) determined through simulation that surface temperatures of wood was less than $0.5^{\circ} \mathrm{C}$ difference than monitoring depth. A $10^{\circ} \mathrm{C}$ change in wood only has a change in the range of $0.10-0.15 \%$ MC reading (Straube et al, 2002).

Electrode pins were spaced at $25.4 \mathrm{~mm}$ and were installed parallel to the grain of the studs. Pins were $14 \mathrm{~mm}$ long and readings were taken at a depth of $7-9 \mathrm{~mm}$ into the studs and OSB due to plastic stoppers installed beneath the chip board. Insulating varnish was applied to the length of the pin except at the ends. The moisture content reported relates to the location of the uninsulated portion of the pins ( $7-9 \mathrm{~mm}$ into the wood/OSB). MC pins were installed at approximately $25 \mathrm{~mm}$ away from the sheathing into the plates and the studs. To avoid any electrical interference with MC pins, sensors were placed to avoid knots and metal fasteners. An approximate $12 \mathrm{~V}$ current (dependent on supply voltage to DAU) was sent through the pins and the resistivity of the wood was measured by determining the drop-in voltage caused by the wood. Resistivity was calculated by using a number of resistors in series and parallel. A mathematical equation found in Appendix A applies appropriate factors based on resistors used within the circuit. The moisture content of the wood was than determined by converting the resistivity of the wood into moisture content by Equations 3 and 4 . 
Studies conducted by US Forest labs have looked extensively at the moisture content of Douglas-Fir and corresponding resistivity values. Equation 3 has been developed to translate measured resistivity values to moisture content for Douglas Fir.

$$
\log M C_{u}=2.99-2.113 \cdot\left(\log \left(\log R_{w}\right)\right)
$$

$\mathrm{MC}_{\mathrm{u}}=$ Uncorrected Moisture Content (\%) for Douglas-Fir

$\mathrm{R}_{\mathrm{W}}=$ Measured Resistivity of Wood $(\Omega-\mathrm{Ohms})$

Equation 4 was developed by Garrahan, and outlined in Straube et. al. (2002). to convert moisture content readings of different wood species. The error of using this equation for different species is unclear however may be in the order of $0.5 \%$. However, some individual readings may be as much as $5 \%$. Species variables pertinent to this study can be found in Table 3-2 and were taken from Straube, Schumacher, Onysko (2002). The calculations used within the study can be found in the field data processing code, which is located in Appendix A.

$$
M C_{c}=\left\{\left[\frac{M C u+0.567-0.0260 t+0.000051 t^{2}}{0.881 \cdot(1.0056 t)}\right]-b\right\} / a
$$

$\mathrm{MC}_{\mathrm{c}}=$ Moisture Content Correct $(\%)$

$\mathrm{MC}_{\mathrm{u}}=$ Moisture Content uncorrected Reading (\%)

$\mathrm{t}=$ Temperature $\left({ }^{\circ} \mathrm{C}\right)$

$\mathrm{b}=$ Specie Specific Coefficient $b$

$\mathrm{a}=$ Specie Specific Coefficient a

\section{Table 3-2 : Moisture Content Species Variables}

\begin{tabular}{|c|c|c|}
\hline Species & $\mathrm{a}$ & $\mathrm{b}$ \\
\hline OSB & 1.1114 & 0.366 \\
\hline Black Spruce & 0.8200 & -0.378 \\
\hline
\end{tabular}

It was noted in Straube et al. (2002) that the accuracy of applying the formula to the resistivity was in the range of $0.5 \%$ overall with as much as $2.0 \%$ for individual readings. It should be noted that the supply voltage to the DAU had a large impact on moisture content results. When the supply voltage dropped, there was a noticeable decrease in moisture content. This was exemplified by sharp drops in MC data. The other implication from voltage supply dependency was noise caused by changes in test structure electric consumption. The effects of this were muted by the installation of a $12 \mathrm{~V}$ battery backup. 


\subsubsection{Heat Flux Kit}

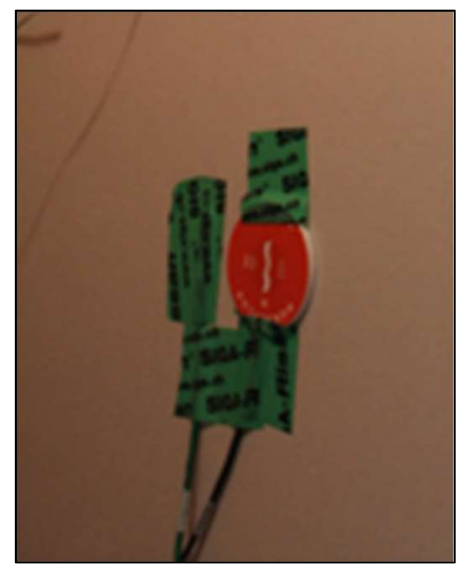

Figure 3-11 : HFP01 Plate and Thermocouple

Heat flux and surface temperatures taken at the middle height sensor location were provided by a packaged field testing kit. This kit was separate from the enclosure sensors and had its own data logger. The portable heat flux kit the Huskseflux TRYS01. This kit included, (2) HFP01 heat flux plates, (2x2) thermocouple type KX, and a CR1000 Data Logger.

The HFP01 Heat Flux plates measured thermal energy that passes through its sensing area. The HFP01 has a sensor area of $0.0008 \mathrm{~m}^{2}$. The sensors have an accuracy of $\pm 5 \%$. Plates were adhered to the wall with silicon gel, ensuring smooth contact with the drywall and eliminating the potential for trapped air. Tape was added to ensure longevity of the sensor placement. Location of studs was known prior to installation of heat flux plates. The heat flux plates were located mid-way between studs on the North and South wall.

Thermocouples were placed next to the heat flux plates on the interior and on the cladding on the exterior side. Thermocouples were type $\mathrm{kx}$ and had a differential temperature accuracy of $\pm 0.1^{\circ} \mathrm{C}$. (Huskeflux, 2004).

The data logger included in the kit was the Campbell Scientific CR1000. Data logger coding was provided by the manufacturer and can be found in Appendix C. Data was collected every second and averaged over a 10-minute period. Data was then averaged over an hour time step during processing. The total kit has an accuracy of $\pm 7 \%$ when calculating in-situ thermal resistance (Huskeflux, 2004). 


\subsubsection{Sensor Calibration}

A series of tests were completed on the sensors before installation to ensure each sensor properly worked and was calibrated. Calibration of the enclosure sensors occurred at GBC in November of 2016. Several testes were run on the RHT sensors including placement within a controlled environmental chamber where $\mathrm{RH}$ and $\mathrm{T}$ was maintained at $25^{\circ} \mathrm{C}\left( \pm 0.3^{\circ} \mathrm{C}\right)$ and $50 \%( \pm 2 \%) \mathrm{RH}$ and the use of the Omega Equipment RHCL-2 RH and T calibrating machine. The Omega Equipment RHCL-2 has an accuracy of $\pm 0.5 \% \mathrm{RH}$ and $\pm 0.2^{\circ} \mathrm{C}$. Conditions were kept the same for both pieces of equipment. Temperature sensors were tested with the OMEGA RHCL-2 equipment.

Moisture content silicon boards were tested to ensure circuit continuity with the use of a voltmeter. A $5000 \mathrm{Ohm}$ resistor was placed between the metal touch pads of the moisture content pin and the voltmeter was used to ensure the same resistance was measured within the wire circuit.

The TRSYS01 system was calibrated by the manufacturer prior to purchase, however, individual heat flux plates sensitivities had to be added into the data collection code. These sensitivities slightly modify readings for unique heat flux plates based on individual biases. The sensitivity adjustment can found in Appendix D.

\subsubsection{Data Acquisition Unit (DAU)}

A Campbell Scientific CR1000 data logger was used to collect enclosure sensor data and to control the interior air conditions. The data logger was programed with the help of staff at GBC. The complete code for collection can be found in Appendix C. Two Campbell Scientific multiplexers were used in conjunction with the data logger to account for the multitude of sensors used during the research. The multiplexors are essentially relay stations where input/output voltage from and to the data logger is relayed to the proper sensor.

Data was collected every two minutes for enclosure sensors. This data was then averaged over a 10-minute interval. The 10-minute average was then further averaged over an hour time span during processing. 


\subsubsection{Data Collection Periods}

Field data was collected from February $12^{\text {th }}$ to August $20^{\text {th }}, 2017$. The data was split into four arbitrary periods that represented changes in interior and exterior conditions of the test structure. The segmentation of data was useful during processing

Table 3-3: Data Collection Time Frames

\begin{tabular}{|c|c|c|}
\hline Collection Period & Time period & $\begin{array}{c}\text { \# of Hours } \\
\text { of Data }\end{array}$ \\
\hline Winter & Feb $12^{\text {th }}$ to March $20^{\text {th }}$ & 888 \\
\hline Early Spring & March $20^{\text {th }}$ to April $20^{\text {th }}$ & 744 \\
\hline Late Spring & April $20^{\text {th }}$ to May $20^{\text {th }}$ & 720 \\
\hline Summer & May $20^{\text {th }}$ to August $16^{\text {th }}$ & 1944 \\
\hline
\end{tabular}

\subsubsection{Issues with data collection.}

Power outages occurred twice during the data collection period; March $31^{\text {st }}$-April $1^{\text {st }}$ and July $1^{\text {st }}$ to July $8^{\text {th }}$. Battery backup provided power for the duration of the March $31^{\text {st }}$ to April $1^{\text {st }}$ and data was collected. Data was removed from dataset for July1st to July $8^{\text {th }}$ due to failure of the battery backup.

\subsubsection{Interior Conditions}

Interior conditions were controlled during the winter, early spring, and late spring by the DAU and an internal RHT sensor placed at $1.6 \mathrm{~m}$ above the floor in the middle of the test hut. The interior air was sampled every minute and adjusted as necessary. Heating was provided by a small space heater $(1500 \mathrm{~W}$ ) and humidity was provided by a space humidifier (Honeywell Cool Mist). Interior condition targets were set as $21^{\circ} \mathrm{C}$ and $50 \% \mathrm{RH}$.

Interior targets were exceeded at several points during the winter, early spring and late spring, however only for a short time. Interior air temperature drastically rose during the later portion of the late spring months and interior temperatures temporarily reached above $28^{\circ} \mathrm{C}$. An airconditioning unit was installed into the test structure to maintain target temperatures on June $6^{\text {th }}$, 2016. A hole was cut in test structure floor as an air in-take. Relative humidity was unable to be controlled during the summer months. 
Table 3-4 : Interior Air Climate Averages

\begin{tabular}{|c|c|l|l|l|}
\hline \multirow{2}{*}{ Collection Period } & \multicolumn{2}{|c|}{ Temperature } & \multicolumn{2}{c|}{ Mean RH } \\
\cline { 2 - 5 } & Mean & Std. Dev. & Mean & Std. Dev. \\
\hline Winter & $21.4^{\circ} \mathrm{C}$ & $0.22^{\circ} \mathrm{C}$ & $49.2 \%$ & $5.98 \%$ \\
\hline Early Spring & $21.2^{\circ} \mathrm{C}$ & $0.93^{\circ} \mathrm{C}$ & $51.9 \%$ & $1.39 \%$ \\
\hline Late Spring & $22.6^{\circ} \mathrm{C}$ & $2.00^{\circ} \mathrm{C}$ & $51.0 \%$ & $0.89 \%$ \\
\hline Summer & $22.6^{\circ} \mathrm{C}$ & $2.06^{\circ} \mathrm{C}$ & $61.4 \%$ & $13.97 \%$ \\
\hline
\end{tabular}

\subsubsection{Meteorological Data}

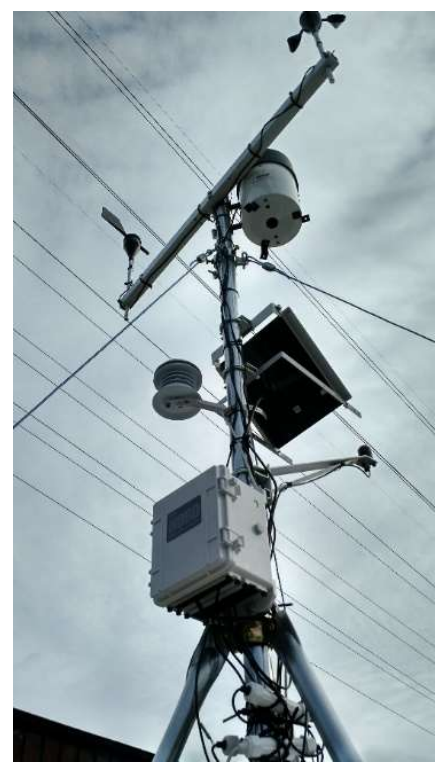

Figure 3-12: Micro-Climate Weather Station

A weather station was installed on top of the test hut to collect local climatic data in November 2016. The weather station can be seen in Figure 3-14. Table 3-5 has a list of weather data collected. Meteorological data was collected in 5-minute intervals and averaged over a timespan of 10 minutes. Data was later processed to average over an hour time-step. Global horizontal radiation was further processed and split into long and short wave components according to procedures laid out in Fox, 2014. Conversation methods can be found in Appendix A. 
Table 3-5 : Climate Data Sensor Information

\begin{tabular}{|c|c|c|c|c|}
\hline $\begin{array}{l}\text { Meteorological } \\
\text { Instrumentation }\end{array}$ & $\begin{array}{l}\text { Instrument } \\
\text { Name }\end{array}$ & $\begin{array}{c}\text { Measurement } \\
\text { Range \& } \\
\text { Resolution (Res.) } \\
\end{array}$ & Accuracy & $\begin{array}{l}\text { Height } \\
\text { Above } \\
\text { Grade } \\
\end{array}$ \\
\hline Wind Speed & $\begin{array}{l}\text { Onset Wind } \\
\text { Speed Smart } \\
\text { Sensor } \\
\text { S-WSA-M003 }\end{array}$ & $\begin{array}{c}0-45 \mathrm{~m} / \mathrm{s} \\
0.38 \mathrm{~m} / \mathrm{s} \text { (Res.) }\end{array}$ & $\begin{array}{c} \pm 1.1 \mathrm{~m} / \mathrm{s} \text { or } \pm 4 \% \text { of reading, } \\
\text { whichever is greater }\end{array}$ & $6.40 \mathrm{~m}$ \\
\hline Wind Direction & $\begin{array}{c}\text { Onset } \\
\text { Wind Direction } \\
\text { Smart Sensor } \\
\text { S-WDA-M003 } \\
\end{array}$ & $\begin{array}{l}0-355^{\circ}, 5^{\circ} \text {-degree } \\
\text { dead band } \\
\left.1.4^{\circ} \text { (Res. }\right)\end{array}$ & $\pm 5^{\circ}$ & $6.40 \mathrm{~m}$ \\
\hline $\begin{array}{l}\text { Atmospheric } \\
\text { Pressure }\end{array}$ & $\begin{array}{c}\text { Onset } \\
\text { S-BPB-CM50 }\end{array}$ & $\begin{array}{l}660 \text { to } 1010 \text { mbar } \\
0.1 \text { mbar (Res.) }\end{array}$ & $\begin{array}{l} \pm 3.0 \mathrm{mbar}(0.088 \text { in. } \mathrm{Hg}) \text { over full } \\
\text { pressure range at } 25^{\circ} \mathrm{C}\left(77^{\circ} \mathrm{F}\right) \\
\text { maximum error of } \pm 5.0 \mathrm{mbar}(0.148 \\
\text { in. } \mathrm{Hg}) \text { over }-40^{\circ} \text { to } 70^{\circ} \mathrm{C}\left(-40^{\circ} \text { to }\right. \\
\left.158^{\circ} \mathrm{F}\right)\end{array}$ & $5.16 \mathrm{~m}$ \\
\hline $\begin{array}{c}\text { Solar Radiation } \\
\text { (Global } \\
\text { Horizontal) }\end{array}$ & $\begin{array}{l}\text { Onset Silicon } \\
\text { Pyranometer } \\
\text { Smart Sensor } \\
\text { S-LIB-M003 }\end{array}$ & $\begin{array}{c}0-1280 \mathrm{~W} / \mathrm{m}^{2} \\
300-1100 \mathrm{~nm} \\
\text { (spectral range) } \\
1.25 \mathrm{~W} / \mathrm{m}^{2} \text { (Res.) }\end{array}$ & $\begin{array}{l}\text { Typically, within } \pm 10 \mathrm{~W} / \mathrm{m}^{2} \text { or } \pm 5 \% \text {, } \\
\text { whichever is greater in sunlight; } \\
\text { Additional temperature induced error } \\
\pm 0.38 \mathrm{~W} / \mathrm{m}^{2} /{ }^{\circ} \mathrm{C} \text { from } 25^{\circ} \mathrm{C} \text {. }\end{array}$ & $5.49 \mathrm{~m}$ \\
\hline Air Temperature & $\begin{array}{c}\text { Onset } \\
\text { Temperature/RH } \\
\text { Smart Sensor }\end{array}$ & $\begin{array}{l}-40^{\circ} \mathrm{C} \text { to } 75^{\circ} \mathrm{C} \\
0.02^{\circ} \mathrm{C} \text { at } 25^{\circ} \mathrm{C} \\
\text { (Res.) }\end{array}$ & $\pm 0.21^{\circ} \mathrm{C}$ from $0^{\circ}$ to $50^{\circ} \mathrm{C}$ & $5.59 \mathrm{~m}$ \\
\hline $\begin{array}{l}\text { Air Relative } \\
\text { Humidity }\end{array}$ & $\begin{array}{c}\text { Onset } \\
\text { Temperature/RH } \\
\text { Smart Sensor }\end{array}$ & $\begin{array}{l}0-100 \% \mathrm{RH} \text { at }-40^{\circ} \\
\text { to } 75^{\circ} \mathrm{C} \\
0.1 \% \mathrm{RH} \text { at } 25^{\circ} \mathrm{C} \\
\text { (Res.) }\end{array}$ & $\begin{array}{l} \pm 2.5 \% \text { from } 10 \% \text { to } 90 \% \mathrm{RH} \\
\text { (typical), to a maximum of } \pm 3.5 \% \\
\text { including hysteresis. }\end{array}$ & $5.59 \mathrm{~m}$ \\
\hline Normal Rain & $\begin{array}{c}\text { Onset Rain } \\
\text { Gauge Smart } \\
\text { Sensor } \\
\text { S-GBB-M002 }\end{array}$ & $\begin{array}{l}0-12.7 \mathrm{~cm} / \mathrm{hr} \\
0.2 \mathrm{~mm} \text { (Res.) }\end{array}$ & $\pm 1.0 \%$ at up to $20 \mathrm{~mm} /$ hour. & $6.22 \mathrm{~m}$ \\
\hline $\begin{array}{c}\text { Data Acquisition } \\
\text { Unit } \\
\end{array}$ & $\begin{array}{c}\text { HOBO RX3000 } \\
\text { Station - Wi-Fi } \\
\end{array}$ & N/A & N/A & $5.16 \mathrm{~m}$ \\
\hline
\end{tabular}

The individual sensors were attached to the $2.0 \mathrm{~m}$ metal pole at different heights or attached to the cross arm atop the pole. The pole was installed perpendicular to earth and was levelled using wooden blocks. Each installed sensor location was to limit any effects that other attachments may have had.

\subsection{Results Analysis and Discussion}

\subsection{In-Situ Thermal Analysis}

The in-situ thermal resistance was measured on both the North and South walls for all collection periods; however, the winter collection period was the focus of this research due to the greater temperature gradient (resulting in increased accuracy). A temperature difference of $10^{\circ} \mathrm{C}$ is 
preferred to minimize errors with the chosen technique used for analysis as higher heat flows allow for more certain calculations (Desogus et al., 2011) (Biddulp et. al. 2014). Layer analysis was not completed for the south wall due to solar radiation influences; however, three techniques have been presented to overcome the influence of solar radiation on thermal resistance calculations.

\subsubsection{Site Selection}

Heat flux plates (HFP01) and corresponding thermocouple pairs were placed at mid-height within the test structure. Mid-height placement adequately represents average interior air temperature stratification, as well allows for averaging of temperature sensors located at height 1 and height 2. Installation of heat flux plates and thermocouples followed the procedures specified in ASTM C1046 In-Situ Measurement of Heat Flux and Temperature on Building Envelope Components.

Heat flux plates were placed at the mid-point between studs to minimize three dimension effects and thermal imaging were completed to ensure temperature uniformity at sensor site shots show uniformity between studs see Figure 4-1 for example of imaging shot.
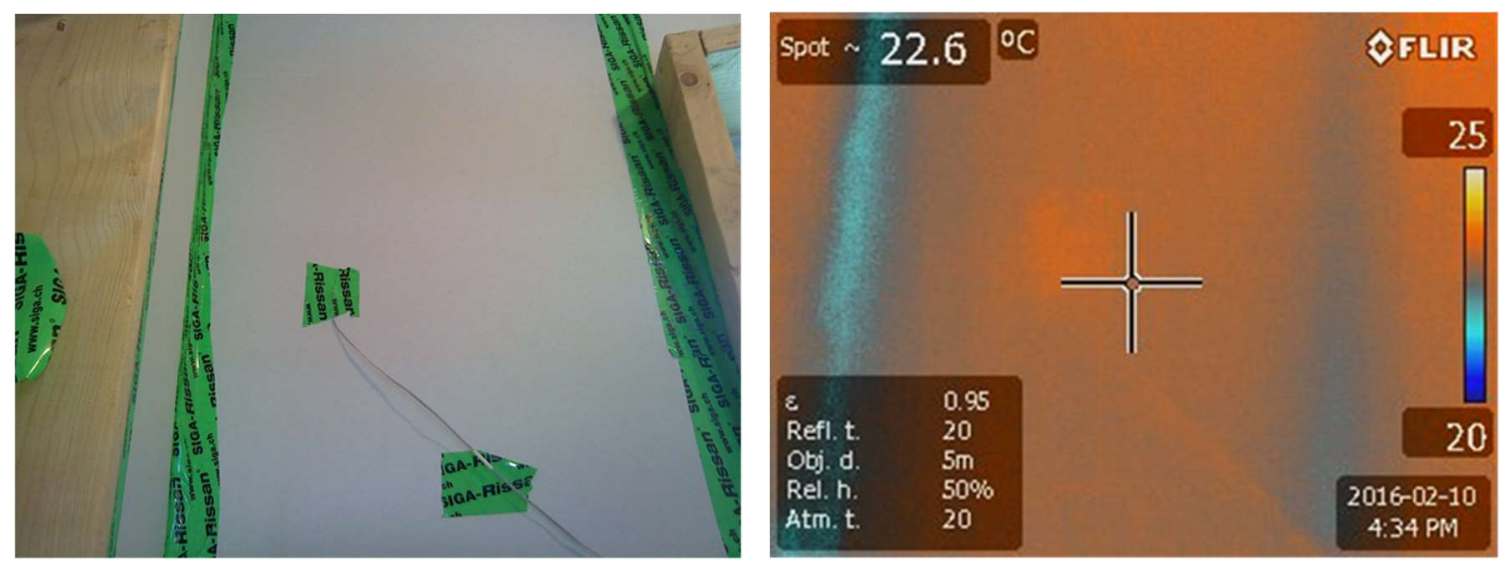

Figure 4-1 : Thermal Imagining of Sensor NH2L8-T - Example

\subsubsection{Analysis Technique Selection}

The assessed in-situ thermal resistance of the wall ASTM C1155 - Standard Practice for Determining Thermal Resistance of Building Envelope Components from the In-Situ Data was used (ASTM, 2013a). The summation technique was selected for its simplicity and is shown in Equation 5. This is also known as the "running RSI". 


$$
R_{e}=\frac{\sum_{k=1}^{M} \Delta T_{s k}}{\sum_{k=1}^{M} q_{k}}
$$

$\mathrm{R}_{\mathrm{e}}=$ Resistance Estimate $\left(\mathrm{m}^{2} \mathrm{~K} / \mathrm{W}\right)$

$\Delta \mathrm{T}_{\mathrm{s}}=$ Difference in Surface Temperatures $\left({ }^{\circ} \mathrm{C}\right)$

$\mathrm{q}=$ Heat Flux $\left(\mathrm{W} / \mathrm{m}^{2}\right)$

$\mathrm{k}=$ Counter for Summation of Time-Series Data.

$\mathrm{M}=$ Number of Data Points

This technique sums temperature during the collection period. The summed temperature difference was than divided by the accumulated heat flux. The summation technique relies on basic thermodynamic laws, where heat flow is driven by temperature differences, and the resistance is calculated by dividing the temperature difference by the heat flux through the enclosures. The summation technique relies on long collection periods, three days to two weeks depending on mass of the enclosure (Biddulp et. al. 2014). This accounts for the effects of thermal mass, as there is a delay in heat flux changes due to temperature differences. To ensure that significant periods of time have passed for accurate assessment it is required to satisfy convergence factor requirements. Resistivity is only calculated from $R_{e}$ values that occur when the convergence requirements are met.

$$
C R_{n}=\frac{R_{e}(t)-R_{e}(t-n)}{R_{e}(t)}
$$

$\mathrm{CR}_{\mathrm{n}}=$ Convergence Factor

$\mathrm{R}_{\mathrm{e}}=$ Thermal Resistance $\left(\mathrm{m}^{2} \mathrm{~K} / \mathrm{W}\right)$

$\mathrm{t}=$ Time $(\mathrm{h})$

$\mathrm{n}=$ Test for Convergence Interval (h)

ASTM C1155 states that the convergence factor must be below 0.1 for convergence to have occurred (ASTM, 2013a). The convergence factor compares summed calculated resistances to previous time step summed resistances. As the convergence factor approaches zero the calculated resistances between time steps becomes closer, ensuring calculation accuracy. ASTM C1155 recommends that a convergence time step of between 6 and 48 hours be selected. Final thermal resistivity is calculated from the running RSI once convergence requirements have been meet for at least three convergence intervals. 


\subsubsection{Convergence Factor Analysis}

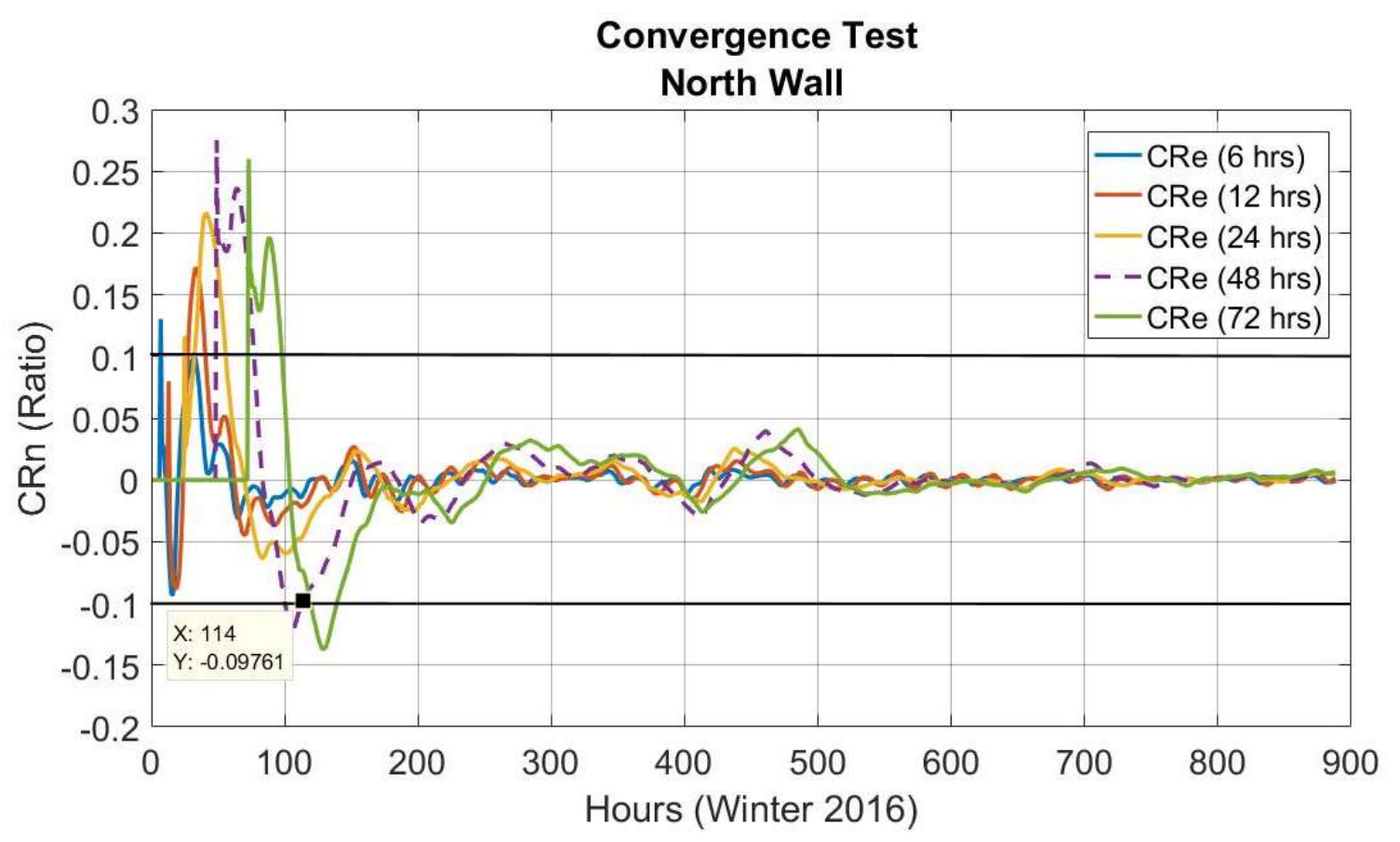

Figure 4-2 : North Wall Convergence Analysis

The convergence interval and hour of convergence satisfaction was determined before the final

RSI was calculated. This was completed to ensure a suitable convergence time step was selected. The running RSI for the North wall was tested for convergence at several different time steps as recommended by ASTM C1155. Figure 4-2 shows an analysis of the convergence factor for the north wall. The $48 \mathrm{~h}$ time step was selected since it displayed the highest amplitude (most severe) and is also the largest recommended time step in ASTM C1155. The convergence time step interval of $48 \mathrm{~h}$ was used during the rest of the analysis. The winter data achieves a convergence value after 114 hours (16-Feb-2016, 18:00) for the north wall. ASTM C1155 specifies that three periods of $48 \mathrm{hr}$ must occur after convergence for $\mathrm{R}_{\mathrm{e}}$ to be assumed as proper. This occurred at hour 258 (22-Feb-2016 18:00:00). 


\subsubsection{North Wall In-situ Analysis Results}

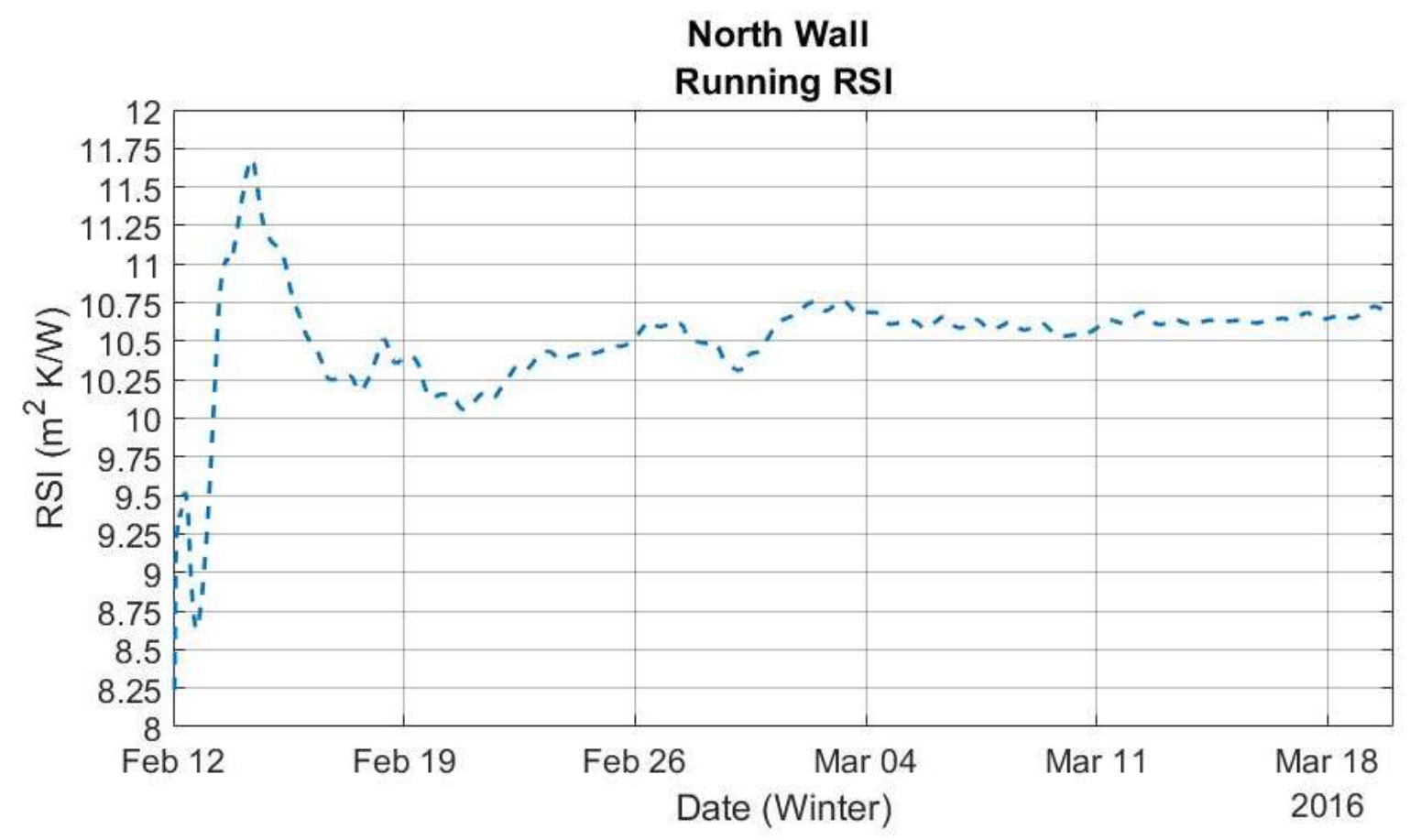

Figure 4-3: North Wall Running RSI-Value - Winter

Shown in Figure 4-3 is the running RSI Value for the north wall during the winter period. The Running -RSI fluctuated greatly during the first week of data collection as the cumulative RSI value converged. This is typical for the summation technique. The RSI at hour 258 (hour of convergence) was $10.3 \mathrm{~m}^{2} \mathrm{~K} / \mathrm{W}$, however as can be seen in Figure 4-3, the accumulated RSI rises above $10.5 \mathrm{~m}^{2} \mathrm{~K} / \mathrm{W}$ and below $10.7 \mathrm{~m}^{2} \mathrm{~K} / \mathrm{W}$.

An average RSI was used from hour 258 to the end of the collection period. This was to account for low frequency changes within the RSI. Ideally the running RSI would converge to a single number but it appeared to fluctuate somewhat over time. It is thought that this is caused by the low-frequency delta temperature and heat flux changes which is discussed further in Section 4.1.2.6.

The average RSI calculated from hour 258 (hour of convergence) to the end of the collection period ( $888 \mathrm{~h}-$ March 20 ) was $10.6 \mathrm{~m}^{2} \mathrm{~K} / \mathrm{W} \pm 7 \%$. This value is larger than the calculated nominal value of $9.258 \mathrm{~m}^{2} \mathrm{~K} / \mathrm{W}$ by approximately $14.4 \%$. The calculated nominal thermal resistance falls outside of the accuracy range of the heat flux kit. Further analysis was undertaken on the north wall in an attempt to identify possible factors that increased thermal resistance. 


\subsubsection{1. $\quad$ North Wall Layer Analysis}

To identify possible causes of the increased thermal resistance a layer analysis was completed on the north wall. ASTM C1155 (ASTM, 2013a) is used in conjunction with the process outlined in the literature review for the analysis. The summation technique was used but the outside surface temperature had been interchanged with interstitial temperatures.

$$
R_{e}=\frac{\sum_{k=1}^{M} T_{s k}-T_{L_{i} k}}{\sum_{k=1}^{M} q_{k}}
$$

$\mathrm{R}_{\mathrm{e}}=$ Resistance Estimate $\left(\mathrm{m}^{2} \mathrm{~K} / \mathrm{W}\right)$

$\mathrm{T}_{\mathrm{s}}=$ Average HF Temp Surface Temperatures $\left({ }^{\circ} \mathrm{C}\right)$

$\mathrm{T}_{\mathrm{li}}=$ Temperature of Layer

$\mathrm{q}=$ Measured Heat Flux $\left(\mathrm{W} / \mathrm{m}^{2}\right)$

$\mathrm{k}=$ Counter for Summation of Time-Series Data.

$\mathrm{M}=$ Number of Data Points

The same time frames for convergence were used as the initial north wall analysis. No interstitial temperature sensors were installed at the height of the heat flux plates; however, layers were monitored at heights 1 and 2. Temperatures used for the summation technique were an average of the height 1 and 2 temperatures, except for the inside surface temperature. Temperatures from thermistors were used in lieu of RHT bundle where both exist. The difference between averaged height 1 and height 2 surface temperatures is compared with the thermocouples at height 1.5.

Table 4-1: Temperature Differences Between Thermocouples and Thermistors

\begin{tabular}{|c|c|c|}
\hline & $\begin{array}{c}\text { Mean Difference } \\
\mathrm{H} 1.5-(\mathrm{H} 1+\mathrm{H} 2) / 2\end{array}$ & Standard Deviation \\
\hline Interior Surface & $0.206{ }^{\circ} \mathrm{C}$ & $0.204{ }^{\circ} \mathrm{C}$ \\
\hline Exterior Surface & $0.133^{\circ} \mathrm{C}$ & $0.220^{\circ} \mathrm{C}$ \\
\hline
\end{tabular}

The averages show that the heat flux kit had a marginally higher temperature than the average of height 1 and height 2 . This technique introduced a systematic error into the results. To account for the temperature difference between the averages of $\mathrm{H} 1$ and $\mathrm{H} 2$ and the temperature at the heat flux sensor a correction constant was calculated. This correction constant is the theoretical thermal resistivity caused by the temperature differences. 


\subsubsection{Layer Running RSI}

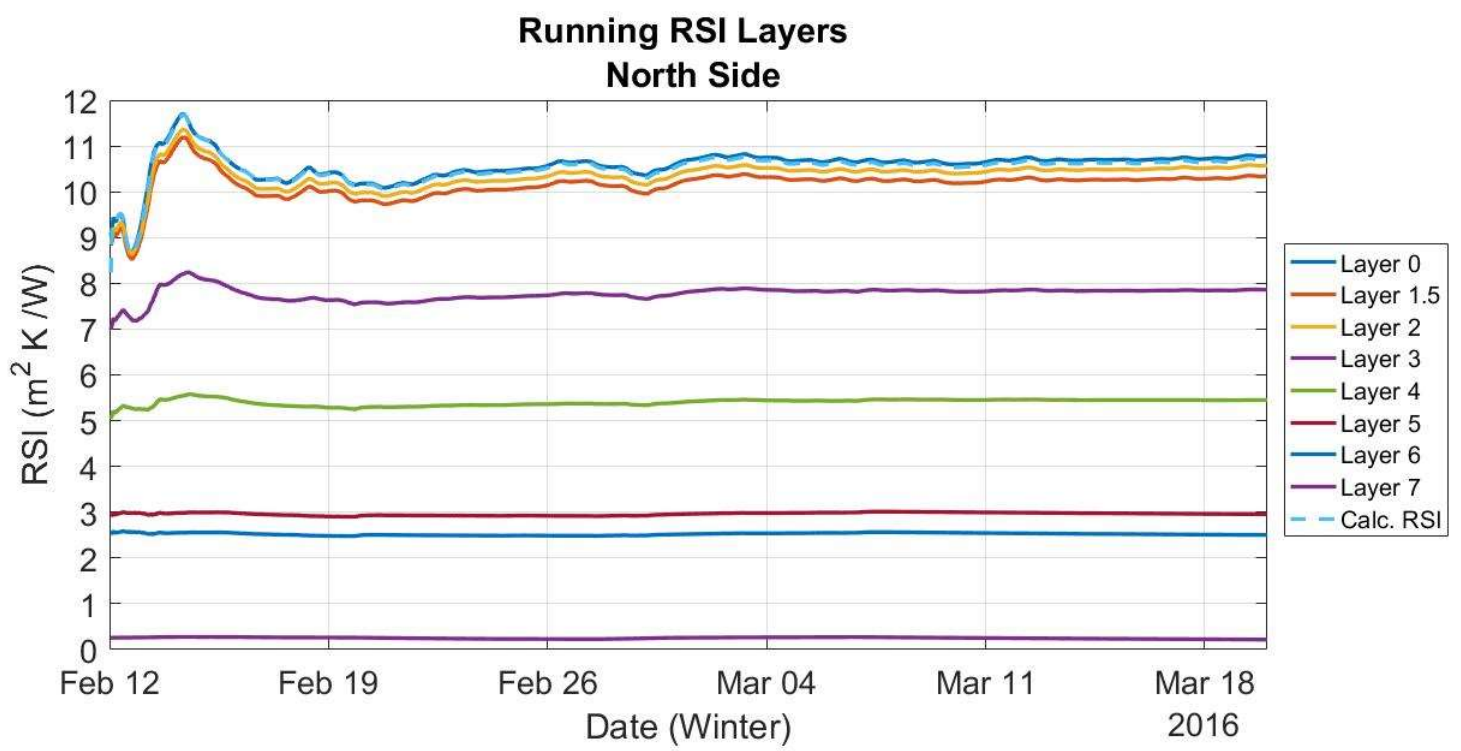

Figure 4-4 : Running RSI for North Wall Layers

Shown in Figure 4-4 are the running layer RSI results. The variability at the beginning of the calculations is more pronounced for the outer layers. As specified in the background section the accuracy of the summation technique increases as the temperature difference increases.

Table 4-2: In-Situ Layer Analysis Results

\begin{tabular}{|c|c|c|c|c|}
\hline $\begin{array}{c}\text { Material } \\
\text { (exterior - interior) }\end{array}$ & $\begin{array}{c}\text { Layer } \\
\text { Interfaces }\end{array}$ & $\begin{array}{c}\text { RSI -Value } \\
\text { @ outer layer } \\
\left(\mathrm{m}^{2} \mathrm{~K} / \mathrm{W}\right)\end{array}$ & $\begin{array}{c}\text { RSI } \\
\text { Adjusted for } \\
\text { Temp Diff. }\end{array}$ & RSI Layer \\
\hline Cedar Cladding & $0-1$ & 10.648 & 10.520 & 0.424 \\
\hline Air Gap & $1-2$ & 10.224 & 10.096 & -0.209 \\
\hline 1. Roxul CIS -76 mm & $2-3$ & 10.433 & 10.305 & 2.624 \\
\hline 2. Roxul CIS -76 mm & $3-4$ & 7.809 & 7.681 & 2.386 \\
\hline 3. Roxul CIS - 76 mm & $4-5$ & 5.423 & 5.295 & 2.456 \\
\hline 4. OSB & $5-6$ & 2.967 & 2.839 & 0.444 \\
\hline 5. Roxul Comfortbatt -89mm & $6-7$ & 2.523 & 2.395 & 2.277 \\
\hline 6. Gypsum* & $7-8$ & 0.246 & 0.118 & 0.118 \\
\hline 7. Correction Constant RSI & & 0.128 & 0.0 & N/A \\
\hline
\end{tabular}

*Gypsum value is skewed due to small temperature differences

The total RSI for the wall using average temperatures is $10.5 \mathrm{~m}^{2} \mathrm{~K} / \mathrm{W}$ compared with the data from the heat flux meter at $10.6 \mathrm{~m}^{2} \mathrm{~K} / \mathrm{w}$. The layer analysis reveals that the installed insulation experiences significant differences from nominal values. The difference from nominal can be seen in Table 4-3. 
Table 4-3: Difference from Nominal RSIs

\begin{tabular}{|c|c|c|c|c|}
\hline Layer & $\begin{array}{c}\text { Thickness } \\
(\mathrm{mm})\end{array}$ & $\begin{array}{c}\text { Measured } \\
\text { Centre- } \\
\text { of-Cavity } \\
\text { RSI } \\
\mathrm{m}^{2} \mathrm{~K} / \mathrm{W}\end{array}$ & $\begin{array}{c}\text { Published } \\
\text { Nominal RSI } \\
\text { @ 24 }{ }^{\circ} \mathrm{C} \\
\mathrm{m}^{2} \mathrm{~K} / \mathrm{W}\end{array}$ & $\begin{array}{c}\% \text { Change } \\
\text { from } \\
\text { Published } \\
\text { Nominal }\end{array}$ \\
\hline $\begin{array}{c}\text { Layers 2-3 } \\
\text { Roxul Comfortboard }\end{array}$ & 76 & 2.624 & 2.10 & $125 \%$ \\
\hline $\begin{array}{c}\text { Layers 3-4 } \\
\text { Roxul Comfortboard }\end{array}$ & 76 & 2.386 & 2.10 & $114 \%$ \\
\hline $\begin{array}{c}\text { Layers 4-5 } \\
\text { Roxul Comfortboard }\end{array}$ & 76 & 2.456 & 2.10 & $117 \%$ \\
\hline $\begin{array}{c}\text { Layers 6-7 } \\
\text { Roxul Comfortboard }\end{array}$ & 89 & 2.277 & 2.46 & $93 \%$ \\
\hline
\end{tabular}

\subsubsection{RSI-Variation Theories}

The in-situ RSI exceeds that of expected values and this section explores potential reasons for the increase. Each layer experienced higher values, however, the exterior layer of insulation (L2L3) exhibits a much higher thermal resistivity. Two theories are proposed as to why this may be; (i) thermal properties associated with temperature sensor installation, and (ii) the mean temperature of the insulation. The mean temperature of the layers is explored further on within this section.

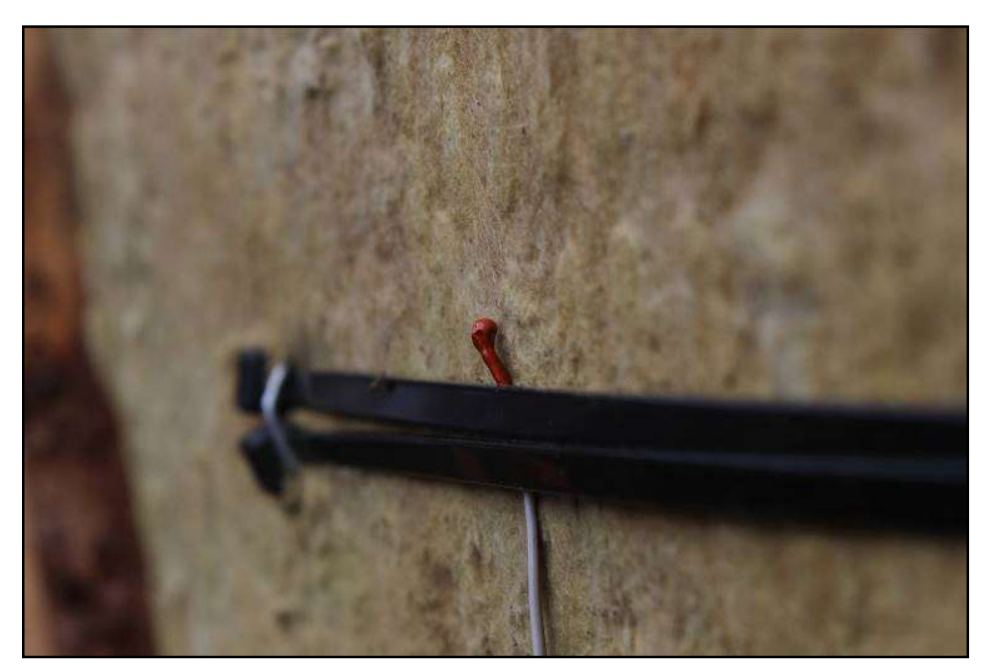

Figure 4-5 : Temperature Sensor - Layer 2

Figure 4-5 shows the temperature sensor installed at layer 2. It is speculated that the temperature reported was, on average, less than the surface temperature of the mineral wool causing an 
inflated RSI for this layer. The suspected temperature difference from the surface of the mineral wool and the temperature may be caused by convection over the sensor and with differences in emissivity of the materials. The low thermal mass of the sensor would cause rapid shifts in temperatures (both decreases and increases).

Table 4-4 : Sensor Temperature Differences

\begin{tabular}{|c|c|c|c|}
\hline Season & $\begin{array}{c}\text { Temperature } \\
\text { Difference } \\
\mathrm{T}_{(1.5)}-\mathrm{T}_{(2)}\end{array}$ & $\begin{array}{c}\text { Standard } \\
\text { Deviation } \\
\mathrm{T}_{(1.5)}-\mathrm{T}_{(2)}\end{array}$ & $\begin{array}{c}\text { RSI * } \\
\text { Layer 2-3 } \\
\mathrm{m}^{2} \mathrm{~K} / \mathrm{W}\end{array}$ \\
\hline $\begin{array}{l}\text { Winter } \\
\text { (Avg.) }\end{array}$ & $0.66^{\circ} \mathrm{C}$ & $0.48^{\circ} \mathrm{C}$ & 2.415 \\
\hline
\end{tabular}

Table 4-4 shows a comparison between temperatures of the layer 1.5 and layer 2 . The layer 2 temperature is on average $0.66^{\circ} \mathrm{C}$ less than the air cavity temperature. The typical difference between RHT and T sensors was $0.5^{\circ} \mathrm{C}$ more detail can be found in Appendix E.

This change in temperature resulted in a change in the RSI of the external insulation from 2.624 $\mathrm{m}^{2} \mathrm{~K} / \mathrm{W}$ to $2.415 \mathrm{~m}^{2} \mathrm{~K} / \mathrm{W}$. The later of which aligns much closer to nominal values and HEAT3 values. This may account for a portion of the increased RSI of the outer layer but does not account for the increase in other layers.

\subsubsection{Mean Temperature}

This section explores the mean temperature of each layer and compares it to projected nominal values for the winter period. Mean temperatures (MT) were calculated using the procedure in ASTM C1155 as shown in Equation 8. The inside surface temperature of each layer was used as a surrogate temperature to replace the inside surface temperature. The temperature difference was calculated by the exterior surface temperature of the layer subtracted from the inside surface temperature of the layer. Temperature values from height 1 and height 2 were averaged. Stratification effects can be seen in Appendix E. MT's for each layer were calculated for the winter collection period. 


$$
T_{e}=\frac{\sum_{k=1}^{M} \Delta T_{k}\left[T_{i s k}-(1 / 2)\left(\Delta T_{k}\right)\right]}{\sum_{k=1}^{M}\left[\Delta T_{k}\right]}
$$

$\mathrm{T}_{\mathrm{e}}=$ Mean Temperature $\left({ }^{\circ} \mathrm{C}\right)$

$\mathrm{T}_{\text {isk }}=$ Inside Surface Temperature $\left({ }^{\circ} \mathrm{C}\right)$

$\Delta \mathrm{T}=$ Delta Temperature $\left({ }^{\circ} \mathrm{C}\right)$

$\mathrm{k}=$ Time Step - Data Series

$\mathrm{M}=$ End of Data Series

The projected nominal thermal resistivity was calculated based on information provided by manufacturer data for Roxul Comfortboard 110. No information was found for Roxul Comfortbatt. A linear relationship was used to find intermittent values of thermal conductivities. (Lepage \& Schumacher, 2013) (Abdou \& Budaiwi, 2005).

\section{Linear Regression}

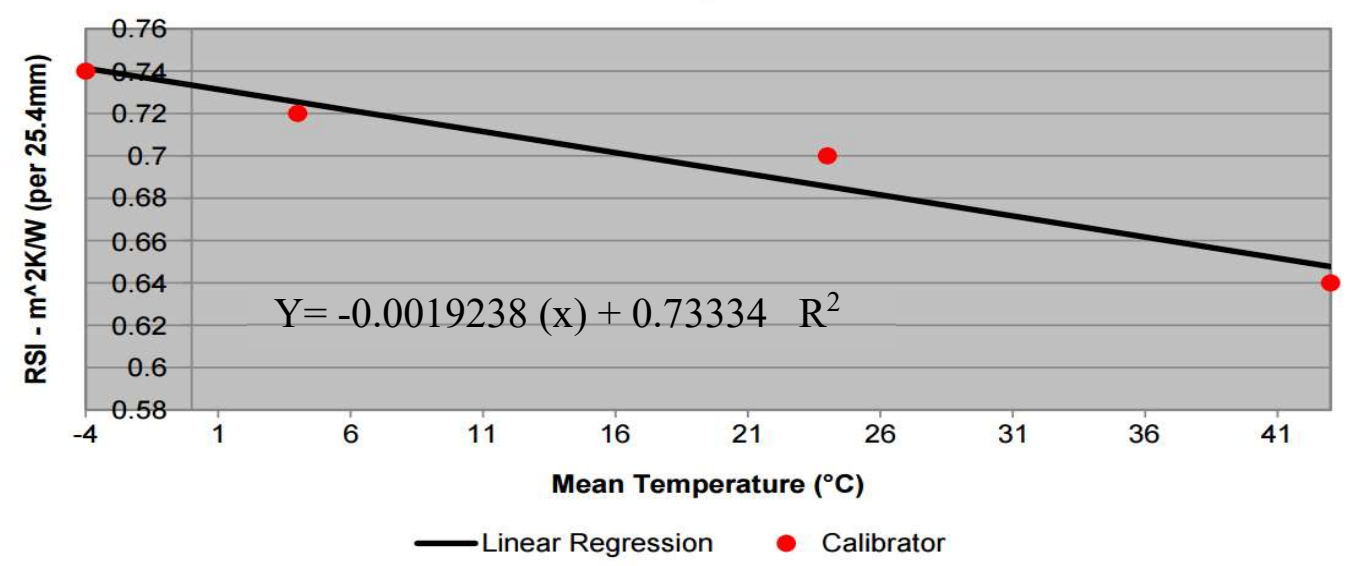

Figure 4-6: Nominal Thermal Resistivity Based on MT (Courtesy of https://mycurvefit.com/)

Table 4-5 presents the projected nominal thermal resistance for each layer based on its MT and compares it to the calculated in-situ layer RSI. Although the mean temperature increases the nominal resistance slightly, it cannot account for the measured increase in each layer. 
Table 4-5 : In-Situ RSI vs Mean Temperature RSI

\begin{tabular}{|c|c|c|c|c|c|}
\hline Layer & $\begin{array}{c}\text { Thickness } \\
(\mathrm{mm})\end{array}$ & $\begin{array}{c}\text { MT } \\
\text { Winter }\end{array}$ & $\begin{array}{c}\text { Nominal } \\
\text { MT } \\
\text { Conductivity } \\
125.4 \mathrm{~mm}\end{array}$ & $\begin{array}{c}\text { Nominal } \\
\text { MT } \\
\text { RSI } \\
\left(\mathrm{m}^{2} \mathrm{~K} / \mathrm{W}\right)\end{array}$ & $\begin{array}{c}\text { In-Situ } \\
\text { Layer } \\
\text { RSI } \\
\left(\mathrm{m}^{2} \mathrm{~K} / \mathrm{W}\right)\end{array}$ \\
\hline $\begin{array}{c}\text { Layers 2-3 } \\
\text { Roxul Comfortboard }\end{array}$ & 76 & $1.0{ }^{\circ} \mathrm{C}$ & 0.731 & 2.193 & 2.624 \\
\hline $\begin{array}{c}\text { Layers 3-4 } \\
\text { Roxul Comfortboard }\end{array}$ & 76 & $7.20^{\circ} \mathrm{C}$ & 0.719 & 2.157 & 2.386 \\
\hline $\begin{array}{c}\text { Layers 4-5 } \\
\text { Roxul Comfortboard }\end{array}$ & 76 & $12.47^{\circ} \mathrm{C}$ & 0.708 & 2.124 & 2.456 \\
\hline
\end{tabular}

\subsubsection{Contact Resistances}
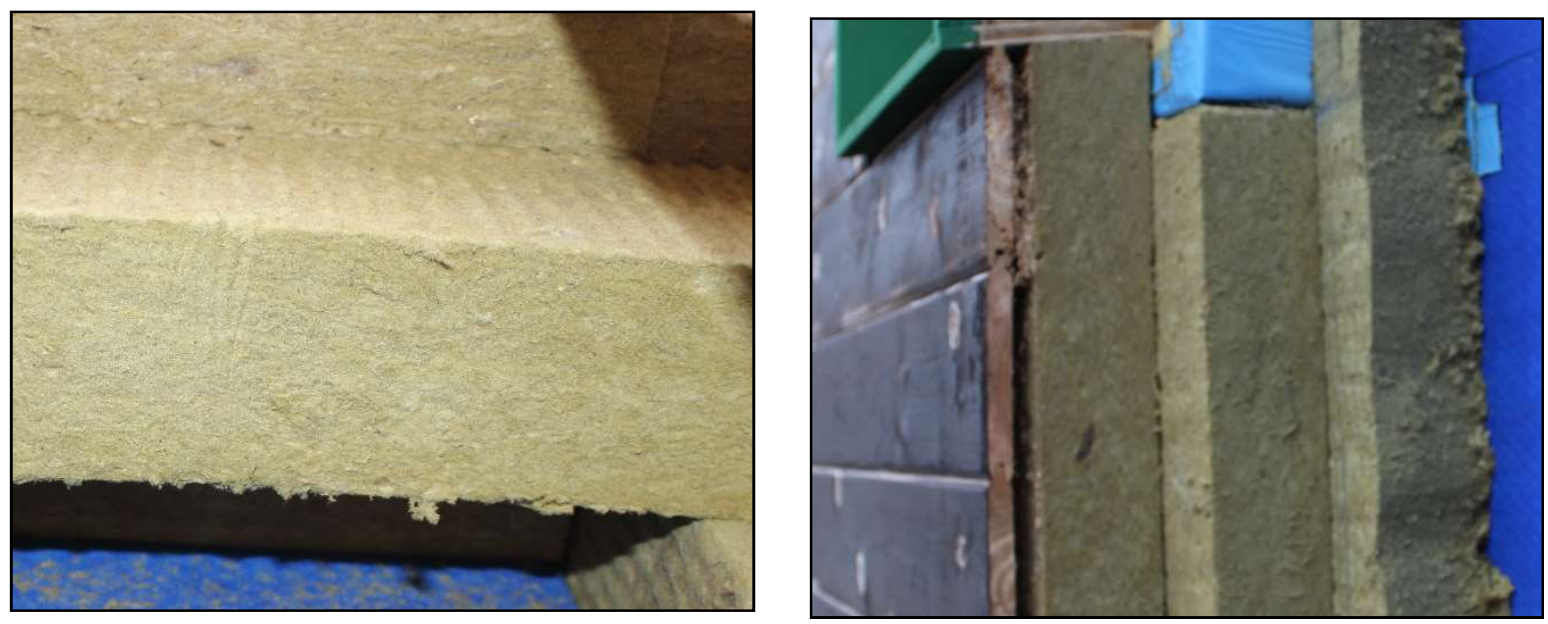

Figure 4-7 : Exterior Insulation Layer Interfaces

It is speculated that small air gaps exist between insulation layers and building material layers. Micro-gaps also occur at material interfaces. Gaps at insulation layer interfaces can be seen in Figure 4-7. This phenomenon is known as contact resistance. One study conducted by Trethowen and Cox-Smith (1996) estimated contact resistances to range between $0.02 \mathrm{~m}^{2} \mathrm{~K} / \mathrm{W}$ for $0.5 \mathrm{~mm}$ gaps and $0.1 \mathrm{~m}^{2} \mathrm{~K} / \mathrm{W}$ for gaps of $3 \mathrm{~mm}$ for gaps between a steel framed wall and gypsum facing.

It is difficult to estimate with certainty what the impact of contact resistances has on the increased thermal resistance as interstitial parameters of air speed and gap sizes are unknown. However, the estimated gap resistances in Trethowen and Cox-Smith (1996) would not account for the complete difference between nominal MT and in-situ measured values. It is speculated that the contact resistances marginally increase total thermal resistance, however, does not account for the total increase in resistance. 


\subsubsection{Temperature Difference and Heat Flux Polarity}

One of the sources of error that may account for the increased in-situ thermal resistance may be the temperature differences between interior and exterior that fell below $10^{\circ} \mathrm{C}$. This occurred several times during the collection period. The heat flux readings in some instances had reversed polarity, indicating heat was flowing from the exterior to the interior. The hourly average heat flux flow moved from interior to the exterior, however, some of the 10-minute readings indicated an interior flow. Average temperature differences and average heat flux readings for the winter period are shown in Figure 4-8.

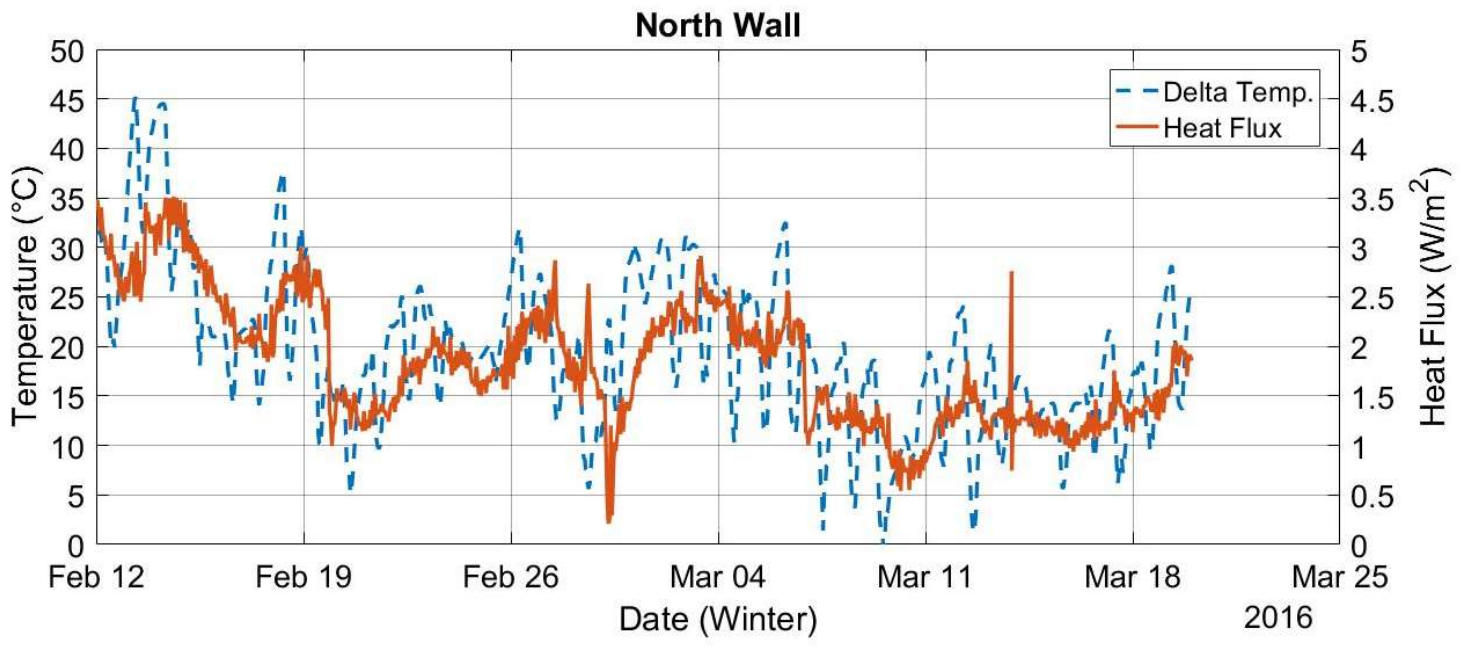

Figure 4-8 : Surface Temperature Differences and Heat Flux - North Wall

The reduction of surface temperatures and the lowering of heat flux that occur during the later half of the winter collection period have an impact on the in-situ thermal resistance calculations however.

\subsubsection{Material Variability}

There is a possibility that the insulation installed in the test structure has some slight physical property differences than the reference material used by the manufacturer to provide thermal conductivity values. The thermal conductivity testing performed during this research revealed that an alternate batch of Roxul Comfortboard 110 tested had a difference of 12\% in thermal conductivity as reported from manufacturer data. Although the batch tested had increased thermal conductivity (decreased thermal resistance) it is possible that the batch used in the test structure has decreased thermal conductivity (increased thermal resistance). There are a number 
of physical properties that can have an impact on the individual performance of mineral wool such as; fibre diameter, density of fibres, fibre matrix connectivity and thickness of insulation board. Other physical properties may have been modified during installation such as pressure on the insulation boards or surface modifications from wear and tear. The density and apparent thermal conductivity of the insulation used in the test structure was not tested. It is recommended that further lab testing be conducted on the installed insulation to help determine physical properties that may have impacted expected in-situ thermal resistivity values.

\subsubsection{Southern In-situ Analysis}

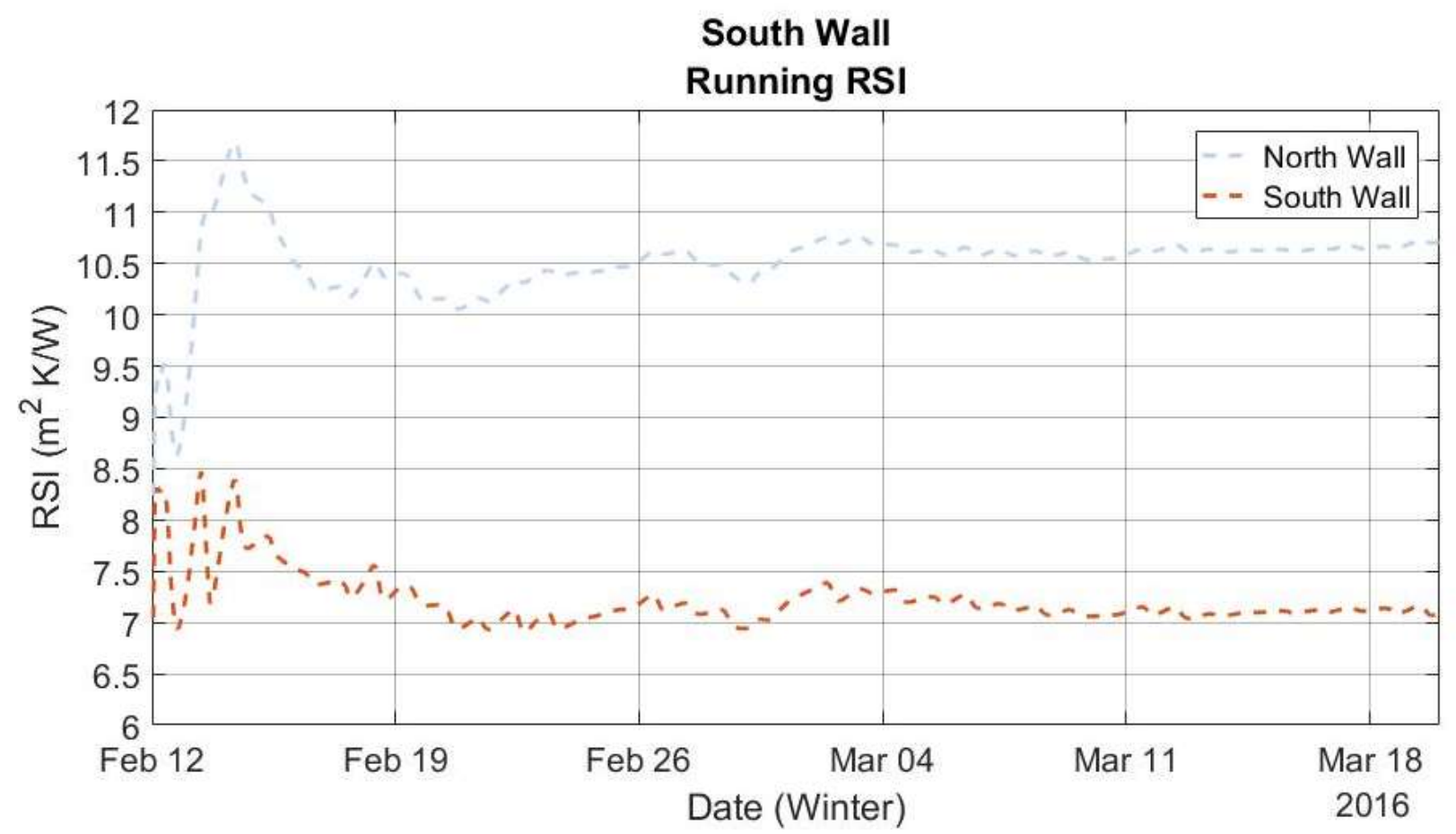

Figure 4-9 : Initial South Wall Running RSI-Value

Figure 4-9 shows the running RSI for the southern wall. The significant difference in the RSI and the shape of the line compared with that of the north wall indicated that there were issues with the calculation procedure. Further investigation revealed that the solar radiation drastically affected the temperature of the cladding which in turn modified the outcome of the RSI calculation. The rapid temperature change on the southern façade did not last for long enough to fully reverse the heat flow. The temperature spike limited some of the heat flow from inside to outside but effects were muted due to thermal mass. Further investigation into the southern wall was required to determine in-situ thermal resistance. 


\subsubsection{North and South Wall Comparison}

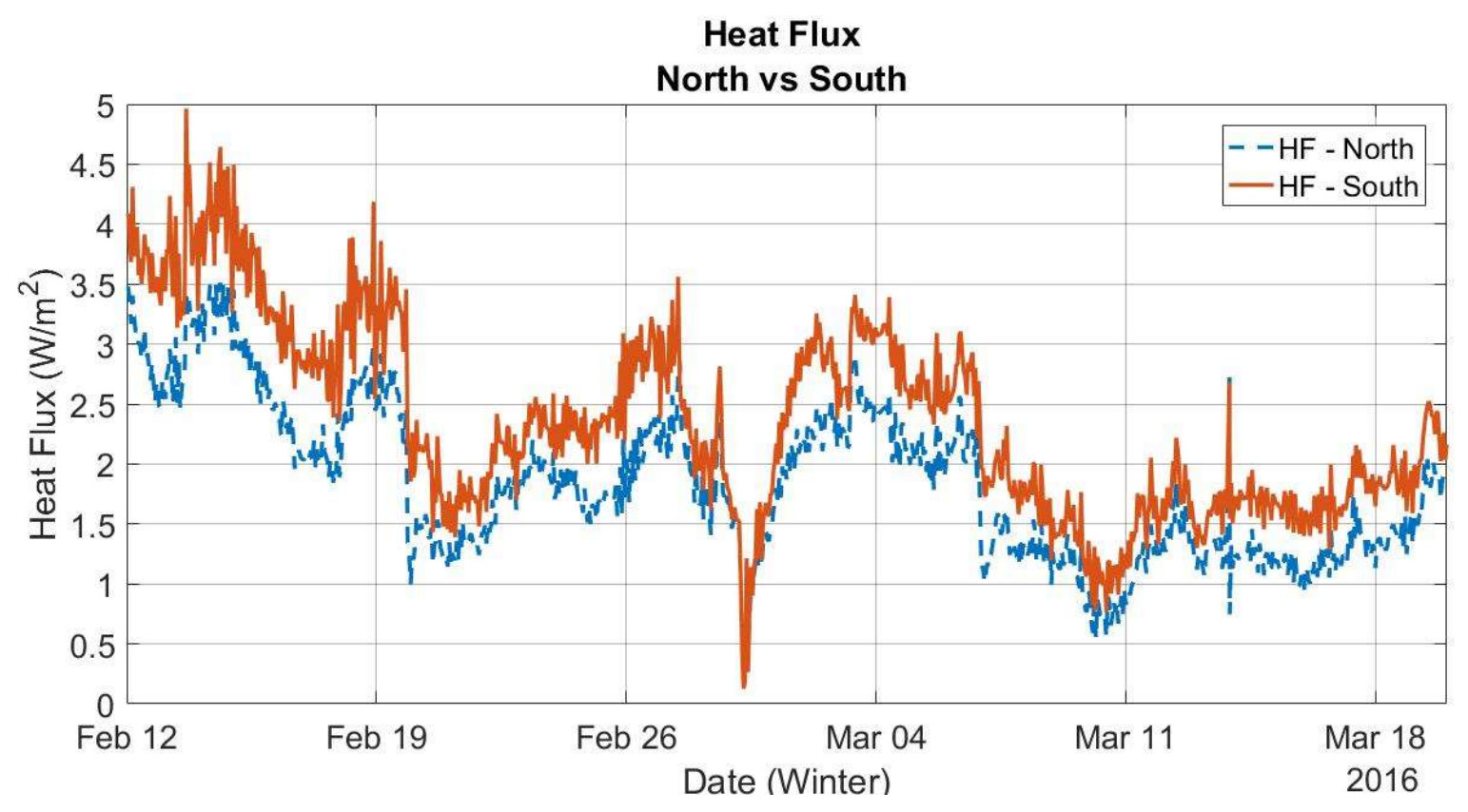

Figure 4-10:North and South Wall Heat Flux Comparison

It can be seen in Figure 4-10 that the heat flux comparisons between the north and south wall that there is increased amount of energy flowing through the south wall. There is also increased variation within the heat flows of the southern wall (Table 4-6). This variation may be caused by solar exposure and other factors that will be discussed below.

Table 4-6 : North vs South Wall Heat Flux

\begin{tabular}{|c|c|c|}
\hline & $\begin{array}{c}\text { Mean Heat Flux } \\
\mathrm{W} / \mathrm{m}^{2}\end{array}$ & $\begin{array}{c}\text { Standard Devation } \\
\mathrm{W} / \mathrm{m}^{2}\end{array}$ \\
\hline North Wall & 1.836 & 0.643 \\
\hline South Wall & 2.356 & 0.800 \\
\hline Difference & 0.52 & $\mathrm{~N} / \mathrm{A}$ \\
\hline
\end{tabular}

If the walls had equivilant thermal resistances the opposite should be true. Solar radiation should be heating the southern wall and subsquently reduce the heat flux during the heating season. A comparison of the delta temperatures between the north and the south wall shows the effect of solar exposure on the southern wall. Where negative values are present, it is an indication that the external surface temperature is greater than the internal surface temperature. 


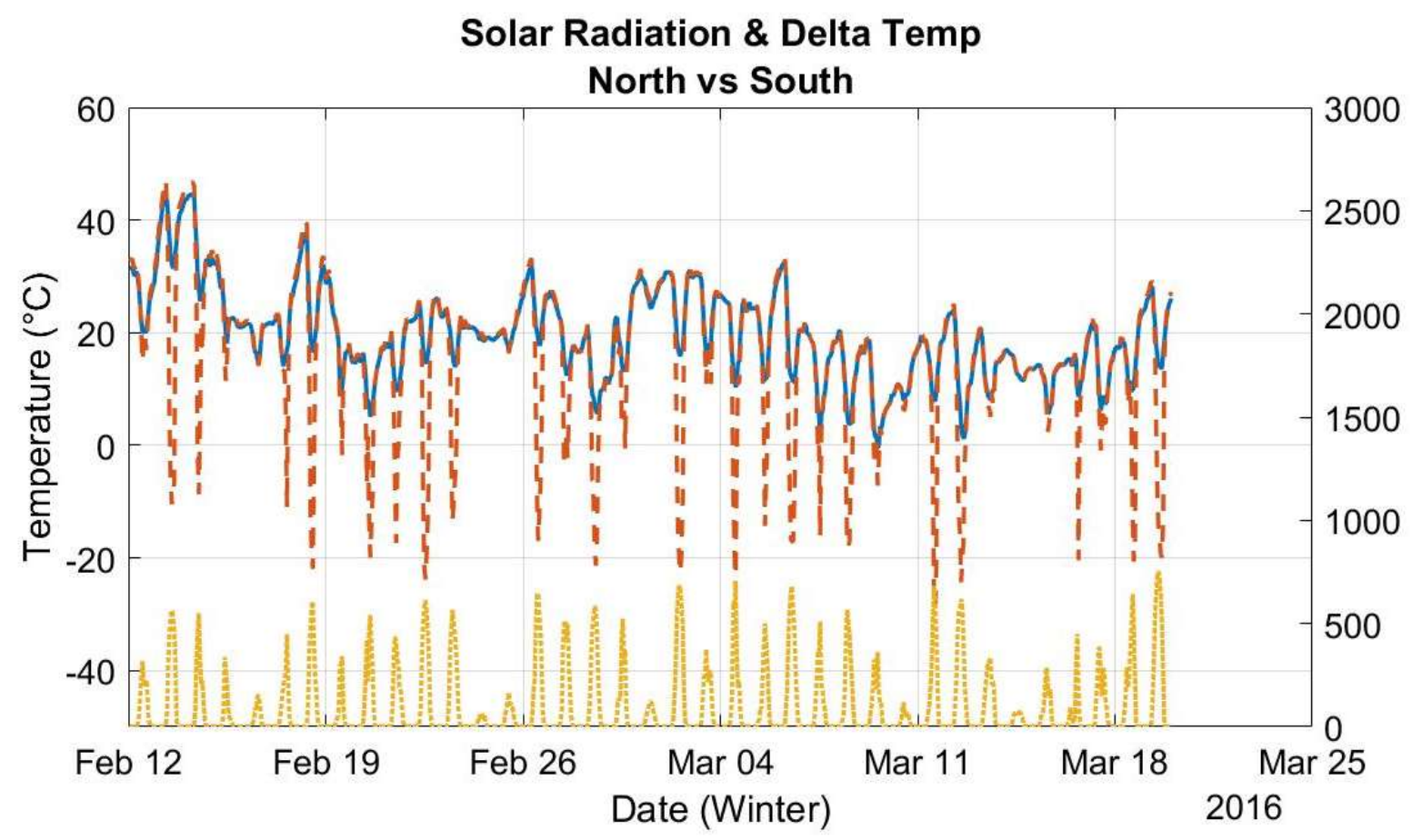

Figure 4-11 : Solar Radiation and Delta Temperatures

The large spikes indicate direct solar exposure of the southern wall. Figure 4-11 shows that there was good alignment between the delta temperatures of the north and south wall during times of low solar radiation (i.e. night time and overcast days). It can also be seen from Figure 4-11 that from Feb $23^{\text {rd }}-26^{\text {th }}$ and March $9^{\text {th }}-11^{\text {th }}$ that there is little direct solar radiation occurring on the southern wall.

Table 4-7 : Variation in Temperature Differences

\begin{tabular}{|c|c|c|}
\hline & $\begin{array}{c}\text { Mean Delta } \\
\text { Temp } \\
{ }^{\circ} \mathrm{C}\end{array}$ & $\begin{array}{c}\text { Standard } \\
\text { Deviation } \\
{ }^{\circ} \mathrm{C}\end{array}$ \\
\hline North Wall & 19.68 & 8.11 \\
\hline South Wall & 16.71 & 13.14 \\
\hline Difference & 2.97 & N/A \\
\hline
\end{tabular}




\subsubsection{Thermal Resistance Based off North Delta Temperatures}

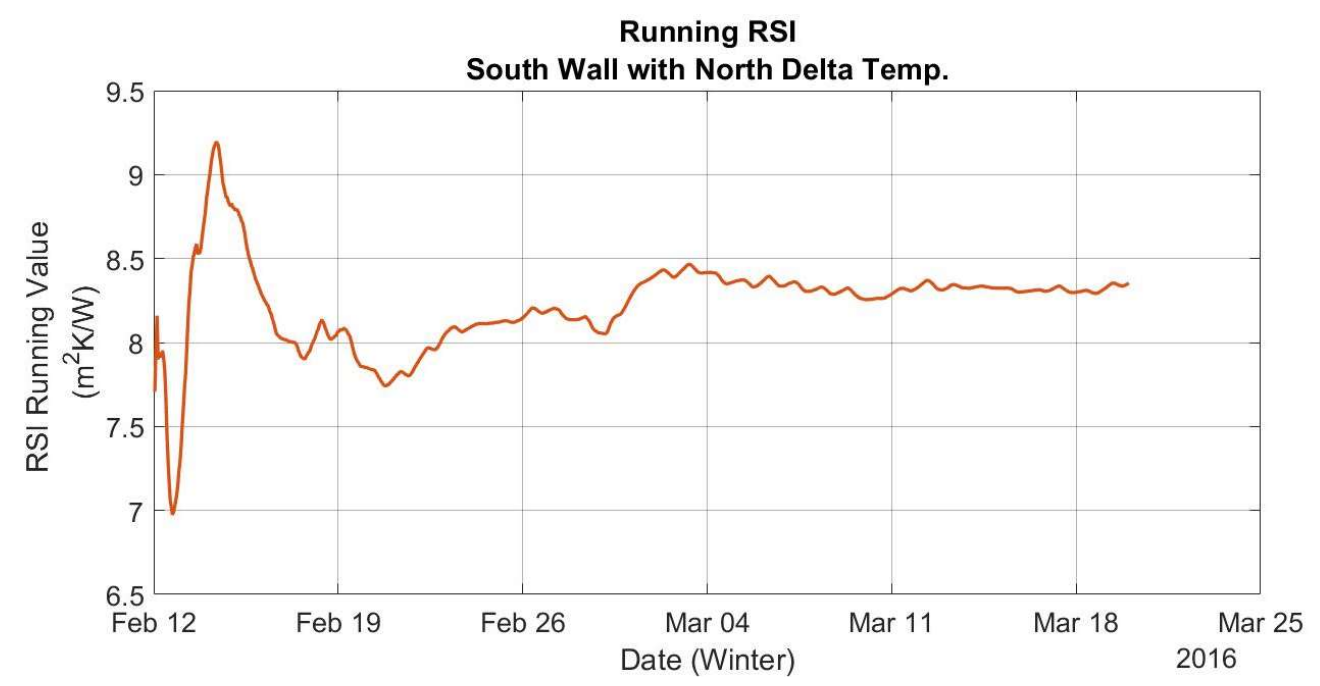

Figure 4-12 : South Wall RSI-Value Using North Delta Temperature.

The southern wall was analyzed using the delta temperatures from the north side at H1.5. The assumption was that the solar radiation spikes had little impact on the heat flux through the southern wall. The solar radiation did have some impact on the heat flux and this is investigated further on. This estimate provides a lower limit to the in-situ effective RSI of the southern wall. The running RSI is shown in Figure 4-12. The shape of the line is similar to the north running RSI and is significantly higher than the initial analysis. Results and time of convergence are shown in Table 4-8.

Table 4-8 : South Wall RSI Based on North Delta Temperatures

\begin{tabular}{|c|c|c|}
\hline Time Period & $\begin{array}{c}\text { Convergence Date } \mathrm{n} \\
=48 \text { hours }\end{array}$ & $\begin{array}{c}\text { Effective } \\
\text { RSI } \\
\left(\mathrm{m}^{2} \mathrm{~K} / \mathrm{W}\right)\end{array}$ \\
\hline Feb 12 - Mar 20 & Feb. 16 -2016 21:00 & 8.2 \\
\hline
\end{tabular}

\subsubsection{Overcast Thermal Resistance Analysis}

The north and south wall comparison section revealed that there were two times during the winter collection period that the southern wall was not subjected to intense and direct solar radiation $\left(\mathrm{Feb} 23^{\text {rd }}-26^{\text {th }}\right.$, March $\left.9^{\text {th }}-11^{\text {th }}\right)$. The temperature profiles for those periods revealed that cladding and subsequently layer temperatures were more uniform when compared with the adjacent days. The thermal resistance of the southern wall was analyzed for these times. 

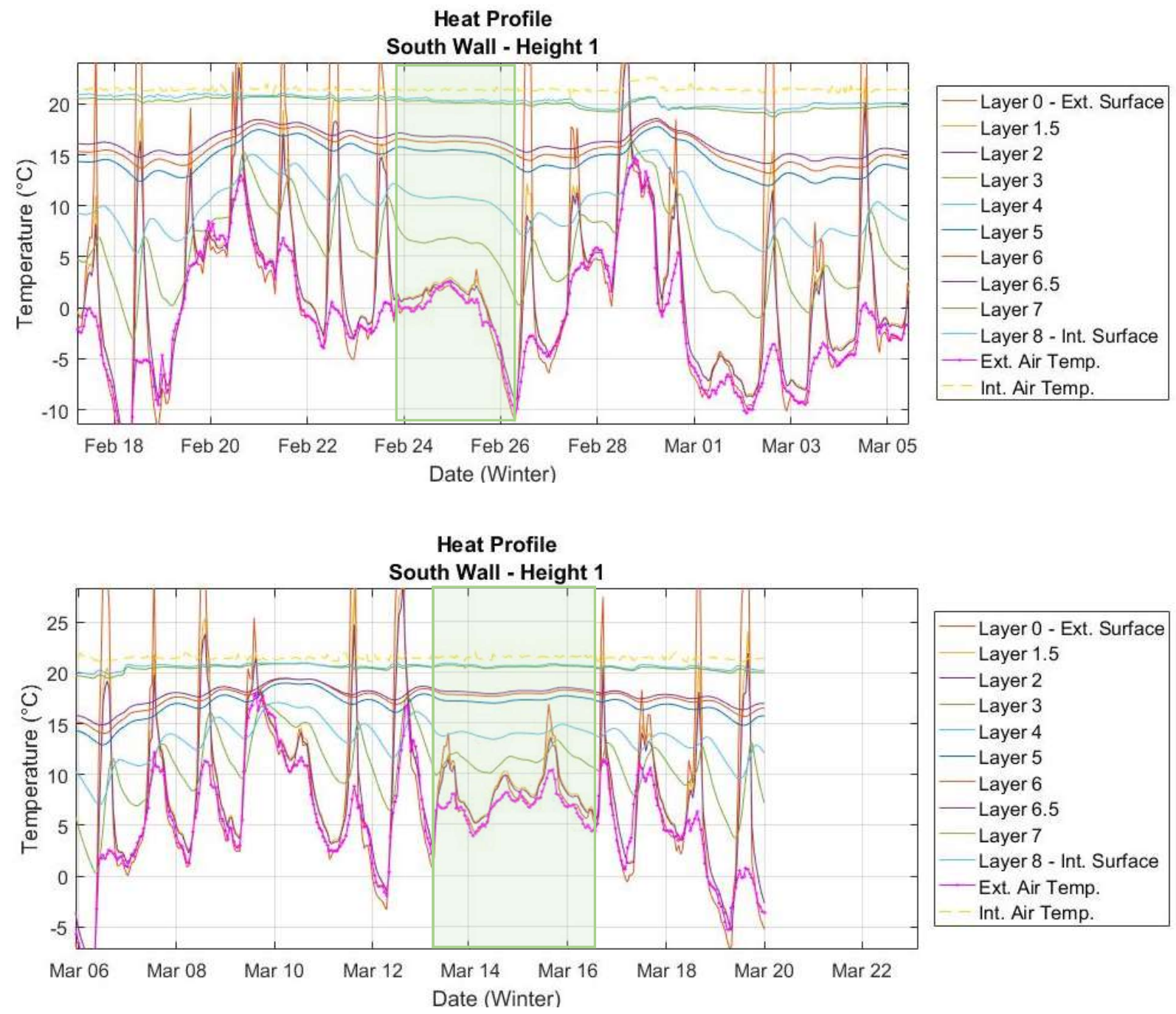

Figure 4-13 : Overcast Period Temperature Profiles

\subsubsection{Overcast Period Analysis Technique}

The summation technique was used to analyze the overcast periods; however, due to the shorter time period ( $\sim 3$ days) the convergence time step was reduced from 48 hours to 12 hours. To limit the impact of the solar radiation energy that occurred the day prior to the overcast period, it was necessary to remove the first 12 hours of heat flux data. The heat flux data 12 hours after the overcast period ended was added into the analysis, as this thermal energy drive was influenced by the temperature differential that occurred during the overcast period. The results from the over cast period are shown below. 


\subsubsection{Overcast Period Analysis Results}

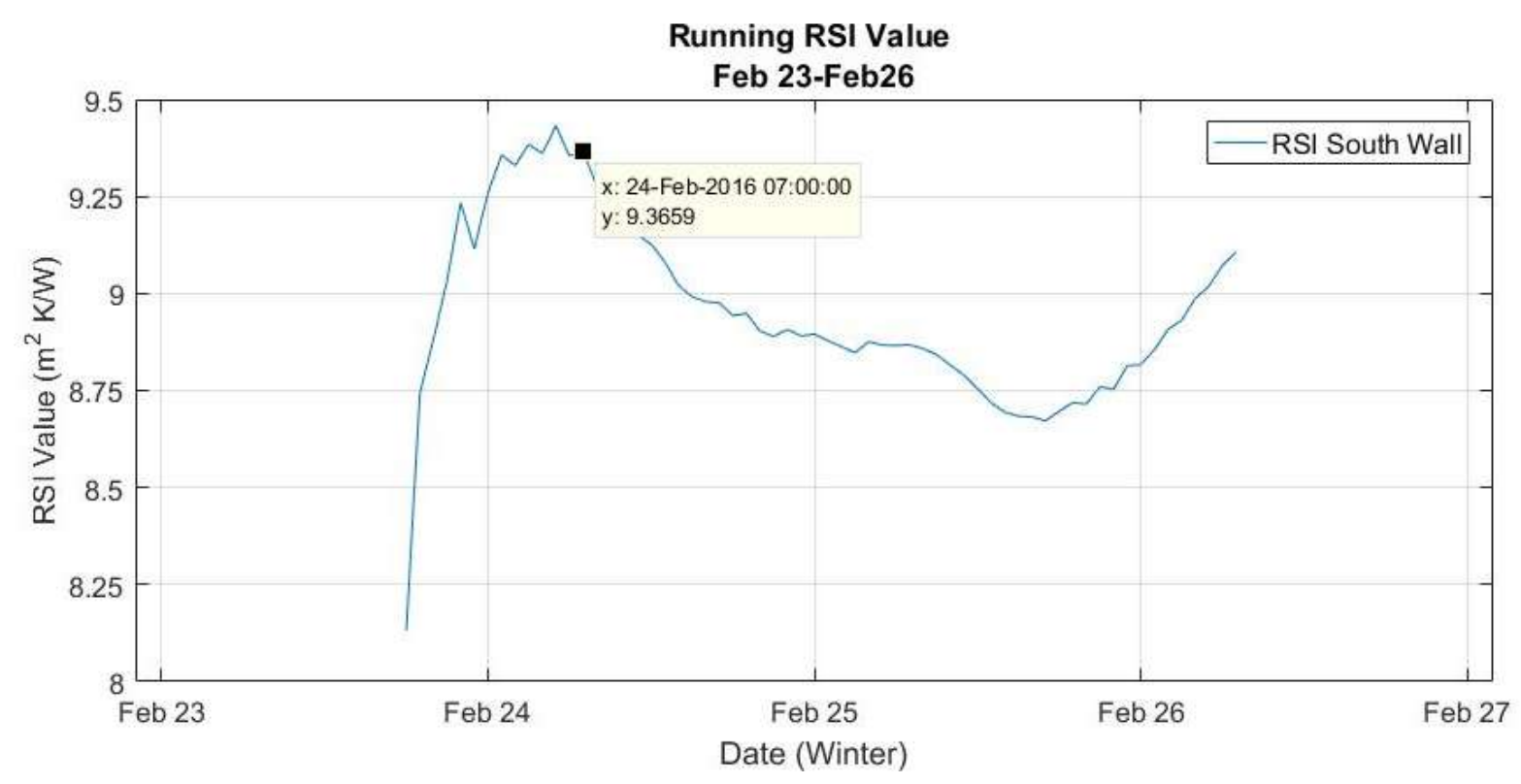

Figure 4-14 : Running RSI - Feb 23 - Feb 26

Shown in Figure 4-14 is the running RSI curve for the $1^{\text {st }}$ period of over cast. The curve exhibits similar trends to the north wall running RSI. The curve however does not seem to converge on a single value as it should. The shortened period of evaluation is the cause for this. The data point marked is the hour of convergence. The convergence graph for this period can be seen in Appendix F.

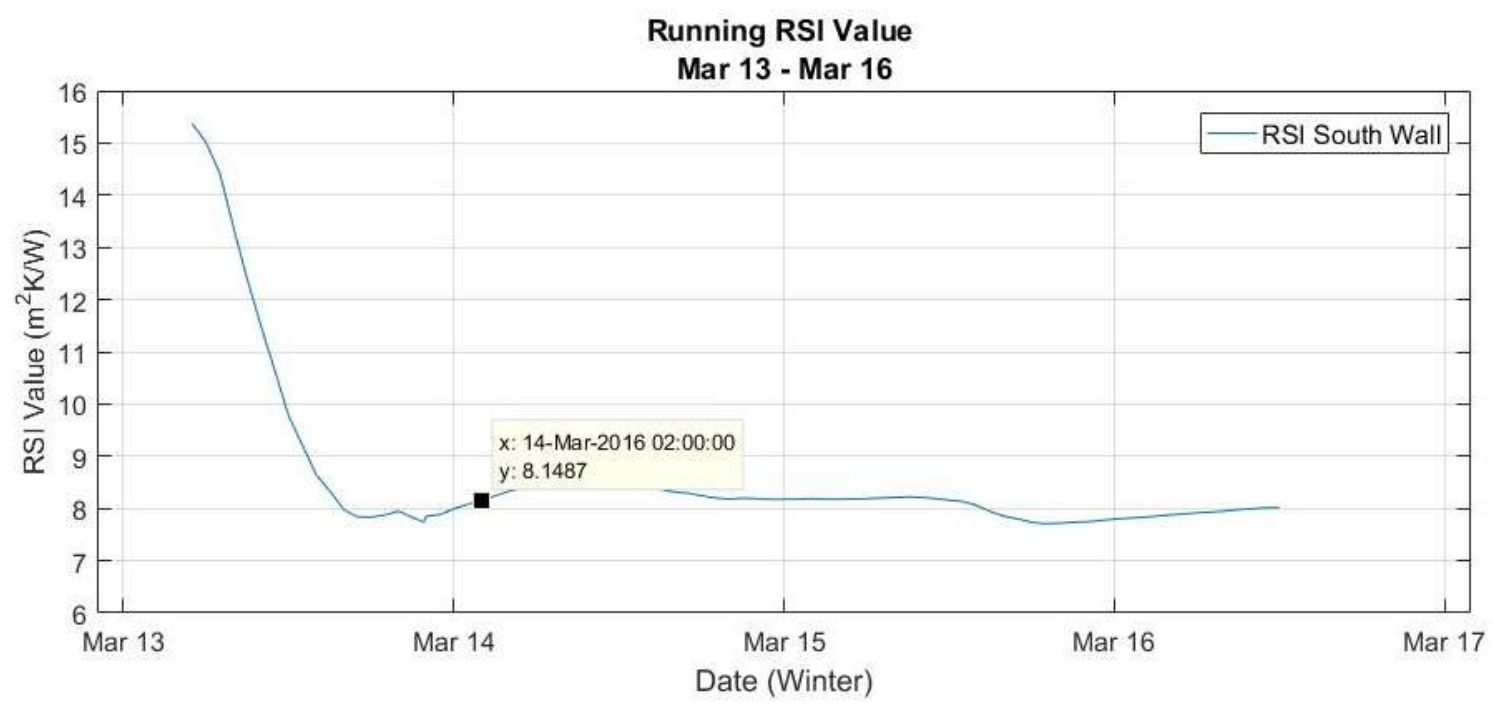

Figure 4-15 : Running RSI - Mar. 13-16 
Shown in Figure 4-15 is the running RSI for the southern wall during the period of March $13^{\text {th }}$ to the $16^{\text {th }}$. The shape of the curve is highly different from that of both the North wall and the modified southern wall analysis. A summary of the results from the two-time periods can be seen in Table 4-9.

Table 4-9: Overcast Analysis Results Summary

\begin{tabular}{|c|c|c|c|c|c|}
\hline $\begin{array}{c}\text { Analysis } \\
\text { Period }\end{array}$ & Duration & $\begin{array}{c}\text { Convergence } \\
\text { Date } \\
\mathrm{n}=12 \mathrm{~h}\end{array}$ & $\begin{array}{c}\text { Sum of } \\
\text { Delta Temp } \\
\left({ }^{\circ} \mathrm{C}\right)\end{array}$ & $\begin{array}{c}\text { Sum of Heat } \\
\text { Flux } \\
\left(\mathrm{W} / \mathrm{m}^{2}\right)\end{array}$ & $\begin{array}{c}\text { Effective } \\
\text { RSI } \\
\left(\mathrm{m}^{2} \mathrm{~K} / \mathrm{W}\right)\end{array}$ \\
\hline $\begin{array}{c}\text { Feb.23 18:00- } \\
\text { Feb. 26 8:00 }\end{array}$ & 62 hours & $\begin{array}{c}\text { Feb. 24 -2016 } \\
07: 00\end{array}$ & 1108.2 & 121.929 & 9.09 \\
\hline $\begin{array}{c}\text { Mar.13 5:00- } \\
\text { Mar 16 13:00 }\end{array}$ & 80 hours & $\begin{array}{c}\text { Mar. 14-2016 } \\
02: 00\end{array}$ & 791.7 & 98.75 & 8.02 \\
\hline
\end{tabular}

The analysis period from Mar. $13^{\text {th }}$ to the $16^{\text {th }}$ resulted in a RSI of $8.02 \mathrm{~m}^{2} \mathrm{~K} / \mathrm{W}$ and was lower than the value of $8.2 \mathrm{~m}^{2} \mathrm{~K} / \mathrm{W}$, which in theory should be the lower limit of the RSI as found in Section 4.1.3.4. The $2^{\text {nd }}$ period value was also lower than the $1^{\text {st }}$ overcast period value, which was found to be $9.09 \mathrm{~m}^{2} \mathrm{~K} / \mathrm{W}$. A closer look at cladding temperatures for the $2^{\text {nd }}$ period reveals that the cladding temperature exceeded the exterior air temperature several times and that some solar radiation was occurring. The influence of the solar radiation decreased the effective RSI. The $1^{\text {st }}$ period analysis resulted in a RSI of $9.09 \mathrm{~m}^{2} \mathrm{~K} / \mathrm{W}$. The cladding temperature was much closer to the exterior air temperature and it is speculated that this value was closer to the actual in-situ effective RSI of the southern wall. The short duration of the overcast period and the visual shape of the running RSI curve are potential sources of error however and further investigation was undertaken to determine the effective in-situ thermal resistance.

\subsubsection{Solar Radiation Effected Data Removed}

The extreme temperature of the cladding caused by solar radiation incorrectly lowered the effective RSI of the wall when the summation technique was used. This can be seen in the previous sections. The use of the northern delta temperatures for analysis does not account for the reduced heat flux caused by the solar radiation. This section explores a technique to remove both temperature and heat flux data on the southern wall that was affected by direct solar radiation in attempts to determine the in-situ effective in-situ RSI. 


\subsubsection{Determining Radiation Thresholds}

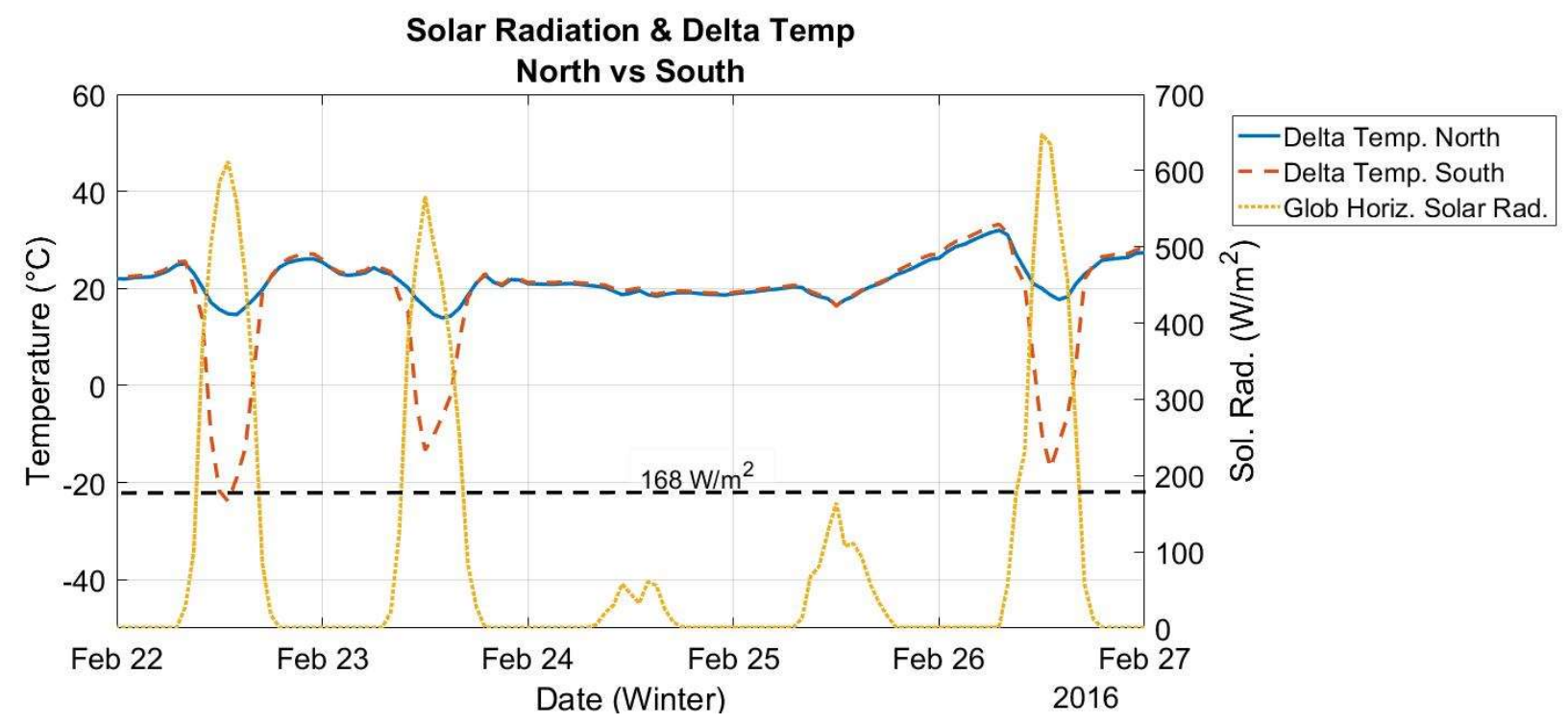

Figure 4-16 : Solar Radiation and Delta Temperatures

Visual analysis of the data indicates that if radiation exceeds a threshold of roughly $168 \mathrm{~W} / \mathrm{m}^{2}$ than the delta temperatures begin to deviate between the north and the south walls. If the delta temperature data on the south wall is eliminated when the solar radiation exceeds this $168 \mathrm{~W} / \mathrm{m}^{2}$ there is much closer agreement between the two delta temperatures (Figure 4-17). 


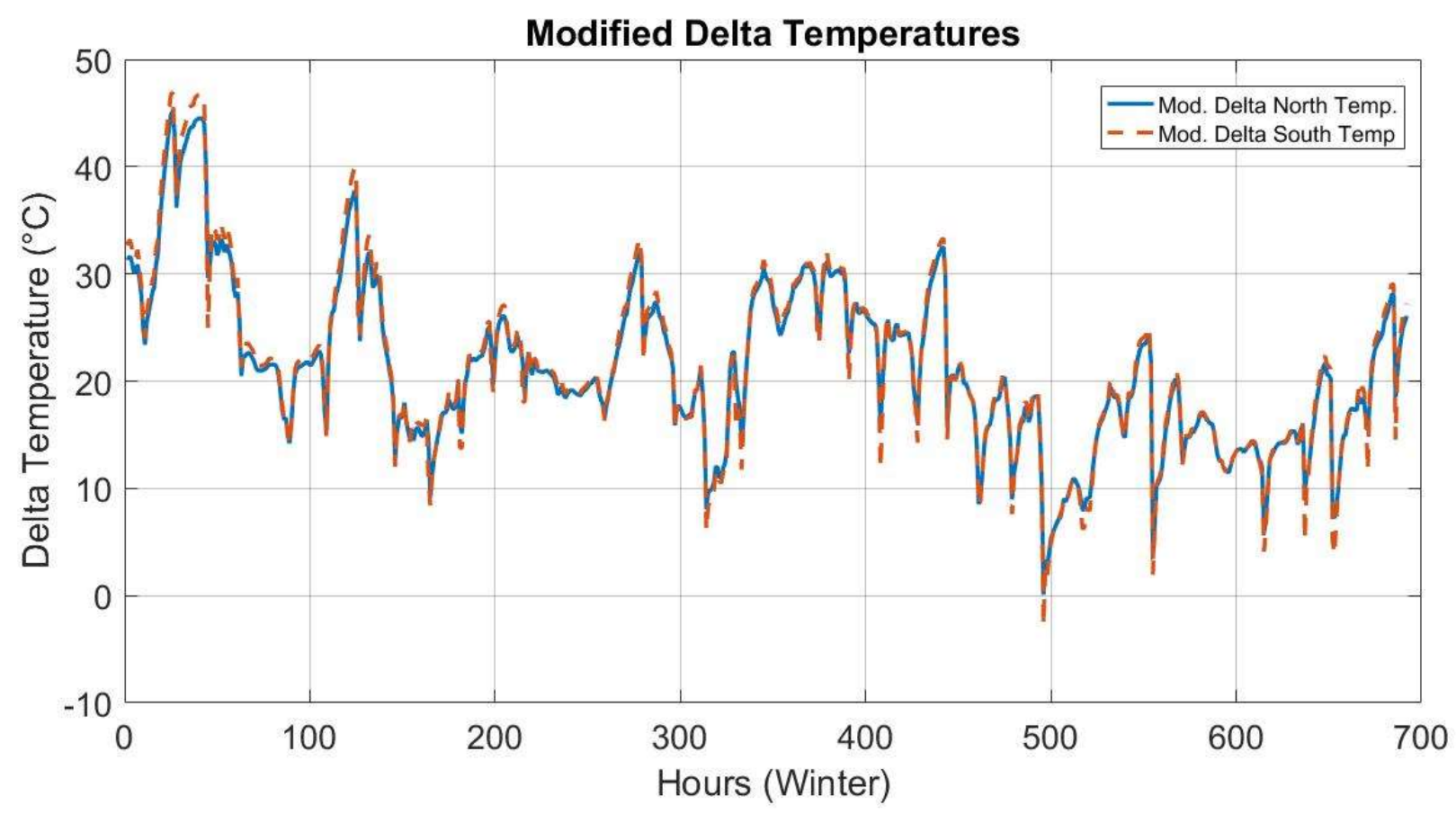

Figure 4-17 : Modified Comparisons of North and South Delta Temps

Delta temperature data from the north wall was removed to ensure accurate comparison. A total of 192 hours was removed from a total of 888 hours collected. A summary of the differences can be seen in the in Table 4-10.

Table 4-10: Comparison of North and South Delta Temp with Modified Data Sets

\begin{tabular}{|c|c|c|}
\hline & $\begin{array}{c}\text { Mean } \\
\text { Delta } \\
\text { Temp }\left({ }^{\circ} \mathrm{C}\right)\end{array}$ & $\begin{array}{c}\text { Standard } \\
\text { Deviation } \\
\left({ }^{\circ} \mathrm{C}\right)\end{array}$ \\
\hline North Wall & 21.26 & 7.65 \\
\hline South Wall & 21.54 & 8.17 \\
\hline $\begin{array}{c}\text { Absolute } \\
\text { Difference }\end{array}$ & 0.28 & N/A \\
\hline
\end{tabular}

\subsubsection{Removal of Heat Flux Data}

To accommodate the new delta temperature differential data set it was required to remove the heat flux data from the south wall that corresponds to the direct solar radiation. To do this it was nesscary to find the time it took for a change in temperature on the exterior surface to impact the heat flux measurements. 


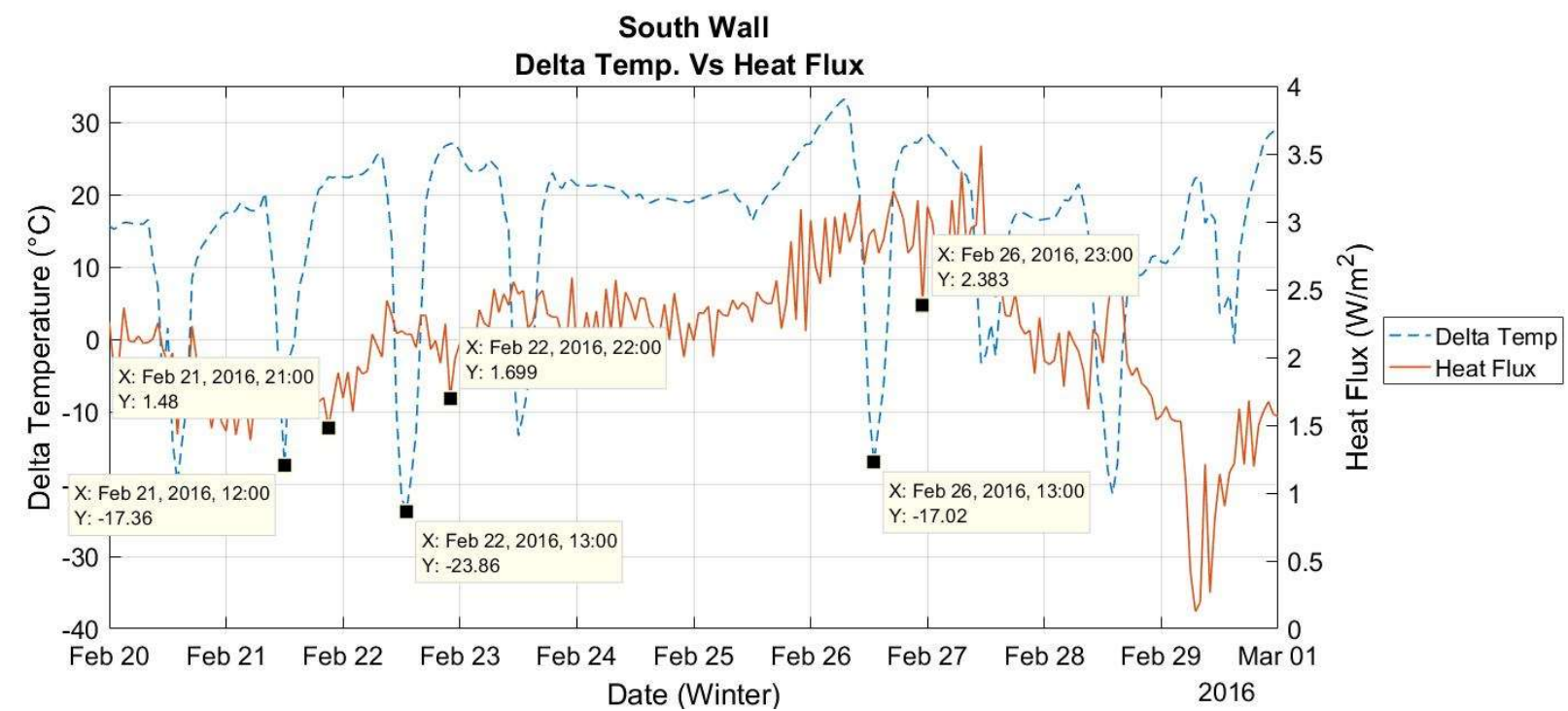

Figure 4-18 : Heat Flux Time Lag South

A visual analysis of the southern walls (from February $20^{\text {th }}$ to March $2^{\text {nd }}$ ) reveals that it takes approximatly 9-12 hours for a spike in temperature on one side of the wall to have implications on the heat flux data. This can be seen in Figure 4-18 and is a portion is summerized in Table 411.

Table 4-11 : Heat Flux Lag Summary

\begin{tabular}{|c|c|c|c|c|}
\hline Date /Time & $\begin{array}{c}\text { Lowest } \\
\text { Delta } \\
\text { Temperature } \\
\left({ }^{\circ} \mathrm{C}\right)\end{array}$ & Date / Time & $\begin{array}{c}\text { Lowest } \\
\text { Heat Flux } \\
\left(\mathrm{W} / \mathrm{m}^{2}\right)\end{array}$ & $\begin{array}{c}\text { Time Lag } \\
(\text { Hours })\end{array}$ \\
\hline 21-Feb / 12:00 & -17.36 & $21-\mathrm{Feb} / 21: 00$ & 1.48 & 9 \\
\hline $22-\mathrm{Feb} / 13: 00$ & -23.86 & $22-\mathrm{Feb} / 22: 00$ & 1.70 & 9 \\
\hline $26-\mathrm{Feb} / 13: 00$ & -17.02 & $26-\mathrm{Feb} / 23: 00$ & 2.38 & 10 \\
\hline
\end{tabular}

It should be noted that the heat flux measurements are quite variable and the spike in temperature may not specifically be responsible for the drop in heat flux. The points have been placed at the discretion of the author. However a more thorough look at the temperatures through the layers of the envelope showed a similar trend 


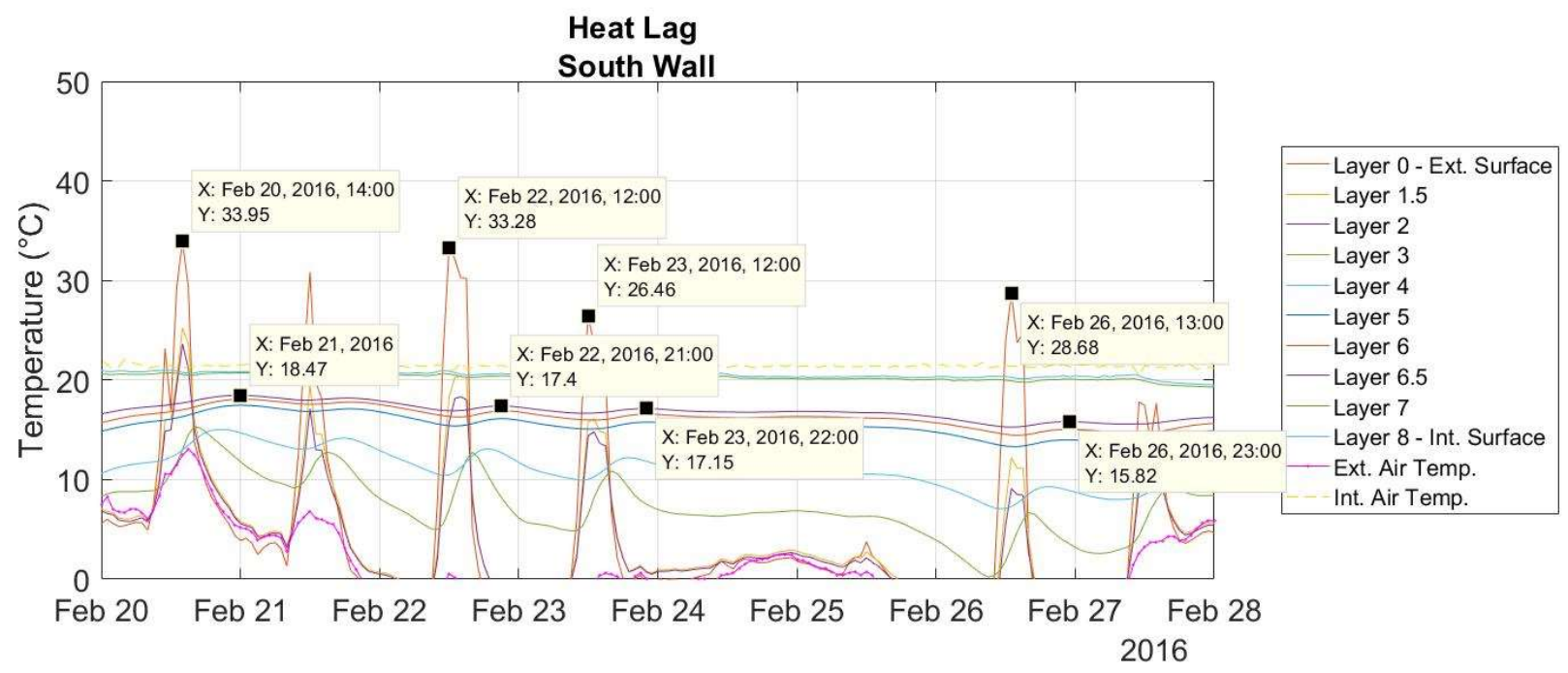

Figure 4-19 :Temperature Time Lag South Wall

Figure 4-19 reveals that a spike in the cladding temperature takes approximatly 10-12 hours to increase the temperature of the sensor at Layer $6.5(25 \mathrm{~mm}$ inside the sheating on the stud). This confirms the analysis of the heat flux data analysis, which has a similar time lage between incident solar radiation and a reduction in heat flux. A summary of the heat lag effect is found in Table 4-12.

Table 4-12 : Summary of Heat Lag in South Facing Wall

\begin{tabular}{|c|c|c|c|c|}
\hline Date /Time & $\begin{array}{c}\text { Highest } \\
\text { Temperature } \\
\left({ }^{\circ} \mathrm{C}\right)\end{array}$ & Date / Time & $\begin{array}{c}\text { Layer } \\
6.5 \\
\text { Temp } \\
\left({ }^{\circ} \mathrm{C}\right)\end{array}$ & $\begin{array}{c}\text { Time } \\
\text { Lag } \\
(\text { Hours })\end{array}$ \\
\hline 20-Feb / 14:00 & 33.95 & $21-\mathrm{Feb} / 00: 00$ & 18.47 & 10 \\
\hline $22-\mathrm{Feb} / 12: 00$ & 33.28 & $22-\mathrm{Feb} / 21: 00$ & 17.40 & 11 \\
\hline $23-\mathrm{Feb} / 12: 00$ & 26.46 & $23-\mathrm{Feb} / 22: 00$ & 17.15 & 12 \\
\hline $26-\mathrm{Feb} / 13: 00$ & 28.68 & $26-\mathrm{Feb} / 23: 00$ & 15.82 & 10 \\
\hline
\end{tabular}

It can be concluded from both the heat flux analysis and the temperature profile analysis that the large temperatures caused by the solar radiation take approximately 9-12 hours to influence heat flow through the assembly. 


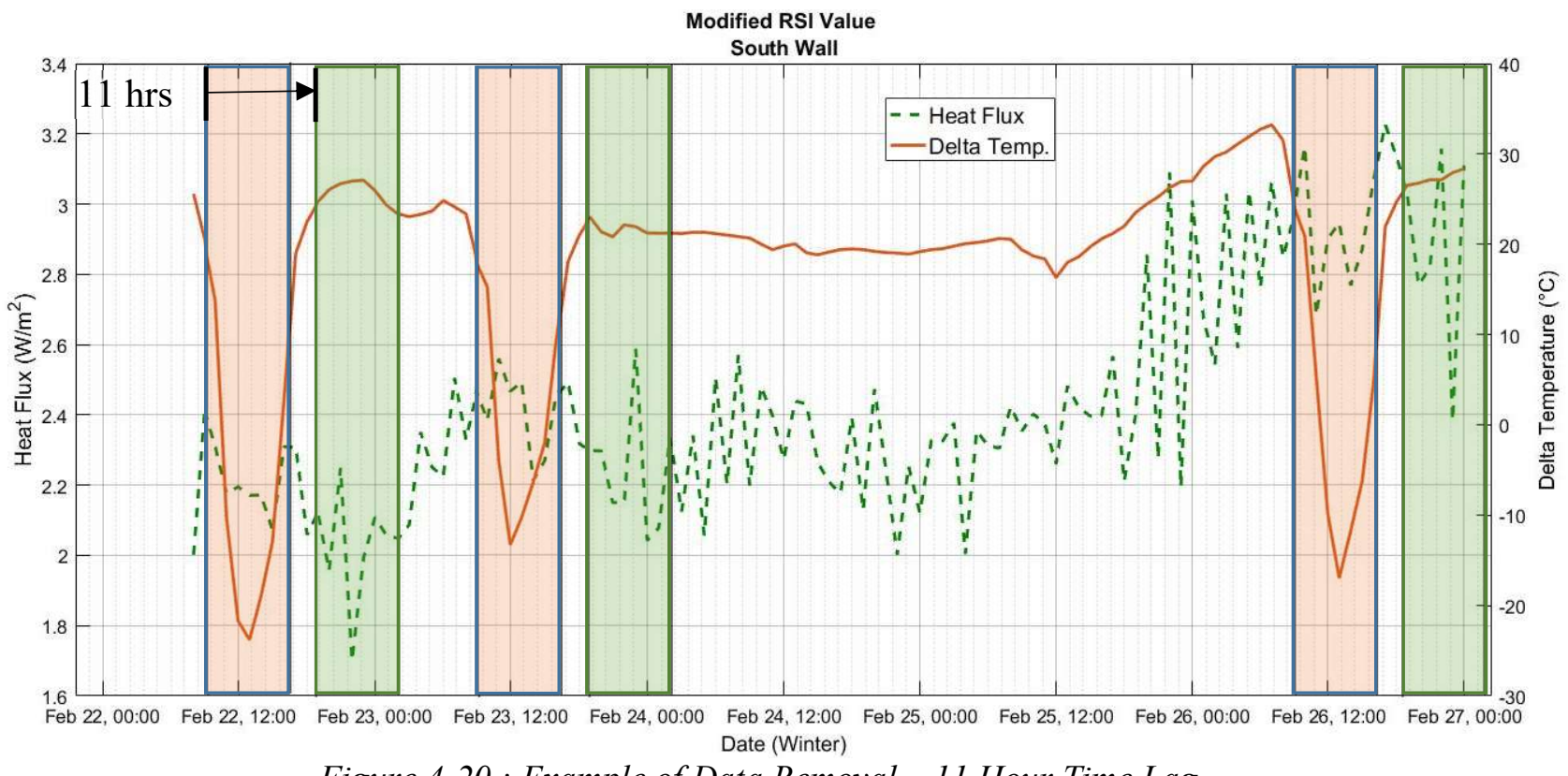

Figure 4-20 : Example of Data Removal - 11 Hour Time Lag

Figure 4-20 shows an example of the data removed from both the temperatures and the heat flux data sets. The temperature data has been removed when the measured global solar radiation exceeds $168 \mathrm{~W} / \mathrm{m}^{2}$. The heat flux data was removed beginning at $9-13$ hours after the solar radiation threshold was breached. It should be noted that temperature data for each of these scenarios was the same and the only thing being modified was the heat flux data. Seven cases were run to determine the most accurate time lag. 


\subsubsection{Removal of Affected Heat Flux Data Results}

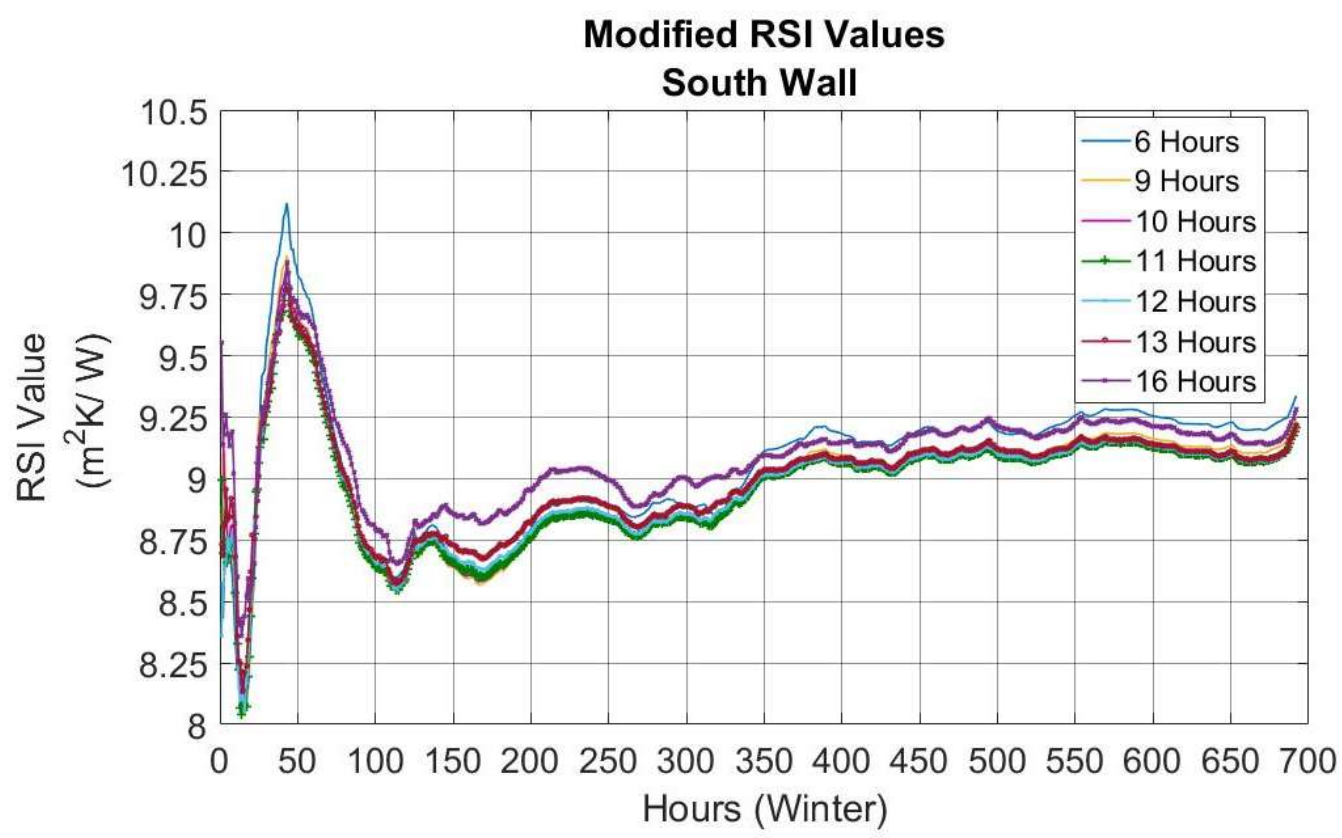

Figure 4-21: Modified Running RSI-value

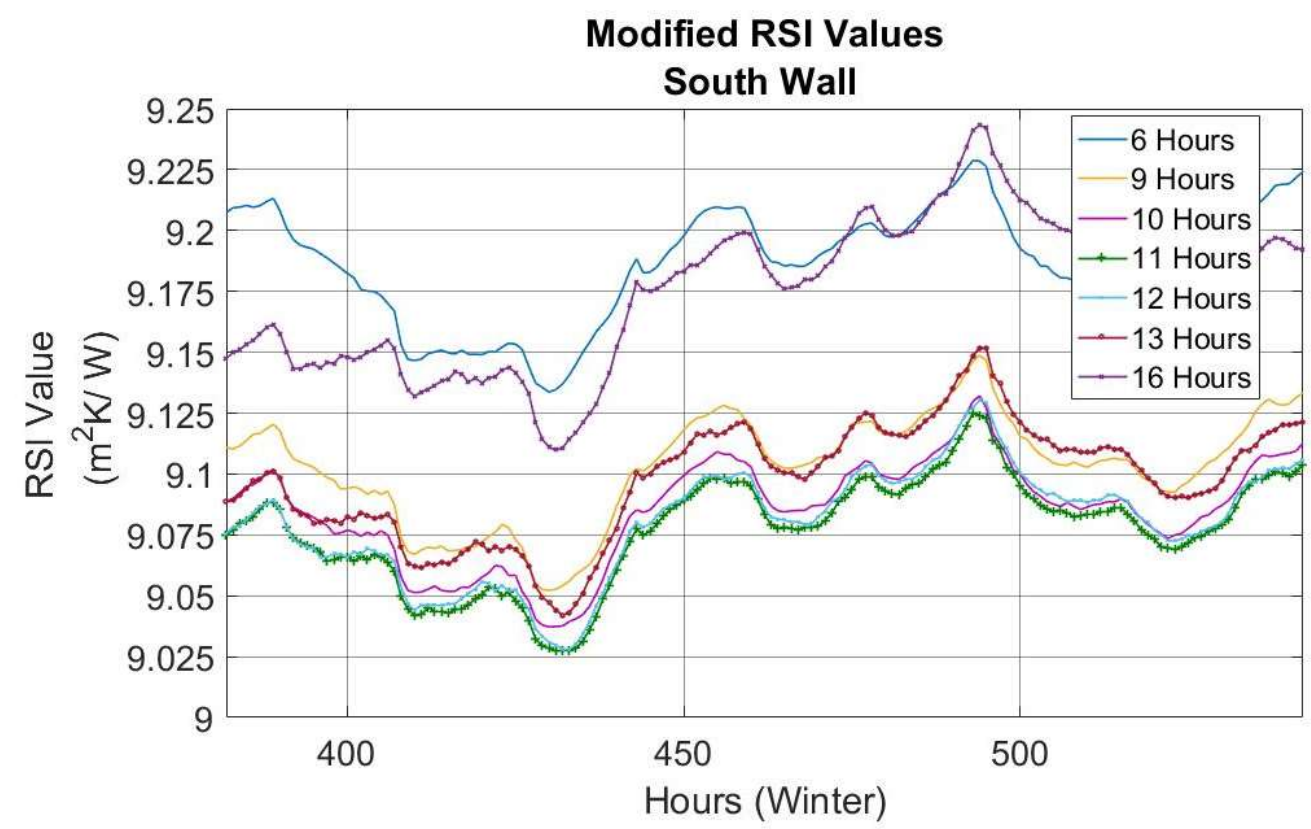

Figure 4-22 : Close up of Modified Running RSI - value

Figure 4-21 shows the resulting running RSI for the southern wall when both temperature and heat flux data effected from solar radiation is removed. Time lag cases were run for 9, 10, 11, 12, 
and 13 hours as indicated by the heat flux and temperature analysis above. Cases for 6 hour and 16 hours were run as examples.

The resulting differences in RSI occur due to changes in the summed heat flux data (sum of delta temperature stays the same). The 6 hour and 16-hour case have a lower summed heat flux denominator, due to inclusion of solar radiation effected data, which results in a higher RSI value. Their resultant high RSIs can be seen in Table 3-13. Given this information it can be assumed that the lowest RSI would indicate the proper time lag and provide the most accurate RSI.

Table 4-13 : Time Lag RSI Summary

\begin{tabular}{|l|l|l|}
\hline $\begin{array}{l}\text { Lag Time } \\
\text { Removal }\end{array}$ & $\begin{array}{l}\text { Convergence } \\
\text { Hours }(\mathrm{n}=48)\end{array}$ & $\begin{array}{l}\text { RSI } \\
\left(\mathrm{m}^{2} \mathrm{~K} / \mathrm{W}\right)\end{array}$ \\
\hline 6 Hours & 113 & 9.047 \\
\hline 9 Hours & 112 & 8.973 \\
\hline 10 Hours & 112 & 8.962 \\
\hline $\mathbf{1 1}$ Hours & $\mathbf{1 1 1}$ & $\mathbf{8 . 9 5 7}$ \\
\hline 12 Hours & 111 & 8.965 \\
\hline 13 Hours & 110 & 8.987 \\
\hline 16 Hours & 111 & 9.075 \\
\hline
\end{tabular}

The results indicate that the 11-hour time lag has the lowest RSI at $8.957 \mathrm{~m}^{2} \mathrm{~K} / \mathrm{W}$. The results from this analysis are similar to the first result found in the overcast period analysis of 9.09 $\mathrm{m}^{2} \mathrm{~K} / \mathrm{W}$ and are higher than the minimum value set in the use of north wall temperatures of 8.124 $\mathrm{m}^{2} \mathrm{~K} / \mathrm{W}$.

\subsubsection{0. $\quad$ South Wall Summary}

Three methods of analysis were undertaken in an attempt to determine the in-situ RSI of the southern wall. The south wall presented significantly challenges when determining the RSI using the summation technique due to direct influence of solar radiation on the data. The three unique methods of analysis presented here include: (i) Use of North Delta Temperatures, (ii) Overcast Periods Analysis, and (iii) Removal of Data Affected by Solar Radiation. The first method, Use of North Temperature Data, underestimated the RSI of the wall. The second method had short analysis time frames, and was also influenced by slight incident solar radiation. The third method appears to have provided the most accurate picture of the RSI of the southern wall as temperatures and heat flux data had been removed for the entire portion of the analysis period. 
As discussed in the background and literature review section, thermal resistance is a dynamic property influenced by a number of factors. The analysis provided a reasonable estimation and average of the dynamic RSI of the southern wall over the winter collection period. Table 4-14 contains a summary of values found from the three analysis.

Table 4-14 : Summary of South Wall RSI

\begin{tabular}{|c|c|}
\hline Analysis Method & $\begin{array}{c}\text { South Wall } \\
\text { In-situ RSI } \\
\mathrm{m}^{2} \mathrm{~K} / \mathrm{W}\end{array}$ \\
\hline $\begin{array}{c}\text { North Wall Delta } \\
\text { Temperatures }\end{array}$ & $8.12 \pm 7 \%$ \\
\hline $\begin{array}{c}\text { Overcast Period } \\
\text { Analysis }\end{array}$ & $9.09 \pm 7 \%$ \\
\hline $\begin{array}{c}\text { Solar Affected Data } \\
\text { Removal }\end{array}$ & $8.96 \pm 7 \%$ \\
\hline
\end{tabular}

The southern wall RSI that has been determined was considerably less than that found for the north wall $10.590 \mathrm{~m}^{2} \mathrm{~K} / \mathrm{W}$, however, seems to much closer to that of the predicted nominal RSI of $9.258 \mathrm{~m}^{2} \mathrm{~K} / \mathrm{W}$. The cause of the southern wall RSI-reduction is not explored in depth; however, some possible explanations are presented below.

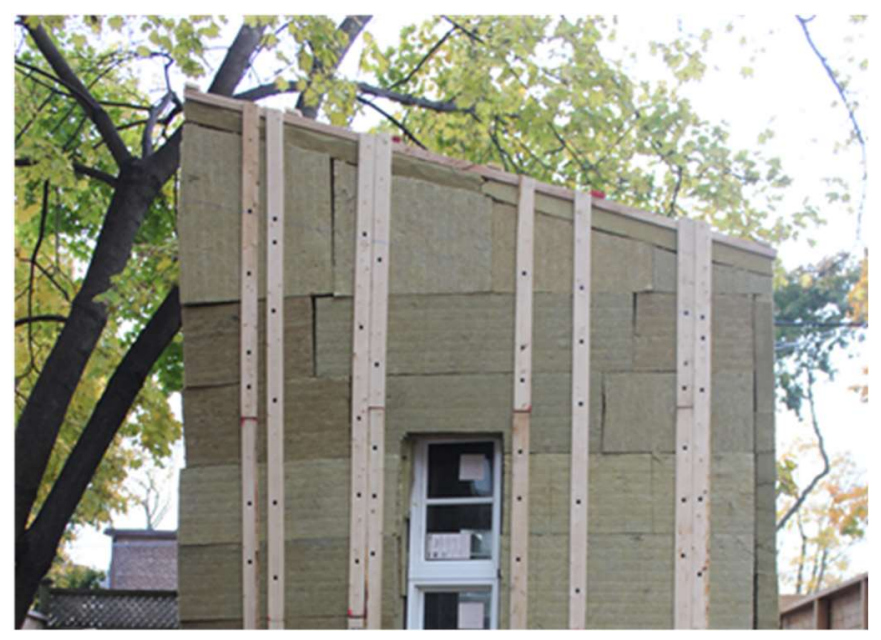

Figure 4-23 : Southern Wall of Structure

(i) Air gaps in external insulation: The southern wall had a curved façade as described in Section 3.1.2 Test Structure. The three layers of external mineral wool boards were rigid and did not completely bend with the wall. Air gaps between the insulation occurred as can be seen in Figure 4-23. The largest gaps occurred on the top left of the structure. The data used in this analysis was collected on the right-hand side of the 
structure. Some gaps can be seen on the right side of the structure where data was collected for this analysis. Thermal imaging (Figure 4-24) reveals heat loss through

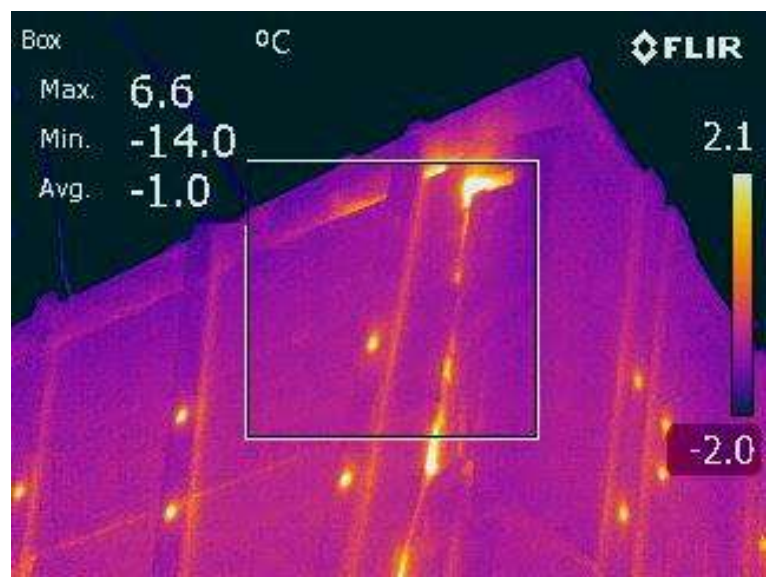

Figure 4-24 : Thermal Imaging South Wall

some gaps in insulation. These large air gaps may account for heat loss by increased convection through the external insulation, either by forced (wind washing) or natural convection.

(ii) Three dimensional effects and thermal bridging: The stud spacing on the southern wall, where the heat flux sensor had been installed was only $305 \mathrm{~mm}$ as compared with $405 \mathrm{~mm}$ on the northern wall. The fastener spacing was also reduced on the southern façade. The heat flux sensor was installed as close as possible to the middle of the cavity; however, this was still close to the corner location as shown in Figure 425. The combined effects of the corner location, small stud spacing, and deceased fastener spacing may account for the increased heat flow through this assembly.

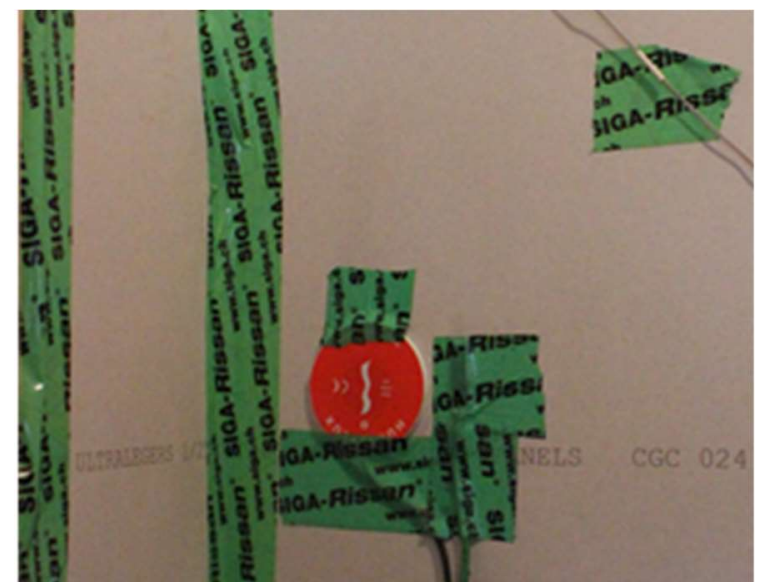

Figure 4-25 : Southern Wall Heat Flux Sensor 
(iii) Material variation: The insulation used within the test structure was not tested for thermal conductivity and as indicated in Section 4.2 Apparent Thermal Conductivity, there was often variation from reported nominal values and actual thermal conductivities. Variation occurred within batts of insulation, as well as, between bundles of insulation. Variations in thickness and in density will cause thermal resistivity values to change.

\subsection{Apparent Thermal Conductivity}

Apparent thermal conductivity testing was performed on samples of Roxul Comfortboard 110 using a Netzsch HFM 436 Lambda heat flow meter and following the methodology of ASTM C518. The HFM \pm 436 Lamda has an accuracy of 1 to $3 \%$. It should be noted that samples were not conditioned to 50\% RH as dictated in ASTM C518; however, changes in RH should not significantly affect apparent thermal conductivity of hydrophobic mineral wool. Insulation boards were $76 \mathrm{~mm}$ thick. Samples were extracted from two bundles of packaging and subdivided into $305 \mathrm{~mm} \times 305 \mathrm{~mm}$ portions. Five random portions were selected from the cuts of each bundle for a total of 10 pieces. Tested bundles had the same manufacturer batch number and therefore are suspected to have closer similarities than between manufacturer batches.

The majority of the testing was completed at a mean temperature of $24^{\circ} \mathrm{C}$ as this is the temperature generally used by the manufacturer when testing thermal conductivity. The top plate temperature was set at $34^{\circ} \mathrm{C}$ and bottom plate was set at $12^{\circ} \mathrm{C}$. A summary of results is shown in Table 4-15. Raw testing data can be found in Appendix G.

Table 4-15 : ASTM C518 Test Results

\begin{tabular}{|c|c|c|c|c|c|c|}
\hline & $\begin{array}{c}\text { Mean } \\
\text { Temperature }\end{array}$ & $\begin{array}{c}\text { Mean } \\
\text { Conductivity } \\
(\mathrm{W} / \mathrm{mK})\end{array}$ & $\begin{array}{c}\text { Standard } \\
\text { Deviation } \\
(\mathrm{W} / \mathrm{mK})\end{array}$ & $\begin{array}{c}\text { Mean } \\
\text { RSI } \\
/ 25.4 \mathrm{~mm} \\
\left(\mathrm{~m}^{2} \mathrm{~K} / \mathrm{W}\right)\end{array}$ & $\begin{array}{c}\text { Max } \\
\text { Conductivity } \\
(\mathrm{W} / \mathrm{mK})\end{array}$ & $\begin{array}{c}\text { Minimum } \\
\text { Conductivity } \\
\text { (W/mK) }\end{array}$ \\
\hline $\begin{array}{c}\text { Lab } \\
\text { Test }\end{array}$ & $23.4^{\circ} \mathrm{C}$ & 0.0407 & 0.00029 & 0.624 & 0.0411 & 0.0403 \\
\hline $\begin{array}{c}\text { Manuf. } \\
\text { Data }\end{array}$ & $24^{\circ}$ & 0.0363 & N/A & 0.70 & N/A & N/A \\
\hline
\end{tabular}

The apparent thermal conductivity testing showed that there was a significant difference between manufacturer and reported values, an increase of $12 \%$, while there were not significant 
differences between tested bundles. From the results of the thermal conductivity testing, one would expect the thermal resistance of the in-situ wall to be less than what is expected from manufacturer data, however the opposite was the case for the North wall. The south wall experienced a reduction in expected RSIs more in line with thermal conductivity testing. It is suspected that there exists greater variability between manufacturer batches than shown in thermal conductivity testing.

One test was conducted at varying temperatures to define thermal conductance dependence on mean temperature. These values were compared against data that was provided by the manufacturer. Results can be seen in Figure 4-26.

\section{Lab Testing vs Manufacturer Date \\ $\mathrm{RSI} / 25.4 \mathrm{~mm}$}

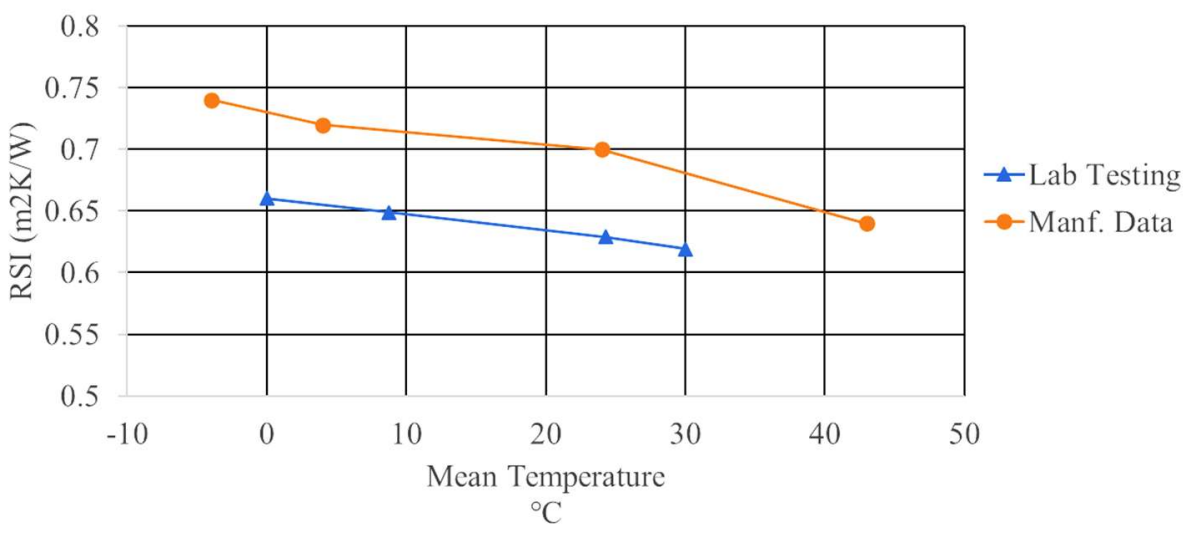

Figure 4-26: Thermal Resistivity Compared to Mean Temperature

Similar trends existed between provided data and tested data for the thermal dependence of Roxul Comfortboard 110. As noted in the direct comparison, there was a noticeable decrease in thermal resistance between data sets. The difference becomes less pronounced when mean temperature increases. There was a difference of approximately $90 \%$ in thermal resistances when temperatures in the range of $-10^{\circ} \mathrm{C}$ and $20^{\circ} \mathrm{C}$ were entered into linear data trendlines.

The purpose of testing was to investigate material variability and not explicitly state insulation thermal conductivity values. The testing concluded there was no significant difference in apparent conductivity within the same batch or bundle however there was a significant difference from reported values. A summary of thermal resistances can be found in Section 4.4. 


\subsection{Effective Thermal Resistance Analysis}

This section will determine the thermal effects caused by the metal fasteners and how several variations of the same wall assembly performed in terms of effective clear-wall thermal resistances. Thermal imaging photos of the test structure revealed metal fasteners exhibited higher temperatures than surrounding areas indicating thermal bridging (Figure 4-27).

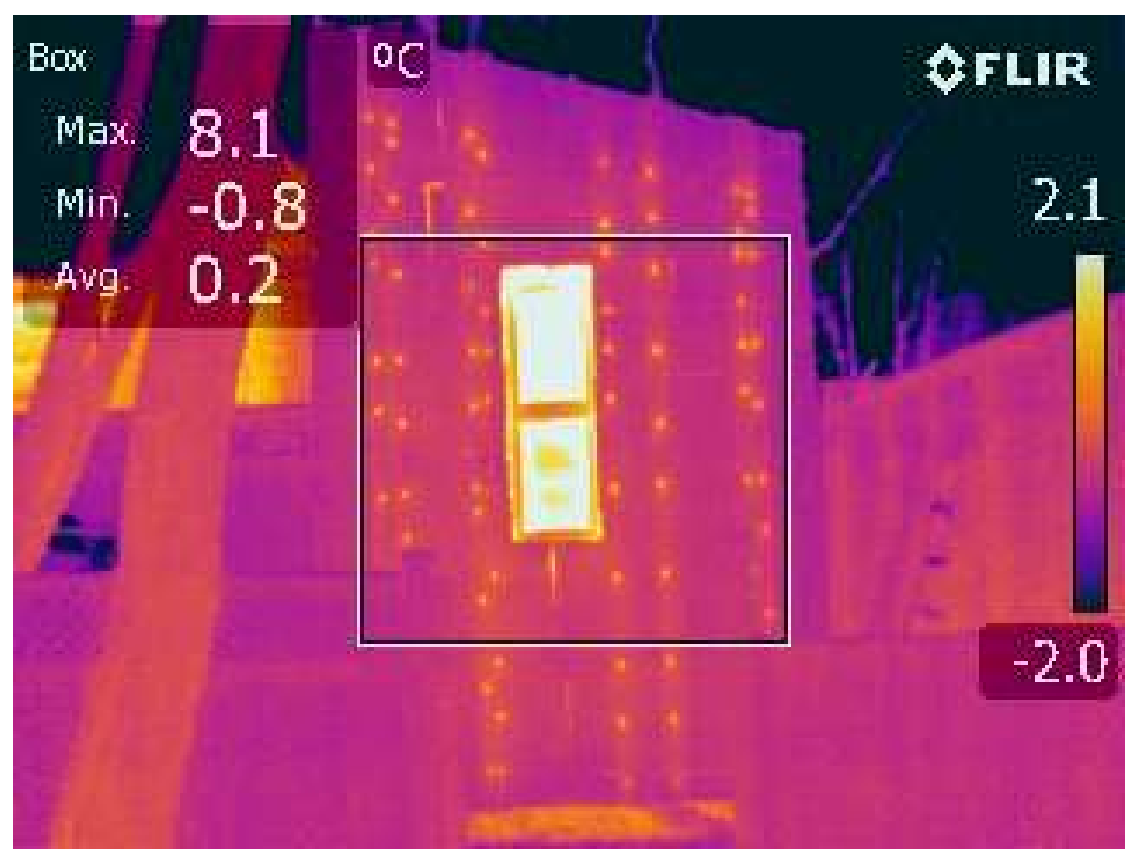

Figure 4-27: Thermal Imaging - No Cladding

Heat3, a steady-state and transient three-dimensional heat transfer simulation program, was used to conduct this study. To ensure that the simulations accurately reflect the proposed wall assembly it was necessary to first calibrate a model and validate it against the collected field data.

\subsubsection{Three-dimensional Thermal Simulation Calibration}

\subsubsection{Site Selection}

The north wall was selected as the primary focus for calibration. This was due to its typical (i.e. $405 \mathrm{~mm}$ stud spacing) and plumb construction. Direct solar radiation, which may cause irregularities in the modelling, was minimized on the north wall. Height 2 was chosen as the sensor field for calibration as this sensor area was less affected by the orientation/placement of the space heater. 


\subsubsection{Time Period Selection}

The period from February $12^{\text {th }}$ to the $19^{\text {th }}$ was selected as the calibration time. A period of 5 days was selected to both allow for the simulation to converge and not prolong simulation execution times. February $12^{\text {th }}$ to the $19^{\text {th }}$ exhibited some of the coldest temperatures during the testing period allowing for maximum one-directional heat flow through the enclosure.

\subsubsection{Model Geometry}
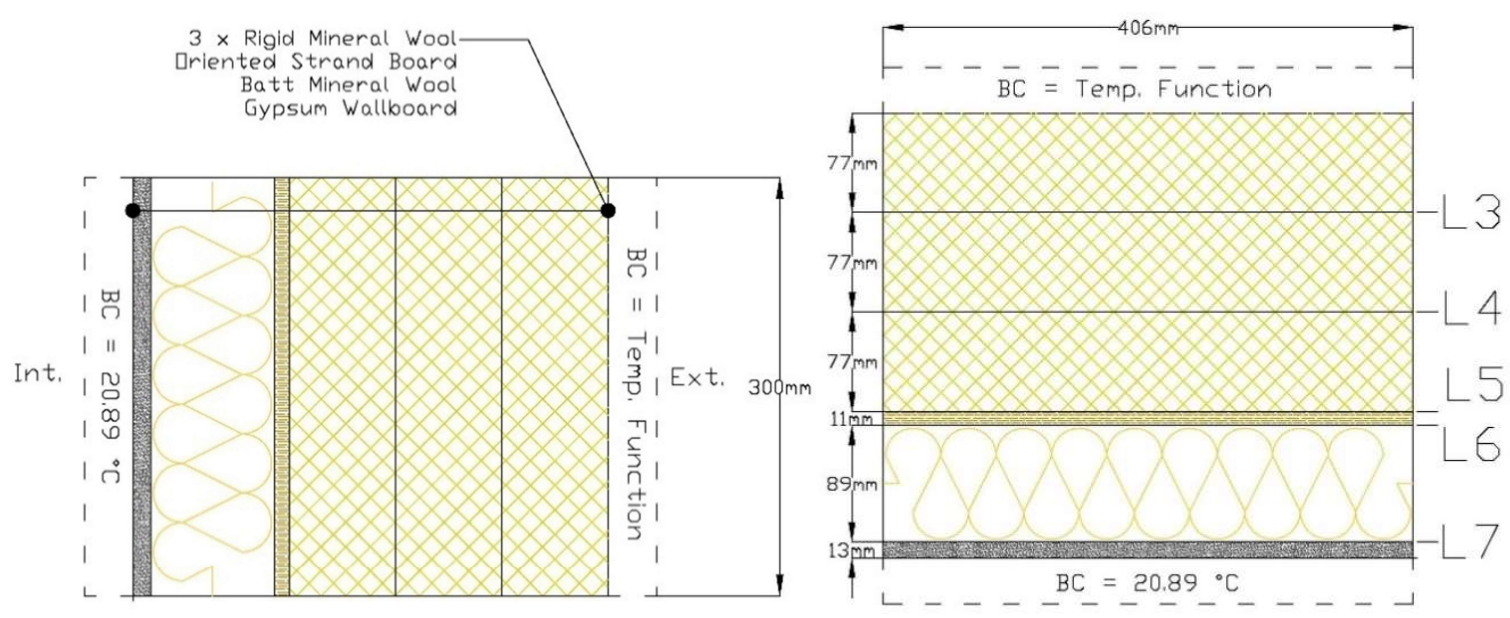

Figure 4-28: HEAT3 Model Geometry

The initial model was selected to represent a center of cavity portion of the proposed assembly. This excluded all framing and metal fasteners. It provided a highly simplified 2-dimensional view of the wall. See Figure 4-28 for a layout of the initial modelled geometry. The initial model was based on the wall assembly constructed for the field test structure with studs spaced at $406 \mathrm{~mm} \mathrm{c} / \mathrm{c}$ and fasteners placed $305 \mathrm{~mm}$ apart. The purpose of this simplified geometry was to reduce the required computing time for dynamic simulation and to eliminate potential issues caused by improper placement (i.e. not representative of field conditions) of fasteners and studs within model. Calibration was completed with a numerical grid size of 60x60x60 $(5 \mathrm{~mm} \times 6.8 \mathrm{~mm}$ $\mathrm{x} 4.3 \mathrm{~mm})$.

\subsubsection{Initial Conditions}

The initial temperature for each layer was calculated from temperature data on Feb. $12^{\text {th, }} 2016$. An average temperature was used for each layer based on the heat sensors on either side of that layer. The purpose of selecting the initial temperature is to reduce computing time and to 
increase accuracy of the simulation. Initial temperatures can be seen in the Table 4-16. The initial conductivity values were selected from default values or from manufacturer material data sheets and can be seen in Table 4-16.

\subsubsection{Boundary Conditions}

The interior boundary condition was set to a constant $20.9^{\circ} \mathrm{C}$ derived from the temperature sensor (NH2L8-T) which had an average reading of $20.9^{\circ} \mathrm{C}$ and had a standard deviation of $0.11^{\circ} \mathrm{C}$. HEAT3 is only able to handle one dynamic function when simulating transient calculations. The exterior boundary conditions were set to an hourly linear function. The data from the RH/T sensor (NH2-L1.5-RHT) was used as the exterior boundary condition as this is believed to more accurately reflect the surface temperature of the exterior mineral wool at layer 2.

\subsubsection{Calibration Procedure}

Temperature recorders were placed at L3, L4, L5, and L6 within the Heat3 model and compared to field data temperature collected from Feb. $12^{\text {th }}-15^{\text {th }}$. The thermal conductivities and heat capacities of materials were changed subsequently through iterative processes until the temperature profile from HEAT3 matched that of collected field data. A total of 22 iterations were completed before calibration was considered achieved. Figure 4-29 shows the initial and final temperatures of the calibration against the collected field data. 
HEAT3

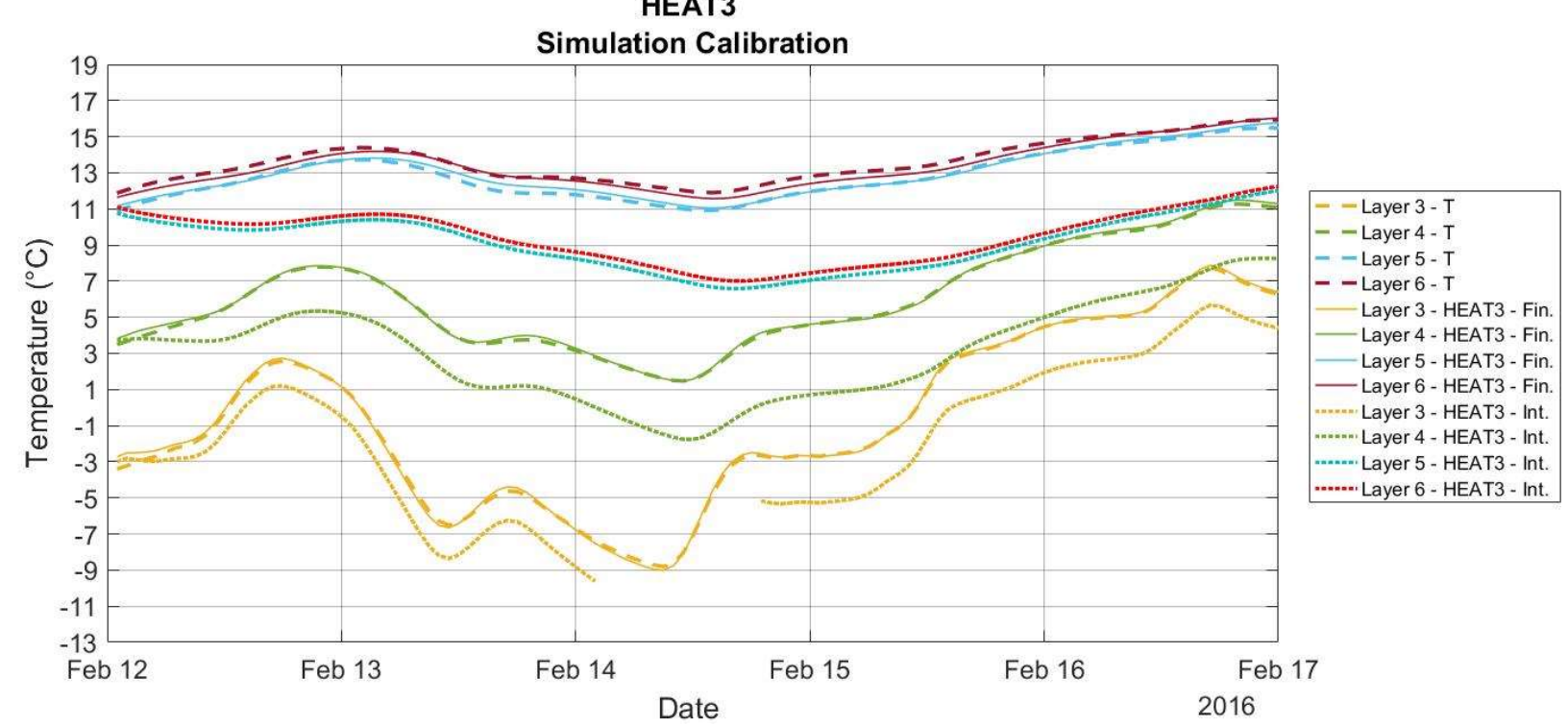

Figure 4-29: HEAT3 Temperature Profiles

Calibration was considered complete when temperature profiles aligned visually or final values fell within $+/-3 \%$. A test case was run after calibration to see if there would be potential influence from the studs and metal fasteners on the temperature field of the clear wall. The metal fastener was placed on the same horizontal plane as the temperature recorder. The fastener had minimal impact $\left(0.2^{\circ} \mathrm{C}\right.$ in Layer 3$)$ on the temperature field and the model was considered calibrated. Another model was created with a numerical grid size of 130x130x $130(2.3 \mathrm{~mm} \times$ $3.1 \mathrm{~mm} \times 2.0 \mathrm{~mm}$ ) to confirm resolution did not affect results. 


\subsubsection{Final Material Values}

Table 4-16 : Final HEAT3 Material Resistivity

\begin{tabular}{|c|c|c|c|c|c|}
\hline Material & $\begin{array}{c}\text { Thickness } \\
(\mathrm{mm})\end{array}$ & $\begin{array}{c}\text { Final } \\
\text { Thermal } \\
\text { Conductivity } \\
(\mathrm{W} / \mathrm{m} \mathrm{K})\end{array}$ & $\begin{array}{c}\text { Final } \\
\text { Thermal } \\
\text { Resistivity } \\
\left(\mathrm{m}^{2} \mathrm{~K} / \mathrm{W}\right)\end{array}$ & $\begin{array}{c}\text { Final } \\
\text { Volumetric } \\
\text { Heat Capacity } \\
\left(\mathrm{MJ} / \mathrm{m}^{3} \mathrm{~K}\right)\end{array}$ & $\begin{array}{c}\text { Initial } \\
\text { Temperature }\end{array}$ \\
\hline $\begin{array}{c}\text { Gypsum Wall } \\
\text { Board }\end{array}$ & 13 & 0.16 & 0.081 & 0.4176 & 18 \\
\hline $\begin{array}{c}\text { Roxul } \\
\text { ComfortBatt }\end{array}$ & 89 & 0.040 & 2.225 & 0.0306 & 15 \\
\hline $\begin{array}{c}\text { Oriented Strand } \\
\text { Board }\end{array}$ & 11 & 0.085 & 0.129 & 1.22 & 11.5 \\
\hline $\begin{array}{c}\text { Roxul } \\
\text { ComfortBoard } \\
110 \text { (Layer 5-4) }\end{array}$ & 76 & 0.034 & 2.235 & 0.10 & 7.5 \\
\hline $\begin{array}{c}\text { Roxul } \\
\text { ComfortBoard } \\
110 \text { (Layer 4-3) }\end{array}$ & 76 & 0.033 & 2.303 & 0.10 & 0 \\
\hline $\begin{array}{c}\text { Roxul } \\
\text { ComfortBoard } \\
110 \text { (Layer 3-2) }\end{array}$ & 77 & 0.032 & 2.406 & 0.11 & -7 \\
\hline
\end{tabular}

The results from the calibration can be seen in Table 4-16. The external insulation layers showed an increase in thermal resistance compared with manufacturer data, which was consistent with the in-situ field analysis period for that location. The interior insulation showed a reduction compared with manufacturer data, which was also consistent with in-situ thermal resistance. The impact of metal fasteners on the thermal resistance is examined in the next section.

\subsubsection{Effective Thermal Resistance Analysis}

HEAT3 simulations were completed on a number of different insulation configurations, fastener spacing, fasteners types, and stud spacing. This provided a range of thermal resistances depending on selected configurations. The impact of high conductivity steel was compared to that of a lower conductivity stainless steel. This section explores the results from multi-case analysis

\subsubsection{Simulation Information}

A numerical grid of $130 \times 130 \times 130(2.3 \mathrm{~mm} \times 3.1 \mathrm{~mm} \times 2.0 \mathrm{~mm})$ was selected to provide increased resolution compared to the calibration simulations. The dimensions of each element 
varied with each case, as the size of the model was adjusted to account for varied insulation, fastener and stud configurations. Complete case dimensions and results can be found in Appendix H. Steady state conditions were selected for the multi-case analysis. Boundary conditions were set as $20^{\circ} \mathrm{C}$ and $-10^{\circ} \mathrm{C}$.
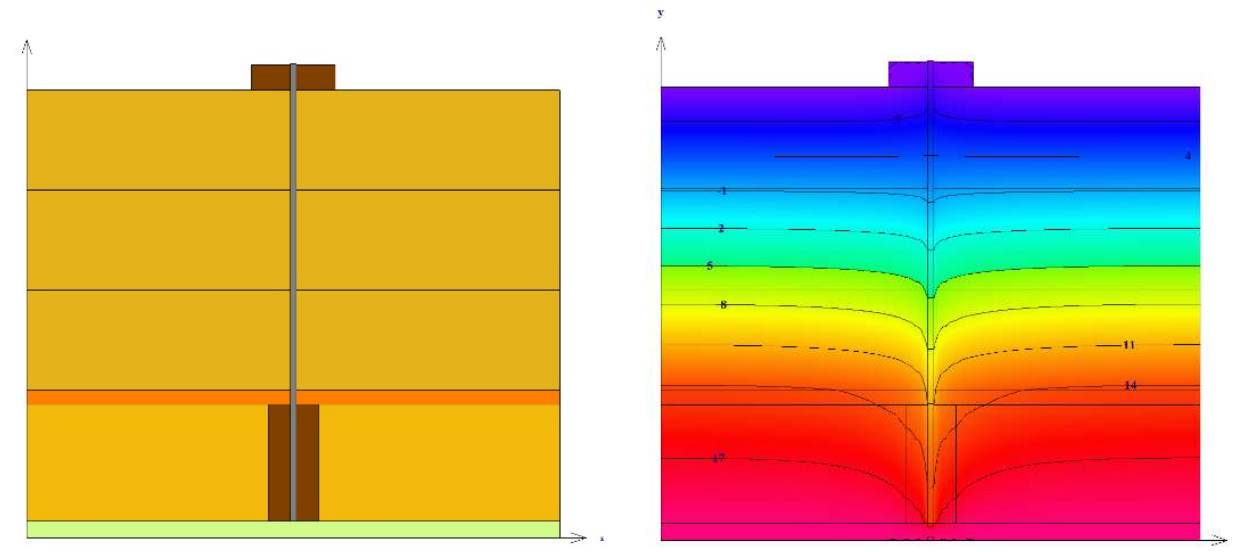

Figure 4-30 : Heat3 2D Cross Section. Materials (Left). Temperature Isotherm (Right)

\subsubsection{Material Values}

Standard material values were selected for the multi-case analysis. The conductivities used in simulations were considered "nominal" and are shown in Table 4-17.

Table 4-17 : Nominal Conductivities for Enclosure Materials

\begin{tabular}{|c|c|c|}
\hline Material & $\begin{array}{c}\text { Thermal } \\
\text { Conductivity } \\
(\mathrm{W} / \mathrm{mK})\end{array}$ & Reference \\
\hline Steel & 50 & HEAT3 Material Library \\
\hline Stainless Steel & 25 & HEAT3 Material Library \\
\hline OSB & 0.0902 & $\begin{array}{c}\text { Simpson \& TenWolde } \\
(1999)\end{array}$ \\
\hline Gypsum & 0.1588 & CGC (2014) \\
\hline $\begin{array}{c}\text { Interior Mineral } \\
\text { Wool }\end{array}$ & 0.03606 & Roxul (2016) \\
\hline $\begin{array}{c}\text { Exterior } \\
\text { Mineral Wool }\end{array}$ & 0.03629 & Roxul (2013) \\
\hline
\end{tabular}

Fastener size $(4.5 \mathrm{~mm} \times 4.5 \mathrm{amm})$ was simulated as a square with functionally the same area as installed fasteners (which had a diameter of $4.8 \mathrm{~mm}$.) The grade/type of metal fasteners was not known. It was assumed that they were steel for the purposes of analysis. 


\subsubsection{3. $\quad$ Clear Wall Effective Thermal Resistance}

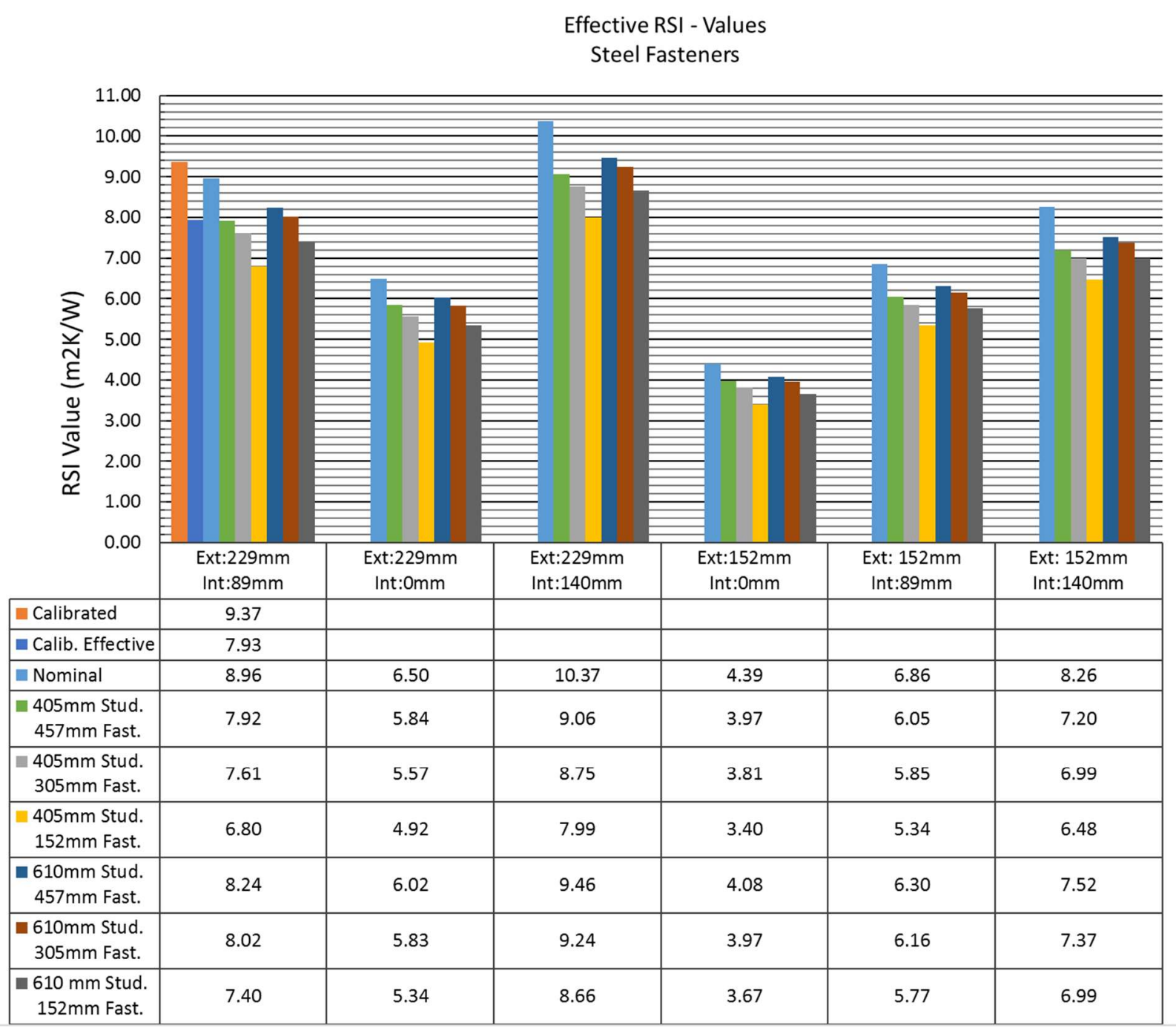

Figure 4-31: Clear Wall Effective Thermal Resistance - Steel

Shown in Figure 4-31 are the results from the multi-case analysis with steel fasteners. There was a $15.3 \%$ reduction in the RSI of the calibrated model with the addition of fasteners. This was a similar reduction $(\sim 15.1 \%)$ to the "nominal" RSI when field testing fastener and stud spacing were considered. The largest reduction (24.4\%.) from "nominal" was the 405mm stud spacing and $152 \mathrm{~mm}$ fastener spacing with $229 \mathrm{~mm}$ of exterior insulation and no interior insulation. The smallest reduction occurred in the $610 \mathrm{~mm}$ stud and $457 \mathrm{~mm}$ fastener spacing with $152 \mathrm{~mm}$ and no interior insulation at $7.1 \%$. These results were as expected, as the further studs and fasteners were spaced, the more area occupied by low conductivity insulation. 


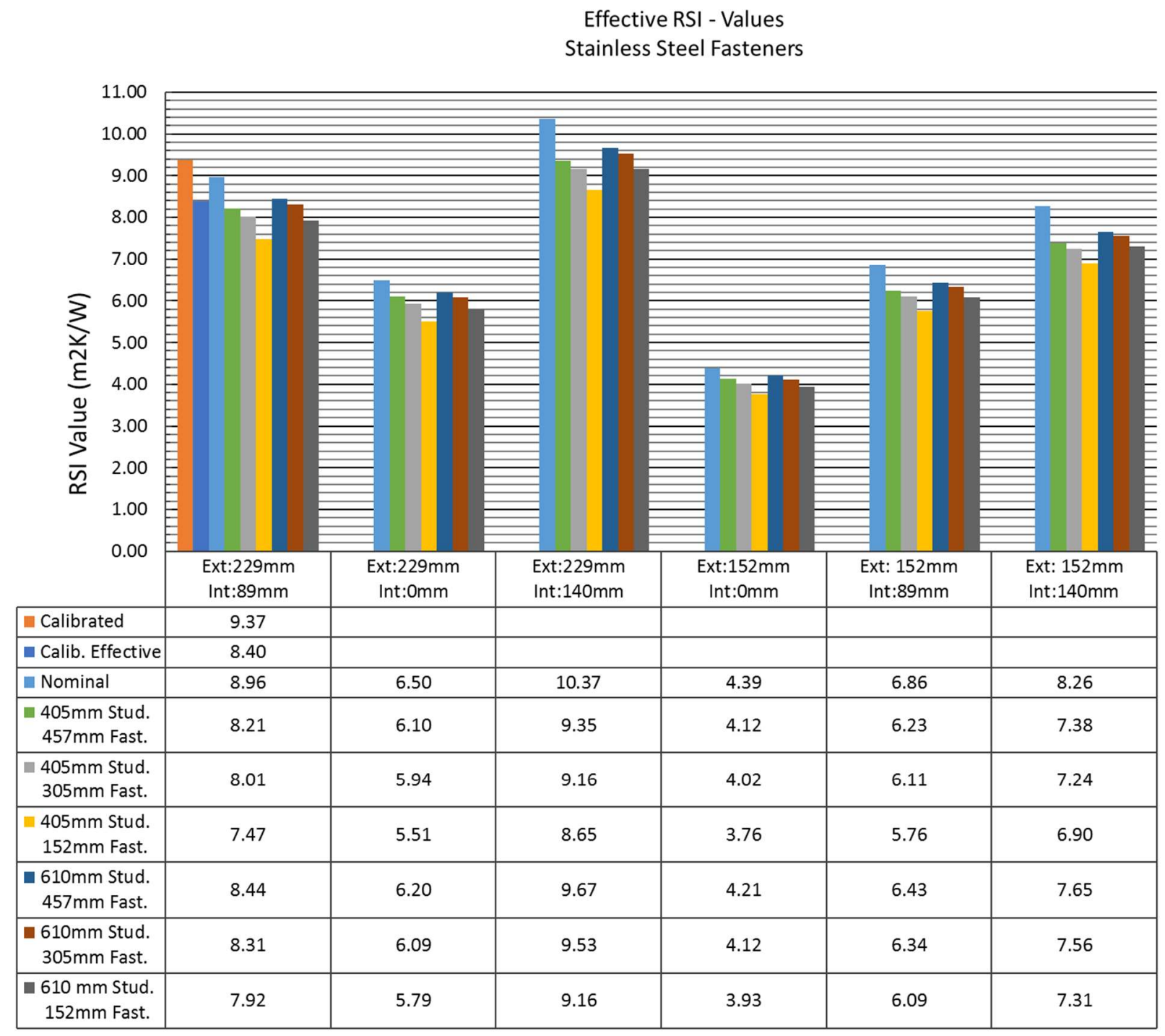

Figure 4-32 : Clear Wall Effective Thermal Resistance - Stainless Steel

Shown in Figure 4-32 are the results from the stainless steel clear-wall effective thermal resistance analysis. The effective RSI from the calibrated model saw a $10.3 \%$ reduction when stainless steel fasteners and studs as compared with the $15.3 \%$ reduction when steel fasteners were used. An effective RSI of $8.40 \mathrm{~m}^{2} \mathrm{~K} / \mathrm{W}$ was found with stainless steel compared with that of $7.93 \mathrm{~m}^{2} \mathrm{~K} / \mathrm{W}$ with steel for the calibrated effective scenario.

The largest reduction (16.6\%) from nominal RSI was seen in the case with the $405 \mathrm{~mm}$ stud spacing and $152 \mathrm{~mm}$ fastener spacing with $229 \mathrm{~mm}$ of exterior insulation and $89 \mathrm{~mm}$ of interior 
insulation. This was different from the steel fastener cases, and it is speculated that simulation errors and rounding errors account for the differences in these cases. The smallest reduction occurred in the $610 \mathrm{~mm}$ stud and $457 \mathrm{~mm}$ fastener spacing with $152 \mathrm{~mm}$ and no interior insulation at $4.2 \%$. It can be concluded that the use of less conductive fastening materials is beneficial in limiting impacts caused by the fasteners however reducing the number of fasteners is much more important.

\subsection{Thermal Resistances Summary}

The results from the thermal analysis reveal a significant difference between expected nominal centre of cavity values and in-situ centre of cavity values, especially for the North wall during the winter months. Table 4-18 presents a summary of results from the different analyses performed. Table 4-18 compares individual layer values to each other. Cells have dashed where they are not applicable. 
Table 4-18: Thermal Resistance Summary of North and South Walls

\begin{tabular}{|c|c|c|c|c|c|c|}
\hline Material & $\begin{array}{l}\text { Thick } \\
(\mathrm{mm})\end{array}$ & $\begin{array}{l}\text { Nominal } \\
\text { Thermal } \\
\text { Resistivity } \\
\left(\mathrm{m}^{2} \mathrm{~K} / \mathrm{W}\right)\end{array}$ & $\begin{array}{c}\text { ASTM } \\
\text { C518@ } \\
24^{\circ} \mathrm{C} \\
\left(\mathrm{m}^{2} \mathrm{~K} / \mathrm{W}\right)\end{array}$ & $\begin{array}{l}\text { HEAT3 } \\
\text { Thermal } \\
\text { Resistivity } \\
\left(\mathrm{m}^{2} \mathrm{~K} / \mathrm{W}\right)\end{array}$ & $\begin{array}{l}\text { In-Situ } \\
\text { North } \\
\text { Wall } \\
\text { Winter } \\
\left(\mathrm{m}^{2} \mathrm{~K} / \mathrm{W}\right)\end{array}$ & $\begin{array}{c}\text { In-Situ } \\
\text { South } \\
\text { Wall } \\
\text { Winter } \\
\left(\mathrm{m}^{2} \mathrm{~K} / \mathrm{W}\right)\end{array}$ \\
\hline $\begin{array}{l}\text { Gypsum Wall } \\
\text { Board } \\
\text { (Layer 8-7) }\end{array}$ & 12.7 & 0.080 & - & 0.081 & 0.118 & - \\
\hline $\begin{array}{c}\text { Roxul } \\
\text { ComfortBatt } \\
\text { (Layer 7-6) }\end{array}$ & 88.9 & 2.466 & - & 2.225 & 2.277 & - \\
\hline $\begin{array}{c}\text { Oriented Strand } \\
\text { Board } \\
\text { (Layer 6-5) }\end{array}$ & 11.1 & 0.121 & - & 0.129 & 0.444 & - \\
\hline $\begin{array}{c}\text { Roxul } \\
\text { ComfortBoard } 110 \\
\text { (Layer 5-4) }\end{array}$ & 76.2 & 2.100 & 1.872 & 2.235 & 2.456 & - \\
\hline $\begin{array}{c}\text { Roxul } \\
\text { ComfortBoard } 110 \\
\text { (Layer 4-3) }\end{array}$ & 76.2 & 2.100 & 1.872 & 2.303 & 2.386 & - \\
\hline $\begin{array}{c}\text { Roxul } \\
\text { ComfortBoard } 110 \\
\text { (Layer 3-2) }\end{array}$ & 76.2 & 2.100 & 1.872 & 2.406 & 2.624 & - \\
\hline $\begin{array}{c}\text { Total } \\
\text { w/o } \\
\text { Exterior }\end{array}$ & - & 8.967 & - & 9.379 & 10.305 & - \\
\hline $\begin{array}{l}\text { Ventilation Air } \\
\text { Gap } \\
\text { (Layer 1-2) }\end{array}$ & 19.0 & 0.146 & - & - & -0.209 & - \\
\hline $\begin{array}{c}\text { Cedar } \\
\text { Cladding } \\
\text { (Layer 1-0) }\end{array}$ & 16.0 & 0.145 & - & - & 0.424 & - \\
\hline $\begin{array}{c}\text { Center of Cavity } \\
\text { Wall }\end{array}$ & 376.3 & 9.258 & - & - & 10.590 & 8.97 \\
\hline
\end{tabular}

The layer analysis shows that the expected RSI of the exterior insulation, in this case Roxul Comfortboard 110, ranges from apparent thermal conductivity values of $1.872 \mathrm{~m}^{2} \mathrm{~K} / \mathrm{W}$ to 2.624 $\mathrm{m}^{2} \mathrm{~K} / \mathrm{W}$ in-service. This differs from nominal values by $-10.9 \%$ and $+25.0 \%$. The calibrated HEAT3 model results indicate an increase in in-situ exterior insulation thermal resistance however, changes are not as significant as the layer analysis concluded. One potential difference 
is the measured thermal resistance of the OSB in-situ, as compared with HEAT3 and nominal values.

The southern wall has a significantly lower in-situ thermal resistance as compared with the North wall. The southern wall aligns more closely with the expected centre-of-cavity value. It is suspected that the thermal resistance of the southern wall has been influenced by three dimensional effects and gaps in insulation. In summary, the north wall experiences an increase of $+14.4 \%$ to nominal centre of cavity and the south wall experiences a reduction of $-4.2 \%$. It is suspected that the north wall's increase is due to contact resistances, in-service temperatures, material variability, and in-situ data collection errors.

The proposed enclosure may experience a reduction in the centre of cavity nominal RSIs of anywhere between $24.4 \%$ and $4.2 \%$ based on various stud spacing's, fastener spacing's and fastener types. The tested enclosure had an unknown grade of screws and had $410 \mathrm{~mm}$ stud spacing and 305mm spacing (on the north Wall) so it is suspected the drop in expected RSI is in the range of $15.3 \%-10.3 \%$ from $9.258 \mathrm{~m}^{2} \mathrm{~K} / \mathrm{W}$ to $7.84 \mathrm{~m}^{2} \mathrm{~K} / \mathrm{W}$ or $8.30 \mathrm{~m}^{2} \mathrm{~K} / \mathrm{W}$. This is a significant reduction in expected RSIs and should be accounted for within whole building energy prediction models. The southern wall has smaller stud spacing and increased fastener densities and is suspected to cause an even larger reduction the effective RSI.

\subsection{In-situ Hygrothermal Results}

This section explores the hygrothermal performance of the test structure during the collection period from February to August. The performance is compared against the three-metrics identified during literature review and include;

- Moisture Content of Wood Components,

- Relative Humidity at the Surface of the Sheathing,

- Interior Air Dew Point Temperature Analysis, 


\subsubsection{Exterior Climate}

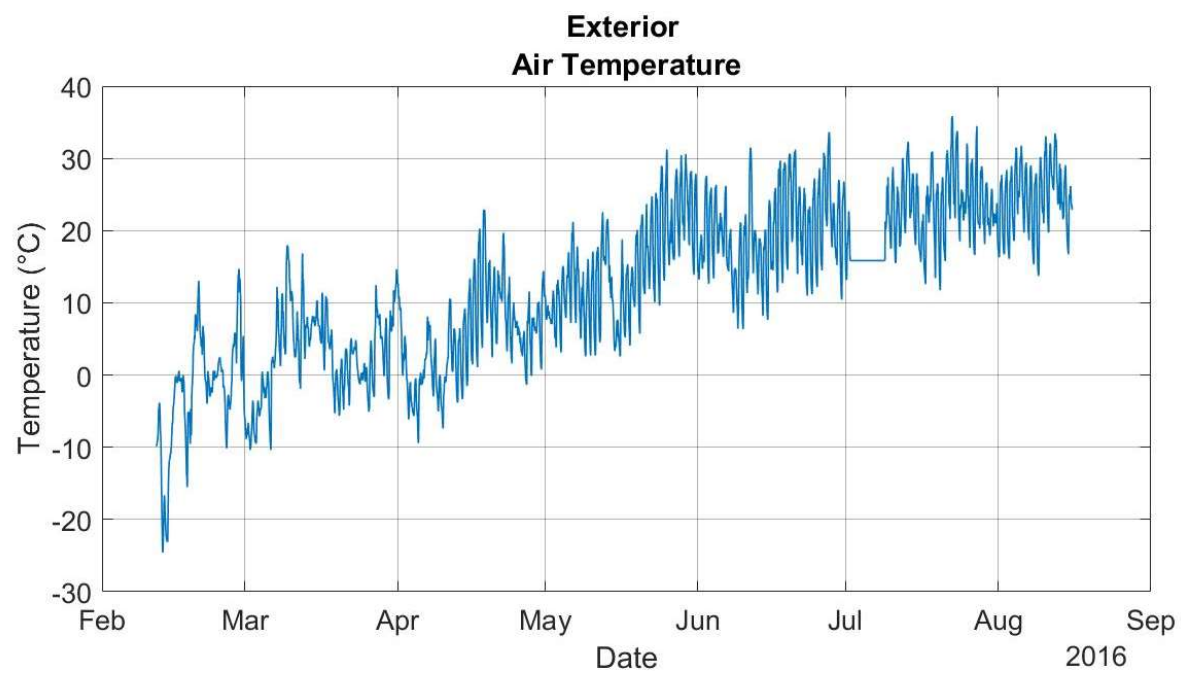

Figure 4-33 : Field Data-Exterior Air Temperature

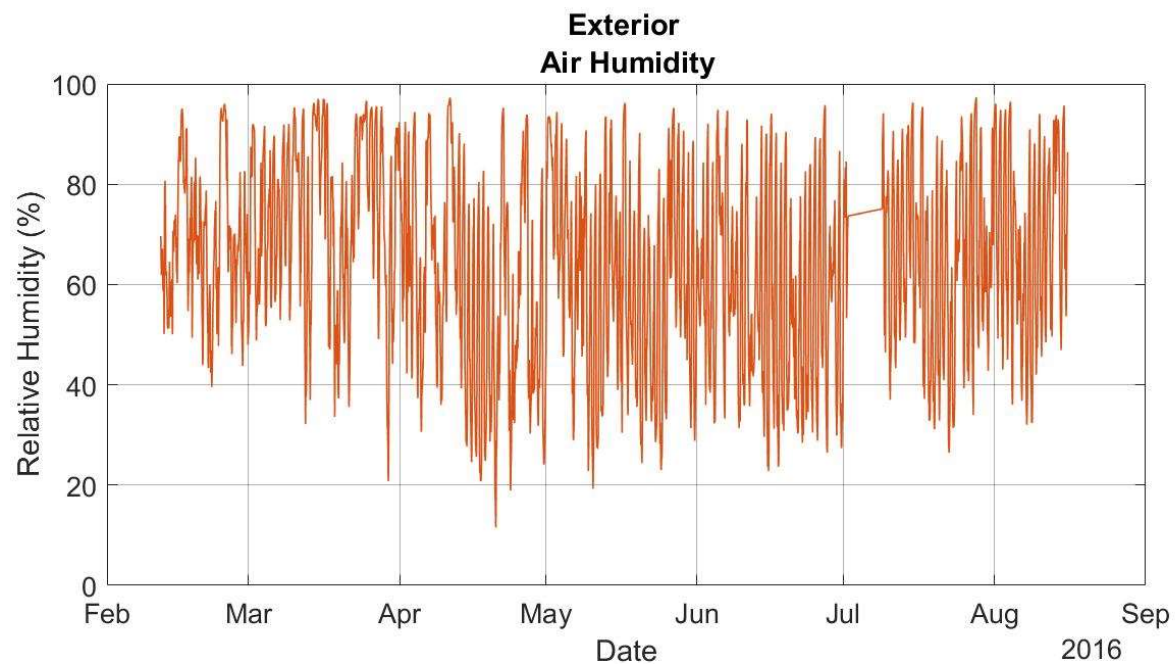

Figure 4-34: Field Data-Exterior Air Relative Humidity

Shown in Figure 4-33 and 4-34, is the temperature and RH data for the exterior climate during the in-situ analysis. It should be noted that the exterior air temperature only reached below $-20^{\circ} \mathrm{C}$ a few times during the collection period. More extreme and longer duration cold periods would be beneficial to confirming the in-situ hygrothermal performance. The climate period was on average warmer than is 'normal' for the Toronto region. Table 4-19 has a summary of historical norm for Toronto. Averages were only taken for the months shown due to complete field records for the month of February and August 
Table 4-19: Historical Averages (1981-2010) vs. Field Data. (Canadian Government)

\begin{tabular}{|c|c|c|c|c|}
\hline & \multicolumn{2}{|c|}{ Temperature $\left({ }^{\circ} \mathrm{C}\right)$} & \multicolumn{2}{c|}{ Rainfall $(\mathrm{mm})$} \\
\hline & $\begin{array}{c}\text { Historical } \\
\text { Average }\end{array}$ & Field Data & $\begin{array}{c}\text { Historical } \\
\text { Average }\end{array}$ & Field Data \\
\hline March & 0.1 & 2.74 & 32.6 & 82.0 \\
\hline April & 7.1 & 5.19 & 63 & 42.4 \\
\hline May & 13.1 & 14.78 & 74.3 & 29.2 \\
\hline June & 18.6 & 19.72 & 71.5 & 43.8 \\
\hline July & 21.5 & 23.29 & 75.7 & 49.4 \\
\hline
\end{tabular}

*Canadian Climate Normal 1981-2010 (Gov. Can)

Table 4-19 also displays the average rainfall amounts from March to July for field data and historical records. While March experienced more rainfall than the historical average, the other months had significantly less. While there were several other variables that impact the hygrothermal performance of an enclosure, the temperature, relative humidity and rainfall were good indicators of exterior moisture loading. The collection period experienced mild moisture loading as compared with historical averages, and even may be considered 'good' as compared with severe years.

\subsubsection{Interior Climate}

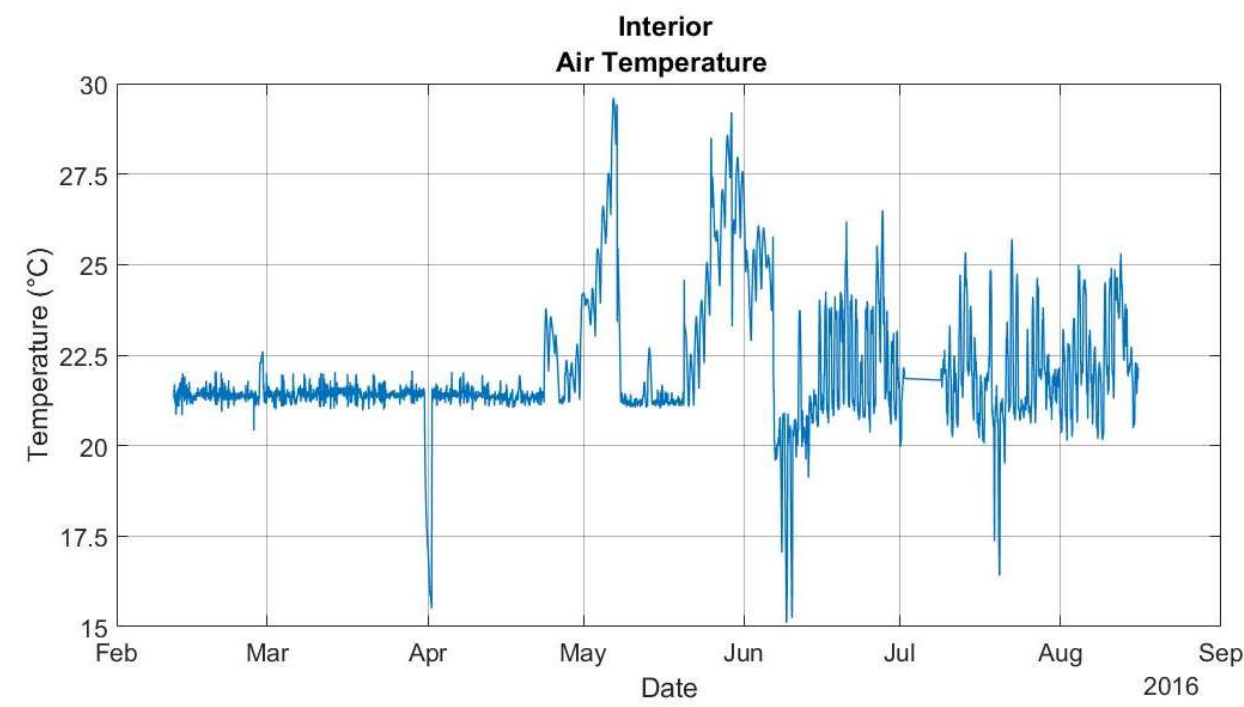

Figure 4-35 : Field Data-Interior Air Temperature

Shown in Figure 4-35 is the interior air temperature of the test structure over the course of collection. It should be noted that the set temperature of $21^{\circ} \mathrm{C}$ was consistently maintained over the winter and early spring. The structure began to heat up significantly at the beginning of May 
until an air conditioning unit was installed. Air temps fluctuated between $\sim 20-25^{\circ} \mathrm{C}$ during the summer period after the AC unit was installed.

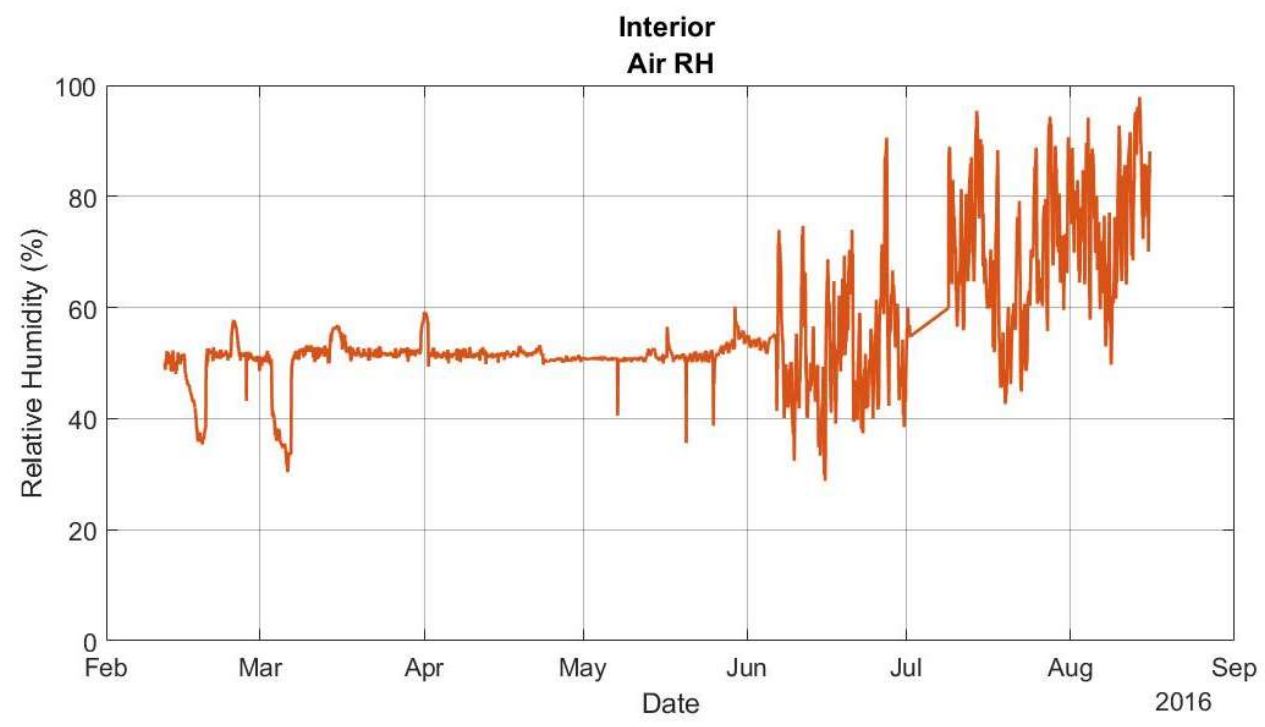

Figure 4-36: Field Data - Interior Air Relative Humidity

The interior air relative humidity is shown in Figure 4-36. Again, the set conditions (50\%), could be more tightly maintained during the winter and spring seasons. The summer period experienced uncontrolled RH which had an impact on the moisture content of the wooden structure as is described in the results section.

\subsubsection{Moisture content}

The following section investigates the in-situ moisture content of the test structure. A moisture content limit of $20 \%$ was identified through literature review as safe threshold to limit biodeterioration. This section will present the moisture content readings and provide explanations for notable trends. Data will be broken down into the different collection periods. 


\subsubsection{Winter}

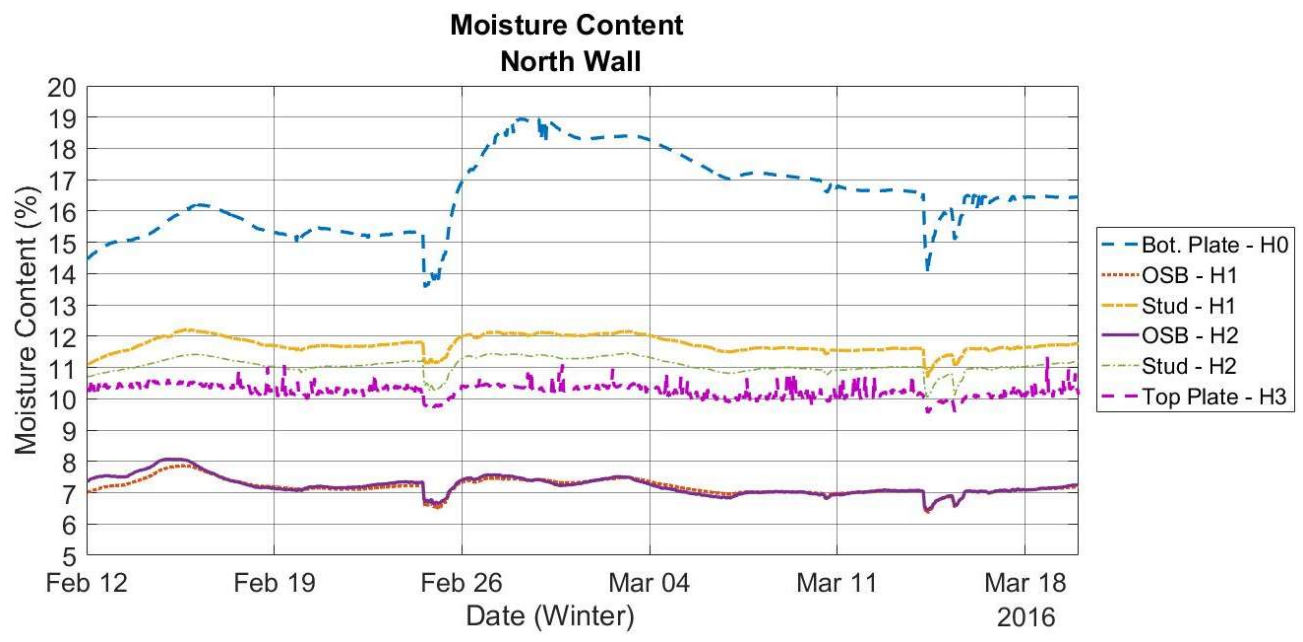

Figure 4-37: North Wall Winter - Moisture Content

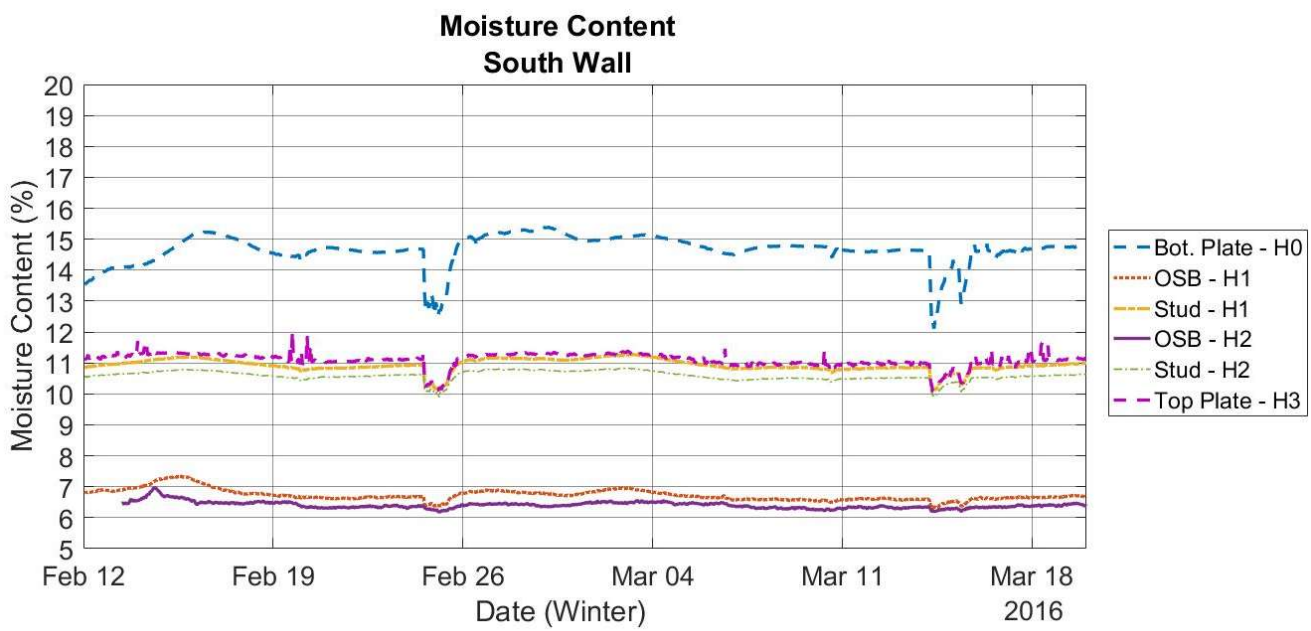

Figure 4-38 : South Wall Winter - Moisture Content

The winter period experienced the highest $\mathrm{MC}$ of all testing periods. The bottom plate on the north wall experienced the highest MC of $19 \%$ on February $28^{\text {th }}$. This may be attributed to overfilling the humidifier around the $25^{\text {th }}$ of February and causing liquid water to touch the bottom plate. The moisture dries to a stable level around March $17^{\text {th }}$. The bottom plates experienced the highest MC of any of the wood components. The bottom plates experienced the coldest temperatures within the structure due to stratification (average $4.2{ }^{\circ} \mathrm{C}$ difference from bottom plate to top over winter period). The top plates and studs experienced similar moisture contents throughout the winter. The OSB sheathing had the lowest moisture content of any 
wood structures. This is typical of OSB, which has a lower MC at equilibrium than standard lumber. General trends that occurred were that the north had marginally higher moisture contents than the southern wall. The direct solar radiation that the southern wall experienced raised internal temperatures and dried out the structure. Overall, the winter period, experienced the highest moisture content of the collection period and was still below the $20 \% \mathrm{MC}$ threshold set.

\subsubsection{Early + Late Spring}

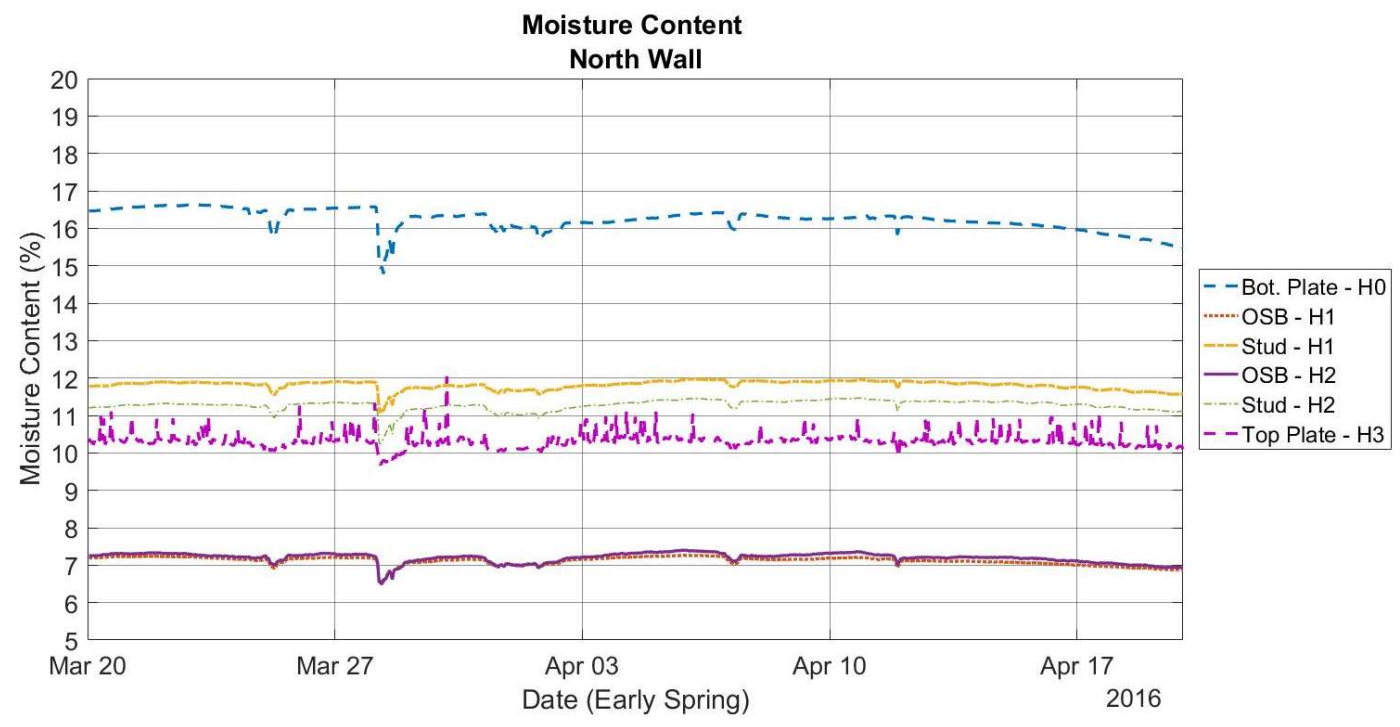

Figure 4-39 : North Wall Late Spring -Moisture Content

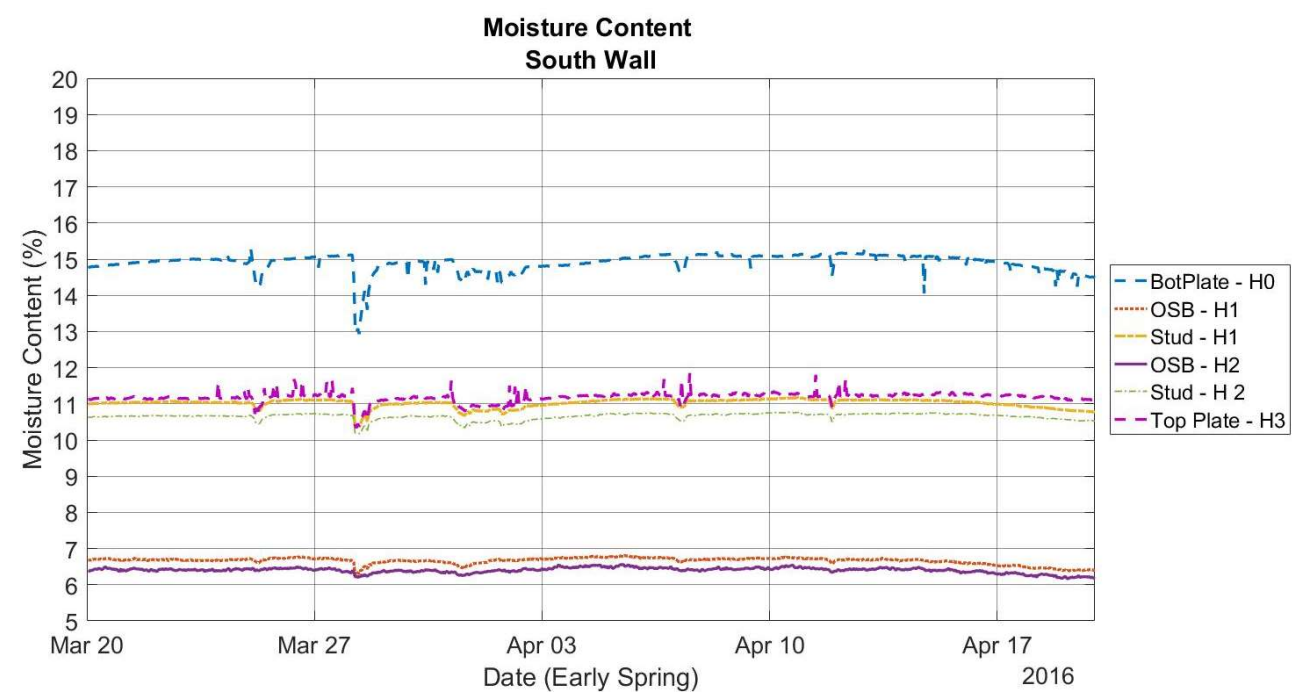

Figure 4-40 : South Wall Late Spring - Moisture Content 
The early spring experienced steady moisture content for all locations throughout the collection period. Similar trends were seen from the winter and early spring, such as increased moisture content for the north wall and bottom plates. The moisture content of wood began to taper at the very end of the period indicating further drying.

\subsubsection{Late Spring}

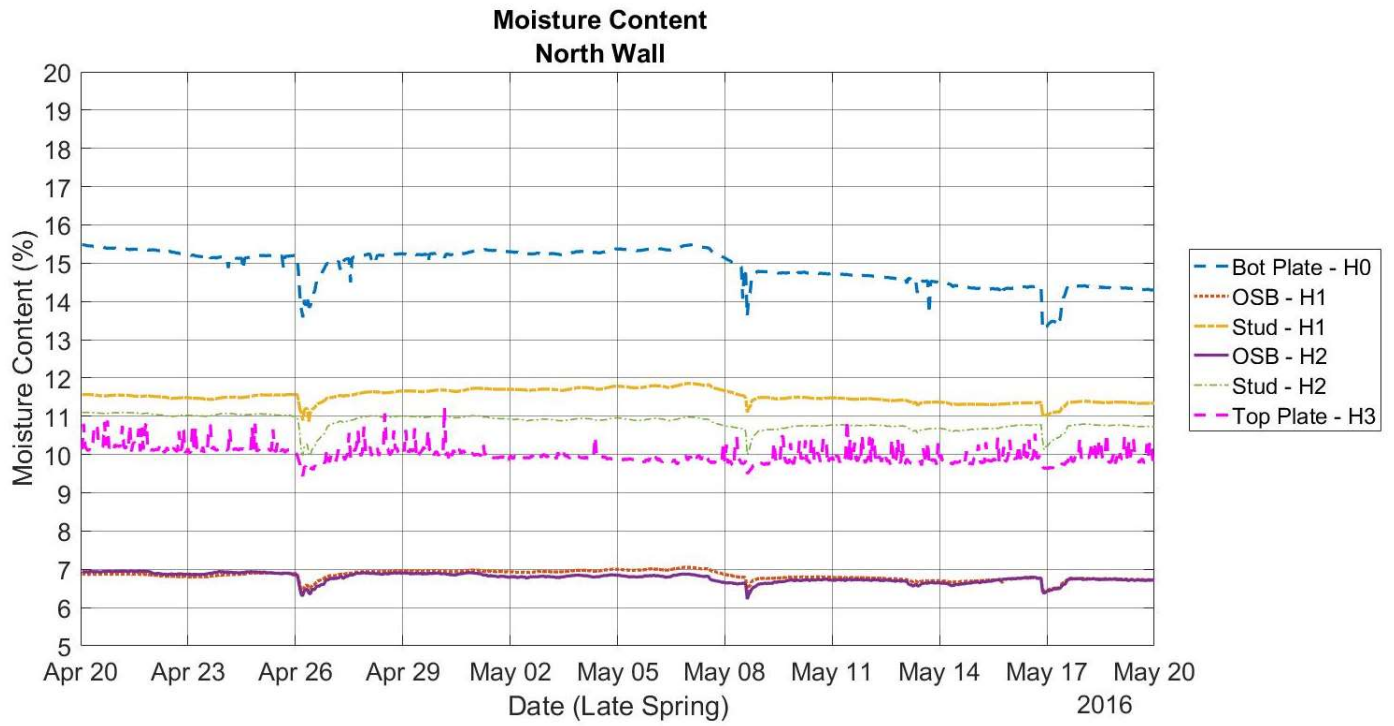

Figure 4-41 : North Wall Late Spring - Moisture Content

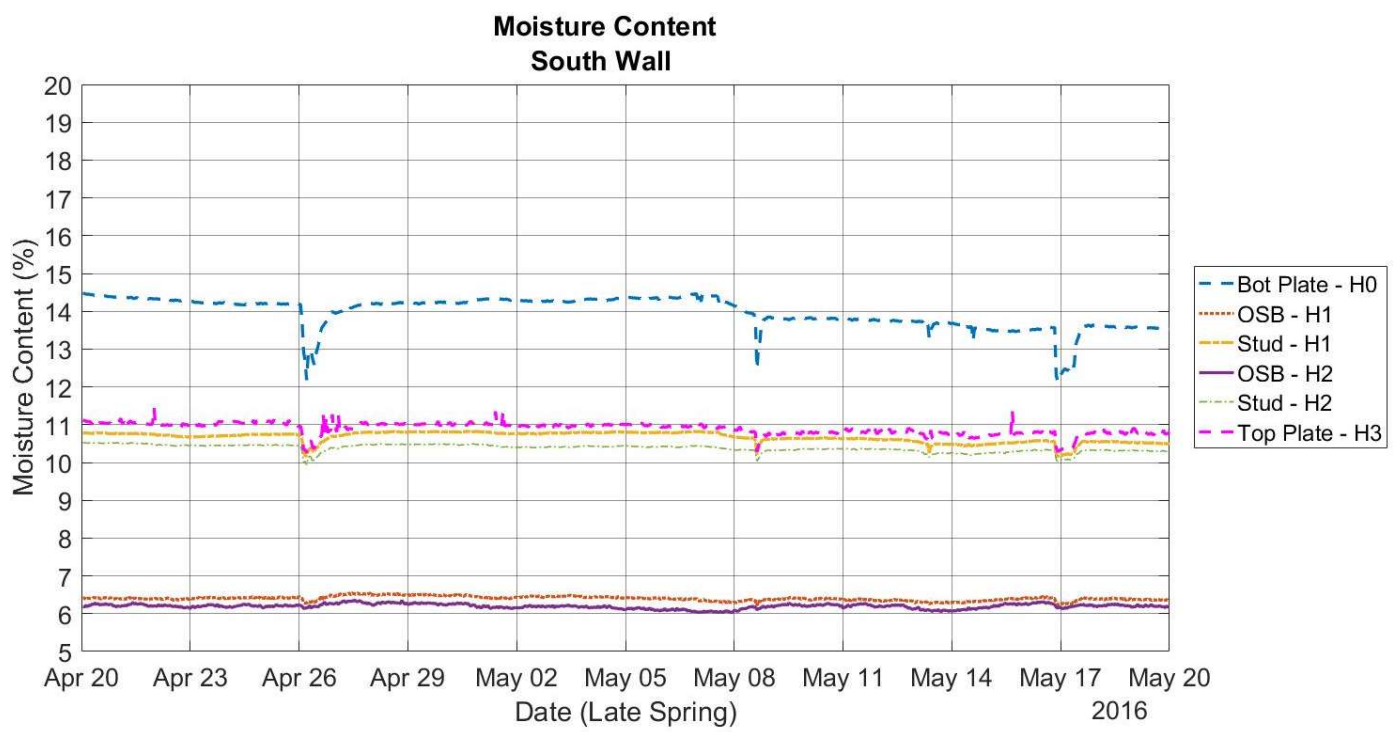

Figure 4-42 : South Wall Late Spring - Moisture Content 
The late spring period was very similar to the early spring period. Moisture content of the wood and OSB were maintained consistently until approximately May $7^{\text {th }}$, when the plates and studs experienced a small drop in MC. This drop in MC seems to correspond with the increased interior temperatures. The downward trend in the $\mathrm{MC}$ of the bottom plates was quite obviously on the north wall. This downward trend continued into the summer period.

\subsubsection{Summer}

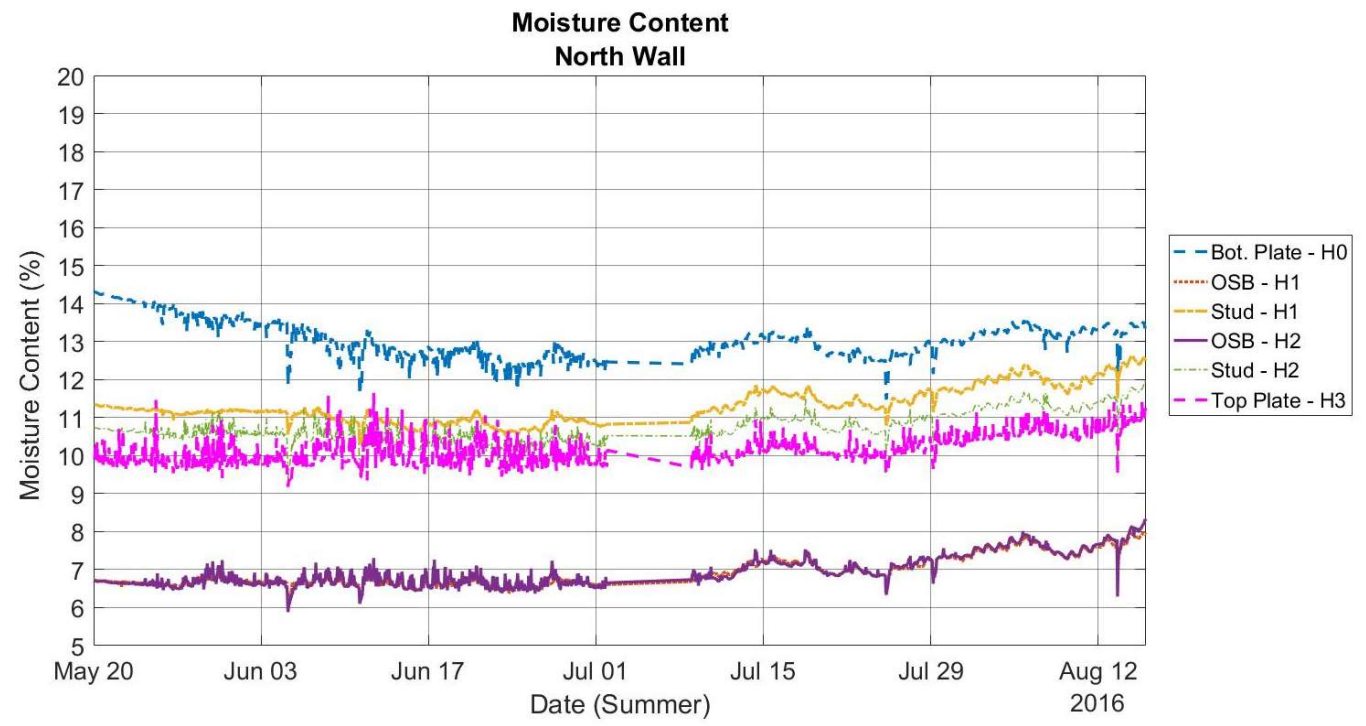

Figure 4-43 : North Wall Summer-Moisture Content

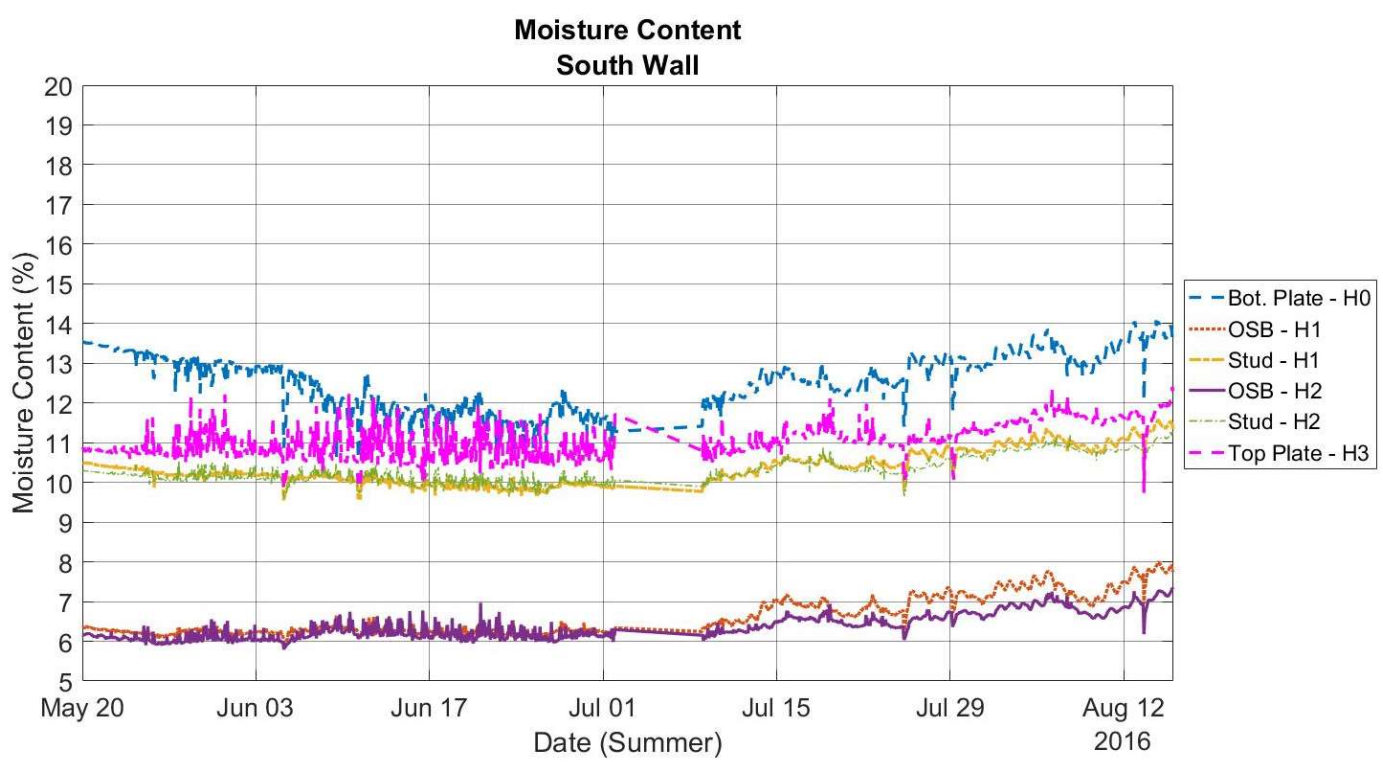

Figure 4-44 : South Wall Summer - Moisture Content 
Figure 4-43 and 4-44 show the moisture content readings for the summer months. The drying trend of the framing lumber continued from the late spring well into the month of June. The effect of solar radiation was seen on the bottom plate which experienced a drop-in MC as compared with the north wall bottom plate. The drying trend was marginally noticed in the studs as well. The drying trend ended around the start to mid-July where the MC began to increase. This is the only portion of the collection period where an upward trend was noticed in the MC of the wood. The upward trend coincided with the increased interior air relative humidity (see Figure 4-44). The moisture content of the studs and the top plate actually increased to a MC above winter time levels. At no point during the summer months did the MC exceed the $20 \%$ threshold.

\subsubsection{ASHRAE 160 Standard (2011)}

ASHRAE Standard 160-2009 addendum A (ASHRAE, 2011) states the RH of a surface must remain below $80 \%$ over a running 30 -day average and the temperature needs to be above $5^{\circ} \mathrm{C}$ and below $40^{\circ} \mathrm{C}$. The following section presents the $\mathrm{RH}$ and $\mathrm{T}$ for the moisture sensitive sheathing. The RHT sensors were located at layer 6, which was on the interior side of the OSB sheathing.

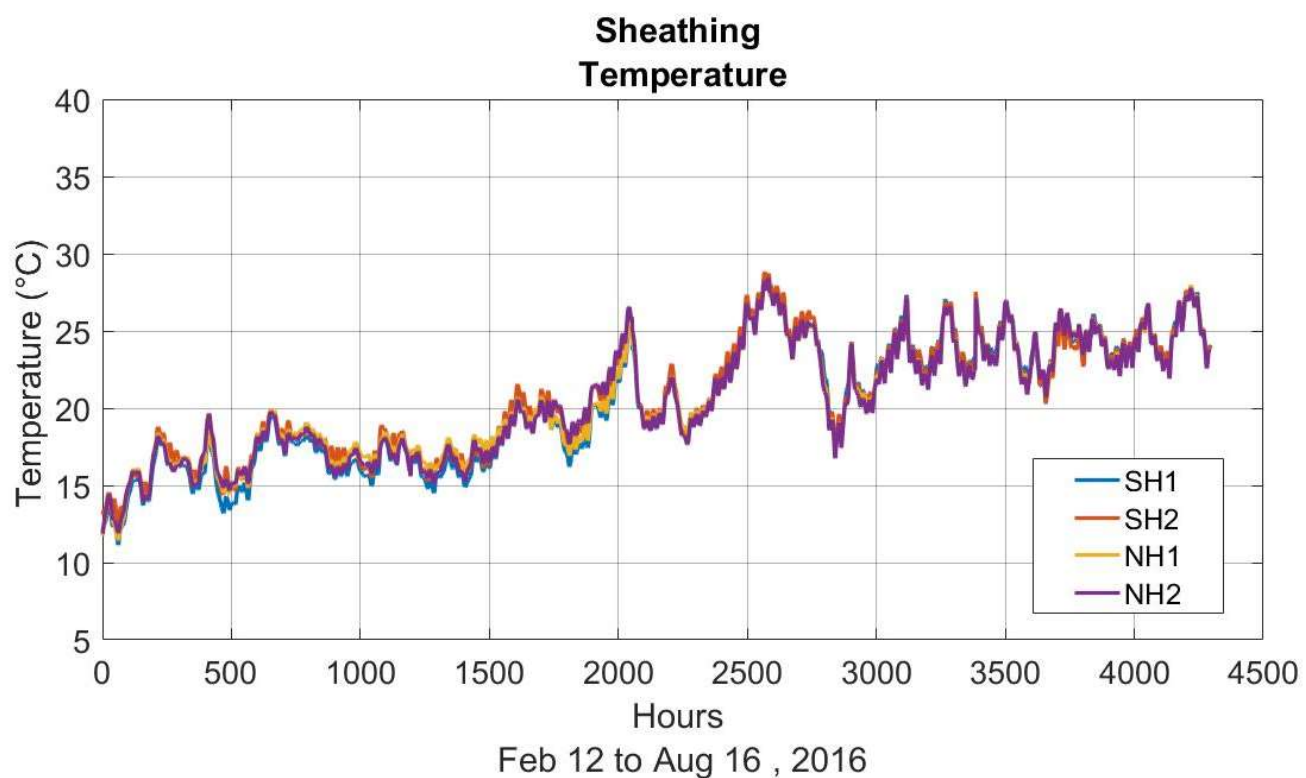

Figure 4-45 : Temperature of OSB 
The temperature of the $\mathrm{OSB}$ always resides between the $5^{\circ} \mathrm{C}$ and the $40^{\circ} \mathrm{C}$ temperature range defined in the standard. There was a noticeable increase in sheathing temperatures during the summer months. Even with the temperature in the critical range the likely hood of moisture damage was assessed as zero due to the measured relative humidity.

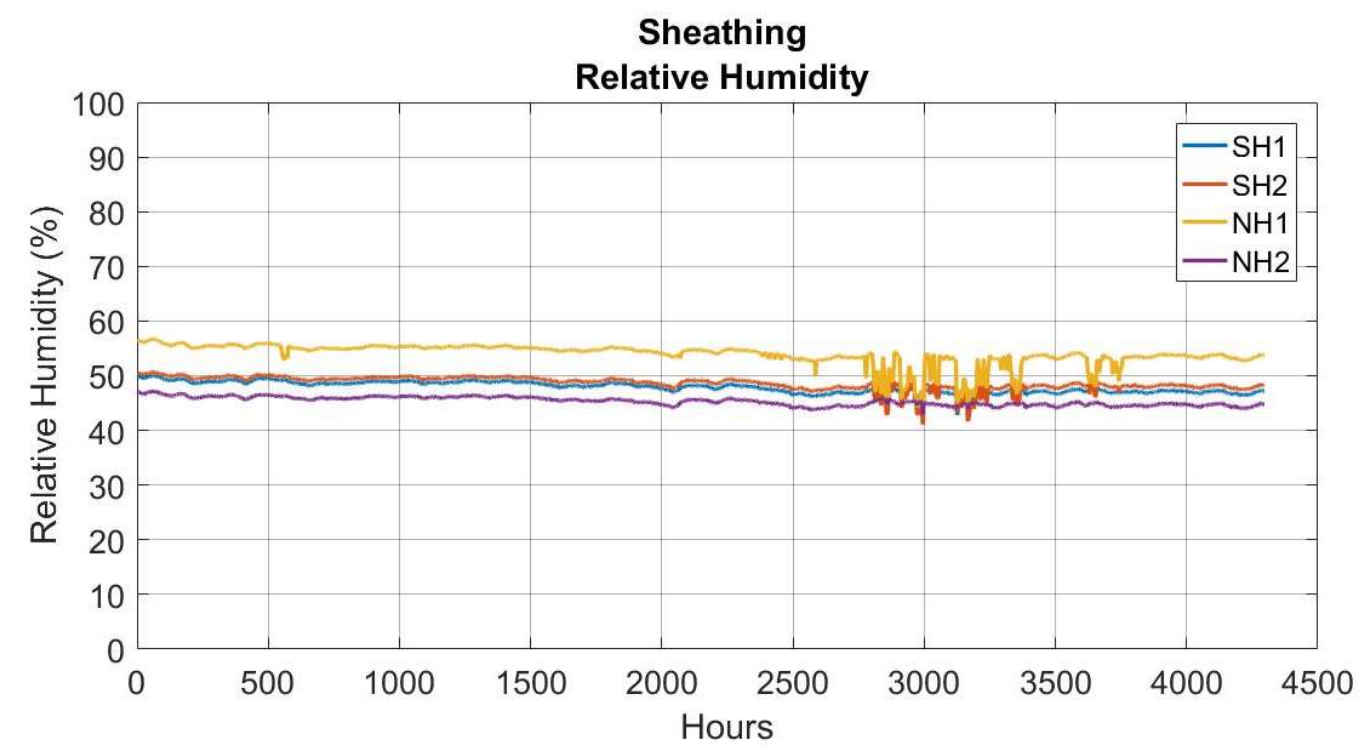

Feb 12 to Aug 16,2016

Figure 4-46 : Relative Humidity of OSB

As shown in Figure 4-46, the relative humidity on the interior side of the sheathing never exceeded $60 \%$ for the entire duration of collection, well below the $80 \%$ threshold defined in standard 160. The data indicated a slight downward trend reaching a steady state in the RH at the interface of the sheathing over the collection period. The RH data does not however reflect the increased moisture content of the sheathing during the summer months. Nor does it 
experience much variation. It is suspected that the cavity mineral wool may be muting the $\mathrm{RH}$ readings at the interior side of the sheathing by hygric buffering.

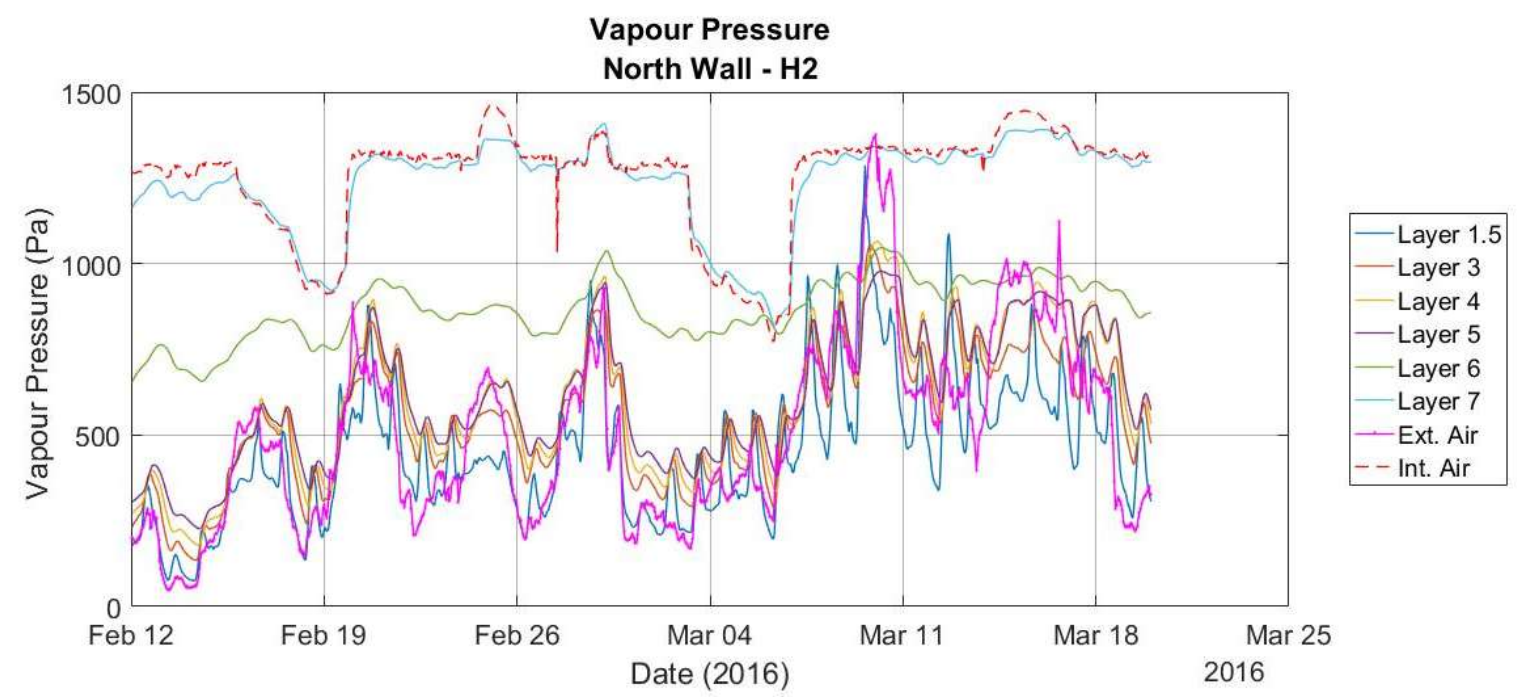

Figure 4-47 : Vapour Pressure Profile

The vapour pressure profiles were investigated to determine if the steady $\mathrm{RH}$ values were consistent with the exterior vapour pressure. It should be noted that vapour pressure was calculated using the collected RH and temperature as shown in Equations 9 and 10. The layered profile shows consistency with external vapour pressures. It was therefore deemed that the $\mathrm{RH}$ readings were consistent and accurate.

$$
\begin{gathered}
p_{\text {sat }}=6.112 e^{\left(\frac{17.62 T}{243.12+T}\right)} \\
p_{w}=R H \cdot p_{\text {sat }}
\end{gathered}
$$

$p_{\text {sat }}=$ Saturation pressure $(\mathrm{Pa})$

$\mathrm{T}=$ Temperature $\left({ }^{\circ} \mathrm{C}\right)$

$p_{w}=$ Water vapour pressure $(\mathrm{Pa})$

$\mathrm{RH}=$ Relative Humidity (\%)

\subsubsection{Interior Air Condensation Potential}

Interior air condensation potential compares the temperature of the OSB sheathing to the dew point temperature of the interior air. This can be considered a conservative measure. Interior air may transport moisture around the thermal layers to the colder sheathing. Exterior insulation can or may keep the temperature of the sheathing above interior air dew point temperature. The dew 
point of the interior air was calculated per Equation 11 and 12 which is based on the World Metrological Organization standards and recommended practice (WMO, 2010). This section presents the in-situ results from this analysis.

$$
\begin{gathered}
T_{\text {dew }}=\frac{243.12 \cdot \ln \left[e^{\prime} / 6.112 f(p)\right]}{17.62-\ln \left[e^{\prime} / 6.112 f(p)\right]} \\
f(p)=1.0016+3.15 \cdot 10^{-6} \cdot p-(0.074 / p)
\end{gathered}
$$

$\mathrm{T}_{\text {dew }}=$ Dew point Temperature $\left({ }^{\circ} \mathrm{C}\right)$

$\mathrm{p}=$ Moist Air Pressure $(\mathrm{Pa})$

$\mathrm{e}^{\prime}=$ Vapour Pressure $(\mathrm{Pa})$

\subsubsection{Winter}

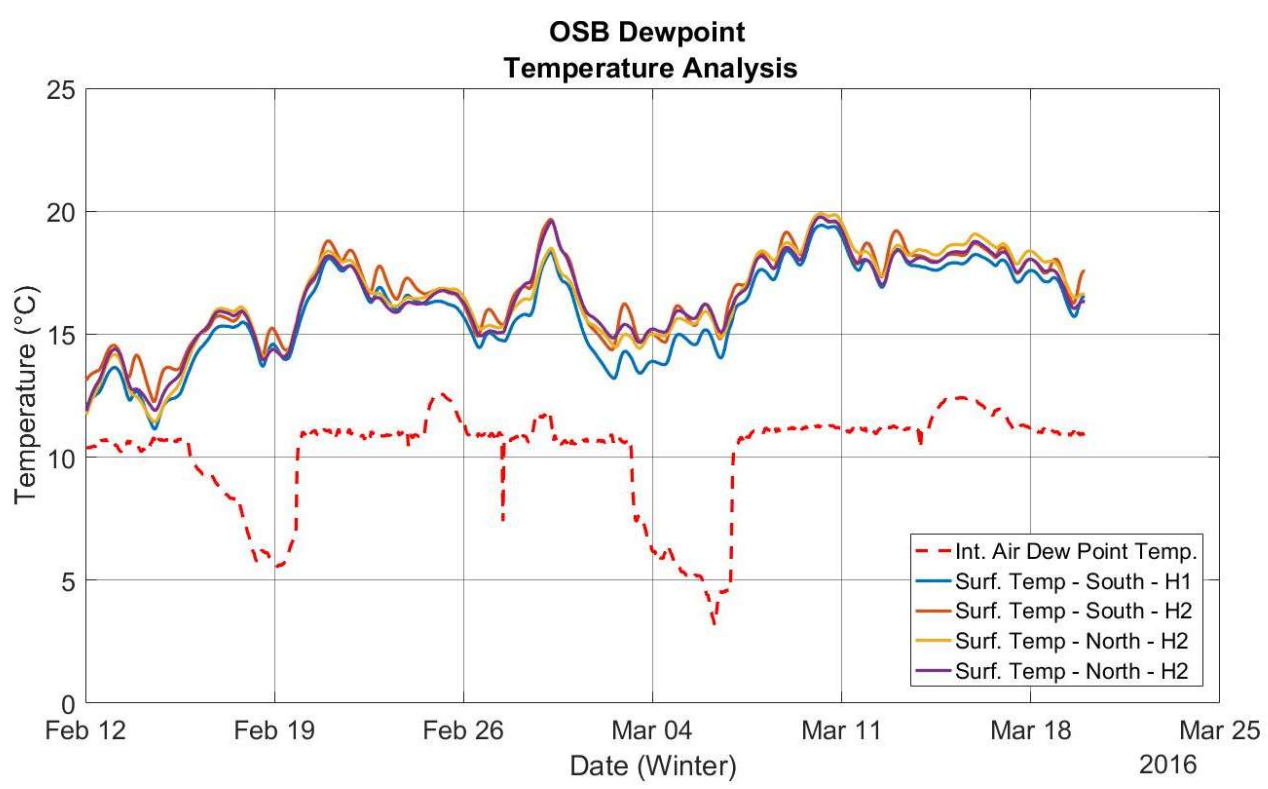

Figure 4-48 : Interior Air Dew Point - Winter

The winter period experienced the closest period of sheathing and interior dew point temperatures. This occurred on February $14^{\text {th }}$ after the coldest portion of the collection period. The temperature of the sheathing was only $0.35^{\circ} \mathrm{C}$ warmer than the dew point temperature. It is suspected that if temperatures had remained below $-20^{\circ} \mathrm{C}$ for several days that the temperature of the sheathing may have dropped below dew point temperatures. The southern wall at height 1 had the coldest sheathing temperatures. The southern wall experienced reduced in-situ thermal resistances as compared with the north wall which caused the temperature to be lower. The 
temperature of the sheathing began to increase after February $14^{\text {th }}$, which is consistent with the exterior air temperature.

\subsubsection{2. $\quad$ Early Spring + Late Spring}

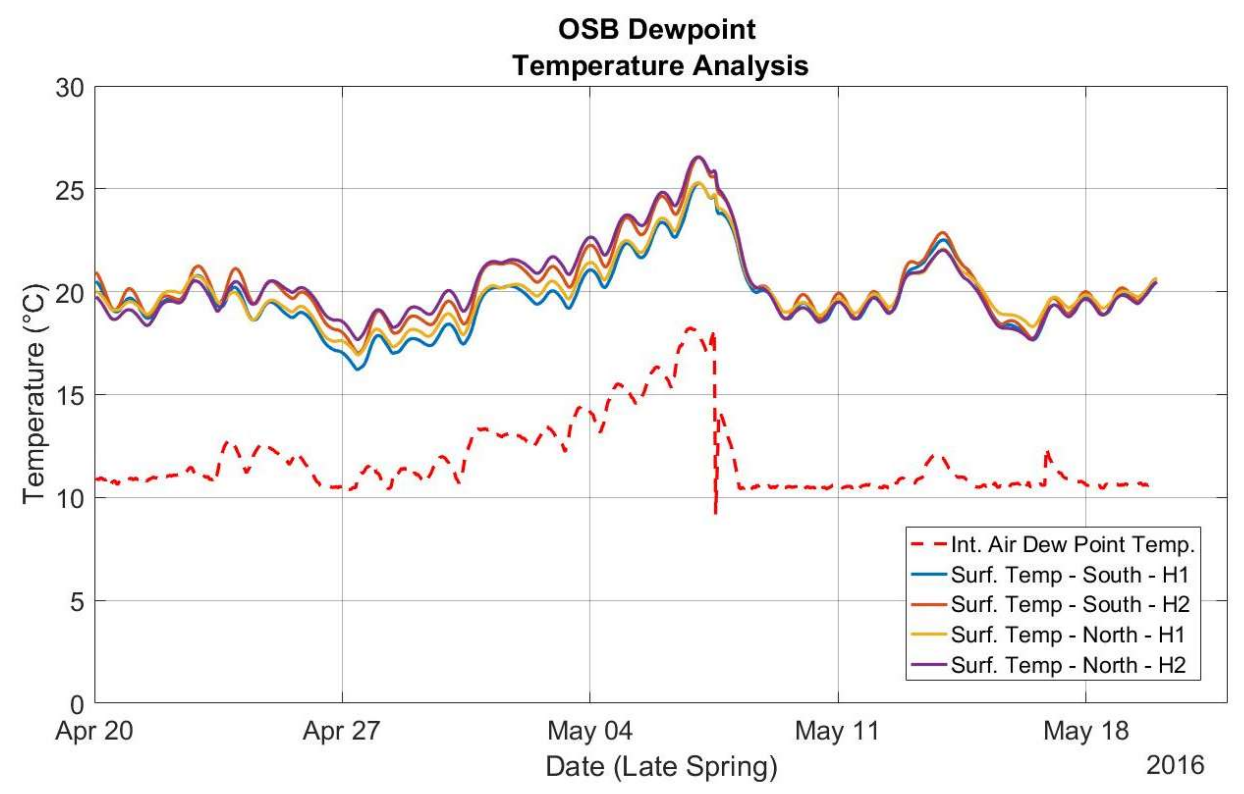

Figure 4-49 : Interior Air Dew Point - Late Spring

The early spring analysis maintained a steady spread between interior air temperatures and dew point temperatures and is not shown in this report. The temperature of the sheathing rose significantly compared with the dew point temperature at the end of early spring into the late spring period. Late spring also exhibited a large difference between temperatures. A spike in dew point temperature occurred around May $7^{\text {th }}$ and corresponded with the increase in interior temperatures. The increased air temperature carried more moisture than the previous months and increased the dew point temperature. This trend was seen in the summer as well. 


\subsubsection{Summer}

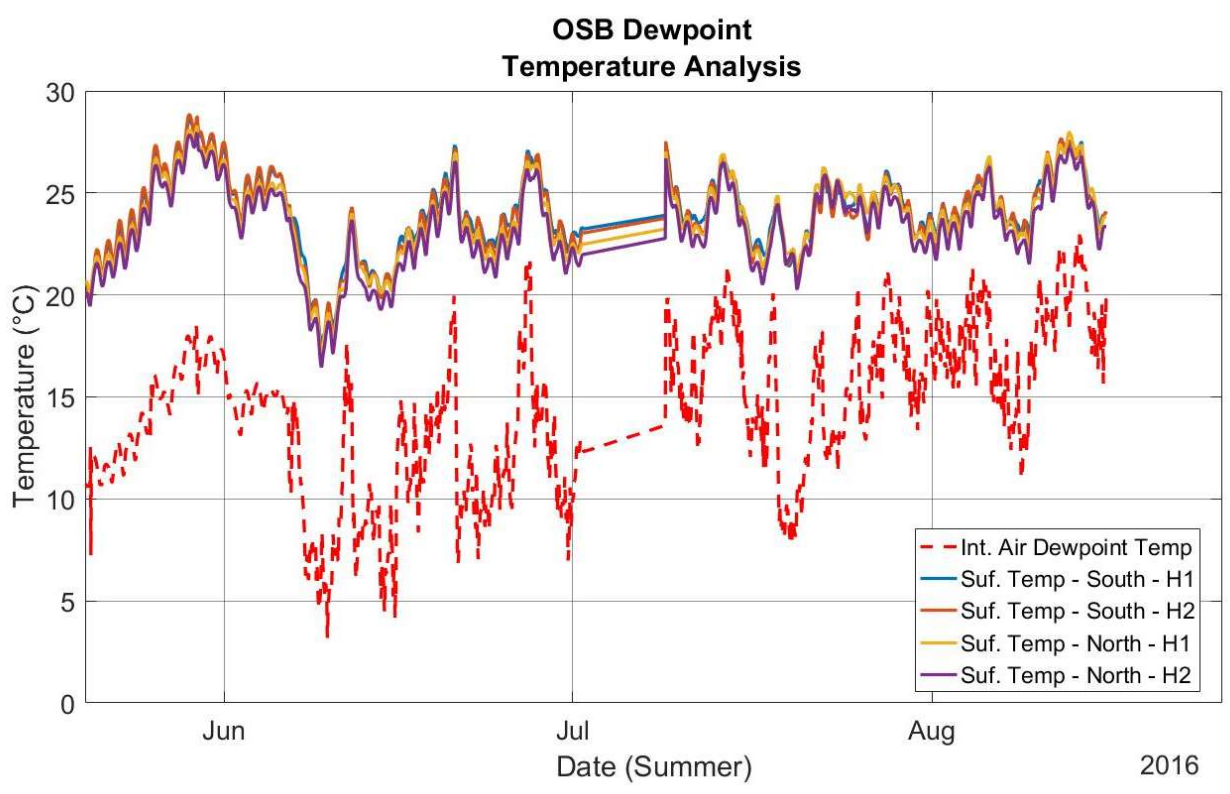

Figure 4-50 : Interior Air Dew Point - Summer

The summer months showed a highly variable dew point temperature range but there was a general upward trend towards the end of the summer. The increased temperatures and increased humidity of the interior air increased the dew-point temperature. The moisture content of the sheathing trended with this increase in $\mathrm{RH}$ and dew point temperature. The summer experienced the second closest dew point and sheathing temperature during the collection period on July $31^{\text {st }}$. The sheathing temperature was only $2.5^{\circ} \mathrm{C}$ above dew point.

\subsubsection{In-Situ Analysis Summary}

Three hygrothermal assessment methods were undertaken on the proposed enclosure for a six month in-situ experiment. None of the set thresholds were breached during the entire period. This indicated that the system performed well under the climate experienced. There were several points during the collection period where the threshold was almost breached. The interior relative humidity conditions were set above typical values experienced in a home to stress the enclosure, however the exterior climate may be considered as mild for this period. The limited collection period and the unique physical conditions of the test structure only provide a snap-shot of the hygrothermal performance of the proposed wall enclosure. Built enclosures will experience a 
highly-varied range of elemental stressors unable to be captured within the in-situ analysis. To fully determine the hygrothermal suitability of the enclosure, hygrothermal simulations were required to amplify possible loading scenarios in cold climates.

\subsection{Hygrothermal Simulation}

Hygrothermal simulation was completed to determine if the proposed enclosure was suitable for Toronto and several other cold climates. As climate can be highly variable and unpredictable it is necessary to assess the enclosure under more strenuous moisture conditions than were experienced during the field testing period. A common technique is to use computer simulation to predict enclosures hygrothermal performances for different locations, climate conditions, and extended durations. WUFI ${ }^{\circledR}$ Pro is a commonly used one-dimensional hygrothermal simulation program and was selected to be used for this research. The software uses balancing equations for both moisture and heat to determine the moisture content and relative humidity of the materials at any particular point within the assembly and at any particular time. Equations 13 and 14 are the interrelated heat and moisture balance formula used by WUFI (Kunzel, 1995).

$$
\begin{gathered}
\frac{\partial \mathrm{w}}{\partial \varphi} \cdot \frac{\partial \varphi}{\partial t}=\nabla \cdot\left(D_{\varphi} \nabla \varphi+\delta_{p} \nabla\left(\varphi p_{s a t}\right)\right) \\
\frac{\partial \mathrm{H}}{\partial \vartheta} \cdot \frac{\partial \vartheta}{\partial t}=\nabla \cdot(\lambda \nabla \vartheta)+h_{v} \nabla \cdot\left(\delta_{p} \nabla\left(\varphi p_{s a t}\right)\right)
\end{gathered}
$$

$\mathrm{dH} / \mathrm{d} \vartheta=$ heat storage capacity of the moist building material $\left(\mathrm{J} / \mathrm{m}^{3} \mathrm{~K}\right)$

$\mathrm{dw} / \mathrm{d} \varphi=$ moisture storage capacity of the building material $\left(\mathrm{kg} / \mathrm{m}^{3}\right)$

$\lambda=$ thermal conductivity $(\mathrm{W} / \mathrm{mK})$

$\varphi=$ relative humidity $(\%)$.

$\mathrm{t}=$ time $(\mathrm{h})$

$\vartheta=$ temperature, $(\mathrm{K})$

$\mathrm{D}_{\varphi}=$ liquid conduction coefficient of the building material $(\mathrm{kg} / \mathrm{ms})$

$\mathrm{W}=$ moisture content, $\left(\mathrm{kg} / \mathrm{m}^{3}\right)$

$\mathrm{h}_{\mathrm{V}}=$ evaporation enthalpy of the water, $(\mathrm{J} / \mathrm{kg})$

$\delta_{\mathrm{p}}=$ water vapour permeability of the building material $(\mathrm{kg} / \mathrm{msPa})$

$\mathrm{P}_{\text {sat }}=$ water vapour saturation pressure $(\mathrm{Pa})$

Hygrothermal simulations depend on many inputs related to materials and climates, which are often assumed by the user. As explored in the literature review section enclosures frequently perform differently than expected. Therefore, simulation calibration was required for the 
proposed enclosure to ensure an accurate and relevant simulation assessment. This section will outline the calibration procedure and the final relevant inputs obtained from calibration.

\subsubsection{Calibration Procedure}

Four distinct calibrated WUFI-Pro models were created; (i) Winter -North Wall, (ii) Winter South Wall, (iii) Summer - North Wall, (iv) Summer - South Wall, to achieve calibration. Each case exhibited differences in hygrothermal performance from the other due to changes in environment exposure and physical properties. Calibration was preformed to identify the different factors that influenced the hygrothermal performance for each case.

Figure 4-51 shows a generalized work flow for the WUFI calibration completed for this research. The initial steps for calibration were to create generalized models that most accurately represented the field enclosure. Accurate base models allowed for more accurate and quicker calibration. Once initial models were created (geometry and material properties) localized climatic data was re-formatted and adapted for use in WUFI-Pro. Output from these initial model files was then checked against relevant field data for suitability.

The boundary conditions, which control both heat and moisture flow through the simulation, were checked for accuracy. Modifications to the initial material properties, climatic data, and boundary condition variables were completed until simulation output matched field data. Surface temperatures were calibrated before moisture boundary conditions as completed by Fox (2014). 


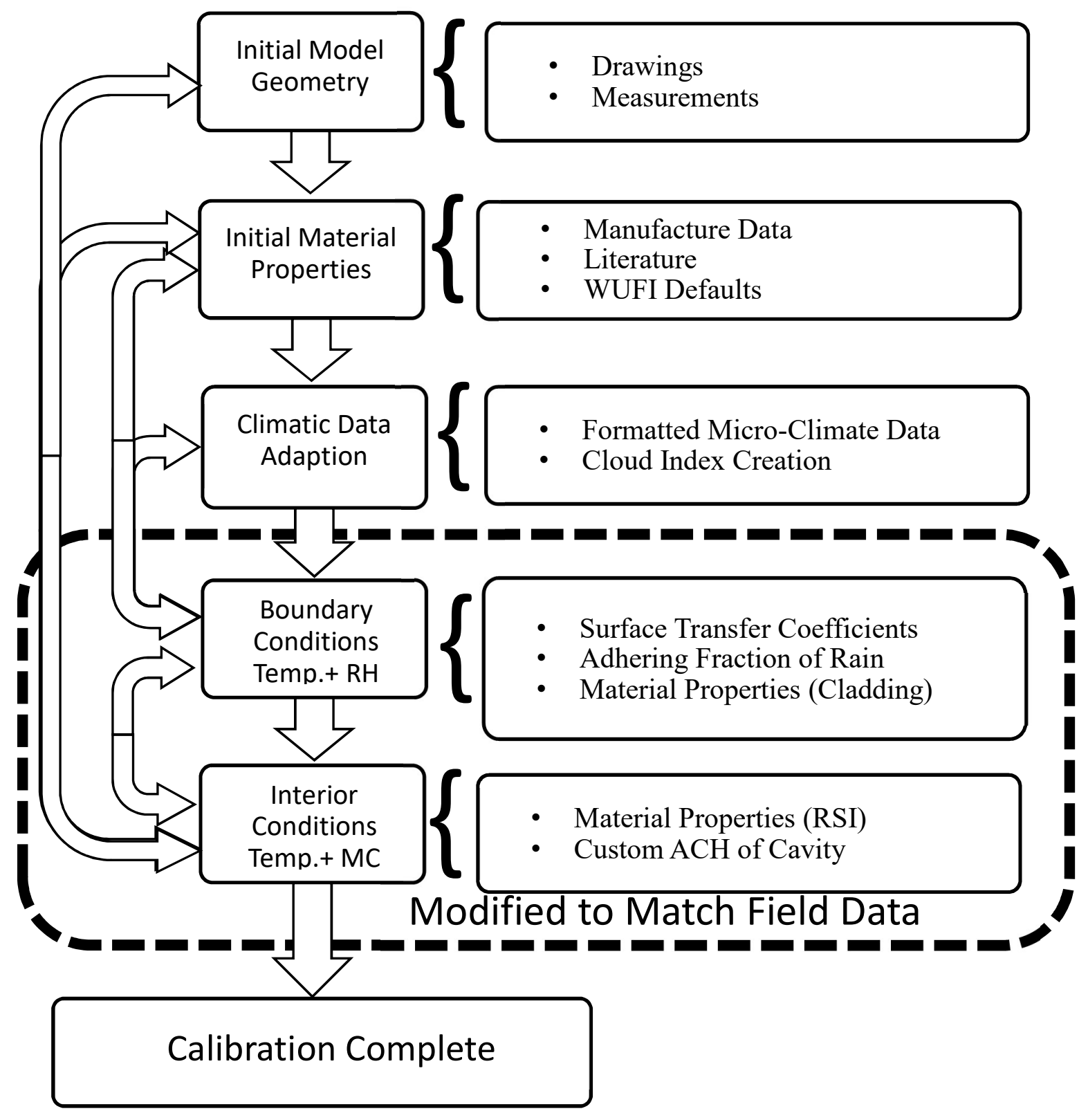

Figure 4-51 : WUFI Calibration Work-Flow

The interior enclosure conditions were assessed for accuracy after the boundary conditions were calibrated. It should be noted that moisture content of the OSB sheathing was also used to derive the exterior moisture boundary condition. Interior enclosure conditions included the temperature and moisture content of the OSB sheathing. Changes were made to the boundary conditions (moisture only), initial model geometry and initial material properties (thermal properties only) 
until moisture content of the simulations matched that of the collected data. Complete model calibration was considered achieved when the moisture content of the simulation matched that of the collected field data.

\subsubsection{Field Data vs. Simulation Output}

Determining WUFI variable input values was an iterative process. A single variable was simulated with a range of values and the output was compared to field data. The values that most accurately represented field conditions were than focused on. The next values entered for that variable were closer to the identified values from the first calibration step. This procedure continued until divergence from previous value or the simulation closely resembled field data.

Comparison of WUFI output and data was completed by assessing goodness of fit statistically and visually if necessary. The Square Root Mean Error function (Equation 15) and Mean Bias (Equation 16), where noted, were used to determine suitability of the prediction.

$$
\begin{aligned}
R M S E & =\sqrt{\frac{\sum_{t=1}^{n}\left(\hat{\mathrm{y}}_{t}-y_{t}\right)^{2}}{n}} \\
M B & =\frac{\left(\sum_{t=1}^{n} y_{t}-\hat{\mathrm{y}}_{t}\right)}{n}
\end{aligned}
$$

RMSE $=$ Root mean square error

$\mathrm{n}=$ number of data points

$\mathrm{t}=$ current data point

$\hat{\mathrm{y}}=$ predicted value

$\mathrm{y}=$ actual value

$\mathrm{MB}=$ Mean bias

Typically, a range of input variables was assessed and their corresponding RMSE were compared. The input with the smallest RMSE was than explored further. Another series of variables was assessed closer in scale to the first selected input. These variables were assessed in steps, with each resulting RMSE compared to the last. Variables continued to be inputted until the RMSE increased. The input value with the lowest RMSE was then selected. A smaller RMSE indicated a better prediction than a larger value.

Variable values were chosen when the smallest RMSE and Mean Bias Error were achieved, except as noted. Visual assessment identified key trends in simulation data that could not be 
extracted from statistical analysis. It is noted where visual confirmation was used in lieu of statistics.

\subsubsection{Field Data Sensor Location}

The field data from the height 2 sensor location $(2.51 \mathrm{~m})$ was used for comparison in simulation calibration. Height 2 was selected for comparative purposes due to the consistency of the data and the proximity of $\mathrm{H} 2$ to the collected interior air conditions. Shown in Figure 4-52 is a comparison of the north wall interior gypsum surface temperatures for different sensor heights.

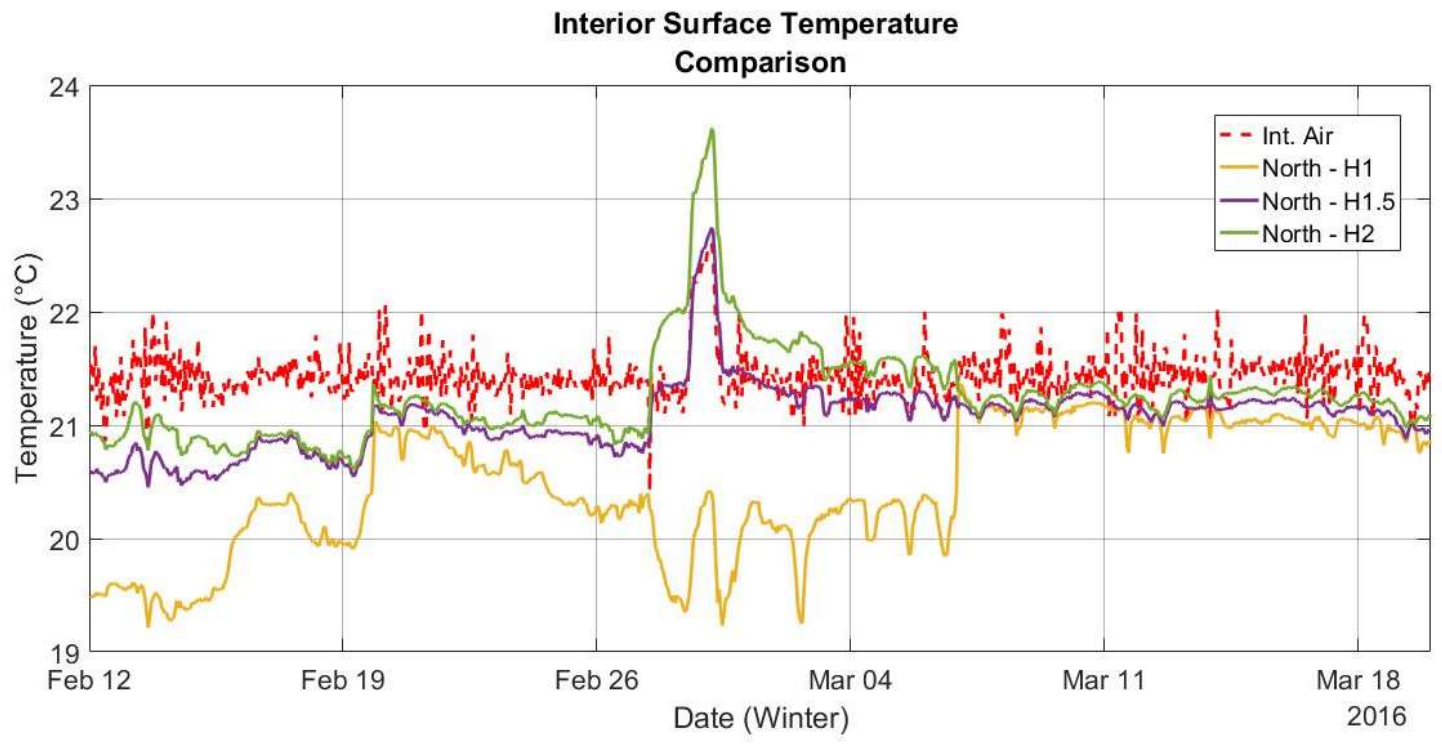

Figure 4-52 : North Wall Surface Temperatures

The interior air sensor was located slightly below the height 2 location and was closer to the HF temperature sensor height. The differences between the HF temp and Height 2 -Temp were marginal, however, the difference between $\mathrm{H} 1$ and $\mathrm{H} 2$ were quite large. Therefore, $\mathrm{H} 2$ was selected for comparison. 


\subsubsection{Initial Model Parameters}

\subsubsection{Initial Model Geometry}

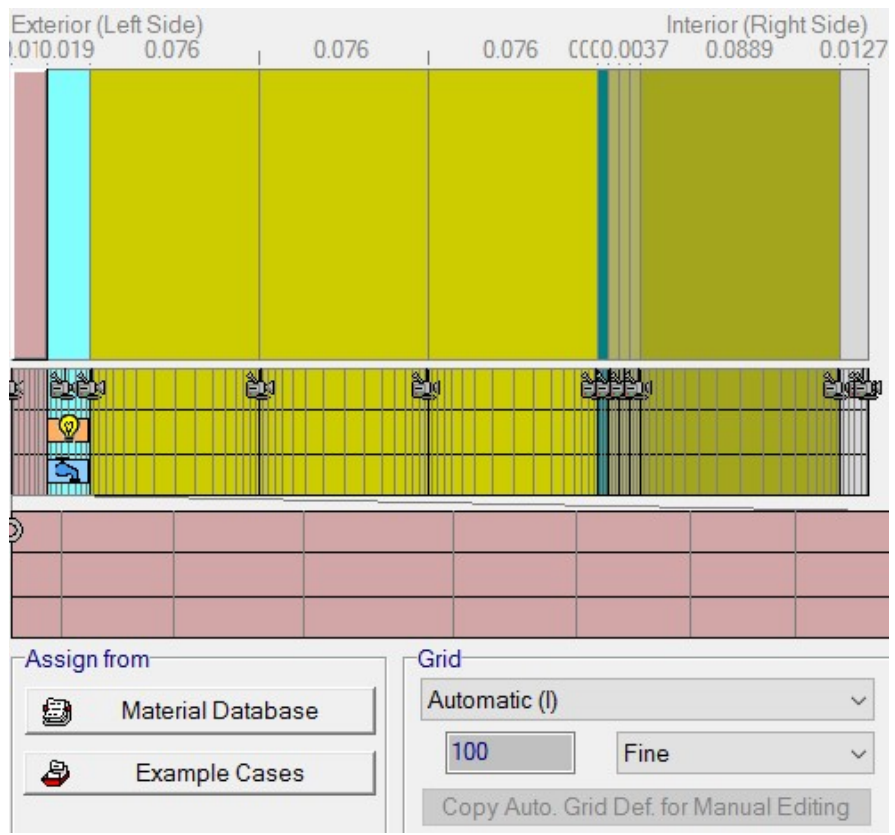

Figure 4-53 : Initial WUFI Geometry

The initial model geometry was created using information from drawings and direct field measurements. The OSB sheathing was divided into three (3) $3.7 \mathrm{~mm}$ slices to better represent moisture content at interior and exterior conditions. A numerical grid of 100 was selected. An initial ACH of 200 was selected for the air cavity. Orientations were set as due north and due south and inclination is set at $90^{\circ}$.

\subsubsection{Initial Material Temperature and Moisture Content}

Initial conditions of the material included the starting moisture content and the temperature of each component. Field data provided the temperature at each layer of construction and was entered in a custom text file used by WUFI-Pro. The initial moisture content of the OSB sheathing was provided by field data while the other components were left in their default condition. This was due to the lack of information regarding their starting moisture content.

\subsubsection{Initial Material Properties}

Material properties were gathered from various sources that included product data sheets, literature, and the default WUFI database. Initial property values are shown in Table 4-20. 
Table 4-20: WUFI Material Properties

\begin{tabular}{|c|c|c|c|c|c|c|}
\hline Material & Product & Thick & $\begin{array}{c}\text { Bulk } \\
\text { Density } \\
\text { kg/m } \mathbf{m}^{3}\end{array}$ & $\begin{array}{c}\text { Thermal } \\
\text { Conductivity } \\
\mathbf{W} / \mathbf{m} \cdot \mathbf{K}\end{array}$ & $\begin{array}{c}\text { Water Vapour } \\
\text { Diffusion } \\
\text { Resistance Factor } \\
\text { (WVDRF) } \\
\end{array}$ & References \\
\hline $\begin{array}{c}\text { Cedar } \\
\text { Cladding }\end{array}$ & N/A & $16 \mathrm{~mm}$ & 330 & $\begin{array}{c}0.10 @ \\
12 \% \mathrm{MC}\end{array}$ & 1963 & $\begin{array}{c}\text { WUFI } \\
\text { Database }\end{array}$ \\
\hline $\begin{array}{c}\text { Air } \\
\text { Space }\end{array}$ & N/A & $19 \mathrm{~mm}$ & 1.3 & 0.23 & 0.38 & $\begin{array}{c}\text { WUFI } \\
\text { Database }\end{array}$ \\
\hline $\begin{array}{l}\text { High } \\
\text { Density } \\
\text { Mineral } \\
\text { Wool }\end{array}$ & $\begin{array}{c}\text { Roxul } \\
\text { Comfortboard } \\
110 ®(\text { CIS })\end{array}$ & $\begin{array}{l}\text { (3) } 76 \\
\mathrm{~mm}\end{array}$ & 176 & $\begin{array}{l}0.0363 \\
\left(24^{\circ} \mathrm{C}\right)\end{array}$ & $1.29 *$ & $\begin{array}{l}\text { Roxul } \\
(2013)\end{array}$ \\
\hline $\begin{array}{c}\mathrm{AB} / \mathrm{WB} \\
\text { Barrier }\end{array}$ & $\begin{array}{c}\text { Henry } \\
\text { Blueskin }{ }^{\circledR V P 1} \\
60 \\
\end{array}$ & $\begin{array}{c}0.58 \mathrm{~m} \\
\mathrm{~m}\end{array}$ & 342 & 2.3 & $205.2^{*}$ & $\begin{array}{l}\text { Henry } \\
(2013)\end{array}$ \\
\hline $\begin{array}{c}\text { Oriented } \\
\text { Strand } \\
\text { Board } \\
\end{array}$ & N/A & $11 \mathrm{~mm}$ & 650 & 0.092 & $812.8^{*}$ & $\begin{array}{c}\text { WUFI } \\
\text { Database }\end{array}$ \\
\hline $\begin{array}{c}\text { Batt } \\
\text { Mineral } \\
\text { Wool } \\
\end{array}$ & $\begin{array}{c}\text { Roxul } \\
\text { ComfortBatt } \AA\end{array}$ & $89 \mathrm{~mm}$ & 36 & 0.036 & 1.1 & $\begin{array}{l}\text { Roxul } \\
(2016)\end{array}$ \\
\hline $\begin{array}{l}\text { Gypsum } \\
\text { Board }\end{array}$ & $\begin{array}{c}\text { SHEETROCK } \\
\text { UltraLight } \\
\text { Drywall } \\
\end{array}$ & $13 \mathrm{~mm}$ & 480 & 0.16 & 7.03 & $\begin{array}{c}\text { CGC (2014) } \\
\text { / WUFI } \\
\text { Database }\end{array}$ \\
\hline
\end{tabular}

The only values that changed through calibration were the heat capacities and thermal conductivities of the insulation and OSB. The remaining properties remained constant throughout calibration.

\subsubsection{Initial Surface Coefficients.}

The initial variables for the exterior side were selected based on best-guess and WUFI Pro default parameters. For example, WUFI Pro provided a short-wave radiation absorptivity for wood that has been painted brown which was a similar condition to the field hut. 
Table 4-21 : Initial WUFI Surface Coefficients

\begin{tabular}{|c|c|c|}
\hline & Surface Co-efficient & Initial Values \\
\hline Convection Resistance & $\alpha_{\text {conv }}\left(\mathrm{W} / \mathrm{m}^{2}\right)$ & 4.5 \\
\hline Radiation Resistance & $\alpha_{r a d}\left(\mathrm{~W} / \mathrm{m}^{2}\right)$ & 6.5 \\
\hline Wind-Factor (Wind-Ward) & $f_{w w}\left(\mathrm{Ws} / \mathrm{m}^{2} \mathrm{~K}\right)$ & 1.6 \\
\hline Wind-Factor (Lee-ward) & $f_{l w}\left(\mathrm{Ws} / \mathrm{m}^{2} \mathrm{~K}\right)$ & 0.33 \\
\hline $\begin{array}{c}\text { Short-Wave Radiation } \\
\text { Absorptivity }\end{array}$ & $\alpha_{\text {swra }}$ & 0.8 \\
\hline Long-Wave Radiation Emissivity & $\varepsilon_{l w r e}$ & 0.9 \\
\hline Ground Long Wace Emissivity & $\varepsilon_{g l w e}$ & 0.9 \\
\hline Ground Long Wave Reflectivity & $\rho_{g l w r}$ & 0.1 \\
\hline Ground Short Wave Reflectivity & $\rho_{g s w r}$ & 0.66 \\
\hline
\end{tabular}

\subsubsection{Climate Data}

Interior climate data was directly collected from the test structure and included relative humidity and temperature. No modification was needed for interior climate data. Exterior climate included air temperature, relative humidity, wind speed, wind direction, air pressure, rain accumulation (horizontal), and solar radiation. Data was collected on site using the weather station installed on the roof of the structure. All variables, except for rain accumulation, wind direction solar radiation, were used directly by WUFI. Rain was entered as horizontal load. WUFI was set to calculate to apply this load in full to the wall. The adhering fraction of rain was changed later during calibration. The formulas included input from wind speed and wind direction. Wind direction was averaged into vectors over an hour time span.

Solar radiation was entered WUFI in two components; horizontal direct solar radiation and horizontal diffuse solar radiation. WUFI has internal formulas to apply horizontal radiation to a vertical inclination. Solar radiation was only collected as horizontal global radiation and had to be converted into direct and diffuse components. The methodology for conversion, followed in this research, is outlined in Fox (2014) and generally follows ASHRAE Fundamental Handbook Chapter 14 (ASHRAE, 2009a) guidelines. The process of solar radiation conversion can be found in Appendix A. 


\subsubsection{Hygrothermal Model Calibration}

\subsubsection{Interior Surface Resistance}

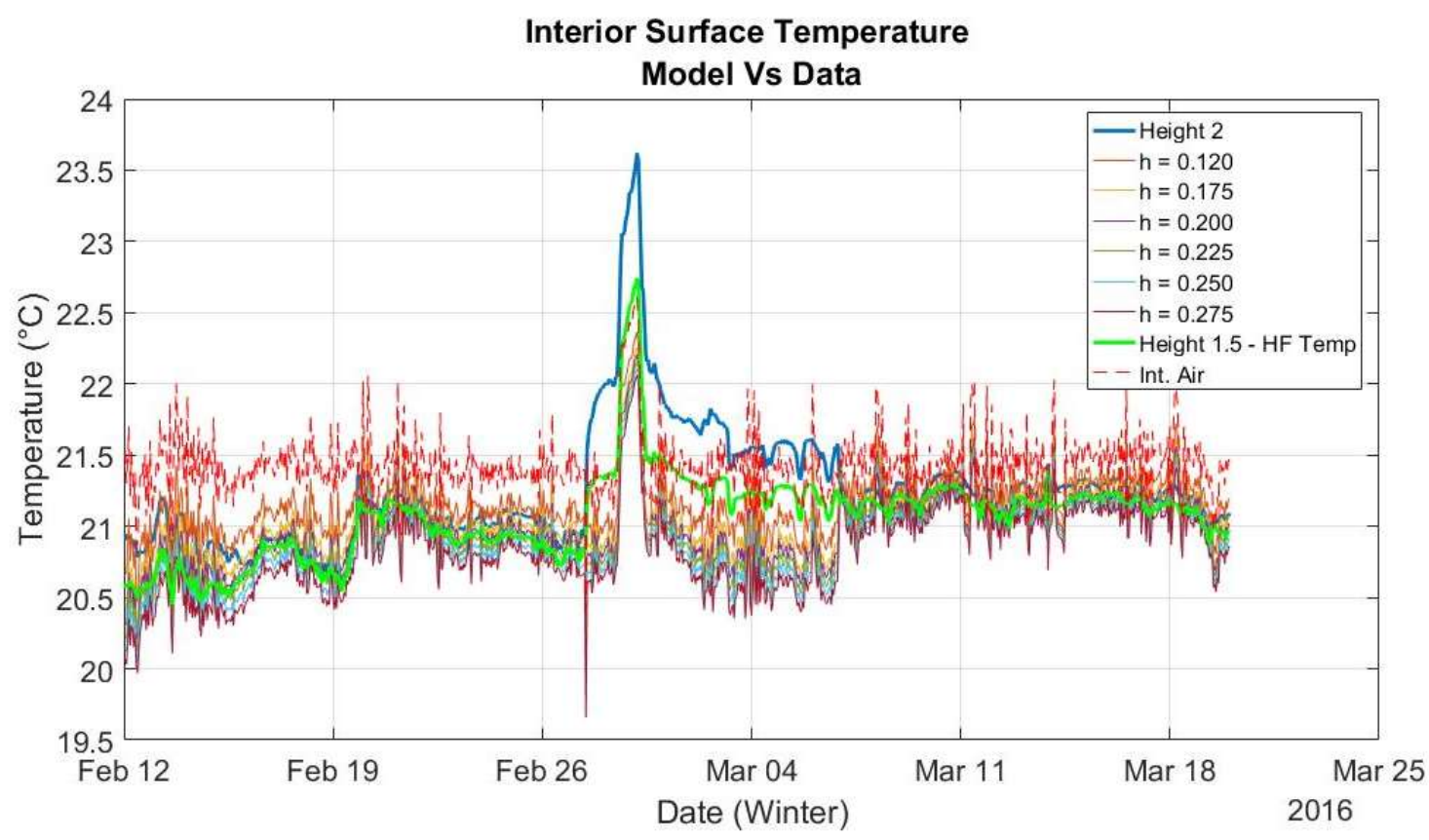

Figure 4-54 : Surface Temperature Profiles WUFI vs. DATA

Shown in Figure 4-54 is the temperature profiles for several interior surface resistances compared with the interior temperatures on the north Wall. It should be noted that the temperature of the sensor seemed to spike for a period in the middle of the winter time and exceeded the internal air temperature indicating that an external heat source was causing the sensor to heat up. It is suggested that radiation was causing this large spike (either from solar radiation or a surrounding surface, which is also experiencing solar radiation gain). The beginning of this testing period also experienced some unusual trends believed to be caused by the location and direction of the space heater. Data from $12-16^{\text {th }}$ of February and from the $27^{\text {th }}$ of February to the $7^{\text {th }}$ of March are excluded from the analysis. A value of $h_{c}=0.175\left(\mathrm{~m}^{2} \mathrm{~K} / \mathrm{W}\right)$ was selected from this process. Complete case values can be found in Appendix I. The interior surface resistance was kept constant throughout calibration for both the north wall and the southern wall. 


\subsubsection{Calibration of Exterior Winter Coefficients}

The calibration of the exterior surface temperature was more complex than calibrating the interior surface temperature. The exterior cladding surface experienced a high number of variables that experienced large magnitudes of change. The variables were often interrelated and influenced each other. The calibration procedure consisted of visual analysis and use of situational data to pin-point specific variables that had the largest impact. This section will break down the inputs of the exterior boundary conditions.

\subsubsection{Exterior Surface Heat Effective Resistance}

The wind-dependent option was selected for this model as the variables could be more closely controlled. The options within this selection control for both surface air film resistances and the radiation thermal resistance coefficient. The north wall was used to calibrate these factors as solar radiation has a large impact on the radiative co-efficient.

$$
h_{o}=\frac{1}{\alpha_{\text {conv }}+\alpha_{\text {rad }}+f_{\text {windfactor }} \cdot V_{\text {wind }}}
$$

$\mathrm{h}_{0}=$ Exterior heat resistant coefficient $\left(\mathrm{m}^{2} \mathrm{~K} / \mathrm{W}\right)$

$\mathrm{V}=$ Wind Speed $(\mathrm{m} / \mathrm{s})$

$f=$ Wind Factor $\left(\mathrm{Ws} / \mathrm{m}^{3} \mathrm{~K}\right)$

$\alpha_{c o n v}=$ effective conductance for convection $\left(\mathrm{W} / \mathrm{m}^{2} \mathrm{~K}\right)$

$\alpha_{\text {rad }}=$ effective conductance for radiation $\left(\mathrm{W} / \mathrm{m}^{2} \mathrm{~K}\right)$

Natural convection conductance was left at the default value of $4.5 \mathrm{~W} / \mathrm{m}^{2} \mathrm{~K}$. The radiation was initially left at the default value of $6.5 \mathrm{~W} / \mathrm{m}^{2} \mathrm{~K}$ as an estimation of radiation resistant effects. Both the windward and leeward factors were found first. 


\subsubsection{Windward Factor Coefficient}
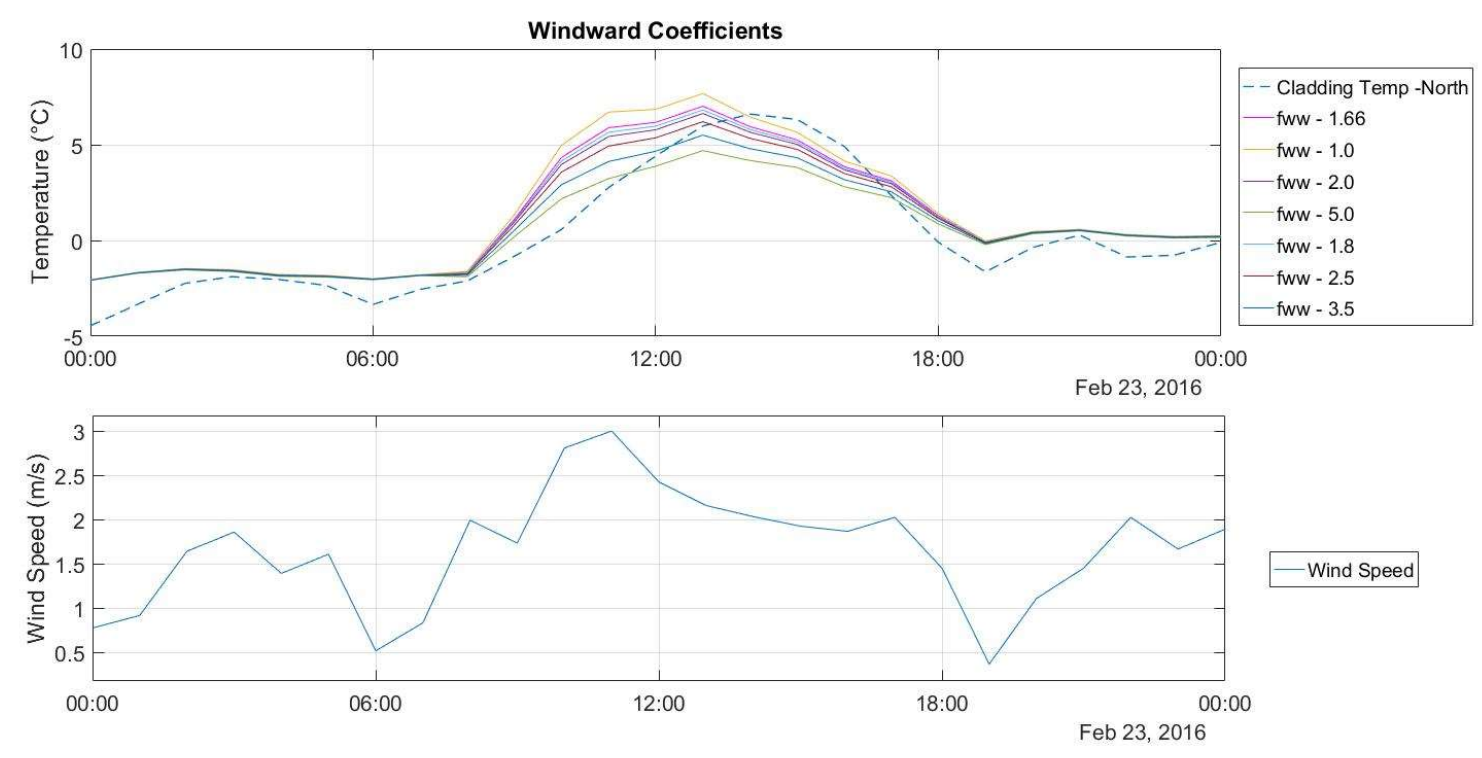

Figure 4-55 : Windward Factor Selection

WUFI uses a standard value of $1.66 \mathrm{Ws} / \mathrm{m}^{3} \mathrm{~K}$ for windward factor coefficients. Internal calculations assume that wind speed is collected at a height of $10 \mathrm{~m}$ and that obstacles are considered in its effect on convective heat transfer. February $23^{\text {rd }}$ demonstrated one of the highest degrees of variance from the initial f-factors for wind and was used to determine the windward factor. A value of $1.8 \mathrm{Ws} / \mathrm{m}^{3} \mathrm{~K}$ was selected for the windward resistance. It was found to have little effect on the simulation temperature, however, the value selected was chosen for its ability to most closely resemble the field data curve. 


\subsubsection{Leeward Factors Coefficient}

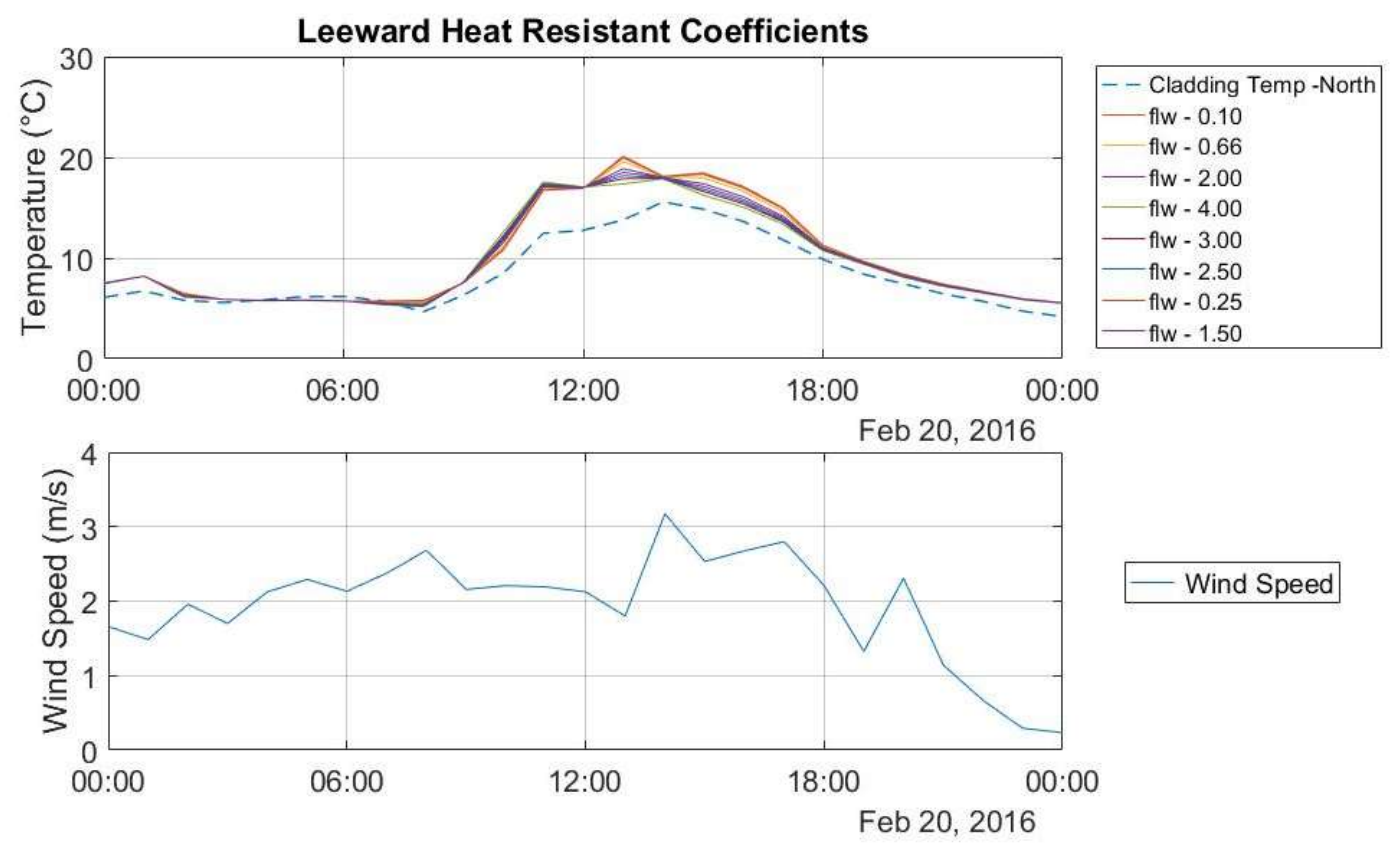

Figure 4-56 : Leeward Wind Factors

To select the leeward factors similar principles to selecting the windward factor were applied. The factor selected was based off the shape of the curve and how it reflected the shape of the field data. In the case of leeward it was determined that the value of $1.5 \mathrm{Ws} / \mathrm{m}^{3} \mathrm{~K}$ provided the most similar curve. It was extremely difficult to attribute a drop-in cladding temperature to an increase in wind speed within the field data specifically due to numerous other variables. It was noted during this analysis that wind factors did not play a large role in the temperature of the cladding and that other variables such as long and short wave radiation had a much larger impact.

\subsubsection{Explicit Radiation Balance}

The option for explicit radiation balance was then selected after determining an approximation for the wind factors. Initially the radiation portion of this resistance was removed from the calculation, as WUFI Pro accounts for radiation transfer through its "explicit radiation balance" calculations, however through several trials it was found that WUFI simulations over estimated several parameters such as night time cooling and shortwave diffuse radiation during the day (Refer to Figure 4-57.) 


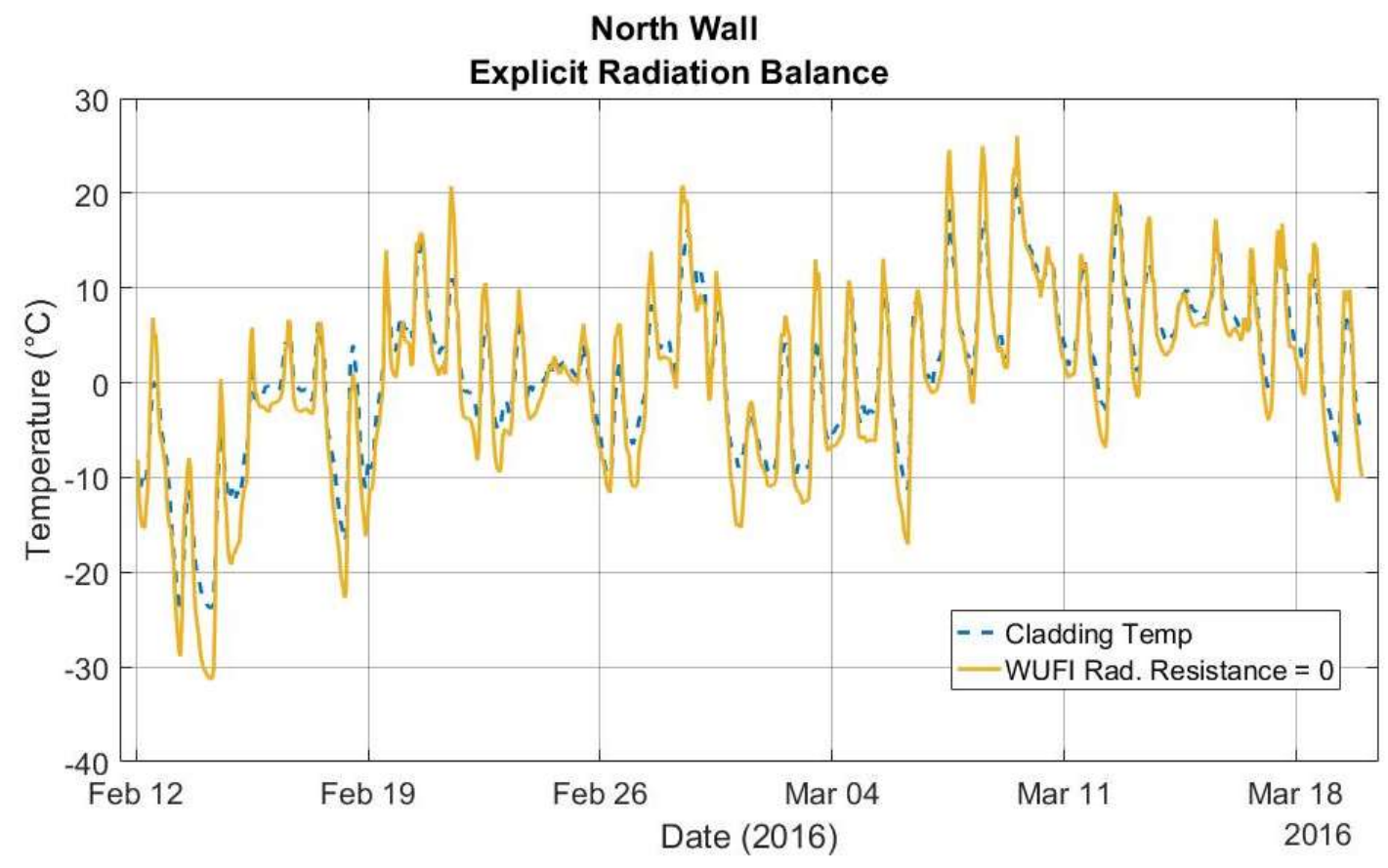

Figure 4-57 - Explicit Radiation Balance and Surface Temperatures

WUFI assumed a clear horizon and that the surface was equally exposed to both a uniform sky (depending on cloud index) and a uniform ground. There were many terrestrial objects that occupied space above the theoretical horizon. Exposure to the sky was reduced due to these terrestrial objects and explaining the exaggerated night-time counter-radiation simulated by WUFI. The terrestrial objects limited the clear-sky night time counter radiation.

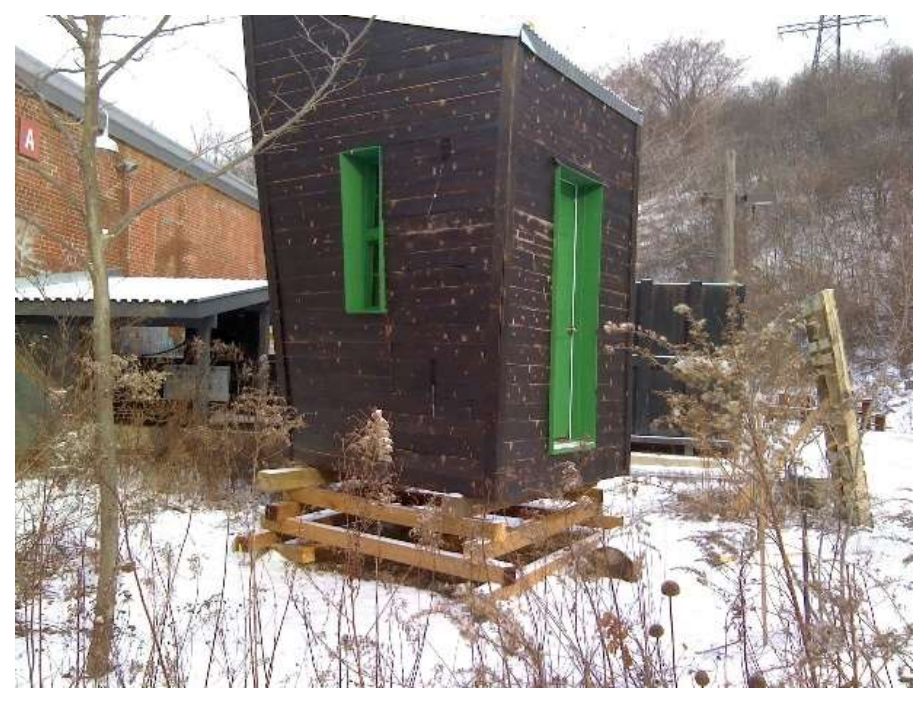

Figure 4-58 : Test Structure - Looking North 
During the day, the simulation temperature exaggerations occurred during peak solar events and may be accounted for by the same principles. Times of overcast appeared relatively closer to sensor temperatures indicating it was diffuse short wave solar radiation. The terrestrial objects surrounding the test hut limited the amount of diffuse short wave radiation reaching the temperature sensor. From this analysis and previous knowledge of simulations it was deemed appropriate to modify the radiation heat conductance value.

\subsubsection{Determination of Radiation Heat Conductance Coefficient}

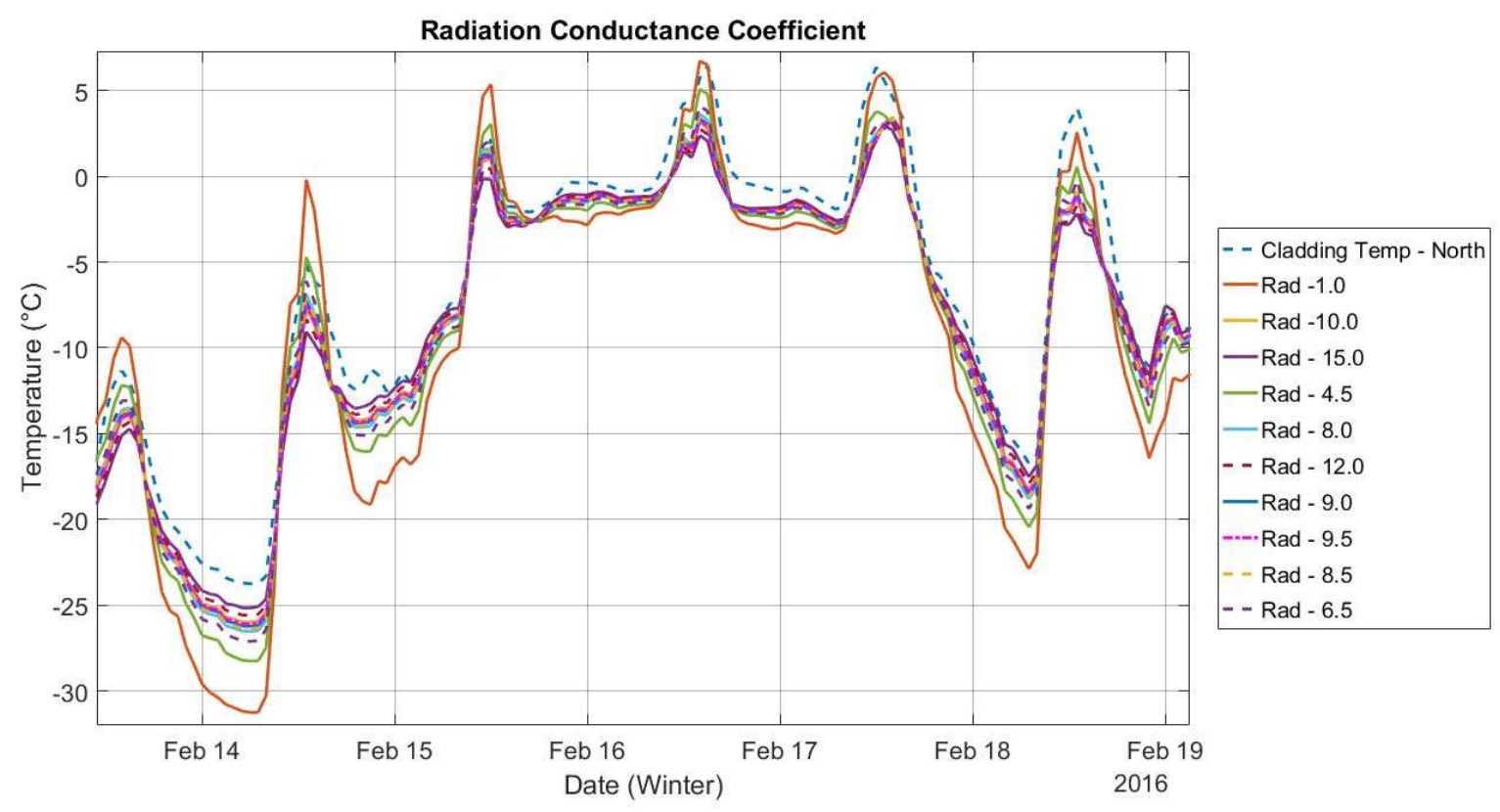

Figure 4-59: North Wall Radiation Conductance Component

Figure 4-59 shows that the simulated temperatures were below the measured data during cloudy periods and during the night time (Figure 4-59). This was confirmed in a mean bias error calculation. To account for the drop-in temperature the Ground Wave Long Wave Reflectivity was increased from the default value of 0.1 to 0.2 . Temperatures of the simulation increased and there was a better fit for the radiation values due to the increase in simulated temperatures. The final radiation value and its mean bias are shown in Table 4-22. The complete RSME and Mean Bias Tables can be found in Appendix I. The value of 9.5 was shown be best for both GLWR scenarios. 
Table 4-22 : Final North Wall Winter Coefficients

\begin{tabular}{|c|c|c|c|}
\hline Case \# & $\alpha_{\text {rad }}\left(\mathrm{W} / \mathrm{m}^{2}\right)$ & RSME & Mean Bias \\
\hline 12 & 9.5 & 1.5201 & 0.9330 \\
\hline 23 & 9.5 & 1.2695 & 0.0892 \\
\hline
\end{tabular}

\subsubsection{Ground Long Wave Reflectivity}

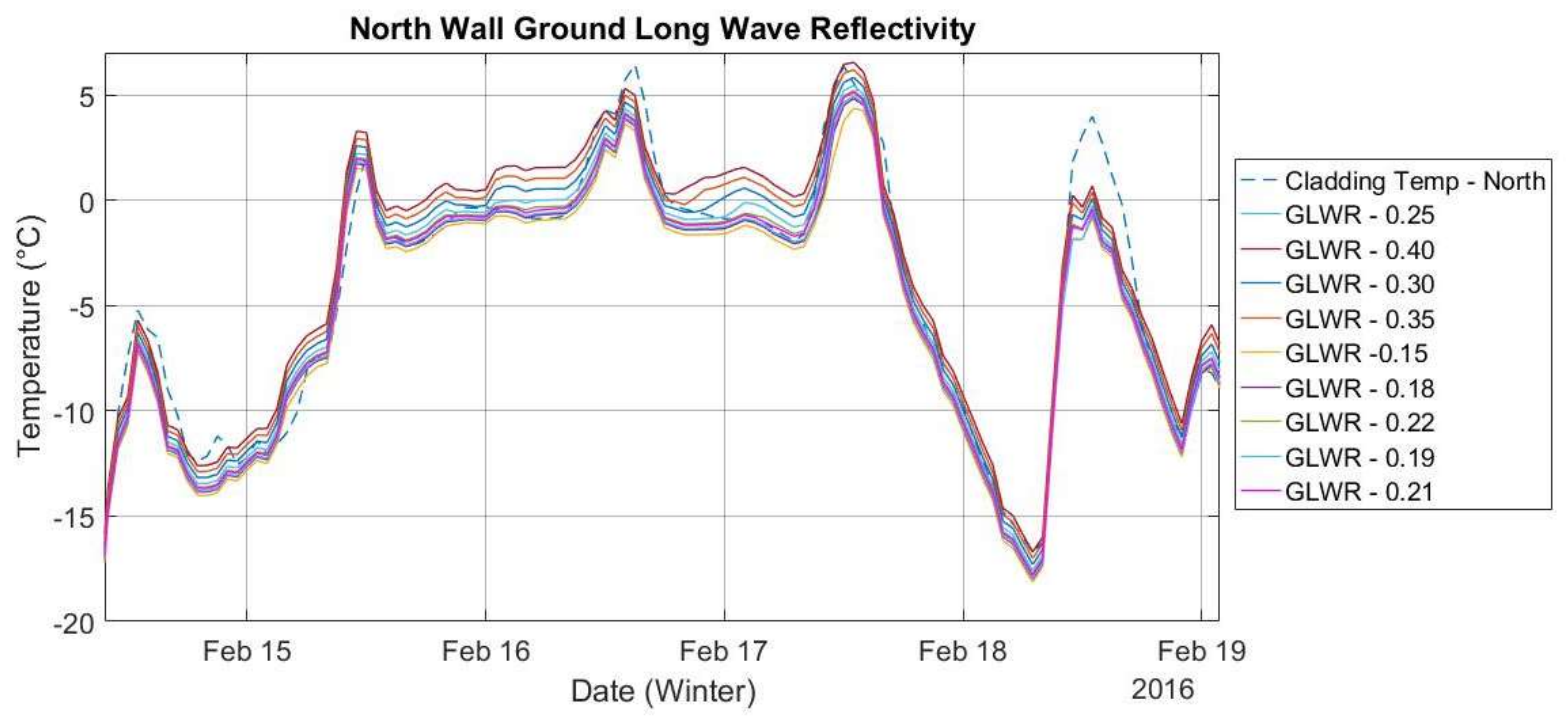

Figure 4-60: Excerpt from GLWR Calibration - North Wall

A value of 0.21 was selected for the GLWR coefficient. This value was selected due to its low RMSE and low MEAN error bias. The value of 0.22 provided the lowest mean error bias however there was an increase in RMSE compared with 0.20 or 0.21 ; this indicates that 0.22 has larger deviations during extreme events, while 0.2 and 0.21 respond more appropriately to extreme events.

\subsubsection{Ground and Cladding Long-Wave Radiation Emissivity}

Ground long wave emissivity was modified and assessed for several values. It was found that the original value of 0.9 provided the best goodness of fit against the collected data. Seven cases were run for cladding long wave emissivity and a value of 0.86 was selected. Full RMSE Tables can be found in Appendix I. 


\subsubsection{Custom Cloud Index Creation}

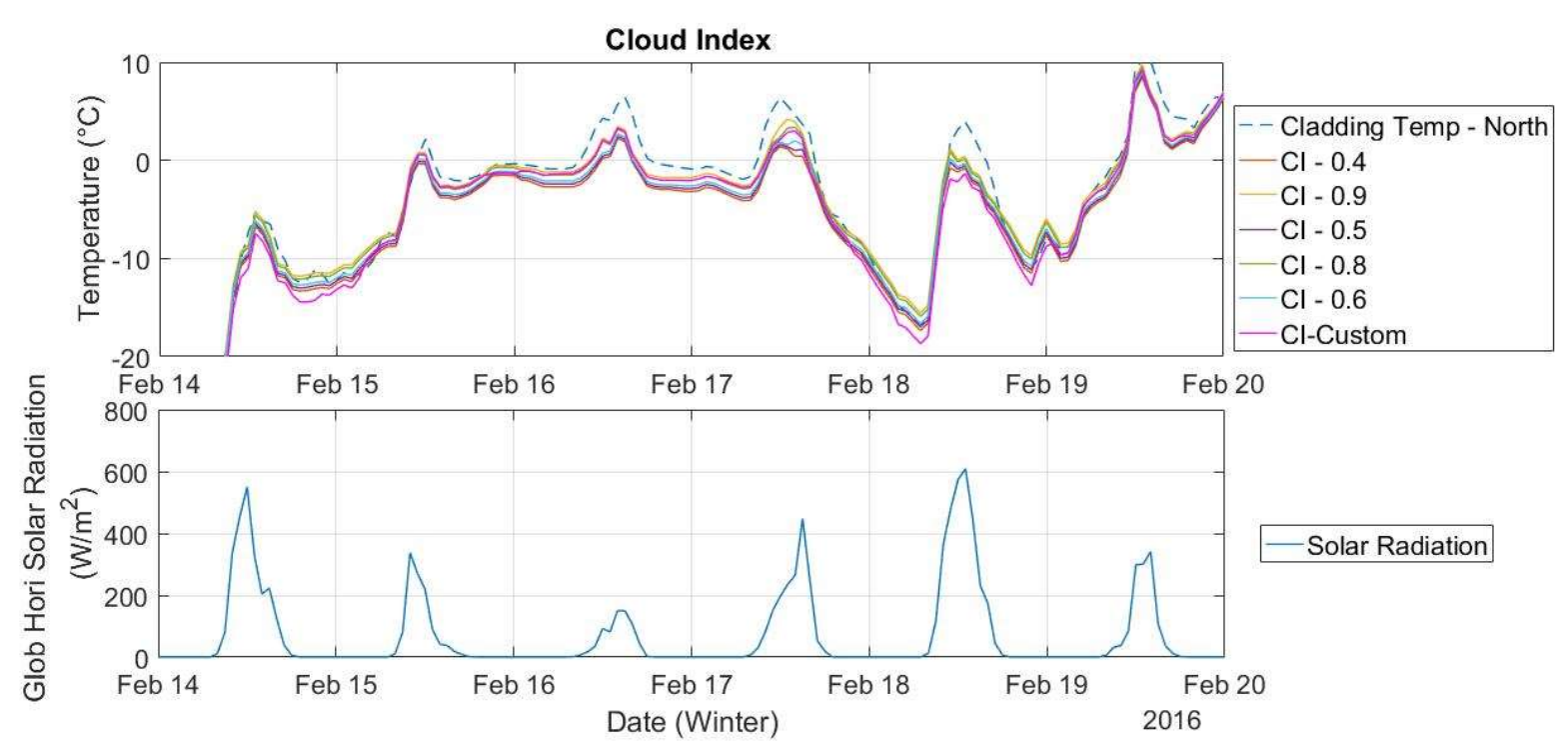

Figure 4-61 : Custom Cloud Index

It was found after several trials of different cloud index values that each variable suited different climate conditions. Solar radiation data indicated a cloudy period occurred from Feb $15^{\text {th }}$ to the $18^{\text {th }}$. The temperature data also corresponded more appropriately with a higher cloud index in WUFI Pro. It was deemed appropriate to create a custom CI file based on these findings.

Additional weather data was obtained from Environment Canada. The Toronto Pearson Airport station was selected for its reports on hourly weather conditions. Weather conditions were reported by text descriptor (i.e. "Cloudy" or "Mainly Clear"). WUFI requires a numerical format for the CI on a scale of 0.0 to 1.0. The author's best judgment was used to convert the text descriptor to a usable CI. A full list of text variables and corresponding CI can be found in Appendix J.

The Custom CI file performed better during overcast however seemed to underestimate the temperature of the cladding during clear nights. In contrast to the static $\mathrm{CI}$ that generalizes cloud cover with a single index, the custom index responds to the dynamic situation that exists in field testing. Sources of error would include the localized weather conditions at the recording station compared with the structure location and/or inadequate estimation of assigned CI. 


\subsubsection{Cladding Short-Wave Radiation Absorptivity}

The south wall experienced direct short-wave solar radiation and was used to determine the short-wave absorptivity value for the cladding. Peak temperatures of the cladding were matched with the peak temperatures of the WUFI Simulation to find the SWRA coefficient.

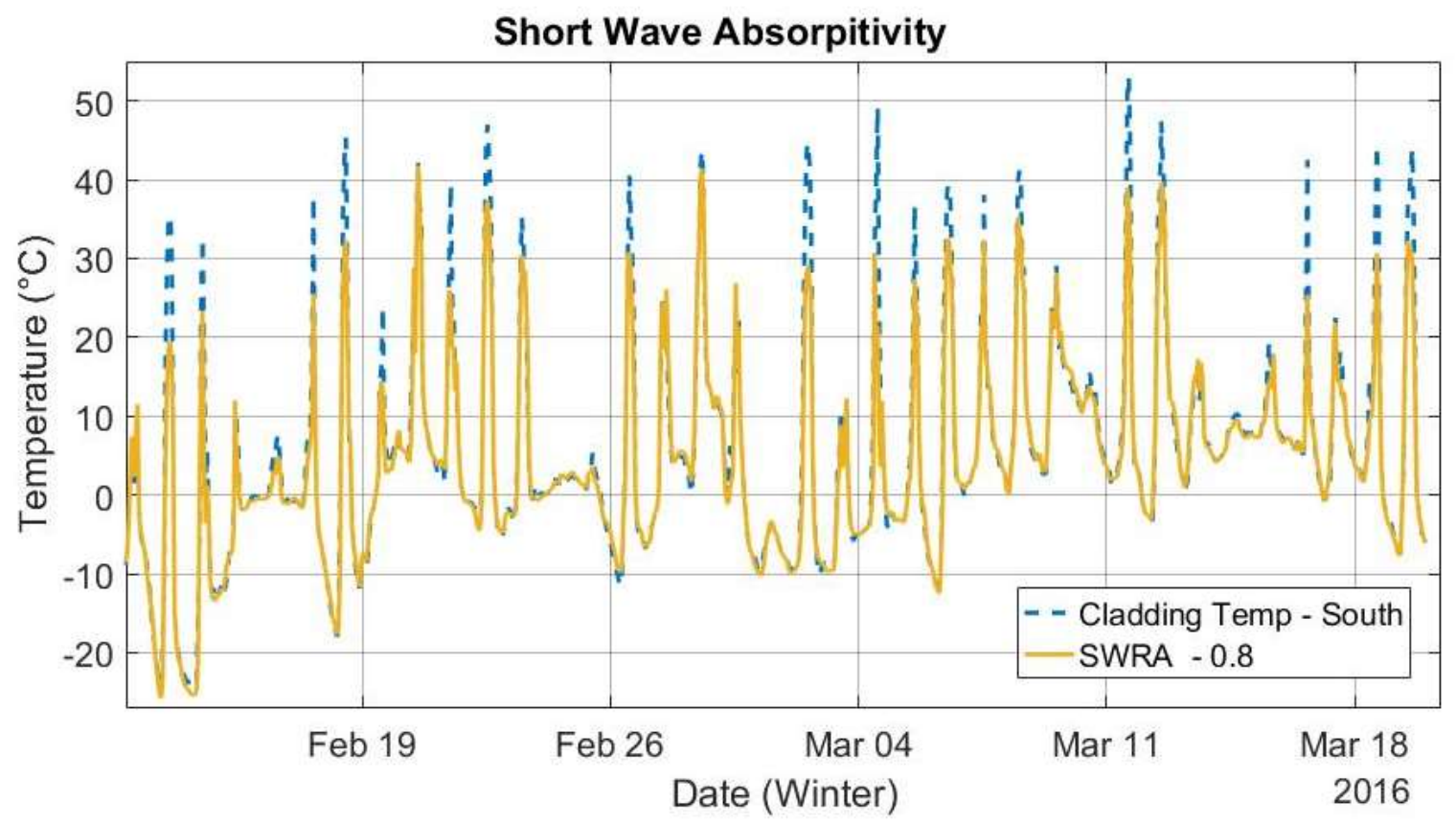

Figure 4-62 : Short Wave Absorptivity Estimation

The first simulation case revealed that the south facing cladding temperature sensors were regularly experiencing a much higher temperature during midday, yet matched relatively close during the night and during cloudy periods. The SWRA was adjusted and found that maximum and unrealistic values were still not able to meet peak daytime temperatures. 


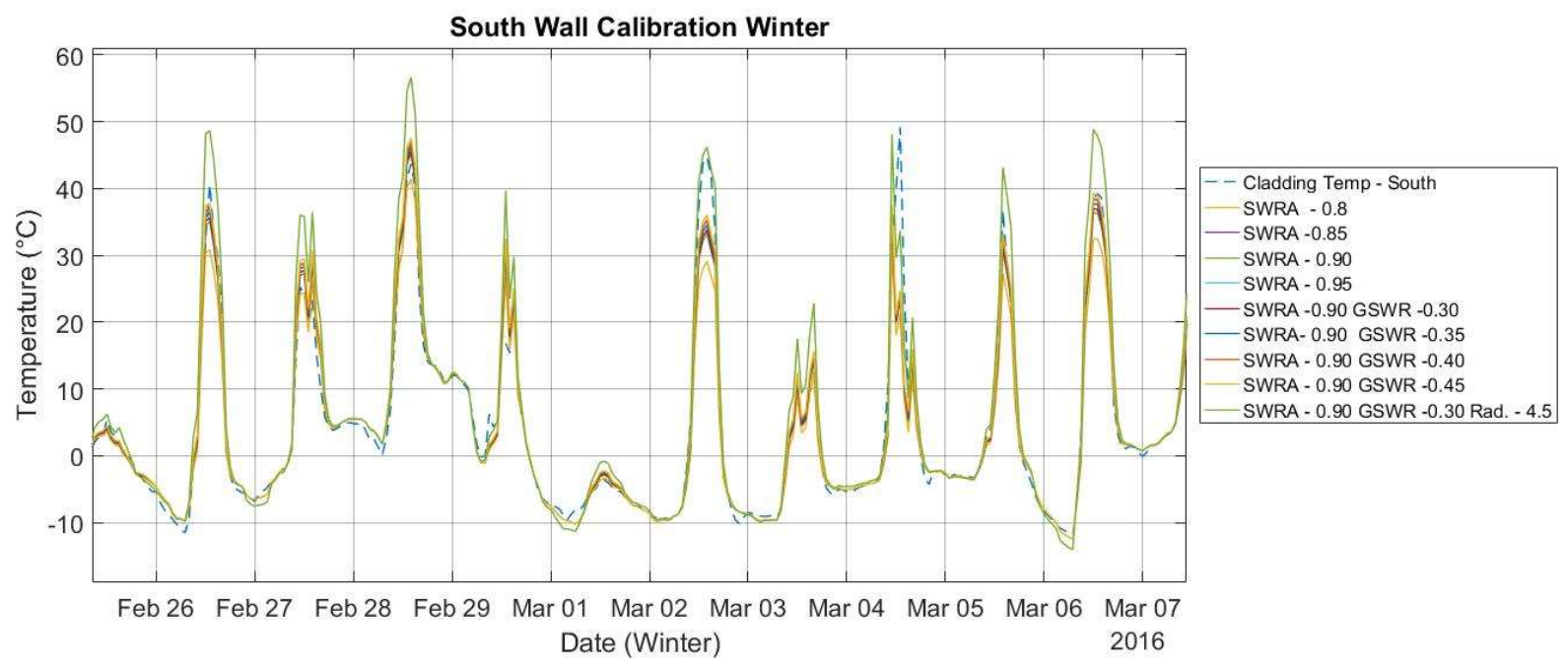

Figure 4-63 : Short Wave Absorptivity Final Calibration

The short-wave reflectivity of the ground, can influence the temperature of the cladding as well. For example, if snow is present, a portion of the short-wave radiation will be reflected up to the cladding and cause an increase in temperature.

Changes were made to the ground short wave reflectivity to increase temperatures. However even when these changes were made, higher values were unable to simulate the higher temperatures in some instances. Modifications were made to the radiation coefficient, as performed in Section 4.6.4.5 Determination of Radiation Heat Resistant Coefficient, for the southern wall. 


\subsubsection{0. $\quad$ South Wall Radiation Heat Conductance Value}

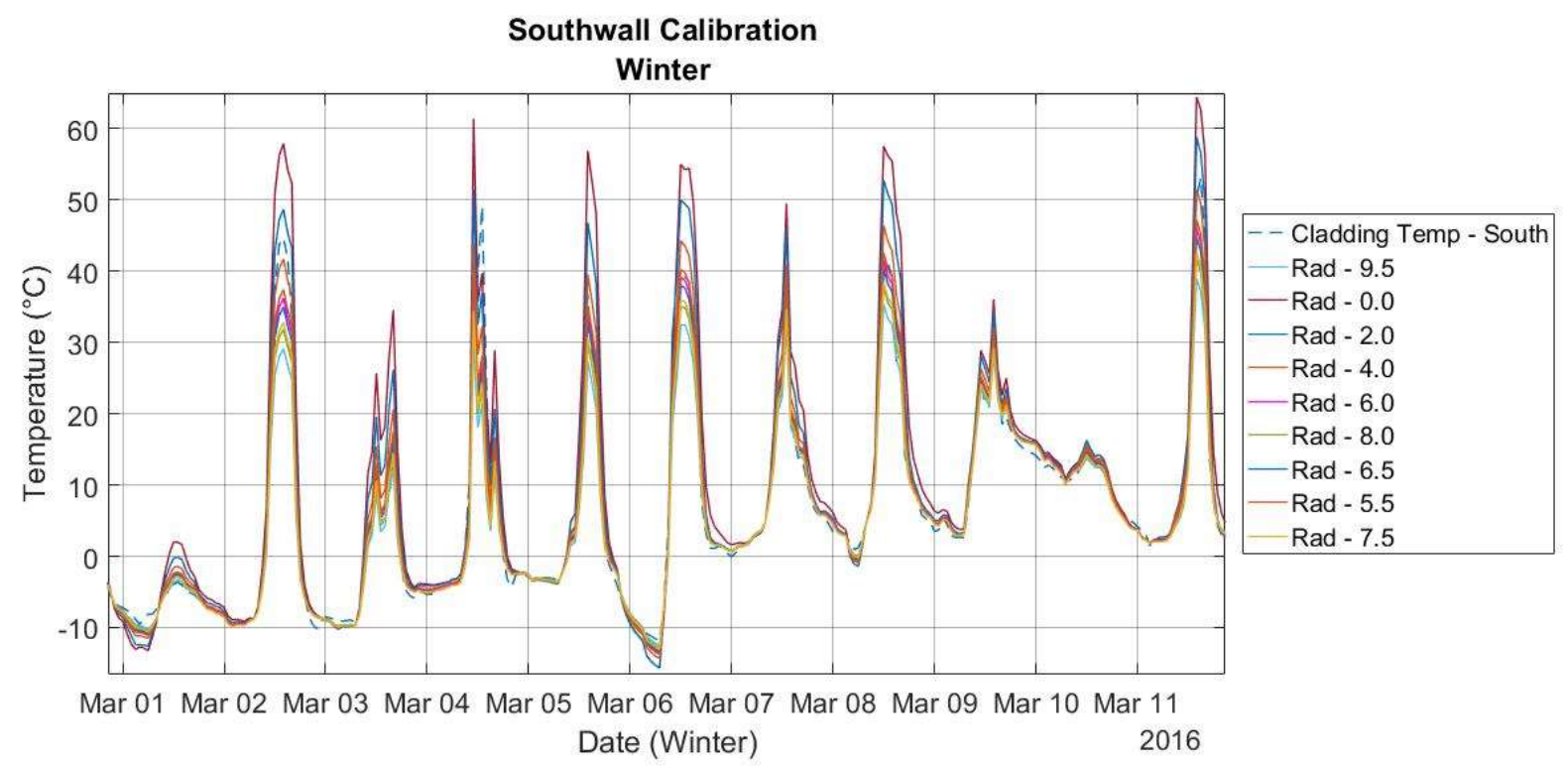

Figure 4-64 : South Wall Radiation Coefficients

An approximation for the radiation thermal resistance was found first by default values for the shortwave absorptivity and the ground short-wave reflectivity. The RMSE for the radiation trials can be found in Appendix I. It was found that a radiation conductance of $6.0 \mathrm{~W} / \mathrm{m}^{2}$ provided the best fit for the southern wall. Changing the radiation value allowed for a more responsive model that reached peak cladding temperatures, however, the lower value caused increased night time counter radiation.

Once the radiation conductance was determined modifications were made to both the short-wave absorptivity and the short-wave ground reflectivity to determine the best fit. Values of 0.79 for the SWRA and 0.26 for the GSWR were determined to be sufficient. The RMSE Tables for this analysis can be found in Appendix I. The SWRA was then entered back into the north wall simulation model to ensure conformity. The RMSE was reduced from 1.2681 to 1.2629 supporting the value for short wave radiation absorptivity of the cladding.

\subsubsection{Resultant Winter Values}

Shown in Table 4-23 are the results from the calibration procedure for the Winter Period for the north and south wall. 
Table 4-23 : Final Winter WUFI Calibration Values

\begin{tabular}{|c|c|c|c|}
\hline Variable & Surface Coefficient & North & South \\
\hline Convection Conductance & $\alpha_{\text {conv }}\left(\mathrm{W} / \mathrm{m}^{2}\right)$ & 4.5 & 4.5 \\
\hline Radiation Conductance & $\alpha_{r a d}\left(\mathrm{~W} / \mathrm{m}^{2}\right)$ & 9.5 & 6.0 \\
\hline Wind-Factor (Wind-Ward) & $f_{w w}\left(\mathrm{Ws} / \mathrm{m}^{3} \mathrm{~K}\right)$ & 1.8 & 1.8 \\
\hline Wind-Factor (Lee-ward) & $f_{l w}\left(\mathrm{Ws} / \mathrm{m}^{3} \mathrm{~K}\right)$ & 1.5 & 1.5 \\
\hline Short-Wave Radiation Absorptivity & $\alpha_{s w r a}$ & 0.79 & 0.79 \\
\hline Long-Wave Radiation Emissivity & $\varepsilon_{l w r e}$ & 0.86 & 0.86 \\
\hline Ground Long Wave Emissivity & $\varepsilon_{\text {glwe }}$ & 0.9 & 0.9 \\
\hline Ground Long Wave Reflectivity & $\rho_{g l w r}$ & 0.21 & 0.21 \\
\hline Ground Short Wave Reflectivity & $\rho_{g s w r}$ & 0.26 & 0.26 \\
\hline
\end{tabular}

The south wall exhibited a poor fit for cladding temperatures as compared with the north wall due to the large variations caused by solar radiation. It was later discovered that the south wall was oriented at $195^{\circ}$ causing peak cladding temperatures to exceed those capable of simulations. The variables estimated using the procedure outlined above, were still considered applicable, as the moisture content of the model matched that the field data.

\subsubsection{Calibration of Summer Coefficients}

The summer model calibrations included investigating the radiation resistant coefficient, the GLWR coefficient, and the GSWR coefficient. These coefficients were most affected by site context environmental factors which changed significantly from winter to summer. The material property parameters found from the winter calibrations such as cladding SWRA and LWRE remained the same. It was assumed that material properties were not affected by solar radiation or other environmental wear and tear throughout the relatively short period of this research.

\subsubsection{Interior Surface Resistance}

The interior surface resistance coefficient was checked for the north wall to ensure that it was still applicable during the summer months. The addition of the air conditioning unit may have had an impact on the air flow in the test structure and changed the interior surface resistance 
coefficient. After running several trials, it was noted that the initial value of 0.175 was adequate. Appendix I contains relevant RMSE results.

It was noted during this analysis that the latter portion of the data collection experienced a divergence between simulated surface temperatures and the collected surface temperature data. The change in the surface sensor temperature may have been caused by solar radiation heating up interior surfaces. Figure 4-65 demonstrates this divergence of simulated surface temperatures and collected data temperatures.

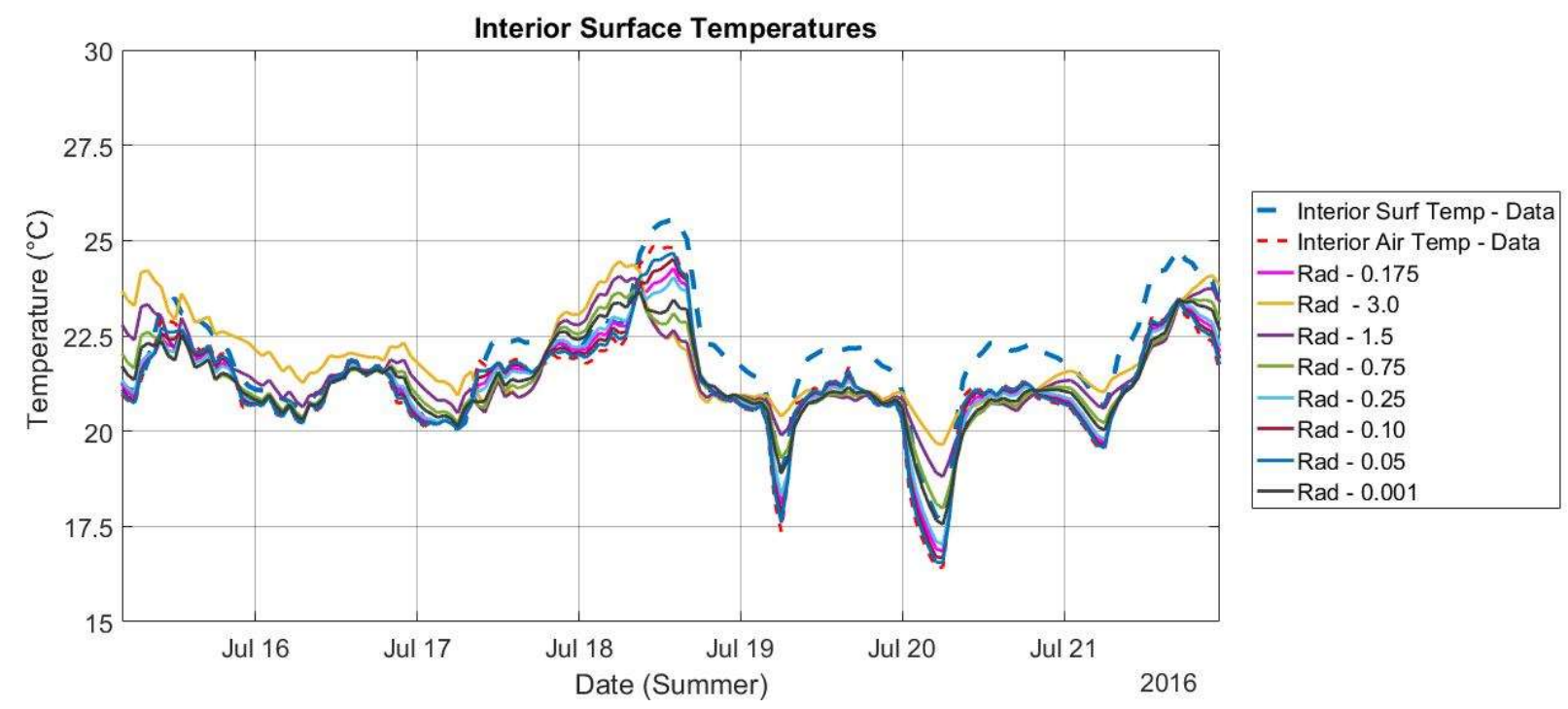

Figure 4-65 :Divergent Surface Temperatures

\subsubsection{Exterior Surface Coefficients - North Wall}

Nine trials were conducted to determine the radiation coefficient and the ground longwave radiation reflection coefficient. Values were assessed simultaneously for the summer models. Several values were selected to provide a rough estimate, with the intent of refining the values. This can be seen in Table 4-24. 
Table 4-24 : Summer Rad. and GLWR Variables

\begin{tabular}{|c|c|c|c|c|}
\hline Case & $\begin{array}{c}\text { Radiation } \\
\text { Coefficient }\end{array}$ & GLWR & RMSE & $\begin{array}{c}\text { Low } \\
\text { ISD* } \\
\text { RMSE }\end{array}$ \\
\hline 1 & 18 & 0.1 & 2.2427 & 2.1338 \\
\hline 2 & 18 & 0.3 & 1.6838 & 1.4573 \\
\hline 3 & 18 & 0.5 & 1.9322 & 1.6513 \\
\hline 4 & 22 & 0.1 & 2.2663 & 2.0211 \\
\hline 5 & 22 & 0.3 & 1.6310 & 1.3631 \\
\hline 6 & 22 & 0.5 & 1.5784 & 1.3686 \\
\hline 7 & 26 & 0.1 & 2.3352 & 1.9520 \\
\hline 8 & 26 & 0.3 & 1.7012 & 1.3308 \\
\hline 9 & 26 & 0.5 & 1.4560 & 1.2081 \\
\hline
\end{tabular}

It was noted during analysis that these values had a large impact on the peak temperature values at midday. The peak temperature, which was heavily influenced by short wave radiation, skews accurate results for long wave ground reflection and the radiation coefficient. It was deemed appropriate to check only periods of low short-wave activity (i.e. Night and cloudy periods). All temperature data was eliminated during times with greater than $100 \mathrm{~W} / \mathrm{m}^{2}$ of direct solar radiation. Goodness of fit was assessed for this period and can be found in Table 4-24. A second round of simulations was performed to refine the radiation coefficient and GLWR variables. Final values for the radiation input and GLWR were $28 \mathrm{~W} / \mathrm{m}^{2}$ and 0.5 respectively with a RMSE of 1.1603. Cases were subsequently run for the GSWR and a value of 0.36 was selected. All three variables (GLWR, Radiation Coefficient, and GSWR) are quite different from their winter equivalents. This can be mainly attributed to the change in the test structures surroundings. As can be seen in Figure 4-66. A deciduous tree was located close to the structure and limited a large portion of the temperatures sensor line-of-sight to the sky. This had a large impact on night-time counter radiation. The tree acted as a radiation shield to clear night skies, and limited cooling due to counter radiation. The radiation co-efficient and GLWR coefficient had the largest impact on night-time temperatures and were adjusted to simulate the change in the structures surroundings. 


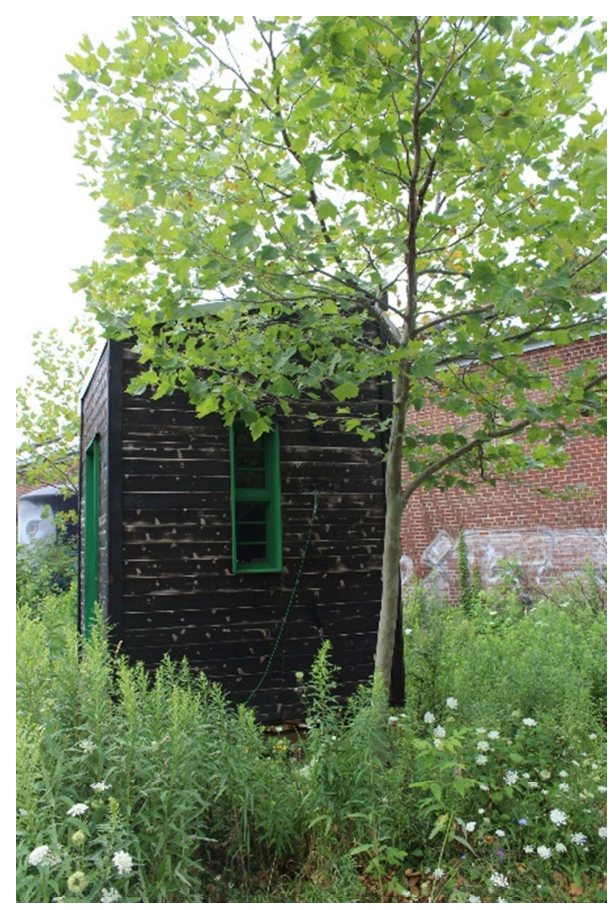

Figure 4-66 : North Wall Summer Conditions

\subsubsection{3. $\quad$ Exterior Surface Coefficients - South Wall}

The south wall was calibrated with the same procedure as the north wall. A radiation coefficient and ground long-wave reflectivity were found using periods of low direct solar periods. Full results from this analysis can be found in Appendix I. A value of $15.0 \mathrm{~W} / \mathrm{m}^{2}$ and 0.3 was chosen for the radiation and GLWR coefficient.

The comparatively large radiation coefficient compared to its winter equivalent may be attributed to a deciduous tree that was located a short distance from the structure that limited a portion of the sky. The tree was not close enough, however, to limit the high incident of direct solar radiation during some summer months with high solar altitude. It was not found at what date or angle that the tree obstructed direct solar radiation. It should be noted that the pyranometer was 
located above the tree and may not have been shaded. A shaded pyranometer would have had implications on the accuracy of radiation inputted into the WUFI simulation.

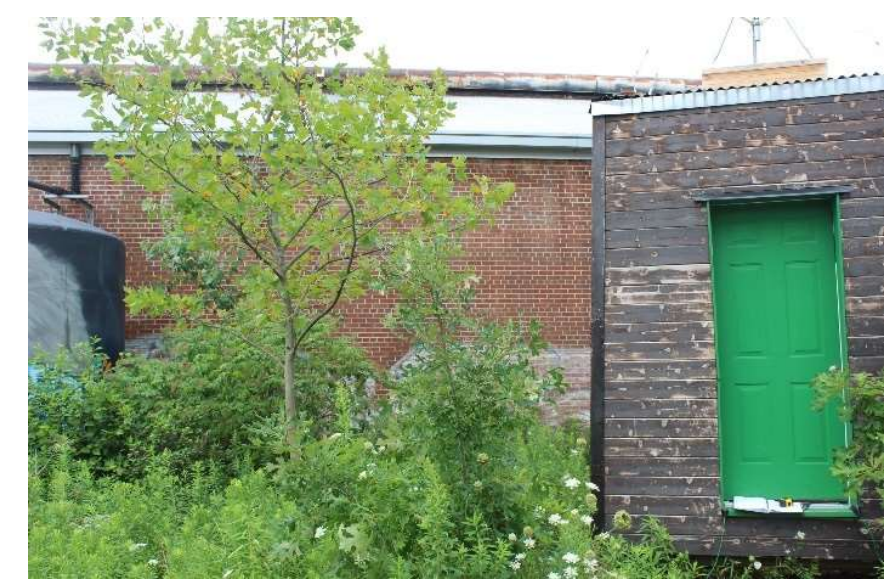

Figure 4-67 : South Side of Structure

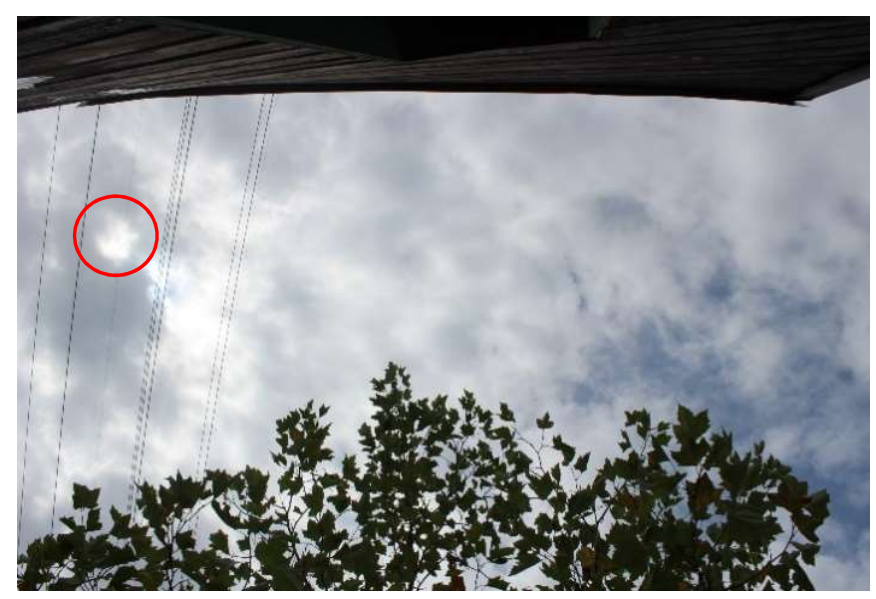

Figure 4-68: Solar Angle on July 28th

\subsubsection{Summer South Short-Wave Reflection}

The short-wave reflection co-efficient was then found after the GLWR and the Radiation factor. The ground shortwave reflectivity value was found to be approximately 0.5 . This value is much higher than commonly found values for surrounding surfaces (Santamouris, 2005)

- Green Grass $=0.26$ (WUFI database)

- Deciduous Trees $=0.20-0.30$

- Concrete surface (parking lot) $=0.10-0.35$

- $\quad$ Brick Wall = 0.2-0.40 
It is suspected that this was caused by the inability of the model to account for both limiting counter radiation and allowing for significant short-wave radiation gain at the same time. This was caused by the muting effect of the radiation coefficient.

It was also noticed during the analysis that peak temperatures of the data occurred slightly later than the peak temperatures of the model. The orientation was changed to south-west and model peak temperatures occurred later and were higher than that of the south orientation. The field test structure south wall faced at a bearing of $195^{\circ}$. WUFI Pro was unable to account for the slight off-south orientation.

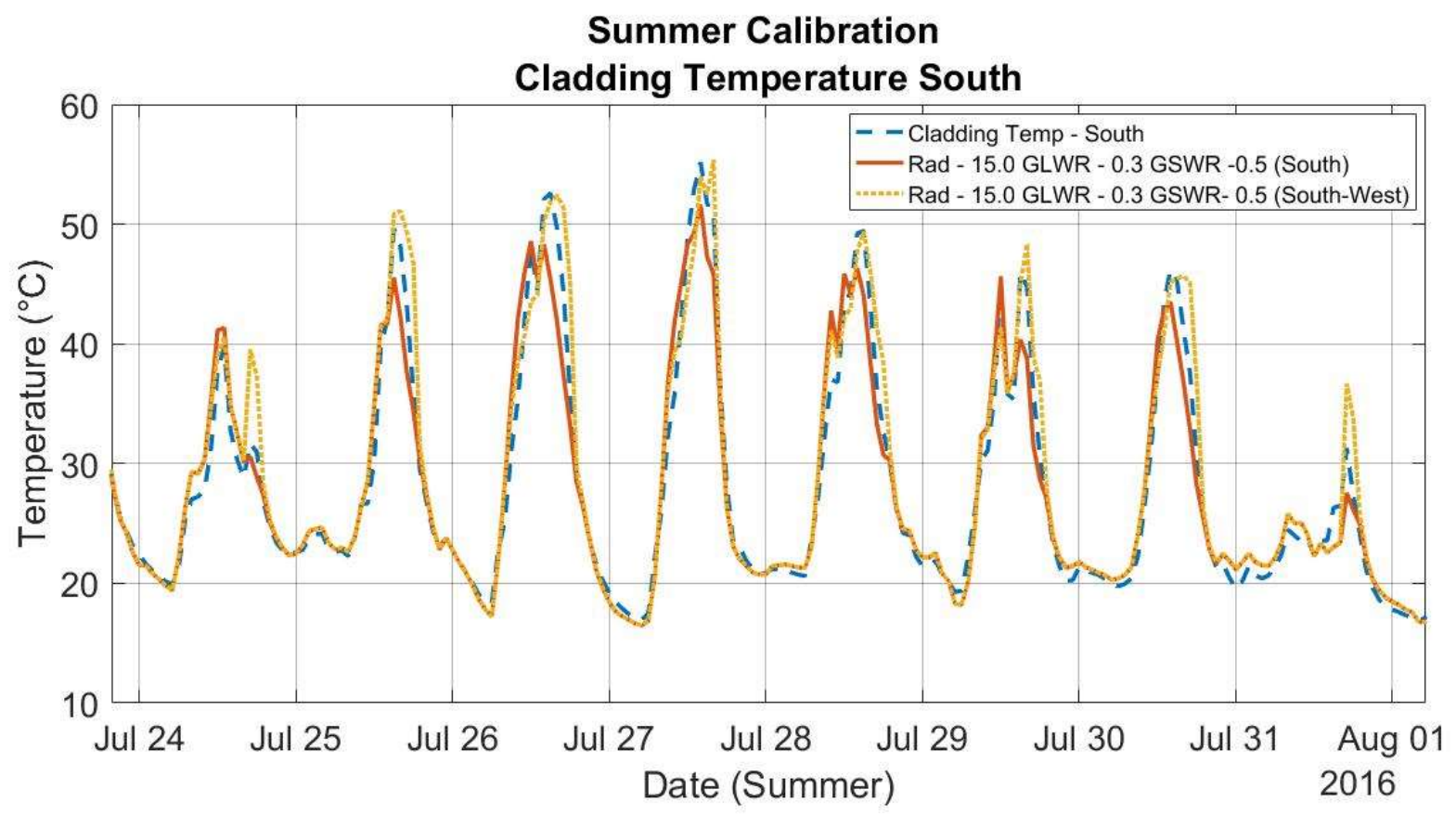

Figure 4-69: Effect of Orientation on Cladding Temperatures

The orientation of the field structure had a significant influence on the temperature of the cladding; however, WUFI could not replicate the slight orientation change. The modification of the coefficients above provided the best fitting curve possible for a south orientation. 


\subsubsection{Resultant Summer Values}

Table 4-25 : Resultant Summer WUFI Variable Coefficients

\begin{tabular}{|l|c|c|c|}
\hline & Surface Co-efficient & North & South \\
\hline Convection Resistance & $\alpha_{\text {conv }}\left(\mathrm{W} / \mathrm{m}^{2}\right)$ & 4.5 & 4.5 \\
\hline Radiation Resistance & $\alpha_{r a d}\left(\mathrm{~W} / \mathrm{m}^{2}\right)$ & 28 & 15.0 \\
\hline Wind-Factor (Wind-Ward) & $f_{w w}\left(\mathrm{Ws} / \mathrm{m}^{2} \mathrm{~K}\right)$ & 1.8 & 1.8 \\
\hline Wind-Factor (Lee-ward) & $f_{l w}\left(\mathrm{Ws} / \mathrm{m}^{2} \mathrm{~K}\right)$ & 1.5 & 1.5 \\
\hline $\begin{array}{l}\text { Short-Wave Radiation } \\
\text { Absorptivity }\end{array}$ & $\alpha_{\text {swra }}$ & 0.79 & 0.79 \\
\hline $\begin{array}{l}\text { Long-Wave Radiation } \\
\text { Emissivity }\end{array}$ & $\varepsilon_{l w r e}$ & 0.86 & 0.86 \\
\hline $\begin{array}{l}\text { Ground Long Wave } \\
\text { Emissivity }\end{array}$ & $\varepsilon_{g l w e}$ & 0.9 & 0.9 \\
\hline $\begin{array}{l}\text { Ground Long Wave } \\
\text { Reflectivity }\end{array}$ & $\rho_{g l w r}$ & 0.50 & 0.30 \\
\hline $\begin{array}{l}\text { Ground Short Wave } \\
\text { Reflectivity }\end{array}$ & $\rho_{g s w r}$ & 0.36 & 0.50 \\
\hline
\end{tabular}

\subsubsection{Moisture Boundary Conditions}

Once an acceptable surface temperature was found for both interior and exterior conditions it was necessary to correct the moisture boundary conditions. It should be noted that vapour pressure differences are one of the driving forces for diffusion within enclosures. The exterior conditions and interior conditions for relative humidity were based on custom climate files directly inputted into WUFI. Vapour pressure of exterior boundary was calculated based on this information.

However, within this wall system the vented cavity was an important driver of vapour through the wall system. Ensuring a close fit between field and simulation data was critical to ensuring a well calibrated model.

The exterior air cavity vapour pressure was related to the exterior air through both direct air changes and through moisture exchange with the wood cladding. Moisture exchange with the wood cladding was dependent on the moisture content of the wood cladding. The moisture content of the cladding was heavily reliant on the adhering fraction of rain factor and its liquid water redistribution and transport function within WUFI. Material properties were left as default conditions. 


\subsubsection{Adhering Fraction of Rain}

The goal of this section was to determine the appropriate coefficient for adhering fraction of rain. The north winter wall was used as the basis for initial calibration. It was shown within the WUFI simulations that the wood cladding absorbed too much water during rain events compared with field data. This was seen clearly on Feb $24-25^{\text {th }}$ (Figure 4-70), where a rain event induced a rise in the vapour pressure within the cavity. However little effect was seen on the actual cavity vapour pressure in the field data. A series of cases were run to determine a correct adhering fraction of rain for the field structure wall. The $\mathrm{ACH}$ rate of 33.0 was used as a constant due to its responsiveness and its similar shape to the field data.

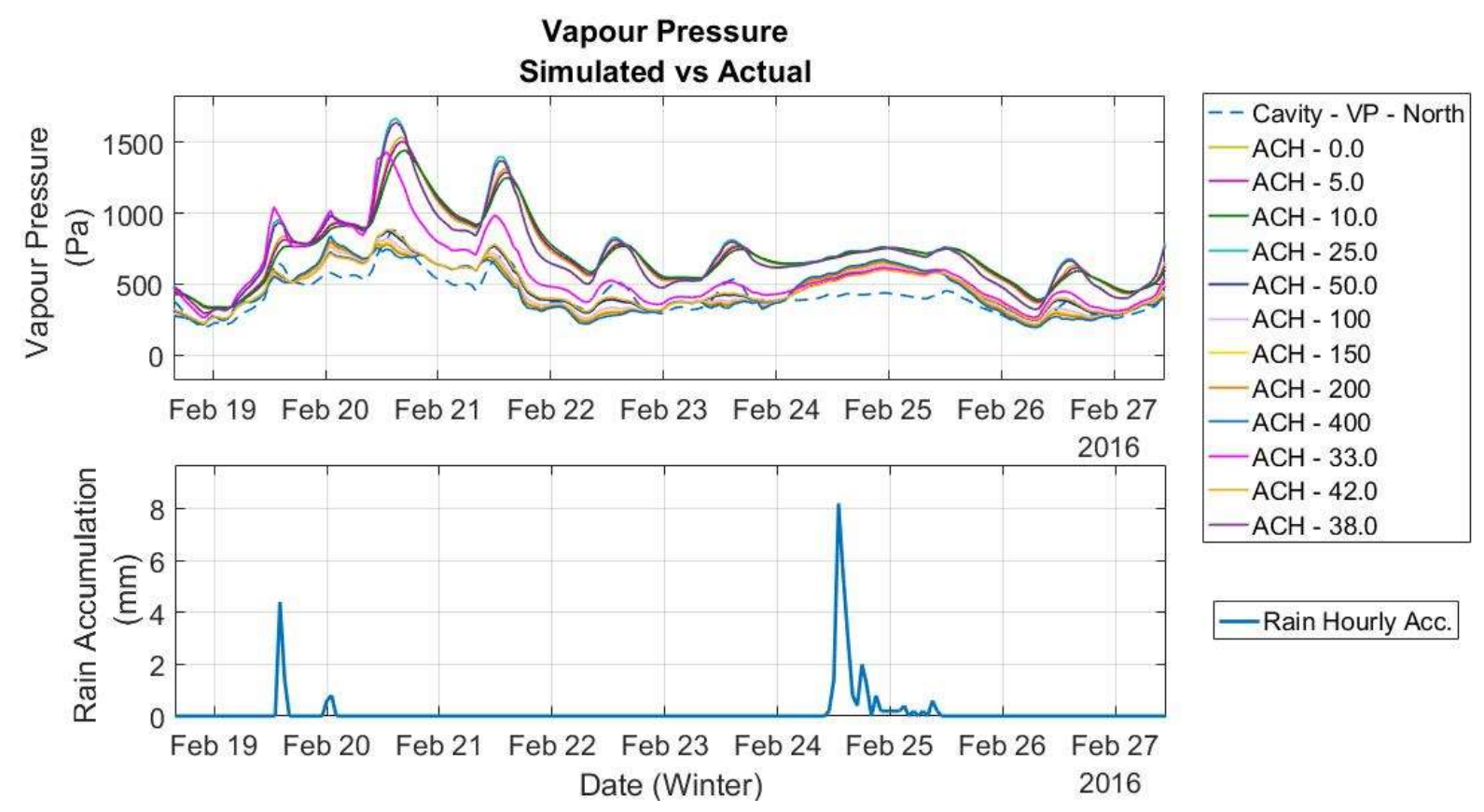

Figure 4-70: ACH Effect on Rain and Cavity VP

Values for adhering fraction of rain were lowered from the default value of 0.7 due to the field data exhibiting little change during rain events. A value of 0.6 was selected but had little impact on the goodness of fit on the $\mathrm{ACH}$ vapour pressure. 


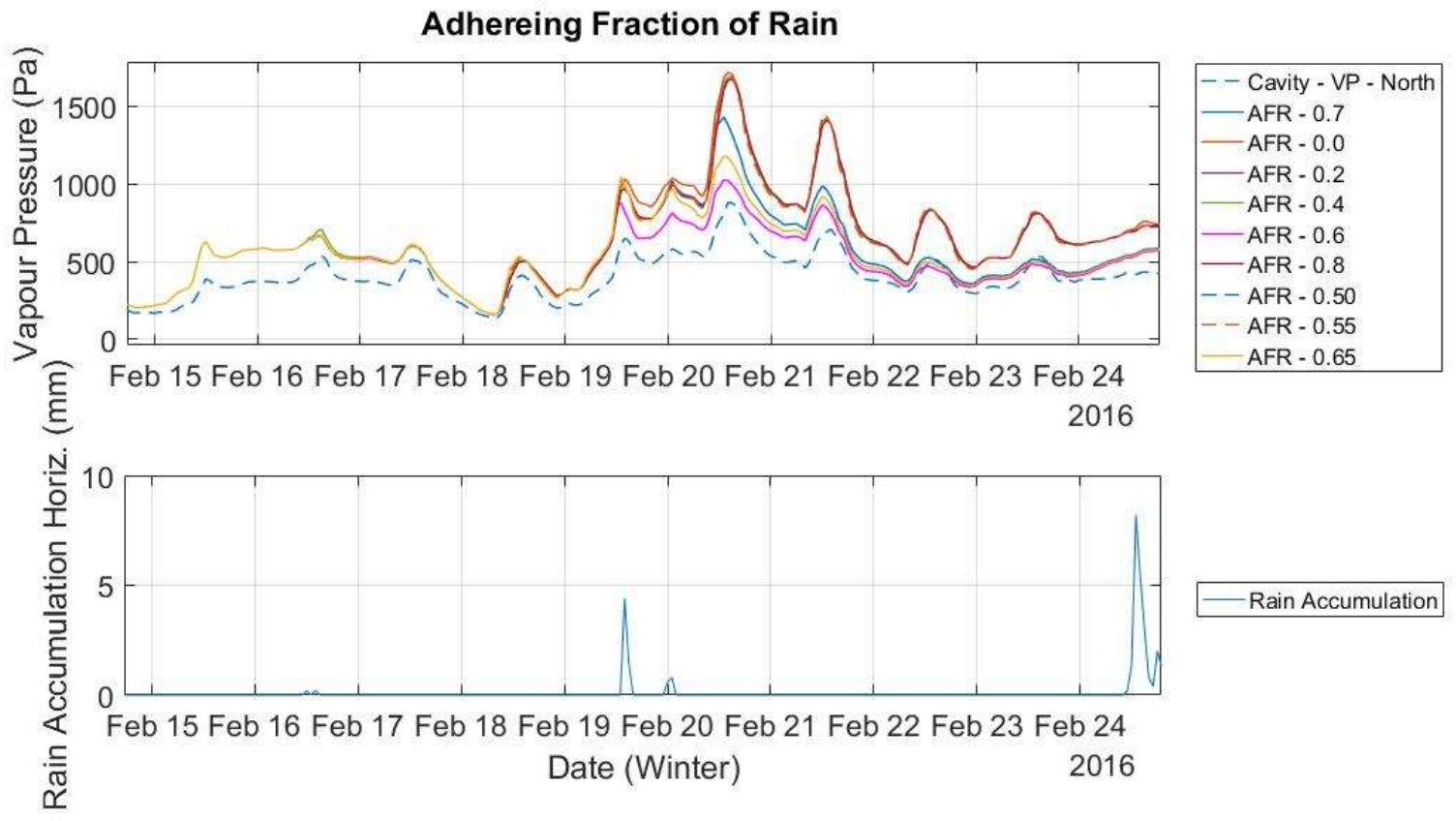

Figure 4-71: Adhering Fraction of Rain

It should be noted that the rain load was changed for the AFR calibration. The rain load was set to simulate that all rain fell on the cladding. This was not the case however. The intention was to allow WUFI to shed the access rain through modification of the AFR factor. The 0.6 value found in the north winter wall calibration was used in the other simulation files. The most critical component in ensuring proper moisture boundary conditions was matching vapour pressures of the air cavity. This was completed by creating a custom air changes per hour file for the cavity.

\subsubsection{Air Changes Per Hour in the Cavity.}

The movement of air between the cavity and the exterior fluctuated continuously throughout the day and throughout the year, and was dependent on many factors such as wind speed, wind direction, air temperature, and air pressure. WUFI simulated the air exchange of the vented cavity through a combined moisture and heat source located within the air cavity layer. WUFI used both a static air change rate and a dynamic custom file. To reflect the continuously changing condition within the air cavity a custom $\mathrm{ACH}$ file was created. This section will 
explore how this file was created.

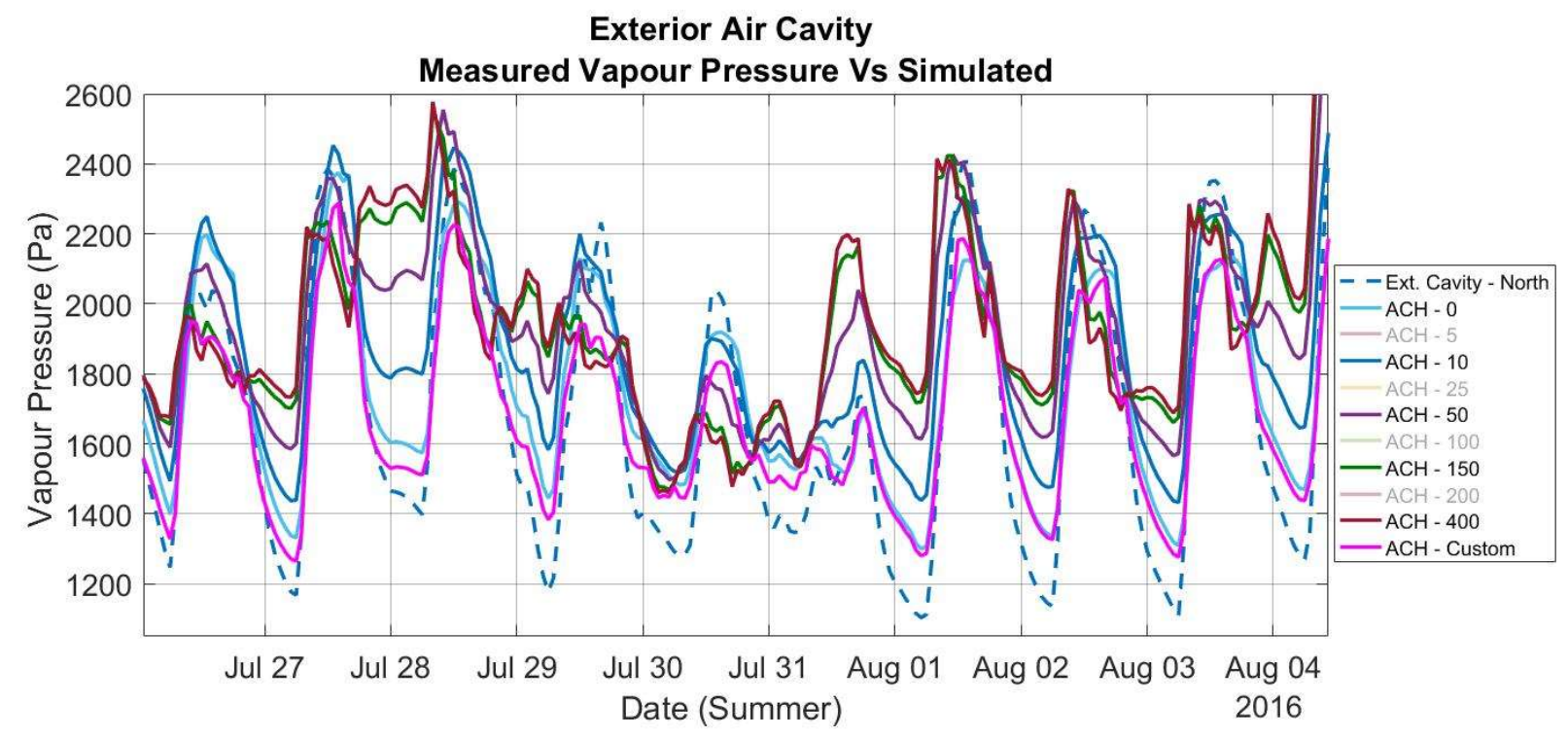

Figure 4-72: Creation of Custom Cavity ACH File

RHT sensors were placed in the cavities of both the north and the south wall (Layer-1.5). A series of simulations were conducted using different constant $\mathrm{ACH}$ for the vented cavity from 0400. The vapour pressure from the simulations was then compared on an hourly basis to the collected data. The $\mathrm{ACH}$ case that most closely matched the field data was then selected for that hour. The different cases were then compiled into a custom ACH file and were imported into WUFI. This was completed for all four wall models and a sample graph of the procedure is shown in Figure 4-72.

The simulations from the custom $\mathrm{ACH}$ were then compared against the field data and it was found that it could more accurately recreate the vapour pressure conditions within the vented cavity than static $\mathrm{ACH}$. It was noted during this analysis that the simulations were unable to reach the low levels of vapour pressure during the cooler night times. It may be possible that a custom 'exaggerated' ACH file could more accurately reflect field data, however was not completed for this analysis. The moisture content of the OSB was then compared against the field collected data to ensure that it reflected the conditions in the field. This can be seen during a snap-shot from the summer files. 


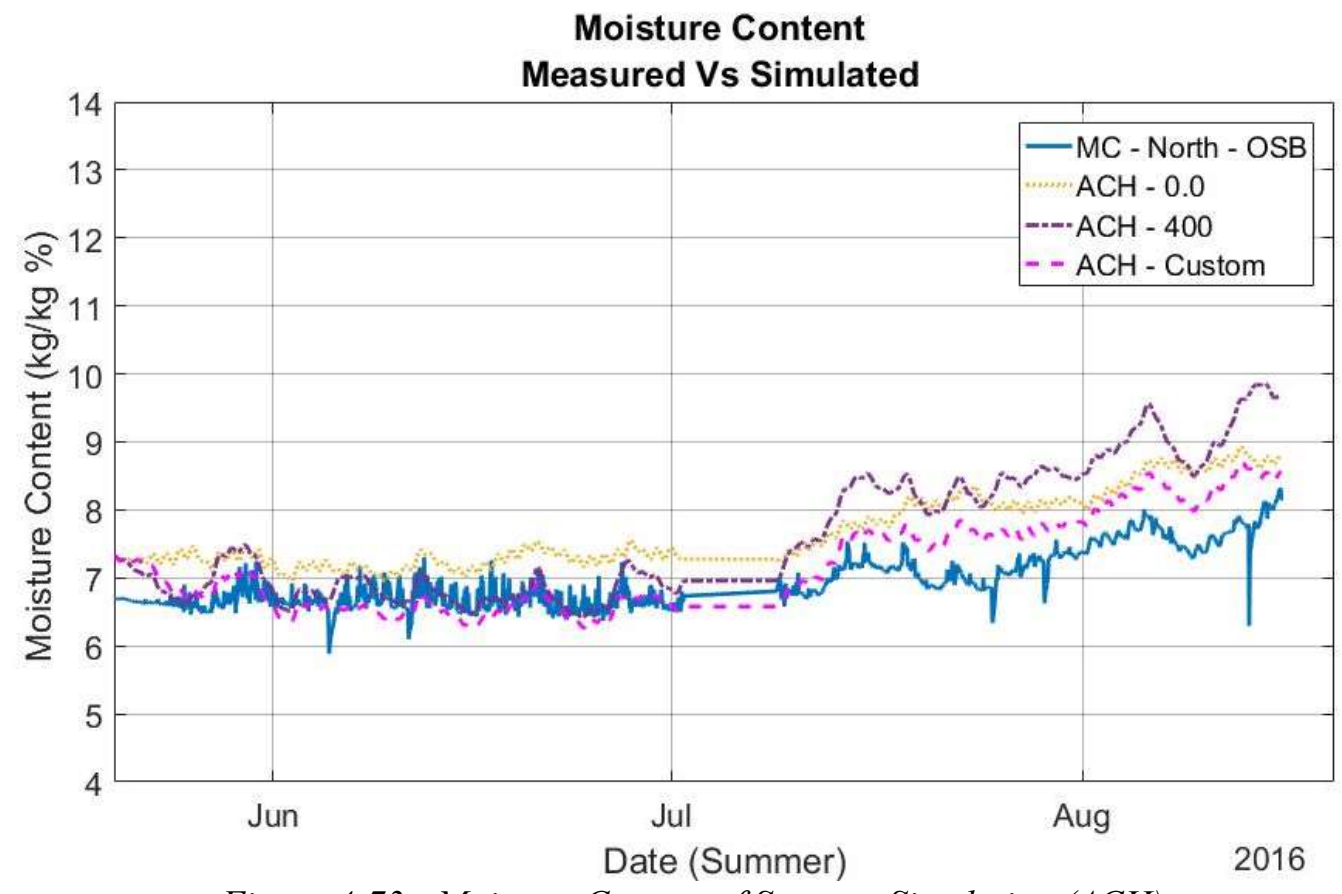

Figure 4-73 : Moisture Content of Summer Simulation (ACH)

The moisture content of the OSB was more accurately reflected using the custom ACH file than with the two-extreme static ACHs. A custom ACH file was created for all four simulation models. The creation of the custom ACH file for the vented air cavity completed the temperature and moisture boundary conditions. Interior enclosure conditions and material properties were explored next.

\subsubsection{Material Properties}

The next step in calibration included ensuring that the material properties of the simulation matched that of the wall assemblies. Of interest were the thermal properties of the insulation. It was demonstrated during the in-situ analysis of the north and south walls that the thermal resistance of the assembly was significantly different than values expected using manufacturer information. Other indications that the thermal properties of the materials were different were from the HEAT3 simulation calibration and the thermal conductivity laboratory testing.

The procedure for material property calibration included changing the thermal properties of the insulation (both interior and exterior) and OSB until the temperature of the simulations most closely simulated that of collected field data. The temperature data on the exterior side of the OSB sheathing was used as the primary comparison point (Layer 5). Layer 5 was chosen for its 
proximity to the moisture sensitive OSB and for being located between both interior and exterior insulations.

\subsubsection{Material Conductivity Changes}

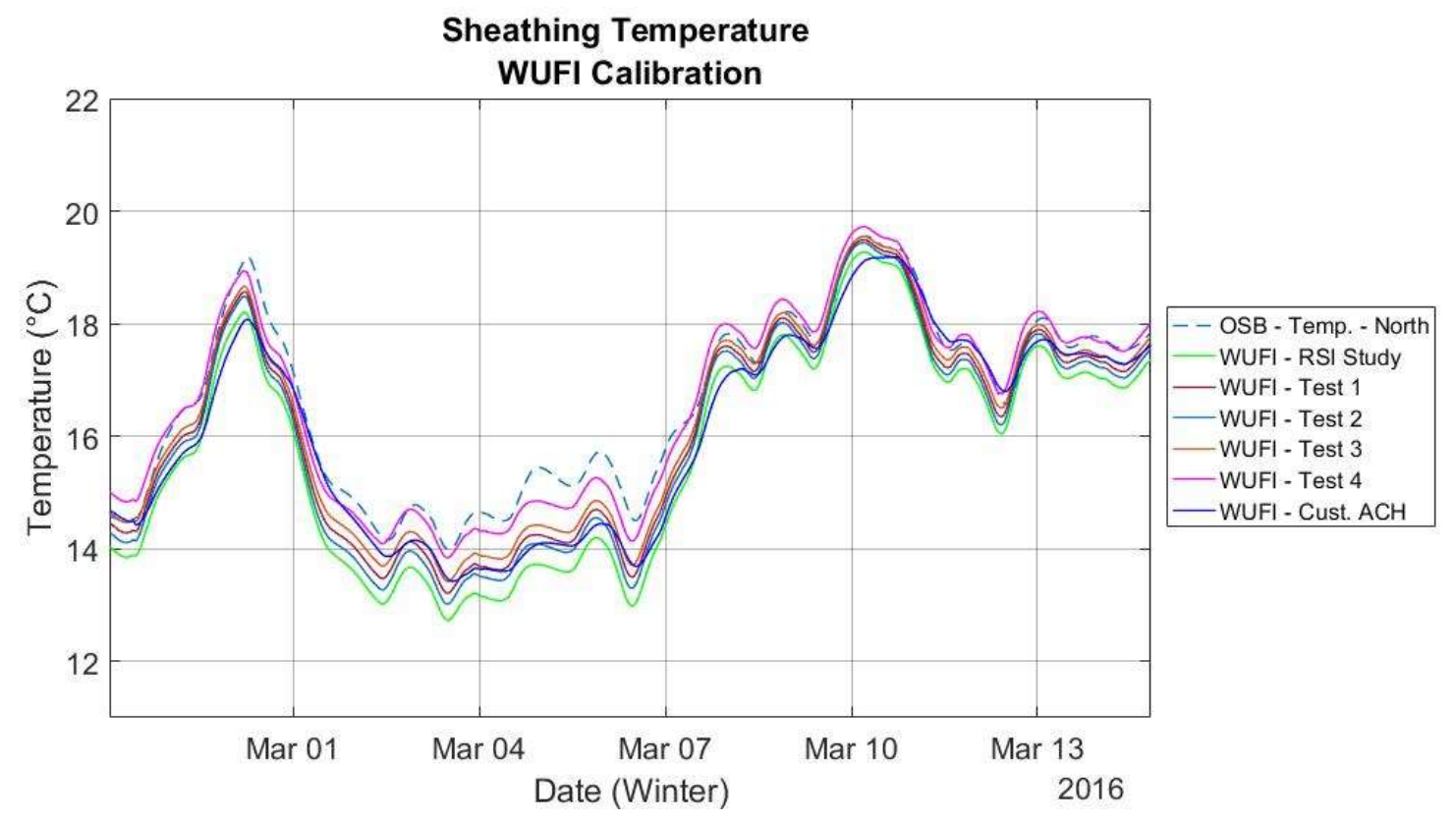

Figure 4-74: Thermal Conductivity Assessment

An initial assessment of the OSB temperature from the Custom ACH simulation showed that the simulation temperature of the OSB was below the collected data. This indicated that materials simulated thermal resistances were not representative of field conditions. The results were consistent with both the Heat3 simulation and the in-situ thermal resistance analysis. It was noted during the HEAT3 simulation that the default specific heat capacities of the mineral wool insulation were too high. Temperature amplitudes within the simulation were muted. This may have been caused by both changes in density or specific heat capacity.

Insulation and OSB conductivity and specific heat capacities were changed to represent the HEAT3 simulations and the resultant OSB temperatures were low. The thermal conductivities from the in-situ analysis were then entered into WUFI and the resulting temperatures were still to low. Incremental changes to the conductivities of the material were then completed in WUFI until a proper fit was found for the temperature. This procedure was completed for the rest of the simulation models. 
The south wall exhibited similar relationships between the in-situ thermal analysis and the temperature of the OSB during the winter months. The simulated temperatures were above the collected data which indicated a drop in the exterior insulation thermal resistance. No HEAT3 or in-situ layer analysis was completed for the south wall during the winter or summer months and the calibration was based off changes to the WUFI model alone.

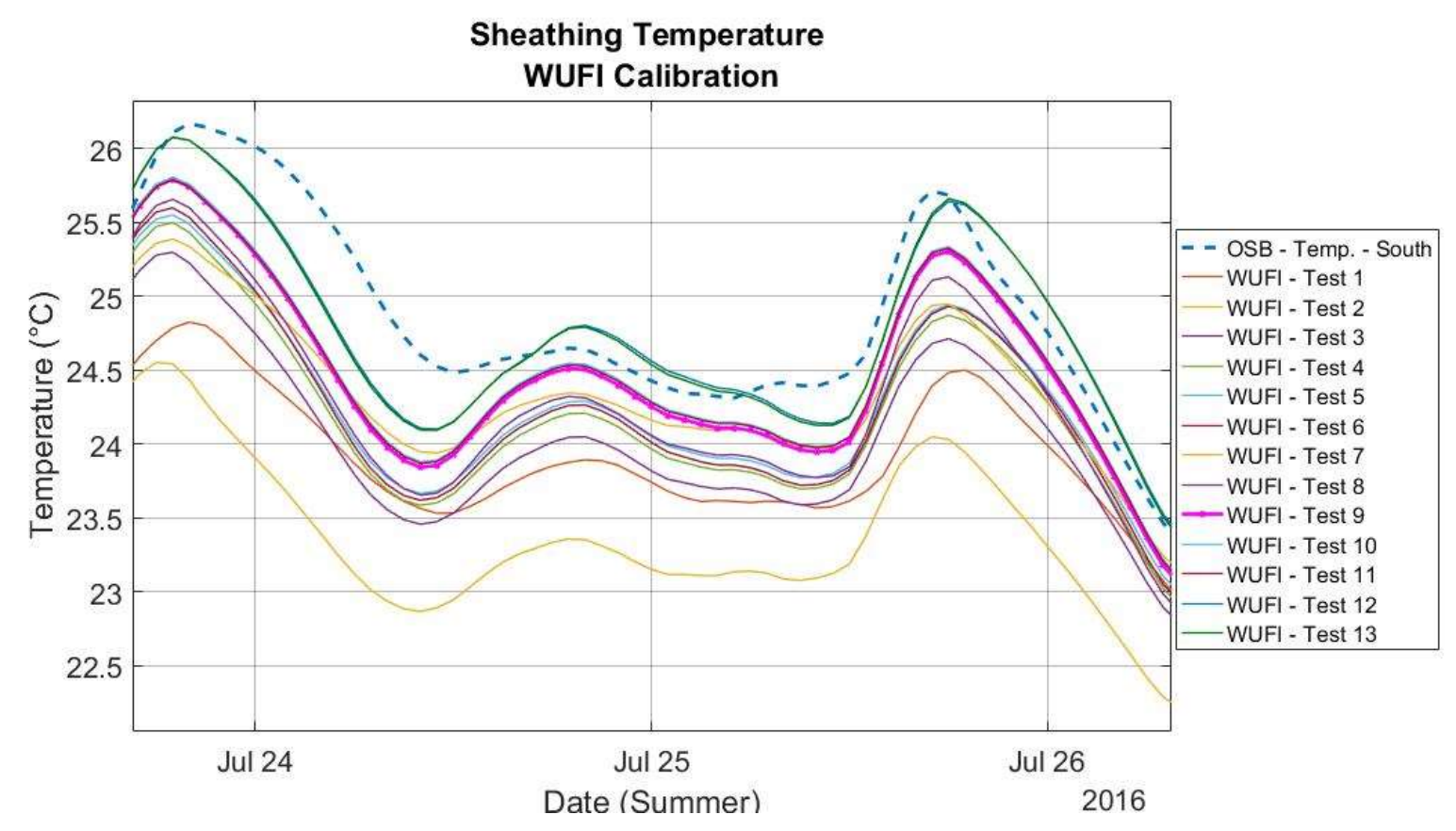

Figure 4-75 : Temperature Assessment South Wall Summer

The summer months showed an interesting phenomenon where the thermal conductivities needed to be inversed from the winter months. For example, the southern summer wall simulation had lower OSB temperatures compared to the temperature data (Figure 4-75). A decrease in the thermal conductivity of the interior insulation and an increase in the thermal conductivity for the exterior insulation were required to match temperature profiles. 


\subsubsection{Final Material Conductivity Values}

Table 4-26 : Final WUFI Conductivity Values

\begin{tabular}{|c|c|c|c|c|c|c|c|c|}
\hline \multirow{2}{*}{ Material } & \multicolumn{2}{|c|}{ Winter - North } & \multicolumn{2}{|c|}{ Winter - South } & \multicolumn{2}{c|}{ Summer - North } & \multicolumn{2}{c|}{ Summer - South } \\
\cline { 2 - 9 } & $\begin{array}{c}\lambda= \\
\mathrm{w} / \mathrm{mK}\end{array}$ & $\begin{array}{c}\mathrm{C}= \\
\mathrm{J} / \mathrm{kgK}\end{array}$ & $\begin{array}{c}\lambda= \\
\mathrm{w} / \mathrm{mK}\end{array}$ & $\begin{array}{c}\mathrm{C}= \\
\mathrm{J} / \mathrm{kgK}\end{array}$ & $\begin{array}{c}\lambda= \\
\mathrm{w} / \mathrm{mK}\end{array}$ & $\begin{array}{c}\mathrm{C}= \\
\mathrm{J} / \mathrm{kgK}\end{array}$ & $\begin{array}{c}\lambda= \\
\mathrm{w} / \mathrm{mK}\end{array}$ & $\begin{array}{c}\mathrm{C}= \\
\mathrm{J} / \mathrm{kgK}\end{array}$ \\
\hline $\begin{array}{c}\text { Roxul CIS } \\
\text { Layer 2-3 }\end{array}$ & 0.0279 & 618 & 0.0410 & 618 & 0.0450 & 618 & 0.0355 & 618 \\
\hline $\begin{array}{c}\text { Roxul CIS } \\
\text { Layer 3-4 }\end{array}$ & 0.0310 & 562 & 0.0410 & 562 & 0.045 & 562 & 0.0355 & 562 \\
\hline $\begin{array}{c}\text { Roxul CIS } \\
\text { Layer 4-5 }\end{array}$ & 0.0310 & 562 & 0.0410 & 562 & 0.045 & 562 & 0.0355 & 562 \\
\hline $\begin{array}{c}\text { OSB } \\
\text { Layer 5-6 }\end{array}$ & 0.0850 & 1880 & 0.0920 & 1880 & 0.085 & 1880 & 0.092 & 1880 \\
\hline $\begin{array}{c}\text { Roxul } \\
\text { Comfortbatt } \\
\text { Layer 6-7 }\end{array}$ & 0.0500 & 850 & 0.0360 & 850 & 0.034 & 850 & 0.032 & 850 \\
\hline
\end{tabular}

Final material conductivities do not necessary reflect the apparent thermal conductivity of the material as they were impacted by certain field conditions. The conductivities entered in the WUFI simulation best represented the temperature profile of the sensor at Layer 5 for the specific simulations.

\subsubsection{Model Geometry Change}

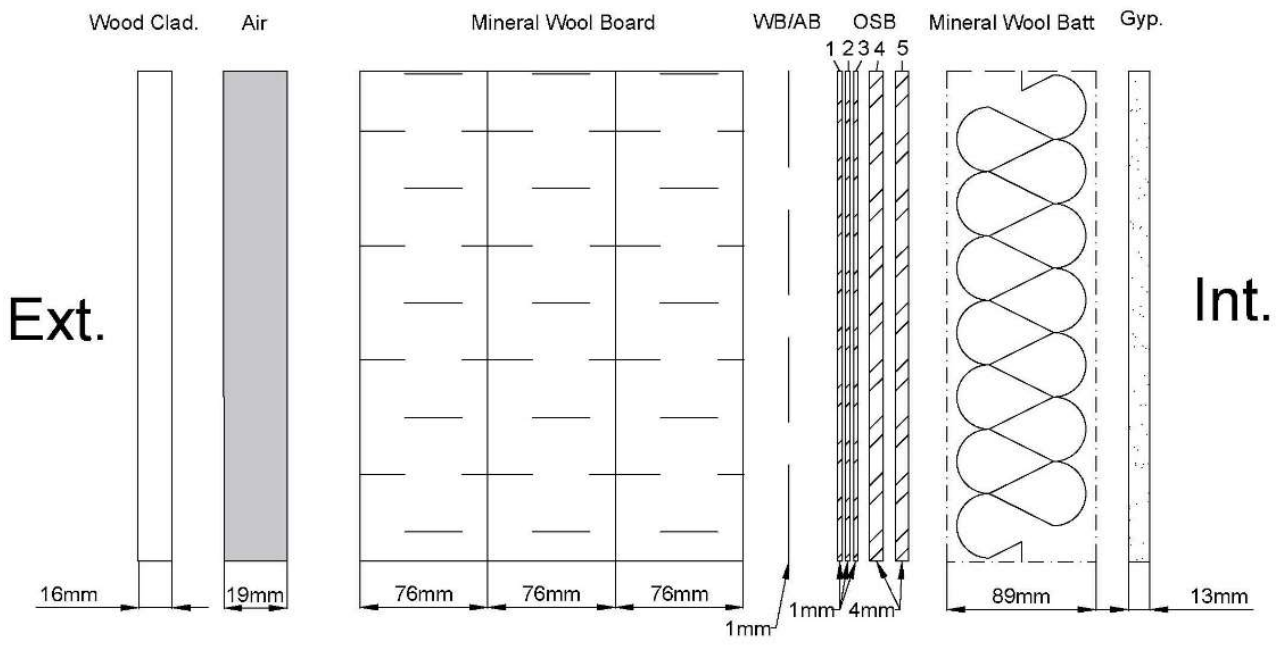

Figure 4-76 : Final WUFI Geometry

It was noted during analysis that the daily and weekly amplitude of the moisture content was affected by the location of where the simulated moisture content was observed within in the 
WUFI Model. The moisture content of an OSB portion in the simulation is averaged over the entire specimen and can be highly variable throughout the material itself. The collection method used insulated painted nails and penetrated to a certain depth into the OSB, thereby only recording that once depth. An 'observation' layer was created between the exterior layer and the middle layer to try and capture some of the hourly moisture content variations that was exhibited in the collected data during the summer months. The location of the observation layer was chosen to both reflect the location of uninsulated portion of the moisture content pins, and to simulate the hourly fluctuations within the collected data.

\subsubsection{Hygrothermal Simulation Calibration Results}

The primary gauge of calibration was the simulated sheathing moisture content compared to the collected sheathing moisture content. The following section will discuss the final moisture content outputs of each of the four calibrated walls.

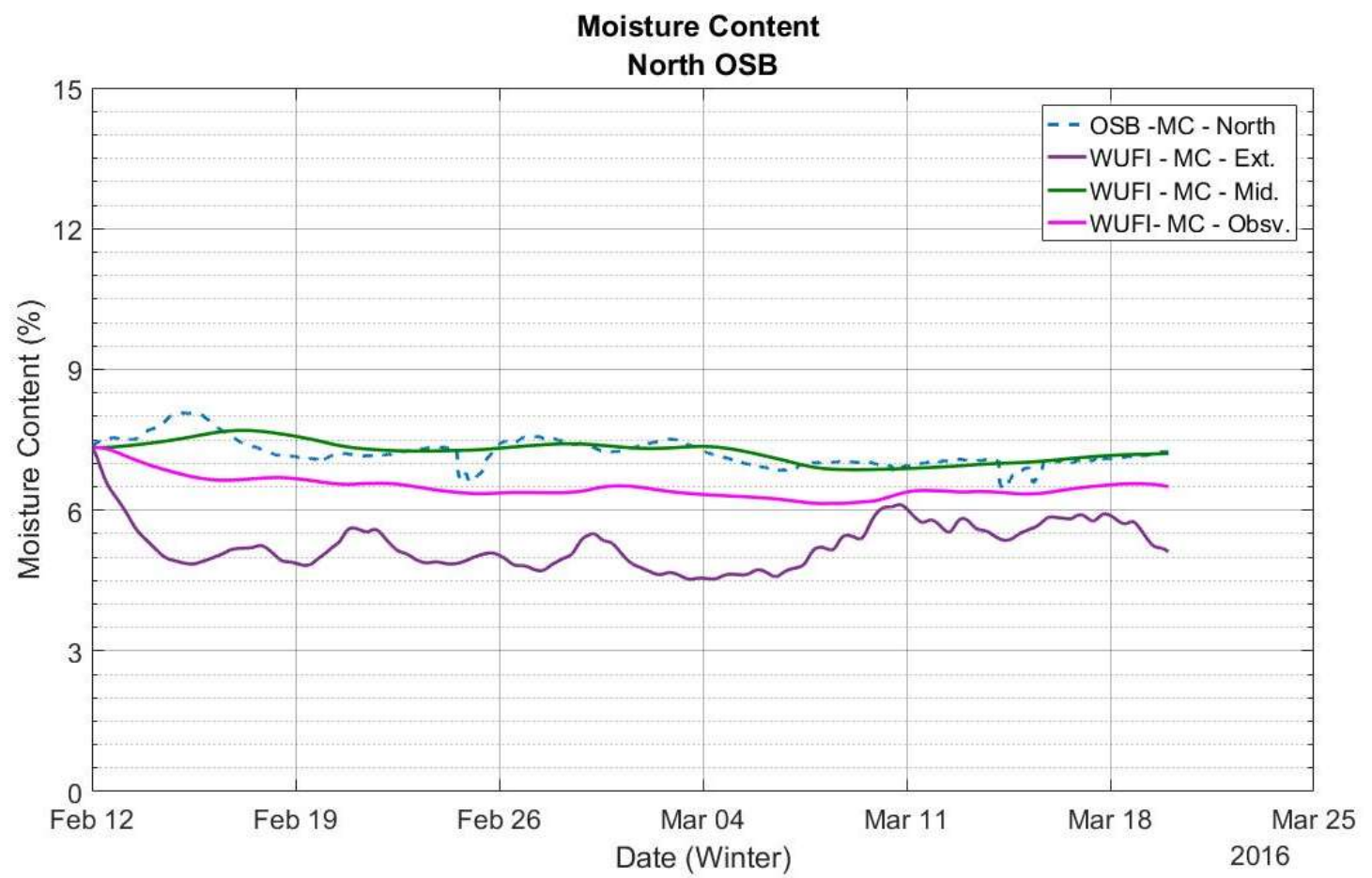

Figure 4-77 : WUFI Calibration vs. Data - North Wall Winter

Figure 4-77 shows a comparison of the calibrated WUFI simulation moisture content of the OSB sheathing to that of the collected data for the north wall during the winter period. The graph above displays that the simulation data, when taken from the middle OSB slice, follows the collected data very closely $(0.22 \%$ RMSE with a $-0.03 \%$ mean bias). However, the observation 
layer, which is used in other simulations is slightly below ( $0.78 \%$ RMSE with a $-0.74 \%$ mean bias) the moisture content of the data. It is possible that the moisture content was read from the middle of the OSB due to insulated pin installation errors.

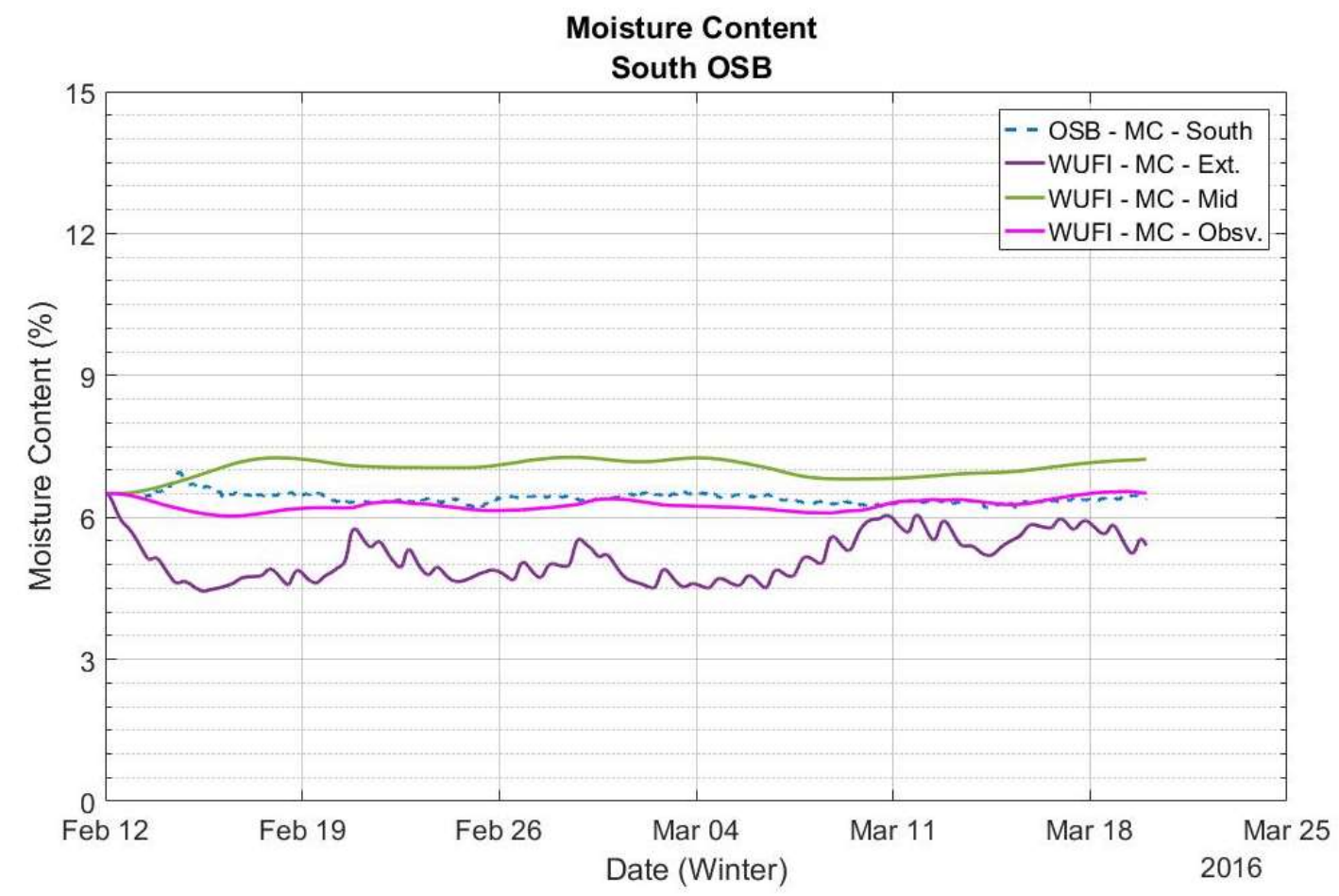

Figure 4-78: WUFI Calibration vs. Data - South Wall Winter

The south wall during the winter months showed a close resemblance $(0.23 \%$ RMSE with a $0.15 \%$ mean bias) to the collected data when the moisture content of the observation layer was extracted from the simulations. The observation layer moisture content was generally slightly less than the collected data yet increased during the end of the collection cycle. A similar trend was found in the north wall. 


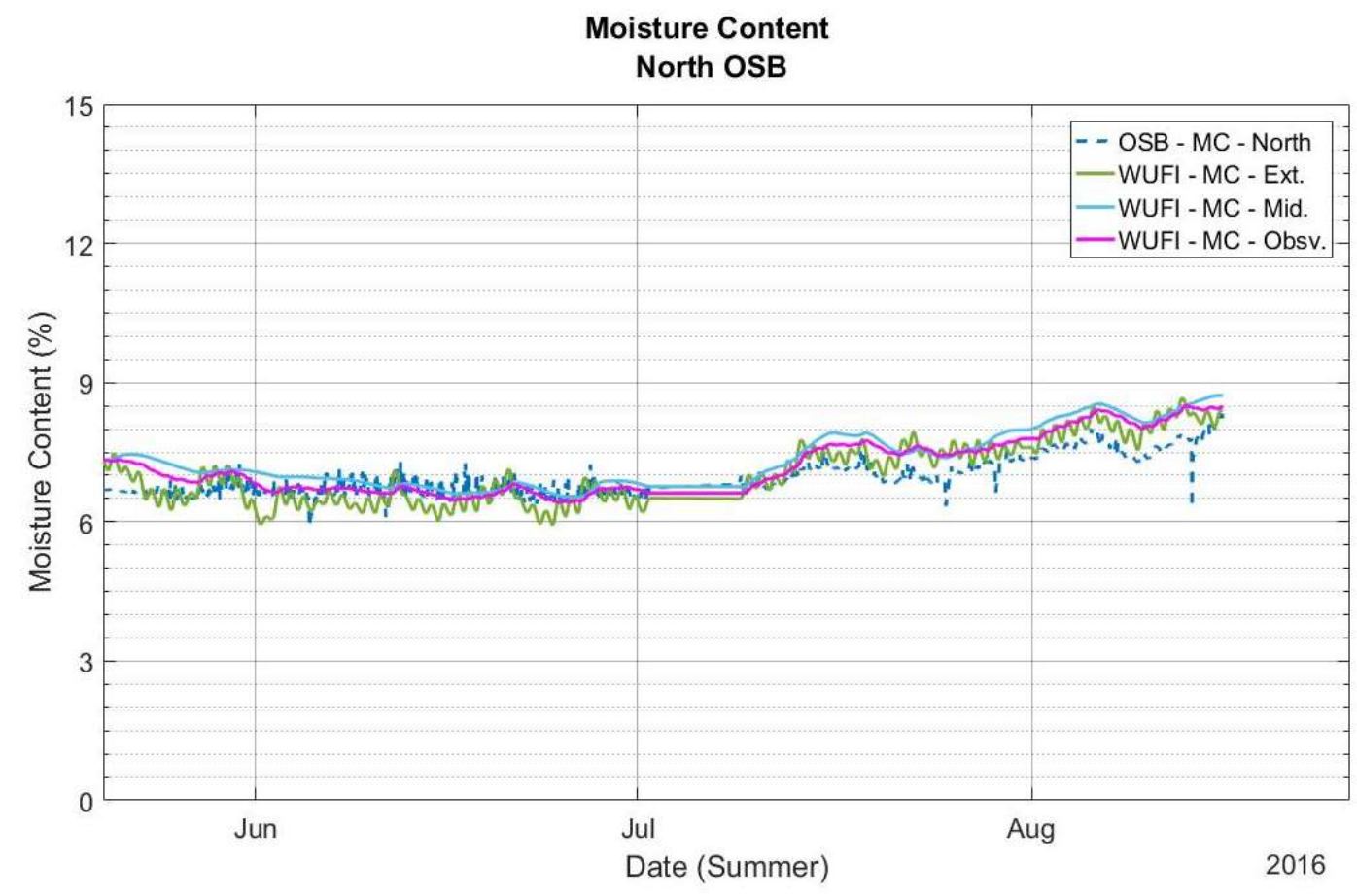

Figure 4-79 : WUFI Calibration vs. Data-North Wall Summer

The moisture content for the north wall during the summer months is shown above. The observation layer exhibits close resemblance to the collected moisture content (0.51\% RMSE with a $+0.26 \%$ mean bias). There was a noticeable convergence of moisture content throughout the OSB layers within the simulation. It is assumed that this is due to the uniformity of the temperature throughout the layers. The collected data was less smooth then the winter months and exhibited greater hourly fluctuations. The general trend of the collected data, however, remained quite constant. The 'noise' within the collected data may be attributed to variations in the electrical supply, variations in the path of the electrical current through the OSB, and hourly fluctuations in the OSB moisture content.

A divergence occurred between the collected data and the simulation data around July $13^{\text {th }}$. The increase shown in the moisture content within the simulation can be attributed to changes in the boundary conditions between the input data for the simulation and the localized conditions of the test structure. The general upward trend and the v-shaped dip at the end of the collection period are closely mimicked by the simulations. The simulation was also able to closely mimic hourly 
variations within the data and the less pronounced daily variations. This can be seen in Figure 480 .

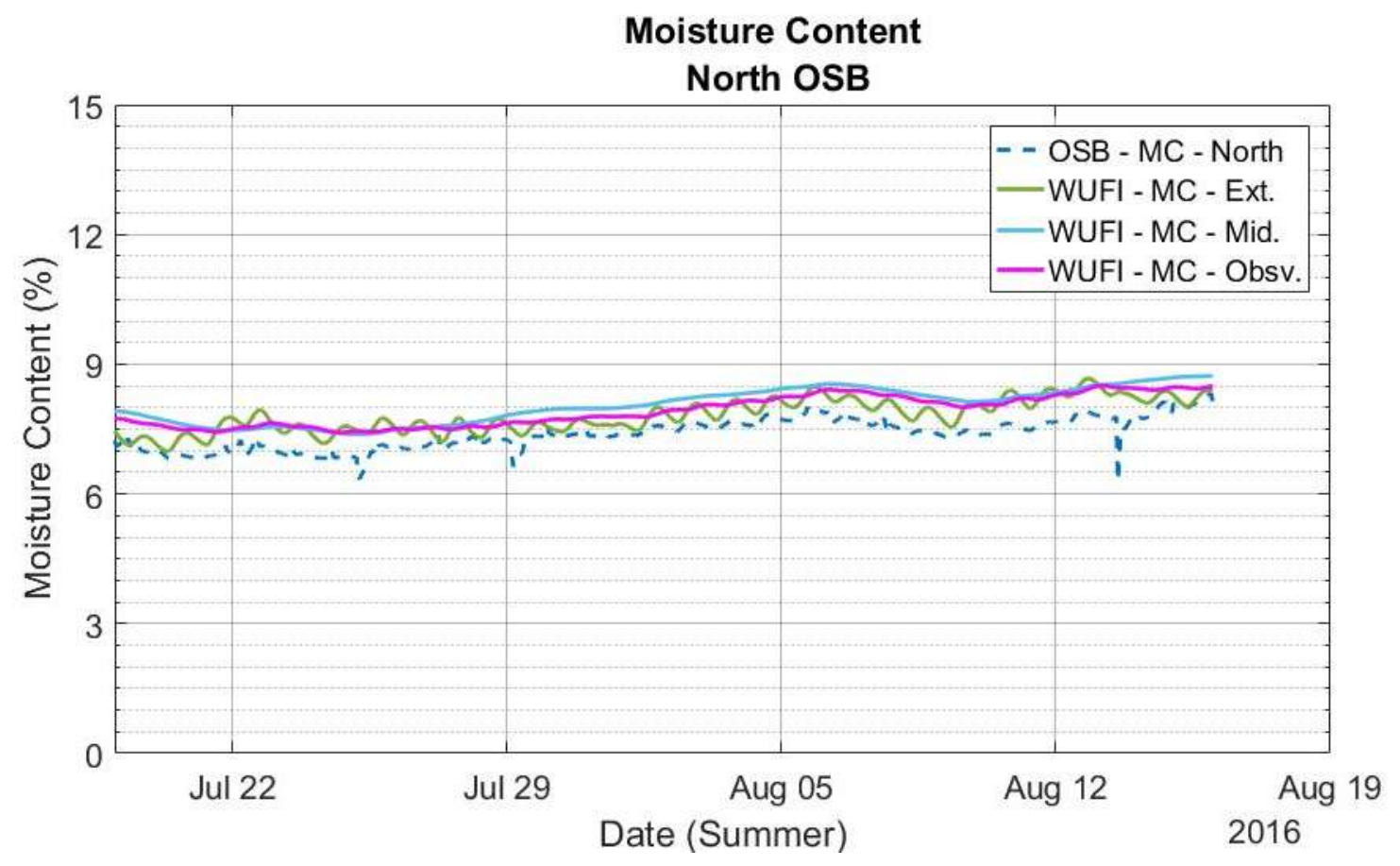

Figure 4-80 : North Wall Summer - Excerpt

The moisture content of the simulation was within $1 \%$ and closely resembled the trends taken by the field data. For these reasons the model was deemed sufficient to accurately reflect the walls behaviour and the WUFI model was considered calibrated. 


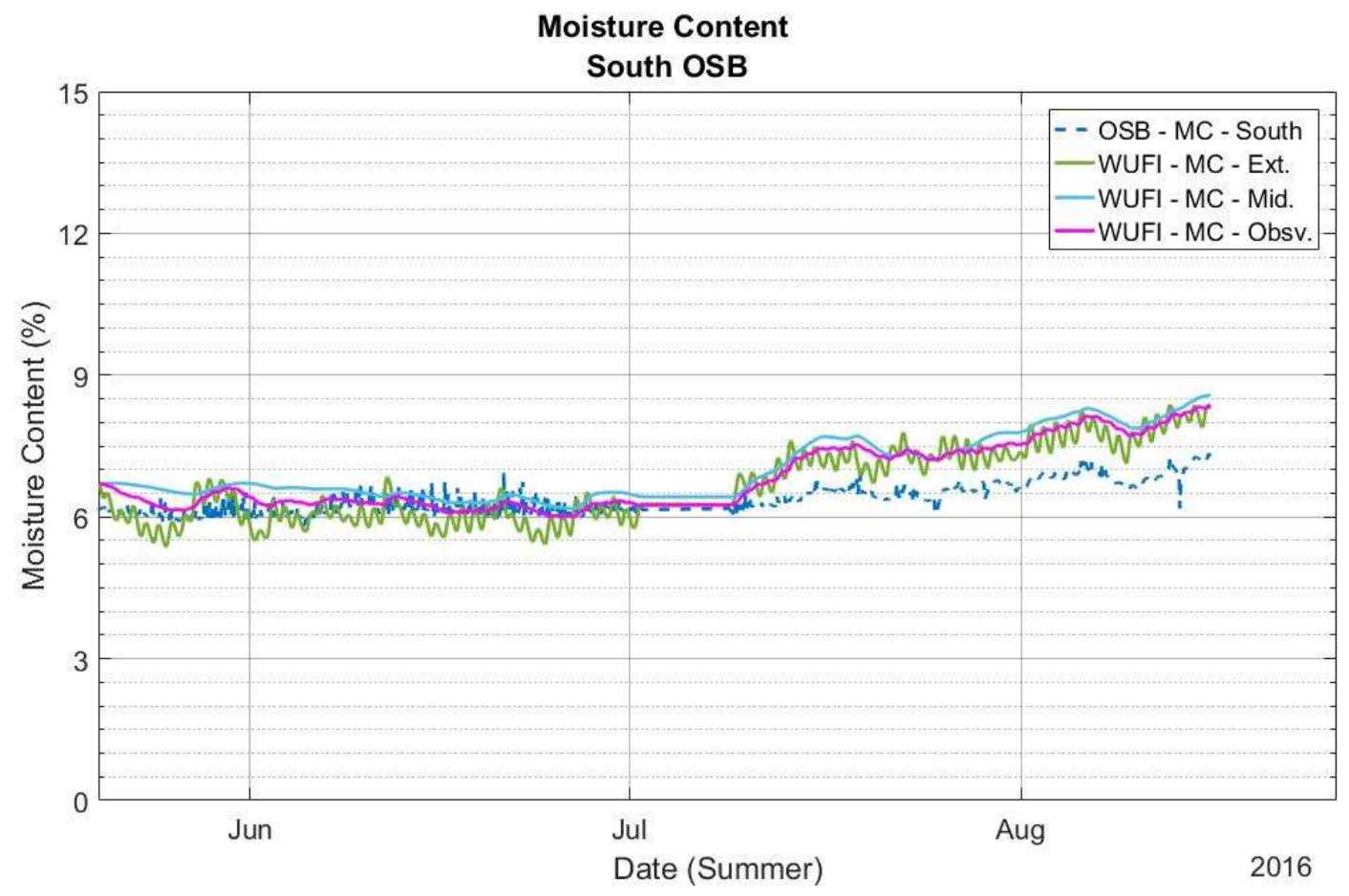

Figure 4-81 : WUFI Calibration vs. Data - South Wall Summer

The simulation data was in close agreement with collected data $(0.79 \%$ RMSE with a $+0.48 \%$ mean bias). The south wall simulation was similar to the north wall however a more pronounced deviation occurred during the later months of the simulation. Again, the reason for this is the difference in boundary conditions entered into the simulation and those experienced by field structure. The south wall experienced a more drastic change in the inputs and localized conditions. This was due to its exposure to direct solar radiation and slight orientation differences.

\subsubsection{Boundary Condition Differences}

During the summer months, there was a wider spread between measured moisture contents and that of the WUFI simulations. It is speculated that the interior conditions inputted into the WUFI simulation did not exactly match the conditions of the test structure. An air conditioning unit was added on June $6^{\text {th }}$ which changed the interior conditions of the hut significantly. The placement of the interior air sensor was inadequate to assess the conditions that existed at each of the wall sensor locations. The sensor was located above the air-conditioning unit and was closer in adjacency then the wall sensors. It can be noted that the temperature of the wall at the 
observation locations on the north and south wall are much higher than expected during the summer months. These local temperature differentials had an impact on the moisture content of the wall and could not be accurately simulated within the WUFI Simulation

\subsubsection{Calibration Summary}

The outcome of the WUFI calibration has provided four files that have been specifically calibrated to represent conditions that occurred at the test structure during specific times of the year for both the north facing wall and the south facing wall. The objective of this stage was to ensure that the models could accurately represent the physical enclosures in field conditions. It has been shown through this section that the models accurately represent the moisture content of the sheathing. These calibrated wall files are used in further analysis to determine suitability in the Toronto climate under varying moisture loading conditions. Testing was also completed for four other North America locations during the parametric analysis.

\subsection{Parametric Analysis}

The parametric analysis determined the possible implications of using this enclosure design and variants of this design, in different cold climates in North America. The analysis also helped determine moisture sensitives of the enclosure with respect to different moisture loading scenarios. A more in-depth analysis of the results in Toronto will be provided. The assessment will include determining at what threshold the variable will cause "failure" within the wall assembly.

\subsubsection{Parametric Analysis Approach}

From the calibration procedure outlined in Section 4.6, four distinct wall models were created; (1) North Wall - Winter, (2) South Wall - Winter, (3) North Wall - Summer, (4) South WallSummer. All surface transfer coefficients and material properties were left "as is" from this procedure, except for cases where materials were substituted. The behaviour of the wall was directly related to the context specific nature of these variables, therefore a change in these variables would result in a behaviour change of the enclosure. This analysis examines the field enclosure in-depth under various climatic and moisture loading scenarios. 
Parameters were identified through literature review that may have impacted on an enclosures' ability to management moisture. These deficiencies were combined with the standard wall calibration and split into three categories; (i) standard wall model (ii) defects in environment/construction, and (iii) changes in construction. The North Wall Winter and North Wall Summer models have been used for (ii) and (iii) except for the brick construction configurations.

i) Standard construction - The standard four wall models have been assessed in the different climates. This analysis will determine if the enclosure is suitable for the climates assessed under a strenuous moisture loading year.

ii) Defects in environment and construction - This category looks at construction and environmental defects. Examples of construction effects include; interior air leakage to the sheathing, exterior air leakage to the sheathing, and driving rain leaks. Environmental defects include an elevated interior relative humidity compared with best practices of $30-50 \% \mathrm{RH}$ and saturated OSB sheathing at time of construction. Parameters for leakage rates have been assessed in a low and high configuration.

iii) Changes in construction - This category investigated potential changes that may be made to the enclosure design. This includes changes to insulation levels and 'interior and exterior' insulation ratios. Potential issues caused by solar vapour drive were explored. This included substituting the light wooden cladding with brick. Brick has the ability for the moisture storage capacity necessary for solar driven vapour issues to occur. The south wall calibration model was used for these cases. Additionally, some cases were run with impermeable layers on the inside and outside to determine impacts of some typical construction practices (e.g. inclusion of an interior vapour retarder).

A relative humidity and temperature index was used to assess moisture sensitivity. This index, known as the RHT index, was developed by the National Research Council of Canada to assess several different types of wall assemblies under various moisture loading scenarios (Beaulieu et. al. (2002). It is also used in the ASHRAE Research Report-1325 titled Environmental Weather Loads for Hygrothermal Analysis and Design of Buildings (Zhang et al., 2011). 
The RHT index is a single value metric and is a combination of the relative humidity and temperature of a material. Limits are set for both $\mathrm{RH}$ and $\mathrm{T}$ (typically above $80 \% \mathrm{RH}$ or $95 \%$ $\mathrm{RH}$ and $5^{\circ} \mathrm{C}$ as these are common values for corrosion and biodegradation). The index evaluates every hour that the selected material experiences conditions above the set threshold and sums up the resultant multiple of the RH and T. The index does not provide a good indication of how the enclosure performs hourly or daily, as extremely high relative humilities and temperatures may skew results. However, the RHT index provides a simple and easy evaluation tool to compare enclosures and simulations comparatively. The RHT index is calculated as shown in Equation 18.

$$
R H T(X)=\Sigma(R H-X) \cdot\left(T-5^{\circ} C\right)
$$

$\mathrm{RHT}(\mathrm{X})=$ Relative humidity and temperature index set to either $80 \% \mathrm{RH}$ or $95 \% \mathrm{RH}$.

$\mathrm{X}=$ Relative humidity threshold.

$\mathrm{RH}=$ Relative humidity $(\%)$

$\mathrm{T}=$ Temperature. $\left({ }^{\circ} \mathrm{C}\right)$

\subsubsection{RHT80 Index}

The RHT80 index results showed an initial comparison of the enclosure under the various loadings. It should be noted that results from this analysis do not necessary indicate the potential for moisture damage. There was some evidence that a relative humidity may induce some corrosive reactions in some metals (Beaulieu, 2002). This metric is generally used for comparison between the different cases and climates.

\subsubsection{RHT95 Index}

The RHT95 index was used as a more stringent comparison tool and there has been evidence that serious moisture damage (decay fungi) is possible when the relative humidity breaches the $95 \%$ threshold (Beaulieu, 2002).

\subsubsection{Parametric Case Description}

Shown in Table 4-27 are the 33 cases that have been selected for analysis for the five cities. 
Table 4-27 : Parametric Cases Descriptions

\begin{tabular}{|c|c|c|c|c|}
\hline $\begin{array}{l}\text { Testing } \\
\text { Category }\end{array}$ & $\begin{array}{c}\text { Case } \\
\#\end{array}$ & Case Name & $\begin{array}{c}\text { Calibrated } \\
\text { Model File } \\
\text { (Season / } \\
\text { Orientation) }\end{array}$ & Description \\
\hline \multirow{4}{*}{$\begin{array}{l}\text { Standard } \\
\text { Cases }\end{array}$} & 1 & $\begin{array}{c}\text { Standard -Winter - North } \\
\text { Wall }\end{array}$ & Winter/North & $\begin{array}{l}\text { ASHRAE YEAR } 1 \text { Climate for Selected } \\
\text { City }\end{array}$ \\
\hline & 2 & $\begin{array}{l}\text { Standard - Winter - } \\
\text { South Wall }\end{array}$ & Winter/South & $\begin{array}{l}\text { ASHRAE YEAR } 1 \text { Climate for Selected } \\
\text { City }\end{array}$ \\
\hline & 3 & $\begin{array}{c}\text { Standard - Summer - } \\
\text { North Wall } \\
\end{array}$ & Summer/North & $\begin{array}{l}\text { ASHRAE YEAR } 1 \text { Climate for Selected } \\
\text { City }\end{array}$ \\
\hline & 4 & $\begin{array}{c}\text { Standard - Summer - } \\
\text { South Wall } \\
\end{array}$ & Summer/South & $\begin{array}{l}\text { ASHRAE YEAR } 1 \text { Climate for Selected } \\
\text { City }\end{array}$ \\
\hline \multirow{12}{*}{$\begin{array}{c}\text { Defect } \\
\text { Conditions }\end{array}$} & 5 & High Indoor Humidity & Winter/North & $\begin{array}{c}\text { Indoor RH Mean: } 60 \% \\
\text { Amplitude: } 10 \%\end{array}$ \\
\hline & 6 & High Indoor Humidity & Summer/North & $\begin{array}{c}\text { Indoor RH Mean: } 60 \% \\
\text { Amplitude: } 10 \%\end{array}$ \\
\hline & 7 & 1\% Rain Leak & Winter/North & $\begin{array}{l}\text { 1\% Driving Rain penetrates to outside of } \\
\text { OSB }\end{array}$ \\
\hline & 8 & 5\% Rain Leak & Winter/North & $\begin{array}{l}5 \% \text { Driving Rain penetrates to outside of } \\
\text { OSB }\end{array}$ \\
\hline & 9 & 1\% Rain Leak & Summer/North & $\begin{array}{l}1 \% \text { Driving Rain penetrates to outside of } \\
\text { OSB }\end{array}$ \\
\hline & 10 & 5\% Rain Leak & Summer/North & $\begin{array}{l}5 \% \text { Driving Rain penetrates to outside of } \\
\text { OSB }\end{array}$ \\
\hline & 11 & $\begin{array}{l}0.016 \mathrm{~L} / \mathrm{s} \cdot \mathrm{m}^{2} \text { Interior Air } \\
\text { Leak }\end{array}$ & Winter/North & $\begin{array}{l}\text { High Indoor RH Conditions (case } 5 \& 6 \text { ) } \\
\text { with simulated air leakage to inside of OSB }\end{array}$ \\
\hline & 12 & $\begin{array}{c}0.084 \mathrm{~L} / \mathrm{s} \cdot \mathrm{m}^{2} \text { Interior Air } \\
\text { Leak }\end{array}$ & Winter/North & $\begin{array}{l}\text { High Indoor RH Conditions (case } 5 \text { \& } 6 \text { ) } \\
\text { with simulated air leakage to inside of OSB }\end{array}$ \\
\hline & 13 & $\begin{array}{l}0.016 \mathrm{~L} / \mathrm{s} \cdot \mathrm{m}^{2} \text { Exterior Air } \\
\text { Leak }\end{array}$ & Winter/North & $\begin{array}{c}\text { Simulated exterior air leakage to exterior of } \\
\text { AB/WB membrane outside of OSB }\end{array}$ \\
\hline & 14 & $\begin{array}{l}0.084 \mathrm{~L} / \mathrm{s} \cdot \mathrm{m}^{2} \text { Exterior Air } \\
\text { Leak }\end{array}$ & Winter/North & $\begin{array}{c}\text { Simulated exterior air leakage to exterior of } \\
\text { AB/WB membrane outside of OSB }\end{array}$ \\
\hline & 15 & $32 \%$ Initial MC & Winter/North & $\begin{array}{l}\text { OSB Sheathing was set to } 32 \% \mathrm{MC} \\
(93 \% \mathrm{RH}) \text { at time of construction. }\end{array}$ \\
\hline & 16 & $32 \%$ Initial MC & Summer/North & $\begin{array}{l}\text { OSB Sheathing was set to } 32 \% \mathrm{MC} \\
(93 \% \mathrm{RH}) \text { at time of construction. }\end{array}$ \\
\hline \multirow{8}{*}{$\begin{array}{l}\text { Changes in } \\
\text { Construction }\end{array}$} & 17 & $\begin{array}{l}\text { Ext Insulation: } 229 \mathrm{~mm} \\
\text { Int. Insulation: } 0 \mathrm{~mm} \\
\end{array}$ & Winter/North & Changes in insulation levels. \\
\hline & 18 & $\begin{array}{l}\text { Ext. Insulation: } 229 \mathrm{~mm} \\
\text { Int. Insulation: } 0 \mathrm{~mm}\end{array}$ & Summer/North & Changes in insulation levels. \\
\hline & 19 & $\begin{array}{l}\text { Ext Insulation: } 229 \mathrm{~mm} \\
\text { Int. Insulation: } 140 \mathrm{~mm}\end{array}$ & Winter/North & Changes in insulation levels. \\
\hline & 20 & $\begin{array}{l}\text { Ext Insulation: } 229 \mathrm{~mm} \\
\text { Int. Insulation: } 140 \mathrm{~mm}\end{array}$ & Summer/North & Changes in insulation levels. \\
\hline & 21 & $\begin{array}{l}\text { Ext Insulation: } 152 \mathrm{~mm} \\
\text { Int. Insulation: } 0 \mathrm{~mm} \\
\end{array}$ & Winter/North & Changes in insulation levels. \\
\hline & 22 & $\begin{array}{l}\text { Ext Insulation: } 152 \mathrm{~mm} \\
\text { Int. Insulation: } 0 \mathrm{~mm} \\
\end{array}$ & Summer/North & Changes in insulation levels. \\
\hline & 23 & $\begin{array}{l}\text { Ext Insulation: } 152 \mathrm{~mm} \\
\text { Int. Insulation: } 140 \mathrm{~mm}\end{array}$ & Winter/North & Changes in insulation levels. \\
\hline & 24 & $\begin{array}{l}\text { Ext Insulation: } 152 \mathrm{~mm} \\
\text { Int. Insulation: } 140 \mathrm{~mm}\end{array}$ & Summer/North & Changes in insulation levels. \\
\hline
\end{tabular}




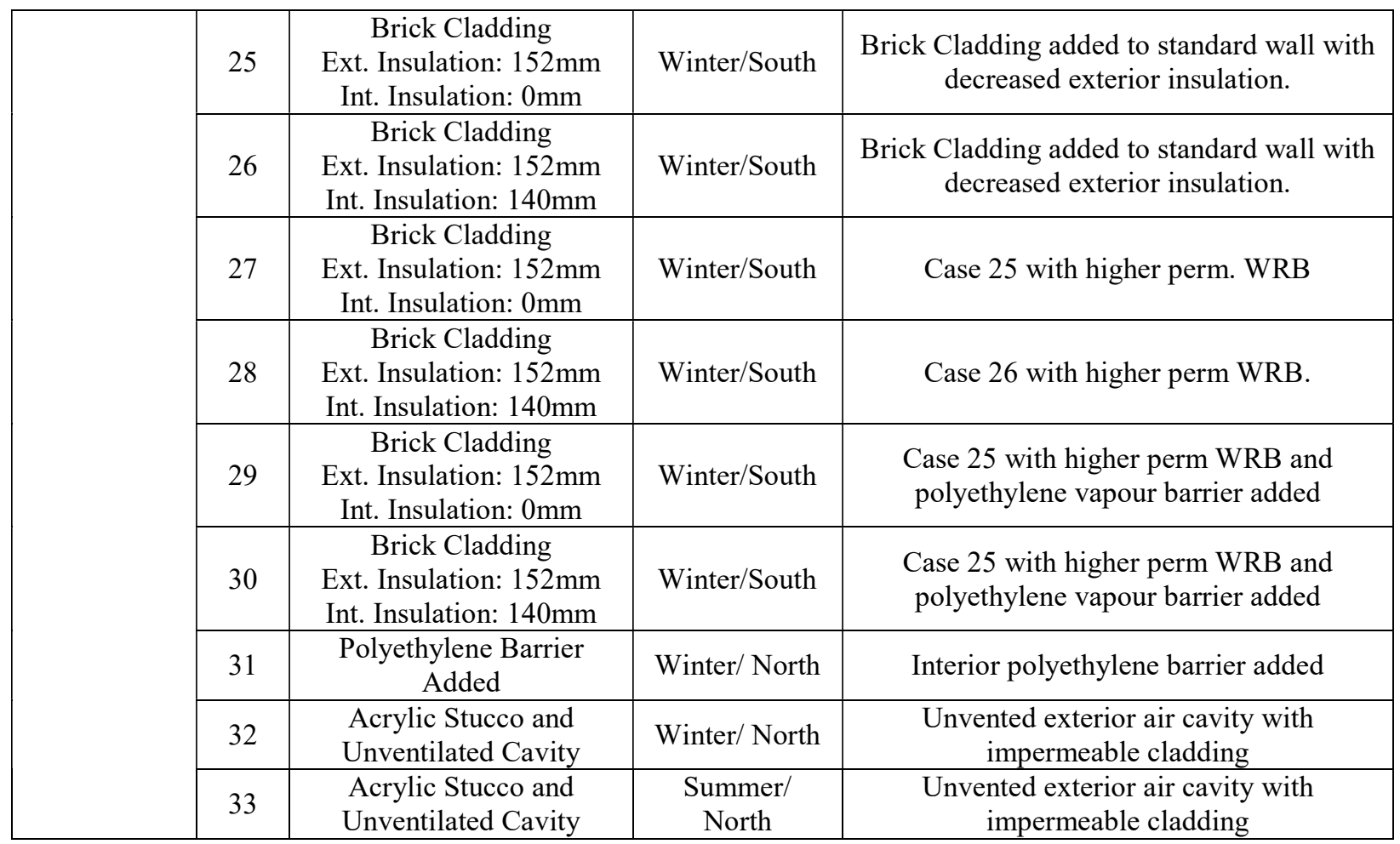

It should be noted that these cases try to identify one or two factors that influence the enclosures ability to handle moisture management, while it is often a combination of several factors that work together against an enclosures ability to handle moisture. Further description on some cases is provided below.

\subsubsection{Cases 11-14 Air Leakage}

Cases 11-14 simulated air leakage within the building envelope. To simulate these air leakages a $1 \mathrm{~mm}$ air layer was inserted on either on the inside or outside of the sheathing depending on direction of air leakage. The air layer for exterior air leakage was placed on the exterior side of the AB/WB. ASHRAE 160 (ASHRAE, 2009b) identifies common air leakage rates of $0.016 \mathrm{~L} / \mathrm{sm}^{2}$ and $0.084 \mathrm{~L} / \mathrm{sm}^{2}$. The air leakage rates were converted to $\mathrm{ACH}, 58$ and 302 respectively, for the $1 \mathrm{~mm}$ thick layer.

\subsubsection{5. $\quad$ Simulated Rain and Rain Leaks}

The rain load was calculated in WUFI by selecting the short building type. The default rain load calculations were left for the parameter analysis. This applies a $0.07 \mathrm{~m} / \mathrm{s}$ factor to the calculated wind velocity (wind speed and wind direction derivative) and is multiplied by the total horizontal accumulated rain. The rain leaks were calculated as a percentage of this rain load. 


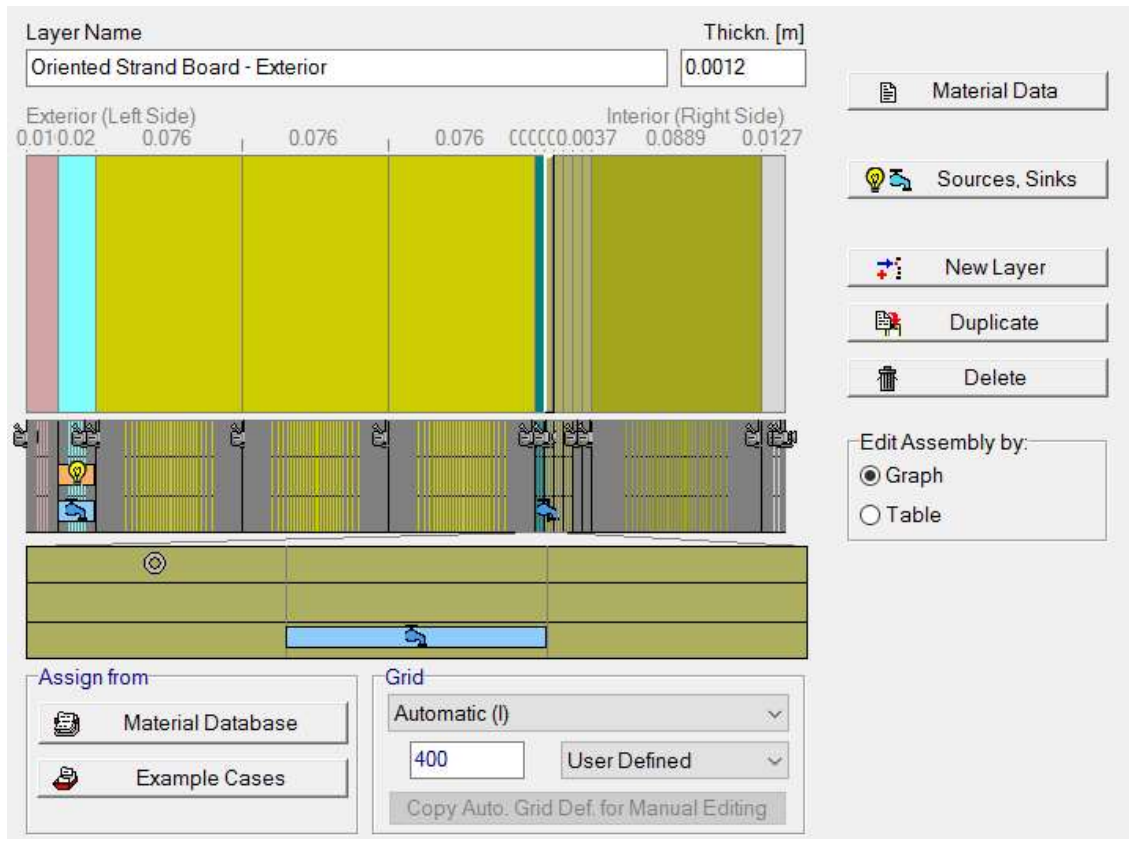

Figure 4-82 : Simulated Rain Leak Location

A water source was placed in the exterior layer of the OSB sheathing within WUFI-Pro to simulate a rain leak in cases 7-10. The leak was placed in the middle of the $1.2 \mathrm{~mm}$ exterior OSB layer. The 'leak' was adjusted to $1 \%$ or $5 \%$ of the driving rain that fell on the respective orientated façade. In some climates, such as St. John's, the 5\% rain leak deposited a volume of water greater than the storage capacity of the OSB. In these cases, WUFI does not release the excess moisture. This unreleased moisture may cause significant changes in the results from the simulated cases. Further explanation of this case can be found in Section 4.7.3.4: St. John's.

\subsubsection{Orientation Selection}

The majority of cases have been simulated with a direct north orientation, except for cases 2 and 4 and 25-30. The "standard" or calibrated wall files needed to be assessed in both orientations, while cases 25 to 30 relay on solar radiation as a moisture driving force. The north orientation typically exhibited the worst moisture management of the orientations due to the lack of direct solar radiation (in the northern hemisphere). The ASHRAE RP-1325, simulated northern facing walls to determine the 'design moisture reference year' and therefore similar trends should be exhibited in these simulation scenarios. It should be noted that north orientation does not necessary provide the worst-case scenario, site context and direction of driving rain play a large factor in moisture management. This can be seen in the results from Calgary. 


\subsubsection{Outdoor Climate Selection}

The outdoor climate is a very important parameter when assessing a wall for its moisture management ability. The outdoor climate not only provides the source of moisture from the outside, but also may influence the interior conditions experienced by the enclosure. It is a major driver of moisture and energy through the enclosure; therefore, selecting a suitable exterior climate file for analysis is important. To critically assess the enclosure an extreme climate condition was selected for analysis.

The climate files were selected from the ASHRAE Research Report-1325 (Zhang et. al., 2011). The 'worst' moisture design year was selected from a 30-year data set and was used for each location. Use of the YEAR-1 ASHRAE RP-1325 climate file considers a 1/30-year worst case situation and can be considered as a strenuous load compared with typical conditions. The exterior climate file was used throughout the six-year simulation period.

\subsubsection{8. $\quad$ Selected Locations}

Five cities have been selected to assess the enclosure approach. The cities have been selected to represent varied climates within North America. The five cities and information about their climates are found in Table 4-28 and described below. 
Table 4-28 : Parametric Climate Locations

\begin{tabular}{|c|c|c|c|c|c|c|}
\hline Municipality & Lat. & Long. & $\begin{array}{c}\text { ASHRAE } \\
\text { Climate } \\
\text { Zone }\end{array}$ & HDD18.3 & CDD18.3 & $\begin{array}{c}\text { Mean } \\
\text { Precipitation } \\
\text { (mm) }\end{array}$ \\
\hline $\begin{array}{c}\text { Toronto, } \\
\text { Ontario }\end{array}$ & $43.68 \mathrm{~N}$ & $79.63 \mathrm{~W}$ & $\begin{array}{c}\text { Zone 5 } \\
\text { (A) Moist }\end{array}$ & 3892 & 292 & 780 \\
\hline $\begin{array}{c}\text { St. John's, } \\
\text { Newfoundland }\end{array}$ & $47.62 \mathrm{~N}$ & $52.74 \mathrm{~W}$ & Zone 6 & 4848 & 90 & 1547 \\
\hline $\begin{array}{c}\text { Calgary, } \\
\text { Alberta }\end{array}$ & $51.11 \mathrm{~N}$ & $114.02 \mathrm{~W}$ & $\begin{array}{c}\text { Zone 7 } \\
\text { (B) Dry }\end{array}$ & 5052 & 36 & 425 \\
\hline $\begin{array}{c}\text { Vancouver, } \\
\text { British } \\
\text { Columbia }\end{array}$ & $49.20 \mathrm{~N}$ & $123.18 \mathrm{~W}$ & $\begin{array}{c}\text { Zone 4 } \\
\text { (C)Marine }\end{array}$ & 2903 & 44 & 1209 \\
\hline $\begin{array}{c}\text { Fairbanks, } \\
\text { Alaska }\end{array}$ & $64.82 \mathrm{~N}$ & $147.86 \mathrm{~W}$ & Zone 8 & 7509 & 40 & 349 \\
\hline
\end{tabular}

*Information from ASHRAE Fundamentals 2013 (ASHRAE, 2009)

Toronto - Toronto represents a varied cold and warm climate with the highest cooling degree days of the set. Humidity can reach high levels during summer months and the city has the third highest amount of precipitation per year. Warm temperatures and high humidity can cause moisture issues during the summer months in low-energy building types.

St. John's - This is a very wet and cold climate. St. John's experiences the most precipitation per year of all the cities and has the third most HDD. The combination of cold and precipitation can limit the drying potential of enclosure and therefore can create conditions for mould and mildew conditions.

Calgary - Calgary represents a building in climate zone 7 in a dry climate. The extreme colds reached in Calgary may cause dew point issues, however the dry climate provides the ability for drying. Calgary has the second highest HDD and the second lowest amount of precipitation.

Vancouver - Represents a temperate climate with high levels of precipitation. Many buildings have experienced moisture issues due to rain leakage in the past. The combined humidity, precipitation and warm temperatures can lead to fast levels of degradation. Vancouver has the lowest HDD and the second highest amount of precipitation.

Fairbanks - Fairbanks has the highest amount of HDD and represents an extreme cold climate. The extreme cold can force the dew-point temperature inward in the enclosure however can also limit the implications of mould/mildew growth due to the decreased temperatures. Fairbanks 
receives little precipitation during the year and has the lowest amount of the five selected climates.

\subsubsection{Interior Climate}

The indoor climate is the other boundary condition that drives moisture and energy through the enclosure. The 'ASHRAE 160' method in WUFI-Pro was selected for to generate indoor conditions. This method applies modification formulas to the exterior climate and includes some user set parameters to generate the interior climate. However, cases 5-6 and cases 11-12 use a sinusoidal curve for heat and relative humidity. Table 4-29 outlines the user set parameters set for the cases.

Table 4-29: Interior Climate Variables

\begin{tabular}{|c|c|c|c|c|c|c|c|c|}
\hline \multirow[b]{2}{*}{ Cases } & \multirow[b]{2}{*}{$\begin{array}{c}\text { Set } \\
\text { Conditioning } \\
\text { Type }\end{array}$} & \multicolumn{4}{|c|}{ Conditioning System } & \multicolumn{3}{|c|}{ Relative Humidity } \\
\hline & & $\begin{array}{l}\text { Floating } \\
\text { Indoor } \\
\text { Temp } \\
\left({ }^{\circ} \mathrm{C}\right)\end{array}$ & $\begin{array}{c}\text { Set Point } \\
\text { for Heating } \\
\left({ }^{\circ} \mathrm{C}\right)\end{array}$ & $\begin{array}{l}\text { Set Point } \\
\text { for } \\
\text { Cooling } \\
\left({ }^{\circ} \mathrm{C}\right)\end{array}$ & $\begin{array}{c}\text { RH } \\
\text { Control } \\
\text { Set Point } \\
(\%)\end{array}$ & $\begin{array}{c}\text { Moisture } \\
\text { Generation } \\
\text { Rate }(\mathrm{kg} / \mathrm{s})\end{array}$ & $\begin{array}{c}\text { Air } \\
\text { Exchange } \\
\text { Rate (1/h) }\end{array}$ & $\begin{array}{c}\text { Building } \\
\text { Volume } \\
\left(\mathbf{m}^{3}\right)\end{array}$ \\
\hline \multirow[t]{3}{*}{$\begin{array}{c}1-4,6- \\
10,13- \\
33 \\
\end{array}$} & $\begin{array}{c}\text { AC with } \\
\text { Dehumidification }\end{array}$ & 2.8 & 21.1 & 24.0 & 55 & 0.000131 & 0.2 & 500 \\
\hline & & \multicolumn{3}{|c|}{ Temperature } & & \multicolumn{3}{|c|}{ Relative Humidity } \\
\hline & & $\begin{array}{l}\text { Mean } \\
\text { Temp } \\
\left({ }^{\circ} \mathrm{C}\right)\end{array}$ & $\begin{array}{l}\text { Amplitude } \\
\left({ }^{\circ} \mathrm{C}\right)\end{array}$ & $\begin{array}{l}\text { Day of } \\
\text { Max. }\end{array}$ & & $\begin{array}{l}\text { Mean RH } \\
(\%)\end{array}$ & $\begin{array}{l}\text { Amplitude } \\
\text { (\%) }\end{array}$ & $\begin{array}{l}\text { Day of } \\
\text { Max }\end{array}$ \\
\hline $\begin{array}{c}5-6,11- \\
12 \\
\end{array}$ & $\begin{array}{l}\text { Sinusoidal } \\
\text { Curves }\end{array}$ & 21.0 & 3.0 & Aug/01 & & 60 & 10 & Aug/01 \\
\hline
\end{tabular}

\subsubsection{Parametric WUFI Pro Variables}

Several variables within the WUFI simulation had to be adjusted to allow for a more ubiquitous analysis. Outlined below are several of the changes made within the WUFI simulations for the parametric analysis.

\subsubsection{Material Properties}

Most material properties were determined from the calibration procedure; however, some new materials were introduced into the enclosure assembly. WUFI default material properties were used for this analysis. A list of material properties used in the parametric analysis (that differ from the calibration procedure) can be found in Appendix K. 


\subsubsection{Initial Moisture Content}

Each material has been set to a moisture content equivalent of $80 \% \mathrm{RH}$ in equilibrium in accordance with ASHRAE 160 (i.e. dried and reasonably sheltered from weather during storage) except for cases 15-16, where the OSB sheathing has been set to $93 \% \mathrm{RH}$. The $80 \% \mathrm{RH}$ starting condition ensures that the materials had a significant amount of moisture initially and allowed assessment of drying or wetting of the enclosure.

\subsubsection{Air Cavity $\mathrm{ACH}$}

Due to the unpredictable nature of the air cavity in terms of air exchange with the outdoors a constant $\mathrm{ACH}$ had to be set. The calibration analysis revealed that this variable change drastically and is highly erratic. The ACH has been set to 50 in all cases except for in cases 3233. The value of 50 has been recommended by WUFI-PRO (WUFI, 2016).

\subsubsection{Simulation Period}

A period of six years has been chosen to assess the different cases. The six-year time frame should allow the enclosures to equalize with the boundary conditions repeatable. Equalization can be defined as a multi-year moisture and energy balance between the materials in the enclosure and the boundary condition. The six-year period should allow analysis of any longterm wetting or drying trends of the enclosure to be exposed.

\subsubsection{Moisture Sensitivity Assessment Procedure}

An initial assessment of the results occurred in WUFI prior to further analysis. This assessment included defining the layer of OSB that had the highest relative humidity and temperature. The interior and exterior layers of the OSB sheathing were monitored at $0.2 \mathrm{~mm}$ from the exterior and $0.6 \mathrm{~mm}$ from the interior. This selection was then imported into MATLAB for the RHT index assessment. In some cases, it was not possible to visually assess the layers as exemplified below. In these cases, both the interior and exterior layers were brought in MATLAB for further processing. The layer that exhibited the highest RH within WUFI was then selected as the worst case. RHT80 and RHT95 results from all 33 cases and 5 different cities was then generated based on this worst-case sheathing layer. 


\subsubsection{Air Layer Simulation Errors}

It was noted during analysis that numerous cases exhibited large spikes in relative humidity within the OSB. The spikes were often sporadic and may have only occurred once or twice during the six-year simulation period. Further investigation revealed that extensive errors were occurring in the vented air cavity layer. Moisture and temperature balancing equations used by WUFI were not converging in this air layer.

The vented air cavity layer material was selected as "Air-Layer; without additional moisture capacity" for the initial parametric analysis. The non-convergence cases resulted in extremely unrealistic moisture contents within this vented air-cavity layer. In some instances, the moisture content of the layer exceeded $600 \mathrm{~kg} / \mathrm{m}^{3}$. These unrealistic moisture contents had implications of the RH of the OSB.

Numerical grid sizes were changed from 100 to 400 or more for cases that experienced this error. Often this satisfied the calculation errors by providing WUFI finer elements for balancing. However, in limited cases this did not solve the error. The air layer material was switched to the standard "Air Layer". The simplified material allowed WUFI the ability for equation balancing. An example case is provided below to demonstrate the differences between grid size selection and simplified material

\section{Toronto}

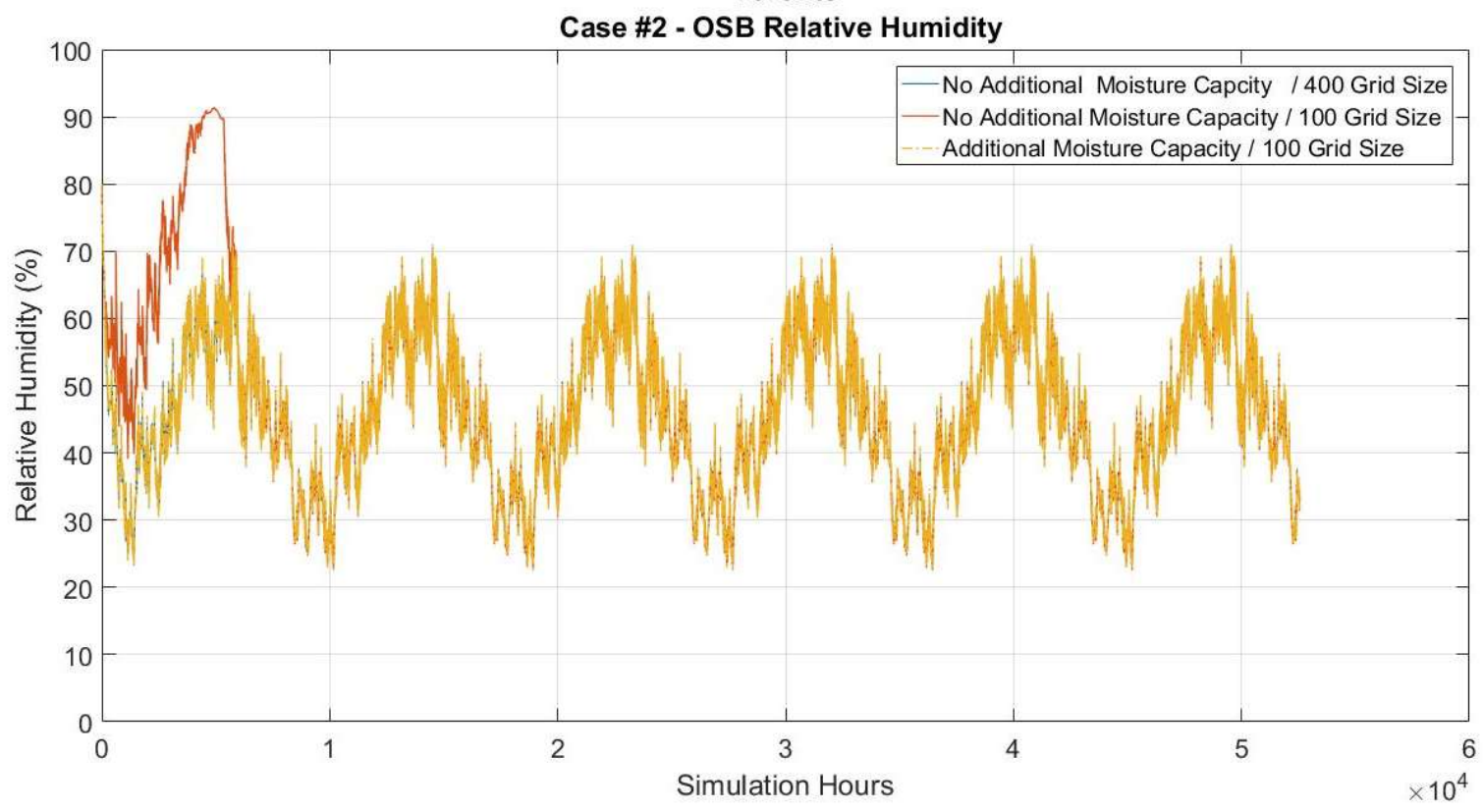

Figure 4-83 : RH of OSB Layer with Two Types of Air Layers

Figure 4-83 shows the relative humidity of the exterior layer of the OSB sheathing with three different air cavity layer configurations. The orange peak that reaches $90 \% \mathrm{RH}$ occurs when the air layer material 
was of the type, "No additional moisture capacity" and the numerical grid was set to 100 divisions. The spike in OSB relative humidity was caused by a convergence failure within the air cavity layer. The moisture content of the air cavity layer exceeded realistic levels and caused an increase in the relative humidity within the OSB sheathing. To correct this, the numerical grid was increased to 400 for a finer equation balance. The material "Air Layer - With additional moisture Capacity" was also selected. Results (Table 4-30) between the finer numerical grid and the simpler material choice gave very similar results for the relative humidity of the OSB.

Table 4-30 : Error and Accuracy of Air Layer Changes

\begin{tabular}{|l|l|l|}
\hline Grid Size & $\begin{array}{l}\text { Mean Difference with } \\
\text { Additional Moisture Content }\end{array}$ & $\begin{array}{l}\text { RMSE With Additional } \\
\text { Moisture Capacity }\end{array}$ \\
\hline 400 & 0.940 & 0.2901 \\
\hline 100 & -2.3771 & 8.0273 \\
\hline
\end{tabular}

\subsubsection{Parametric Analysis Results}

This section will outline the results from the parametric analysis for all cities. Only select cases will be discussed in depth. This is a comparative analysis and it should be noted that results do not necessarily equate to wall failure. Specific results from each city will be explored briefly.

\subsubsection{RHT80 Results}

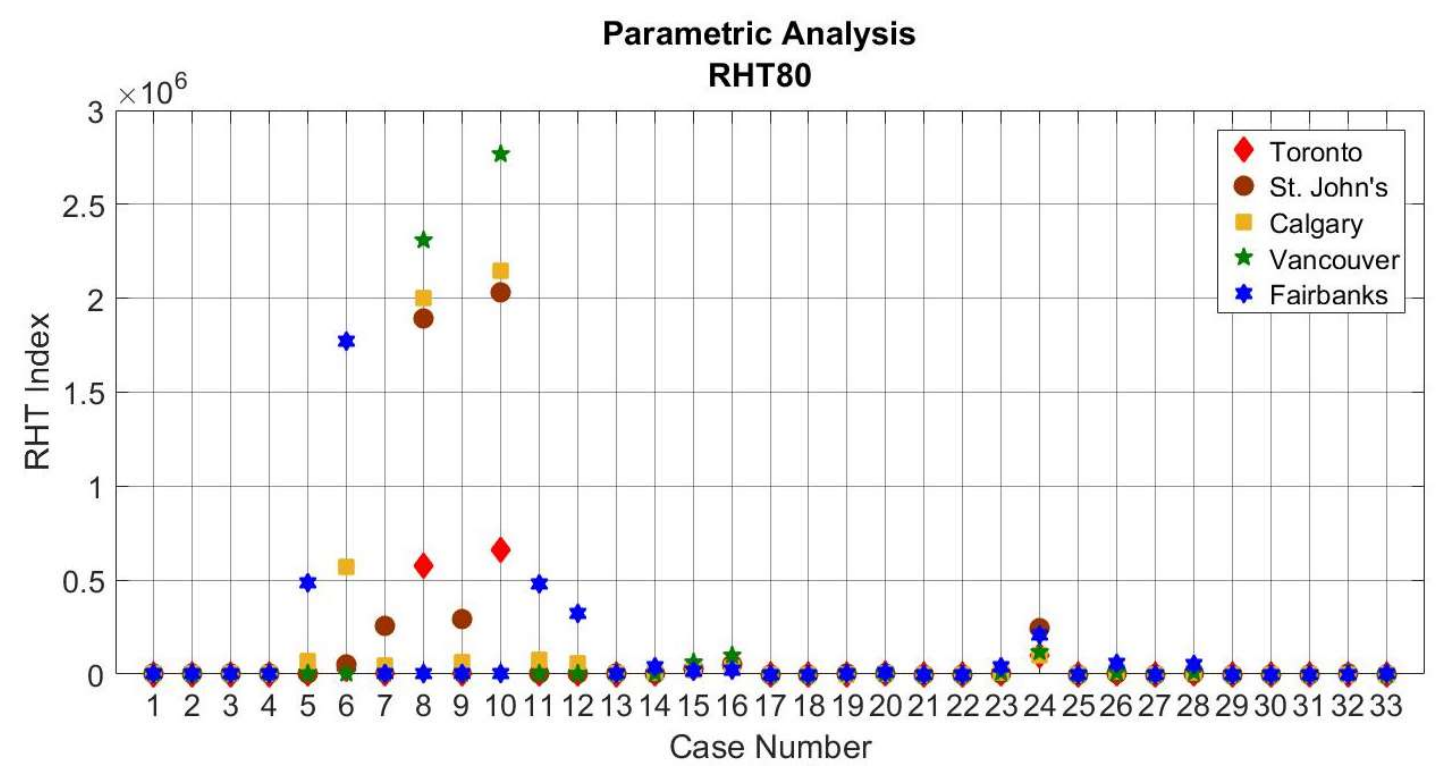

Figure 4-84:Parametric RHT80 Results 
Shown in Figure 4-84 are the results for the parametric analysis for each city. Results from simulations appear normal, except for the high RHT index for cases 8 and 10 for Calgary. These cases are explored in depth further on. The numerical results Table can be found in Appendix L. The worst performing cases for every city, except for Fairbanks, were cases 8 and 10, which represent the $5 \%$ driving rain leak. The $1 \%$ driving rain cases performed significantly better and only St. Johns and Calgary had noticeably high RHT80 values. The impact of driving rain is explored further in the Toronto results section.

The standard wall cases 1-4 performed well in all climates. The RHT80 threshold was breached in all cities except Toronto; however, the RHT80 index is low with a maximum value of 1,460 in Vancouver for case 3. Relative to the other cases this value is extremely low.

Cases 5, 6 and 11 were the worst cases for Fairbanks. The high indoor humidity cases (5-6, 1112) performed worse in the extreme cold climates of Calgary and Fairbanks. Of interest is the reduction in RHT80 with an increased interior air leakage. This will be expanded upon in the Fairbanks analysis. The humidity of the interior air should be adequately controlled in extreme cold climates to mitigate any damage to walls. The exterior air leakage cases 13 and 14 had relatively low results except for case 14 in Fairbanks which had a value of 40,160. The extreme cold exterior air is reducing the temperature of the sheathing resulting in higher humidity at the interior of the sheathing.

Cases 15-16 represent built-in moisture of the sheathing and essentially exemplify the ability of the enclosure to dry out. The Vancouver simulations exhibit the slowest drying rate of any of the climates. All the assemblies manage to dry and none accumulate moisture as exemplified by the RHT95 results.

Cases 23-24 performed the worst in the "Changes in construction" categories. These cases represent $152 \mathrm{~mm}$ of external insulation with $140 \mathrm{~mm}$ of internal insulation. This shift in insulation ratios causes a reduction in the temperature of the sheathing which results in higher humidity and subsequently reduces drying potential. The best performing cases for this category are cases 17-18, 21-22, 25, 27, 29-31. These cases did not breach the RHT80 threshold in any climate. They represent the cases with exclusive external insulation, except for case 31 , which has a polyethylene barrier included into construction. The sheathing is maintained at a temperature and relative humidity close to the interior air conditions. This allows for excellent 
moisture management as the vulnerable wood sheathing can maintain equilibrium with the interior conditions.

A polyethylene barrier has been placed in the construction in cases 29-31, with case 31 being of standard construction. The introduction of a poly-barrier indicates that the majority of moisture flow is from the interior to the exterior and moisture diffusion is limited by this barrier. This is exemplified in case 30 which is similar to cases 28 and 24; however, the inclusion of the polyethylene barrier inhibits the wall from breaching the RHT80 threshold. It is recommended that a polyethylene barrier is included in future simulations as it impacts the drying potential of the wall assembly. For example, cases 32-33 have an impermeable exterior cladding and an unvented air cavity yet perform well under the RHT80 index. These results indicate that limited moisture is reaching the sheathing or that moisture is drying to the interior. A polyethylene barrier would significantly reduce the potential for inward drying.

It should be noted that the 'summer' condition for the enclosure preformed worse than the 'winter' condition in every scenario. In some cases, this caused drastic differences between results, for example the cases 5-6 and 23-24 show that the WUFI variables significantly differentiate results between 'winter' and 'summer' coefficients. The differences are due to the surface transfer variables and material properties. The 'winter' conditions have a higher external thermal resistance and lower internal thermal resistance causing the temperature of the sheathing to be much higher. Summer conditions have lower external thermal resistance and higher internal thermal resistance causing the temperature of the sheathing to be lower. This lowered sheathing temperature may result in OSB higher humidity. This is exemplified in the colder climates of Calgary and Fairbanks. 


\subsubsection{RHT95 Results}

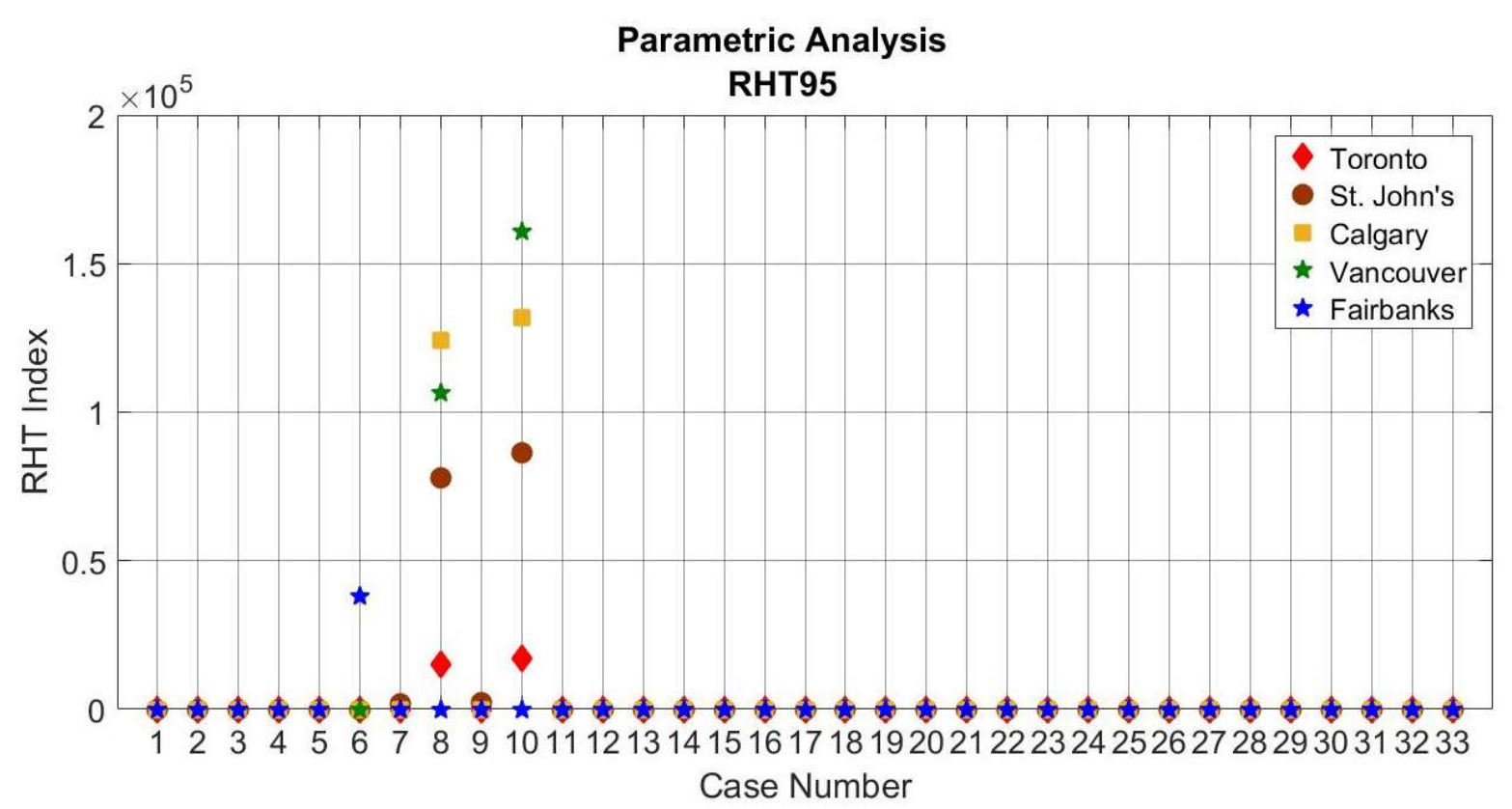

Figure 4-85 : Parametric Analysis RHT95 Results

The RHT95 analysis reveals that only several cases exceeded the RHT95 threshold. These cases include Case 6 in Fairbanks, Cases 7 and 9 in St. John's, and Cases 8 and 10 in all cities except for Fairbanks. Breaching the RHT95 threshold indicates potential for moisture damage. The rain penetration cases indicated that proper water detailing is required even with a vapour open assembly. The direct application of significant amounts of moisture will cause deterioration of any vulnerable enclosure.

Case 6 indicates the importance of controlling the indoor humidity of a highly-insulated building in arctic conditions. The high interior humidity is being driven outwards by a large vapour pressure difference and the temperature at the sheathing is causing an increase in humidity levels. 


\subsubsection{Calgary, Alberta}

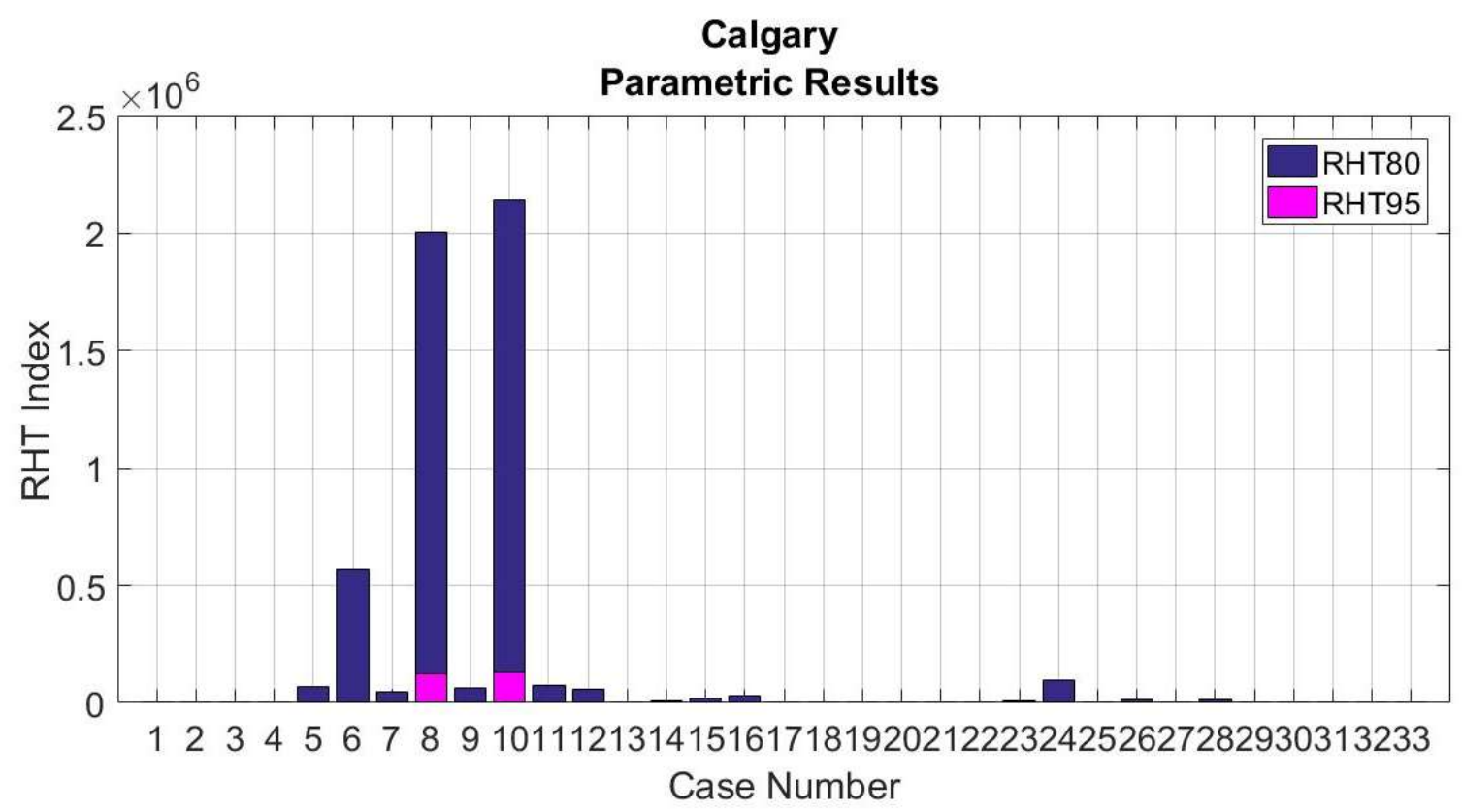

Figure 4-86: Parametric Calgary Results

Figure 4-86 shows the results from the Calgary parametric analysis. As discussed above the driving rain cases have a significant impact on the RHT80 index and RHT95 index. Even though Calgary has relatively little precipitation as compared with cities such as Vancouver, St. Johns, and even Toronto, the direction of the driving rain causes significant accumulation within the envelope. The primary direction of driving rain was from the north and Northwest in 
Calgary. The north orientation was selected to simulate for rain penetration cases and this caused more rain to accumulate into the assembly in Calgary.

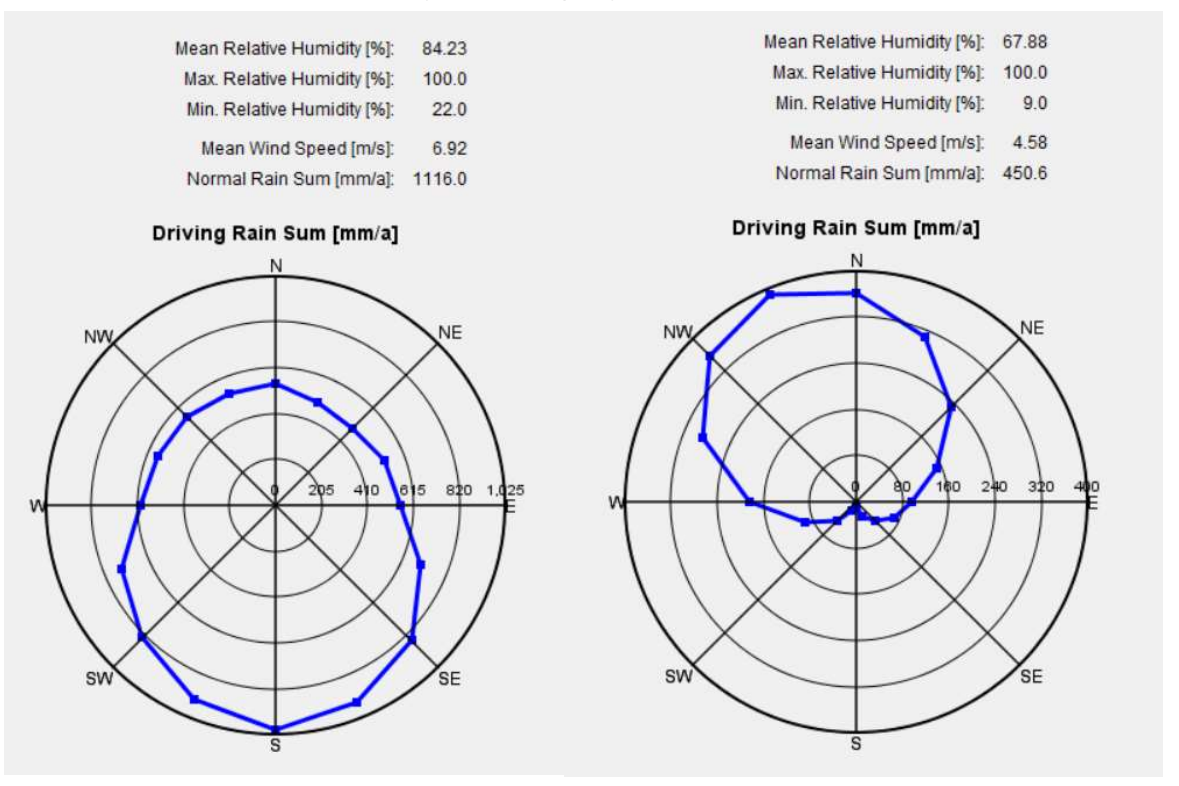

Figure 4-87 : Driving Rain Directions - St. Johns / Calgary

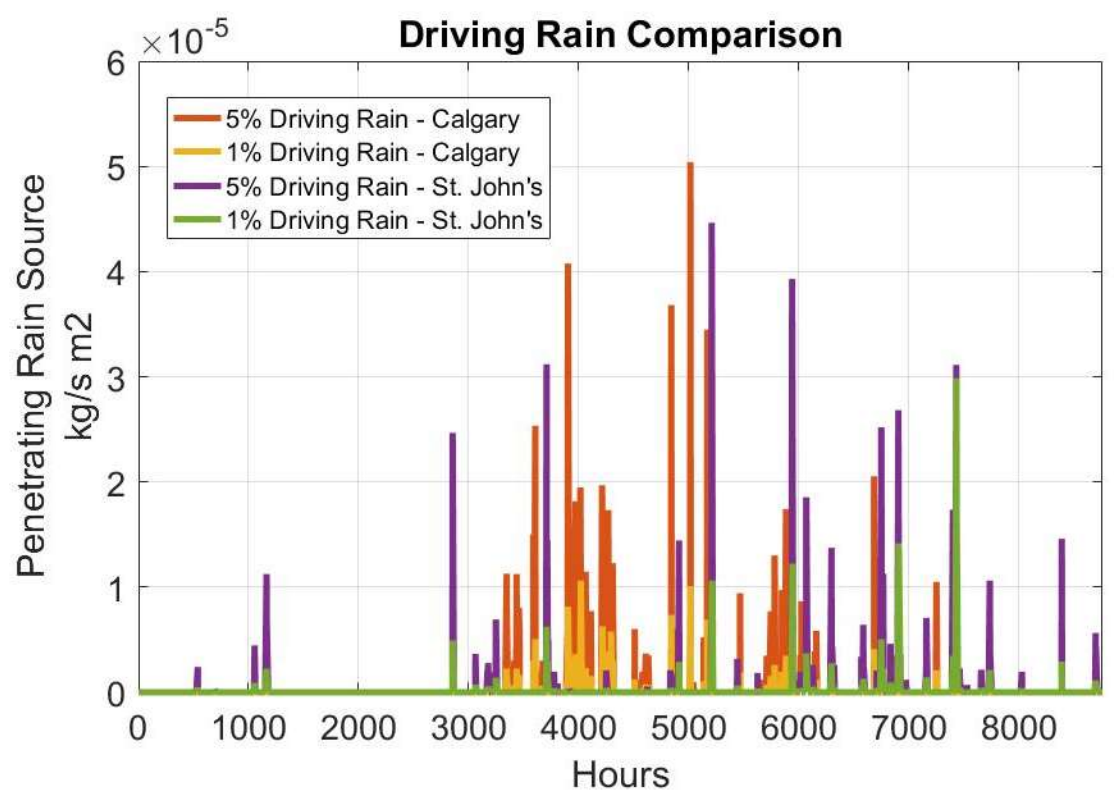

Figure 4-88 : Penetrating Rain Amounts for St. Johns and Calgary

Figure 4-87 shows the direction of driving rain in each of the two cities as extracted from WUFI. Figure 4-88 shows a comparison between Calgary and St. John's and the amount of rain that was deposited due to rain leakage. 
Coupled with the rain penetration was the high sheathing temperature during the summer months in Calgary as compared with St. John's. The combined effects of temperature and moisture cause for a high RHT index. A 5\% driving rain leakage is an extreme scenario and was completed to demonstrate the impact of high levels of direct moisture on an envelope. The $1 \%$ driving rain leak prescribed by ASHRAE 160 showed much better performance in Calgary.

The other notable cases that breached the RHT80 threshold were the high indoor humidity and the split insulation levels. These results are understated compared with the Fairbanks simulation and will be discussed more in-depth in the Fairbanks analysis. Overall, the performance of the enclosure under standard operating conditions preformed fine. Attention should be paid to water detailing, controlling indoor humidity levels and further analysis when split levels of insulation are used.

\subsubsection{St. John's, Newfoundland}

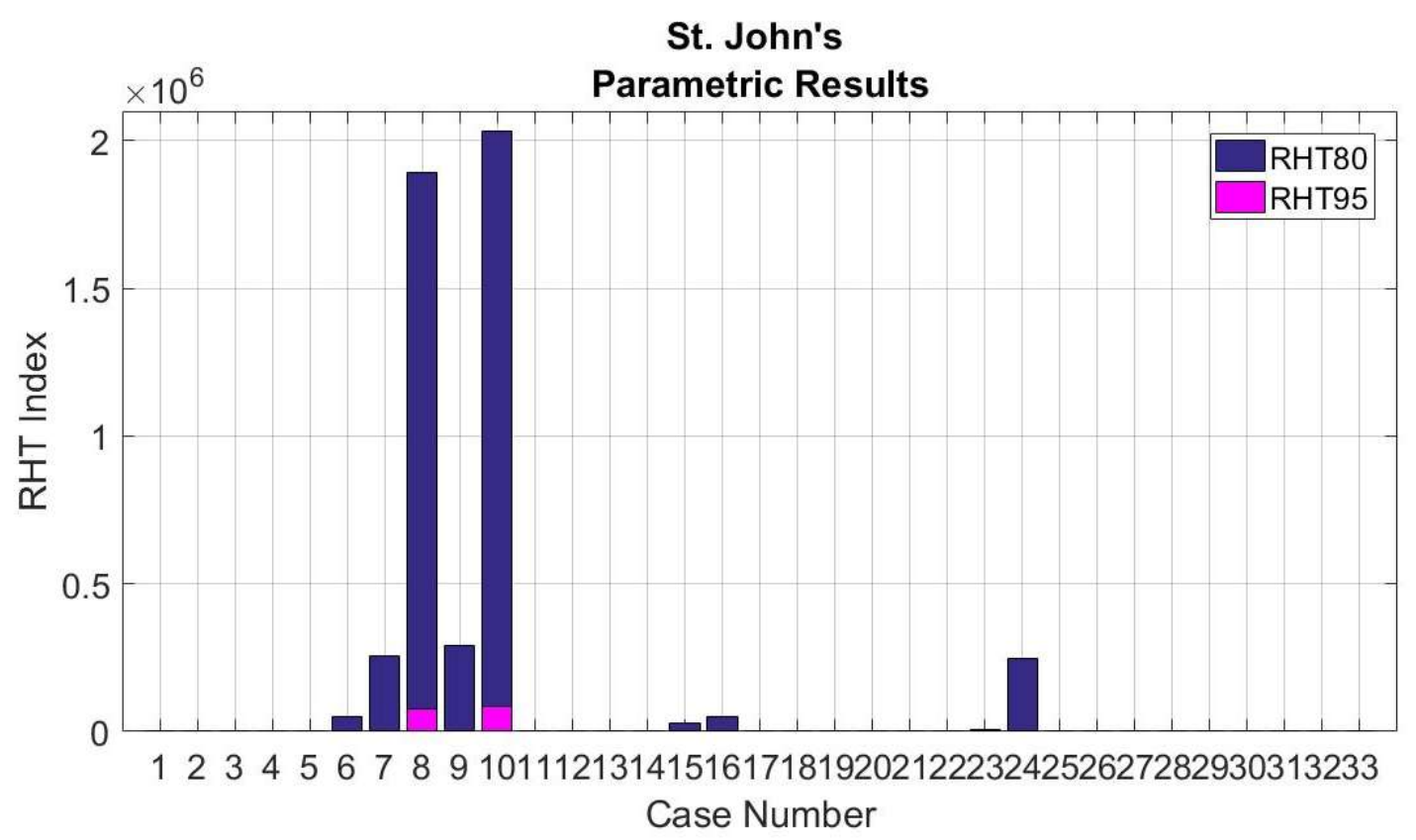

Figure 4-89 : Parametric Results St. John's

St. John's was the only case that exceeded the RHT95 threshold for the 1\% driving rain scenario. The result is not visible in Figure 4-89 due to the scale of the results from the 5\% driving rain scenario. As can be seen in Figure 4-90 (the driving rain chart), the 1\% driving rain leak, in some instances, caused the amount of moisture deposited on the sheathing was half or almost equivalent to the $5 \%$ driving rain leak. Three noticeable events occurred around the 5940 
(September $\left.4^{\text {th }}\right), 6909$ (October $\left.14^{\text {th }}\right)$, and 7434 (November $6^{\text {th }}$ ) hours of each simulation year. These three events lead to an increase in the RH of the sheathing past the $95 \% \mathrm{RH}$ threshold as can be seen in Figure 4-89.

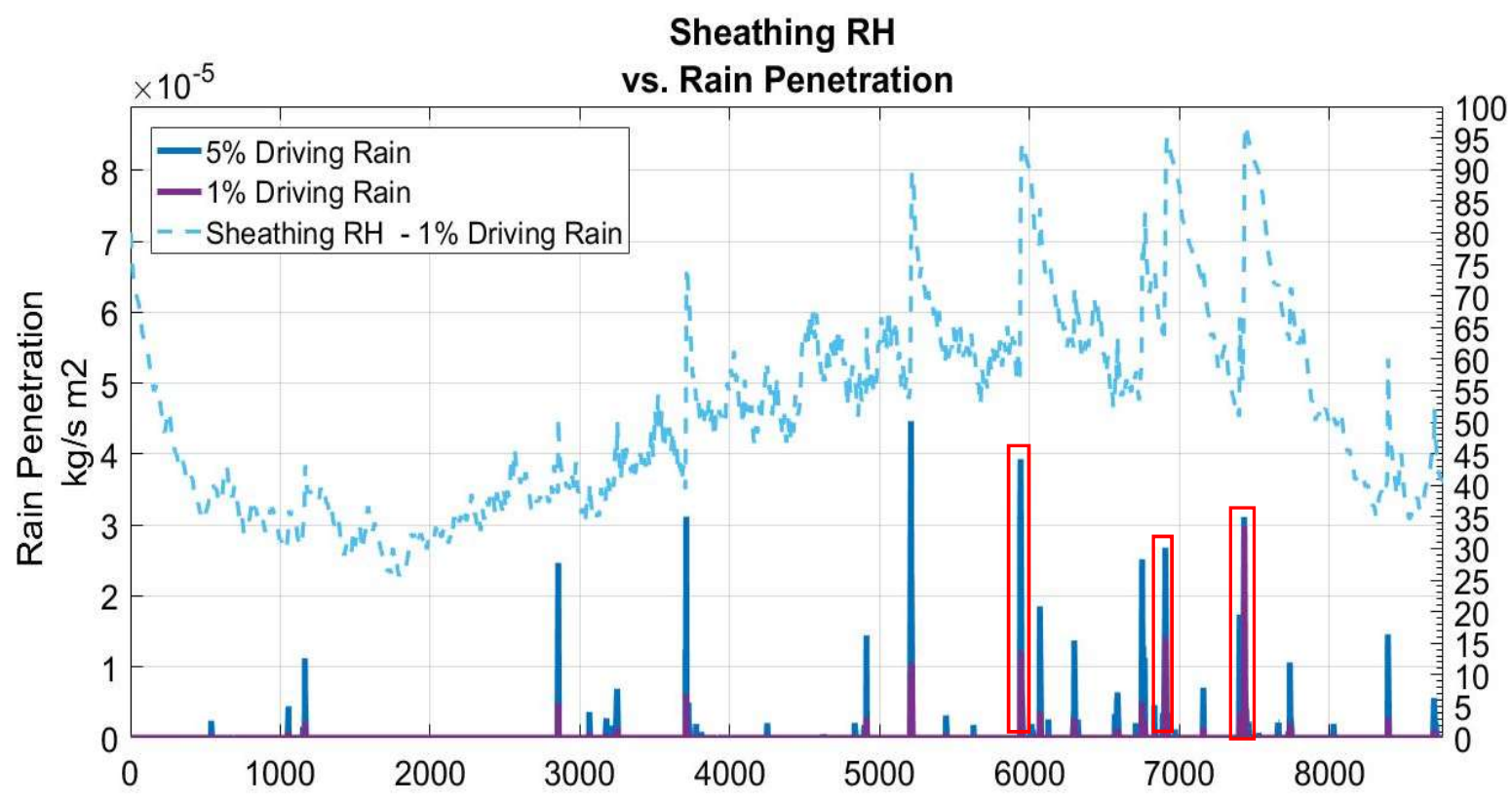

Figure 4-90 : Rain Penetration Compared with OSB RH - St. John's

The reason that these events are higher in proportion to the $5 \%$ rain leak than the other events is due to an exceeding amount of moisture being deposited during the 5\% rain leak than the OSB sheathing can absorb. The maximum moisture content of the sheathing layer was reached and the excess rain moisture was unable to be released. In cases 8 and 10 approximately $24.5 \mathrm{~kg} / \mathrm{m}^{2}$ of water was unable to be placed into the sheathing out of a total of $56.8 \mathrm{~kg} / \mathrm{m}^{2}$ being deposited over the six-year simulation period.

The excess moisture would likely be more evenly distributed between the layers of the OSB sheathing and there would be an increase in both the RHT95 and RHT80 index. The amount of moisture unable to be deposited would also likely be more than the sheathing could uptake, even with a more uniform distribution. The excess moisture would likely penetrate deeper into the assembly, and begin accumulating, causing significant damage to materials. It should be noted that the results from the one dimensional hygrothermal analysis are unable to account for this excess moisture. 
St. John's exceeded the RHT80 threshold in several other cases; however, these cases were generally exceeded in all climates and are explained in more depth in the climate with the most noteworthy results. As St. John's was the only city to experience a breach in the RHT95 threshold and exhibits an extremely wet climate exceptional attention should be placed on water sealing details.

\subsubsection{Fairbanks, Alaska}

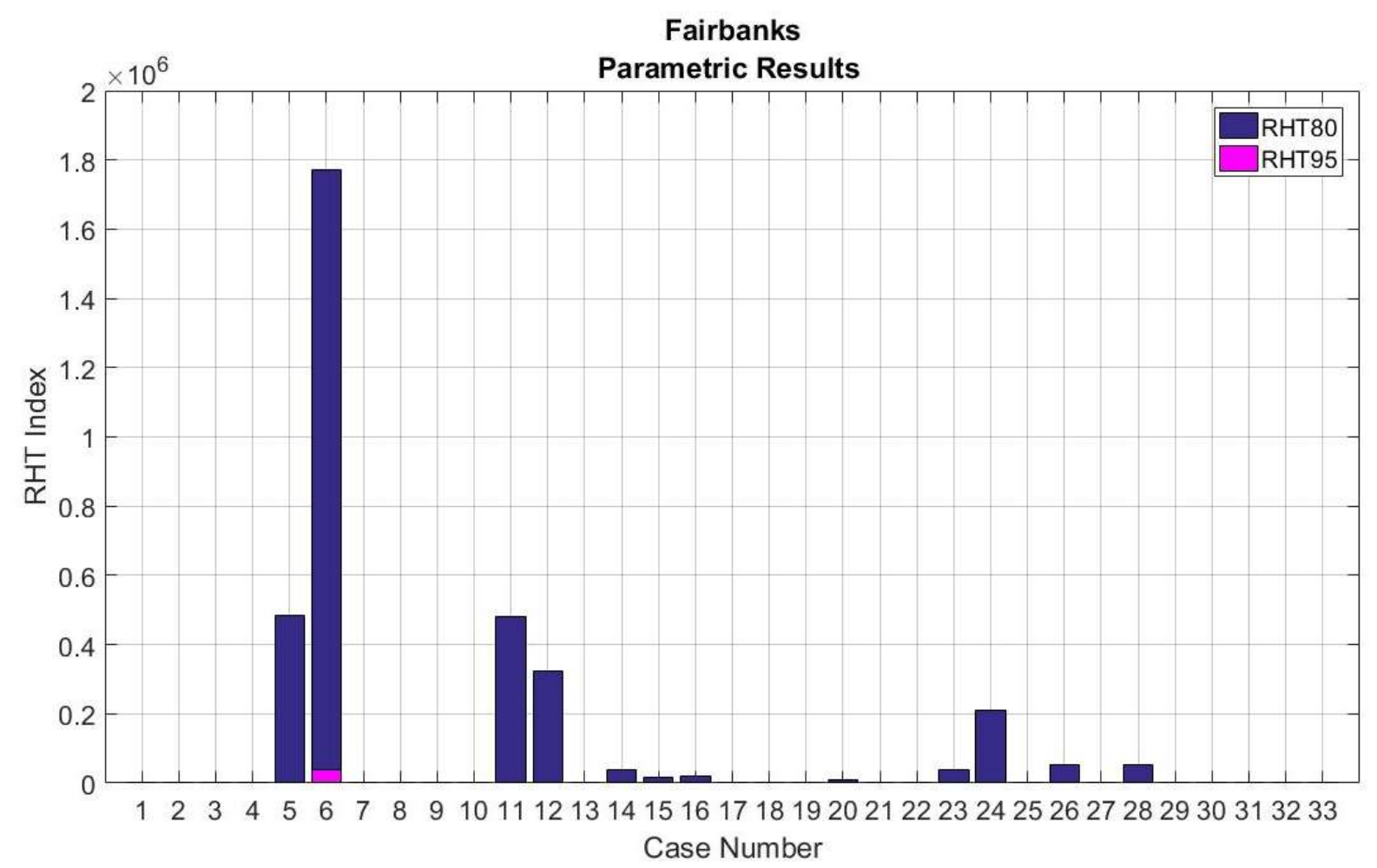

Figure 4-91 : Parametric Analysis Fairbanks

Fairbanks has an arctic climate and is the coldest location of any of the cities assessed. Being in the coldest climate created varied results from the other cities. Fairbanks was the only location to exceed the RHT95 threshold for case 6. Case 6 represented a high interior air RH $(60 \pm 10 \%)$. The high interior air humidity caused a dramatic vapour pressure difference between the interior and the exterior during the cold winter. This caused a significant amount of moisture to move through the wall. The reduced temperature of the sheathing caused an increase in humidity and in some instances created dew-point conditions 
Case 6 has reduced external insulation thermal resistance and increased internal insulation thermal resistance as compared with Case 5. Case 5 preformed more adequately in this cold climate. Case 6 was simulated with a polyethylene vapour barrier (and the results were significantly improved with the RHT80 being reduced to zero). This suggests that the inclusion of a polyethylene barrier would improve the moisture performance of this wall assembly in an extremely cold climate when interior humidity is high. It should be noted that this simulation only encompasses vapour diffusion and excludes interior air leakage, which is a significant source of moisture and inferences to a poly-barrier only refer to this case.

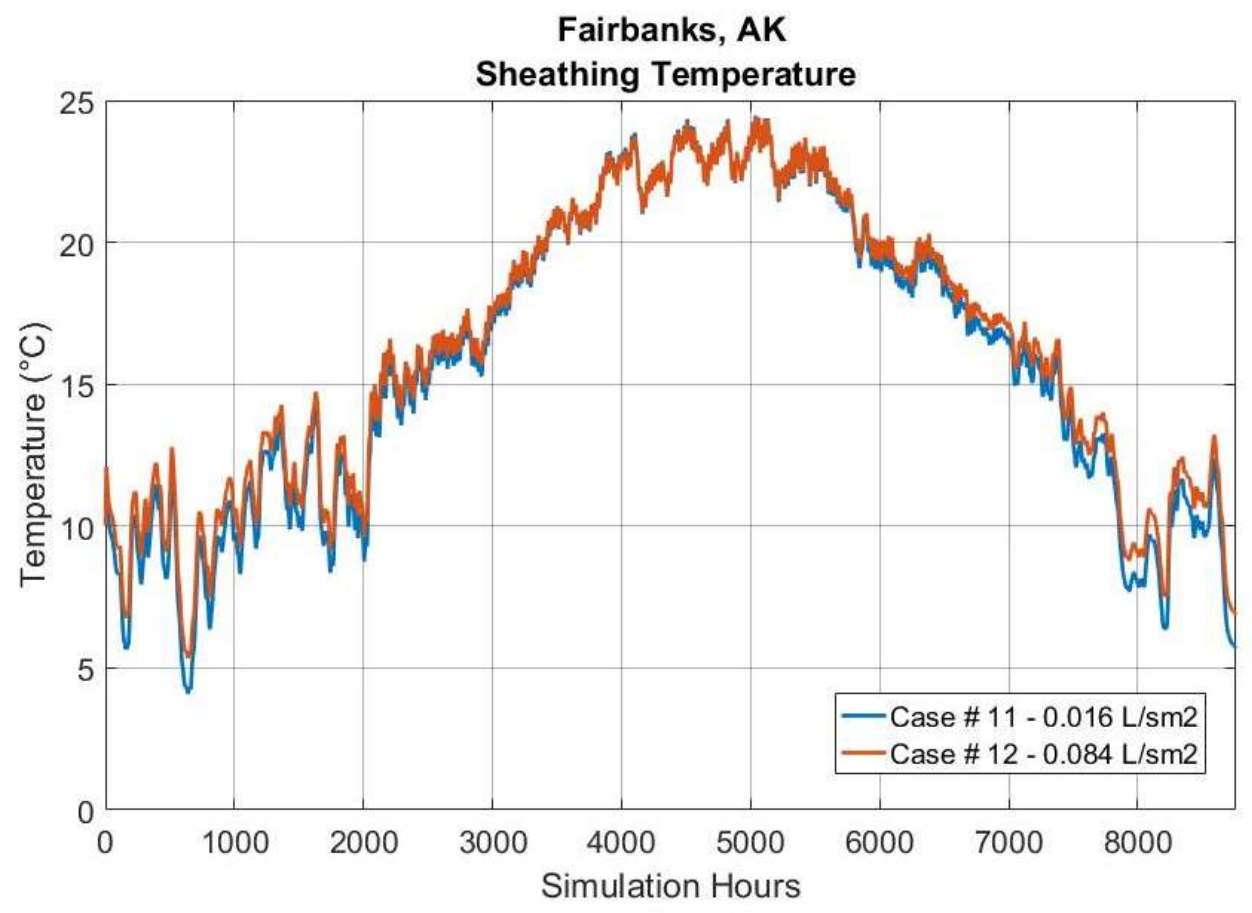

Figure 4-92: Sheathing Temperature - Case $11 \& 12$ - Fairbanks

An interesting phenomenon occurred when an interior air leakage was simulated with high indoor RH. The RHT index saw a reduction in values due to this air leakage. This was caused by the warming of the sheathing due to the interior air. In case 12, which simulated a greater air leakage than case 11, had a reduced RHT index. The temperatures of the sheathing are shown in Figure 4-92 and case 12 displays warmer temperatures during the cold winter months when the $\mathrm{RH}$ was the highest in the wall assembly. Air leakage is a major source of heat loss within a building envelope and should be reduced as much as possible. The results from this simulation indicate that keeping the sheathing warm is an important part of moisture management, 
especially in Fairbanks extreme cold climate. The importance of this can also be seen in cases $20,23,24,26$, and 26 , where split levels of insulation cause a reduction in sheathing temperatures and an increase in sheathing $\mathrm{RH}$.

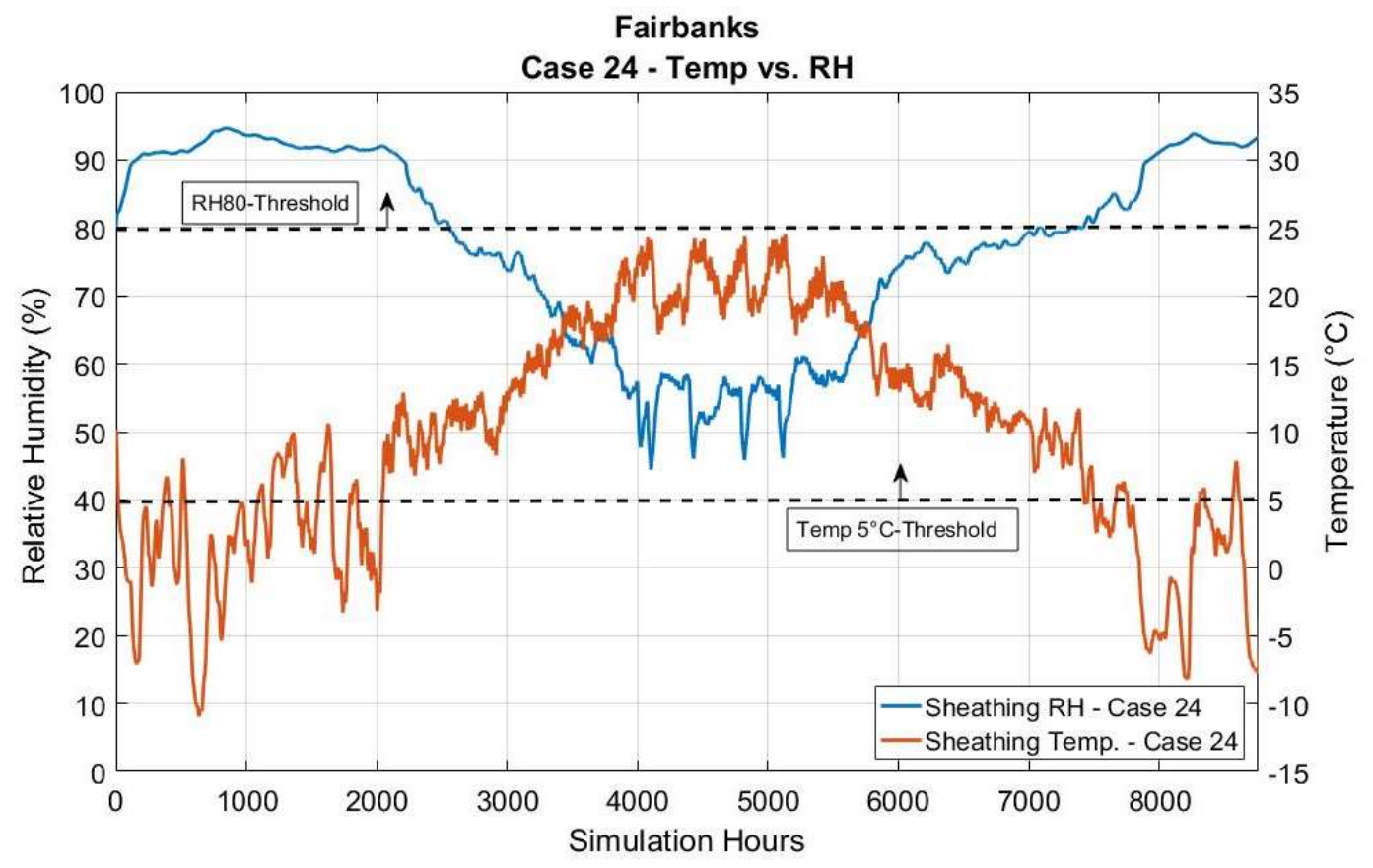

Figure 4-93 :Fairbanks Case 24

Shown in Figure 4-93 is the temperature and relative humidity of the interior side of the sheathing of Case 24 during the first simulation year. Case 24 has the highest RHT80 index of the split-insulation cases including cases with brick cladding (Case 17-30). Figure 4-93 also displays the RH and $\mathrm{T}$ threshold set out by the index. It can be clearly seen that at certain times during the year the sheathing temperature falls below the $5^{\circ} \mathrm{C}$ temperature required for organic growth on substrates, however, this low temperature leads to high relative humidity. The RH$80 \%$ threshold is exceeded for a large portion of the year during the winter and potions of the shoulder seasons. The RHT index only includes values when both thresholds are passed.

The reduced sheathing temperature was caused by both the extraordinarily cold temperatures of Fairbanks and the inclusion of interior insulation which limits the interior energy from reaching the sheathing. This phenomenon can be seen in to occur in Calgary to a lesser degree. As shown in cases $17,18,21,22,25,27$, and 29, the best practice for moisture management is to place all the insulation on the exterior side of vulnerable sheathing. In many cases, it is impractical to 
place all insulation on the exterior as cost and structural stability must be considered in the envelope design. In these cases, interior insulation is required to meet energy targets and building codes. A balance should be struck between interior and external insulation for moisture performance. This balance is determined by expected interior and exterior climate conditions. For the split-insulation enclosure approach in Fairbanks a more in-depth hygrothermal and energy analysis should be completed on a project specific basis to ensure suitability.

\subsubsection{Vancouver, British Columbia}

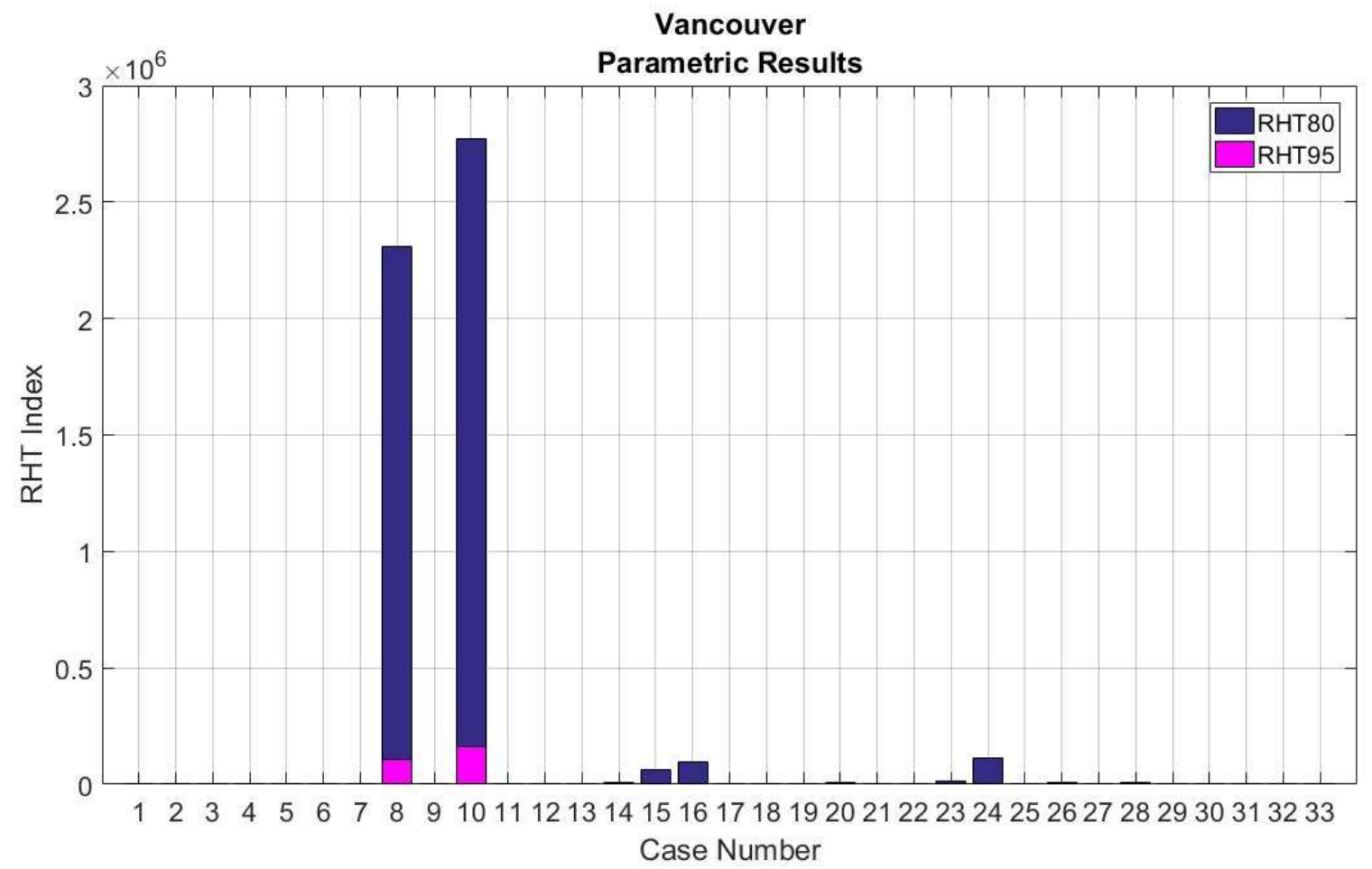

Figure 4-94 : Parametric Results Vancouver 
Vancouver demonstrates an overall reduced RHT index as compared with the other cities except for the $1 \%$ and 5\% driving rain leak cases. Vancouver had the highest the RHT80 and RHT95 index results for the 5\% driving rain leak, except for Calgary Case 8 RHT95. This can be explained by the significant amount and frequency of precipitation and the relatively warmer climate as compared with other cities.

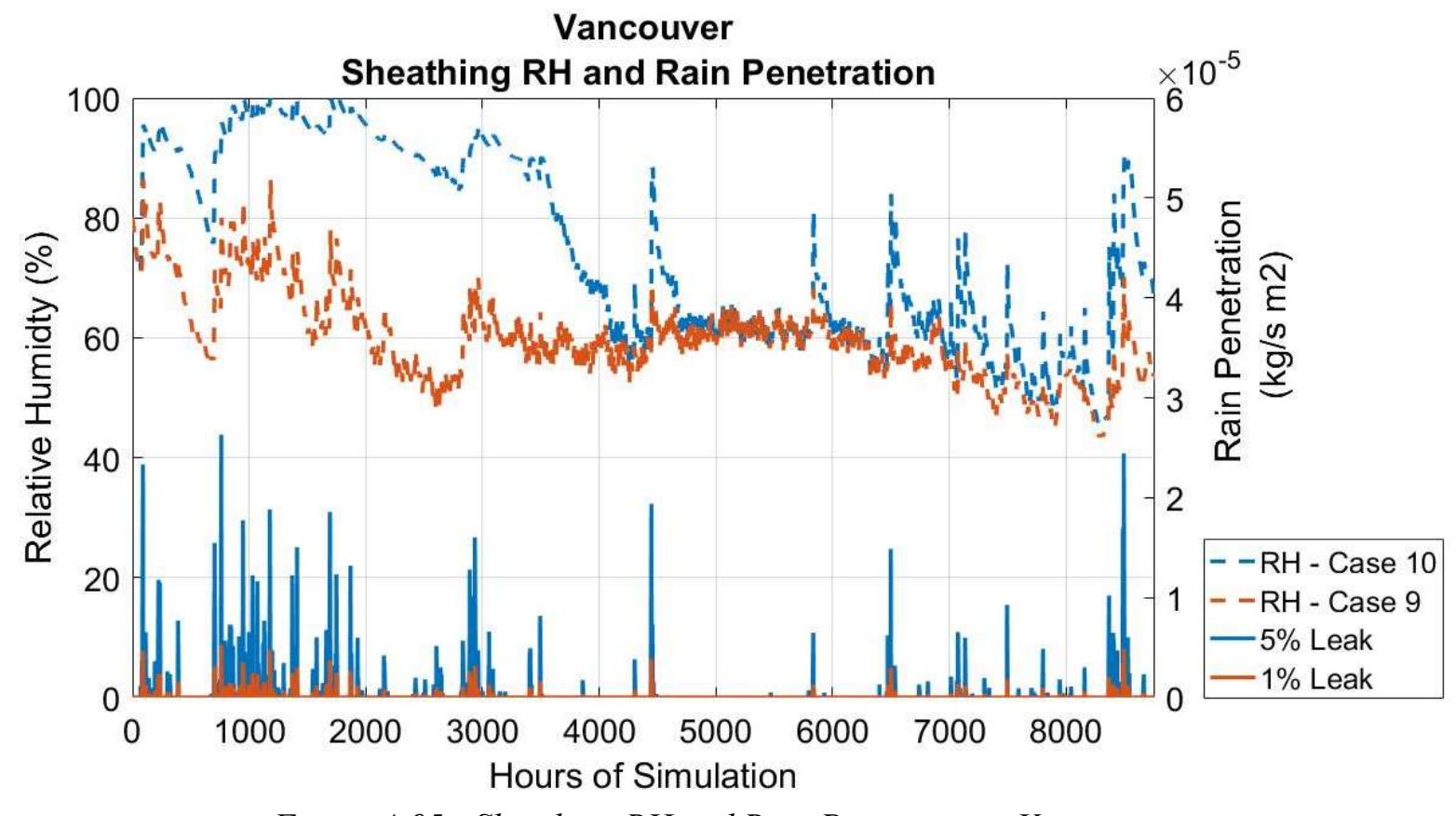

Figure 4-95 : Sheathing RH and Rain Penetration - Vancouver

Figure 4-95 shows the frequency of rain and the corresponding RH of the sheathing for cases 9 and 10 . The $1 \%$ and $5 \%$ rain leak results in a rapid increase in the $\mathrm{RH}$ at the start of the year. The 5\% rain leak results in an elevated sheathing RH that is unable to dry significantly before the continuous rain events that occur around the 1000-hour mark. The elevated RH at that time and the significant amount of moisture entering the enclosure results in an extremely high $\mathrm{RH}$ for many months in the first half of the year. As discovered during the "Leaky Condo Crisis," rain penetration and the inability of the enclosure to dry out was a major cause for moisture damage (Lawton, 1999.) The greater Vancouver area's warm and humid climate is unique in Canada and moisture trapped within walls experience a more difficult time drying. Cases 15 and 16, which simulate a built-in moisture content of $32 \%$, have the highest RHT 80 index of any of five climates. 


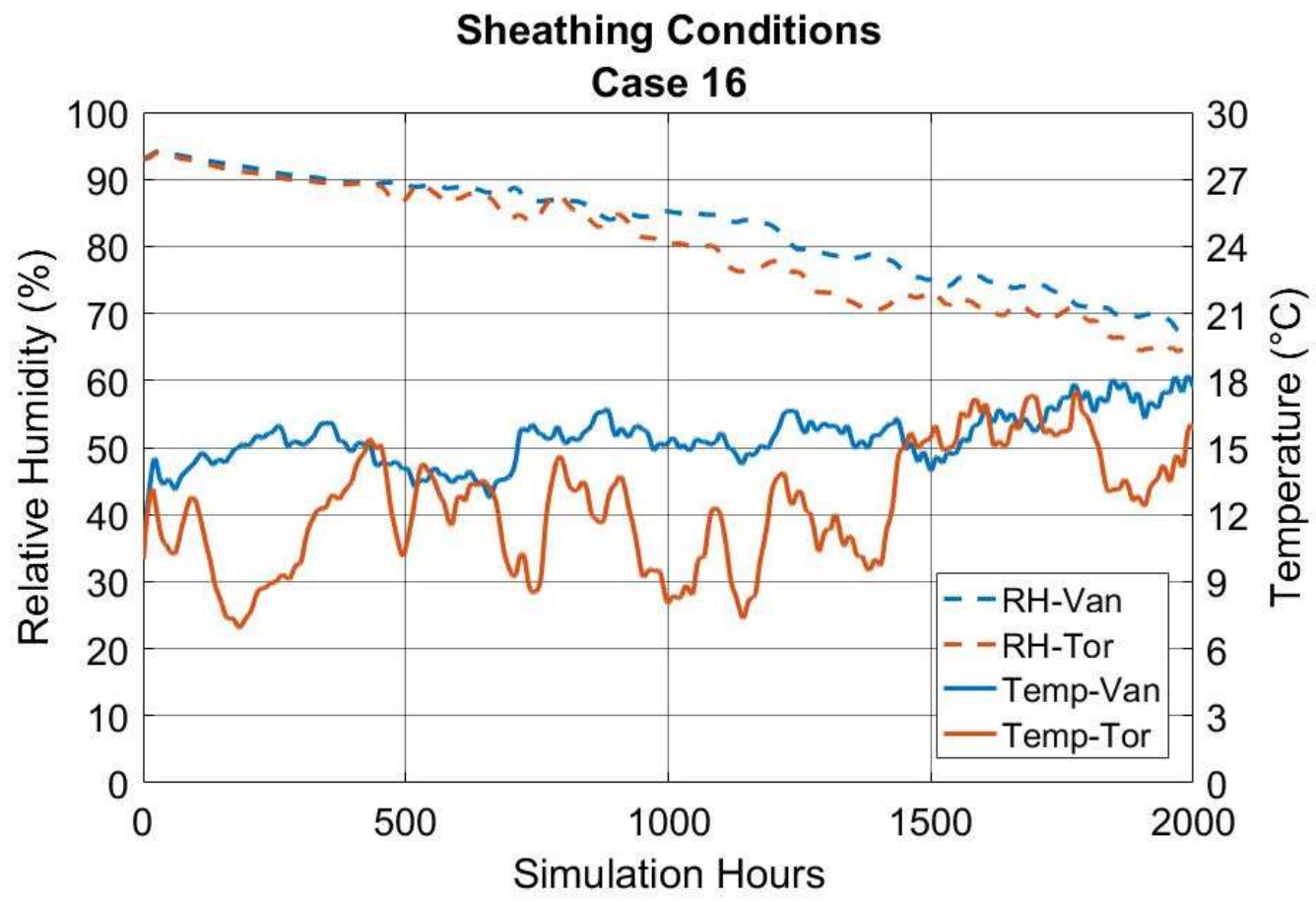

Figure 4-96: Sheathing Drying Comparison - Vancouver/Toronto

Figure 4-96 shows the results for Case 16 for Vancouver and Toronto. Toronto had the second highest RHT80 index value for case 16 of all five cities. The RH of the sheathing in Vancouver takes several days longer to reach a $\mathrm{RH}$ of $80 \%$ than Toronto and it experiences higher temperatures during this period. The coupled high RH and temperature in Vancouver results in a higher RHT80 index than Toronto and increases potential for moisture deterioration. These results stress the importance of proper detailing for water management and for an enclosures ability to dry. Overall the enclosure approach performed well in terms of moisture management other than the typical cases that experienced high levels of RHT80 and the rain penetration cases discussed above. 


\subsubsection{Toronto, Ontario}

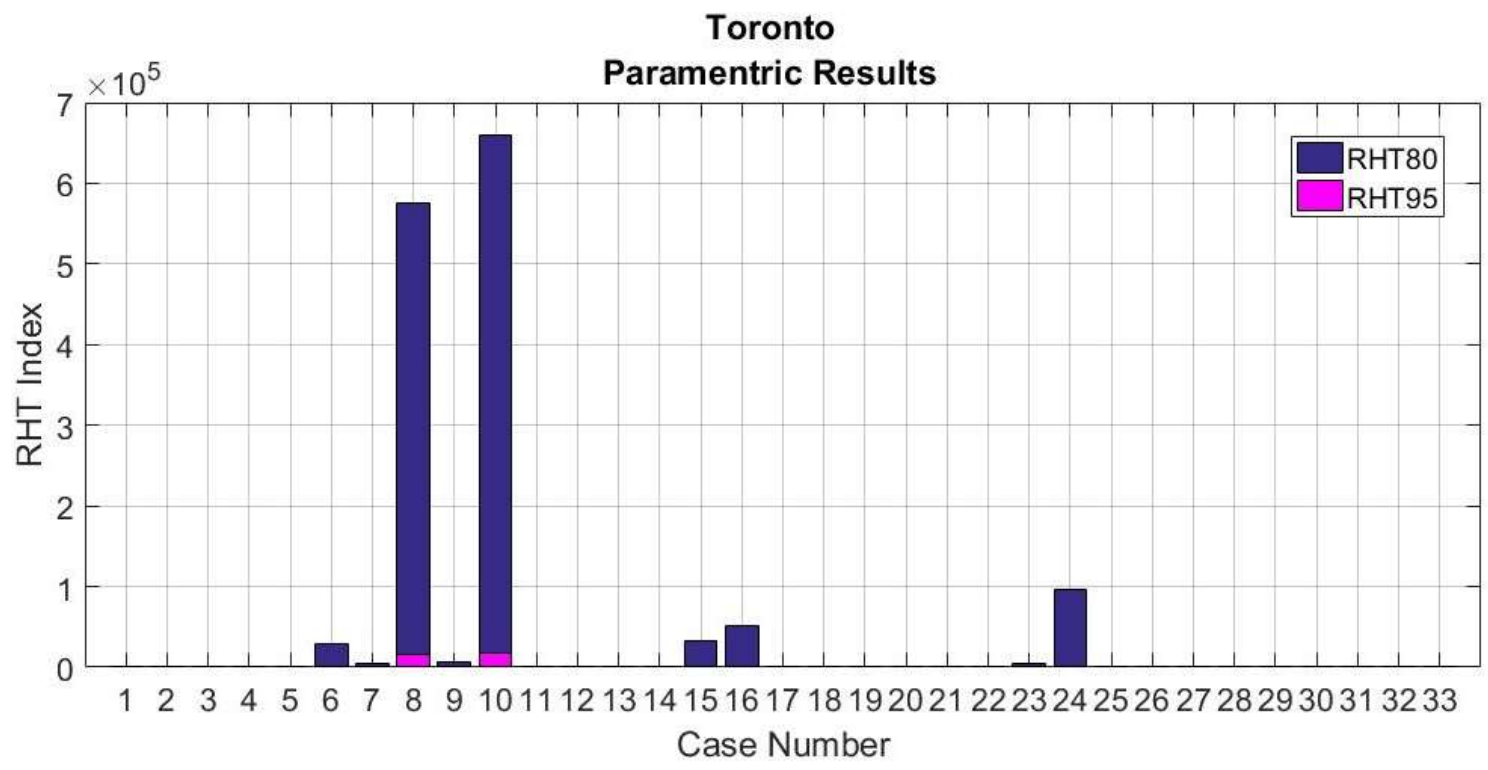

Figure 4-97 : Parametric Analysis Toronto

Shown in Figure 4-97 are the results from the Toronto simulations. The results show that 16 of the 33 cases have breached the RHT80 threshold, however only nine can be seen on the graph due to the scale of other cases. Only two cases have crossed the RHT95 threshold. These are case 8 and 10, which represent a 5\% driving rain water leak. Cases 7 and 9 have much lower values for RHT80 and represent the 1\% driving rain water leak. Case 6 , the high indoor relative humidity, has breached the RHT80 threshold. Cases 15-16, which represent the built-in sheathing moisture, began the simulations above the RHT80 threshold. Cases 23-24 represent a change in insulation levels and have $152 \mathrm{~mm}$ exterior and $140 \mathrm{~mm}$ of interior insulation

\section{Standard Cases (Cases 1-4)}

The results represent the current field test structure wall being simulated under increased moisture loading both from the exterior and the interior. The standard cases do not breech the RHT80 threshold at any point during the simulation and exhibit good moisture management even with the increased moisture loading. The $\mathrm{RH}$ of the sheathing reaches a maximum of $71 \%$ during the simulation period, other than the initial starting conditions of $80 \% \mathrm{RH}$. The results from this indicate that under normal operating conditions the proposed assembly is appropriate 
for the Toronto climate. Normal operating conditions can be considered as proper installation of materials, no defects in construction and materials, and normal indoor conditions.

\section{Defect Conditions (Case 5-16)}

Toronto

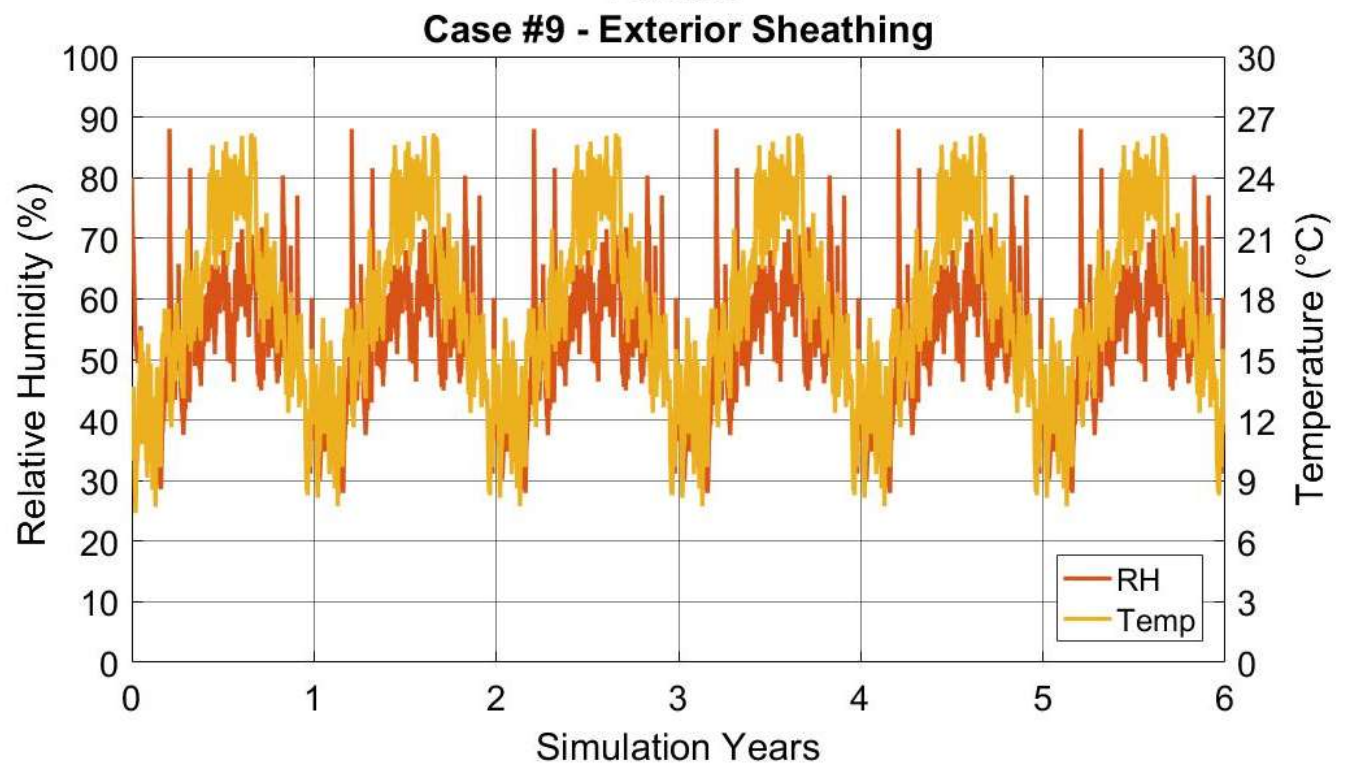

Figure 4-98: Toronto Case 9

Case 8 and 10 are the only two cases that have breached the RHT95 and have the highest RHT80 index of the Toronto cases. Cases 7 and 9, which represent the 1\% driving rain leak, breach the RHT80 threshold however do not cross the 95\% RH mark. The RH and T profile for Case 9 is shown in Figure 4-98. The localized rain events cause a spike in the $\mathrm{RH}$ of the sheathing to above the $80 \%$ threshold; however, this increase in RH does not last for a significant period indicating the enclosure can dry before the next wetting event. The largest RH spikes occur around the 18:15 hour of the simulation year only resides above $80 \%$ for 18 hours on an annual basis. This case exemplifies the caution that should be taken when utilizing the RHT index as a metric for moisture durability, as the resultant RHT80 index of case nine exceeds a value of 5000, however assessment under the criteria of ASHRAE 160-2009 indicates acceptability. 


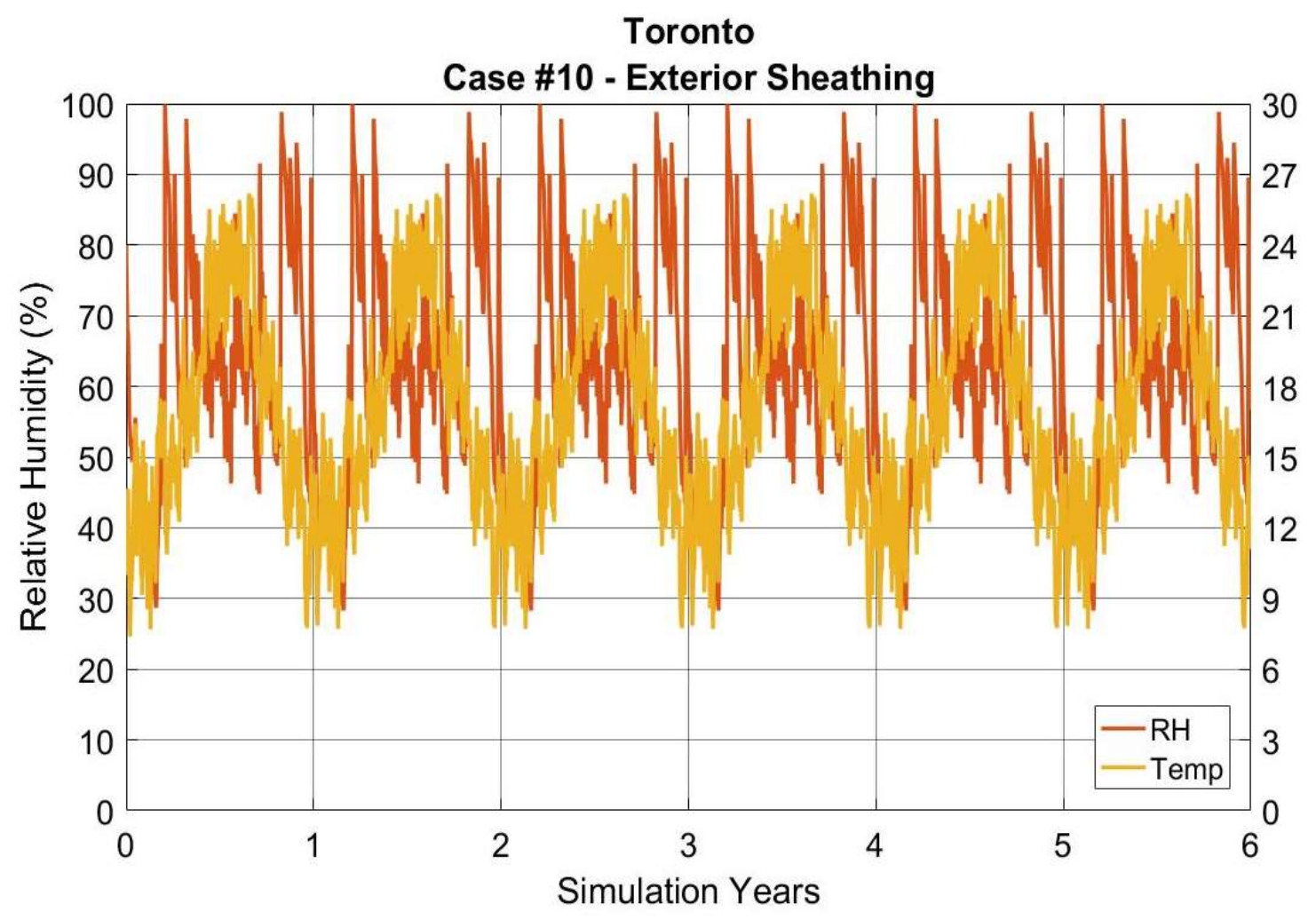

Figure 4-99 : Toronto Case 10

Case 10 breaches the RHT95 several times during the simulation period is shown in Figure 4-99. This case also exhibited the largest RHT80. The longest period above $80 \%$ occurred in the second half of the simulation year and rose above $80 \%$ at hour 7220 of the simulation and had an average of $85 \%$ RH over the next 30-day period. This exceeds ASHRAE-160 RH and T thresholds. Caution should be taken as high levels of rain water penetration can cause significant damage to envelopes. 


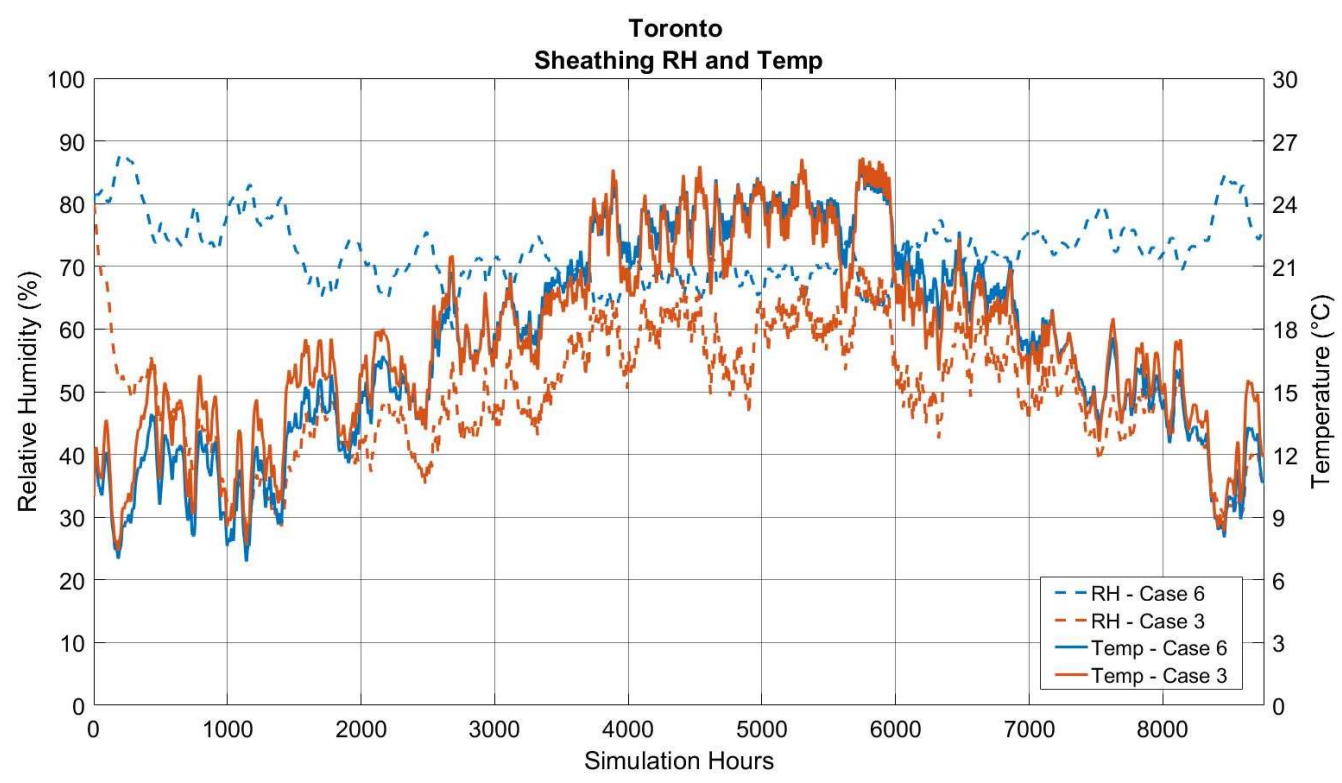

Figure 4-100 : Toronto Case 6 - High Interior RH

Case 6 also exceeds the RHT80 threshold. A comparison between case 3 and case 6 can be seen in Figure 4-100. The reduced temperature of the sheathing in the winter causes an increase in the RH and pushes it above $80 \%$. Case 6 also has a noticeable increase in the average relative humidity of the sheathing due to the internal moisture source. Case 6 does not breach the ASHRAE 160 threshold. 


\section{Changes in Construction (Cases 17-33)}

The majority of cases from 17-33 performed well and only cases 20,23, 24, 26 and 28 exceed the RHT80 threshold. These cases represent split insulation ratios. Case 24 showed the worst performance of any of these cases. Case 24 has decreased external insulation thermal resistance as compared with case 23 as calibrated. This decrease in external thermal resistance coupled with the increased amount of insulation $(140 \mathrm{~mm})$ limits the amount of energy reaching the sheathing and creates a scenario of increased $\mathrm{RH}$.

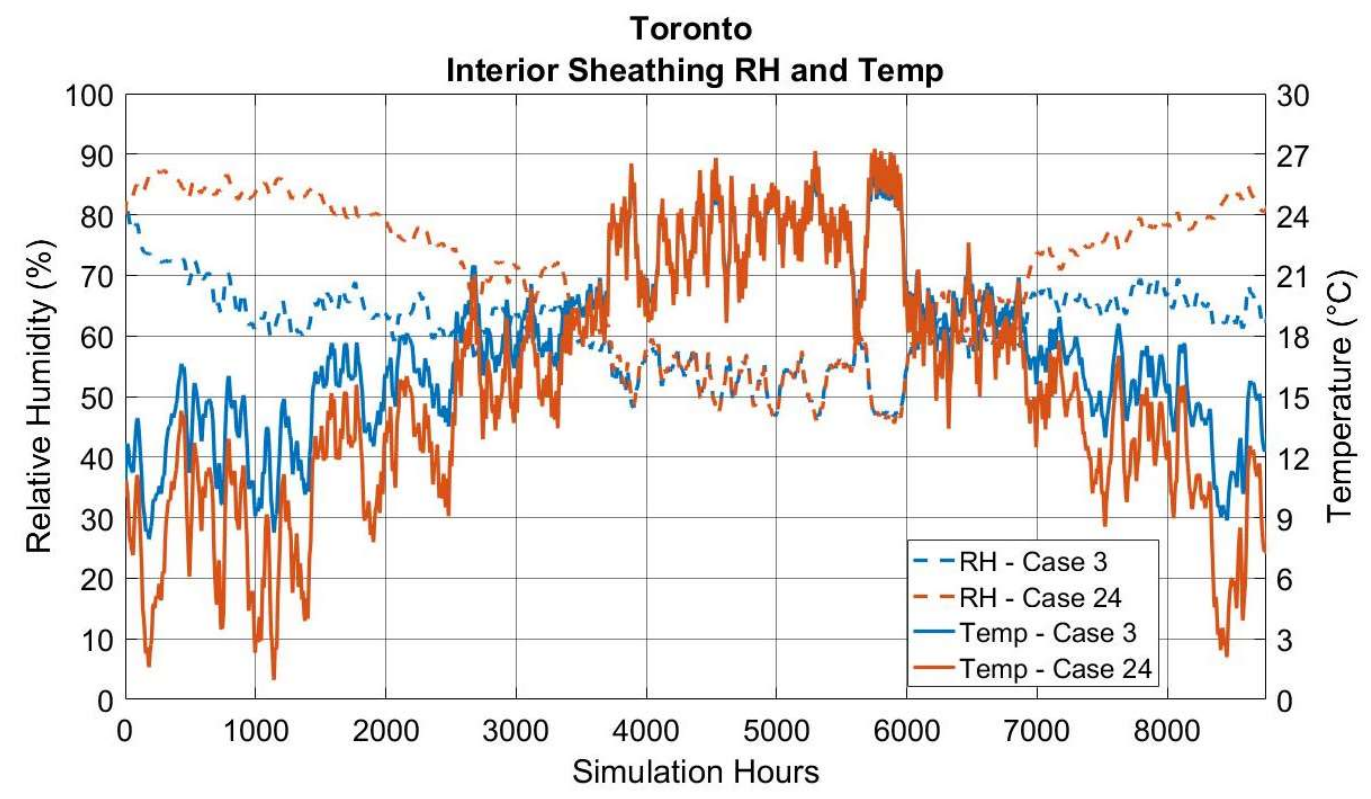

Figure 4-101 : Toronto Split Insulation

Figure 4-101 shows a comparison of RH and $\mathrm{T}$ for cases 3 and 24, which are equivalent, except for insulation levels. Case 3 drops below the $80 \%$ RH threshold quickly, case 24 is unable to dry out due to colder sheathing temperatures. This increased RH level continues until the summer months when the temperatures and the RH's converge. The divergence begins again during the colder seasons and the $\mathrm{RH}$ of the sheathing exceeds $80 \%$ late in the simulation year.

The reduction of thermal resistance on the exterior side of the OSB with the inclusion of significant amounts of interior insulation caused a marked increase in the sheathing RH. No other construction defects were considered in this situation, and it is possible that with several negative factors, such as exterior air leakage, rain leakage, and an increased interior RH there may be potential for problems. Scenarios involving split levels of insulation should be investigated more closely. 
The addition of impermeable layers into the enclosure in cases 31-33 resulted in negligible effects on the RHT index. Case 31 simulates the addition of a polyethylene barrier on the interior side of the enclosure, while cases 32 and 33 represent the use of impermeable acrylic stucco cladding. From the results of the simulation it appears that assembly can breathe to the exterior or the interior depending on where the impermeable layer is place. Even though these cases performed well it should be mentioned that additional factors, such as rain leaks or air leaks, could cause a disruption to the moisture balance. Maintaining the enclosure as a vapour open system allows it to have flexibility when required. The purpose of this analysis was to identify individual factors that may cause failure in the wall, and while the addition of impermeable layers does not cause a significant moisture problem, it is recommended that the wall remain as a vapour open system.

\section{Toronto Summary}

The enclosure approach performed well overall and several of the cases that had significant results were discussed above. The high indoor humidity, rain leakage, built in moisture, and the split levels of insulation, all had significant RHT80 indexes. While the built-in-moisture was able to dry fairly quickly, the other three scenarios had an increase in moisture within the enclosure through natural events. To determine thresholds or limits for this enclosure a critical failure testing methodology has been proposed and will be used to explore these three scenarios for further testing. 


\subsection{Conclusions}

The following research investigated the thermal resistance and hygrothermal performance of a highly-insulated enclosure that consisted of exterior mineral wool installed on a typical wood frame structure. The in-situ thermal resistance and thermal bridging affects were found and compared with installed nominal values. The hygrothermal performance of the enclosure was assessed for the Toronto climate. Hygrothermal sensitivity to several variables were identified through calibrated computer simulations.

\subsection{Differences in Installed Nominal and In-situ Effective RSI}

The in-situ thermal resistance of the north and south wall was assessed with ASTM C1155 methods and found to have a thermal resistance of $10.6 \mathrm{~m}^{2} \mathrm{~K} / \mathrm{W}$ and $9.0 \mathrm{~m}^{2} \mathrm{~K} / \mathrm{W}$ respectively. These differed from the nominal centre-of-cavity wall value of $9.3 \mathrm{~m}^{2-} \mathrm{K} / \mathrm{W}$, by an increase of $14.4 \%$ and a decrease of $3.2 \%$. The southern wall's thermal resistance falls within the $\pm 7 \%$ accuracy of the testing equipment however the North wall does not. It is suspected that the North wall has a higher in-situ thermal resistance than both the nominal and south wall. The layer analysis identified increased thermal resistances of the exterior layers, which were confirmed by a calibrated HEAT3 dynamic simulation. Several theories were presented for the experienced increase in thermal resistance; sensor thermal mass, mean temperature, contact resistances, potential error induced by shifting heat flux polarity, and material variation. It is recommended that the assembly be disassembled and the insulation be tested for thermal conductivity to determine if the increased thermal resistance stems from material variation.

The southern wall experienced a drop in thermal resistance as compared with the North wall. A direct summation method specified by ASTM C1155, and used for the North wall, was unable to be used for the southern wall due to high levels of solar radiation exposure. Three techniques that utilized modified data with the summation method were completed in an attempt to quantify the southern wall in-situ thermal resistance. These techniques attempted to limit surface temperature data that was affected by solar radiation. The three techniques used were; combining North wall delta temperatures and southern wall heat flux data, using data during long periods of overcast, and eliminating temperature and heat flux data that has been affected by solar radiation. The first method, of utilizing north wall exterior temperatures, underestimated the in-situ thermal 
resistance due to the reduction of heat flux caused by solar radiation. The second method did not allow for a significant time span to occur for accurate results and was influenced by radiation through lighter cloud cover. The third method eliminated solar radiation influenced data by determining the time it took for surface temperature highs to create a heat flux low. This was confirmed by analyzing the enclosure temperature profile. The third technique was judged to be the most accurate of the three. The reduced in-situ thermal resistance found for the southern wall (as compared with the north wall) was attributed to several potential variables. This included material variation, air gaps in insulation, and three-dimensional heat losses which includes the effects of the metal fasteners.

\subsubsection{Expected Effective Thermal Resistance with Various Fastener Types, Insulation Amounts and Stud Spacings}

To quantity the potential reduction in thermal resistance caused by the metal screw fasteners, three-dimensional thermal modelling was completed using HEAT3. A model was calibrated using temperature profile data from a five-day period in February. Insulation layer resistivity's were compared to nominal and layer analysis in-situ results. Metal fasteners were added into the thermal modelling with in-situ stud and fasteners spacing and resulted in a reduction of $15.3 \%$ effective thermal resistance. A number of fastener, stud, insulation, and fasteners type cases were simulated to determine a range of potential thermal resistance reductions. Reduction ranged between $24.4 \%$ and $4.2 \%$ depending on configuration. It can be determined from this analysis that designers and builders should have an understanding of potential losses caused by the metal fasteners to include within whole building energy models.

In conclusion, the thermal analysis revealed that the enclosure preformed as or better than expected as compared with the expected nominal value calculated $\left(10.6 \mathrm{~m}^{2} \mathrm{~K} / \mathrm{W}\right.$ and $9.0 \mathrm{~m}^{2} \mathrm{~K} / \mathrm{W}$ in-situ vs $9.3 \mathrm{~m}^{2-} \mathrm{K} / \mathrm{W}$ installed nominal). The increase in thermal resistance of the north wall may be attributed to a number of variables. Designers and builders should understand that the effective thermal resistance of the clear-wall is influenced by the metal fasteners (potential reduction of $24.2 \%$ to $4.2 \%$ depending on configurations). 


\subsection{Hygrothermal Suitability for the Toronto Climate and Hygrothermal Sensitivity.}

To determine the hygrothermal suitability of the proposed enclosure for Toronto and other cold climates a number of assessment techniques were used. In-situ field testing in Toronto provided raw data on hygrothermal performance for a test structure constructed of the proposed enclosure. The three-metrics used during the in-situ monitoring; moisture content measurements, ASHRAE 160 limits, and interior air condensation potential, indicate that the proposed enclosure was under no risk of moisture damage given the experienced boundary conditions for that period.

One dimensional hygrothermal simulations using the program WUFI-Pro were completed to assess the proposed enclosure under different and more severe climatic loads. The WUFI-Pro model was calibrated to ensure the accuracy of the simulations. The calibration procedure included defining the physical characterises to match the boundary condition data (for temperature and moisture) from the field collection period. Modifications were made to the geometry and thermal conductivities of the model to match in-situ field data. Four distinct models were created to replicate the different conditions experienced for the north and south wall during the winter and summer collection period. The calibrated models predicted the MC of the OSB to within $\sim 2 \%$ for all models and closely resembled in-situ trends.

The calibrated hygrothermal models were used to assess the proposed enclosure for Toronto Ontario, and several locations within North America that represent different climates across Canada. Locations for analysis included St. John's, Newfoundland; Calgary, Alberta; Vancouver, British Columbia; and Fairbanks, Alaska. Initial cases (1-4) were preformed with calibrated models without modification or defects. Severe exterior and interior climate boundary conditions were used to stress the enclosure under high moisture loads. The results from this analysis indicate that the proposed enclosure "as is" would perform well in all climate conditions including Toronto.

A number of cases were run with intentional defects and modifications to the assembly. The modifications and defects may be realised by some enclosures constructed which are based on the proposed enclosure. The defects and modifications combined with the multi-location hygrothermal analysis revealed potential sensitive variables for this enclosure type. Variables identified by the parametric analysis include; 
- High indoor humidity in extremely cold climates: The increased vapour pressure difference between interior and exterior conditions causes outward vapour flow. The colder climate also reduces the temperature of the sheathing. The two coupled effects cause an increase in the moisture content and $\mathrm{RH}$ of the sensitive sheathing material. Controlling the interior RH and outward vapour drive would help reduce potential moisture damage in extremely cold climates.

- Direct water penetration: The potential for moisture damage due to large amounts of leakage is still a risk for this proposed enclosure. The proposed enclosure performs well under normal conditions, however, will still experience issues if enough water is applied to the sheathing. This will occur to all assemblies however. It should be noted that proper water detailing is required for all assemblies. The impact of rain leaks in wetter climates, like St. John's and Vancouver, can be extremely detrimental to enclosures.

- Exterior air penetration in extremely cold climates: If cold air is able to penetrate into the enclosure, it may reduce the temperature of the sheathing. The reduction in temperature raises the moisture content and relative humidity of the sheathing increasing risk for moisture damage. The potential for external air to reach the sheathing is minimized by the use of higher density insulation, however caution should be taken to ensure installation and design inhibit air penetration.

- Insulation placement ratio: It is common knowledge that insulation ratios, interior vs. exterior thermal resistances, have a large impact on the moisture management of an enclosure. The same is true for the proposed enclosure. The assemblies with lower amounts of external insulation compared with internal, preformed worse in every climate zone. Care should be taken to ensure proper insulation ratios are maintained for each project.

- Summer condition variables: The calibrated summer model preformed worse than the calibrated winter model in most cases. This may be attributed to the reduced thermal resistance of the exterior insulation and differences in surface transfer variables. The differences caused decreased temperatures of the sheathing and increased moisture content. It should be noted that the context of the enclosure is an important variable to consider when assessing sensitive hygrothermal assemblies. 
In conclusion, the proposed enclosure should not experience risk of moisture damage if constructed normally in Toronto or in the other climate locations assessed. Care should be taken in construction to minimize direct water leakage to the sensitive components of the enclosure. The variable that had the largest impact on the enclosure moisture management, other than direct water penetration, was high interior relative humidity when the building is located in an extremely cold climate. Measures should be taken to limit exterior vapour flow, i.e. installation of a vapour retarder, or humidity levels should be controlled.

\subsection{Further Work}

Several items were revealed during the research where it might beneficial to conduct additional research to broaden knowledge and provide greater insight into the performance of the proposed enclosure;

1 Further testing to determine the effective clear wall RSI of the enclosure using guarded hot box methods. This will allow for increased knowledge of the impact of the metal fasteners on reducing the effective RSI.

2 Analysis of the potential moisture implications of the reduced temperature caused by the metal fastener. The thermal simulation revealed a drop-in temperature at the OSB and stud location where fasteners were attached. Research should confirm that moisture damage will not be an issue due to this.

3 It would be beneficial to conduct research on potential solutions for limiting thermal bridging caused by metal fasteners through exterior insulation. There is potential to develop high-strength and low conductive materials that may be used within the building industry to attach exterior insulation to the structure.

4 The development of a limit states design methodology for the hygrothermal performance of enclosure assemblies. This would be similar to typical structural design, where both factored loads and factored resistances are determined and compared to each other. 


\section{Appendix A : Data Processing Code Field Data Processing Code: Program MATLAB}

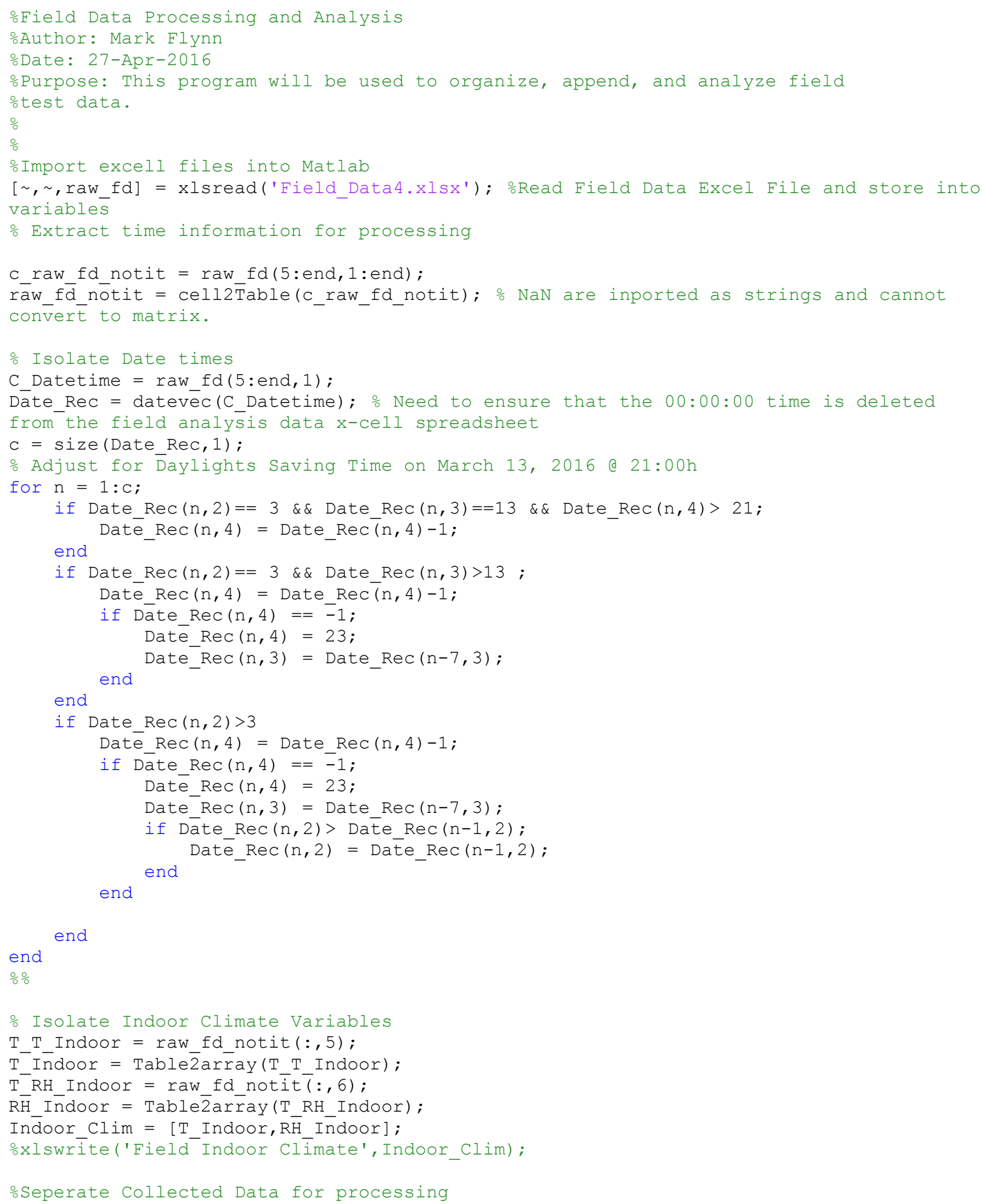




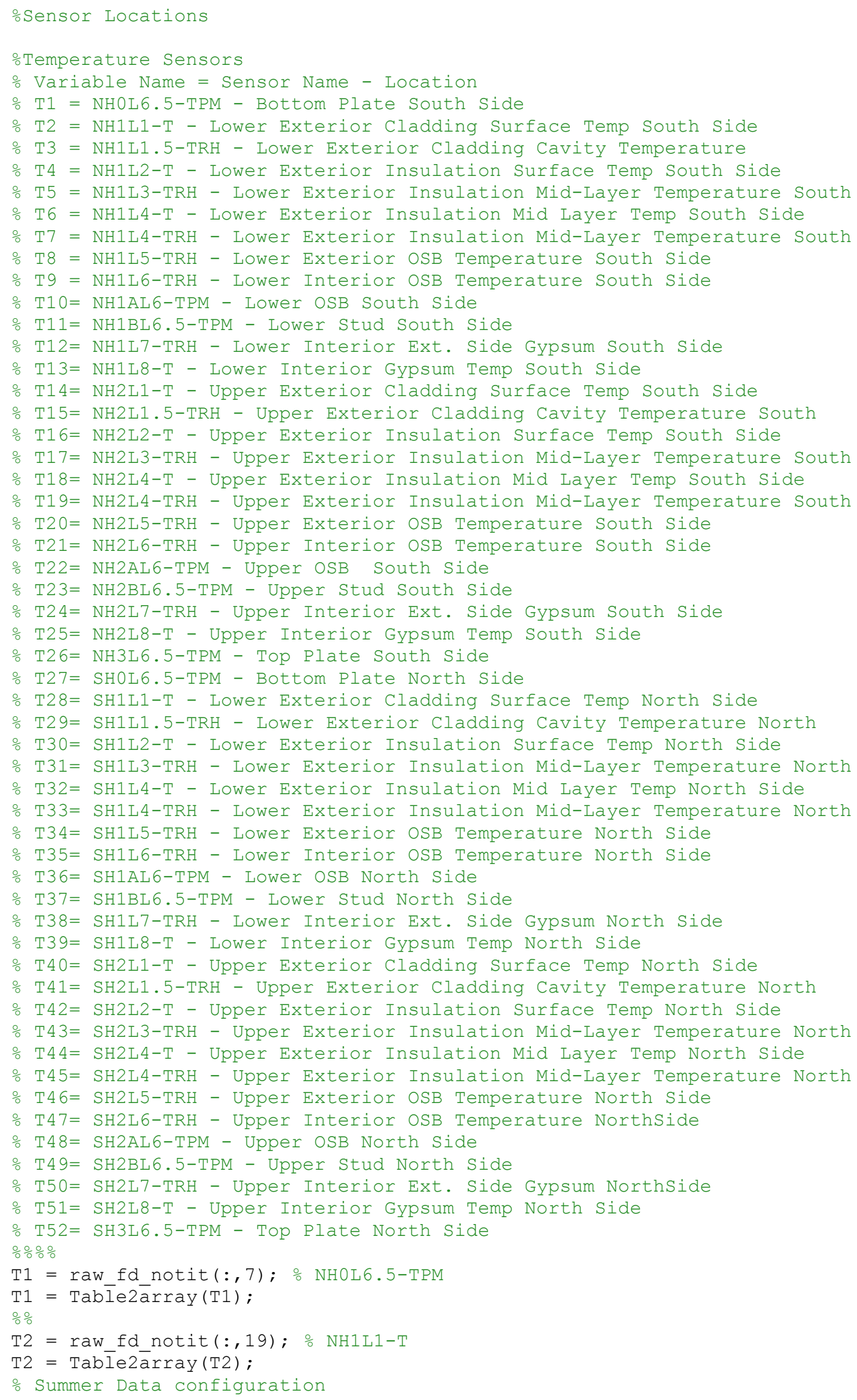




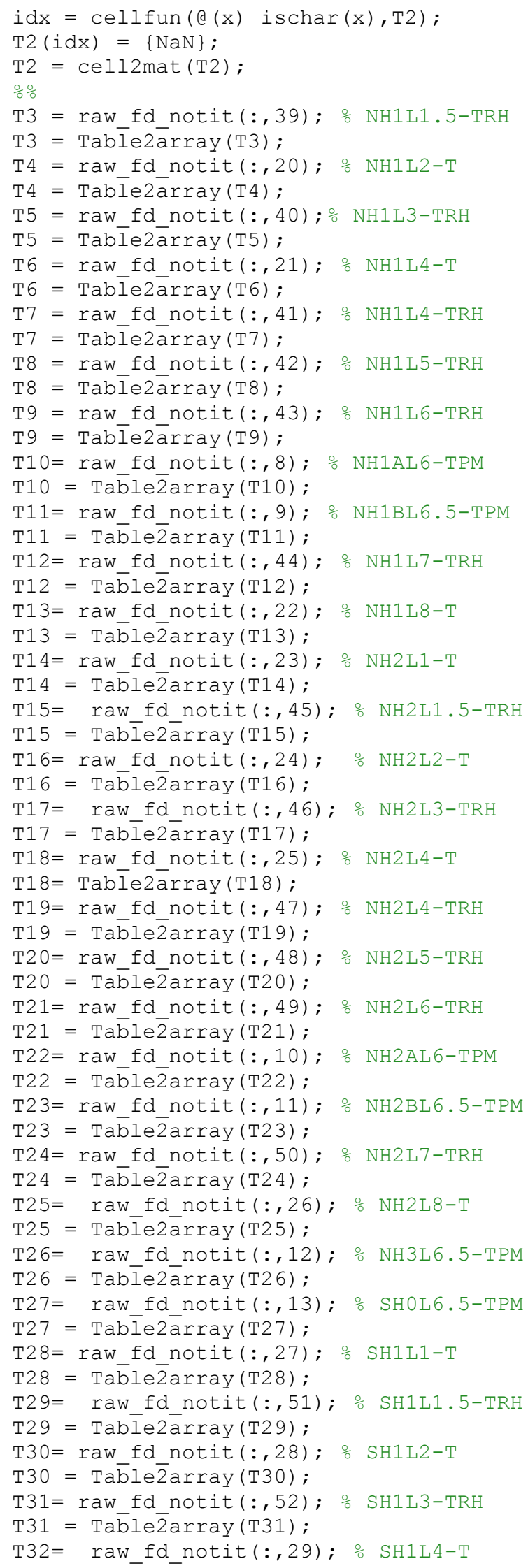




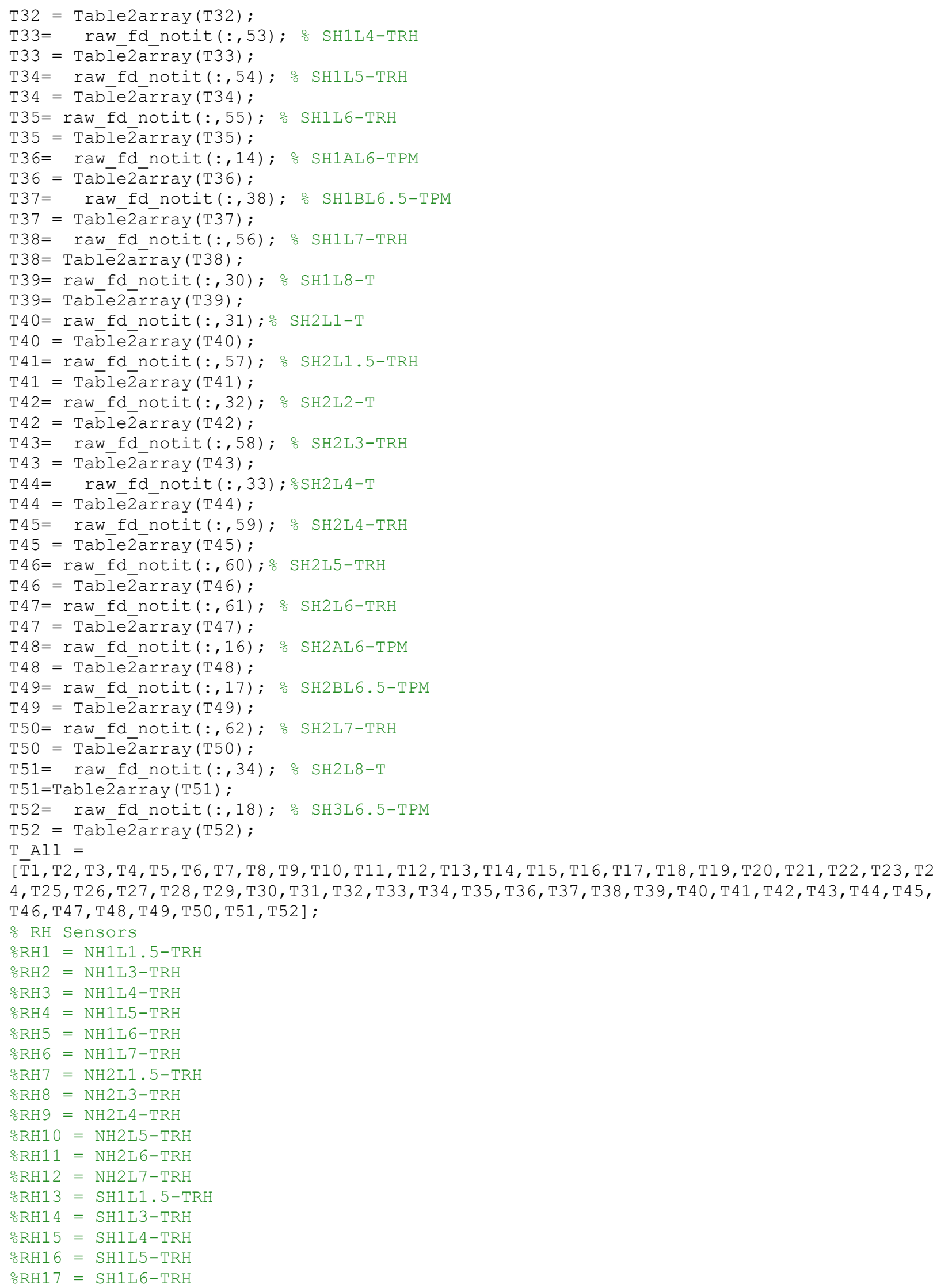




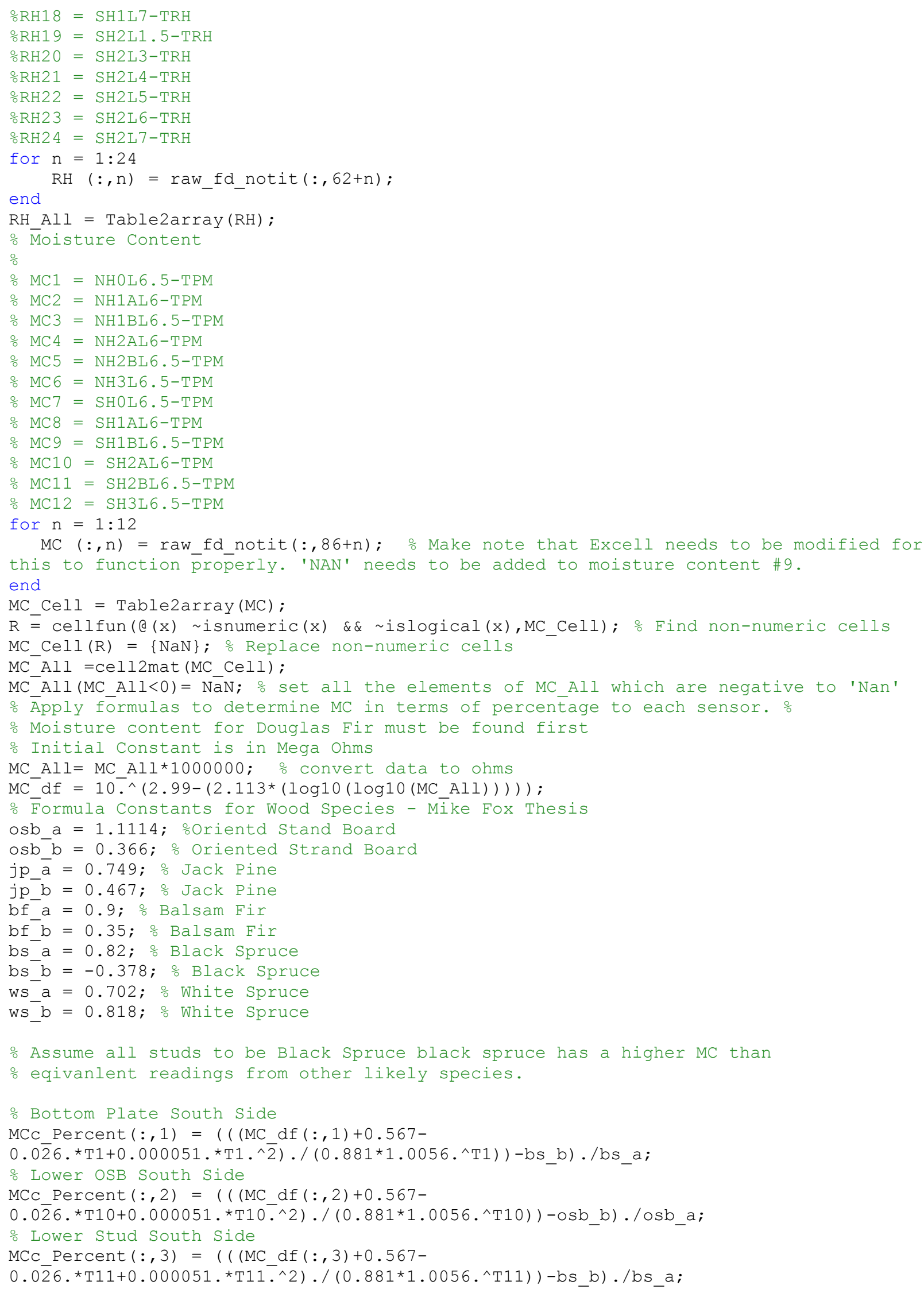




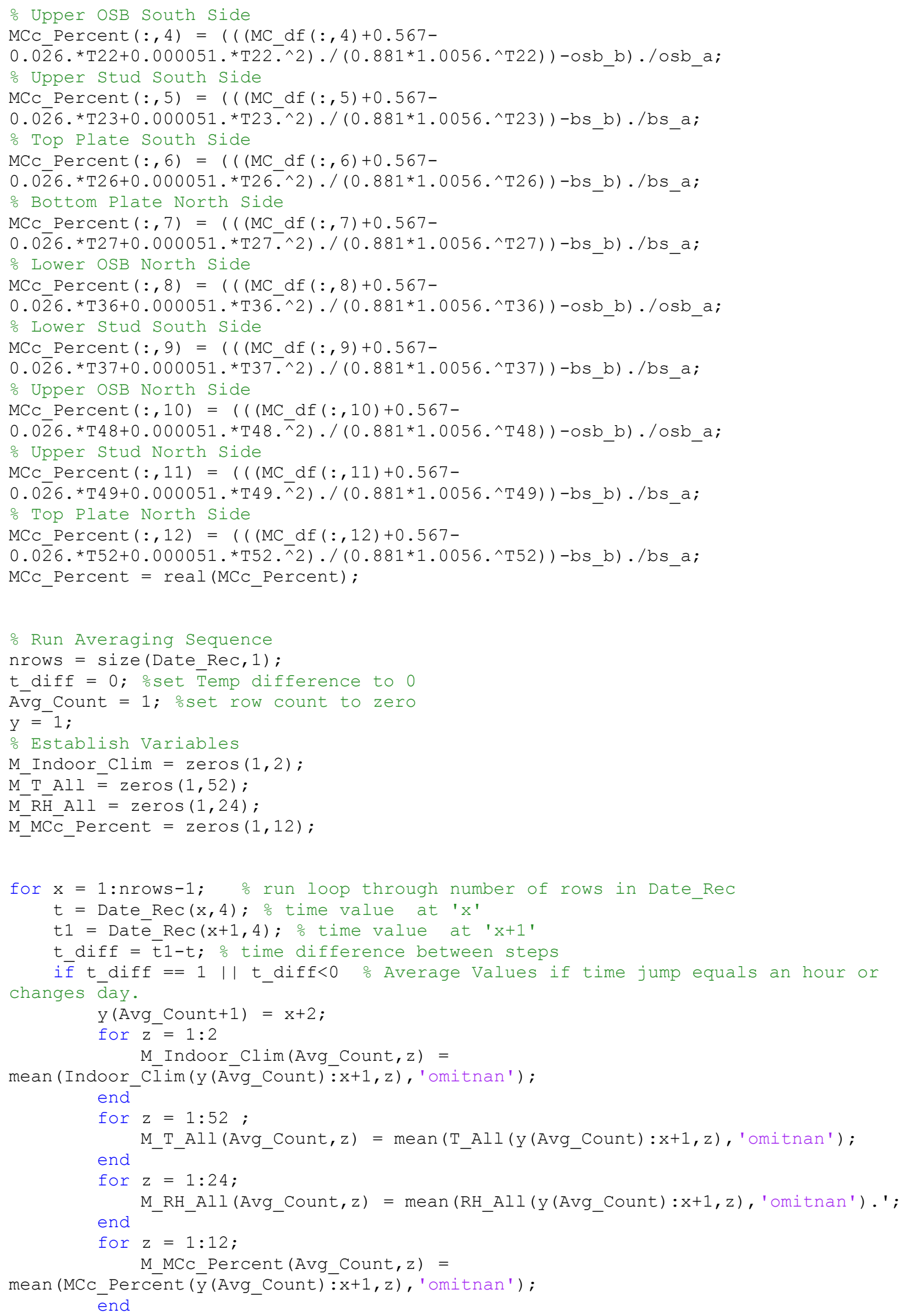




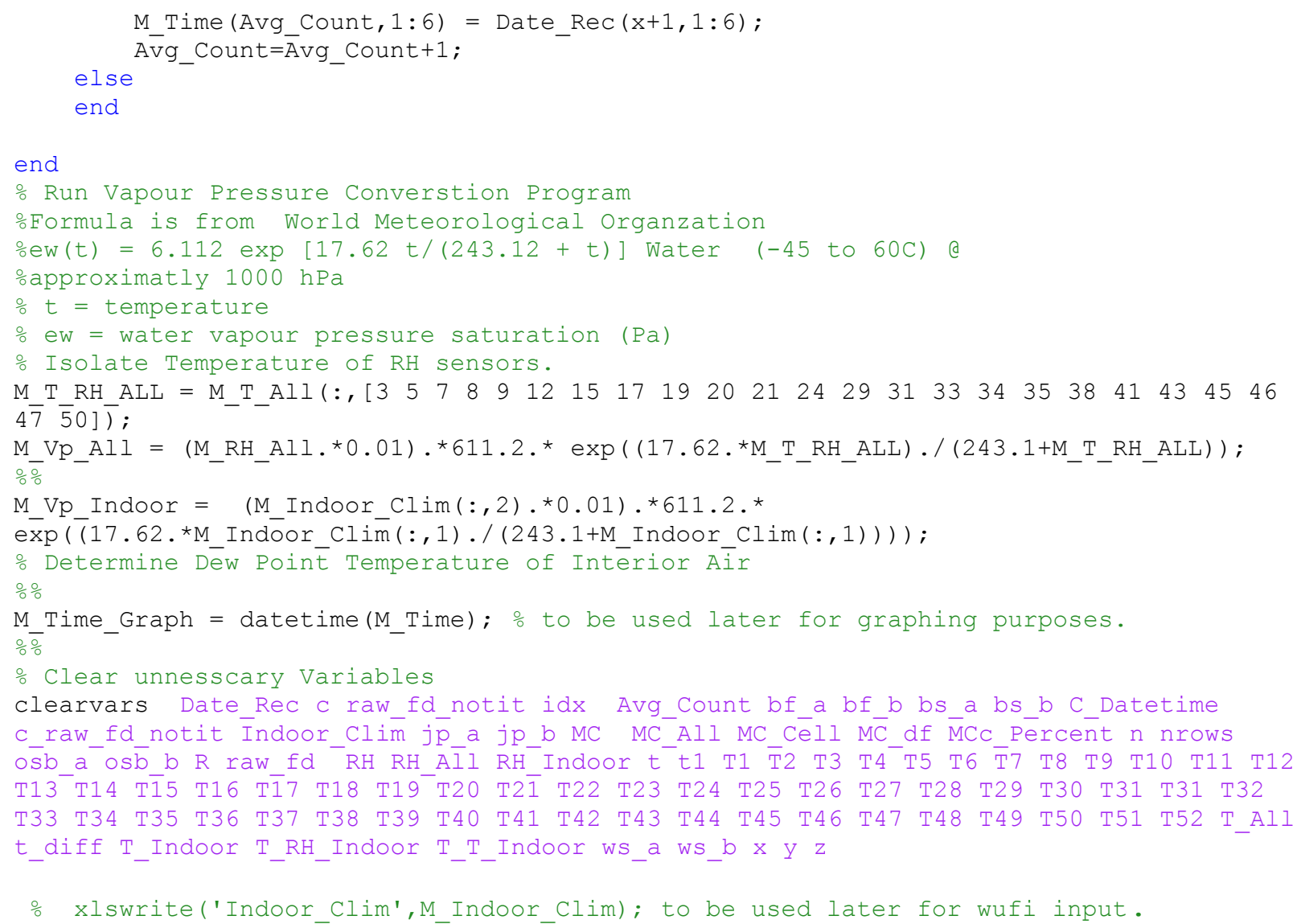

\section{Weather Processing Code}

This program is intended to import and append individual weather Excel Files and convert them 


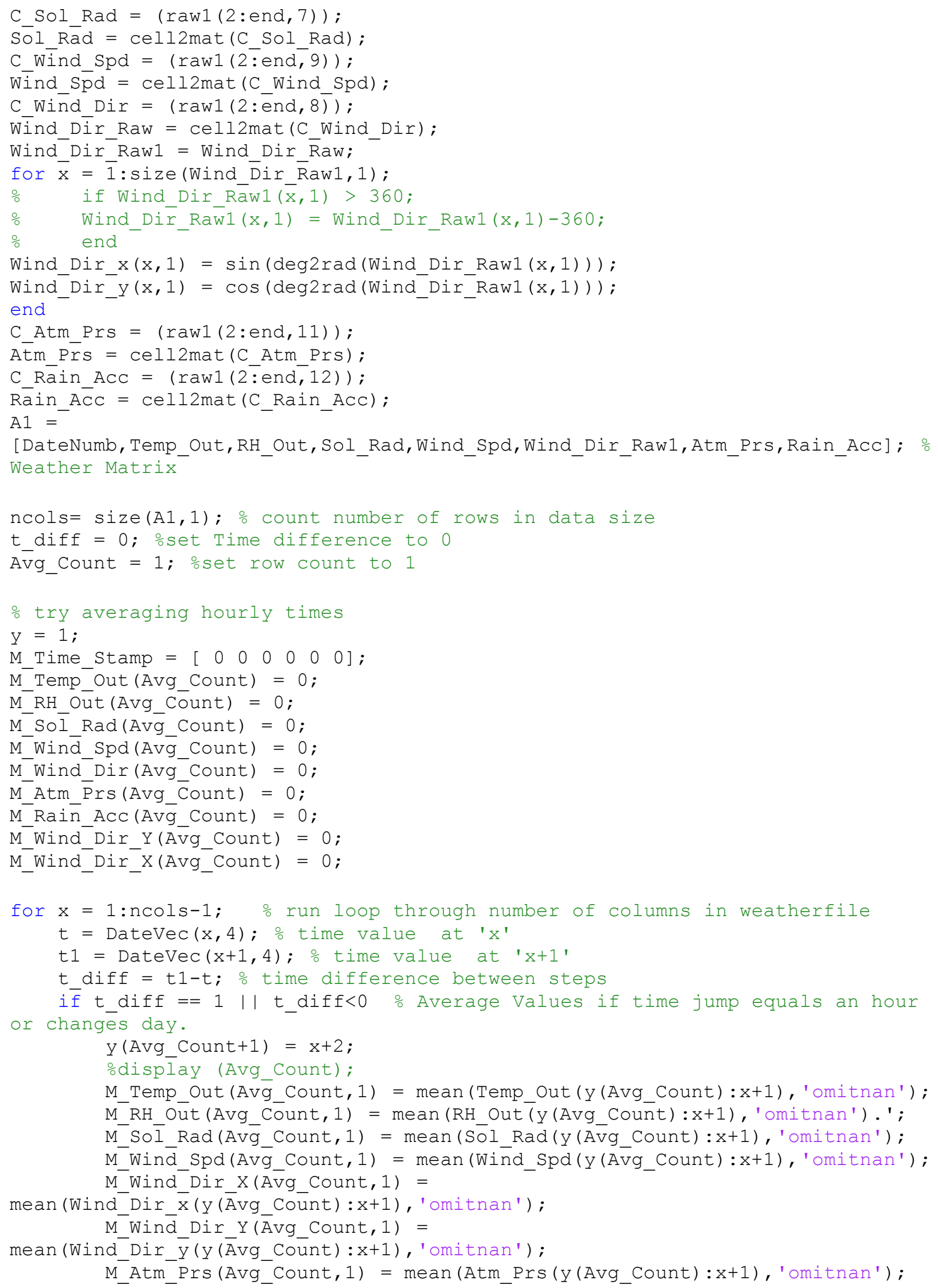




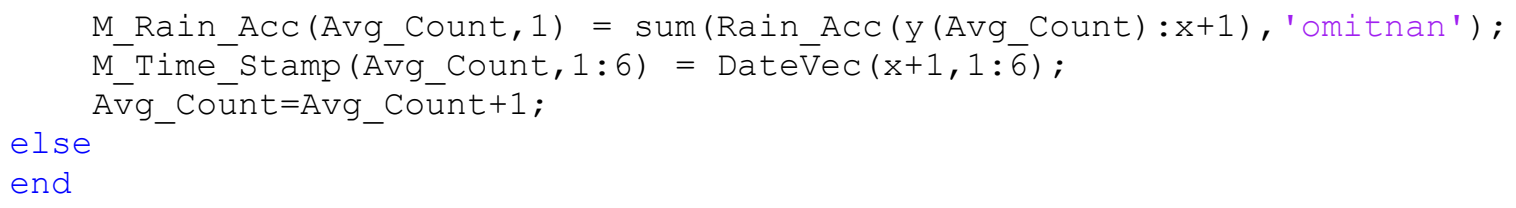




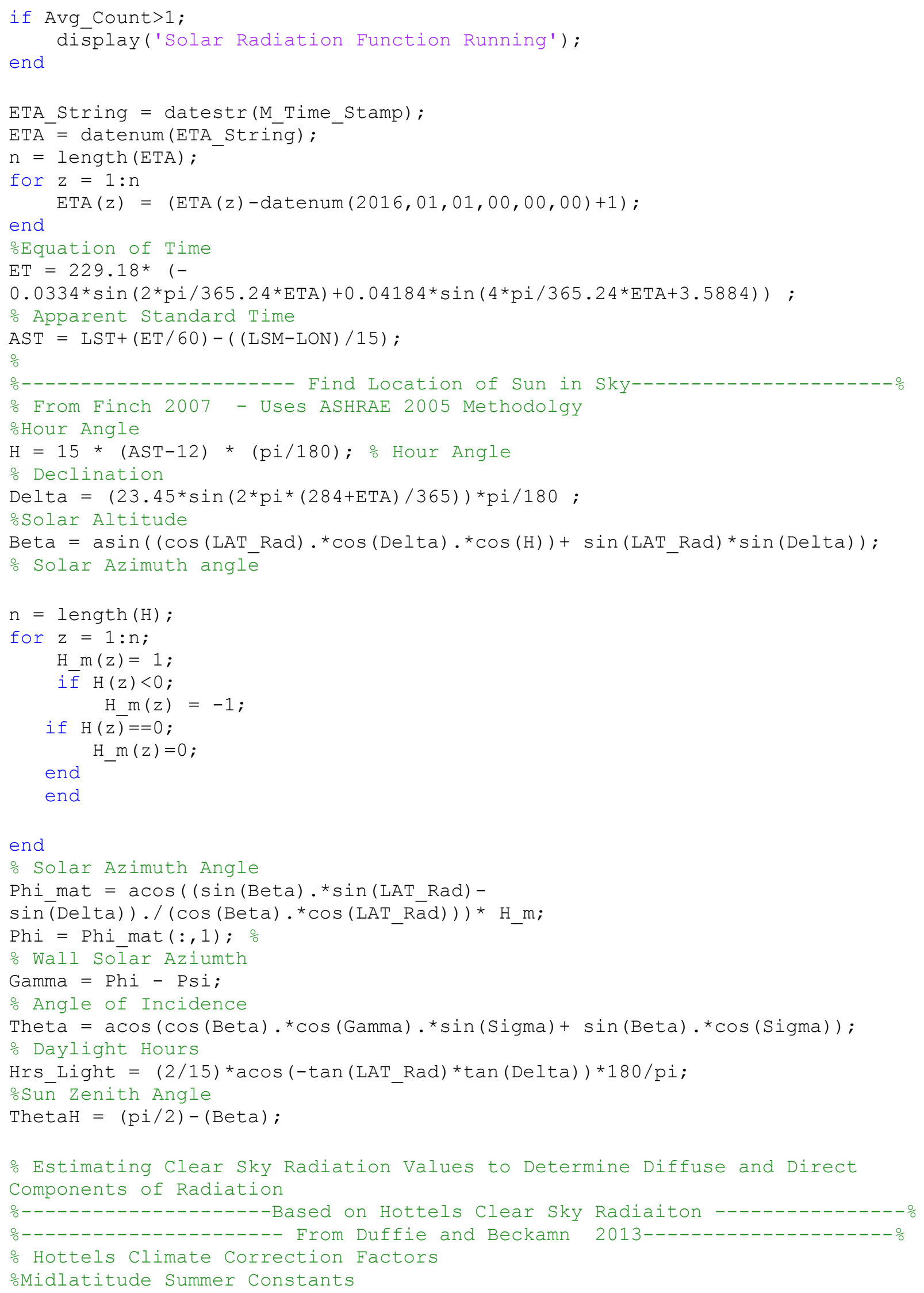




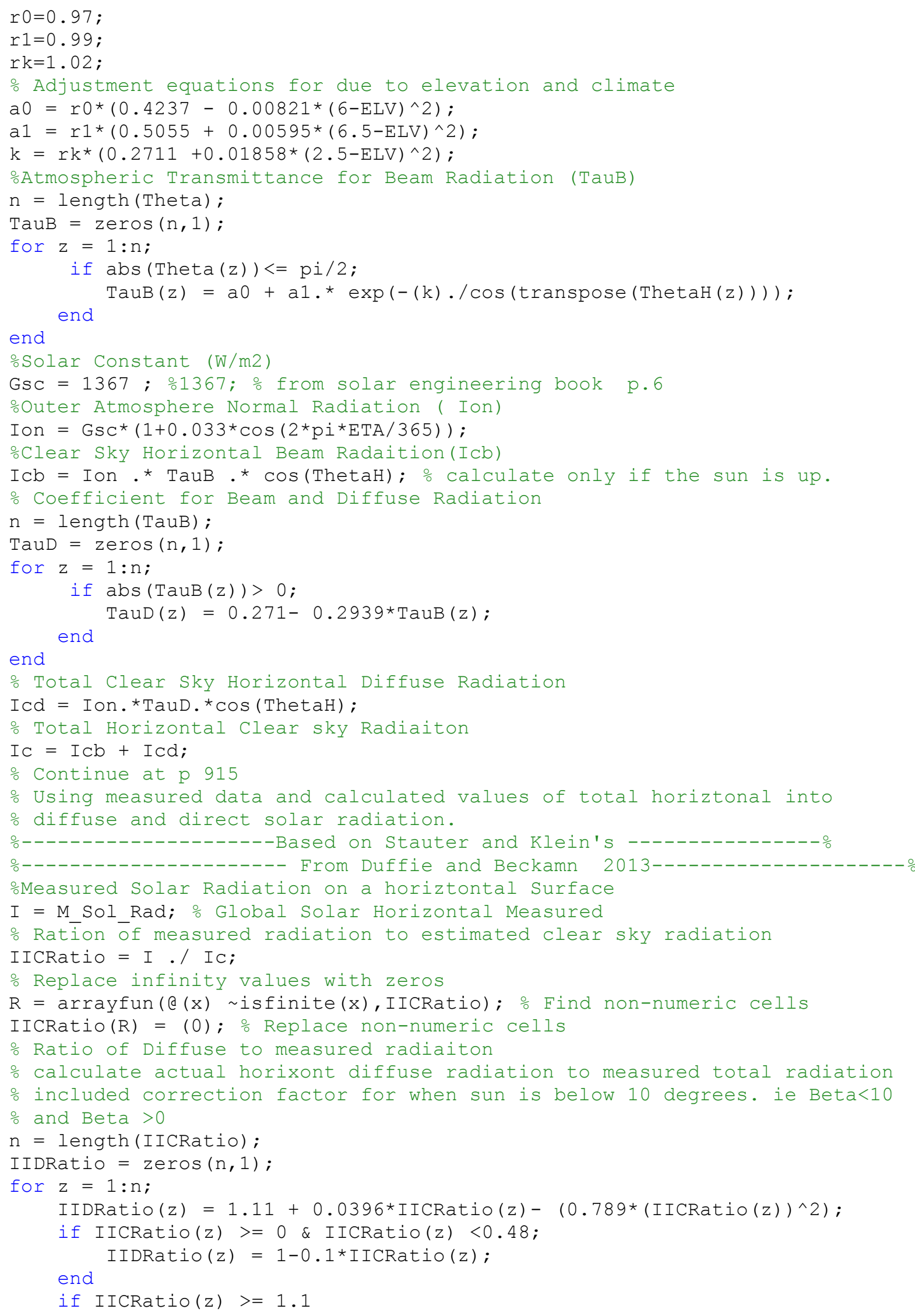




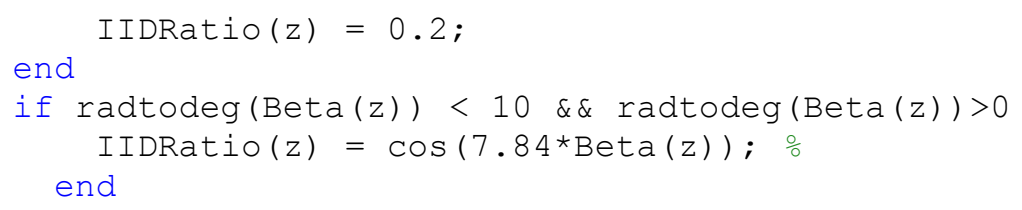

\section{HEAT FLUX DATA PROCESSING}

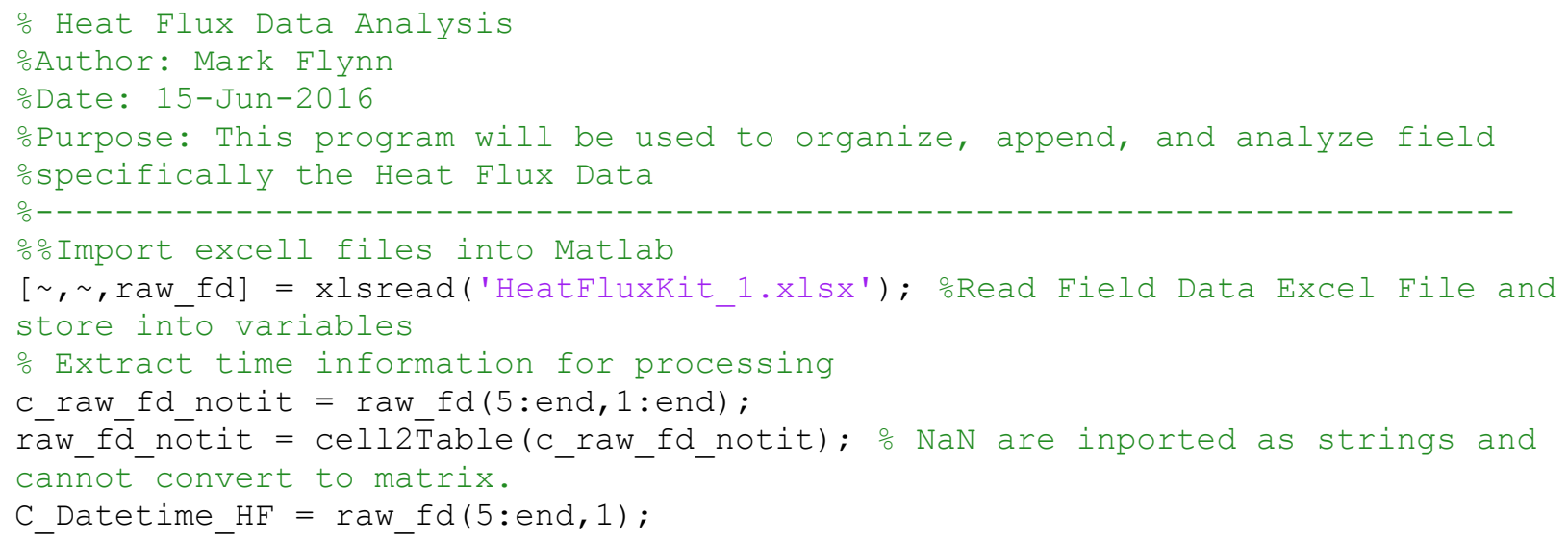




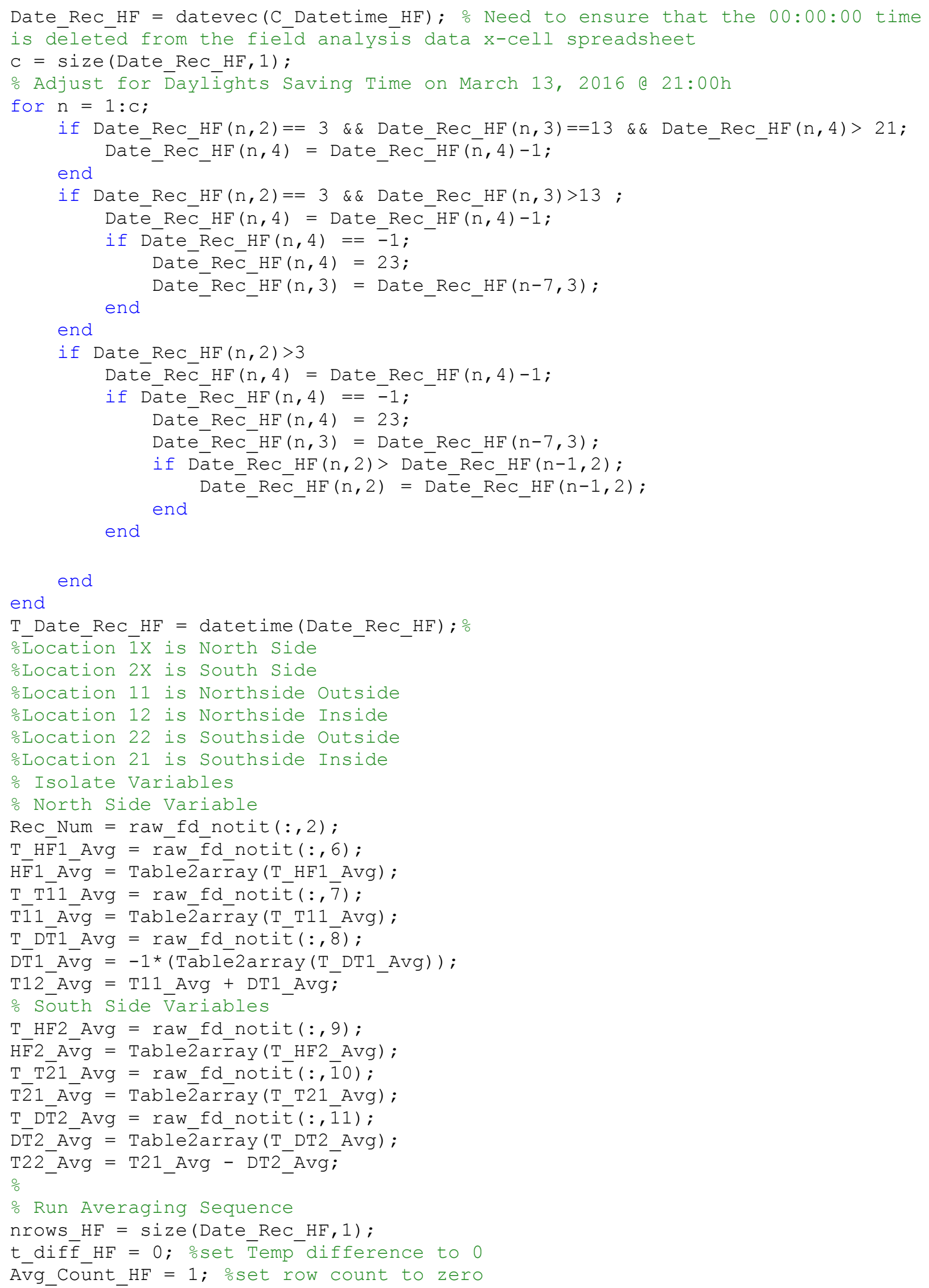




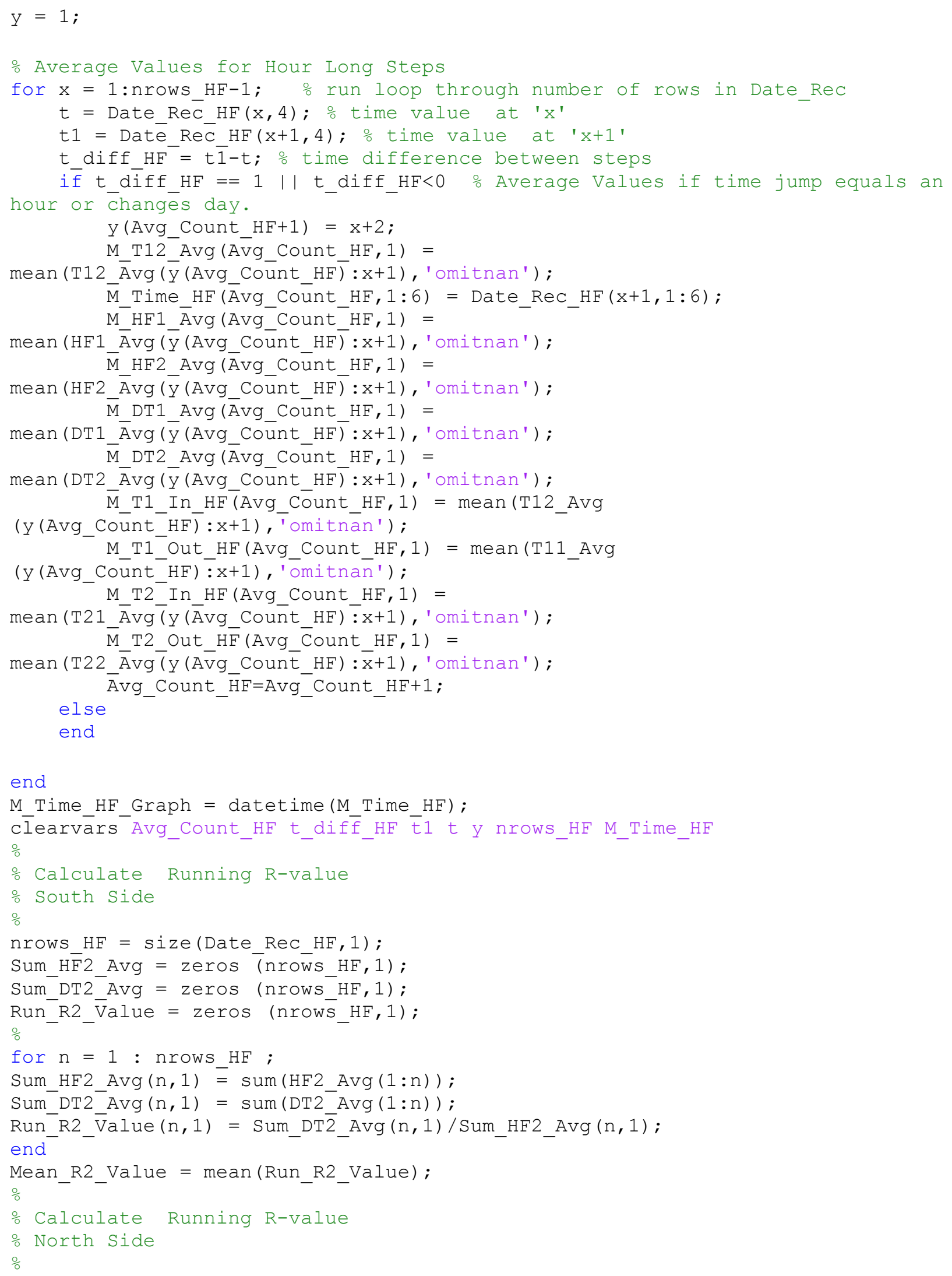




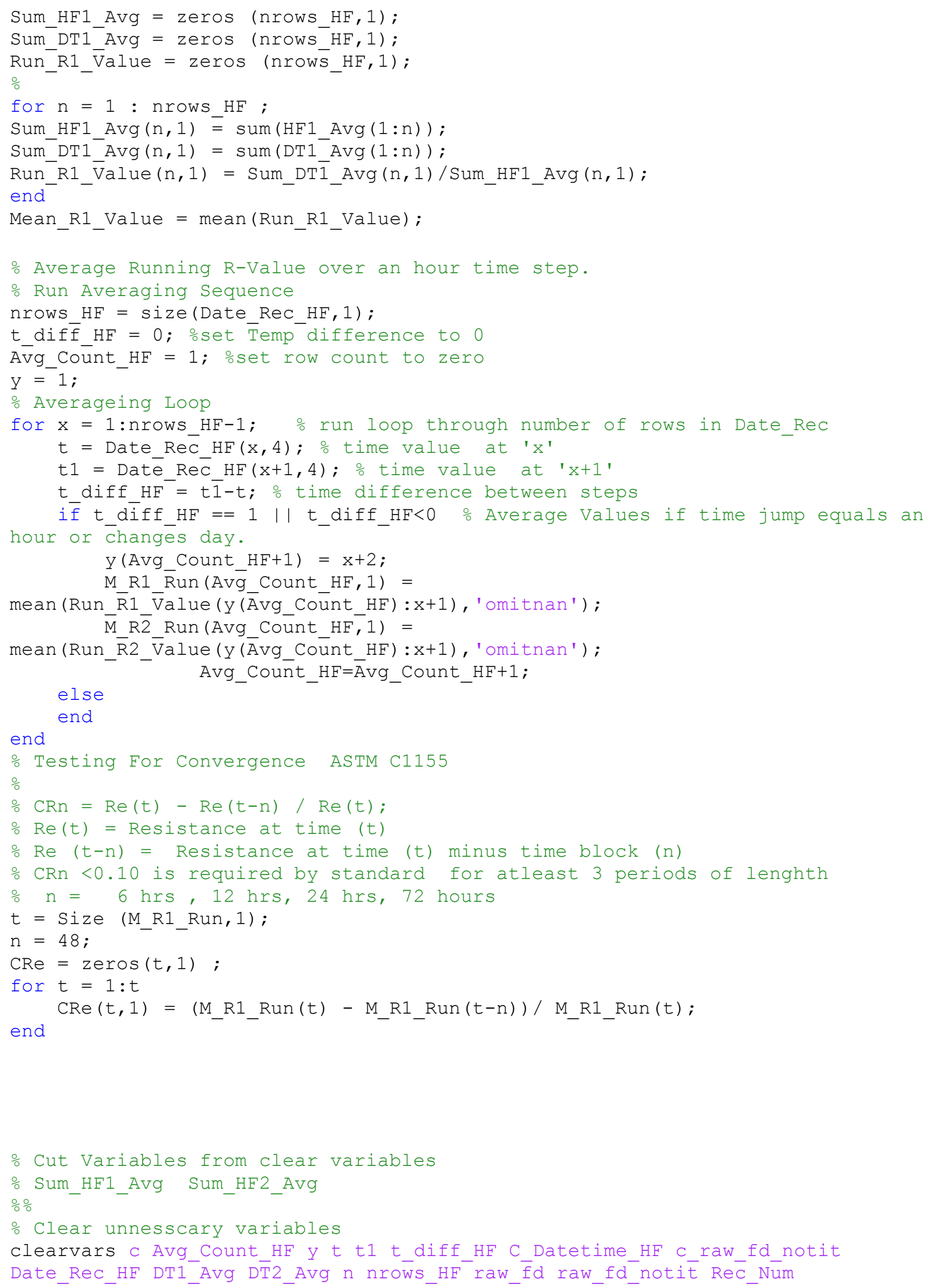




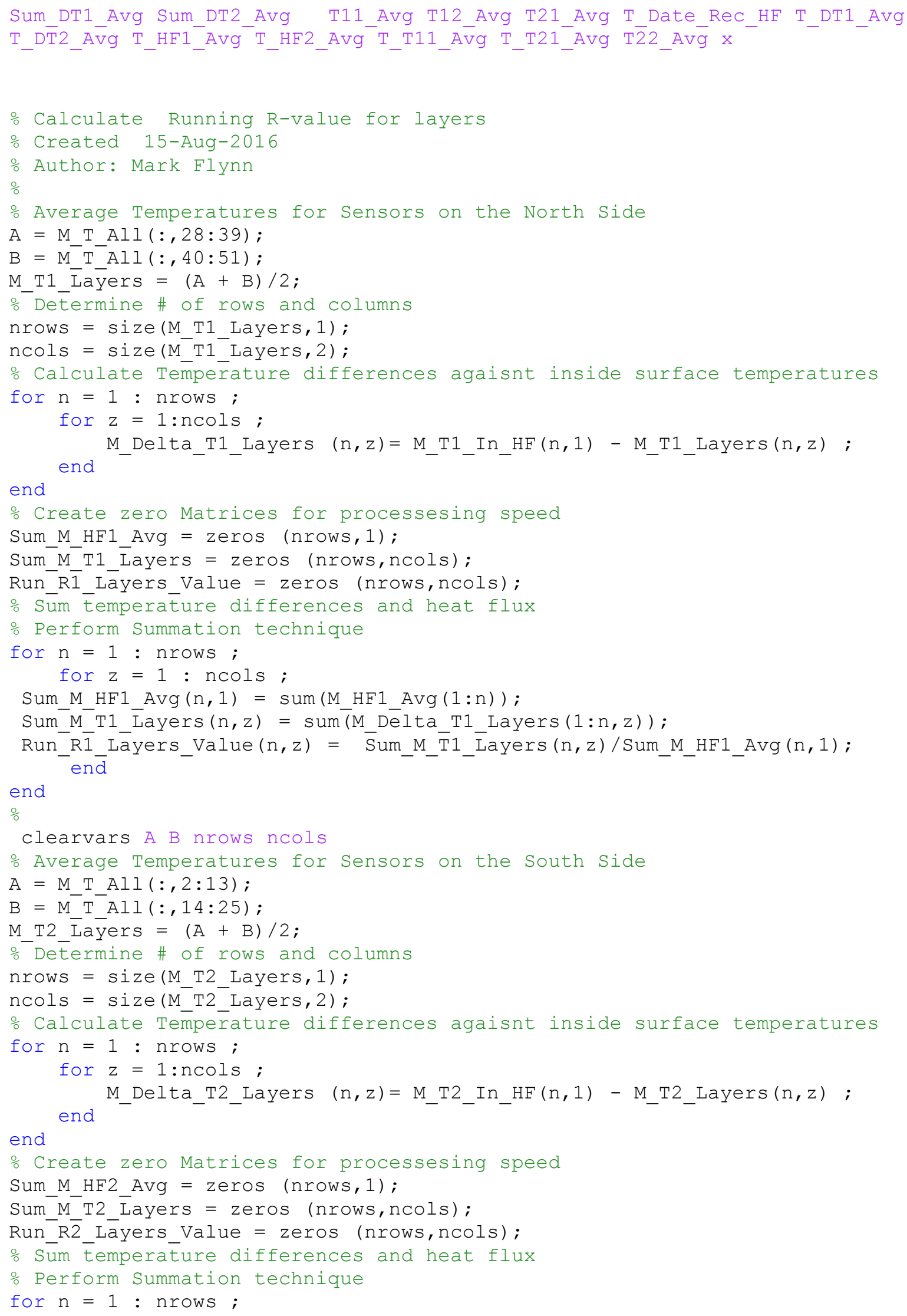


for $z=1: \operatorname{ncols}$;

$\operatorname{Sum} M \operatorname{HF} 2 \operatorname{Avg}(\mathrm{n}, 1)=\operatorname{sum}(\mathrm{M} \operatorname{HF} 2 \operatorname{Avg}(1: \mathrm{n}))$;

Sum M-T2 $\bar{L}$ -

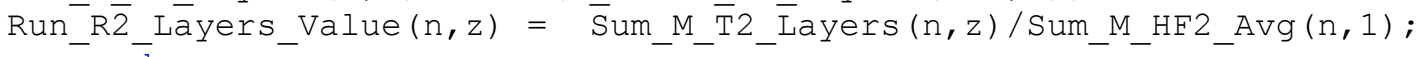
en $\bar{d}$

end

응응

응

\% M_Delta_T1_Layers

\% M-T1_Lāyers

\% $\bar{C} l e \bar{r}$ unnesscary varabiles

clearvars nrows A B nrows ncols Sum_M_HF1_Avg Sum_M_T1_Layers n z

M_T2_Layers M_Delta_T2_Layers Sum_M_HF2_Avgr Sum_M_T2_L̄̄ēers 


\title{
Appendix B : Sensor Location List
}

\author{
$\%$ Heat Flux \\ $\%$ Location $1 \mathrm{X}$ is North Side \\ $\%$ Location $2 \mathrm{X}$ is South Side \\ \%Location 11 is Northside Outside \\ $\%$ Location 12 is Northside Inside \\ $\%$ Location 22 is Southside Outside \\ \%Location 21 is Southside Inside
}

\section{*IT SHOULD BE NOTED THAT LABELLING OF SENSORS ACCIDENTLY SWITCHED NORTH AND SOUTH SIDES. THE PROGRAMING CODE HAS THE SENSORS AS LABELED.}

\section{THIS SECTION HAS CHANGED THE ORIENTATION TO SUIT ACTUAL CHARACTERISTICS OF SENSORS IN FIELD $* *$}

\author{
\%Temperature Sensors \\ $\% \mathrm{~T} 1=$ SH0L6.5-TPM - Bottom Plate South Side \\ $\% \mathrm{~T} 2=$ SH1L0-T - Lower Exterior Cladding Surface Temp South Side \\ $\% \mathrm{~T} 3=\mathrm{SH} 1 \mathrm{~L} 1.5-\mathrm{TRH}$ - Lower Exterior Cladding Cavity Temperature \\ $\%$ T4 $=$ SH1L2-T - Lower Exterior Insulation Surface Temp South Side \\ $\%$ T5 $=$ SH1L3-TRH - Lower Exterior Insulation Mid-Layer Temperature South \\ $\%$ T6 = SH1L4-T - Lower Exterior Insulation Mid Layer Temp South Side \\ $\% \mathrm{~T} 7=\mathrm{SH} 1 \mathrm{~L} 4-\mathrm{TRH}-$ Lower Exterior Insulation Mid-Layer Temperature South \\ $\%$ T8 $=$ SH1L5-TRH - Lower Exterior OSB Temperature South Side \\ $\%$ T9 = SH1L6-TRH - Lower Interior OSB Temperature South Side \\ $\% \mathrm{~T} 10=\mathrm{SH} 1 \mathrm{AL} 6-\mathrm{TPM}$ - Lower OSB South Side \\ $\%$ T11 = SH1BL6.5-TPM - Lower Stud South Side \\ $\% \mathrm{~T} 12=$ SH1L7-TRH - Lower Interior Ext. Side Gypsum South Side \\ $\%$ T13= SH1L8-T - Lower Interior Gypsum Temp South Side \\ $\%$ T14= SH2L0-T - Upper Exterior Cladding Surface Temp South Side \\ $\% \mathrm{~T} 15=\mathrm{SH} 2 \mathrm{~L} 1.5-\mathrm{TRH}-$ Upper Exterior Cladding Cavity Temperature South \\ $\%$ T16= SH2L2-T - Upper Exterior Insulation Surface Temp South Side \\ $\%$ T17= SH2L3-TRH - Upper Exterior Insulation Mid-Layer Temperature South \\ $\%$ T18= SH2L4-T - Upper Exterior Insulation Mid Layer Temp South Side \\ $\% \mathrm{~T} 19=\mathrm{SH} 2 \mathrm{~L} 4-\mathrm{TRH}-$ Upper Exterior Insulation Mid-Layer Temperature South \\ $\%$ T20 $=$ SH2L5-TRH - Upper Exterior OSB Temperature South Side \\ $\%$ T21= SH2L6-TRH - Upper Interior OSB Temperature South Side \\ $\%$ T22= SH2AL6-TPM - Upper OSB South Side \\ $\%$ T23= SH2BL6.5-TPM - Upper Stud South Side \\ $\%$ T24= SH2L7-TRH - Upper Interior Ext. Side Gypsum South Side
}


$\% \mathrm{~T} 25=$ SH2L8-T - Upper Interior Gypsum Temp South Side

$\%$ T26= SH3L6.5-TPM - Top Plate South Side

$\% \mathrm{~T} 27=$ NH0L6.5-TPM - Bottom Plate North Side

$\%$ T28 $=$ NH1L0-T - Lower Exterior Cladding Surface Temp North Side

$\%$ T29= NH1L1.5-TRH - Lower Exterior Cladding Cavity Temperature North

$\% \mathrm{~T} 30=$ NH1L2-T - Lower Exterior Insulation Surface Temp North Side

$\% \mathrm{~T} 31=\mathrm{NH} 1 \mathrm{~L} 3-\mathrm{TRH}-$ Lower Exterior Insulation Mid-Layer Temperature North

$\% \mathrm{~T} 32=\mathrm{NH} 1 \mathrm{~L} 4-\mathrm{T}$ - Lower Exterior Insulation Mid Layer Temp North Side

$\%$ T33 $=$ NH1L4-TRH - Lower Exterior Insulation Mid-Layer Temperature North

$\%$ T34= NH1L5-TRH - Lower Exterior OSB Temperature North Side

$\%$ T35 = NH1L6-TRH - Lower Interior OSB Temperature North Side

$\%$ T36=NH1AL6-TPM - Lower OSB North Side

$\% \mathrm{~T} 37=$ NH1BL6.5-TPM - Lower Stud North Side

$\%$ T38= NH1L7-TRH - Lower Interior Ext. Side Gypsum North Side

$\% \mathrm{~T} 39=$ NH1L8-T - Lower Interior Gypsum Temp North Side

$\%$ T40 $=$ NH2L0-T - Upper Exterior Cladding Surface Temp North Side

$\% \mathrm{~T} 41=\mathrm{NH} 2 \mathrm{~L} 1.5-\mathrm{TRH}$ - Upper Exterior Cladding Cavity Temperature North

$\%$ T42 $=$ NH2L2-T - Upper Exterior Insulation Surface Temp North Side

$\% \mathrm{~T} 43=\mathrm{NH} 2 \mathrm{~L} 3-\mathrm{TRH}-$ Upper Exterior Insulation Mid-Layer Temperature North

$\%$ T44= NH2L4-T - Upper Exterior Insulation Mid Layer Temp North Side

$\%$ T45= NH2L4-TRH - Upper Exterior Insulation Mid-Layer Temperature North

$\%$ T46= NH2L5-TRH - Upper Exterior OSB Temperature North Side

$\%$ T47 = NH2L6-TRH - Upper Interior OSB Temperature NorthSide

$\%$ T48= NH2AL6-TPM - Upper OSB North Side

$\%$ T49= NH2BL6.5-TPM - Upper Stud North Side

$\%$ T50= NH2L7-TRH - Upper Interior Ext. Side Gypsum NorthSide

$\%$ T51= NH2L8-T - Upper Interior Gypsum Temp North Side

$\%$ T52 = NH3L6.5-TPM - Top Plate North Side

\%Relative Humidity

$\%$ RH1 $=$ SH1L1.5-TRH

$\%$ RH2 $=$ SH1L3-TRH

$\%$ RH3 $=$ SH1L4-TRH

$\%$ RH4 = SH1L5-TRH

$\%$ RH5 = SH1L6-TRH

$\%$ RH6 $=$ SH1L7-TRH

$\% \mathrm{RH} 7=\mathrm{SH} 2 \mathrm{~L} 1.5-\mathrm{TRH}$

$\%$ RH $8=$ SH2L $3-\mathrm{TRH}$

$\%$ RH9 $=$ SH2L4-TRH

$\%$ RH10 $=$ SH2L $5-$ TRH

$\%$ RH11 $=$ SH2L6-TRH

$\%$ RH12 $=$ SH2L 7-TRH

$\%$ RH13 $=$ NH1L1.5-TRH

$\%$ RH14 $=$ NH1L3-TRH

$\%$ RH15 = NH1L4-TRH 
$\%$ RH16 $=$ NH1L5-TRH

$\%$ RH17 = NH1L6-TRH

$\%$ RH1 $=$ NH1L 7-TRH

$\%$ RH19 $=$ NH2L1.5-TRH

$\%$ RH20 $=$ NH2L $3-\mathrm{TRH}$

$\%$ RH21 $=$ NH2L4-TRH

$\%$ RH22 $=$ NH2L5-TRH

$\%$ RH23 = NH2L6-TRH

$\%$ RH24 = NH2L 7-TRH

\%Moisture Content

$\% \mathrm{MC} 1=\mathrm{SH} 0 \mathrm{~L} 6.5-\mathrm{TPM}$

$\% \mathrm{MC} 2=\mathrm{SH} 1 \mathrm{AL} 6-\mathrm{TPM}$

$\%$ MC3 = SH1BL6.5-TPM

$\% \mathrm{MC} 4=\mathrm{SH} 2 \mathrm{AL} 6-\mathrm{TPM}$

$\%$ MC5 = SH2BL6.5-TPM

$\%$ MC6 $=$ SH3L6.5-TPM

$\%$ MC7 $=$ NH0L6.5-TPM

$\%$ MC8 = NH1 AL6-TPM

$\%$ MC9 = NH1BL6.5-TPM

$\%$ MC10 = NH2AL6-TPM

$\% \mathrm{MC} 11=\mathrm{NH} 2 \mathrm{BL} 6.5-\mathrm{TPM}$

$\% \mathrm{MC} 12=\mathrm{NH} 3 \mathrm{~L} 6.5-\mathrm{TPM}$ 


\section{Appendix C: Field Data Logging Code}

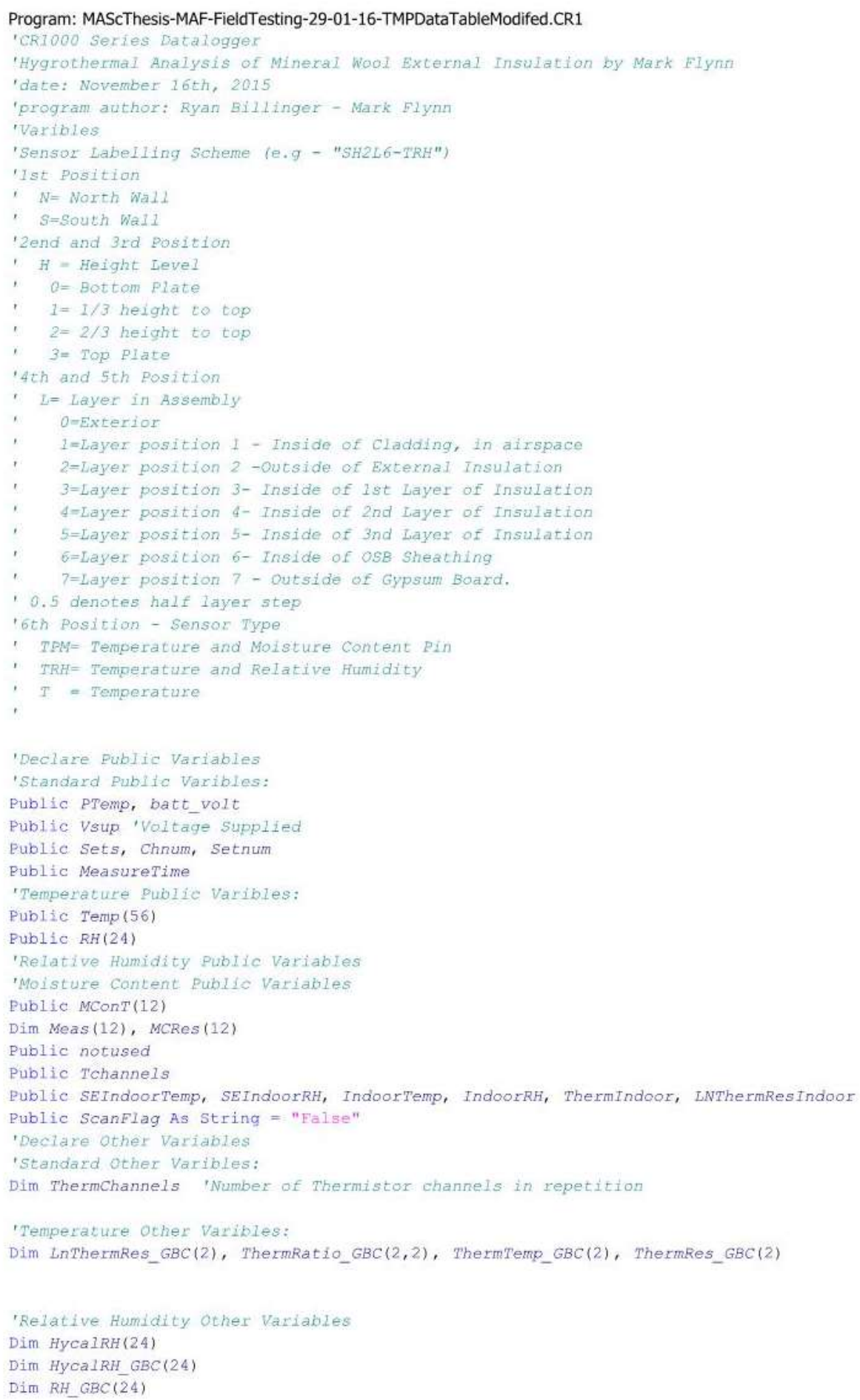




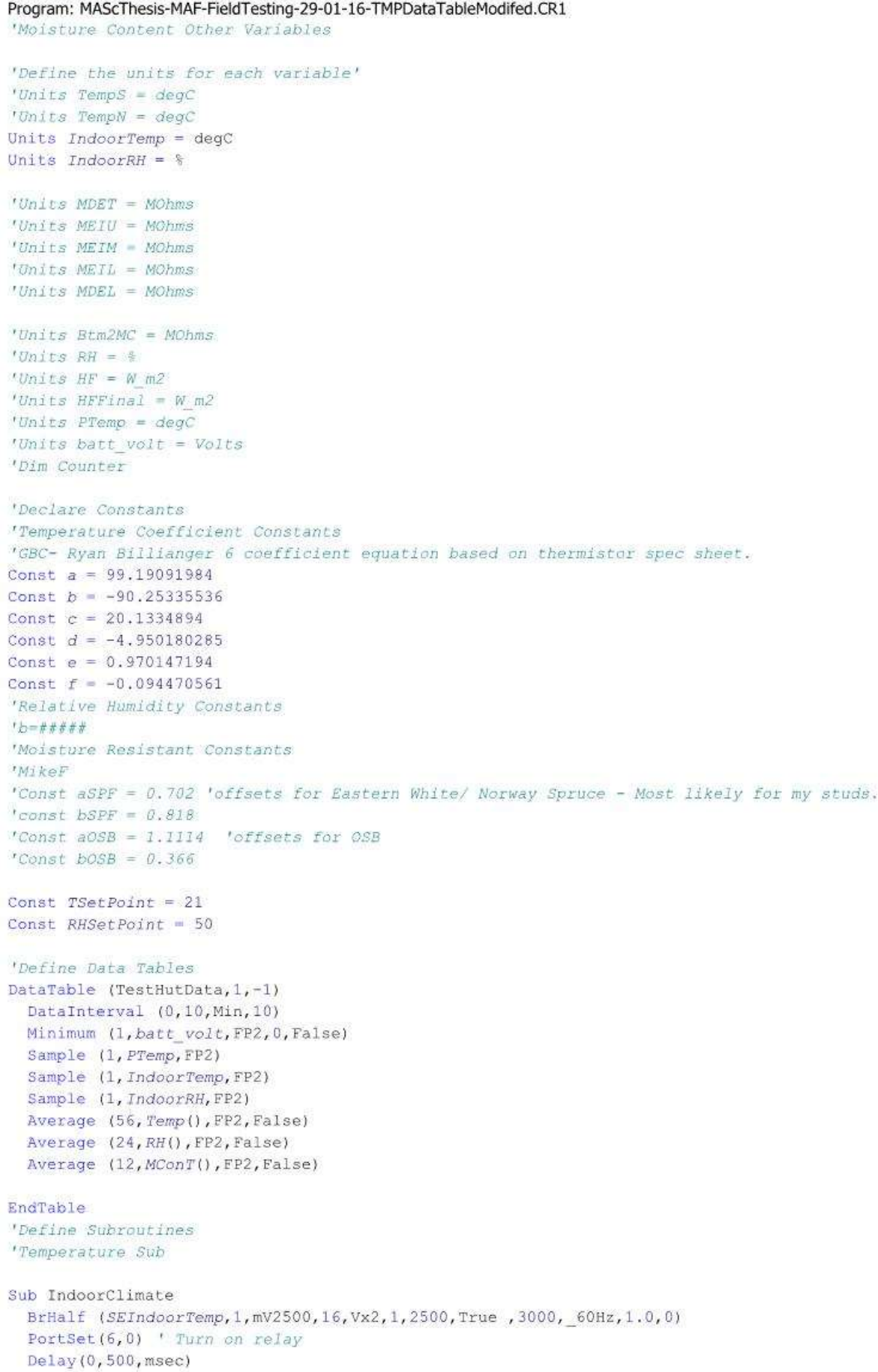

Page 2 of 5 


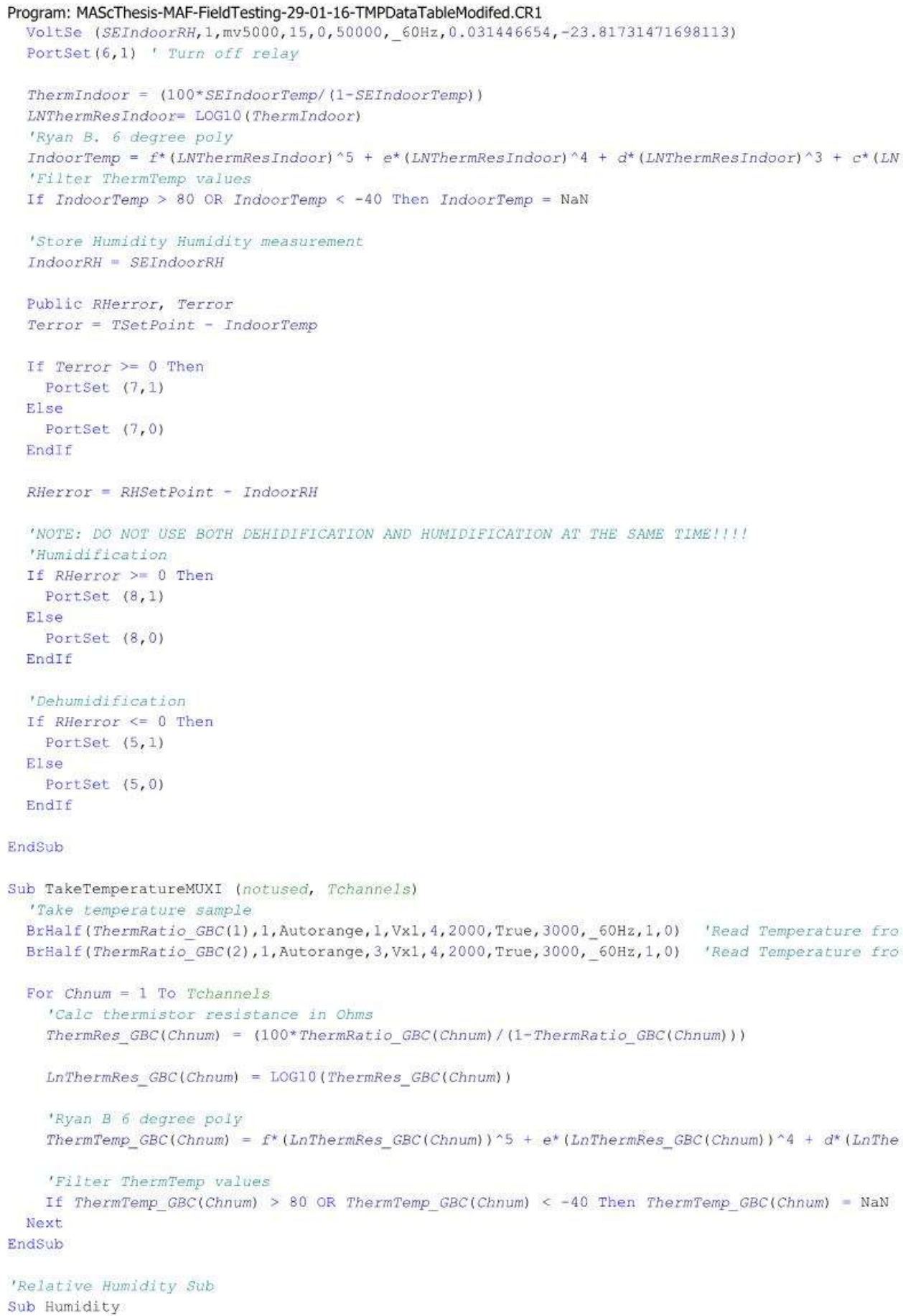

Page 3 of 5 


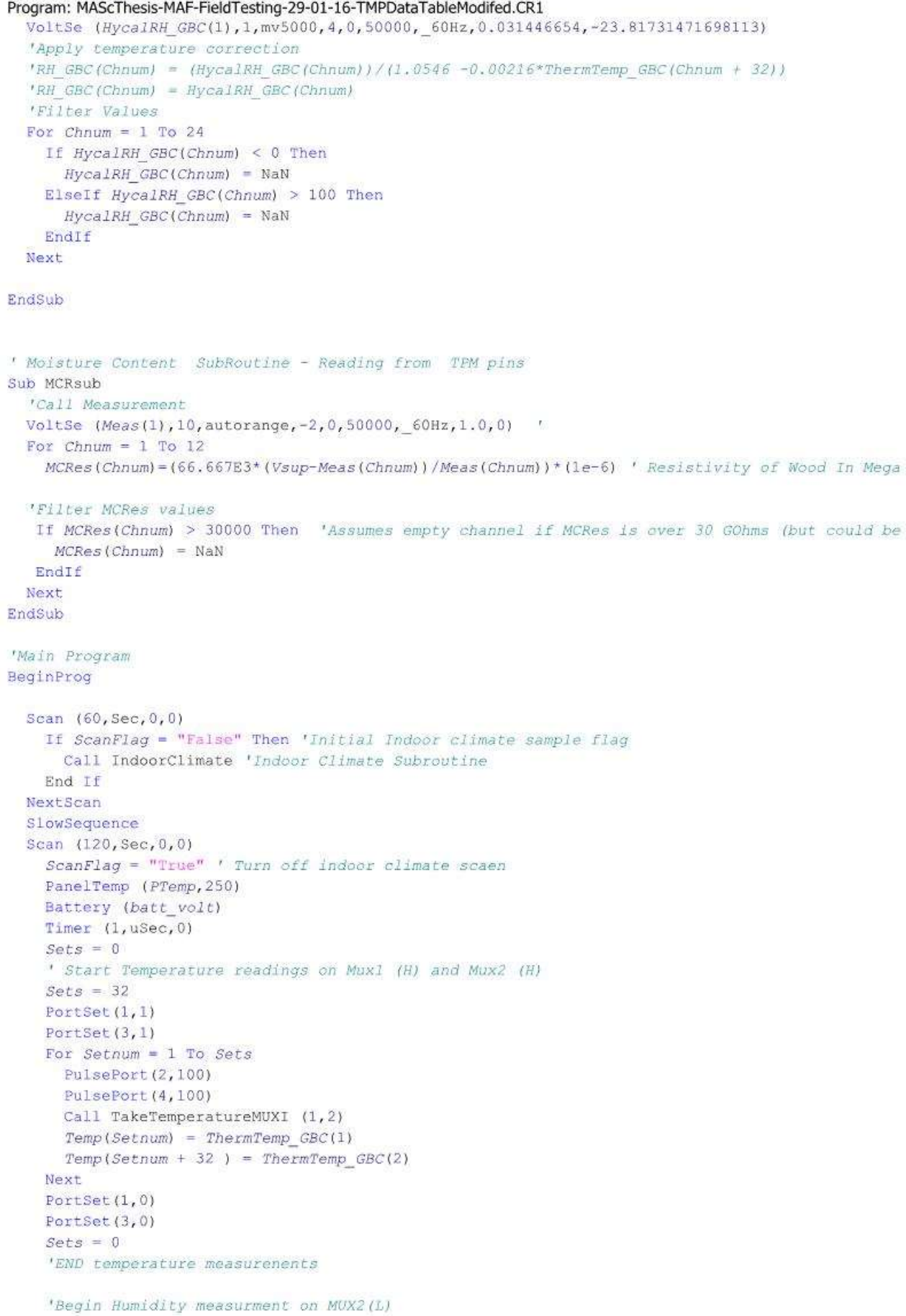

Page 4 of 5 


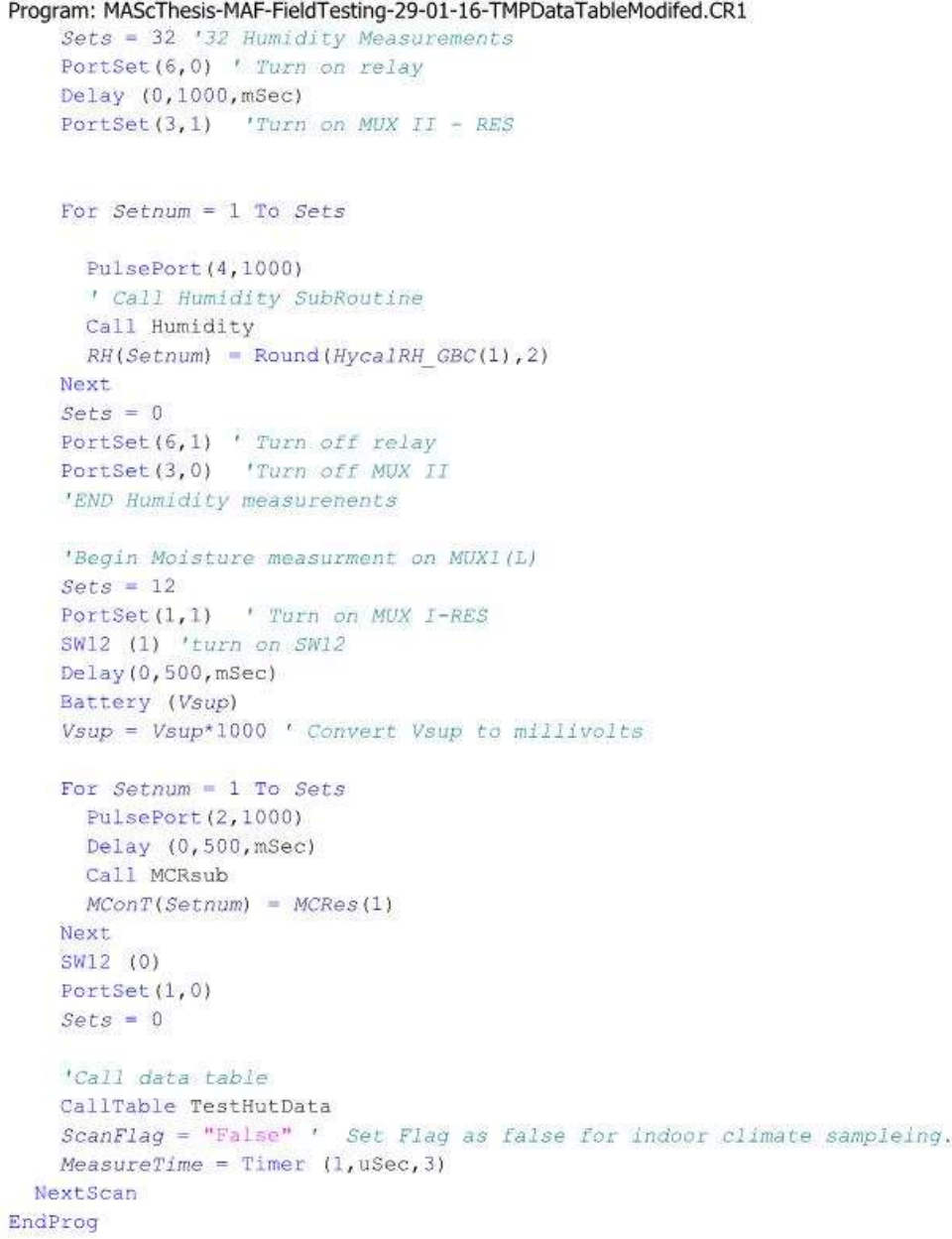

Page 5 of 5 


\section{Appendix D: Heat Flux Data Logging Code}

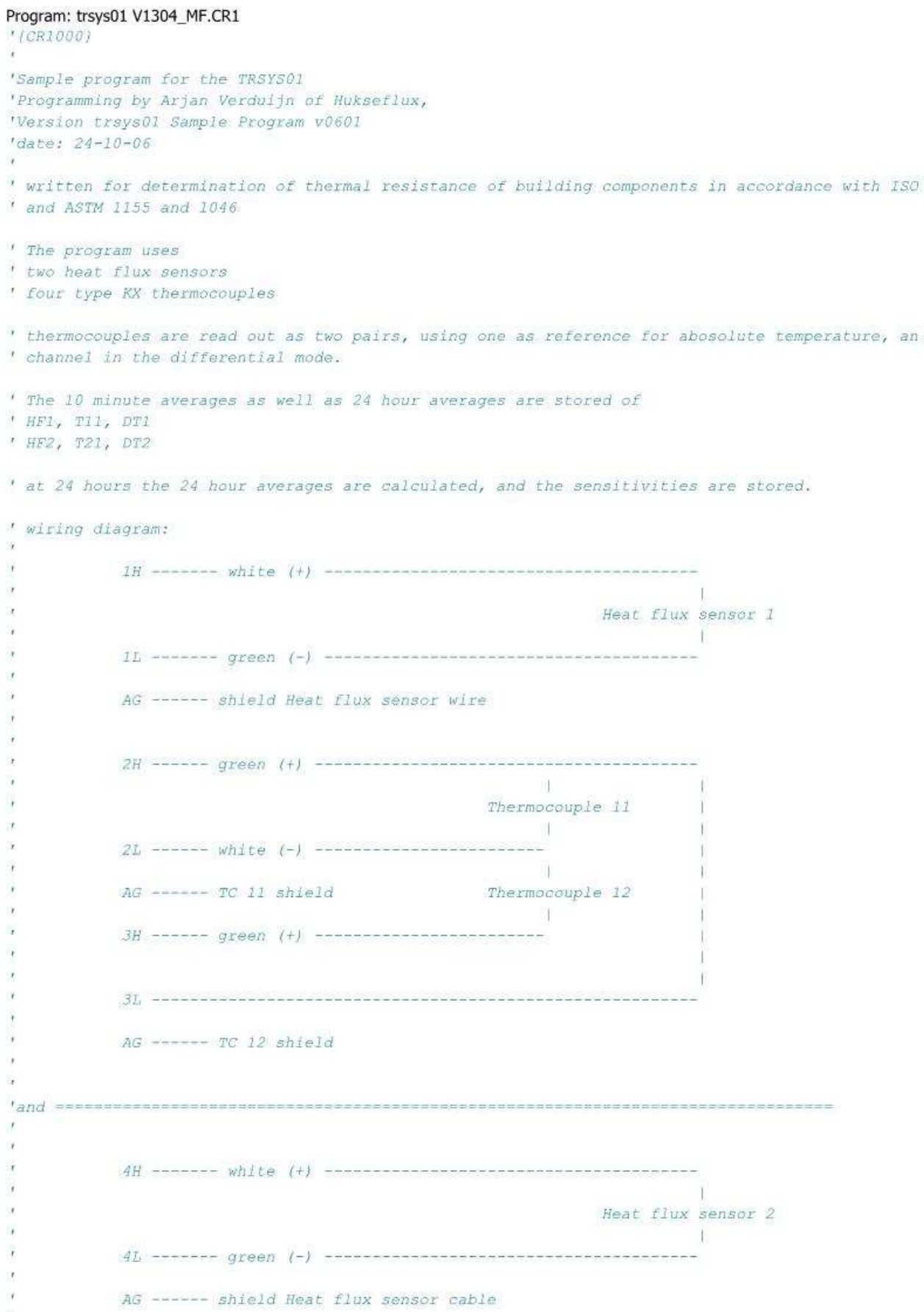




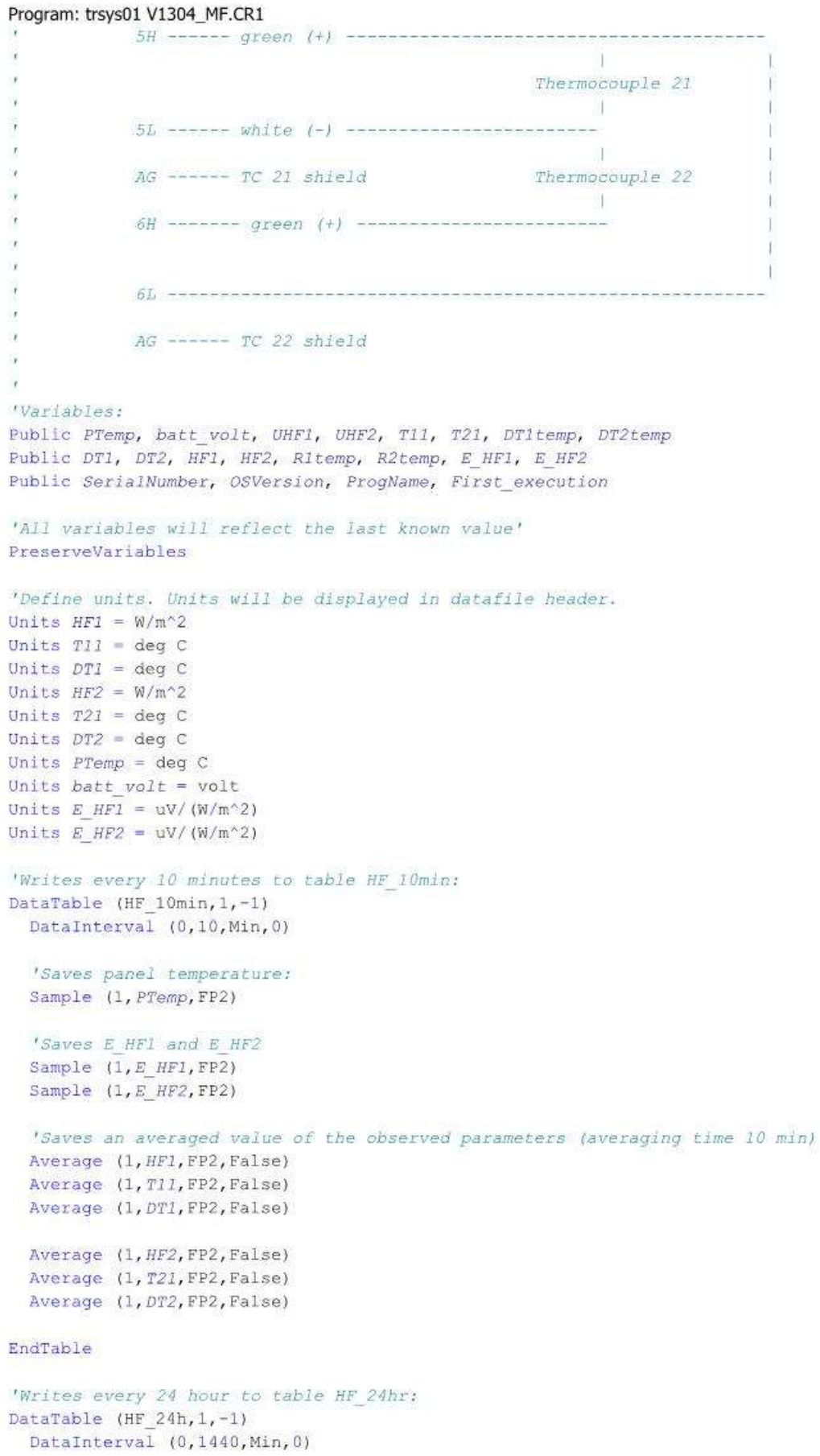

Page 2 of 4 


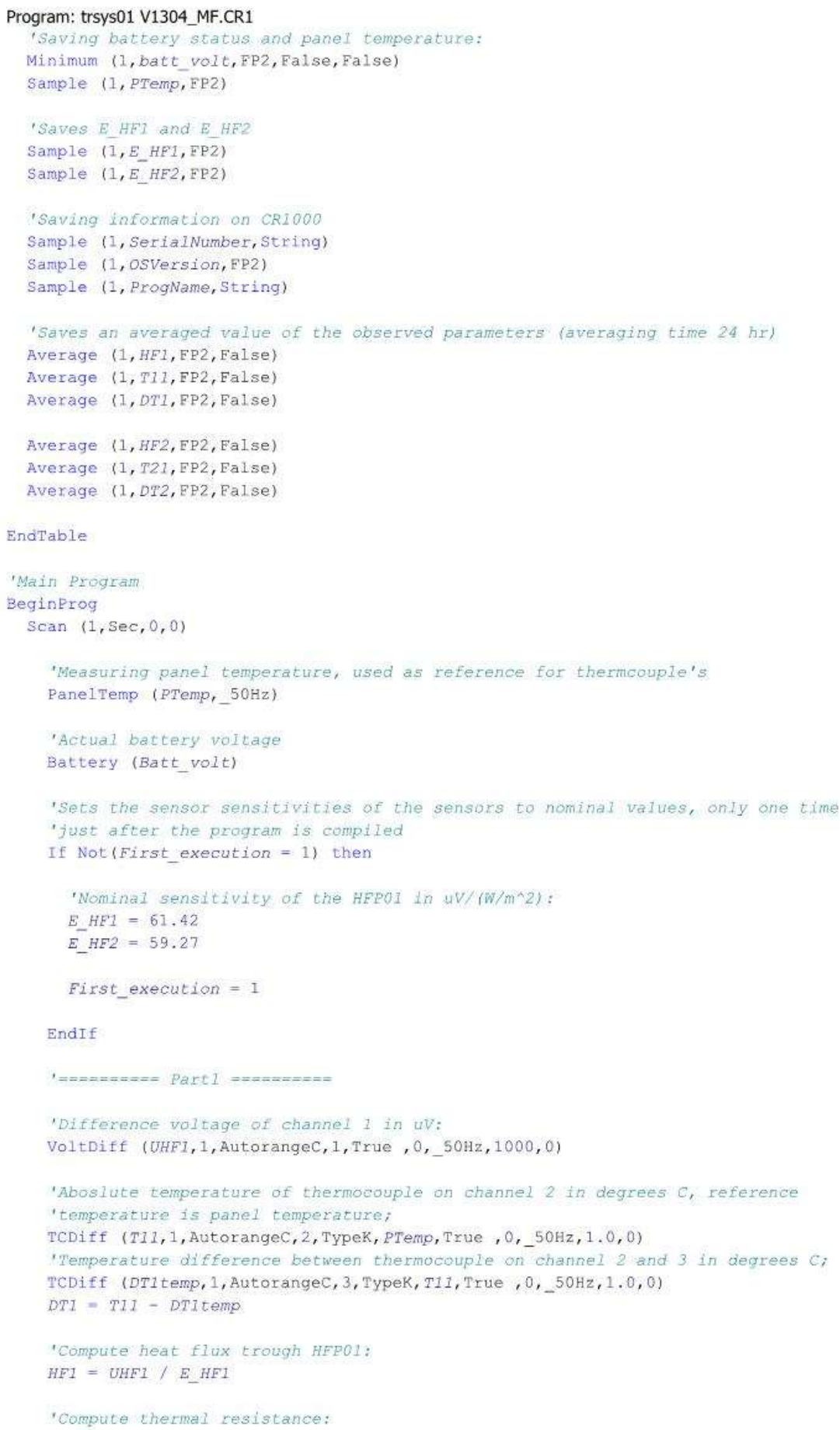

Page 3 of 4 


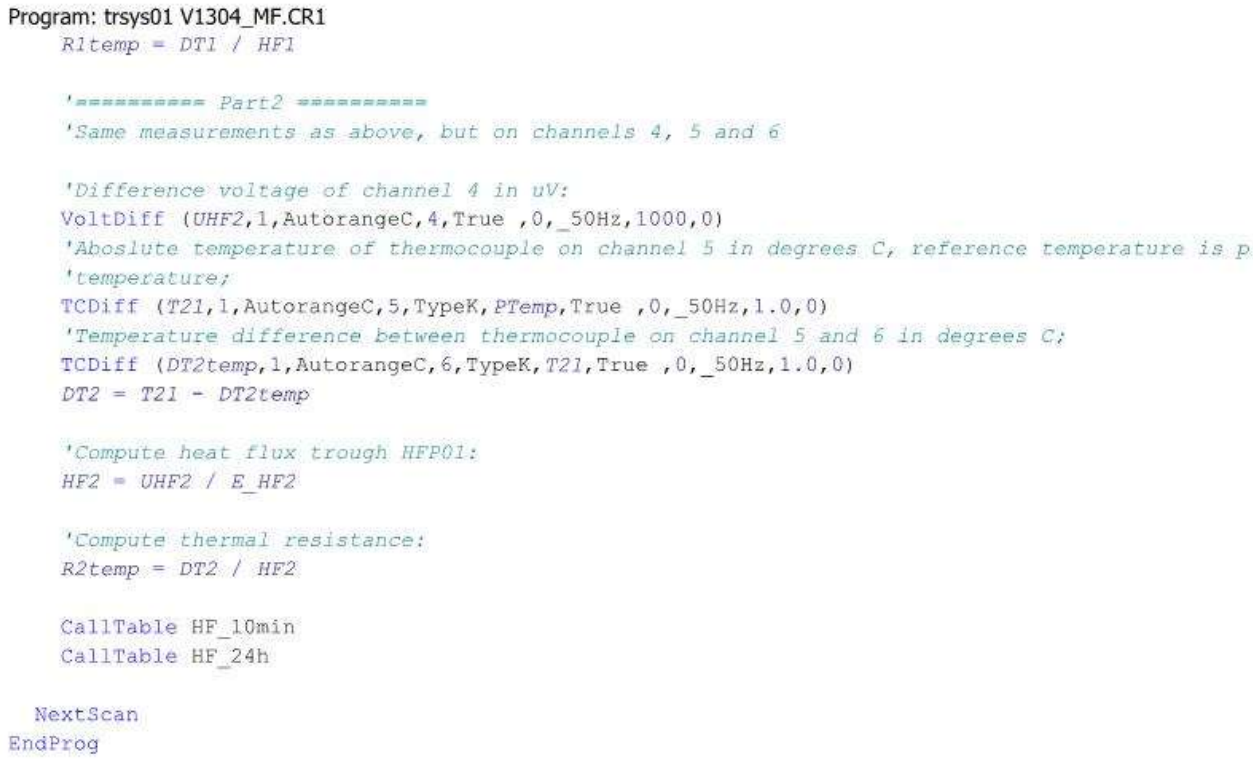

Page 4 of 4 


\section{Appendix E: Temperature Sensor Differences \& Stratification}

At some locations, multiple types sensors have been placed. At layer 4 and layer 6 multiple types of sensors were placed. At layer 4 a thermistor and a RHT bundle have been placed, and at layer 6 a RHT bundle and a Moisture Pin and T (TPM) have been placed. A comparison of these temperatures show that a slight difference exists between the two. It should be noted this comparison was only completed on the south side at height 1 during the winter time-period.

\begin{tabular}{|c|c|c|c|c|}
\hline Location & Sensors & $\begin{array}{c}\text { Average } \\
\text { Difference }\end{array}$ & Max Difference & $\begin{array}{c}\text { Standard } \\
\text { Deviation }\end{array}$ \\
\hline Layer 4 & RHT \& T & $0.5^{\circ} \mathrm{C}$ & $0.9^{\circ} \mathrm{C}$ & $0.12^{\circ} \mathrm{C}$ \\
\hline Layer 6 & RHT \& TPM & $0.7^{\circ} \mathrm{C}$ & $1.2^{\circ} \mathrm{C}$ & $0.14^{\circ} \mathrm{C}$ \\
\hline
\end{tabular}

\section{Differences between Height 1 and 2.}

The data indicates that there are differences between the temperatures at height 1 and height 2. With height 2 being warmer than height 1. This is expected as stratification of the air would result in higher air temperatures at the ceiling of the structure than the floor.

\section{South}

(Height 2 - Height 1)

\begin{tabular}{|c|c|c|c|}
\hline Layer & $\begin{array}{c}\text { Average } \\
\text { Difference } \\
{ }^{\circ} \mathrm{C}\end{array}$ & $\begin{array}{c}\text { Max Difference } \\
{ }^{\circ} \mathrm{C}\end{array}$ & $\begin{array}{c}\text { Standard } \\
\text { Deviation } \\
{ }^{\circ} \mathrm{C}\end{array}$ \\
\hline 0 & 1.65 & 24.9 & 3.34 \\
\hline 1.5 & 1.58 & 19.9 & 3.13 \\
\hline 2 & 1.55 & 17.2 & 2.98 \\
\hline $3^{*}$ & N/A* & N/A* & N/A* \\
\hline 4 & 0.78 & 2.94 & 0.50 \\
\hline 5 & 0.90 & 2.14 & 0.36 \\
\hline 6 & 0.72 & 1.94 & 0.35 \\
\hline 6.5 & 1.29 & 2.43 & 0.40 \\
\hline
\end{tabular}




\begin{tabular}{|c|c|c|c|}
\hline 7 & 0.91 & 2.31 & 0.46 \\
\hline 8 & 0.63 & 2.26 & 0.53 \\
\hline Total $^{*}$ & 0.87 & & 0.23 \\
\hline
\end{tabular}

. Layer 3 sensor placement was completed incorrectly

\begin{tabular}{|c|c|c|c|}
\hline Layer & $\begin{array}{c}\text { Average } \\
\text { Difference }\end{array}$ & Max Difference & $\begin{array}{c}\text { Standard } \\
\text { Deviation }\end{array}$ \\
\hline 0 & 0.14 & 1.42 & 0.28 \\
\hline 1.5 & 0.56 & 1.82 & 0.41 \\
\hline 2 & 0.08 & 2.48 & 0.57 \\
\hline 3 & 0.61 & 1.66 & 0.34 \\
\hline 4 & 0.75 & 1.72 & 0.37 \\
\hline 5 & 0.66 & 1.76 & 0.46 \\
\hline 6 & 0.03 & 1.14 & 0.33 \\
\hline 6.5 & 0.06 & 1.58 & 0.35 \\
\hline 7 & 0.59 & 2.90 & 0.69 \\
\hline 8 & 0.79 & 3.29 & 0.73 \\
\hline Total & 0.43 & & 0.31 \\
\hline
\end{tabular}

North Wall Winter H1 and H2 


\section{Appendix F: Convergence Graphs Southern Wall Analysis OVER CAST CONVERGANCE}
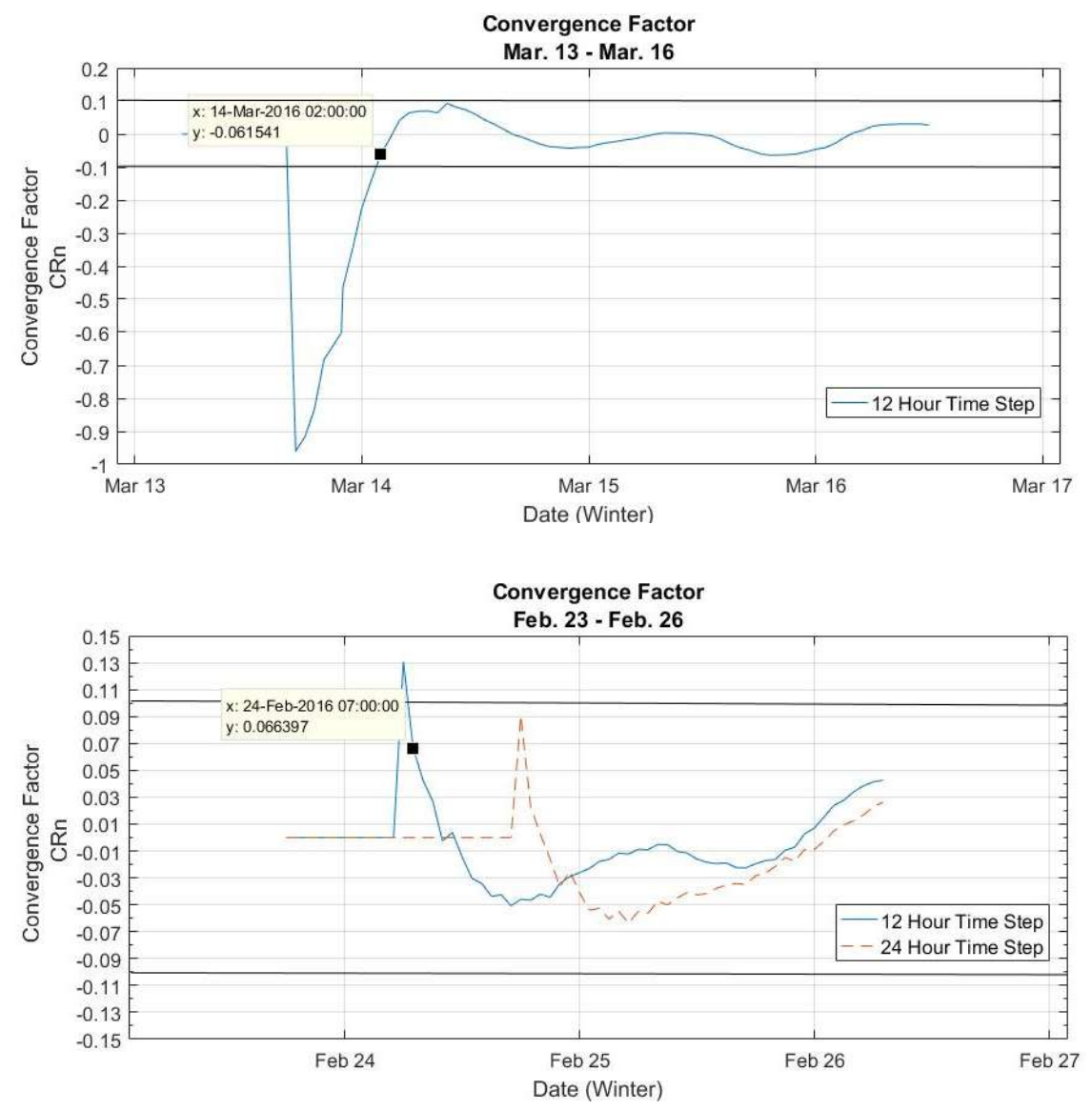

SOUTHWALL USES NORTH DELTA TEMPERATURE DATA CONVERGANCE

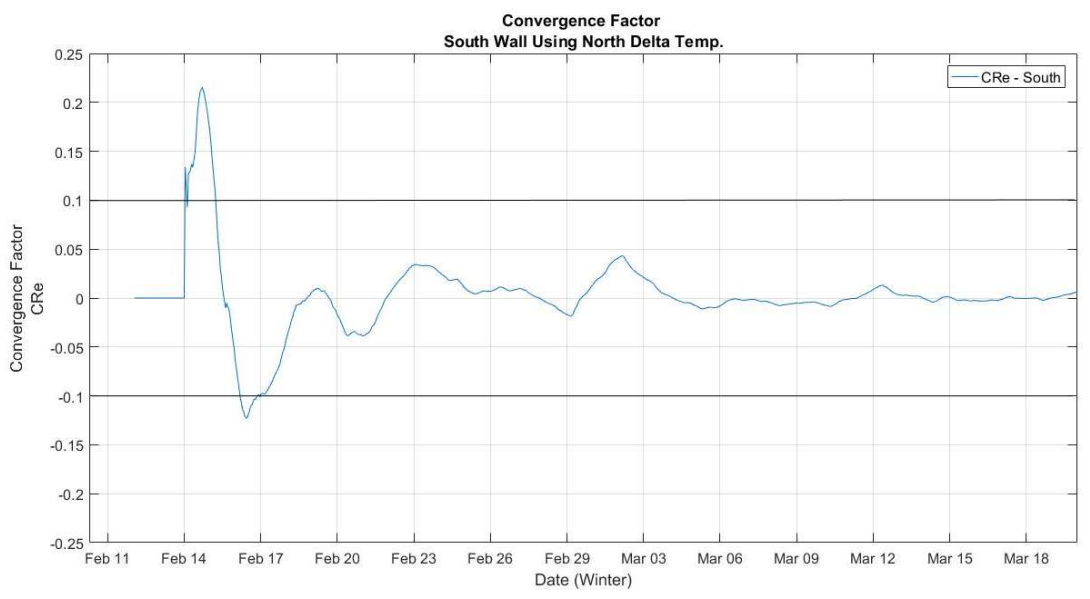




\section{Appendix G: Raw Thermal Conductivity Data}

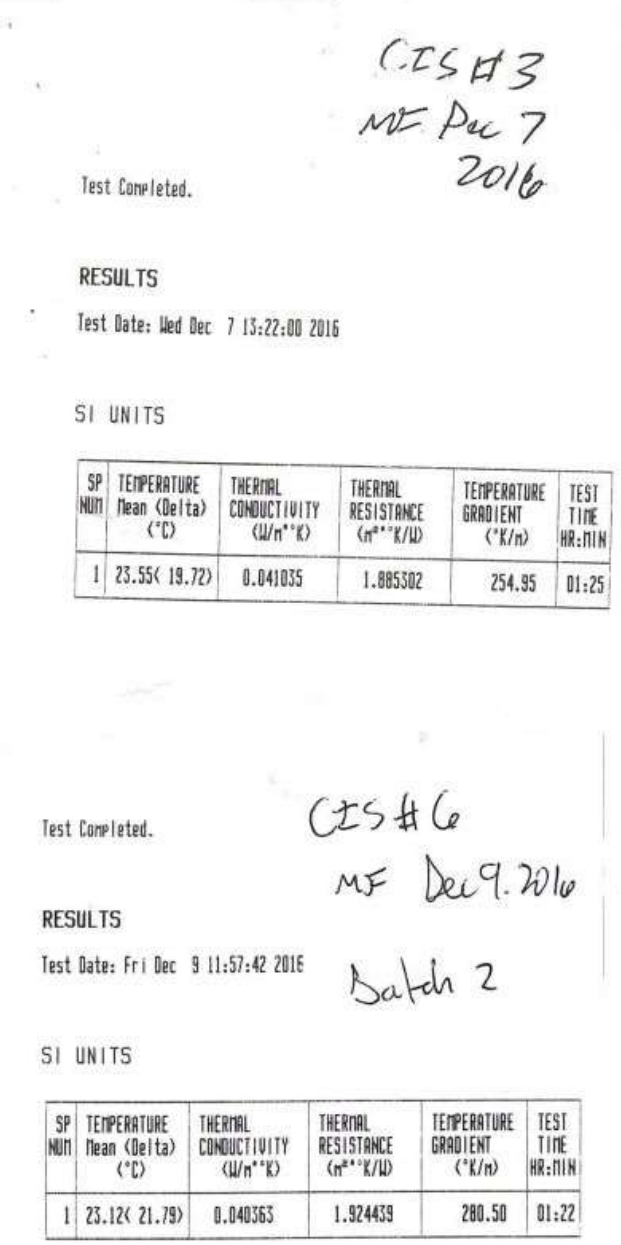

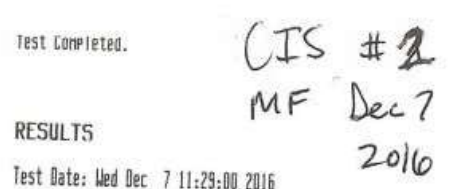

SI UNITS

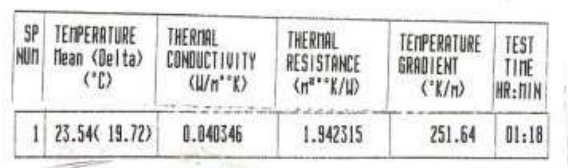

Test Cunpleted,
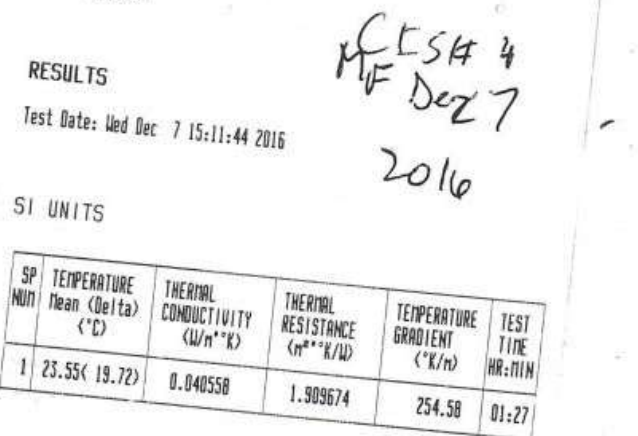

Iest coipleted. CTS \#1

RESULTS M.F DeE?

Test Date: lled Dec $706559: 49$ 2015 $20 / 6$.

SI UNITS

\begin{tabular}{|c|c|c|c|c|}
\hline 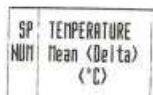 & 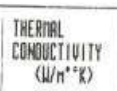 & 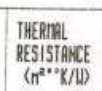 & 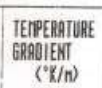 & 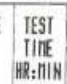 \\
\hline $123.54(19.72)$ & 0.047704 & 1.9355608 & 250.38 & $01: 34$ \\
\hline
\end{tabular}

est conpleted. $\quad$ IS स 5

$$
\text { MV Dec 9, 2olk }
$$

RESULTS

Test Date: Fri Dee $910: 23: 492016$

\begin{tabular}{|c|c|c|c|c|}
\hline 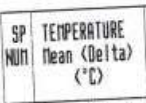 & 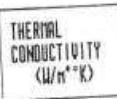 & 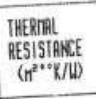 & 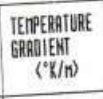 & $\begin{array}{l}\text { IEST } \\
\text { IIIIF } \\
\text { He:NIK }\end{array}$ \\
\hline $23.12(21.79)$ & 0.040803 & 1.909596 & 279.62 & $01: 27$ \\
\hline
\end{tabular}




\section{CIS \#9 ME Deerlo 20}

Test Conpleted.

Bithe 2

RESULTS

Test Date: Hed Dec 14 09:03:17 2016

SI UNITS

\begin{tabular}{|c|c|c|c|c|c|}
\hline $\begin{array}{c}\text { SP } \\
\text { NiII }\end{array}$ & $\begin{array}{l}\text { IETPEratupe } \\
\text { liean (Delta) } \\
\text { ("C) }\end{array}$ & $\begin{array}{l}\text { THERnAL } \\
\text { CONOUCTIUITY } \\
\left(\mathrm{W} / \mathrm{n}^{* * \mathrm{~K})}\right.\end{array}$ & $\begin{array}{l}\text { THEPRRLL } \\
\text { RESISTANCE } \\
\left(n^{2 *} \times K / L\right)\end{array}$ & $\begin{array}{l}\text { TERPERRTUPE } \\
\text { GRERIEKT } \\
\left({ }^{\circ} \mathrm{K} / \mathrm{H}\right)\end{array}$ & $\begin{array}{l}\text { IEST } \\
\text { TIIIEE } \\
\text { HH: IIIN }\end{array}$ \\
\hline 7 & $23.53(20.00)$ & 0.040335 & 1.922980 & 257.90 & $02: 33$ \\
\hline
\end{tabular}

Test Completed.

CtSH 8

RESULTS

$$
\begin{gathered}
\text { MF Dee } 4.2016 \\
\text { Bith2 }
\end{gathered}
$$

Iest Date: fri Dec 9 15:45:51 2016

\begin{tabular}{|c|c|c|c|c|c|}
\hline $\begin{array}{c}\text { sp } \\
\text { Nun }\end{array}$ & $\begin{array}{l}\text { TErperghtupe } \\
\text { llean (Deita) } \\
\text { ("D) }\end{array}$ & $\begin{array}{l}\text { THERrait } \\
\text { CONDictivity } \\
\left(\mathrm{W} / \mathrm{n}^{\circ} \mathrm{*}\right)\end{array}$ & $\begin{array}{l}\text { THERIIAL } \\
\text { RESISTRWCE } \\
\left(\pi^{2} *{ }^{*} k / W\right)\end{array}$ & $\begin{array}{l}\text { TEIPERRTIURE } \\
\text { GRADIENT } \\
\text { ('K/n) }\end{array}$ & $\begin{array}{l}\text { IEST } \\
\text { IIIIE } \\
\text { HR: IIN }\end{array}$ \\
\hline 1 & .5. $13(21.80)$ & 0.040587 & 1.905233 & 281.89 & $01: 21$ \\
\hline
\end{tabular}

SI UNITS
Test Conplated.

$$
61547
$$

RESULTS

MF Dec 9.2016

\begin{tabular}{|c|c|c|c|c|c|}
\hline in & $\begin{array}{c}\text { TEnPERRTuRE } \\
\text { llean (Delta) } \\
\left({ }^{\circ} \mathrm{C}\right)\end{array}$ & $\begin{array}{l}\text { THEERRLL } \\
\text { CONDUCTIUITY } \\
\left(แ / n^{\circ} \mathrm{K} K\right)\end{array}$ & $\begin{array}{l}\text { THER } \\
\text { RES! } \\
\left(\mathrm{nt}^{2}\right.\end{array}$ & $\begin{array}{l}\text { TEIPS } \\
\text { GRAO } \\
(\end{array}$ & $\begin{array}{l}\text { TEST } \\
\text { IIIIE } \\
\text { Hith:IIIN }\end{array}$ \\
\hline & & & & 81 . & Ul: \\
\hline
\end{tabular}

Iest Date: Fri Dec 913:55:20 2016 Batch 2

SI UNITS

\section{CFS H 10 \\ Test Conpleted. \\ Bolh the \\ RESULTS}

\begin{tabular}{|c|c|c|c|c|c|}
\hline & $\begin{array}{c}\text { TEnPFERPTURE } \\
\text { Mean (QBel ta) } \\
\text { ("C) }\end{array}$ & $\begin{array}{l}\text { THERRAL } \\
\text { COKOUCIUITYY } \\
\left(W / \mathrm{n}^{\circ} \mathrm{K}\right)\end{array}$ & $\begin{array}{l}\text { THERRALL } \\
\text { RESISTANCE } \\
\left(n^{2 * *} K / \text { / }\right)\end{array}$ & $\begin{array}{l}\text { TEIPERRTURE } \\
\text { GRABIINT } \\
\text { ("K/H) }\end{array}$ & $\begin{array}{l}\text { TEST } \\
\text { TIIIEE } \\
\text { HR: IIIN }\end{array}$ \\
\hline & & U.UTUJ4C & 279 & 256.91 & $01: 20$ \\
\hline
\end{tabular}

Test Date: Hed Dec 14 11:55:42 2016

SI UNITS 
Test Conpleted.

\section{RESULTS}

Test Date: Hed Dec 14 21:29:38 2016

SI UNITS

\begin{tabular}{|c|c|c|c|c|c|}
\hline$\underset{N U I !}{S P}$ & $\begin{array}{l}\text { IEAPERRTURE } \\
\text { Mean (Del ta) } \\
\text { ('C) }\end{array}$ & $\begin{array}{l}\text { THERHAL } \\
\text { CONOUCTIUITY } \\
\left(W / n^{\circ} \mathrm{K}\right)\end{array}$ & $\begin{array}{l}\text { THERRIAL } \\
\text { RESIIITANCE } \\
\left(\pi^{5 *} \cdot \mathrm{k} / \mathrm{L}\right)\end{array}$ & $\begin{array}{l}\text { IEIPERRTURE } \\
\text { GRROIENT } \\
\left({ }^{\circ} \mathrm{K} / \mathrm{m}\right)\end{array}$ & $\begin{array}{c}\text { IEST } \\
\text { IIIIE } \\
\text { HR: IIIN }\end{array}$ \\
\hline 1 & $0.04(20.16)$ & 0.038469 & 2.019719 & 259.52 & $01: 5$ \\
\hline 2 & $8.74(19.93)$ & 0.039137 & 1.986522 & $256.4 !$ & $01: 1 ?$ \\
\hline 3 & $24.29(19.94)$ & 0.040384 & 1.927332 & 256.14 & $01: 37$ \\
\hline 4 & $29.97(19.82)$ & 0.041027 & 1.897663 & 254.63 & O1: \\
\hline
\end{tabular}

Terninated by user.

Test Conipleted.

-

RESULTS

Test Date: Hed Dec 14 14:5月:47 2016

Buthl, 2

$\operatorname{Sec}$

SI UNITS

\begin{tabular}{|c|c|c|c|c|c|}
\hline SP & $\begin{array}{c}\text { TEtiperpature } \\
\text { llean (Deita) } \\
\text { ("C) }\end{array}$ & $\begin{array}{l}\text { TheRrRL } \\
\text { CONOUCTIVITY } \\
\left(\mathrm{W} / \mathrm{n}^{* *} \mathrm{k}\right)\end{array}$ & $\begin{array}{l}\text { THERRIRL } \\
\text { RESISTANCE } \\
\left\langle\pi^{2 * 0} / \mathrm{K} / \mathrm{W}\right\rangle\end{array}$ & $\begin{array}{l}\text { TEIPERATURE } \\
\text { GRADIENT } \\
\left({ }^{*} K / n\right)\end{array}$ & IEST \\
\hline
\end{tabular}

Test Conpleted.

RESULTS

Iest Date: Hed Dec 14 15:00:47 2016

SI UNITS

\begin{tabular}{|c|c|c|c|c|c|}
\hline $\begin{array}{l}S P \\
N \in I 1\end{array}$ & $\begin{array}{c}\text { IENPERRTURE } \\
\text { liean (Del ta) } \\
\text { ("C) }\end{array}$ & 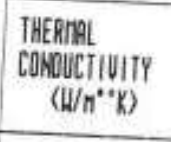 & $\begin{array}{l}\text { ThERRILL } \\
\text { RESISITANEE } \\
\left(n^{2+*} \mathrm{~K} / \mathrm{W}\right) \\
\end{array}$ & $\begin{array}{c}\text { IENPERRTURE } \\
\text { GRRDRENT } \\
\left({ }^{\circ} \mathrm{K} / \mathrm{H} / \mathrm{H}\right) \\
\end{array}$ & 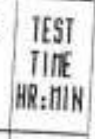 \\
\hline 1 & $1.53(20.35)$ & 0.038725 & 2.000210 & 262.66 & $02: 30$ \\
\hline 2 & $10.38(20.18)$ & 0.039019 & 1.985974 & 260.44 & $01: 09$ \\
\hline 3 & $31.18(19.85)$ & 0.041338 & 1.877235 & 255.77 & $02: 11$ \\
\hline
\end{tabular}




\section{Appendix H : Heat3 Conductivity Results}

\begin{tabular}{|c|c|c|c|c|c|c|c|c|c|c|c|c|c|c|c|c|c|c|c|c|c|}
\hline Case\# & Notes & $\begin{array}{l}\text { Stud } \\
\text { Spacing }\end{array}$ & $\begin{array}{l}\text { Fasterner } \\
\text { Spacing }\end{array}$ & $\begin{array}{l}\text { Exterior } \\
\text { Insluatiol }\end{array}$ & $\begin{array}{l}\text { Interior } \\
\text { Insulatior - }\end{array}$ & $\begin{array}{l}\text { Width } \\
(\mathrm{mm})\end{array}$ & $\begin{array}{l}\text { Height } \\
(\mathrm{mm})\end{array}$ & Area $(\mathrm{m} 2=$ & $Q(w)$ & $\begin{array}{l}\text { Steel RSI } \\
(\mathrm{m} 2 \mathrm{~K} / \mathrm{W})\end{array}$ & \begin{tabular}{|l|} 
Steel R - \\
Value
\end{tabular} & \begin{tabular}{|l|} 
\% Decrease \\
from \\
Nominal
\end{tabular} & Width & $=1$ & Height & $=1$ & Area & $Q(w) 2$ & $\begin{array}{l}\text { Stainless } \\
\text { Steel RSI } \\
(\mathrm{m} 2 \mathrm{~K} / \mathrm{W})\end{array}$ & \begin{tabular}{|l|} 
\% Decrease \\
from \\
Nominal2
\end{tabular} & $\begin{array}{l}\text { Steel vs } \\
\text { Stainless }\end{array}$ \\
\hline & 1 Nominal & $16^{\prime \prime}$ & N/A & 9" & $3.5^{\prime \prime}$ & 400 & 305 & 0.122 & & \#DIV/O! & \#DIV/0! & $0.0 \%$ & & 400 & & 305 & 0.122 & & \#DIV/0! & & \#DIV/O! \\
\hline & 2 Calibrated & $16 "$ & N/A & 9" & $3.5^{\prime \prime}$ & 400 & 305 & 0.122 & 0.3908 & 9.37 & 53.26105425 & $104.5 \%$ & & 400 & & 305 & 0.122 & & \#DIV/0! & & \#DIV/0! \\
\hline & 3 Effictive Calibrated & $16 "$ & $12 "$ & 9" & 3.5" & 406.5 & 305 & 0.1239825 & 0.4689 & 7.93 & 45.11122697 & $15.3 \%$ & & 406.5 & & 305 & 0.1239825 & 0.443 & 8.40 & $10.3 \%$ & $5.5 \%$ \\
\hline & 4 Effective & $16 "$ & $12 "$ & 9" & $3.5^{\prime \prime}$ & 406.5 & 305 & 0.1239825 & 0.4888 & 7.61 & 43.27466106 & $15.1 \%$ & & 406.5 & & 305 & 0.1239825 & 0.4641 & 8.01 & $10.6 \%$ & $5.1 \%$ \\
\hline & 5 Effective & $16 "$ & $12 "$ & 9" & $0^{\prime \prime}$ & 406.5 & 305 & 0.1239825 & 0.6673 & 5.57 & 31.69886756 & $14.2 \%$ & & 406.5 & & 305 & 0.1239825 & 0.6263 & 5.94 & $8.6 \%$ & $6.1 \%{ }_{\epsilon}$ \\
\hline & 6 Effective & $16 "$ & $12 "$ & 9" & $5.5^{\prime \prime}$ & 406.5 & 305 & 0.1239825 & 0.4249 & 8.75 & \begin{tabular}{|l|}
49.78266492 \\
\end{tabular} & $15.6 \%$ & & 406.5 & & 305 & 0.1239825 & 0.4062 & 9.16 & $11.7 \%$ & $4.4 \%$ \\
\hline & 7 Effective & $16 "$ & $12 "$ & 6" & $0^{\prime \prime}$ & 406.5 & 305 & 0.1239825 & 0.9761 & 3.81 & 21.67058122 & $13.2 \%$ & & 406.5 & & 305 & 0.1239825 & 0.9243 & 4.02 & $8.4 \%$ & $5.3 \%$ \\
\hline & 8 Effective & $16 "$ & $12 "$ & 6" & $3.5^{\prime \prime}$ & 406.5 & 305 & 0.1239825 & 0.6357 & 5.85 & 33.27458601 & $14.7 \%$ & & 406.5 & & 305 & 0.1239825 & 0.6087 & 6.11 & $10.9 \%$ & $4.2 \%$ \\
\hline & 9 Effective & $16 "$ & $12 "$ & 6" & $5.5^{\prime \prime}$ & 406.5 & 305 & 0.1239825 & 0.532 & 6.99 & 39.76062843 & $15.4 \%$ & & 406.5 & & 305 & 0.1239825 & 0.5134 & 7.24 & $12.3 \%$ & $3.5 \%$ \\
\hline & 10 Effective & $16^{\prime \prime}$ & 6" & 9" & $3.5^{\prime \prime}$ & 406.5 & 152.5 & 0.06199125 & 0.2736 & 6.80 & 38.65616653 & $24.2 \%$ & & 406.5 & & 152.5 & 0.06199125 & 0.2489 & 7.47 & $16.63 \%$ & $9.03 \%$ \\
\hline & 11 Effective & $16^{\prime \prime}$ & 6" & 9" & $0^{\prime \prime}$ & 406.5 & 152.5 & 0.06199125 & 0.3783 & 4.92 & 27.95751299 & $24.4 \%$ & & 406.5 & & 152.5 & 0.06199125 & 0.3373 & 5.51 & $15.2 \%$ & $10.8 \%$ \\
\hline & 12 Effective & $16^{\prime \prime}$ & 6" & 9" & $5.5^{\prime \prime}$ & 406.5 & 152.5 & 0.06199125 & 0.2328 & 7.99 & \begin{tabular}{|l|}
45.4309586 \\
\end{tabular} & $23.0 \%$ & & 406.5 & & 152.5 & \begin{tabular}{|l|}
0.06199125 \\
\end{tabular} & 0.215 & 8.65 & $16.57 \%$ & $7.65 \%$ \\
\hline & 13 Effective & $16^{\prime \prime}$ & 6" & 6" & $0^{\prime \prime}$ & 406.5 & 152.5 & 0.06199125 & 0.5464 & 3.40 & 19.35638207 & $22.5 \%$ & & 406.5 & & 152.5 & 0.06199125 & 0.4947 & 3.76 & $14.4 \%$ & $9.5 \%$ \\
\hline & 14 Effective & $16 "$ & 6" & 6" & $3.5^{\prime \prime}$ & 406.5 & 152.5 & 0.06199125 & 0.3482 & 5.34 & 30.37428823 & $22.1 \%$ & & 406.5 & & 152.5 & \begin{tabular}{|l|}
0.06199125 \\
\end{tabular} & 0.3228 & 5.76 & $16.0 \%$ & $7.3 \%$ \\
\hline & 15 Effective & $16 "$ & 6" & 6" & $5.5^{\prime \prime}$ & 406.5 & 152.5 & 0.06199125 & 0.287 & 6.48 & 36.85131416 & $21.6 \%$ & & 406.5 & & 152.5 & 0.06199125 & 0.2695 & 6.90 & $16.5 \%$ & $6.1 \%$ \\
\hline & 16 Effective & $16^{\prime \prime}$ & $18 "$ & 9" & $3.5^{\prime \prime}$ & 406.5 & 457.2 & 0.1858518 & 0.7041 & 7.92 & 45.03362533 & $11.6 \%$ & & 406.5 & & 457.2 & 0.1858518 & 0.6794 & 8.21 & $8.4 \%$ & $3.5 \%$ \\
\hline & 17 Effective & $16 "$ & $18 "$ & 9" & $0^{\prime \prime}$ & 406.5 & 457.2 & 0.1858518 & 0.9551 & 5.84 & $\begin{array}{r}33.1988018 \\
\end{array}$ & $10.2 \%$ & & 406.5 & & 457.2 & 0.1858518 & 0.9142 & 6.10 & $6.2 \%$ & $4.3 \%$ \\
\hline & 18 Effective & $16^{\prime \prime}$ & $18 "$ & 9" & $5.5^{\prime \prime}$ & 406.5 & 457.2 & 0.1858518 & 0.6152 & 9.06 & 51.54124772 & $12.6 \%$ & & 406.5 & & 457.2 & 0.1858518 & 0.5962 & 9.35 & $9.8 \%$ & $3.1 \%$ \\
\hline & 19 Effective & $16 "$ & $18 "$ & 6" & $0^{\prime \prime}$ & 406.5 & 457.2 & 0.1858518 & 1.4039 & 3.97 & 22.58577933 & $9.6 \%$ & & 406.5 & & 457.2 & 0.1858518 & 1.3523 & 4.12 & $6.1 \%$ & $3.7 \%$ \\
\hline & 20 Effective & $16^{\prime \prime}$ & $18 "$ & 6" & 3.5" & 406.5 & 457.2 & 0.1858518 & 0.921 & 6.05 & 34.42798653 & $11.7 \%$ & & 406.5 & & 457.2 & 0.1858518 & 0.8947 & 6.23 & $9.1 \%$ & $2.9 \%$ \\
\hline & 21 Effective & $16^{\prime \prime}$ & $18 "$ & 6" & $5.5^{\prime \prime}$ & 406.5 & 457.2 & 0.1858518 & 0.7745 & 7.20 & 40.94018799 & $12.9 \%$ & & 406.5 & & 457.2 & 0.1858518 & 0.7559 & 7.38 & $10.7 \%$ & $2.4 \%$ \\
\hline & 22 Effective & $24 "$ & $12 "$ & 9" & $3.5^{\prime \prime}$ & 609.5 & 305 & 0.1858975 & 0.6956 & 8.02 & 45.59513007 & $10.5 \%$ & & 609.5 & & 305 & 0.1858975 & 0.6712 & 8.31 & $7.3 \%$ & $3.5 \%$ \\
\hline & 23 Effective & $24^{\prime \prime}$ & $12^{\prime \prime}$ & 9" & $0^{\prime \prime}$ & 609.5 & 305 & 0.1858975 & 0.9562 & 5.83 & 33.16876435 & $10.3 \%$ & & 609.5 & & 305 & 0.1858975 & 0.9155 & 6.09 & $6.3 \%$ & $4.3 \%$ \\
\hline & 24 Effective & $24 "$ & $12 "$ & 9" & $5.5^{\prime \prime}$ & 609.5 & 305 & 0.1858975 & 0.6038 & 9.24 & 52.52728134 & $10.9 \%$ & & 609.5 & & 305 & 0.1858975 & 0.5852 & 9.53 & $8.1 \%$ & $3.1 \%$ \\
\hline & 25 Effective & $24^{\prime \prime}$ & $12 "$ & 6" & $0^{\prime \prime}$ & 609.5 & 305 & 0.1858975 & 1.4061 & 3.97 & 22.5559864 & $9.7 \%$ & & 609.5 & & 305 & 0.1858975 & 1.3551 & 4.12 & $6.3 \%$ & $3.6 \%$ \\
\hline & 26 Effective & $24 "$ & $12^{\prime \prime}$ & 6" & $3.5^{\prime \prime}$ & 609.5 & 305 & 0.1858975 & 0.906 & 6.16 & 35.00659214 & $10.2 \%$ & & 609.5 & & 305 & 0.1858975 & 0.8802 & 6.34 & $7.6 \%$ & $2.8 \%$ \\
\hline & 27 Effective & $24 "$ & $12^{\prime \prime}$ & 6" & $5.5^{\prime \prime}$ & 609.5 & 305 & 0.1858975 & 0.7565 & 7.37 & 41.92461662 & $10.8 \%$ & & 609.5 & & 305 & 0.1858975 & 0.7381 & 7.56 & $8.5 \%$ & $2.4 \%$ \\
\hline & 28 Effective & $24^{\prime \prime}$ & 6" & 9" & $3.5^{\prime \prime}$ & 609.5 & 152.5 & 0.09294875 & 0.3767 & 7.40 & \begin{tabular}{|l|}
42.09712301 \\
\end{tabular} & $17.4 \%$ & & 609.5 & & 152.5 & 0.09294875 & 0.3523 & 7.92 & $11.7 \%$ & $6.5 \%$ \\
\hline & 29 Effective & $24^{\prime \prime}$ & 6" & 9" & $0^{\prime \prime}$ & 609.5 & 152.5 & 0.09294875 & 0.5223 & 5.34 & 30.36183465 & $17.9 \%$ & & 609.5 & & 152.5 & 0.09294875 & 0.4818 & 5.79 & $11.0 \%$ & $7.8 \%$ \\
\hline & 30 Effective & $24 "$ & $6^{\prime \prime}$ & 9" & $5.5^{\prime \prime}$ & 609.5 & 152.5 & 0.09294875 & 0.3221 & 8.66 & \begin{tabular}{|l|} 
\\
\end{tabular} 9.23311468 & $16.5 \%$ & & 609.5 & & 152.5 & \begin{tabular}{|l|}
0.09294875 \\
\end{tabular} & 0.3045 & 9.16 & $11.7 \%$ & $5.5 \%$ \\
\hline & 31 Effective & $24 "$ & $6^{\prime \prime}$ & 6" & $0^{\prime \prime}$ & 609.5 & 152.5 & 0.09294875 & 0.7608 & 3.67 & 20.84383049 & $16.5 \%$ & & 609.5 & & 152.5 & 0.09294875 & 0.7089 & 3.93 & $10.4 \%$ & $6.8 \%$ \\
\hline & 32 Effective & $24^{\prime \prime}$ & $6^{\prime \prime}$ & 6" & $3.5^{\prime \prime}$ & 609.5 & 152.5 & 0.09294875 & 0.483 & 5.77 & 32.83226964 & $15.8 \%$ & & 609.5 & & 152.5 & \begin{tabular}{|l|}
0.09294875 \\
\end{tabular} & 0.458 & 6.09 & $11.2 \%$ & $5.2 \%$ \\
\hline & 33 Effective & $24 "$ & 6" & 6" & $5.5^{\prime \prime}$ & 609.5 & 152.5 & 0.09294875 & 0.399 & 6.99 & \begin{tabular}{|l|}
39.74432641 \\
\end{tabular} & $15.4 \%$ & & 609.5 & & 152.5 & 0.09294875 & 0.3817 & 7.31 & $11.6 \%$ & $4.3 \%$ \\
\hline & 34 Effective & $24 "$ & $18^{\prime \prime}$ & 9" & $3.5^{\prime \prime}$ & 609.5 & 457.2 & 0.2786634 & 1.0145 & 8.24 & 46.86324561 & $8.0 \%$ & & 609.5 & & 457.2 & 0.2786634 & 0.99 & 8.44 & $5.8 \%$ & $2.4 \%$ \\
\hline & 35 Effective & $24^{\prime \prime}$ & $18^{\prime \prime}$ & 9" & $0^{\prime \prime}$ & 609.5 & 457.2 & 0.2786634 & 1.3884 & 6.02 & \begin{tabular}{|l|}
4.24284261 \\
\end{tabular} & $7.4 \%$ & & 609.5 & & 457.2 & 0.2786634 & 1.3478 & 6.20 & $4.6 \%$ & $2.9 \%$ \\
\hline & 36 Effective & $24^{\prime \prime}$ & $18 "$ & 9" & $5.5^{\prime \prime}$ & 609.5 & 457.2 & 0.2786634 & 0.8835 & 9.46 & 53.8118423 & $8.7 \%$ & & 609.5 & & 457.2 & 0.2786634 & 0.8648 & 9.67 & $6.8 \%$ & $2.1 \%$ \\
\hline & 37 Effective & $24^{\prime \prime}$ & $18 "$ & 6" & $0^{\prime \prime}$ & 609.5 & 457.2 & 0.2786634 & 2.0491 & 4.08 & 23.20177769 & $7.1 \%$ & & 609.5 & & 457.2 & 0.2786634 & 1.988 & 4.21 & $4.2 \%$ & $3.0 \%$ \\
\hline & 38 Effective & $24^{\prime \prime}$ & $18 "$ & 6" & $3.5^{\prime \prime}$ & 609.5 & 457.2 & 0.2786634 & 1.3266 & 6.30 & 35.83805418 & $8.1 \%$ & & 609.5 & & 457.2 & 0.2786634 & 1.3006 & 6.43 & $6.3 \%$ & $2.0 \%$ \\
\hline & 39 Effective & $24 "$ & $18 "$ & 6" & $5.5^{\prime \prime}$ & 609.5 & 457.2 & 0.2786634 & 1.1114 & 7.52 & \begin{tabular}{|l|}
2.77736429 \\
\end{tabular} & $9.0 \%$ & & 609.5 & & 457.2 & 0.2786634 & 1.0929 & 7.65 & $7.4 \%$ & $1.7 \%$ \\
\hline & & & & & & & & & & & & & & & & & & & & & \\
\hline & Nominal & & & 9" & $3.5^{\prime \prime}$ & 400 & 305 & 0.122 & 0.4084 & 8.96 & & & & & & & & & & & \\
\hline & Nominal & & & 9" & $0^{\prime \prime}$ & 400 & 305 & 0.122 & 0.5631 & 6.50 & w/o gypsum & & & & & & & & & & \\
\hline & Nominal & & & 9" & $5 . \mathrm{H}^{\mathrm{n}}$ & 400 & 305 & 0.122 & 0.353 & 10.37 & & & & & & & & & & & \\
\hline & Nominal & & & 6" & $0^{\prime \prime}$ & 400 & 305 & 0.122 & 0.8334 & 4.39 & w/o gypsum & & & & & & & & & & \\
\hline & Nominal & & & 6" & $3.5^{\prime \prime}$ & 400 & 305 & 0.122 & 0.5338 & 6.86 & & & & & & & & & & & \\
\hline & Nominal & & & 6" & $5.5^{\prime \prime}$ & 400 & 305 & 0.122 & 0.443 & 8.26 & & & & & & & & & & & \\
\hline & & & & & & & & & & & & & & & & & & & & & \\
\hline
\end{tabular}




\section{Appendix I: Calibration Statistics}

\section{North Wall (Winter)}

\begin{tabular}{|c|c|c|c|}
\hline Case \# & $\begin{array}{c}\text { Heat } \\
\text { Resistance }\end{array}$ & RMSE & \\
\hline 1 & 0.120 & 0.175 & \\
\hline $\mathbf{2}$ & $\mathbf{0 . 1 7 5}$ & $\mathbf{0 . 1 3 3}$ & Select \\
\hline 3 & 0.200 & 0.140 & \\
\hline 4 & 0.225 & 0.164 & \\
\hline 5 & 0.250 & 0.196 & \\
\hline 6 & 0.275 & 0.234 & \\
\hline 7 & 0.185 & 0.134 & \\
\hline 8 & 0.160 & 0.138 & \\
\hline
\end{tabular}

\begin{tabular}{|c|c|c|}
\hline Case \# & f leeward & RSME \\
\hline 8 & 0.1 & 1.700 \\
\hline 9 & 0.66 & 1.536 \\
\hline 10 & 2.0 & 1.653 \\
\hline 11 & 4.0 & 1.559 \\
\hline $\mathbf{1 2}$ & $\mathbf{1 . 5}$ & $\mathbf{1 . 5 4 8}$ \\
\hline 13 & 3.0 & 1.538 \\
\hline 14 & 2.5 & 1.534 \\
\hline 15 & 0.25 & 1.671 \\
\hline
\end{tabular}

Wind-Factor (Lee-ward)

\begin{tabular}{|c|c|c|c|}
\hline Case \# & Rad (units) & RMSE & $\begin{array}{c}\text { Mean } \\
\text { Error } \\
\text { Bias }\end{array}$ \\
\hline 16 & 1.0 & 2.4146 & 1.001 \\
\hline 17 & 10.0 & 1.5182 & 0.9334 \\
\hline 18 & 15.0 & 1.5882 & 0.9353 \\
\hline 19 & 4.5 & 1.9141 & 0.9938 \\
\hline 20 & 8.0 & 1.5641 & 0.9411 \\
\hline 21 & 12.0 & 1.5308 & 0.9320 \\
\hline 22 & 9.0 & 1.5278 & 0.9335 \\
\hline 23 & 9.5 & 1.5201 & 0.9330 \\
\hline 24 & 8.5 & 1.5419 & 0.9367 \\
\hline 25 & 6.5 & 1.6433 & 0.9595 \\
\hline Case \# & Rad (Units) & RMSE & $\begin{array}{c}\text { Mean } \\
\text { Error } \\
\text { Bias } \\
\end{array}$ \\
\hline 26 & 1.0 & 2.6795 & -0.657 \\
\hline 27 & 10.0 & 1.2638 & 0.1937 \\
\hline 28 & 15.0 & 1.3656 & 0.3759 \\
\hline 29 & 4.5 & 1.7357 & -0.1867 \\
\hline 30 & 8.0 & 1.3255 & 0.0892 \\
\hline 31 & 12.0 & 1.2826 & 0.2752 \\
\hline 32 & 9.0 & 1.2828 & 0.1482 \\
\hline 33 & 9.5 & 1.2695 & 0.1710 \\
\hline
\end{tabular}




\begin{tabular}{|l|l|l|l|}
\hline 34 & 8.5 & 1.3000 & 0.1207 \\
\hline & & & \\
\hline
\end{tabular}

Ground Long Wave Reflectivity

\begin{tabular}{|c|c|c|c|}
\hline Case \# & GLWR & RMSE & $\begin{array}{c}\text { Mean } \\
\text { Error } \\
\text { Bias }\end{array}$ \\
\hline 43 & 0.25 & 1.3220 & -0.2179 \\
\hline 44 & 0.40 & 2.0055 & -1.3817 \\
\hline 45 & 0.3 & 1.4828 & -.6074 \\
\hline 46 & 0.35 & 1.7200 & -0.9945 \\
\hline 47 & 0.15 & 1.3466 & $\mathbf{0 . 5 5 1 8}$ \\
\hline 48 & 0.18 & 1.2894 & 0.3258 \\
\hline 49 & 0.22 & 1.2762 & 0.0131 \\
\hline 50 & 0.19 & 1.2791 & 0.2486 \\
\hline $\mathbf{5 1}$ & $\mathbf{0 . 2 1}$ & $\mathbf{1 . 2 7 0 0}$ & $\mathbf{0 . 0 8 9 0}$ \\
\hline & & & \\
\hline
\end{tabular}

\begin{tabular}{|c|c|c|}
\hline Case \# & GLWE & RMSE \\
\hline 52 & 0.7 & 2.2774 \\
\hline 53 & 0.8 & 1.5913 \\
\hline 54 & 0.95 & 1.360 \\
\hline 55 & 0.88 & 1.2848 \\
\hline 56 & 0.92 & 1.2885 \\
\hline
\end{tabular}

Ground Long Wace Emissivity

\begin{tabular}{|c|c|c|}
\hline Case \# & $\varepsilon$ & RSME \\
\hline 57 & 0.7 & 1.2957 \\
\hline 58 & 0.8 & 1.2711 \\
\hline 59 & 0.95 & 1.2822 \\
\hline 60 & 0.88 & 1.2687 \\
\hline 61 & 0.92 & 1.2740 \\
\hline $\mathbf{6 2}$ & $\mathbf{0 . 8 6}$ & $\mathbf{1 . 2 6 8 1}$ \\
\hline 63 & 0.84 & 1.2682 \\
\hline & & \\
\hline
\end{tabular}

Long-Wave Radiation Emissivity

South Wall

Short-Wave Radiation Absorptivity Radiation Coefficient

\begin{tabular}{|c|c|c|}
\hline Case \# & $\begin{array}{c}\text { Radiation } \\
\text { (units }\end{array}$ & RSME \\
\hline 63 & 9.5 & 3.3256 \\
\hline 64 & 0.0 & 7.8646 \\
\hline 65 & 2.0 & 5.1623 \\
\hline 66 & 4.0 & 3.1981 \\
\hline $\mathbf{6 7}$ & $\mathbf{6 . 0}$ & $\mathbf{2 . 5 2 0 1}$ \\
\hline 68 & 8.0 & 2.8351 \\
\hline 69 & 6.5 & 2.5308 \\
\hline 70 & 5.5 & 2.5662 \\
\hline 71 & 7.5 & 2.7102 \\
\hline
\end{tabular}

Ground Short Wave Reflectivity 


\begin{tabular}{|c|c|c|}
\hline Case \# & $\begin{array}{c}\text { SWRA / GSWR } \\
\text { @ } 0.26\end{array}$ & RSME \\
\hline 72 & 0.85 & 2.6637 \\
\hline 73 & 0.90 & 2.9941 \\
\hline 74 & 0.95 & 3.443 \\
\hline 75 & 0.75 & 2.5944 \\
\hline 76 & 0.78 & 2.5208 \\
\hline $\mathbf{7 7}$ & $\mathbf{0 . 7 9}$ & $\mathbf{2 . 5 1 7 7}$ \\
\hline & GSWR & \\
\hline 78 & 0.30 & 2.5217 \\
\hline 79 & 0.22 & 2.5306 \\
\hline
\end{tabular}

Summer RSME Tables

Interior Surface Heat Resistance

\begin{tabular}{|c|c|c|}
\hline Case & $\begin{array}{c}\text { Radiation/Convection } \\
\text { Coefficient }\end{array}$ & RMSE \\
\hline 1 & 0.175 (winter value) & 0.5608 \\
\hline 2 & 3.0 & 1.4409 \\
\hline 3 & 1.5 & 1.0777 \\
\hline 4 & 0.75 & 0.8128 \\
\hline 5 & 0.25 & 0.5834 \\
\hline 6 & 0.10 & 0.5579 \\
\hline 7 & 0.05 & 0.5720 \\
\hline 8 & 0.001 & 0.6986 \\
\hline & & \\
\hline
\end{tabular}

Radiation Coefficient and GLWR

\begin{tabular}{|c|c|c|c|c|}
\hline Case & $\begin{array}{c}\text { Radiation } \\
\text { Coefficient }\end{array}$ & GLWR & RMSE & $\begin{array}{c}\text { Low ISD* } \\
\text { RMSE }\end{array}$ \\
\hline 1 & 18 & 0.1 & 2.2427 & 2.1338 \\
\hline 2 & 18 & 0.3 & 1.6838 & 1.4573 \\
\hline 3 & 18 & 0.5 & 1.9322 & 1.6513 \\
\hline 4 & 22 & 0.1 & 2.2663 & 2.0211 \\
\hline 5 & 22 & 0.3 & 1.6310 & 1.3631 \\
\hline 6 & 22 & 0.5 & 1.5784 & 1.3686 \\
\hline 7 & 26 & 0.1 & 2.3352 & 1.9520 \\
\hline 8 & 26 & 0.3 & 1.7012 & 1.3308 \\
\hline 9 & 26 & 0.5 & 1.4560 & 1.2081 \\
\hline
\end{tabular}

*Incident Solar Direct (short-wave radiation)

Radiation Coefficient and GLWR - Continued

\begin{tabular}{|c|c|c|c|c|}
\hline Case & $\begin{array}{c}\text { Radiation } \\
\text { Coefficient }\end{array}$ & GLWR & RMSE & $\begin{array}{c}\text { Low ISD* } \\
\text { RMSE }\end{array}$ \\
\hline 10 & 24 & 0.4 & 1.4948 & 1.2073 \\
\hline 11 & 24 & 0.5 & 1.4941 & 1.2759 \\
\hline 12 & 24 & 0.6 & 1.6522 & 1.5185 \\
\hline 13 & 28 & 0.4 & 1.5490 & 1.1642 \\
\hline $\mathbf{1 4}$ & $\mathbf{2 8}$ & $\mathbf{0 . 5}$ & $\mathbf{1 . 4 5 3 1}$ & $\mathbf{1 . 1 6 0 3}$ \\
\hline 15 & 28 & 0.6 & 1.4880 & 1.3152 \\
\hline
\end{tabular}

\begin{tabular}{|c|c|c|}
\hline Case & GSWR & RMSE \\
\hline 16 & 0.3 & 1.4123 \\
\hline 17 & 0.4 & 1.4501 \\
\hline 18 & 0.5 & 1.5325 \\
\hline $\mathbf{1 9}$ & $\mathbf{0 . 3 6}$ & $\mathbf{1 . 3 9 1 6}$ \\
\hline
\end{tabular}

Ground Short Wave Reflectivity 


\begin{tabular}{|l|l|l|}
\hline 20 & 0.38 & 1.3968 \\
\hline 21 & 0.42 & 1.4210 \\
\hline 22 & 0.44 & 1.4416 \\
\hline 23 & 0.46 & 1.4672 \\
\hline & & \\
\hline
\end{tabular}

South Wall Calibration

\begin{tabular}{|c|c|c|c|c|}
\hline Case & $\begin{array}{c}\text { Radiation } \\
\text { Coefficient }\end{array}$ & GLWR & RMSE & $\begin{array}{c}\text { Low ISD* } \\
\text { RMSE }\end{array}$ \\
\hline 1 & 15.0 & 0.1 & 3.9162 & 1.7500 \\
\hline $\mathbf{2}$ & $\mathbf{1 5 . 0}$ & $\mathbf{0 . 3}$ & $\mathbf{3 . 2 7 3 5}$ & $\mathbf{1 . 0 8 0 8}$ \\
\hline 3 & 15.0 & 0.5 & 3.1778 & 1.8260 \\
\hline 4 & 20.0 & 0.1 & 4.5688 & 1.7529 \\
\hline 5 & 20.0 & 0.3 & 3.9572 & 1.1444 \\
\hline 6 & 20.0 & 0.5 & 3.6216 & 1.4836 \\
\hline 7 & 25.0 & 0.1 & 5.1013 & 1.8076 \\
\hline 8 & 25.0 & 0.3 & 4.5573 & 1.2877 \\
\hline 9 & 25.0 & 0.5 & 4.1740 & 1.3856 \\
\hline 10 & 10.0 & 0.1 & 3.2967 & 1.9241 \\
\hline 11 & 10.0 & 0.3 & 2.9043 & 1.3508 \\
\hline 12 & 10.0 & 0.5 & 3.3368 & 2.6392 \\
\hline
\end{tabular}

\begin{tabular}{|c|c|c|c|c|}
\hline Case & $\begin{array}{c}\text { Radiation } \\
\text { Coefficient }\end{array}$ & GLWR & RMSE & $\begin{array}{c}\text { Low ISD* } \\
\text { RMSE }\end{array}$ \\
\hline 10 & 16.5 & 0.2 & 3.7554 & 1.2932 \\
\hline 12 & 16.5 & 0.3 & 3.4787 & 1.0805 \\
\hline 13 & 16.5 & 0.4 & 3.3118 & 1.2460 \\
\hline 14 & 17.5 & 0.2 & 3.8975 & 1.3116 \\
\hline 15 & 17.5 & 0.3 & 3.6173 & 1.0919 \\
\hline 16 & 17.5 & 0.4 & 3.4332 & 1.2173 \\
\hline 17 & 13.5 & 0.3 & 3.0879 & 1.1101 \\
\hline
\end{tabular}

\begin{tabular}{|c|c|c|}
\hline Case & GSWR & RMSE \\
\hline 18 & 0.20 & 3.5021 \\
\hline 19 & 0.30 & 3.1415 \\
\hline 20 & 0.35 & 3.0029 \\
\hline 21 & 0.40 & 2.8974 \\
\hline 22 & 0.45 & 2.8284 \\
\hline $\mathbf{2 3}$ & $\mathbf{0 . 5 0}$ & $\mathbf{2 . 7 9 8 8}$ \\
\hline 24 & 0.55 & 2.8096 \\
\hline 25 & 0.60 & 2.8601 \\
\hline 26 & 0.65 & 2.9481 \\
\hline
\end{tabular}

Ground Short Wave Reflectivity 


\section{Appendix J: Cloud Index Supplementary Information}

\section{As Reported by Environment}

Canada

\begin{tabular}{|c|c|c|}
\hline 1 & Blowing Snow & 0.66 \\
\hline 2 & Clear & \\
\hline 3 & Cloudy & 0 \\
\hline 4 & Drizzle & 0 \\
\hline 5 & Drizzle,Fog & 0 \\
\hline 6 & Fog & 0 \\
\hline 7 & Freezing Drizzle & 0 \\
\hline 8 & Freezing Drizzle,Snow & 0.8 \\
\hline 9 & Freezing Rain,Freezing Drizzle,Fog & 0. \\
\hline 10 & Freezing Rain,Ice Pellets,Fog & 0 \\
\hline 11 & Freezing Rain,Snow & 0 \\
\hline 12 & Freezing Rain,Snow & 0 \\
\hline 13 & Heavy Rain Showers & \\
\hline 14 & Heavy Rain,Fog & \\
\hline 15 & Ice Pellet Showers,Snow Showers & 0 \\
\hline 16 & Ice Pellets & $0 . \varepsilon$ \\
\hline 17 & Mainly Clear & 0 \\
\hline 18 & Moderate Rain & 0 \\
\hline 19 & Moderate Snow & 0 \\
\hline 20 & Mostly Cloudy & 0.6 \\
\hline 21 & Rain & 0.7 \\
\hline 22 & Rain Showers & 0 \\
\hline 23 & Rain Showers,Fog & 0 \\
\hline 24 & Rain,Fog & 0 \\
\hline 25 & Snow & 0.8 \\
\hline 26 & Snow Grains & 0.7 \\
\hline 27 & Snow Showers & 0.8 \\
\hline 28 & Snow,Blowing Snow & 0 \\
\hline 29 & Snow,Ice Pellets & 0.8 \\
\hline 30 & Thunderstorms & \\
\hline 31 & $\begin{array}{l}\text { Thunderstorms, Moderate Rain } \\
\text { Showers }\end{array}$ & \\
\hline
\end{tabular}

32 Thunderstorms, Rain Showers 1 


\section{Appendix K: WUFI Material Information}

\section{WUF| ${ }^{\circledast}$ Pro 6.0 NonCommercial}

Material: Buff Matt Clay Brick

\begin{tabular}{|l|c|c|}
\hline \multicolumn{1}{|c|}{ Property } & Unit & Value \\
\hline Bulk density & {$\left[\mathrm{kg} / \mathrm{m}^{3}\right]$} & 1719.0 \\
\hline Porosity & {$\left[\mathrm{m}^{3} / \mathrm{m}^{3}\right]$} & 0.351 \\
\hline Specific Heat Capacity. Dry & {$[\mathrm{J} / \mathrm{kgK}]$} & 800.0 \\
\hline Thermal Conductivity. Dry. $10^{\circ} \mathrm{C}$ & {$[\mathrm{W} / \mathrm{mK}]$} & 0.43 \\
\hline Water Vapour Diffusion Resistance Factor & {$[-]$} & 29.3 \\
\hline Temp-dep. Thermal Cond. Supplement & {$\left[\mathrm{W} / \mathrm{mK}^{2}\right]$} & 0.0002 \\
\hline
\end{tabular}
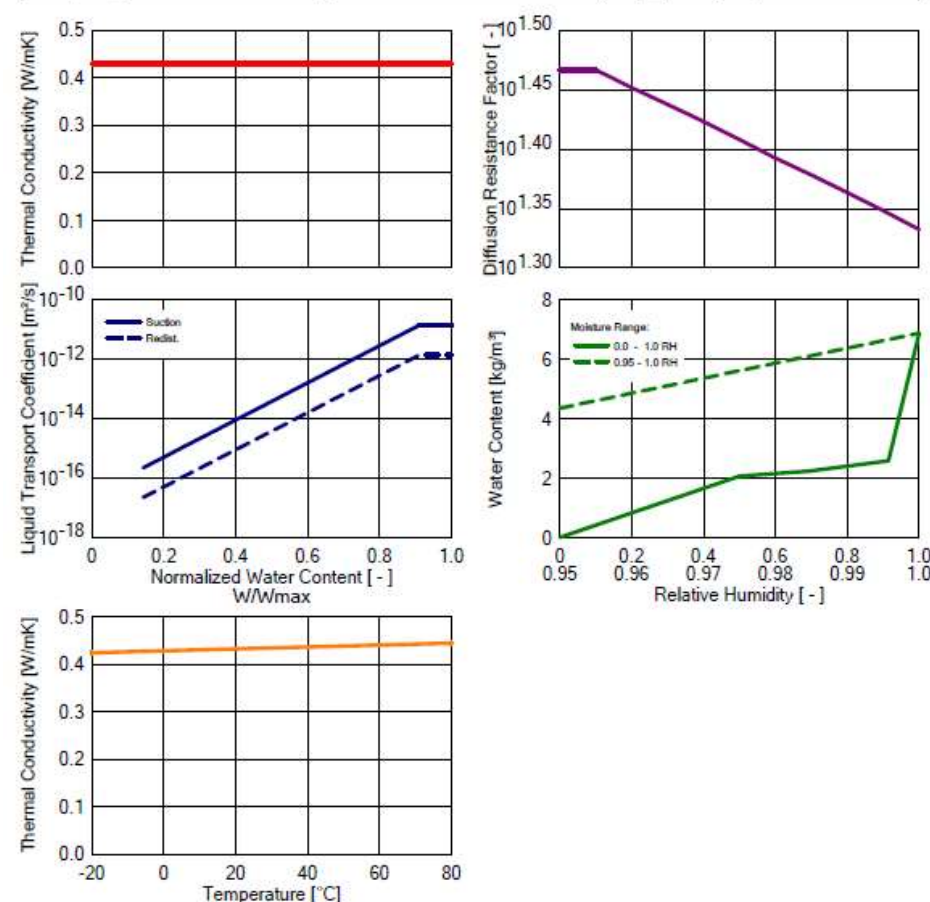

WUF| ${ }^{\otimes}$ Pro 6.0 NonCommercial

Material: DELTA(B-FOXX

\begin{tabular}{|l|c|c|}
\hline \multicolumn{1}{|c|}{ Property } & Unit & Value \\
\hline Bulk density & {$\left[\mathrm{kg} / \mathrm{m}^{2}\right]$} & 270.0 \\
\hline Porosity & {$\left[\mathrm{m}^{2} / \mathrm{m}^{2}\right]$} & 0.001 \\
\hline Specific Heat Capacity. Dry & {$[\mathrm{J} / \mathrm{kgK}]$} & 2300.0 \\
\hline Thermal Conductivity. Dry, $10^{\circ} \mathrm{C}$ & {$[\mathrm{W} / \mathrm{mK}]$} & 2.3 \\
\hline Water Vapour Diffusion Resistance Factor & {$[-]$} & 18.9 \\
\hline Temp-dep. Thermal Cond. Supplement & {$\left[\mathrm{W} / \mathrm{mK}^{2}\right]$} & 0.0002 \\
\hline
\end{tabular}
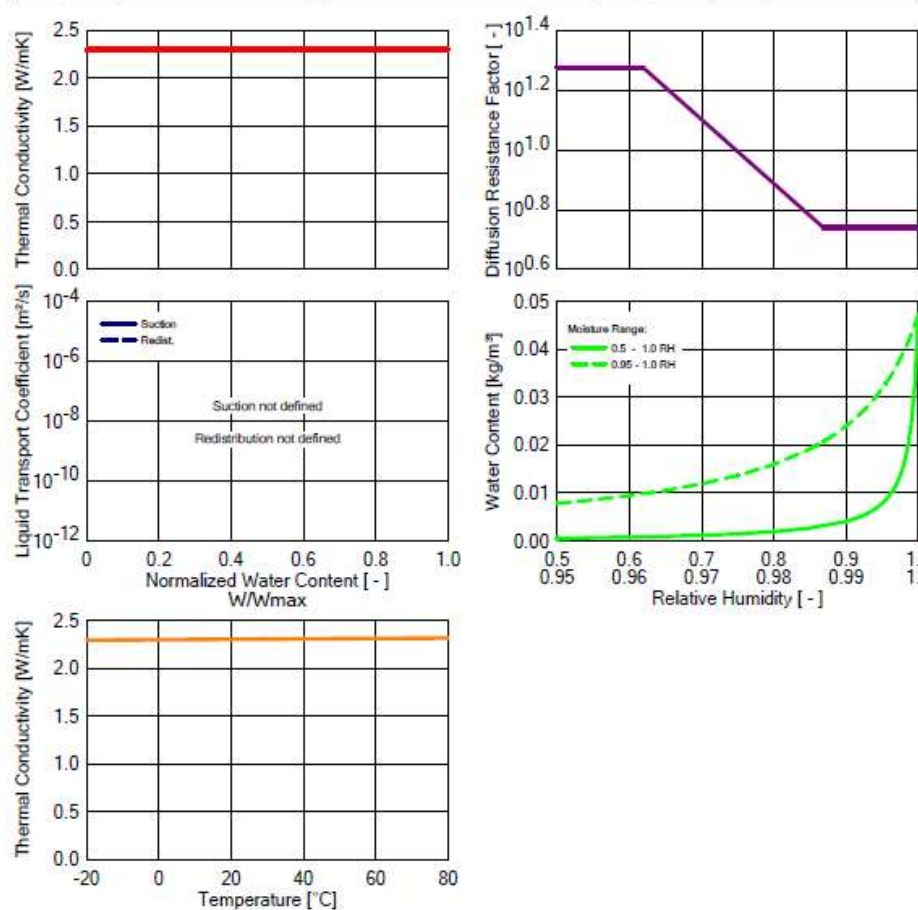
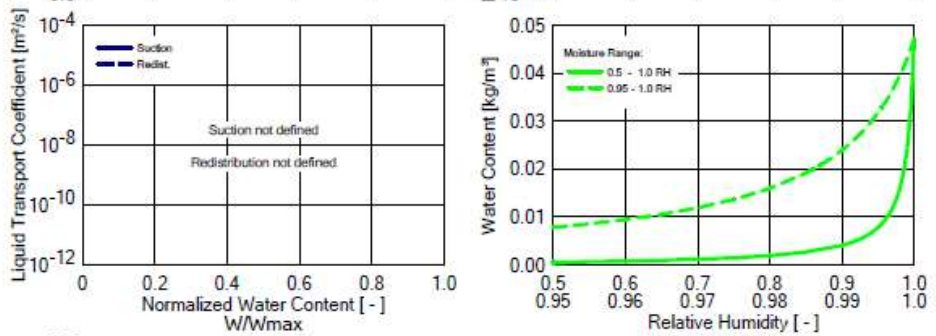

$\begin{array}{llllll}0 & 0.2 & 0.4 & 0.6 & 0.8 & 1.0 \\ 0.95 & 0.96 & 0.97 & 0.98 & 0.99 & 1.0\end{array}$ 


\section{WUF|® Pro 6.0 NonCommercial}

Material: vapor retarder ( 0.1 perm)

\begin{tabular}{|l|c|c|}
\hline \multicolumn{1}{|c|}{ Property } & Unit & Value \\
\hline Bulk density & {$\left[\mathrm{kg} / \mathrm{m}^{2}\right]$} & 130.0 \\
\hline Porosity & {$\left[\mathrm{m}^{2} / \mathrm{m}^{3}\right]$} & 0.001 \\
\hline Specific Heat Capacity. Dry & {$[\mathrm{J} / \mathrm{kgK}]$} & 2300.0 \\
\hline Thermal Conductivity. Dry. $10^{\circ} \mathrm{C}$ & {$[\mathrm{W} / \mathrm{mK}]$} & 2.3 \\
\hline Water Vapour Diffusion Resistance Factor & {$[-]$} & 32800.0 \\
\hline Temp-dep. Thermal Cond. Supplement & {$\left[\mathrm{W} / \mathrm{mK}^{2}\right]$} & 0.0002 \\
\hline
\end{tabular}
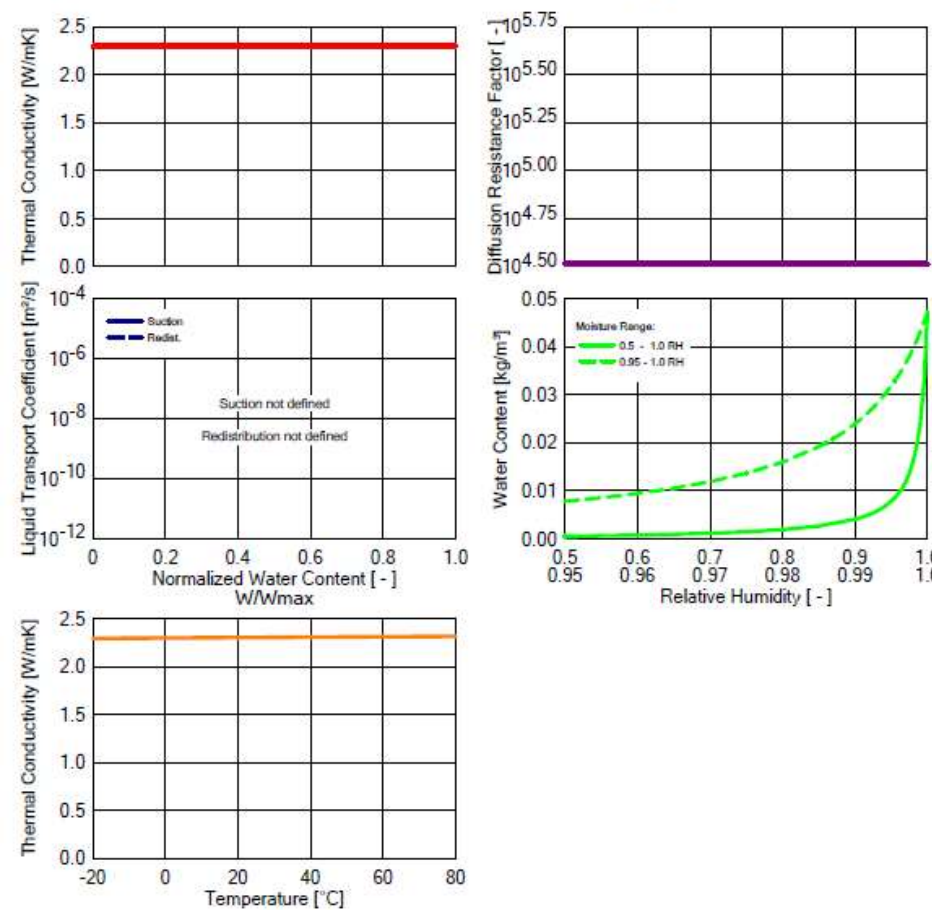

\section{WUFI® Pro 6.0 NonCommercial}

Material: Acrylic Stucco

\begin{tabular}{|l|c|c|}
\hline \multicolumn{1}{|c|}{ Property } & Unit & Value \\
\hline Bulk density & {$\left[\mathrm{kg} / \mathrm{m}^{2}\right]$} & 1795.0 \\
\hline Porosity & {$\left[\mathrm{m}^{2} / \mathrm{m}^{2}\right]$} & 0.275 \\
\hline Specific Heat Capacity. Dry & {$[\mathrm{J} / \mathrm{kgK}]$} & 840.0 \\
\hline Thermal Conductivity. Dry. $10^{\circ} \mathrm{C}$ & {$[\mathrm{W} / \mathrm{mK}]$} & 0.371 \\
\hline Water Vapour Diffusion Resistance Factor & {$[-]$} & 86.7 \\
\hline Temp-dep. Thermal Cond. Supplement & {$\left[\mathrm{W} / \mathrm{mK}^{2}\right]$} & 0.0002 \\
\hline
\end{tabular}
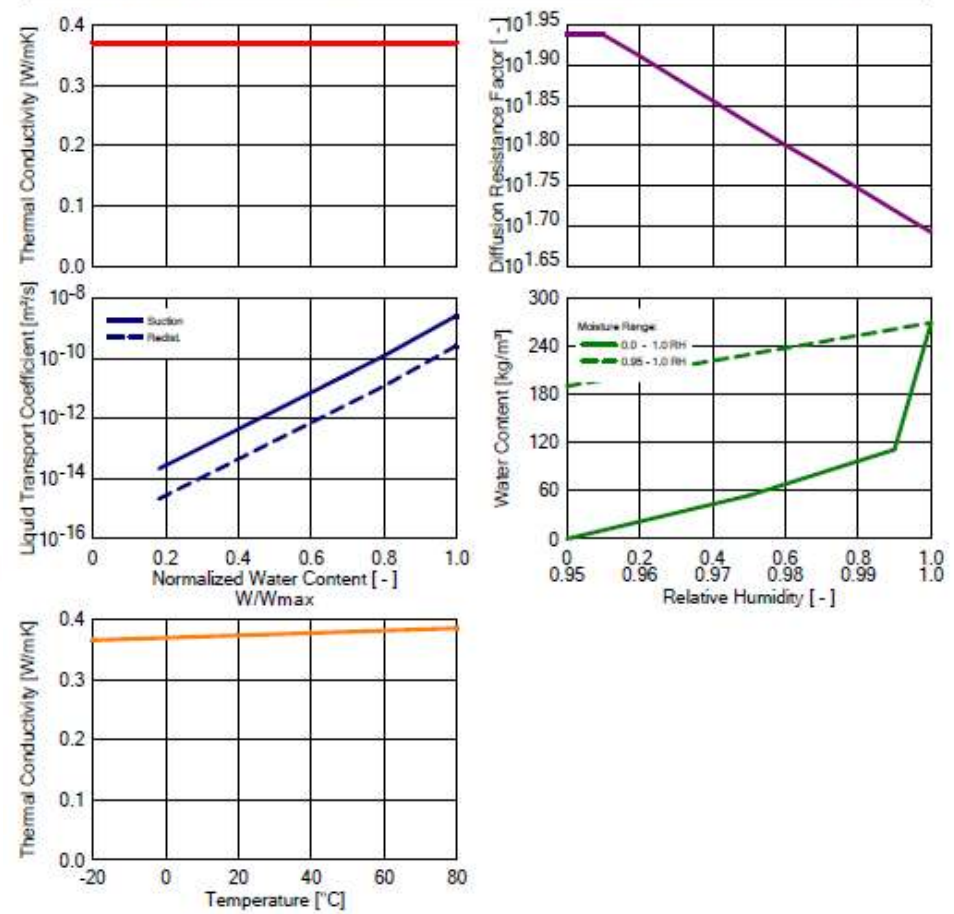


\section{Appendix L: Parametric Numerical Results}

\begin{tabular}{|c|c|c|c|c|c|c|c|c|c|c|}
\hline \multirow{2}{*}{$\begin{array}{c}\text { Cas } \\
\text { e }\end{array}$} & \multicolumn{2}{|c|}{ Toronto } & \multicolumn{2}{c|}{ St. John's } & \multicolumn{2}{c|}{ Calgary } & \multicolumn{2}{c|}{ Vancouver } & \multicolumn{2}{c|}{ Fairbanks } \\
\hline & $\mathbf{R H}$ & $\mathbf{R H T 9}$ & & $\mathbf{R H T 9}$ & & $\mathbf{R H T 9}$ & & $\mathbf{R H T 9}$ & & $\mathbf{R H T 9}$ \\
\hline $\mathbf{1}$ & 0 & 0 & 144 & 0 & 71 & 0 & 663 & 0 & 70 & 0 \\
\hline $\mathbf{2}$ & 0 & 0 & 181 & 0 & 85 & 0 & 0 & 0 & 82 & 0 \\
\hline $\mathbf{3}$ & 0 & 0 & 232 & 0 & 93 & 0 & 1,460 & 0 & 92 & 0 \\
\hline $\mathbf{4}$ & 0 & 0 & 177 & 0 & 86 & 0 & 989 & 0 & 84 & 0 \\
\hline $\mathbf{5}$ & 829 & 0 & 432 & 0 & 68,559 & 0 & 186 & 0 & 483,204 & 0 \\
\hline $\mathbf{6}$ & 29,828 & 0 & 49,852 & 0 & 567,834 & 0 & 263 & 0 & $1,771,47$ & 38,029 \\
\hline $\mathbf{7}$ & 4,092 & 0 & 254,900 & 1,789 & 46,215 & 0 & 1,494 & 0 & 70 & 0 \\
\hline $\mathbf{8}$ & 575,92 & 15,019 & $1,892,56$ & 77,969 & $2,003,72$ & 123,96 & $2,308,04$ & 106,46 & 70 & 0 \\
\hline $\mathbf{9}$ & 5,697 & 0 & 290,267 & 2,318 & 61,402 & 0 & 3,737 & 0 & 92 & 0 \\
\hline $\mathbf{1 0}$ & 660,02 & 16,975 & $2,033,76$ & 86,477 & $2,144,98$ & 131,65 & $2,770,01$ & 160,86 & 92 & 0 \\
\hline $\mathbf{1 1}$ & 5 & 4 & 1 & 2 & 1 & 5 & 92 & $\mathbf{5}$ \\
\hline $\mathbf{1 2}$ & 115 & 0 & 189 & 0 & 56,003 & 0 & 100 & 0 & 323,446 & 0 \\
\hline $\mathbf{1 3}$ & 0 & 0 & 375 & 0 & 221 & 0 & 1,842 & 0 & 281 & 0 \\
\hline $\mathbf{1 4}$ & 913 & 0 & 2,302 & 0 & 6,854 & 0 & 5,851 & 0 & 40,160 & 0 \\
\hline $\mathbf{1 5}$ & 32,736 & 0 & 28,426 & 0 & 19,344 & 0 & 65,014 & 0 & 15,185 & 0 \\
\hline $\mathbf{1 6}$ & 51,562 & 0 & 49,539 & 0 & 31,255 & 0 & 97,491 & 0 & 21,282 & 0 \\
\hline $\mathbf{1 7}$ & 0 & 0 & 0 & 0 & 0 & 0 & 0 & 0 & 0 & 0 \\
\hline $\mathbf{1 8}$ & 0 & 0 & 0 & 0 & 0 & 0 & 0 & 0 & 0 & 0 \\
\hline $\mathbf{1 9}$ & 0 & 0 & 286 & 0 & 0 & 0 & 1,768 & 0 & 90 & 0 \\
\hline $\mathbf{2 0}$ & 1,529 & 0 & 2,555 & 0 & 4,472 & 0 & 5,941 & 0 & 10,495 & 0 \\
\hline $\mathbf{2 1}$ & 0 & 0 & 0 & 0 & 0 & 0 & 0 & 0 & 0 & 0 \\
\hline $\mathbf{2 2}$ & 0 & 0 & 0 & 0 & 0 & 0 & 0 & 0 & 0 & 0 \\
\hline $\mathbf{2 3}$ & 4,201 & 0 & 5,564 & 0 & 9,611 & 0 & 11,121 & 0 & 36,691 & 0 \\
\hline $\mathbf{2 4}$ & 96,803 & 0 & 246,615 & 0 & 98,447 & 0 & 115,225 & 0 & 208,501 & 0 \\
\hline $\mathbf{2 5}$ & 0 & 0 & 0 & 0 & 0 & 0 & 0 & 0 & 0 & 0 \\
\hline $\mathbf{2 6}$ & 1,633 & 0 & 4,242 & 0 & 12,248 & 0 & 6467 & 0 & 54,814 & 0 \\
\hline $\mathbf{2 7}$ & 0 & 0 & 0 & 0 & 0 & 0 & 0 & 0 & 0 & 0 \\
\hline $\mathbf{2 8}$ & 1,498 & 0 & 4,092 & 0 & 11,833 & 0 & 6345 & 0 & 51,530 & 0 \\
\hline $\mathbf{2 9}$ & 0 & 0 & 0 & 0 & 0 & 0 & 0 & 0 & 0 & 0 \\
\hline $\mathbf{3 0}$ & 0 & 0 & 0 & 0 & 0 & 0 & 0 & 0 & 0 & 0 \\
\hline $\mathbf{3 1}$ & 0 & 0 & 0 & 0 & 0 & 0 & 0 & 0 & 0 & 0 \\
\hline $\mathbf{3 2}$ & 0 & 0 & 226 & 0 & 0 & 0 & 282 & 0 & 0 & 0 \\
\hline $\mathbf{3 3}$ & 0 & 0 & 0 & 0 & 0 & 0 & 0 & 0 & 101 & 0 \\
\hline
\end{tabular}




\section{References}

Abdou, A.A., Budaiwi, M. (2005) Comparison of Thermal Conductivity Measurements of Building Insulation Materials Under Various Operating Temperatures. Journal of Building Physics. Vol. 29, No. 2., pp.171-184.

Arena, L., Owens, P. and Mantha, P. (2013) Measured Performance of an R-40 Double-Stud Wall in Climate Zone 5A. Thermal Performance of the Exterior Envelopes of Whole Buildings XII International Conference. Clearwater, FL

ASHRAE. (2016). Criteria for Moisture-Control Design Analysis in Buildings-Addendum e. ANSI/ASHRAE Standard 160-2009. American Society of Heating, Refrigeration and Air Conditioning Engineers, Atlanta, Ga.

ASHRAE. (2013). Energy Standard for Buildings Except Low-Rise Residential Buildings. ANSI/ASHRAE/IED Standard 90.1-2013. American Society of Heating, Refrigeration and Air Conditioning Engineers. Atlanta, Ga.

ASHRAE. (2011). Criteria for Moisture-Control Design Analysis in Buildings-Addendum a. ANSI/ASHRAE Standard 160-2009. American Society of Heating, Refrigeration and Air Conditioning Engineers, Atlanta, Ga.

ASHREA. (2010) ASHRAE Standard 62.2-2010 Ventilation and Acceptable Air Quality in Low-Rise Residential Buildings. Atlanta: American Society of Heating, Refrigerating and Air- Conditioning Engineers Inc. Atlanta, GA

ASHRAE. (2009a). 2009 ASHRAE Handbook: Fundamentals. American Society of Heating, Refrigerating and Air-Conditioning Engineers. Atlanta, GA

ASHRAE. (2009b). Criteria for Moisture-Control Design Analysis in Buildings. ANSI/ASHRAE Standard 160-2009. American Society of Heating, Refrigeration and Air Conditioning Engineers, Atlanta, Ga.

ASTM. (2013a). ASTM-C1155 Standard Practice for Determining Thermal Resistance of Building Envelope Components from the In-Situ Data. America Society for Testing and Materials. West Conshohocken, Pennsylvania.

ASTM. (2013b). ASTM-C1046 Standard Practice for In-Situ Measurement of Heat Flux and Temperature on Building Envelope Components. America Society for Testing and Materials. West Conshohocken, Pennsylvania.

Baldwin, C., Cruickshank, C.A., Schiedel, B.C. (2015). Comparison of Steady-State and In-Situ Testing of High Thermal Resistance Walls. Proceedings from the 6th International Building Physics Conference. Energy Procedia. Vol. 78. p.p. 3246-3251. 
Beaulieu P., Cornick S.M., Dalgliesh W.A., Djebbar R., Kumaran M.K., Lacasse M.A., Lackey J., Maref W., Mukhopadhyaya P., Nofal M., Normandin N., Nicholis M., O'Connor T., Quirt J.D., Rousseau M.Z., Said M.N., Swinton M.C., Tariku F. and van Reenen D. (2002) Final Report from Task 8 of MEWS Project - Hygrothermal Response of Exterior Wall Systems to Climate Loading: Methodology and Interpretation of Results for Stucco, EIFS, Masonry and Siding. Clad Wood-Frame Walls. IRC-RR-118. National Research Council, Ottawa, Canada.

Biddulp, P., Gori, V., Elwell, C., Scott,C., Rye,C., Lowe ,R., Oreszcyn T. (2014). Inferring the Thermal Resistance and Effective Thermal Mass of a Wall Using Frequent Temperature and Heat Flux Measurements. Journal of Energy and Buildings. Vol. 78, pp.10-16.

Bombino, R., Burnett, E.F.P. (1999) Design Issues with Steel-Stud-Framed Wall Systems, PHRC Research Series: Report No. 58. The Pennsylvania Housing Research Center, University Park, PA. p.44.

BSC. (2015). Thermal Metric Summary Report. Building Science Corporation Research Report 0002. Westford, MA.

BSC. (2013). Temperature dependence of R-values in polyisocyanurate roof insulation (Info502). Retrieved from website: http://www.buildingscience.com/documents/informationsheets/info-502-temperature-dependent-r- value/

Brown, W. C., Bomberg, M.T., Ullett, J.M., Rasmussen, J. (1993). Measured Thermal Resistance of Frame Walls with Defects in the Installation of Mineral Fibre Insulation. Journal of Building Physics, Vol. 16, No. 4, pp. 318-339

Byrne, A., Byrne, G., Davies, A., Robinson, A.J. (2013). Transient and Quasi-Steady Thermal Behavior of a Building Envelope due to Retrofitted Cavity Wall and Ceiling Insulation. Journal of Energy and Buildings. Vol. 61, pp.356-365.

Carll. C. G., Highley,T.L. (1990). Decay of Wood and Wood-Based Products Above Ground in Buildings. Journal of Testing and Evaluation. JTEVA, Vol. 27. No.2, March 1999, pp.150158

Carll, C., Wiedenhoeft, A. C. (2009). Moisture-Related Properties of Wood and the Effects of Moisture on Wood and Wood Products. Chapter 4 of Moisture Control in Buildings. Manual 18. ASTM International. West Conshohocken, Pennsylvania.

CGC. (2014). CGC Sheetrock®Brand Ultralight Panels. Material Data Sheet. Retrieved from https://www.usg.com/content/usgcom/en_CA_east/productssolutions/products/wallboard/lightweight-panels/cgc-sheetrock-ultralight-panels.html 
Christian, J., Kosny, J. (1995). Toward a National Opaque Wall Rating Label. Proceedings of Thermal Performance of the Exterior Envelope of Buildings VI, Clearwater, Florida. pp. 221-240.

Christensen, D. (2010). Thermal Impact of Fasteners in High-Performance Wood-Frame Walls. Proceedings from Thermal Performance of the Exterior Envelops of Whole Buildings XI International Conference, Clearwater Beach, Florida.

Climate Change Canada. (2016). National Inventory Report 1990-2014: Greenhouse Gas Sources and Sinks in Canada. Environment and climate Change Canada. Gatineau, QC.

CMHC. (2016). Canadian Housing Statistics 2016. Canada Mortgage and Housing Corporation. Ottawa, Ontario. Retrieved from: https://www.cmhcschl.gc.ca/odpub/esub/61510/61510_2016_A01.pdf?fr=1484201119456

CMHC. (2001). Wood frame Envelopes in the Coastal Climate of British Columbia: Best Practice Guide Building Technology. Canada Mortgage and Housing Corporation. Ottawa, Ontario.

Craven, C., Garber-Slaght, R. (2014). Exterior Insulation Envelope Retrofits in Cold Climates: Implication for Moisture Control. Journal of HVAC\&R Research, Vol. 20. No. 4, pp.384394.

CWC. (2000). Moisture and Wood-Frame Buildings. Building Performance Bulletin. Canadian Wood Council, Ottawa, Ontario.

Deseyve, C., Bednar,T. (2009). Wind induced airflow through lightweight pitched roof constructions: Test roof element-measurements and model validation. Proceedings from $8^{\text {th }}$ Nordic Building Physics Symposium, Copenhagen.

Desogus,G., Mura, S., Ricciu, R. (2011). Comparing Different Approaches to In Situ Measurements of Building Components Thermal Resistance. Journal of Energy and Buildings. Vol. 43, No. 10., pp.2613-2620.

Finch, G. (2012). Building for the Future: Durability Considerations for Energy Efficient Wood Frame Building Enclosure Assemblies. Presnetation to NRC IRAP \& FPInnovations: Energy Code workshop, February 29, 2012.

Finch, G. (2007). The Performance of Rainscreen Walls in Coastal British Columbia. M.A.Sc. Thesis, Civil Engineering, University of Waterloo.

Flanders, S. (1994). Heat Flux Transducers Measure In-Situ Building Thermal Performance. Journal of Building Physics. Vol. 18, No. 1, pp.28-52. 
Fox, M., Straube, J., Ge, H., \& Trainer, T. (2014). Field Test of Hygrothermal Performance of Highly Insulated Wall Assemblies. Proceedings from $14^{\text {th }}$ Canadian Conference on Building Science and Technology, Toronto, Ontario.

Fox, M. (2014). Hygrothermal Performance of Highly Insulated Wood Framed Walls with Air Leakage: Field Measurements and Simulations. Masters Thesis, Ryerson, University, Toronto, Canada

Garrahan, P. (1988). Moisture Meter Correction Factors. Ottawa, Canada: Forintek Canada Corp. Ottawa Canada.

Glass, S.V., Kochkin,V., Drumheller,C., Barta,L. (2015). Moisture Performance of EnergyEfficient and Conventional Wood-Frame Wall Assemblies in a Mixed-Humid Climate. Journal of Buildings. Vol. 5, No. 3, pp. 759-782.

Glass,S.V., Yeh, B., Herzog, B. (2004). Effects of Exterior Insulation on Moisture Performance of Wood-Frame Walls in the Pacific Northwest: Measurements and Hygrothermal Modelling. Proceedings from the $3^{\text {rd }}$ Residential Building Design \& Construction Conference March at Penn State University

Higgins, J., Shane, C., Finch,G. (2014). Thermal Bridging from Cladding Attachment Strategies Through Exterior Insulation. Proceedings from $9^{\text {th }}$ Annual North American Passive House Conference, September, San Francisco Bay Area, CA.

Henry. (2013). Henry Backor BlueskinVP 160. Manufacturer Technical Data Sheet. Retrieved from: http://us.henry.com/air-barrier-systems/commercial-water-resistive-air-barriers-andaccessories/commercial-water-resistive-air-barriers/blueskinvp160

Honeywell. (2010). HIH-2030/5031 Series: Low Voltage Humidity Sensors. Retrieved from https://sensing.honeywell.com/index.php?ci_id=49692

Hukseflux. (2004). TRSYS01: High Accuracy Thermal Resistance Measurement System with 2 Measurement Locations. User Manual produced by Huskeflux Thermal Sensors.

Hutcheon, N.B. and Handegord, G.O. (1983). Building Science for a Cold Climate. National Research Council of Canada.

ISO. (2007). ISO 10211:2007 Thermal bridges in building construction -- Heat flows and surface temperatures -- Detailed calculations. International Organization for Standardization. Geneva, Switzerland.

ISO. (2014). ISO 9869:2014 Thermal insulation -Building elements - In-situ measurement of thermal resistance and thermal transmittance- Part1: Heat flow meter method. International Organization for Standardization. Geneva, Switzerland. 
James, W.L. (1963, rev. 1988). Electric moisture meters for wood. Gen. Tech. Report FPL-GTR6. Madison, WI: U.S. Dept. of Agriculture, Forest Service, Forest Products Laboratory, 1988.

Janssens, A., Hens, H. (2007). Effects of Wind on the Transmission Heat Loss in Duo-pitched Insulated Roofs: A Field Study. Journal of Energy and Buildings, Vol. 39, No. 9, pp. 10471054.

Jiřičková, M., Pavlik, Z., Fiala, L., Cerny, R. (2006). Thermal conductivity of mineral wool materials partially saturated by water. Journal of Thermophysics and Aeromechanics. Vol. 27, No. 4, pp.1214-1227.

Jokisalo, J., Kurnitski, J., Korpi, M., Kalamees, T., Vinha, J. (2009). Building Leakage, Infiltration and Energy Performance Analysis for Finnish Detached Houses. Journal of Building Environment. Vol 44, No. 2, pp.377-387.

Kośny, J., Kossecka., E. (2002). Multi-dimensional Heat Transfer Through Complex Building Envelope Assemblies in Hourly Energy Simulation Programs. Journal of Energy and Buildings. Vol 34, No. 5, pp.445-454.

Künzel, H. M. (1995). Simultaneous Heat and Moisture Transport in Building Componets one and two-diemensional calculation using simple parameters. Fraunhofer Institute of Building Physics. Suttgart, Germany.

Latif, E., Ciupala, M.A., Wijeyesekera, D.C. (2014). The comparative In Situ Hygrothermal Performance of Hemp and Stone Wool Insulations in Vapour Open Timber Frame Wall Panels. Journal of Construction and Building Material. Vol. 73. pp.205-213

Lawton, M., Roppel, P., Fookes., D., Hilaire, A.T.S., Schoohoven, D. (n.d.). Real R-Values of Exterior Insulated Wall Assemblies. Proceedings from BEST Conference. Retrieved from https://c.ymcdn.com/sites/www.nibs.org/resource/resmgr/BEST/BEST1_029.pdf?hhSearchT erms $=\% 22$ real + and $+r$-value $\% 22$.

Lawton, M. (1999). Vancouver's Rotting Condominium Problem-How Did We Get into This Mess? Journal of Envelopes and Building Science. Vol. 22, pp. 356-363.

Lecompte, J. (1989). The Influence of Natural Convection on Thermal Quality of Insulated Cavity Construction. Building Research and Practice: The Journal of CIB., No. 6.

Lepage, R., Lstiburek, J. (2012). Moisture Durability with Vapor Permeable Insulating Sheathing- Building America Report 1313. Retrieved from website: http://www.buildingscience.com/documents/bareports/ba-1313-moisture-durability-withvapor- permeable-insulating-sheathing/

Lepage, R., Schumacher, C., Lukachko, A. (2013). Moisture Management for High R-Value Walls. Building America Report-1316. Building Science Corporation. Somerville, MA. 
Lepage ,R., Schumacher, C. (2013).The Implications of Thermal Conductivity for Exterior Walls with Insulated Sheathing. Report for Roxul Inc. Building Science Consulting Inc. Waterloo, Ontario.

Lstiburek, J. W. (2010). Insight The Perfect Wall. Building Science Corporation. Insight -001. Retrieved from https://buildingscience.com/documents/insights/bsi-001-the-perfect-wall.

Maref, W., Armstrong, M.,Rousseau, M.(2010). A Field Monitoring Investigation of the Effect of Adding Different Exterior Thermal Insulation Materials on the Hygrothermal Response of Wood-Frame Walls in a Cold Climate. Proceedings from BEST Conference, Building Enclosure Science \& Technology, Portland, OR, USA, April 12, 2010, pp. 1-15

McClung, R., Straube, J., Ge, H., Wang, J. (2012). Field Study of Hygrothermal Performance of Cross-Laminated Timber Wall Assemblies with Built-in Moisture. Proceedings from the $5^{\text {th }}$ IBPC, Kyoto, Japan.

Miller., R. (1999). Structure of Wood. Chapter 2. Wood Handbook: Wood as an Engineering Material. Forest Products Laboratory. Madison, WI: U.S. Department of Agriculture, Forest Service, Forest Products Laboratory.

NRCan, (2016). Energy Efficiency Trends in Canada 1990 to 2013. Retrieved from https://www.nrcan.gc.ca/sites/www.nrcan.gc.ca/files/energy/pdf/trends2013.pdf Environment and

NRCan, (2013). Energy Efficiency Trends in Canada 1990 to 2010. Retrieved from http://publications.gc.ca/collections/collection_2014/rncan-nrcan/M141-1-2010-eng.pdf

Qasass, R., Gorgolewski, M., Hua, G. (2014). Timber Framing Factors in Toronto Residential House Construction. Journal of Architectural Science Review. Vol. 57, No. 3, pp. 159-168

Robinson, T. (1992). Moisture Challenges in Canadian Energy Efficient Housing. Journal of Thermal Insulation and Building Environment. Vol 16, October 1992, pp.112 - 120.

Roxul. (2016). Roxul Comfortbatt. Material Technical Data Sheet. Retrieved from http://www.roxul.com/products/residential/products/roxul+comfortbatt

Roxul. (2013). Roxul Comfortboard CIS. Material Technical Data Sheet. Retrieved from http://www.roxul.com/products/commercial/products/roxul+comfortboard+110

Saïd, M.N.A., Brown, W.C., Walker, S. (1997). Long-Term Field Monitoring of an EIFS Clad Wall. The Journal of Building Physics. Vol. 20, No. 4, pp. 320-338.

Santamouris, M. (2005) "Environmental Design of Urban Buildings - An Integrated Approach. International Journal of Sustainability in Higher Education, Vol. 6 No. 3. 
Simpson, W., TenWolde, A. (1999). Physical Properties and Moisture Relations of Wood. Chapter 3. Wood Handbook: Wood as an Engineering Material. Forest Products Laboratory. Madison, WI: U.S. Department of Agriculture, Forest Service, Forest Products Laboratory.

Smegal, J., Straube, J.,Lstiburelk, J., Grin, A. (2013). Moisture-Related Durability of Walls with Exterior Insulation in the Pacific Northwest. Proceedings from the Thermal Performance of the Exterior Envelopes of Whole Buildings XII International Conference.

Smegal, J., \& Straube, J. (2011). Hygrothermal Analysis of Exterior Rockwool Insulation, Research Report. Building Science Consulting, Waterloo, ON.

Smegal, J., Straube.,J. (2010).High-R Walls for the Pacific Northwest-A Hygrothermal Analysis of Various Exterior Wall Systems. Building Science Corporation Research Report - 1014. Waterloo, Ontario.

Straaten, V.R., Trainer, T., Straube, J., Habellion, A. (2016). Wind Washing Effects on Mineral Wool Insulated Sheathings. Proceedings from Thermal Performance of the Exterior Envelopes of Whole Buildings XII International Conference, Clearwater, Florida.

Statistics Canada. (2014). Canada's Population Estimates: Age and Sex 2014. The Daily, September 26, 2014

Straube, J. (2014). Building Enclosure Fundamentals. Building Science Labs. Retrieved from http://buildingscienceeducation.net/wp-content/uploads/2014/06/Building-EnclosureFundamentals.pdf.

Straube, J. (2012). High Performance Enclosures: Design Guide for Institutional Commercial and Industrial Buildings in Cold Climates. Building Science Press. 30 Forest Street. Sommerville, MA.

Straube, J., Onysko, D., Schumacher, C. (2002). Methodology and Design of Field Experiments for Monitoring the Hygrothermal Performance of Wood Frame Enclosures. Journal of Thermal Envelope \& Building Science, Vol. 26, No.2, pp. 123-151

Straube, J. (1998). Moisture Control and Enclosure Wall Systems. Ph.D. Thesis, Civil Engineering Department, University of Waterloo

Straube, J. (2007). Thermal Metrics for High Performance Enclosure Walls: The Limitations of the R-Value. Research Report - 0901, Building Science Corporation. Somerville, Mass.

Timusk,J., Seskus,A.L. (1991).The control of Wind Cooling of Wood Frame Building Enclosures. Journal of Building Physics, Vol. 15, No. 1, pp.8-19

Trechsel, H. (2001). Moisture Primer. Manual on Moisture Analysis in Buildings. Chapter 1. ASTM Manual 40. America Society for Testing and Materials. West Conshohocken, Pennsylvania 
Trethowen, H.A., Cox-Smith, I. (1996). Contact Resistance in a Steel-Frame Wall. Journal of Thermal Insulation and Building Envelopes. Vol. 20, pp.132-143.

Trethowen,H.A. (1991). Sensitivity of Insulated Wall and Ceiling Cavities to Workmanship. Journal of Thermal Insulation. Vol. 15., No.2. pp. 172-179.

Uvsløkk, S. (1996). The Importance of Wind Barriers for Insulated Timber Frame Constructions. Journal of Building Physics, Vol. 20, July 1996. Pp. 40-62

Yarbrough, D.W., Toor., I.A. (1983). Effect of Air Movement on Thermal Resistance of LooseFill Thermal Insulations. Journal of Thermal Insulation, Materials, and Systems for Energy Conservation in the 80s. ASTM STP 789, F.A Govan, D.M. Greason, and J.D. McAllister, EDS., America Society for Testing and Materials, 1983, pp.529-541

World Meteorological Organization (2008). Guide to Meteorological Instruments and Methods of Observation. WMO-No.8. Geneva, Switzland.

WUFI. (2016). WUFI ${ }^{\circledR}$ Pro 6.0 Hygrothermal Simulation Computer Software. Online help Water Vapour Diffusion, Fraunhofer Institut Bauphysik and Oak Ridge National Laboratory (ORNL), 2016.

Zhang, J., Pezoulas, L., and Karagiozis, K. (2011). Environmental Weather Loads for Hygrothermal Analysis and Design of Buildings. ASHREA Research Project Report, RP1325. 